\title{
Innovative Inorganic Synthesis
}

\author{
Edited by \\ Duncan Gregory
}

Printed Edition of the Special Issue Published in Inorganics 
Duncan Gregory (Ed.)

\section{Innovative Inorganic Synthesis}

MDPI 
This book is a reprint of the special issue that appeared in the online open access journal Inorganics (ISSN 2304-6740) in 2013 (available at:

http://www.mdpi.com/journal/inorganics/special_issues/inorganic-synthesis).

\author{
Guest Editor \\ Duncan Gregory \\ School of Chemistry \\ University of Glasgow \\ University Avenue \\ Glasgow, G12 8QQ \\ UK
}

Editorial Office

MDPI AG

Klybeckstrasse 64

Basel, Switzerland

Publisher

Shu-Kun Lin

Assistant Managing Editor

Mary Fan

\title{
1. Edition 2015
}

MDPI • Basel • Beijing • Wuhan

ISBN 978-3-03842-066-8 (Hbk)

ISBN 978-3-03842-067-5 (PDF)

(C) 2015 by the authors; licensee MDPI, Basel, Switzerland. All articles in this volume are Open Access distributed under the Creative Commons License (CC BY), which allows users to download, copy and build upon published articles even for commercial purposes, as long as the author and publisher are properly credited, which ensures maximum dissemination and a wider impact of our publications. However, the dissemination and distribution of copies of this book as a whole is restricted to MDPI, Basel, Switzerland. 


\section{Table of Contents}

List of Contributors V

Foreword to Innovative Inorganic Synthesis VII

\section{Duncan H. Gregory}

Editorial: Innovative Inorganic Synthesis

Reprinted from: Inorganics 2014, 2(4), 552-555

http://www.mdpi.com/2304-6740/2/4/552 .1

\section{Annika Betke and Guido Kickelbick}

Long Alkyl Chain Organophosphorus Coupling Agents for in Situ Surface

Functionalization by Reactive Milling

Reprinted from: Inorganics 2014, 2(3), 410-423

http://www.mdpi.com/2304-6740/2/3/410 .5

Murukanahally Kempaiah Devaraju, Quang Duc Truong, Hiroshi Hyodo, Takaaki Tomai and Itaru Honma

Supercritical Fluid Synthesis of LiCoPO4 Nanoparticles and Their Application to Lithium Ion Battery

Reprinted from: Inorganics 2014, 2(2), 233-247

http://www.mdpi.com/2304-6740/2/2/233

\section{Roberto Rosa, Chiara Ponzoni and Cristina Leonelli}

Direct Energy Supply to the Reaction Mixture during Microwave-Assisted Hydrothermal and Combustion Synthesis of Inorganic Materials

Reprinted from: Inorganics 2014, 2(2), 191-210

http://www.mdpi.com/2304-6740/2/2/191

\section{Andreia Valente and M. Helena Garcia}

Syntheses of Macromolecular Ruthenium Compounds: A New Approach for the Search of Anticancer Drugs

Reprinted from: Inorganics 2014, 2(1), 96-114

http://www.mdpi.com/2304-6740/2/1/96 
Theresia M. M. Richter and Rainer Niewa

Chemistry of Ammonothermal Synthesis

Reprinted from: Inorganics 2014, 2(1), 29-78

http://www.mdpi.com/2304-6740/2/1/29

\section{Annika Betke and Guido Kickelbick}

Bottom-Up, Wet Chemical Technique for the Continuous Synthesis of Inorganic Nanoparticles

Reprinted from: Inorganics 2014, 2(1), 1-15

http://www.mdpi.com/2304-6740/2/1/1

Sabine N. Neal, Samuel A. Orefuwa, Atiya T. Overton, Richard J. Staples and

Ahmed A. Mohamed

Synthesis of Diazonium Tetrachloroaurate(III) Precursors for Surface Grafting

Reprinted from: Inorganics 2013, 1(1), 70-84

http://www.mdpi.com/2304-6740/1/1/70 139

George Marshall, Ashley J. Wooles, David P. Mills, William Lewis, Alexander J. Blake and Stephen T. Liddle

Synthesis and Characterisation of Lanthanide $N$-Trimethylsilyl and -Mesityl

Functionalised Bis(iminophosphorano)methanides and -Methanediides

Reprinted from: Inorganics 2013, 1(1), 46-69

http://www.mdpi.com/2304-6740/1/1/46

\section{Dai Oyama, Ayumi Fukuda, Takashi Yamanaka and Tsugiko Takase}

Facile and Selective Synthetic Approach for Ruthenium Complexes Utilizing a Molecular Sieve Effect in the Supporting Ligand

Reprinted from: Inorganics 2013, 1(1), 32-45

http://www.mdpi.com/2304-6740/1/1/32 


\section{List of Contributors}

Annika Betke: Inorganic Chemistry, Saarland University, Am Markt Zeile 3, Saarbrücken 66125, Germany.

Alexander J. Blake: School of Chemistry, University of Nottingham, University Park, Nottingham, NG7 2RD, UK.

Murukanahally Kempaiah Devaraju: Institute of Multidisciplinary Research for Advanced Materials, Tohoku University, 2-1-1, Katahira, Aoba-ku, Sendai 980-8577, Japan.

Ayumi Fukuda: Department of Industrial Systems Engineering, Cluster of Science and Engineering, Fukushima University, 1 Kanayagawa, Fukushima 960-1296, Japan.

M. Helena Garcia: Centro de Ciências Moleculares e Materiais, Departamento de Química e Bioquímica, Faculdade de Ciências da Universidade de Lisboa, Campo Grande, 1749-016 Lisboa, Portugal.

Duncan H. Gregory: WestCHEM, School of Chemistry, University of Glasgow, Glasgow G12 8QQ, UK.

Itaru Honma: Institute of Multidisciplinary Research for Advanced Materials, Tohoku University, 2-1-1, Katahira, Aoba-ku, Sendai 980-8577, Japan.

Hiroshi Hyodo: Institute of Multidisciplinary Research for Advanced Materials, Tohoku University, 2-1-1, Katahira, Aoba-ku, Sendai 980-8577, Japan.

Guido Kickelbick: Inorganic Chemistry, Saarland University, Am Markt Zeile 3, Saarbrücken 66125, Germany.

Cristina Leonelli: Dipartimento di Ingegneria "Enzo Ferrari", Università degli Studi di Modena e Reggio Emilia, via Vignolese 905/A, 41125 Modena, Italy.

William Lewis: School of Chemistry, University of Nottingham, University Park, Nottingham, NG7 2RD, UK.

Stephen T. Liddle: School of Chemistry, University of Nottingham, University Park, Nottingham, NG7 2RD, UK.

George Marshall: School of Chemistry, University of Nottingham, University Park, Nottingham, NG7 2RD, UK.

David P. Mills: School of Chemistry, University of Nottingham, University Park, Nottingham, NG7 2RD, UK.

Ahmed A. Mohamed: Department of Chemistry, Delaware State University, $1200 \mathrm{~N}$. DuPont Highway, Dover, Delaware 19901, USA.

Sabine N. Neal: Department of Chemistry, Delaware State University, 1200 N. DuPont Highway, Dover, Delaware 19901, USA.

Rainer Niewa: Institut für Anorganische Chemie, Universität Stuttgart, Pfaffenwaldring 55, Stuttgart 70569, Germany. 
Samuel A. Orefuwa: Department of Chemistry, Delaware State University, $1200 \mathrm{~N}$. DuPont Highway, Dover, Delaware 19901, USA.

Atiya T. Overton: Department of Chemistry, Delaware State University, 1200 N. DuPont Highway, Dover, Delaware 19901, USA.

Dai Oyama: Department of Industrial Systems Engineering, Cluster of Science and Engineering, Fukushima University, 1 Kanayagawa, Fukushima 960-1296, Japan.

Chiara Ponzoni: Dipartimento di Ingegneria "Enzo Ferrari", Università degli Studi di Modena e Reggio Emilia, via Vignolese 905/A, 41125 Modena, Italy.

Theresia M. M. Richter: Institut für Anorganische Chemie, Universität Stuttgart, Pfaffenwaldring 55, Stuttgart 70569, Germany.

Roberto Rosa: Dipartimento di Ingegneria "Enzo Ferrari", Università degli Studi di Modena e Reggio Emilia, via Vignolese 905/A, 41125 Modena, Italy.

Richard J. Staples: Department of Chemistry, Center for Crystallographic Research, Michigan State University, East Lansing, Michigan 48824, USA.

Tsugiko Takase: Center for Practical and Project-Based Learning, Cluster of Science and Engineering, Fukushima University, 1 Kanayagawa, Fukushima 960-1296, Japan.

Takaaki Tomai: Institute of Multidisciplinary Research for Advanced Materials, Tohoku University, 2-1-1, Katahira, Aoba-ku, Sendai 980-8577, Japan.

Quang Duc Truong: Institute of Multidisciplinary Research for Advanced Materials, Tohoku University, 2-1-1, Katahira, Aoba-ku, Sendai 980-8577, Japan.

Andreia Valente: Centro de Ciências Moleculares e Materiais, Departamento de Química e Bioquímica, Faculdade de Ciências da Universidade de Lisboa, Campo Grande, 1749016 Lisboa, Portugal.

Ashley J. Wooles: School of Chemistry, University of Nottingham, University Park, Nottingham, NG7 2RD, UK.

Takashi Yamanaka: Department of Industrial Systems Engineering, Cluster of Science and Engineering, Fukushima University, 1 Kanayagawa, Fukushima 960-1296, Japan. 


\section{Foreword to Innovative Inorganic Synthesis}

I was first invited to take the role of founding Editor-in-Chief for Inorganics in 2013. I was delighted to accept and grasp the opportunity to participate in the launch of a unique journal, in which high quality inorganic chemistry research would be made freely available to readers at the point of access. Since the first few weeks of its existence, the journal has quickly established itself and grown in stature. It gives me particular pleasure, therefore, to see this, the first book volume comprising the very first themed issue, in print form between two covers.

I will let the work within this volume speak for itself and say little more other than to again thank the authors, who have made this issue possible and have enabled the journal to get off to such a flying start. However, I would also like to use the opportunity to thank the editorial and publishing staff at MDPI, who have shown outstanding levels of commitment, enthusiasm, and dedication throughout my interactions with them.

Duncan H. Gregory

Guest Editor

WestCHEM, School of Chemistry, University of Glasgow, Glasgow G12 8QQ, UK E-Mail: duncan.gregory@glasgow.ac.uk

Glasgow, 18 February 2015 



\title{
Innovative Inorganic Synthesis
}

\author{
Duncan H. Gregory
}

Reprinted from Inorganics. Cite as: Gregory, D.H. Innovative Inorganic Synthesis. Inorganics 2014, 2, 552-555.

I am delighted to introduce this Special Issue of Inorganics; the first themed issue of the journal and one dedicated to Innovative Inorganic Synthesis. Synthesis is the crucial creative step by which new compounds are made. It is also the means by which important chemicals are formulated and processed from initial laboratory experiments to industrial scale production. Inorganic compounds demonstrate huge diversity and so vastly different approaches are required to achieve a multitude of synthetic targets from delicate complexes to robust extended solids. Unifying this cornucopia of concepts and techniques are principles of inspiration and design; if realising new compounds is a process of discovery, then devising the successful synthesis route is a process of invention. This Special Issue provides examples of the inventive strategies exploited to prepare inorganic compounds. Insightful review papers and original research articles highlight some of the most recent developments in innovative inorganic synthesis.

Nanomaterials chemistry is an area that has emerged and flourished over the last two decades. As the types of materials that exist at the nanoscale have become more numerous, so the library of preparative methods has expanded to meet the challenge of their successful synthesis. An important consideration as such synthesis approaches mature is the need to employ techniques that are environmentally benign and sustainable. In the first of two contributions to this issue, Annika Betke and Guido Kickelbick demonstrate very elegantly how reactive milling can be exploited to prepare surface-functionalised nanoparticles (in this case titania) without the use of solvents [1]. Their study illustrates how ball milling can be used to achieve both physical size reduction and the chemical grafting of species to the titania surface in a simultaneous process. In fact, they show that both surface and bulk reaction chemistry occurs in parallel, with the phase behaviour of the titania particles sensitive to the milling conditions. Such synthetic control could prove to be especially important in the tuning of photocatalytic properties and in the subsequent design of polymer composite materials. By contrast to this arguably "top down" approach of reactive milling, the same authors reveal that a variation of wet chemical nanomaterial synthesis can be employed in the successful "bottom up" production of zinc oxide, magnetite and brushite nanoparticles [2]. Their design of a novel microjet reactor for the processing of these oxide based materials takes a lead from biomaterials synthesis and allows for the continuous flow manufacture of the candidate materials. Both the size and morphology of the products can be manipulated through the available process parameters (such as temperature and flow rate). In a similar vein, Murukanahally Kempaiah Devaraju, Itaru Honma and colleagues at Tohoku University present results of their work using a supercritical water/ethanol mixture as a reactive medium to produce ternary lithium cobalt phosphate [3]. The method produces not only phase-pure material but also nanoparticles that can be controlled in terms of size and shape via choice of precursor, reaction time and temperature. 
Such characteristics prove important in the electrochemical performance of the materials and their potential as cathodes in reversible lithium ion batteries.

Molecular chemistry meets that of extended solids in the design of molecules for functionalization of solid state materials via surface grafting. In their paper, Ahmed Mohamed and co-workers consider the synthesis of diazonium tetrachloroaurate(III) complexes as suitable precursors for surface grafting to create organic monolayers [4]. Typically, the low stability of diazonium salts at room temperature (which are often explosive) coupled with difficulties of isolation and purification enforce approaches where the precursor is prepared and reacted onwards without intermediate isolation. With careful chemical design approaches, however, it is possible to stabilise the diazonium species and complexation is one possibility. In this contribution, a simple but highly effective synthesis procedure is described to yield stable diazonium tetrachloroaurate(III) complexes.

Two other original papers describe very different aspects of progressive synthetic coordination chemistry. In the first, Stephen Liddle and colleagues report the synthesis of several rare earth bis(iminophosphorano)methanediide complexes [5]. To maximise the chances of avoiding salt occlusion and ligand scrambling, a synthetic approach in which iodide precursors were employed in salt metathesis was pursued rather than following an alkane elimination route. The successful synthesis of the various members of this lanthanide series has facilitated a study of how varying the size of the central metal impacts on the structure and reactivity of the methanediide complexes. Meanwhile, Dai Oyama and his team from Fukushima University utilise a phenomenon, which they term as a "Molecular Sieve Effect" in their report on the synthesis of a series of new ruthenium complexes containing the triphenylphosphine ligand [6]. They capitalise on the ability of the tridentate 2,6-di(1,8-naphthyridin-2-yl)pyridine (dnp) ligand not only to stabilise resulting ruthenium complexes but also to improve the stereospecificity of the reactions dramatically. The coordinated dnp thus behaves like a "molecular sieve" in ligand replacement reactions by directing selected ligands into either equatorial or axial positions in the octahedral complexes. Density Functional Theory (DFT) approaches were used to help rationalise this phenomenon; a concept that could be developed (for examples, using thiocyanate, $\mathrm{SCN}^{-}$ligands) in the design of new photosensitizers for dye-sensitized solar cells (DSCs).

The Special Issue also contains three comprehensive review papers, which highlight extremely topical areas in which innovative inorganic synthesis either takes centre stage or contributes significantly to a major scientific challenge. Andreia Valente and M. Helena Garcia discuss the urgent and always relevant issue of how chemistry can respond to the global challenges in public health [7]. Ruthenium chemistry is again highlighted as an important area, this time in the battle against cancer. The authors describe how the continued evolution of macromolecular drugs based on the enhanced permeation and retention (EPR) effect is the key to success and moreover, how advances in chemical synthesis play a central role in the production of new and more effective medicines. Multi-nuclearity is an important concept in developing such drugs and achieving both higher cytotoxicity and selectivity. These properties are often molecular weight-dependent and hence it is vital to develop facile and effective strategies for the coordination of drugs to the carriers. This is where synthesis design can be crucial. In a rather different context, Theresia 
Richter and Rainer Niewa provide a definitive commentary on the current state of the art of ammonothermal chemistry [8]. They describe not only how nitrogen-containing solids such as nitrides, imides and amides might be synthesised but also how ammonia at elevated temperature and pressure (either sub- or supercritical) can be utilised as a solvent in the preparation of hydroxides and chalcogenides. The technique proves to be an extremely useful one in growing crystals (for example of the important III-V semiconductor gallium nitride, GaN) via the judicious choice of starting materials and mineralisers. Three regimes can thus be induced, creating reactions that are driven in ammonobasic, ammononeutral or ammonoacidic conditions. Although the mechanistic steps of reaction and crystal growth are not yet understood in each of these cases, some of the intermediate species that exist can be identified. Finally, Roberto Rosa, Chiara Ponzoni and Cristina Leonelli offer a detailed insight into how microwave methods can be used to synthesise inorganic solids, nanoparticles and materials in solution, via either solvothermal or solution-based combustion techniques [9]. The authors demonstrate how microwave driven hydrothermal synthesis, for example, can be implemented in the formation of numerous oxide and chalcogenide nanostructures with sizes and shapes tunable via experimental conditions. Similarly, the relatively new procedure of solution combustion synthesis by microwaves is revealed to be a means to produce metal, binary oxide and complex oxide nanopowders from the reaction of a metal-containing precursor (such as a nitrate, commonly) with an organic fuel in a homogeneous solution. Developed originally as a concept from a process performed in the solid state, solution combustion syntheses are proving highly effective routes to deliver nanomaterials of controllable size and shape.

Hence overall and in summary, this Special Issue highlights just some of the diverse and creative ways in which novel synthesis forms the foundation in the constant evolution of inorganic chemistry. From the design and controlled coordination of ligands to individual metal centres through the connection of building blocks using weak interactions to the crystal engineering and microstructural construction of materials, the unceasing importance of fresh ideas in synthesis is only too evident as chemistry progresses.

I would like to take this opportunity to thank all of the authors who have contributed such a fine collection of work to this Special Issue. I would also like to thank the editorial staff and publishing staff who, with all their continued hard work, have enabled this issue to be realised.

\section{References}

1. Betke, A.; Kickelbick, G. Long Alkyl Chain Organophosphorus Coupling Agents for in Situ Surface Functionalization by Reactive Milling. Inorganics 2014, 2, 410-423.

2. Betke, A.; Kickelbick, G. Bottom-Up, Wet Chemical Technique for the Continuous Synthesis of Inorganic Nanoparticles. Inorganics 2014, 2, 1-15.

3. Devaraju, M.K.; Truong, Q.D.; Hyodo, H.; Tomai, T.; Honma, I. Supercritical Fluid Synthesis of $\mathrm{LiCoPO}_{4}$ Nanoparticles and Their Application to Lithium Ion Battery. Inorganics 2014, 2 , 233-247.

4. Neal, S.N.; Orefuwa, S.A.; Overton, A.T.; Staples, R.J.; Mohamed, A.A. Synthesis of Diazonium Tetrachloroaurate(III) Precursors for Surface Grafting. Inorganics 2013, 1, 70-84. 
5. Marshall, G.; Wooles, A.J.; Mills, D.P.; Lewis, W.; Blake, A.J.; Liddle, S.T. Synthesis and Characterisation of Lanthanide $N$-Trimethylsilyl and -Mesityl Functionalised Bis(iminophosphorano)methanides and -Methanediides. Inorganics 2013, 1, 46-69.

6. Oyama, D.; Fukuda, A.; Yamanaka, T.; Takase, T. Facile and Selective Synthetic Approach for Ruthenium Complexes Utilizing a Molecular Sieve Effect in the Supporting Ligand. Inorganics 2013, 1, 32-45.

7. Valente, A.; Garcia, M.H. Syntheses of Macromolecular Ruthenium Compounds: A New Approach for the Search of Anticancer Drugs. Inorganics 2014, 2, 96-114.

8. Richter, T.M.M.; Niewa, R. Chemistry of Ammonothermal Synthesis. Inorganics 2014, 2, 29-78.

9. Rosa, R.; Ponzoni, C.; Leonelli, C. Direct Energy Supply to the Reaction Mixture during Microwave-Assisted Hydrothermal and Combustion Synthesis of Inorganic Materials. Inorganics 2014, 2, 191-210. 


\title{
Long Alkyl Chain Organophosphorus Coupling Agents for in Situ Surface Functionalization by Reactive Milling
}

\section{Annika Betke and Guido Kickelbick}

\begin{abstract}
Innovative synthetic approaches should be simple and environmentally friendly. Here, we present the surface modification of inorganic submicrometer particles with long alkyl chain organophosphorus coupling agents without the need of a solvent, which makes the technique environmentally friendly. In addition, it is of great benefit to realize two goals in one step: size reduction and, simultaneously, surface functionalization. A top-down approach for the synthesis of metal oxide particles with in situ surface functionalization is used to modify titania with long alkyl chain organophosphorus coupling agents. A high energy planetary ball mill was used to perform reactive milling using titania as inorganic pigment and long alkyl chain organophosphorus coupling agents like dodecyl and octadecyl phosphonic acid. The final products were characterized by IR, NMR and X-ray fluorescence spectroscopy, thermal and elemental analysis as well as by X-ray powder diffraction and scanning electron microscopy. The process entailed a tribochemical phase transformation from the starting material anatase to a high-pressure modification of titania and the thermodynamically more stable rutile depending on the process parameters. Furthermore, the particles show sizes between $100 \mathrm{~nm}$ and $300 \mathrm{~nm}$ and a degree of surface coverage up to $0.8 \mathrm{mmol}$ phosphonate per gram.
\end{abstract}

Reprinted from Inorganics. Cite as: Betke, A.; Kickelbick, G. Long Alkyl Chain Organophosphorus Coupling Agents for in Situ Surface Functionalization by Reactive Milling. Inorganics 2014, 2, 410-423.

\section{Introduction}

Surface modified particles are important building blocks for various applications in optics [1], electronics [2], material science [3] and in the biomedical field [4]. For this reason, there is increasing interest in economic synthetic strategies. In this context, there has been significant interest in mechanochemical approaches [5,6]. Reactive milling turned out to be a promising technique because it is a solvent-free and environmentally friendly alternative to conventional synthetic strategies $[7,8]$. Reactive milling has proven its suitability for the synthesis of various materials, for example calcium hydride by reactive milling of calcium and phenylphosphonic acid (PPA) under an inert atmosphere [9] or $\mathrm{ZrTiO}_{4}$ [10] to name only two examples out of many others. Recently, we investigated the suitability of reactive milling for the preparation of surface functionalized titania nanoparticles. We were able to show that an in situ surface functionalization using PPA as coupling agent is possible and that the organophosphorus surface functionalization can stabilize crystallographic high-pressure phases [11,12]. Often the surface functionalization of particles with organic coupling agents involves the use of organic solvents; our technique allows a solvent free, ecologically more friendly approach. In case of PPA, the surface functionalization of titania can also be obtained in water as solvent [13]. This is not the case for long alkyl chain 
phosphonic acids. Here, definitely an organic solvent is necessary for the complete dissolution of the respective coupling agent $[14,15]$. This was the reason for us to expand our previous studies to this type of surface modifier. Dodecylphosphonic acid (DDPA) was used to perform a systematic study on the behavior at different process parameters. Afterwards, octadecylphosphonic acid (ODPA) was used to demonstrate that the approach is assignable on other long alkyl chain organophosphorus species.

\section{Results and Discussion}

Reactive milling was carried out using titania as inorganic pigment and long alkyl chain organophosphorus coupling agents. The experiments were performed in a high-energy planetary ball mill using a $\mathrm{ZrO}_{2}$-ceramic grinding bowl and varying the reaction conditions such as milling time and rotational speed (revolutions per minute, rpm). Titania has several crystallographic phases that can be converted into each other depending on the energy input into the system. Consequently, the ratio between the different crystallographic phases is an indicator for the energy applied to the samples. After the milling process, the obtained material was thoroughly washed and dried. The washing solution was analyzed to demonstrate that the coupling agent is not degraded due to the high-energy impact during the milling process. ${ }^{1} \mathrm{H},{ }^{13} \mathrm{C}$ and ${ }^{31} \mathrm{P}$ NMR spectra confirm that DDPA was the only species present in the washing solution (see Supplementary Information Figures S1-S6).

The final products were analyzed applying various techniques. A systematic study on the influence of different process parameters was performed for the DDPA functionalized particles. FTIR analyses show that the milling process results in a bonding between the coupling agent and the titania phase. The starting material reveals no absorption in the typical regions for organic molecules. In contrast, the samples after the milling process display bands that are characteristic for $\mathrm{C}-\mathrm{H}$ vibrations $\left(2900 \mathrm{~cm}^{-1}\right.$ and $\left.1450 \mathrm{~cm}^{-1}\right)$ as well as $\mathrm{P}-\mathrm{O}$ oscillations $\left(1000 \mathrm{~cm}^{-1}\right)$ (Figure 1 and Supplementary Information Figures S7 and S8). The broad band at approximately $1000 \mathrm{~cm}^{-1}$ is characteristic for surface bonded phosphonates; the width of this band is due to the different bonding types (e.g., bi- and tridentate) of the phosphonates on the titania surface [16].

To determine the amount of surface coverage, thermal gravimetric (TGA) and elemental (CHN) analyses were performed and the results were correlated with the process parameters rotational speed and milling time (Figure 2). It turned out that the degree of surface coverage increases with increasing milling time as well as increasing milling speed. This correlation can have two reasons. On the one hand, a better binding of the organic groups to the titana surface can have its origin in the increased energy input. On the other hand, the surface area of the particles is increased which could lead to a higher portion of coupling agent bound to the surface. The results show that the correlation between the surface coverage and the milling time or speed is almost linear. CHN and TGA results show similar development, the slight discrepancies are due to measuring inaccuracies of both methods. 
Figure 1. FTIR-spectra: (a) starting material titania; (b) coupling agent dodecylphosphonic acid and samples after the milling process: (c) $300 \mathrm{rpm} / 12 \mathrm{~h}$; (d) $300 \mathrm{rpm} / 24 \mathrm{~h}$; (e) $300 \mathrm{rpm} / 36 \mathrm{~h}$; (f) $300 \mathrm{rpm} / 48 \mathrm{~h}$; surface modification has taken place after the milling process, which is indicated by the characteristic bands for the $\mathrm{C}-\mathrm{H}$ oscillation $\left(1450 \mathrm{~cm}^{-1}\right.$ and $2900 \mathrm{~cm}^{-1}$ ) and the wide band at $1000 \mathrm{~cm}^{-1}$ (P-O region).

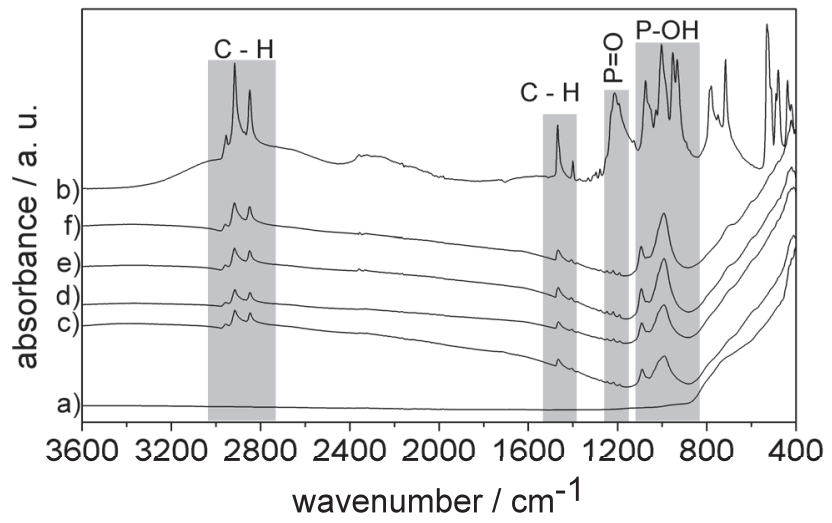

The binding modes of the DDPA to the titania surface were studied by the use of solid-sate NMR spectroscopy. The results reveal that DDPA was bonded to the titania surface. Pure DDPA yields in a solid-state ${ }^{31} \mathrm{P}$ NMR signal at $\delta=31.9 \mathrm{ppm}$ [17], whereas the samples after the milling process show a series of partially broad signals in the range of $\delta=10-35$ ppm. Furthermore, a sharp peak is observed at $\delta=11 \mathrm{ppm}$ (Figure 3 and Supplementary Information Figures S9-S12). This is in good agreement with the variety of possible binding modes of the phosphonate to the metal oxide surface. In literature, for tridentate coordination modes, sharp peaks with chemical shifts of around $20 \mathrm{ppm}$ to lower fields with respect to the free phosphonic acid are reported [18]. For bi- and monodentate binding modes the downfield shift is less pronounced and the corresponding peaks are significantly broader [19]. Consequently, the peaks in the range of 10-35 ppm correspond to the bi- and monodentate bonded phosphonates and the sharp signal at around $11 \mathrm{ppm}$ can be assigned to the tridentate coordinated species for the samples obtained by reactive milling of titania with DDPA. Theoretically, the signal for tridentate phosphonate species at around $11 \mathrm{ppm}$ could be attributed to layered bulk titanium alkylphosphonates [19]. However, these species show a significantly increased decomposition temperature $\left(\sim 750{ }^{\circ} \mathrm{C}\right)$ compared to alkyl phosphonate modified titania nanoparticles $\left(\sim 550{ }^{\circ} \mathrm{C}\right)$ represented by an additional exothermic step in TG measurements. The TG measurements of the samples obtained by reactive milling of titania with DDPA clearly show only one decomposition step for the degradation of phosphonate species at around $550{ }^{\circ} \mathrm{C}$ (Figure 4). Therefore, the presence of layered titanium phosphonate compounds can be excluded [19]. The solid-state ${ }^{13} \mathrm{C}$ NMR spectra of all samples show signals in the alkyl chain region at $\delta=5-30 \mathrm{ppm}$ which reveals that the alkyl chain is still present after the milling process (Figure 3 and Supplementary Information Figures S9-S12). 
Figure 2. Surface modification in dependence of (a) the rpm or (b) the milling time, results calculated from $\mathrm{TG}$ analyses (straight line) and from $\mathrm{CHN}$ analyses (dashed line).
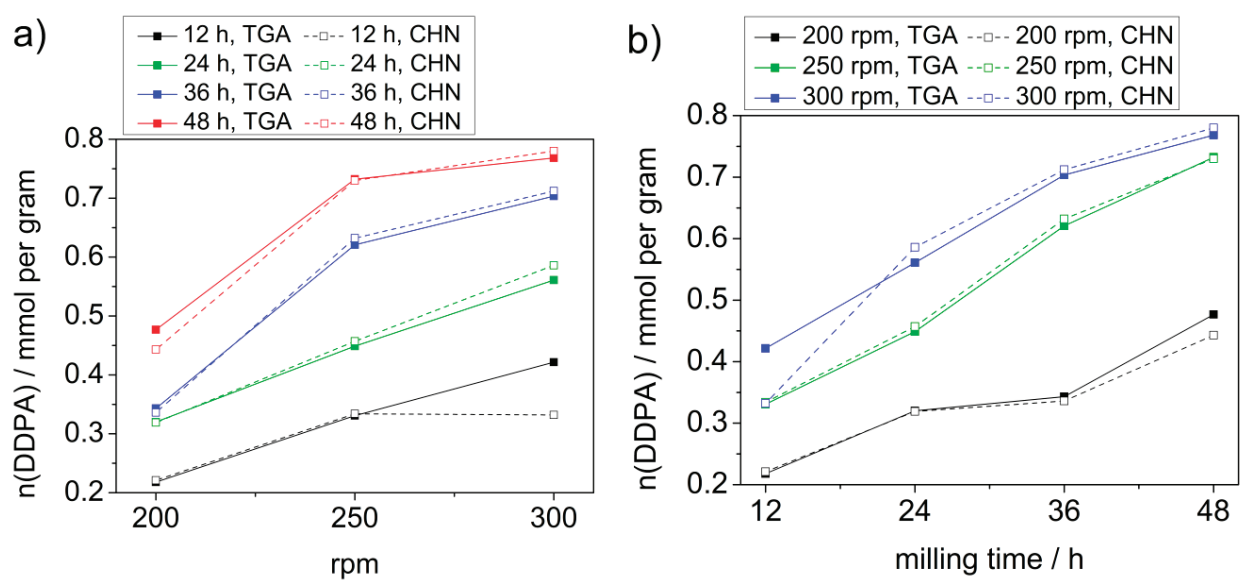

Figure 3. CP-MAS ${ }^{31} \mathrm{P}$ (left) and ${ }^{13} \mathrm{C}$ (right) spectra of titania milled with dodecylphosphonic acid at $200 \mathrm{rpm}$ for $48 \mathrm{~h}$.
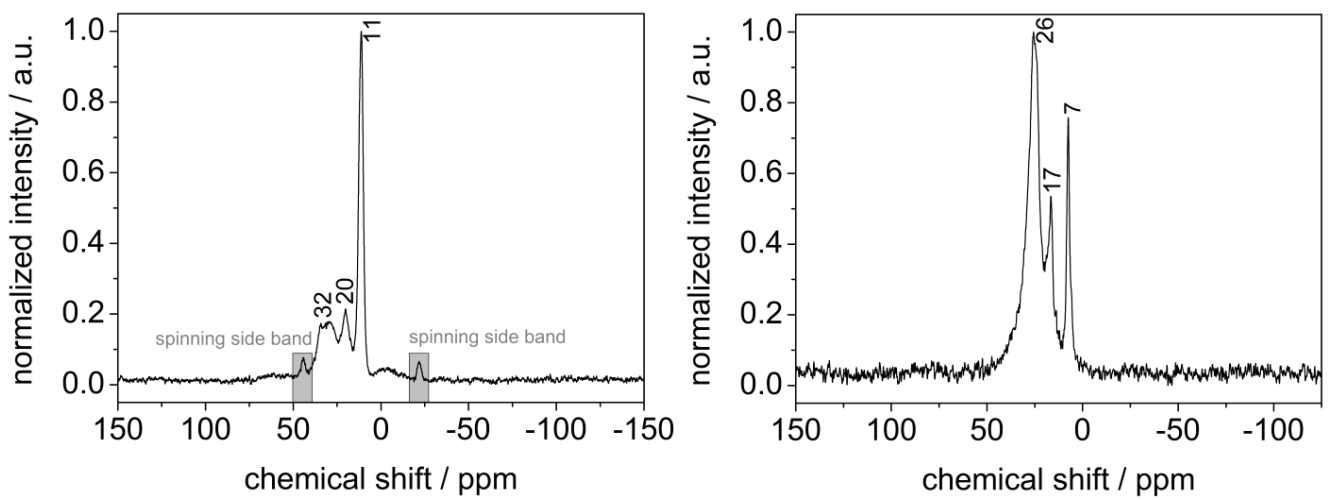

X-ray powder diffraction was used to study the phase composition of the final products. The results show that a tribochemical phase transition from the starting material anatase to the thermodynamic more stable rutile as well as a high-pressure modification of titania occurs. It turned out that the degree of the phase transition is dependent on the process parameters. The reflections belonging to the rutile and the high-pressure phase $\left(2 \theta=27^{\circ}\right.$ or $31^{\circ}, 42^{\circ}$ and $66^{\circ}$, respectively) become more intensive when the milling time or the rotational speed are enhanced (Figure 5 and Supplementary Information Figures S13 and S14). The difference between the rutile and the high-pressure modification present itself in the orientation of the vertex-connected $\mathrm{TiO}_{6}$-octahedra along the $c$-axis. In case of rutile, they form straight lines and in case of high-pressure titania they build zigzag chains. 
Figure 4. Thermal gravimetric analysis (TGA) of a sample obtained by reactive milling of titania with DDPA. All samples reveal the same TGA profile and differ only in the overall mass loss. The following figure shows the sample which was exposed to the highest energy impact (300 rpm, $48 \mathrm{~h}$ ).

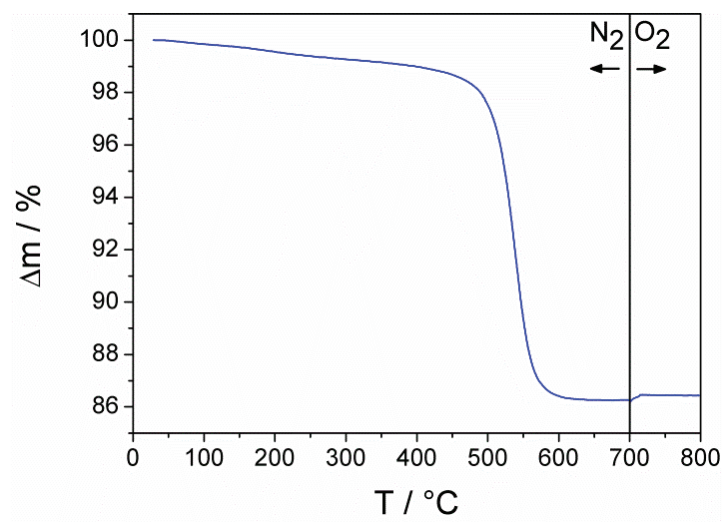

Figure 5. XRD patterns of (a) the starting material anatase (*) and some samples after milling with dodecylphosphonic acid (DDPA): (b) $300 \mathrm{rpm} / 12 \mathrm{~h}$; (c) $300 \mathrm{rpm} / 24 \mathrm{~h}$; (d) $300 \mathrm{rpm} / 36 \mathrm{~h}$; (e) $300 \mathrm{rpm} / 48 \mathrm{~h}$. The selection indicates the main differences in the reflections: The presence of high-pressure $\mathrm{TiO}_{2}(\#)\left(2 \theta=31^{\circ}, 42^{\circ}\right.$ and $\left.66^{\circ}\right)$ and rutile $\left({ }^{\circ}\right)$ $\left(2 \theta=27^{\circ}\right)$ is indicated by additional reflections.

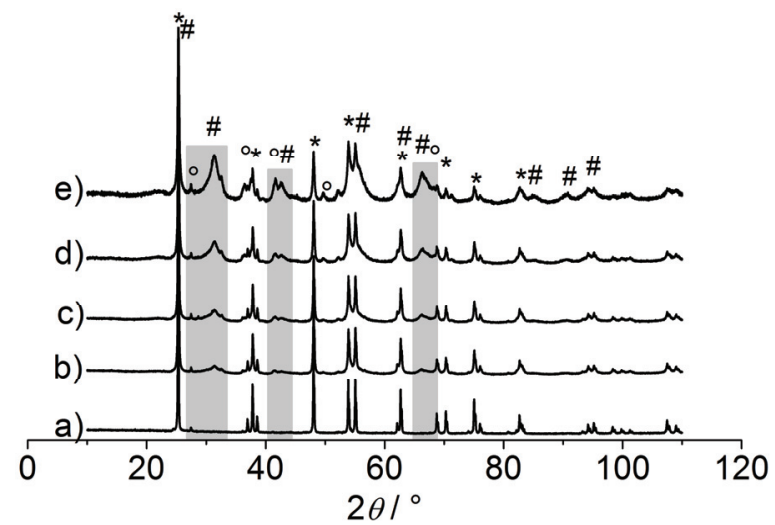

Additional to the qualitatively visible change in the reflection intensity a quantitative Rietveld phase analysis was performed. The development of the background gives no evidence for the presence of an amorphous phase. Nevertheless, the presence of such a phase cannot be excluded but if it should be present its proportion is estimated to be less than $5 \%$. The summarized results are presented in Figure 6 and some results are listed in Table 1 (see also Supplementary Information Table S1). The Rietveld analysis confirms that the fraction of rutile and high-pressure $\mathrm{TiO}_{2}$ increases with longer milling time and higher milling speed. 
Table 1. Titania milled with dodecylphosphonic acid (DDPA), phase composition of some selected samples.

\begin{tabular}{cccc}
\hline Process parameter & Anatase/wt\% & Rutile/wt\% & hp-TiO $\mathbf{2} / \mathbf{w t} \%$ \\
\hline $0 \mathrm{~h} / 0 \mathrm{rpm}$ & $98.2 \pm 0.1$ & $1.8 \pm 0.1$ & 0 \\
$12 \mathrm{~h} / 200 \mathrm{rpm}$ & $91.9 \pm 0.2$ & $1.8 \pm 0.1$ & $6.3 \pm 0.2$ \\
$48 \mathrm{~h} / 200 \mathrm{rpm}$ & $77.8 \pm 0.3$ & $2.6 \pm 0.1$ & $19.6 \pm 0.3$ \\
$12 \mathrm{~h} / 300 \mathrm{rpm}$ & $66.5 \pm 0.2$ & $2.9 \pm 0.2$ & $30.6 \pm 0.2$ \\
$48 \mathrm{~h} / 300 \mathrm{rpm}$ & $24.9 \pm 0.2$ & $3.5 \pm 0.2$ & $71.6 \pm 0.2$ \\
\hline
\end{tabular}

Figure 6. Titania milled with dodecylphosphonic acid (DDPA): Phase composition of the samples after the milling process determined by X-ray powder diffraction and Rietveld analysis. Phase composition occurs from the starting material anatase to rutile and high-pressure (hp) $\mathrm{TiO}_{2}$.

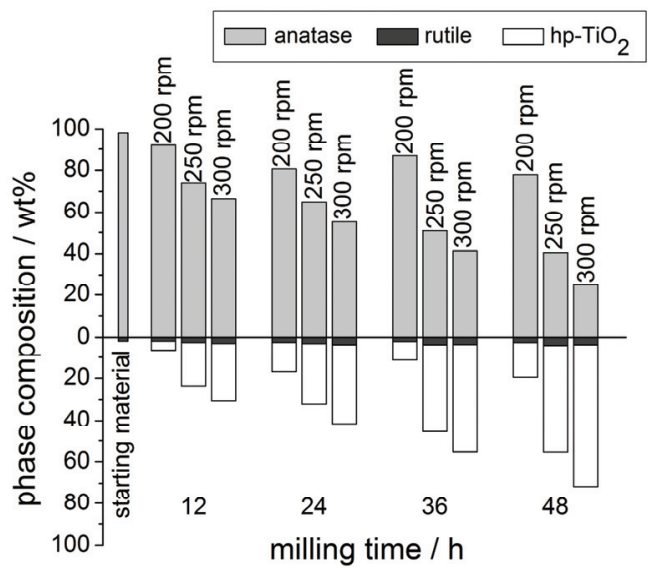

Besides the surface functionalization and phase transition, further important characteristics of the samples are the crystallite as well as the particle size. The crystallite sizes were derived from XRD pattern applying the Pawley method. The starting material was granular crystalline anatase, which exhibits crystallite sizes above $300 \mathrm{~nm}$. The high-pressure $\mathrm{TiO}_{2}$ formed during the milling process has crystallite sizes around $6 \mathrm{~nm}$ but the residual anatase phase remains in the granular crystalline dimension. Compared to the starting material there is only a reduction of about $100 \mathrm{~nm}$. For the rutile phase no reliable refinement of crystallite size could be performed due to the low percentage of this phase in the mixture. These results show that the milling time and the rotational speed primarily have influence on the phase transition but not on the particle size. Regardless of how the process parameters were selected, the resulting high-pressure $\mathrm{TiO}_{2}$ is nano crystalline and the residual anatase remains as granular crystalline. Furthermore, the morphology of the obtained samples was analyzed applying SEM measurements (Figure 7). The SEM images display that the particles are not uniformly shaped and agglomerated with particle sizes in a range of 100-300 nm. It is evident that the particle size decreases with increasing milling time and rotational speed.

In order to determine the particle size, dynamic light scattering was performed. Various organic solvents such as ethanol, hexane, ethyl acetate, toluene or tetrahydrofuran were tested but, even 
with the use of ultrasound, it was not possible to obtain a monodisperse suspension. Consequently, in regards to the particle size, no reliable results could be obtained. This effect is characteristic for long alkyl chain functionalized particles because of the zipper effect which indicates that the surface modifying compoundsmolecules get caught to each other due to Van-der-Waals interactions forming very stable agglomerates [20].

Figure 7. SEM images of two selected samples: titania milled with dodecylphosphonic acid (DDPA) at $200 \mathrm{rpm}$ for $12 \mathrm{~h}$ (left) and at $300 \mathrm{rpm}$ for $48 \mathrm{~h}$ (right). The size of the particles decreases with increasing energy input, but both samples are agglomerated and not uniformly shaped.

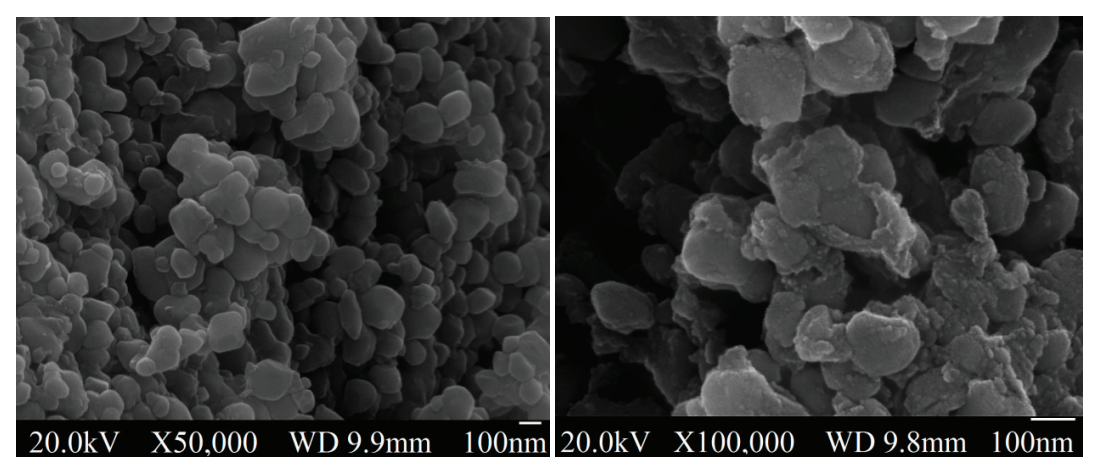

Due to abrasion of the grinding bowl, a contamination of the samples cannot be avoided but it is expected to be insignificantly small. X-ray fluorescence spectroscopy was used to analyze these impurities (Figure 8). The results confirm that the contamination of the samples due to abrasion of the grinding bowl is negligible. The contamination increases with increasing milling time and rotational speed.

The samples after the milling process show a grey discoloration which becomes more intensive with increasing milling time and speed (Figure 9). Based on the fact that starting materials, $\mathrm{TiO}_{2}$ and DDPA, as well as the grinding bowl material are white, this discoloration must have another origin than the impurities due to the abrasion of the grinding bowl. Electron paramagnetic resonance was applied to clarify the reason for the mentioned discoloration (see Supplementary Information Figure S15). The results indicate the presence of $\mathrm{Ti}^{3+}$ ions which are known to entail a darkening of the material [21]. An explanation for the appearance of a subvalent Ti species is the fact that the DDPA acts not only as a coupling but also as a reducing agent under the harsh conditions present during the milling process. Most likely, the organic moiety is oxidized to phenolic/chinoide species or split off from the coupling agent molecule, respectively. However, as the concentration of $\mathrm{Ti}^{3+}$ is low, the amount of possible oxidation products for DDPA in the washing solution is clearly below the detection limit of NMR spectroscopy. Therefore, an identification of these side products was not successful. 
Figure 8. Impurities introduced by the grinding bowl according to (a) rotational speed (rpm) or (b) milling time determined by X-ray fluorescence spectroscopy, titania milled with dodecylphosphonic acid.
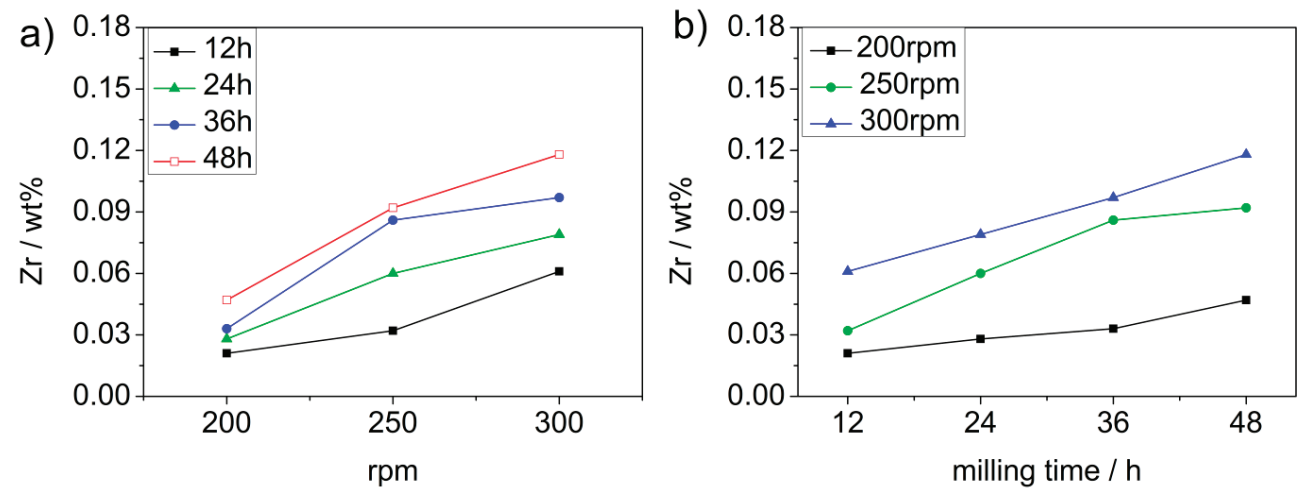

Figure 9. Images of some selected samples: (a) $\mathrm{TiO}_{2}$ (b) $200 \mathrm{rpm} / 12 \mathrm{~h}$ (c) $200 \mathrm{rpm} / 48 \mathrm{~h}$ (d) $300 \mathrm{rpm} / 12 \mathrm{~h}$ (e) $300 \mathrm{rpm} / 48 \mathrm{~h}$. The grey discoloration increases with increasing energy input.

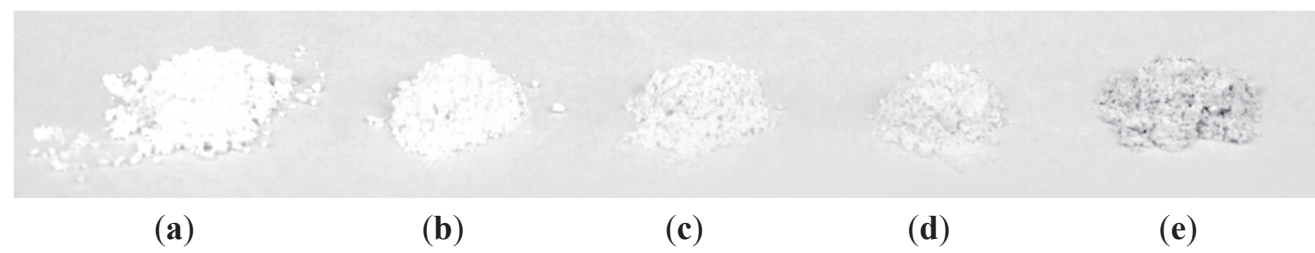

After the successful studies on DDPA as long alkyl chain phosphonate coupling agent, again ODPA was used to demonstrate that this approach is assignable on other long alkyl chain organophosphorus species. The sample was prepared in the same way using those process parameters which end up in the highest surface functionalization (300 rpm and $48 \mathrm{~h}$ ). FTIR analysis showed that a surface functionalization has taken place in case of using ODPA as well (Figure 10). The degree of surface functionalization was determined to be $0.6 \mathrm{mmol} / \mathrm{g}$ by the use of TGA as well as CHN analysis. The binding modes of the ODPA on the titania surface were studied using solid state ${ }^{31}$ P-NMR spectroscopy (Figure 11). Similar to the results of the studies with DDPA, the spectrum show a series of partially broad signals in the range of $\delta=10-30 \mathrm{ppm}$ and a sharp peak at $\delta=6 \mathrm{ppm}$. Pure ODPA shows a solid-state ${ }^{31} \mathrm{P}$ NMR signal at $\delta=30 \mathrm{ppm}$ [22]. The ${ }^{31} \mathrm{P}$ NMR is in good agreement with the variety of possible binding modes of the phosphonate to the metal oxide surface (tridentate coordination modes shift around $20 \mathrm{ppm}$ to lower fields with respect to the free phosphonic acid; for bi- and monodentate binding modes a downfield shift of 5-15 ppm compared to the free acid is reported) [18]. Consequently, the peaks in the range of 10-30 ppm correspond to the bi- and monodentate bonded phosphonates, and the sharp signal at around 6 ppm can be assigned to the tridentate coordinated species. These shifts confirm the covalent bonding of the ODPA on the titania surface and demonstrate the different binding modes. Analogous to DDPA 
functionalized titania, the presence of layered alkyl phosphonates can be excluded by TG measurements of the ODPA functionalized sample (Figure 12).

Figure 10. FTIR-spectra of the starting material, the coupling agent OPDA, and the sample after the milling process.

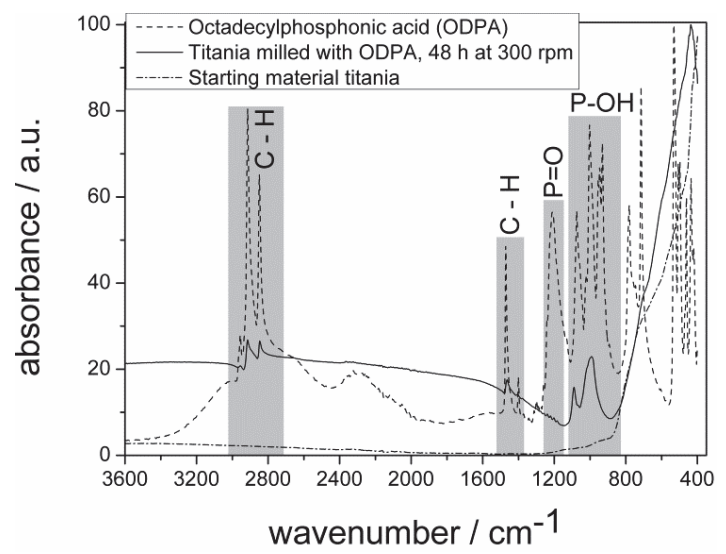

Figure 11. CP-MAS ${ }^{31} \mathrm{P}$ NMR spectrum of titania milled with octadecylphosphonic acid.

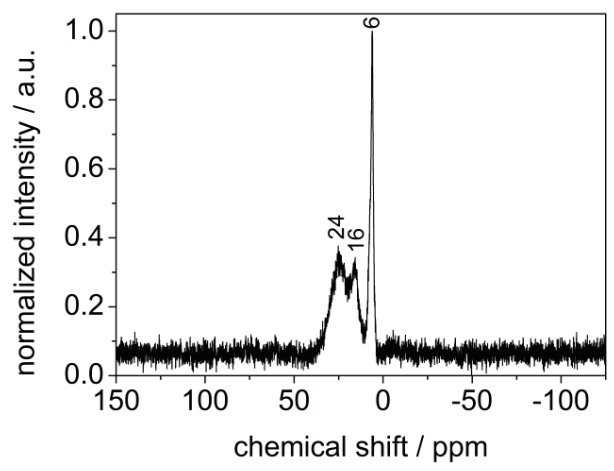

Figure 12. TGA of the sample obtained by reactive milling of titania with ODPA.

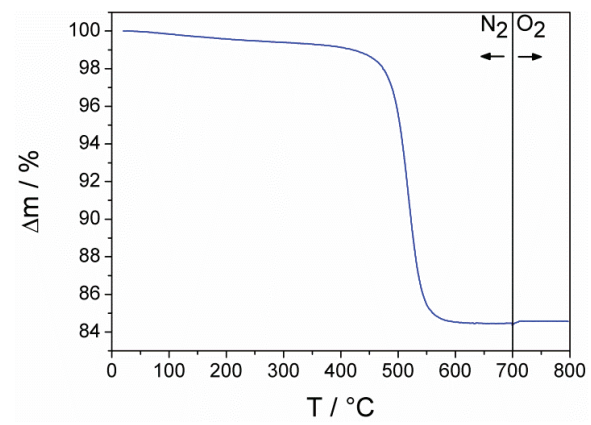


The sample with ODPA as coupling agent was analyzed using X-ray diffraction as well determining the phase composition or rather to describe the tribochemical phase transformation. The sample was composed of $29.1 \% \pm 0.2 \%$ anatase, $2.1 \% \pm 0.2 \%$ rutile and $68.8 \% \pm 0.3 \%$ high-pressure $\mathrm{TiO}_{2}$. Comparing these results with the findings of DDPA as coupling agent, it emphasizes that, in case of DDPA, a slightly higher degree of functionalization can be reached. In contrast, the degree of the tribochemical phase transformation is almost similar. Just as in the case of DDPA, the particles functionalized with ODPA are not uniformly shaped and agglomerated which was determined applying SEM techniques (Figure 13).

Figure 13. SEM image of titania functionalized with ODPA.
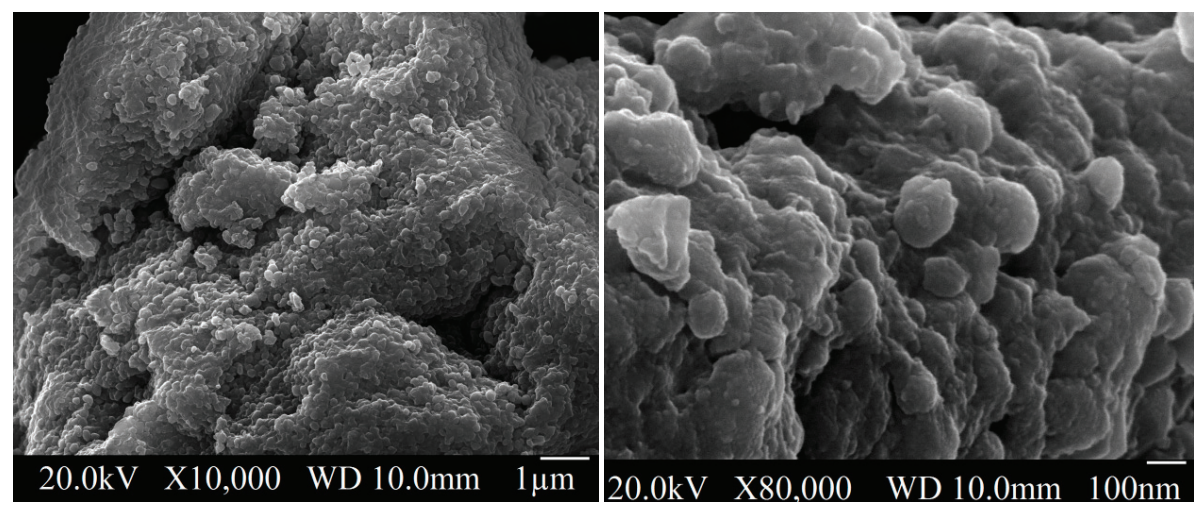

\section{Experimental Section}

\subsection{Materials}

Titanium(IV)-oxide powder anatase (99.8\%) was purchased from Sigma Aldrich (Steinheim, Germany) and has been used without further purification. Dodecylphosphonic and octadecylphosphonic acid were synthesized in the working group.

\subsection{Instruments and Characterization}

FTIR measurements were performed under ambient air (40 scans at a resolution of $4 \mathrm{~cm}^{-1}$ ) in attenuated total reflectance (ATR) mode on a Bruker (Billerica, MA, USA) Vertex 70 spectrometer. X-ray powder diffraction was carried out on two different diffractometers, a Panalytical (Almelo, Netherlands) X'Pert and a Bruker (Billerica, MA, USA) D8 Advance-system, and Bragg-Brentano geometry and $\mathrm{CuK} \alpha$ radiation was used in both cases. The quantitative analysis was carried out by the Rietveld-method using the program TOPAS [23] and crystallographic data for the modifications of titania (anatase [24], rutile [25], high-pressure $\mathrm{TiO}_{2}$ [26]). The same program package was used for the determination of the crystallite sizes applying the Pawley-method. X-ray fluorescence spectroscopy measurements were performed on an EDAX (Wiesbaden, Germany) Eagle II instrument. Thermogravimetric analysis (TGA) was carried out on a Netzsch (Selb, Germany) Iris TG 209. The sample was placed in an alumina crucible which was then heated from 
room temperature to $700{ }^{\circ} \mathrm{C}$ under nitrogen atmosphere followed by heating to $800{ }^{\circ} \mathrm{C}$ under oxygen atmosphere with a rate of $20 \mathrm{~K} \mathrm{~min}^{-1}$. The aim of this procedure is the removal of organic residues which were not completely decomposed during the heating step up to $700{ }^{\circ} \mathrm{C}$. The mass loss during the thermal analysis was used to calculate the amount of coupling agent on the surface of the titania particles. Here, one has to consider that the residue is not only titania, because the phosphonate groups are oxidized to phosphate which remains on the surface of the particles. Equation 1 gives the molar amount of surface-modifying agent per gram of particles.

$$
c_{C A}=\frac{\Delta m \cdot 10}{M_{\Delta m}}
$$

$C_{C A}$ : molar concentration of surface-modifying agent per gram $\left(\mathrm{mmol} \mathrm{g}^{-1}\right)$

$\Delta m$ : mass loss during thermal analysis (\%)

$M_{\Delta m}$ : molar mass of the molecule which leaves during thermal analysis $\left(\mathrm{g} \mathrm{mol}^{-1}\right)$

Elemental analysis was carried out on a Leco (St. Joseph, MI, USA) CHN-900 analyzer. The amount of coupling agent on the surface of the titania particles was calculated by using the percentage of carbon from elemental analysis. The molar amount of coupling agent per gram of particles can be calculated using Equation (2).

$$
c_{C}=\frac{m_{C} \cdot 10}{M_{C} \cdot N_{C}}
$$

${ }_{C C A}$ : molar concentration of coupling agent per gram $\left(\mathrm{mmol} \mathrm{g}^{-1}\right)$

$m_{C}$ : mass of carbon from elemental analysis (\%)

$M_{C}$ : molar mass of carbon $\left(\mathrm{g} \mathrm{mol}^{-1}\right)$

$N_{C}$ : number of carbon atoms per coupling agent

Liquid state NMR spectra were recorded on a Bruker (Billerica, MA, USA) Avance 300 spectrometer operating at $300.13 \mathrm{MHz}$ for ${ }^{1} \mathrm{H}, 75.47 \mathrm{MHz}$ for ${ }^{13} \mathrm{C}$ and at $121.49 \mathrm{MHz}$ for ${ }^{31} \mathrm{P}$. Solid state NMR spectroscopy was carried out on a Bruker (Billerica, MA, USA) Avance DPX 300 instrument equipped with a $4 \mathrm{~mm}$ broad band cross-polarization Magic Angle Spinning probe head operating at $75.40 \mathrm{MHz}$ for ${ }^{13} \mathrm{C}$ and $121.39 \mathrm{MHz}$ for ${ }^{31} \mathrm{P}$ or on a Bruker (Billerica, MA, USA) DSX Avance NMR spectrometer (125.78 MHz for ${ }^{13} \mathrm{C}$ and $202.48 \mathrm{MHz}$ for ${ }^{31} \mathrm{P}$ ). Scanning electron microscopy (SEM) images were recorded on a JEOL (Tokyo, Japan) SEM-7000 microscope. The SEM samples were prepared by placing some grains on a specimen stub with attached carbon adhesive foil followed by deposition of a gold layer.

\subsection{Synthesis}

The experiments were performed in a high energy planetary ball mill Retsch (Haan, Germany) PM 100. The material of the grinding bowl was a $\mathrm{ZrO}_{2}$-ceramic. We used a $50 \mathrm{~mL}$ grinding bowl and 200 corresponding milling balls with a diameter of $5 \mathrm{~mm}$. Systematic studies on the effect of the milling time and the rpm on the result of the milling process were carried out. The milling time was varied between $12 \mathrm{~h}$ and $48 \mathrm{~h}$ and the rpm had values of $200 \mathrm{rpm}, 250 \mathrm{rpm}$ and $300 \mathrm{rpm}$. 
In each case, $4 \mathrm{~g}$ of titania (anatase) and $1 \mathrm{~g}$ of the respective coupling agent (dodecylphosphonic and octadecylphosphonic acid) were placed in the grinding bowl and milled at specific parameters.

After the milling process, the product was washed with ethanol and water. Finally, the functionalized particles were separated by centrifugation $(13,000 \mathrm{rpm})$ and dried at $100{ }^{\circ} \mathrm{C}$.

\section{Conclusions}

Reactive milling can be used for the synthesis of metal oxide particles with in situ surface functionalization. It was shown that this technique can be successfully conducted using long alkyl chain organophosphorus coupling agents. DDPA was used to conduct systematic studies on the influence of the process parameters milling time and rotational speed. The results reveal that increasing milling time as well as increasing rotational speed results in an increasing phase transition of the starting material anatase to rutile and high-pressure titania. Furthermore, an increase of the mentioned process parameters results in an increase of surface functionalization. Afterwards, ODPA was used to successfully demonstrate that the approach is assignable on other long alkyl chain organophosphorus species. The surface functionalization of inorganic particles with long alkyl chain coupling agents is useful for further applications. For instance, such surface functionalized particles can be incorporated into a polymer matrix to obtain a composite material with improved properties. Furthermore, the approach could be conducted applying other organic coupling agents, for example antenna molecules for photo catalysis.

\section{Acknowledgments}

The authors thank Susanne Harling (Saarland University) for the elemental analysis and Matthias Gasthauer (Saarland University) for the synthesis of the coupling agents. Furthermore, we thank Michael Puchberger (Vienna University of Technology) and Dirk Schaffner (University of Kaiserslautern) for the solid state NMR spectroscopy and Martin Hartmann (Friedrich-Alexander University Erlangen-Nürnberg) for the ESR measurements.

\section{Author Contributions}

Annika Betke carried out the experiments and characterizations except elemental analysis, solid state NMR and ESR (see Acknowledgments). Guido Kickelbick provided the resources and infrastructure that allowed the development of this work. He also provided mentoring with data analysis and sample characterization. All co-authors compiled and discussed the manuscript.

\section{Conflicts of Interest}

The authors declare no conflict of interest. 


\section{References}

1. Hameed, S.; Predeep, P.; Baiju, M.R. Polymer Light Emmiting Diodes-A Review on Materials and Techniques. Rev. Adv. Mater. Sci. 2010, 26, 30-42.

2. Chen, W.; Qiu, Y.; Yang, S. Branched $\mathrm{ZnO}$ nanostructures as builing blocks of photoelectrodes for efficient solar energy conversion. Phys. Chem. Chem. Phys. 2012, 14, 10872-10881.

3. Leung, K.C.-F.; Xuan, S.; Zhu, X.; Wang, D.; Chak, C.-P.; Lee, S.-F.; Ho, W.K.-W.; Chung, B.C.-T. Gold and iron oxide hybride nanocomposite materials. Chem. Soc. Rev. 2012, 41, 1911-1928.

4. Mieszawska, A.J.; Mulder, W.J.M.; Fayad, Z.A.; Cormode, D.P. Multifunctional Gold Nanoparticles for Diagnosis and Therapy of Disease. Mol. Pharm. 2013, 10, 831-847.

5. Fernández-Bertran, J.F. Mechanochemistry: An overview. Pure Appl. Chem. 1999, 71, 581-586.

6. Garay, A.L.; Pichon, A.; James, S.L. Solvent-free synthesis of metal complexes. Chem. Soc. Rev. 2007, 36, 846-855.

7. Kaupp, G. Waste-free large-scale synthesis without auxiliaries for sustainable production omitting purifying workup. CrystEngComm 2006, 8, 794-804.

8. James, S.L.; Adams, C.J.; Bolm, C.; Braga, D.; Collier, P.; Friscic, T.; Grepioni, F.; Harris, K.D.M.; Hyett, G.; Jones, W.; et al. Mechanochemistry: Opportunities for new and cleaner synthesis. Chem. Soc. Rev. 2012, 41, 413-447.

9. Ney, C.; Kohlmann, H.; Kickelbick, G. Metal hydride synthesis through reactive milling of metals with solid acids in a planetary ball mill. Int. J. Hydrogen Energy 2011, 36, 9086-9090.

10. Fuentes, A.F.; Takacs, L. Preparation of multicomponent oxides by mechanochemical methods. J. Mater. Sci. 2013, 48, 598-611.

11. Fischer, A.; Ney, C.; Kickelbick, G. Synthesis of Surface-Functionalized Titania Particles with Organophosphorus Coupling Agents by Reactive Milling. Eur. J. Inorg. Chem. 2013, 33, 5701-5707.

12. Betke, A.; Kickelbick, G. Important reaction parameters in the synthesis of phenylphosphonic acid functionalized titania particles by reactive milling. New J. Chem. 2014, 38, 1264-1270.

13. Guerrero, G.; Mutin, P.H.; Vioux, A. Anchoring of Phosphonate and Phosphinate Coupling Molecules on Titania Particles. Chem. Mater. 2001, 13, 4367-4373.

14. Convertino, A.; Leo, G.; Tamborra, M.; Sciancalepore, C.; Striccoli, M.; Curri, M.L.; Agostiano, A. $\mathrm{TiO}_{2}$ colloidal nanocrystals functionalization on PMMA: A tailoring of optical properties and chemical adsorption. Sens. Actuators B 2007, 126, 138-143.

15. Cozzoli, P.D.; Kornowski, A.; Weller, H. Low-Temperature Synthesis of Soluble and Processable Organic-Capped Anatase $\mathrm{TiO}_{2}$ Nanorods. J. Am. Chem. Soc. 2003, 125, 14539-14548.

16. El Malti, W.; Laurencin, D.; Guerrero, G.; Smith, M.E.; Mutin, P.H. Surface modification of calcium carbonate with phosphonic acids. J. Mater. Chem. 2012, 22, 1212-1218. 
17. Brodard-Severac, F.; Guerrero, G.; Maquet, J.; Florian, P.; Gervais, C.; Mutin, P.H. High-Field ${ }^{17} \mathrm{O}$ MAS NMR Investigation of Phosphonic Acid Monolayers on Titania. Chem. Mater. 2008, 20, 5191-5196.

18. Pica, M.; Donnadio, A.; Troni, E.; Capitani, D.; Casciola, M. Looking for New Hybrid Polymer Fillers: Synthesis of Nanosized $\alpha$-Type $\mathrm{Zr}$ (IV) Organophosphonates through an Unconventional Topotactic Anion Exchange Reaction. Inorg. Chem. 2013, 52, 7680-7687.

19. Souma, H.; Chiba, R.; Hayashi, S. Solid-State NMR Study of Titanium Dioxide Nanoparticles Surface-Modified by Alkylphosphonic Acids. Bull. Chem. Soc. Jpn. 2011, 84, 1267-1275.

20. Bedia, A.; Cuccia, L.; Demers, L.; Morin, F.; Lennox, R.B. Structure and Dynamics in Alkanethiolate Monolayers Self-Assembled on Gold Nanoparticles: A DSC, FT-IR, and Deuterium NMR Study. J. Am. Chem. Soc. 1997, 119, 2682-2692.

21. Xiong, L.-B.; Li, J.-L.; Yang, B.; Yu, Y. $\mathrm{Ti}^{3+}$ in the Surface of Titanium Dioxide: Generation, Properties and Photocatalytic Application. J. Nanomater. 2012, 2012, 13, doi:org/10.1155/2012/831524.

22. Tienes, B.M.; Perkins, R.J.; Shoemaker, R.K.; Dukovic, G. Layered Phosphonates in Colloidal Synthesis of Anisotropic ZnO Nanocrystals. Chem. Mater. 2013, 25, 4321-4329.

23. Topas, V4.2; General Profile and Structure Analysis Software for Powder Diffraction Data, User Manual; Bruker AXS: Karlsruhe, Germany, 2008.

24. Kim, D.-W.; Enomoto, N.; Nakagawa, Z.; Kawamura, K. Molecular Dynamic Simulaion in Titanium Dioxide Polymorphs: Rutile, Brookite, and Anatase. J. Am. Ceram. Soc. 1996, 4, 1095-1099.

25. Hill, R.J.; Madsen, C. Rietveld analysis using para-focusing and Debye-Scherrer geometry data collected with a Bragg-Brentano diffractometer. Z. Kristallogr. 1991, 196, 73-92.

26. Fulatov, S.K.; Bendeliani, N.A.; Albert, B.; Kopf, J.; Dyuzheva, T.; Lityagina, L.M. Crystalline structure of the $\mathrm{TiO}_{2}$ II high-pressure phase at 293, 223, and $133 \mathrm{~K}$ according to single-crystal x-ray diffraction data. Dokl. Phys. 2007, 52, 195-199. 


\title{
Supercritical Fluid Synthesis of $\mathrm{LiCoPO}_{4} \mathrm{Nanoparticles} \mathrm{and}$ Their Application to Lithium Ion Battery
}

\author{
Murukanahally Kempaiah Devaraju, Quang Duc Truong, Hiroshi Hyodo, Takaaki Tomai \\ and Itaru Honma
}

\begin{abstract}
In this work, $\mathrm{LiCoPO}_{4}$ nanoparticles were synthesized by supercritical fluid method using cobalt nitrate hexahydrate $\left(\mathrm{Co}\left(\mathrm{NO}_{3}\right)_{2} \quad 6 \mathrm{H}_{2} \mathrm{O}\right)$ and cobalt acetate tetrahydrate $\left(\mathrm{C}_{4} \mathrm{H}_{6} \mathrm{CoO}_{4}\right.$ $4 \mathrm{H}_{2} \mathrm{O}$ ) as starting materials. The effect of starting materials on particle morphology, size, and the crystalline phase were investigated. The as-synthesized samples were systematically characterized by XRD, TEM, STEM, EDS, BET, and TG and charge-discharge measurements. In addition, Rietveld refinement analysis was performed. The electrochemical measurements of $\mathrm{LiCoPO}_{4}$ nanoparticles have shown differences in capacities depending on the starting materials used in the synthesis and the results have been discussed in this paper.
\end{abstract}

Reprinted from Inorganics. Cite as: Devaraju, M.K.; Truong, Q.D.; Hyodo, H.; Tomai, T.; Honma, I. Supercritical Fluid Synthesis of $\mathrm{LiCoPO}_{4}$ Nanoparticles and Their Application to Lithium Ion Battery. Inorganics 2014, 2, 233-247.

\section{Introduction}

In recent years, rechargeable lithium ion batteries have received great attention due to their importance in power sources for electric and hybrid electric vehicles and they offer many more opportunities in electric and electronic domain with higher energy densities than the commercially available rechargeable batteries [1,2]. The crucial factors for the success of new cathode materials depend on the synthesis method, starting materials, particle size, cation order, and other experimental parameters [3]. Since the demonstration of electrochemical properties of $\mathrm{LiFePO}_{4}$ cathode material by Padhi et al. [4] olivine-type $\mathrm{LiMPO}_{4}(\mathrm{M}=\mathrm{Fe}, \mathrm{Mn}, \mathrm{Co}$ and Ni) and Nasicontype $\mathrm{Li}_{3} \mathrm{~V}_{2}\left(\mathrm{PO}_{4}\right)_{3}$ have received great interest owing to their low cost, high reversible capacity, and good stability [5-8]. The potential of the $\mathrm{M}^{3+} / \mathrm{M}^{2+}$ redox couple versus $\mathrm{Li}^{2} / \mathrm{Li}^{+}$of $\mathrm{LiMPO}_{4}$ is as follows; 3.5 $\mathrm{V}$ for $\mathrm{LiFePO}_{4}, 4.1 \mathrm{~V}$ for $\mathrm{LiMnPO}_{4}, 5.2-5.4 \mathrm{~V}$ for $\mathrm{LiNiPO}_{4}$, and 4.8 $\mathrm{V}$ for $\mathrm{LiCoPO}_{4}$. Among these, $\mathrm{LiCoPO}_{4}$ is appealing since it offers both a flat high potential $\left(\sim 4.8 \mathrm{~V} v s . \mathrm{Li} / \mathrm{Li}^{+}\right)$and good theoretical capacity $(167 \mathrm{~mA} \mathrm{~h} / \mathrm{g})$ [9]. The cyclic and rate performances of $\mathrm{LiCoPO}_{4}$ material is affected by electrolyte degradation which is due to high working voltage, low electronic conductivity, and low intrinsic conductivity. Thus far, the first cycle discharge capacities of 30-140 mA h/g with poor or moderate cyclic performances have been observed for $\mathrm{LiCoPO}_{4}$ synthesized via different synthetic routes. In recent days, effort has been made to improve the cyclic performances by cationic doping and decreasing the particle size. Particularly, $\mathrm{LiCoPO}_{4}$ nanoparticles have shown improved electrochemical performances, which is due to a small $\mathrm{Li}$ ion diffusion length. In addition, nanoparticles facilitate fast charge and mass transport because of large surface to volume ratio, as well as enhancing the close contact with the electrolyte and which could speed up the reaction kinetics. 
$\mathrm{LiCoPO}_{4}$ cathode material can be synthesized by various methods, such as solid-state reaction [10-17], hydrothermal synthesis [18-20], sol-gel method [11,21,22], co-precipitation [23], optical floating zone method [24], radio frequency magnetron sputtering [25], electrostatic spray deposition technique [26], and microwave heating method [27]. In addition, some approaches have been applied in order to improve the electronic conductivity of the cathode, such as carbon coating [11], making composite with carbon [10,28]. However, most of the above methods required long duration time to synthesize $\mathrm{LiCoPO}_{4}$ particles, and often it is not easy to control the shape and size of the synthesized particles. Among these methods, hydrothermal and solvothermal process have proved to be beneficial in terms of cost, time and energy savings [29,30]. Very recently, we reported supercritical fluid process for controlled synthesis of plate-like $\mathrm{LiCoPO}_{4}$ nanoparticles within a short reaction time [31]. Supercritical fluid method possess unique properties, such as gas like diffusivity, low viscosity, and the density of the reactants closer to that of liquid, these properties leads to the preparation of high quality materials. In recent days, varieties of electrode materials have been successfully synthesized via supercritical fluid process [32-38]. Recently, our group has reported supercritical fluid synthesis of nanosize lithium metal phosphates [30,38,39], lithium metal silicates [40-44], and flurophosphates [45].

Herein, we report supercritical fluid synthesis of $\mathrm{LiCoPO}_{4}$ nanoparticles using two kinds of starting materials, such as cobalt nitrate hexahydrate $\left(\mathrm{Co}\left(\mathrm{NO}_{3}\right)_{2} \quad 6 \mathrm{H}_{2} \mathrm{O}\right)$ and cobalt acetate tetrahydrate $\left(\mathrm{C}_{4} \mathrm{H}_{6} \mathrm{CoO}_{4} 4 \mathrm{H}_{2} \mathrm{O}\right)$. The reaction was carried out at $400{ }^{\circ} \mathrm{C}$ within a short reaction period $(7 \mathrm{~min})$. The effect of starting materials on the crystalline structure and particles size were investigated and their electrochemical properties have been characterized.

\section{Results and Discussion}

\subsection{One Pot Synthesis}

Supercritical fluid process is a one pot synthesis process for $\mathrm{LiCoPO}_{4}$ nanoparticles as shown in Figure 1. Two kinds of precursor solution were used for the synthesis of $\mathrm{LiCoPO}_{4}$ nanoparticles. For the synthesis, $5 \mathrm{ml}$ of precursor solution was fed into the supercritical reactor and heated at $400{ }^{\circ} \mathrm{C}$ for 7 min to obtain well-crystallized $\mathrm{LiCoPO}_{4}$ nanoparticles.

Figure 1. One pot synthesis of $\mathrm{LiCoPO}_{4}$ nanoparticles using two kinds of starting materials via supercritical fluid process.

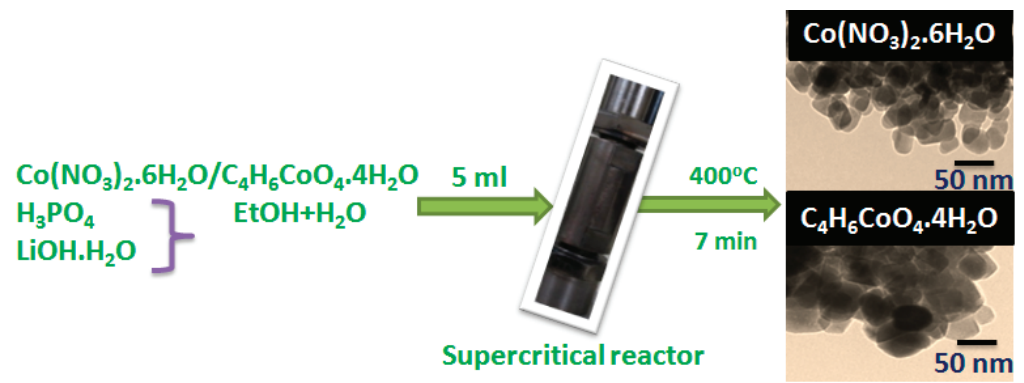




\subsection{X-ray Powder Diffraction Analysis}

The XRD patterns of as-synthesized $\mathrm{LiCoPO}_{4}$ particles at $400{ }^{\circ} \mathrm{C}$ for 7 min using $\mathrm{Co}\left(\mathrm{NO}_{3}\right)_{2}$ $6 \mathrm{H}_{2} \mathrm{O}$ and $\mathrm{C}_{4} \mathrm{H}_{6} \mathrm{CoO}_{4} 4 \mathrm{H}_{2} \mathrm{O}$ as starting materials via supercritical fluid process are shown in Figure 2 .

Figure 2. XRD patterns of $\mathrm{LiCoPO}_{4}$ nanoparticles synthesized using (a) $\mathrm{Co}\left(\mathrm{NO}_{3}\right)_{2}$ $6 \mathrm{H}_{2} \mathrm{O}$ and (b) $\mathrm{C}_{4} \mathrm{H}_{6} \mathrm{CoO}_{4} 4 \mathrm{H}_{2} \mathrm{O}$ via supercritical fluid process; (c) crystal structure of $\mathrm{LiCoPO}_{4}$.

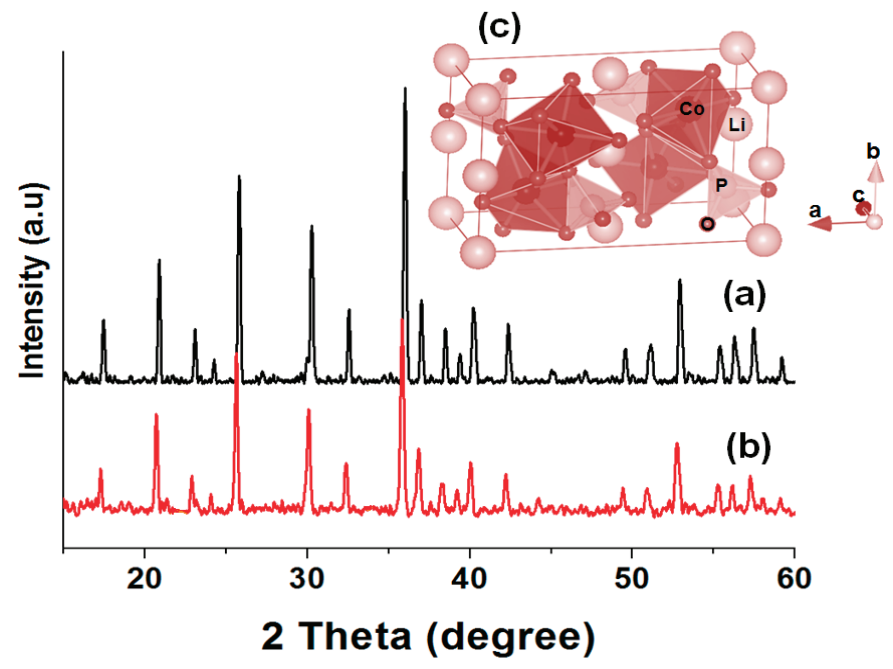

The observed diffraction peaks of both $\mathrm{LiCoPO}_{4}$ particles are well matched with JCPDS file (\# 00-085-0002), and belongs to orthorhombic crystal system with Pnma space group. The XRD patterns are in agreement with the reported pattern [23,31,46-49]. The calculated cell parameters and the Rietveld reliability factors for $\mathrm{LiCoPO}_{4}$ particles synthesized using $\mathrm{Co}\left(\mathrm{NO}_{3}\right)_{2} 6 \mathrm{H}_{2} \mathrm{O}$ and $\mathrm{C}_{4} \mathrm{H}_{6} \mathrm{CoO}_{4} 4 \mathrm{H}_{2} \mathrm{O}$ are $a=10.222 \AA, b=5.9273, c=4.7088, R_{\mathrm{WP}}=29.42 \%, R_{\mathrm{I}}=13.19 \%$ and $a=10.2046 \AA, \mathrm{b}=5.9183, \mathrm{c}=4.6977, R_{\mathrm{WP}}=27.63 \%, R_{\mathrm{I}}=16.22 \%$, respectively. The cell parameters are almost consistent with the reported values [50-52]. The Rietveld refinement results obtained from XRD pattern are shown in Table 1, the results showed almost same structural parameters for $\mathrm{LiCoPO}_{4}$ nanoparticles synthesized using $\mathrm{Co}\left(\mathrm{NO}_{3}\right)_{2} 6 \mathrm{H}_{2} \mathrm{O}$ and $\mathrm{C}_{4} \mathrm{H}_{6} \mathrm{CoO}_{4} 4 \mathrm{H}_{2} \mathrm{O}$. The experimental, calculated and observed XRD pattern are shown in Figure S1(a,b) (Supplementary information), which show no significant changes and impurity phases. From the XRD results, it is confirmed that single phase of $\mathrm{LiCoPO}_{4}$ was synthesized using $\mathrm{Co}\left(\mathrm{NO}_{3}\right)_{2} 6 \mathrm{H}_{2} \mathrm{O}$ (Figure 1(a)) and $\mathrm{C}_{4} \mathrm{H}_{6} \mathrm{CoO}_{4} 4 \mathrm{H}_{2} \mathrm{O}$ (Figure 1(b)) as starting materials via supercritical fluid process. The XRD pattern did not shows much difference except variations in the peak intensity. Due to higher solubility of $\mathrm{Co}\left(\mathrm{NO}_{3}\right)_{2} 6 \mathrm{H}_{2} \mathrm{O}$ in water-ethanol, the particles are well crystallized, so that the peak intensity of $\mathrm{LiCoPO}_{4}$ particles synthesized using $\mathrm{Co}\left(\mathrm{NO}_{3}\right)_{2} 6 \mathrm{H}_{2} \mathrm{O}$ is higher than that of $\mathrm{LiCoPO}_{4}$ particles synthesized using $\mathrm{C}_{4} \mathrm{H}_{6} \mathrm{CoO}_{4} 4 \mathrm{H}_{2} \mathrm{O}$. The model of $\mathrm{LiCoPO}_{4}$ crystal structure is shown in Figure 2(c), which shows the arrangement of cobalt octahedral and phosphor tetrahedral 
linked with oxygen either by corner sharing or edge sharing. It is also proved that, regardless of using different source materials in the present synthesis, supercritical fluid process is capable of producing high quality $\mathrm{LiCoPO}_{4}$ nanoparticles.

Table 1. Rietveld refinement results of XRD pattern of $\mathrm{LiCoPO}_{4}$ synthesized using $\mathrm{Co}\left(\mathrm{NO}_{3}\right)_{2} 6 \mathrm{H}_{2} \mathrm{O}$ and $\mathrm{C}_{4} \mathrm{H}_{6} \mathrm{CoO}_{4} 4 \mathrm{H}_{2} \mathrm{O}$.

\begin{tabular}{|c|c|c|c|c|c|c|c|c|c|c|c|}
\hline \multicolumn{2}{|c|}{$\begin{array}{l}\text { Formula Crystal } \\
\text { system Space } \\
\text { group }\end{array}$} & \multicolumn{5}{|c|}{$\begin{array}{l}\mathrm{LiCoPO}_{4}\left(\mathrm{Using} \mathrm{Co}\left(\mathrm{NO}_{3}\right)_{2} 6 \mathrm{H}_{2} \mathrm{O}\right) \\
\text { Orthorhombic } \\
\text { Pnma }\end{array}$} & \multicolumn{5}{|c|}{$\begin{array}{l}\mathrm{LiCoPO}_{4} \text { (Using } \mathrm{C}_{4} \mathrm{H}_{6} \mathrm{CoO}_{4} 4 \mathrm{H}_{2} \mathrm{O} \text { ) } \\
\text { Orthorhombic } \\
\text { Pnma }\end{array}$} \\
\hline Atom & Site & $\mathbf{X}$ & $\mathbf{Y}$ & $\mathbf{Z}$ & g & $\mathbf{B} / \AA^{2}$ & $\mathbf{X}$ & $\mathbf{Y}$ & $\mathbf{Z}$ & g & $\mathrm{B} / \AA^{2}$ \\
\hline $\mathrm{Li}$ & $4 a$ & 0.5 & 0.5 & 0.5 & 1 & 0.8 & 0.5 & 0.5 & 0.5 & 1 & 0.8 \\
\hline Co & $4 \mathrm{c}$ & 0.2778 & 0.25 & 0.9819 & 1 & 1.0 & 0.2783 & 0.25 & 0.9801 & 1 & 1.0 \\
\hline $\mathrm{P}$ & $4 \mathrm{c}$ & 0.096 & 0.25 & 0.420 & 1 & 1.5 & 0.096 & 0.25 & 0.416 & 1 & 1.5 \\
\hline $\mathrm{O}(1)$ & $4 \mathrm{c}$ & 0.091 & 0.25 & 0.736 & 1 & 1.7 & 0.085 & 0.25 & 0.728 & 1 & 1.7 \\
\hline $\mathrm{O}(2)$ & $4 c$ & 0.453 & 0.25 & 0.240 & 1 & 0.6 & 0.445 & 0.25 & 0.230 & 1 & 0.6 \\
\hline $\mathrm{O}(3)$ & $8 \mathrm{~d}$ & 0.160 & 0.029 & 0.278 & 1 & 0.9 & 0.157 & 0.0276 & 0.275 & 1 & 0.9 \\
\hline
\end{tabular}

\subsection{TEM and HRTEM Analysis}

The as-synthesized particles morphology, size and their crystalline nature are observed by TEM and HRTEM analysis and the results are shown in Figure 3(a-d) and Figure 3(e-h). The particles synthesized at $400{ }^{\circ} \mathrm{C}$ for 7 min using $\mathrm{Co}\left(\mathrm{NO}_{3}\right)_{2} \quad 6 \mathrm{H}_{2} \mathrm{O}$ (Figure $3(\mathrm{a}-\mathrm{d})$ ) and $\mathrm{C}_{4} \mathrm{H}_{6} \mathrm{CoO}_{4} 4 \mathrm{H}_{2} \mathrm{O}$ (Figure $3(\mathrm{e}-\mathrm{h})$ ) as starting materials via supercritical fluid process show mixed type morphologies, such as sphere, plate, and rod. The particles size are ranging from 20-50 nm in diameter for as-synthesized $\mathrm{LiCoPO}_{4}$ particles using $\mathrm{Co}\left(\mathrm{NO}_{3}\right)_{2} 6 \mathrm{H}_{2} \mathrm{O}$ (Figure 3(a,b)) and $\mathrm{C}_{4} \mathrm{H}_{6} \mathrm{CoO}_{4} 4 \mathrm{H}_{2} \mathrm{O}$ (Figure 3(e,f)) as starting materials. The as-synthesized particles are well distributed and softly agglomerated. The ED pattern and HRTEM images of as-synthesized particles using $\mathrm{Co}\left(\mathrm{NO}_{3}\right)_{2} 6 \mathrm{H}_{2} \mathrm{O}$ and $\mathrm{C}_{4} \mathrm{H}_{6} \mathrm{CoO}_{4} 4 \mathrm{H}_{2} \mathrm{O}$ are shown in Figure 3(c,d) and Figure 3(g,h), respectively. The SAED images of both samples (Figure 3(c,g)) are exhibited dot like pattern, which clearly shows the single crystalline nature of $\mathrm{LiCoPO}_{4}$ particles. However, as-synthesized particles using $\mathrm{Co}\left(\mathrm{NO}_{3}\right)_{2} 6 \mathrm{H}_{2} \mathrm{O}$ (Figure 4(c)) show weaker diffraction than the SAED pattern of as-synthesized particle using $\mathrm{C}_{4} \mathrm{H}_{6} \mathrm{CoO}_{4} 4 \mathrm{H}_{2} \mathrm{O}$ (Figure 3(g)). The HRTEM images show well resolved lattice fringes exhibiting interplanar spacing along [001] and [100] axis as shown in Figure 3(d,h). The interplanar spacing along $a$ axis show $1.02 \mathrm{~nm}$ which is consistent with the unit cell parameter of olivine structured $\mathrm{LiCoPO}_{4}$ along $a$-axis $\left(a=10.02 \mathrm{~A}^{\circ}\right)$. $\mathrm{LiCoPO}_{4}$ nanoparticles synthesized using two kinds of starting materials within a short reaction time via supercritical fluid process show well crystalline nanosize particles. In order to investigate effect of temperature and time on the particles formation, synthesis was carried out using $\mathrm{Co}\left(\mathrm{NO}_{3}\right)_{2} 6 \mathrm{H}_{2} \mathrm{O}$ and $\mathrm{C}_{4} \mathrm{H}_{6} \mathrm{CoO}_{4} 4 \mathrm{H}_{2} \mathrm{O}$ as starting materials and the results are shown in Table 2. When the reaction temperature was $300{ }^{\circ} \mathrm{C}$, sphere like particles were observed at 7,10 , and 15 min of reaction time with particles size ranging from 10-30 nm, the XRD pattern of this particles show nearly amorphous phase and particles were covered with lot of carbonaceous materials. When the reaction temperature was increased to $350{ }^{\circ} \mathrm{C}$ for about 7,10 , and $15 \mathrm{~min}$ of reaction time, the obtained particles were sphere and rod like particles with $20-70 \mathrm{~nm}$ in diameter. The XRD of these particles 
show mixed phase of $\mathrm{LiCoPO}_{4}$, and $\mathrm{Li}_{3} \mathrm{PO}_{4}$ phase. Single phase $\mathrm{LiCoPO}_{4}$ particles were obtained only at $400{ }^{\circ} \mathrm{C}$ for about 7,10 , and 15 min of reaction time, which were the optimum experimental conditions for the formation of $\mathrm{LiCoPO}_{4}$ under supercritical fluid conditions.

Figure 3. TEM, HRTEM, SAED images of $\mathrm{LiCoPO}_{4}$ nanoparticles synthesized using (a-d) $\mathrm{Co}\left(\mathrm{NO}_{3}\right)_{2} 6 \mathrm{H}_{2} \mathrm{O}$ and $(\mathbf{e}-\mathbf{h}) \mathrm{C}_{4} \mathrm{H}_{6} \mathrm{CoO}_{4} 4 \mathrm{H}_{2} \mathrm{O}$ as starting materials.
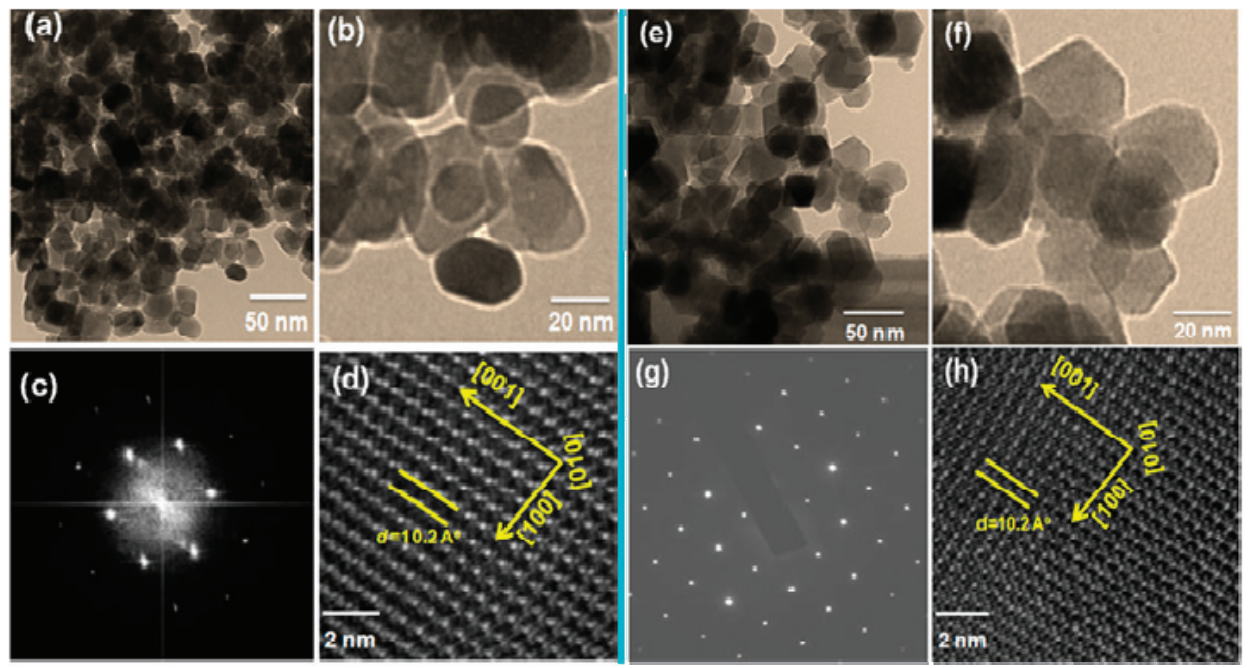

Table 2. Synthesis conditions for $\mathrm{LiCoPO}_{4}$ particles using $\mathrm{Co}\left(\mathrm{NO}_{3}\right)_{2} 6 \mathrm{H}_{2} \mathrm{O}$ and $\mathrm{C}_{4} \mathrm{H}_{6} \mathrm{CoO}_{4}$ $4 \mathrm{H}_{2} \mathrm{O}$ as starting materials.

\begin{tabular}{|c|c|c|c|c|}
\hline $\begin{array}{c}\text { Synthesis } \\
\text { Temperature }\left({ }^{\circ} \mathrm{C}\right)\end{array}$ & $\begin{array}{l}\text { Reaction Time } \\
\text { (min) }\end{array}$ & Morphology & $\begin{array}{l}\text { Particle size } \\
(\text { nm) }\end{array}$ & XRD \\
\hline 300 & $7,10 \& 15$ & \multirow{3}{*}{$\begin{array}{c}\text { Sphere } \\
\text { Sphere \& rods } \\
\text { Sphere, plates \& } \\
\text { rods }\end{array}$} & $10-30$ & nearly amorphous \\
\hline 350 & $7,10 \& 15$ & & $10-30$ & $\mathrm{LiCoPO}_{4}, \mathrm{Li}_{3} \mathrm{PO}_{4}$ \\
\hline 400 & $7,10 \& 15$ & & $10-30$ & $\mathrm{LiCoPO}_{4}$ \\
\hline
\end{tabular}

\subsection{Elemental Mapping}

The as-synthesized particles using $\mathrm{Co}\left(\mathrm{NO}_{3}\right)_{2} 6 \mathrm{H}_{2} \mathrm{O}$ and $\mathrm{C}_{4} \mathrm{H}_{6} \mathrm{CoO}_{4} 4 \mathrm{H}_{2} \mathrm{O}$ as starting materials were subjected to STEM analysis to verify the purity of $\mathrm{LiCoPO}_{4}$ nanoparticles. Figure 4 shows the elemental mapping of both the particles.

The uniform distribution of oxygen, phosphor and cobalt elements can be clearly observed in the STEM images. This result indicated that the as-synthesized particles have homogeneous elemental distribution and high purity without any impurities. The EDS spectrum of the as-synthesized using $\mathrm{Co}\left(\mathrm{NO}_{3}\right)_{2} 6 \mathrm{H}_{2} \mathrm{O}$ and $\mathrm{C}_{4} \mathrm{H}_{6} \mathrm{CoO}_{4} 4 \mathrm{H}_{2} \mathrm{O}$ as starting materials are shown in Figure 5 . The particles exhibited characteristic peaks of $\mathrm{Co}, \mathrm{P}$, and $\mathrm{O}$ elements in $\mathrm{LiCoPO}_{4}$ nanoparticles. The peak below $0.3 \mathrm{eV}$ is corresponds to the carbon peak, the intensity of $\mathrm{C}$ peak is higher for the $\mathrm{LiCoPO}_{4}$ nanoparticles synthesized using $\mathrm{C}_{4} \mathrm{H}_{6} \mathrm{CoO}_{4} 4 \mathrm{H}_{2} \mathrm{O}$ as starting material due to the formation of carbon after dissociation reaction of $\mathrm{C}_{4} \mathrm{H}_{6} \mathrm{CoO}_{4} 4 \mathrm{H}_{2} \mathrm{O}$ at supercritical fluid conditions. However, 
presence of carbon in these cathode materials is beneficial in order improve the conductivity of the $\mathrm{LiCoPO}_{4}$ nanoparticles during electrochemical reactions [46,47].

Figure 4. STEM images of $\mathrm{LiCOPO}_{4}$ nanoparticles synthesized using $\mathrm{Co}\left(\mathrm{NO}_{3}\right)_{2} 6 \mathrm{H}_{2} \mathrm{O}$ and $\mathrm{C}_{4} \mathrm{H}_{6} \mathrm{CoO}_{4} 4 \mathrm{H}_{2} \mathrm{O}$ as starting materials.

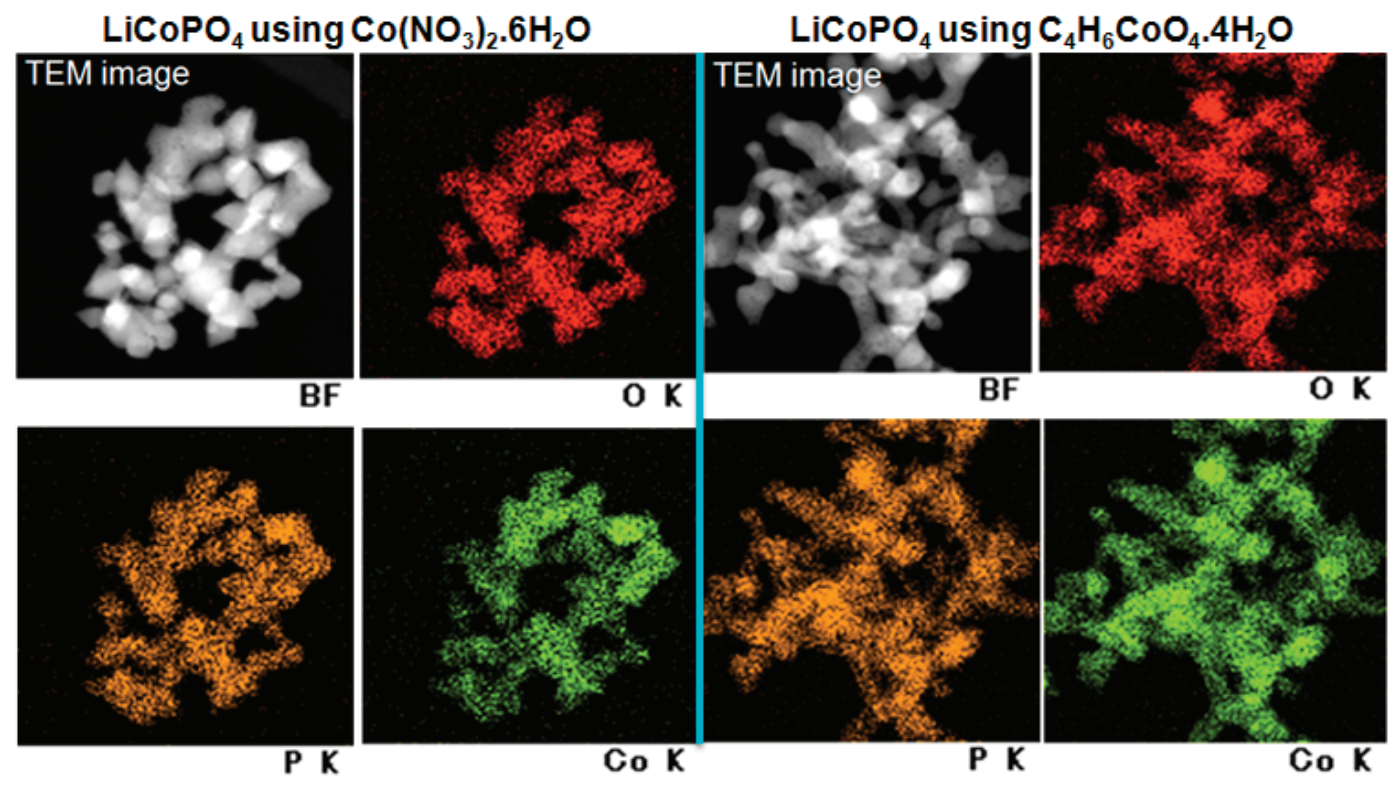

\subsection{BET and TG-Analysis}

The surface area of the as-synthesized particles using $\mathrm{Co}\left(\mathrm{NO}_{3}\right)_{2} 6 \mathrm{H}_{2} \mathrm{O}$ and $\mathrm{C}_{4} \mathrm{H}_{6} \mathrm{CoO}_{4} 4 \mathrm{H}_{2} \mathrm{O}$ are analysed by BET analysis. The surface area of $14.3 \mathrm{~m}^{2} / \mathrm{g}$ for $\mathrm{LiCoPO}_{4}$ nanoparticles synthesized using $\mathrm{Co}\left(\mathrm{NO}_{3}\right)_{2} 6 \mathrm{H}_{2} \mathrm{O}$ and $16.5 \mathrm{~m}^{2} / \mathrm{g}$ for $\mathrm{LiCoPO}_{4}$ particles synthesized using $\mathrm{C}_{4} \mathrm{H}_{6} \mathrm{CoO}_{4} 4 \mathrm{H}_{2} \mathrm{O}$ were observed. Generally, nanosize particles with higher surface area are beneficial for enhanced electrochemical reactions.

The carbon content in the as-synthesized $\mathrm{LiCoPO}_{4}$ nanoparticles using $\mathrm{Co}\left(\mathrm{NO}_{3}\right)_{2} \quad 6 \mathrm{H}_{2} \mathrm{O}$ and $\mathrm{C}_{4} \mathrm{H}_{6} \mathrm{CoO}_{4} 4 \mathrm{H}_{2} \mathrm{O}$ are analyzed by $\mathrm{TG}$ analysis. The weight loss of $16 \mathrm{wt} \%$ for $\mathrm{LiCoPO}_{4}$ nanoparticles synthesized using $\mathrm{Co}\left(\mathrm{NO}_{3}\right)_{2} 6 \mathrm{H}_{2} \mathrm{O}$ and $18 \mathrm{wt} \%$ for $\mathrm{LiCoPO}_{4}$ particles synthesized using $\mathrm{C}_{4} \mathrm{H}_{6} \mathrm{CoO}_{4}$ $4 \mathrm{H}_{2} \mathrm{O}$ were observed as show in Figure 6 . The observed weight loss is the weight of carbon present in the as-synthesized particles. This carbon could be amorphous material and is not conductive, which is not useful in improving the electronic conductivity of $\mathrm{LiCoPO}_{4}$ electrode materials. 
Figure 5. EDS of $\mathrm{LiCoPO}_{4}$ nanoparticles synthesized using (a) $\mathrm{Co}\left(\mathrm{NO}_{3}\right)_{2} 6 \mathrm{H}_{2} \mathrm{O}$ and (b) $\mathrm{C}_{4} \mathrm{H}_{6} \mathrm{CoO}_{4} 4 \mathrm{H}_{2} \mathrm{O}$ as starting materials.
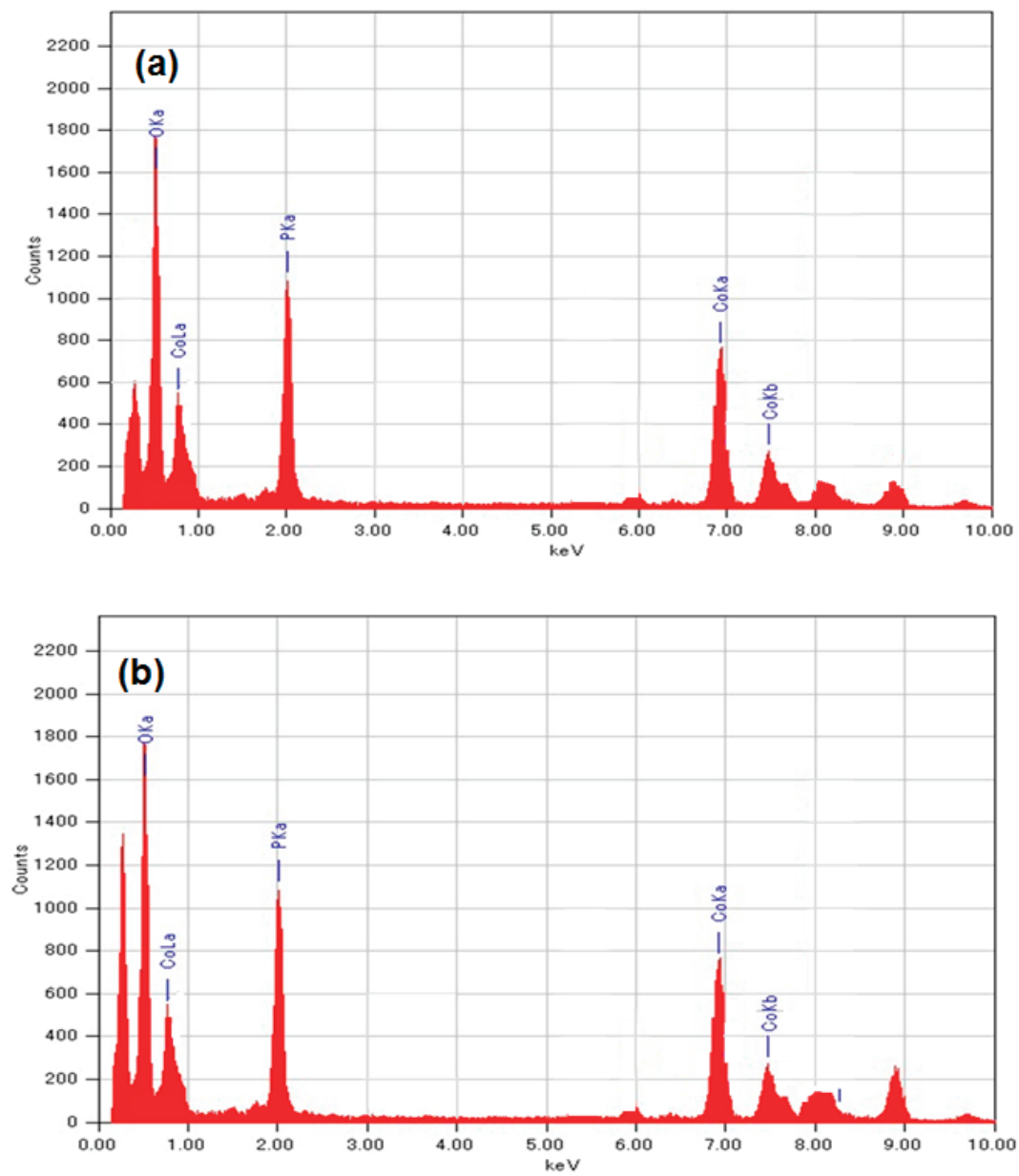

\subsection{Electrochemical Performance}

The electrochemical performances of as-synthesized particles using $\mathrm{Co}\left(\mathrm{NO}_{3}\right)_{2} \quad 6 \mathrm{H}_{2} \mathrm{O}$ and $\mathrm{C}_{4} \mathrm{H}_{6} \mathrm{CoO}_{4} 4 \mathrm{H}_{2} \mathrm{O}$ were measured by galvanostatic charge-discharge method. Figure 7 shows the discharge profiles and cyclic performance (Figure $7(\mathrm{c})$ ) of $\mathrm{LiCoPO}_{4}$ nanoparticles synthesized using $\mathrm{Co}\left(\mathrm{NO}_{3}\right)_{2} \quad 6 \mathrm{H}_{2} \mathrm{O}$ (Figure $7(\mathrm{a})$ ) and $\mathrm{C}_{4} \mathrm{H}_{6} \mathrm{CoO}_{4} 4 \mathrm{H}_{2} \mathrm{O}$ (Figure 7 (b)) at $400{ }^{\circ} \mathrm{C}$ for 7 min via supercritical fluid process. The discharge measurement was carried out at $0.1 \mathrm{C}$ rate for $\mathrm{LiCoPO}_{4}$ nanoparticles, which show a flat discharge curve around $4.75 \mathrm{~V}$. The charge capacities of 150 and $165 \mathrm{mAhg}^{-1}$ for first and second cycle was observed for $\mathrm{LiCoPO}_{4}$ nanoparticles synthesized using $\mathrm{Co}\left(\mathrm{NO}_{3}\right)_{2} 6 \mathrm{H}_{2} \mathrm{O}$ as starting material. The charge capacities of $140 \mathrm{~mA} \mathrm{~h} \mathrm{~g}^{-1}$ and $152 \mathrm{~mA} \mathrm{~h} \mathrm{~g}^{-1}$ for the first and second cycle were observed for $\mathrm{LiCoPO}_{4}$ nanoparticles, which were synthesized using $\mathrm{C}_{4} \mathrm{H}_{6} \mathrm{CoO}_{4} 4 \mathrm{H}_{2} \mathrm{O}$ as starting material. The discharge capacities of $98 \mathrm{~mA} \mathrm{~h} \mathrm{~g}$ and $115 \mathrm{~mA} \mathrm{~h} \mathrm{~g}^{-1}$ (Figure 7 (a)) for the first cycle and $62 \mathrm{~mA} \mathrm{~h} \mathrm{~g}^{-1}$ and $101 \mathrm{~mA} \mathrm{~h} \mathrm{~g}^{-1}$ (Figure 7(b)) for the 
second cycles were observed. The origin of discharge capacity of $20 \mathrm{~mA} \mathrm{~h} \mathrm{~g}$-1 around 2.5-3 V with slope like profile is might be due to the effect of particle size because of high surface area than the bulk particles, which could be responsible for secondary reactions. However, the observed discharge capacities are reasonable and even higher than that of few recently reported discharge capacities of $\mathrm{LiCoPO}_{4}$ particles synthesized by different routes [20,22].

Figure 6. TG analysis of $\mathrm{LiCoPO}_{4}$ nanoparticles synthesized using (a) $\mathrm{Co}\left(\mathrm{NO}_{3}\right)_{2} 6 \mathrm{H}_{2} \mathrm{O}$ and (b) $\mathrm{C}_{4} \mathrm{H}_{6} \mathrm{CoO}_{4} 4 \mathrm{H}_{2} \mathrm{O}$ as starting materials.

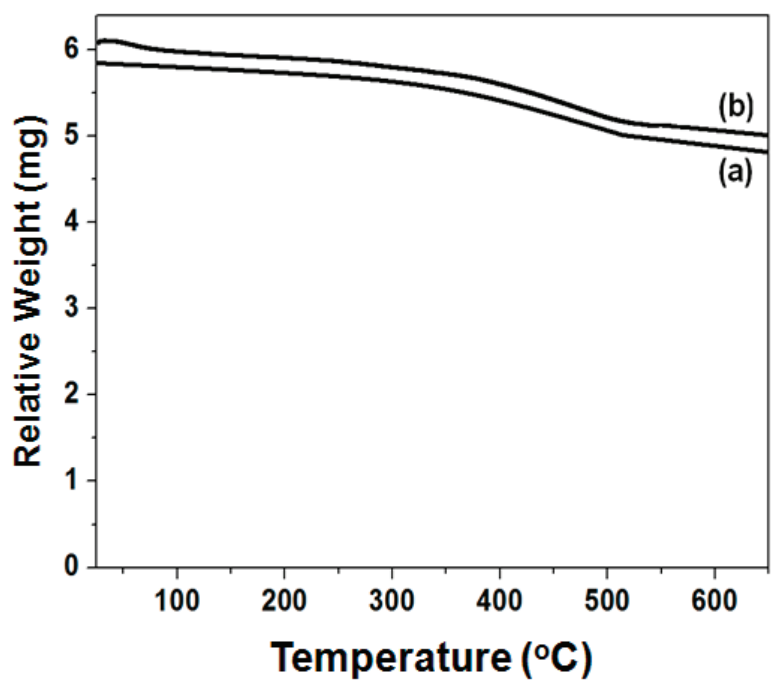

$\mathrm{LiCoPO}_{4}$ nanoparticles synthesized using $\mathrm{C}_{4} \mathrm{H}_{6} \mathrm{CoO}_{4} 4 \mathrm{H}_{2} \mathrm{O}$ show the highest discharge capacities, which might be due to the presence of carbon residue derived from decomposition of $\mathrm{C}_{4} \mathrm{H}_{6} \mathrm{CoO}_{4} 4 \mathrm{H}_{2} \mathrm{O}$ at the supercritical fluid reaction. Probably, this carbon was coated onto the surface of $\mathrm{LiCoPO}_{4}$ nanoparticles, which results in better electronic mobility. However, reasonable discharge capacities observed for both the $\mathrm{LiCoPO}_{4}$ nanoparticles, which are due to the small particle size, good crystallinity, and due to the nature of starting materials used in the synthesis. However, poor cyclic performance was observed for $\mathrm{LiCoPO}_{4}$ nanoparticles (Figure 7 (c)), which is mainly due to the instability of electrolyte at $5 \mathrm{~V}$, and due to the side reactions between electrolyte and electrode and results in the formation a solid-electrolyte interface (SEI) which cause the electrolyte oxidation and lithium loss [47]. Usually, $\mathrm{LiCoPO}_{4}$ cathodes suffered from poor cycling stability [49]. Another possible reason may be due to the antisite defects, where $\mathrm{Li}^{+}$site is occupied by $\mathrm{Co}$ atom upon charge process and which block the $\mathrm{Li}^{+}$during discharge process, so deficiency of lithium is occurred during electrochemical reaction [48]. Further, characterization is necessary to investigate on antisite defects in olivine structured cathode materials, for that $\mathrm{ADF} / \mathrm{ABF}$ analysis might be very useful to locate the cobalt atoms in lithium site. 
Figure 7. Discharge profiles of $\mathrm{LiCoPO}_{4}$ nanoparticles synthesized using (a) $\mathrm{Co}\left(\mathrm{NO}_{3}\right)_{2}$ $6 \mathrm{H}_{2} \mathrm{O}$ and (b) $\mathrm{C}_{4} \mathrm{H}_{6} \mathrm{CoO}_{4} 4 \mathrm{H}_{2} \mathrm{O}$ as starting materials; (c) cyclic performance.
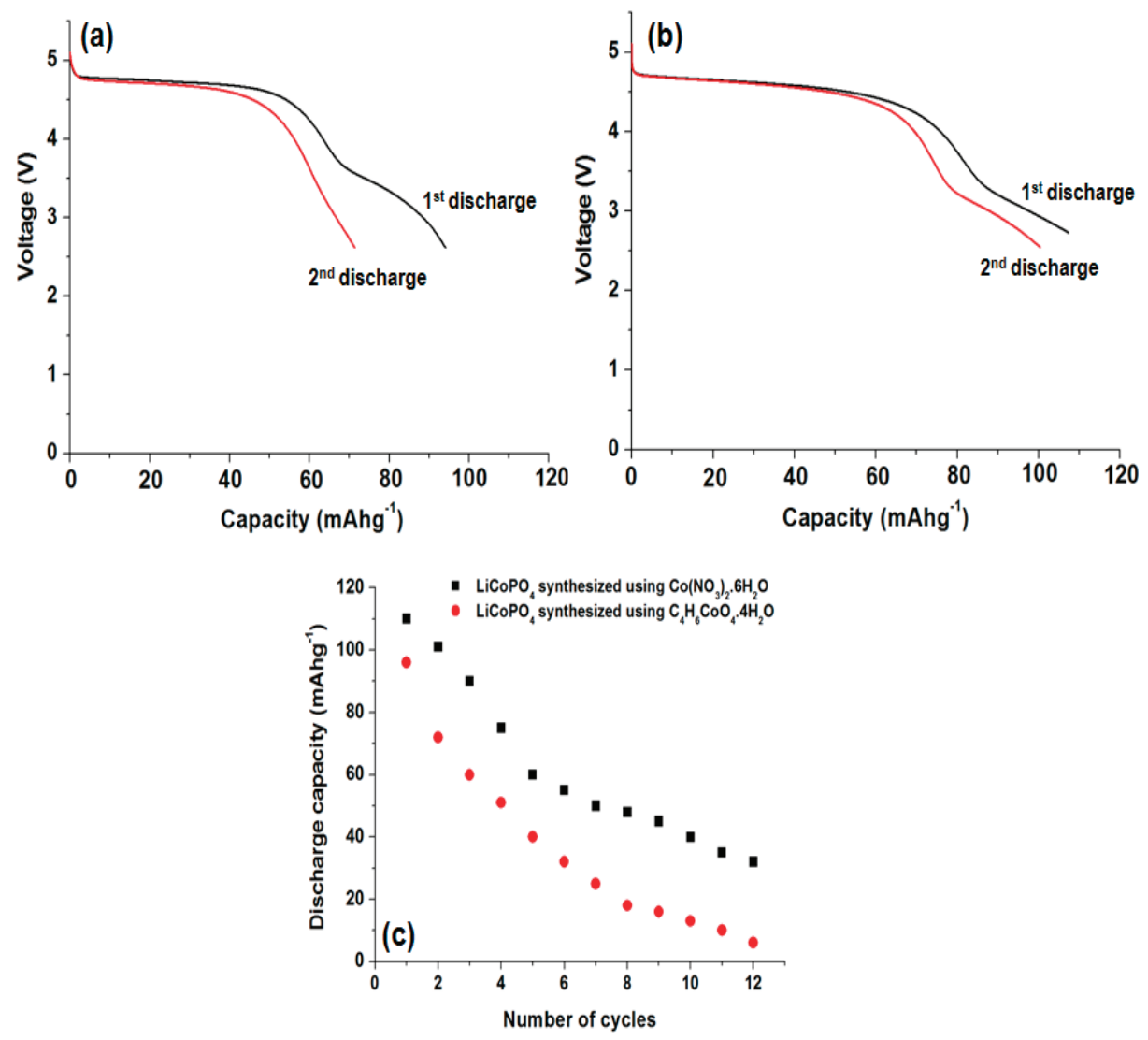

\section{Experimental Section}

\subsection{Synthesis of $\mathrm{LiCOPO}_{4}$ Nanoparticles}

$\mathrm{LiCoPO}_{4}$ nanoparticles were synthesized using two kinds of starting materials such as cobalt (II) nitrate hexahydrate $\left(\mathrm{Co}\left(\mathrm{NO}_{3}\right)_{2} 6 \mathrm{H}_{2} \mathrm{O}\right)$ and cobalt (II) acetate tetra hydrate $\left(\mathrm{C}_{4} \mathrm{H}_{6} \mathrm{CoO}_{4} 4 \mathrm{H}_{2} \mathrm{O}\right)$. In a typical synthesis, cobalt (II) nitrate hexahydrate or cobalt (II) acetate tetra hydrate (Wako, Japan), orthophosphoric acid (o- $\mathrm{H}_{3} \mathrm{PO}_{4}$ : Wako, Japan) and lithium hydroxide monohydrate $\left(\mathrm{LiOH} \mathrm{H}_{2} \mathrm{O}\right.$ : Wako, Japan) were used in 1:1:1 molar ratio. Ascorbic acid (Wako, Japan) was used as reducing agent. The above starting materials were dissolved in mixed solvents of water and ethanol (1:1 volume ratio), the solution was stirred for 15-20 min and then $0.5 \mathrm{~g}$ of ascorbic acid was added to the solution. Later, the solution mixture $(5 \mathrm{~mL})$ was transferred to batch reactors (4 reactors, each $10 \mathrm{~mL}$ volume) followed by heating at $400{ }^{\circ} \mathrm{C}$ for $7 \mathrm{~min}$, then reactors were quenched in cold water, the products were recovered through repeated washings using ethanol and water. 


\subsection{Material Characterization}

The crystalline phase of the samples were characterized using powder X-ray diffraction (XRD; Rigaku RINV-2200, $40 \mathrm{kV}$ and $30 \mathrm{~mA}$ ) with CuK $\alpha$ radiation $(\lambda=1.5406 \AA)$. The XRD patterns were analyzed by the Rietveld method using the program RIETAN-2000 [53]. The particles morphology, purity and elemental distribution was observed by transmission electron microscopy (JEOL TEM-2100F), elemental mapping and energy dispersive spectroscopy (EDS, JEM-2010F at $200 \mathrm{KeV}$ ). Selected area electron diffraction (SAED) and lattice fringes observation done by using high-resolution transmission electron microscopy (HRTEM, JEOL JEM 2100F, $200 \mathrm{kV}$ ). The surface area was measured using a Brunauer-Emmet-Teller (BET, NOVA 4200e) surface area and pore size analyzer. Thermo-gravimetric (TG) analysis was performed in air using a TG-DTA $2000 \mathrm{~S}$ system to ascertain the exact carbon content in the $\mathrm{LiCoPO}_{4}$ cathode material; the temperature was limited to $650{ }^{\circ} \mathrm{C}$ in order to avoid the oxidation of $\mathrm{LiCoPO}_{4}$.

\subsection{Electrochemical Performance}

The electrochemical performance of $\mathrm{LiCoPO}_{4}$ was investigated using coin-type cells (CR2032). The working electrodes is composed of $83 \mathrm{wt} \% \mathrm{LiCoPO}_{4}$ mixed with $10 \mathrm{wt} . \%$ acetylene black and 7 wt.\% PTFE (poly(tetrafluoroethylene)) as a binder. The electrode paste was spread uniformly and vacuum dried for $12 \mathrm{~h}$ at $160{ }^{\circ} \mathrm{C}$. Later, cathode was punched into circular discs and cut into wafers ( $7 \mathrm{~mm}$ in diameter, $0.025 \mathrm{~mm}$ in thickness, 3-5 mg). The tested cell was assembled inside an argon-filled glove box. For electrochemical measurements, the cell is composed of lithium metal counter, reference electrodes and a $\mathrm{LiCoPO}_{4}$ positive electrode. $1 \mathrm{M} \mathrm{LiPF}_{6}$ in a mixed solvent of ethylene carbonate (EC) and dimethyl carbonate (DMC) with 1:1 in volume ratio (Tomiyama Pure Chemical Co., Ltd., Tokyo, Japan) was used as the electrolyte. The galvanostatic charge-discharge cycling was performed between 2.5 and $5.1 \mathrm{~V}$ versus $\mathrm{Li}^{+} / \mathrm{Li}$ on multi-channel battery testers (Hokuto Denko, Japan). Current densities and specific capacities were calculated on the basis of the weight of $\mathrm{LiCoPO}_{4}$ cathode used in the electrode.

\section{Conclusions}

$\mathrm{LiCoPO}_{4}$ nanoparticles were successfully synthesized using cobalt (II) nitrate hexahydrate and cobalt (II) acetate tetrahydrate at $400{ }^{\circ} \mathrm{C}$ for $7 \mathrm{~min}$ via supercritical fluid process. The as-synthesized particles showed $20-50 \mathrm{~nm}$ in diameter with mixed type morphology observed by TEM analysis. The starting materials did not affect much on particles size and morphology of $\mathrm{LiCoPO}_{4}$ particles. The phase purity of as-synthesized particles was confirmed by XRD, Rietveld analysis, STEM, and EDS analysis. Electron diffraction analysis and high-resolution image shows that, the particles are single crystalline and exhibits well-aligned crystal planes without any dislocations or defects. The experimental results show that, supercritical fluid process can synthesize single crystalline $\mathrm{LiCoPO}_{4}$ nanoparticles using different kind of starting materials. Further, application of as-synthesized $\mathrm{LiCoPO}_{4}$ nanoparticles as cathode part to Li-ion battery is tested by galvanostatic charge-discharge methods. $\mathrm{LiCoPO}_{4}$ nanoparticles synthesized using cobalt (II) nitrate hexahydrate and cobalt (II) acetate tetra hydrate show reasonable electrochemical performances. The highest discharge 
capacity of $115 \mathrm{~mA} \mathrm{~h} \mathrm{~g}^{-1}$ for the first cycle is observed for the nanoparticles synthesized using cobalt (II) acetate tetrahydrate. However, poor cyclic performance was observed for these nanoparticles, conductive carbon coating and protection of interface would require improving the cyclic performance.

\section{Acknowledgments}

One of the authors (Murukanahally Kempaiah Devaraju) would like to acknowledge the financial support by Japan Society for Promotion of Science, Japan for their fellowship to carry out the research work.

\section{Author Contributions}

M.K.D. and I.H. conceived and designed this work. The synthesis of the material and characterization was carried out by M.K.D. and the paper was written by M.K.D., H.H performed Rietveld analysis. T.T. and Q.D.T. participated in discussion of the results.

\section{Conflicts of Interest}

The authors declare no conflict of interest.

\section{References}

1. Ceder, G.; Chiang, Y.M.; Sadoway, D.R.; Aydinol, M.K.; Jang, Y.I.; Huang, B. Identification of cathode materials for lithium batteries guided by first-principles calculations. Nature 1998, 392, 694-696.

2. Andersson, A.M.; Abraham, D.P.; Haasch, R.; MacLaren, S.; Liu, J.; Amine, K. Surface characterization of electrodes from high power lithium-ion batteries. J. Electrochem. Soc. 2002, 149, A1358-A1369.

3. Chen, J.; Vacchio, M.J.; Wang, S.; Chernova, N.; Zavalij, P.Y.; Whittingham, M.S. The hydrothermal synthesis and characterization of olivines and related compounds for electrochemical applications. Solid State Ionics 2008, 178, 1676-1693.

4. Padhi, A.K.; Nanjundaswamy, K.S.; Goodenough, J.B. Phospho-olivines as positive-electrode materials for rechargeable lithium batteries. J. Electrochem. Soc. 1997, 144, 1188.

5. Yang, H.; Wu, X.L.; Cao, M.H.; Guo, Y.G. Solvothermal synthesis of $\mathrm{LiFePO}_{4}$ hierarchically dumbbell-like microstructures by nanoplate self-assembly and their application as a cathode material in lithium-ion batteries. J. Phys. Chem. C 2009, 113, 3345-3351.

6. Delacourt, C.; Poizot, P.; Morcrette, M.; Tarascon, J.-M.; Masquelier, C. One-step low-temperature route for the preparation of electrochemically active $\mathrm{LiMnPO}_{4}$ powders. Chem. Mater. 2004, 16, 93-99.

7. Fisher, C.A.J.; Prieto, V.M.H.; Islam, M.S. Lithium Battery Materials $\mathrm{LiMPO}_{4}(\mathrm{M}=\mathrm{Mn}, \mathrm{Fe}$, Co, Ni): Insights into Defect Association, Transport Mechanisms and Doping Behavior. Chem. Mater. 2008, 20, 5907-5915. 
8. Ren, M.M.; Zhou, Z.; Gao, X.P.; Peng, W.X.; Wei, J.P. Core-shell $\mathrm{Li}_{3} \mathrm{~V}_{2}\left(\mathrm{PO}_{4}\right)_{3} @ \mathrm{C}$ composites as cathode materials for lithium-ion batteries. J. Phys. Chem. C 2008, 112, 5689-5693.

9. Amine, A.; Yasuda, H.; Yamachi, M. Olivine $\mathrm{LiCoPO}_{4}$ as $4.8 \mathrm{~V}$ electrode material for lithium batteries. Electrochem. Solid-State Lett. 2000, 3, 178.

10. Rabanal, M.E.; Gutierrez, M.C.; Garcia-Alvarado, F.; Gonzalo, E.C.; Arroyo-de Dompablo, M.E. Improved electrode characteristics of olivine- $\mathrm{LiCoPO}_{4}$ processed by high energy milling. J. Power Sources 2006, 160,523-528.

11. Yang, J.; Xu, J.J. Synthesis and characterization of carbon-coated lithium transition metal phosphates $\mathrm{LiMPO}_{4}(\mathrm{M}=\mathrm{Fe}, \mathrm{Mn}, \mathrm{Co}, \mathrm{Ni})$ prepared via a nonaqueous sol-gel route. J. Electrochem. Soc. 2006,153, A716-A723.

12. Piana, M.; Arrabito, M.; Bodoardo, S.; D’Epifanio, A.; Satolli, D.; Croce, F.; Scrosati, B. Characterization of phospho-olivines as materials for Li-ion cell cathodes. Ionics 2002, 8, 17-26.

13. Wang, D.; Wang, Z.; Huang, X.; Chen, L. Cracking causing cyclic instability of $\mathrm{LiFePO}_{4}$ cathode material. J. Power Sources 2005, 146, 580-583.

14. Ruffo, R.; Mari, C.M.; Morazzoni, F.; Rosciano, F.; Scotti, R. Electrical and electrochemical behaviour of several $\mathrm{LiFe}_{x} \mathrm{Co}_{1-x} \mathrm{PO}_{4}$ solid solutions as cathode materials for lithium ion batteries. Ionics 2007, 13, 287-291.

15. Wolfenstine, J.; Read, J.; Allen, J.L. Effect of carbon on the electronic conductivity and discharge capacity LiCoPO4. J. Power Sources 2007,163, 1070-1073.

16. Jang, I.C.; Son, C.G.; Yang, A.J.W.; Lee, S.M.G.; Cho, A.R.; Aravindan, V.; Park, G.J.; Kang, K.S.; Kim, W.S.; Cho, W.I.; et al. $\mathrm{LiFePO}_{4}$ modified $\mathrm{Li}_{1.02}\left(\mathrm{Co}_{0 .} \mathrm{Fe}_{0.1}\right)_{0.98} \mathrm{PO}_{4}$ cathodes with improved lithium storage properties. J. Mater. Chem. 2011, 21, 6510-6514.

17. Ju, H.; Wu, J.; Xu, Y. Lithium ion intercalation mechanism for $\mathrm{LiCoPO}_{4}$ electrode. Int. J. Energy Env. Eng. 2013, 4, 22.

18. Yujuan, Z.; Suijun, W.; Chunsong, Z.; Dingguo, X. Synthesis and electrochemical performance of $\mathrm{LiCoPO}_{4}$ micron-rods by dispersant-aided hydrothermal method for lithium ion batteries. Rare Met. 2009, 28, 117-121.

19. Huang, X.; Ma, J.; Wu, P.; Hu, Y.; Dai, J.; Zhu, Z.; Chen, H.; Wang, H. Hydrothermal synthesis of $\mathrm{LiCoPO}_{4}$ cathode materials for rechargeable lithium ion batteries. Mater. Lett. 2005, 59, 578-582.

20. Kotobuki, M. Hydrothermal synthesis of carbon-coated $\mathrm{LiCoPO}_{4}$ cathode material from various Co sources. Int. J. Energy Env. Eng. 2013, 4, 25.

21. Gangulibabu, D.; Bhuvaneswari, N.; Kalaiselvi, N.; Jayaprakash, P.; Periasamy, J. CAM sol-gel synthesized $\mathrm{LiMPO}_{4}(\mathrm{M}=\mathrm{Co}$, Ni) cathodes for rechargeable lithium batteries. Sol-Gel Sci. Technol. 2009, 49, 137-144.

22. Rajalakshmi, A.; Nithya, V.D.; Karthikeyan, K.; Sanjeeviraja, K.C.; Lee, Y.S.; Kalai Selvan, R. Physicochemical properties of $\mathrm{V}^{5+}$ doped $\mathrm{LiCoPO}_{4}$ as cathode materials for Li-ion batteries. J. Sol-Gel Sci. Technol. 2013, 65, 399-410. 
23. Sahnmukaraj, D.; Murugan, R. Synthesis and characterization of $\mathrm{LiNi}_{y} \mathrm{Co}_{-y} \mathrm{PO} 4(y=0-1)$ cathode materials for lithium secondary batteries. Ionics 2004, 10, 88-92.

24. Saint-Martin, R.; Franger, S. Growth of $\mathrm{LiCoPO}_{4}$ single crystals using an optical floating-zone technique. J. Cryst. Growth 2008, 310, 861-864.

25. Xie, J.; Imanishi, N.; Zhang, T.; Hirano, A.; Takeda, Y.; Yamamoto, O. Li-ion diffusion kinetics in $\mathrm{LiCoPO}_{4}$ thin films deposited on NASICON-type glass ceramic electrolytes by magnetron sputtering. J. Power Sources 2009,192, 689-692.

26. Shui, J.L.; Yu, Y.; Yang, X.F.; Chen, C.H. LiCoPO 4 -based ternary composite thin-film electrode for lithium secondary battery. Electrochem. Commun. 2006, 8, 1087-1091.

27. Li, H.H.; Jin, J.; Wei, J.P.; Zhou, Z.; Yan, J.J. Fast synthesis of core-shell $\mathrm{LiCoPO}_{4} / \mathrm{C}$ nanocomposite via microwave heating and its electrochemical Li intercalation performances. Electrochem. Commun. 2009, 11, 95-98.

28. Doan, T.N.L.; Taniguchi, I. Cathode performance of $\mathrm{LiMnPO}_{4} / \mathrm{C}$ nanocomposites prepared by a combination of spray pyrolysis and wet ball-milling followed by heat treatment. J. Power Sources 2011,196, 1399-1408.

29. Devaraju, M.K.; Honma, I. Hydrothermal and solvothermal process towards development of $\mathrm{LiMPO}_{4}(\mathrm{M}=\mathrm{Fe}, \mathrm{Mn})$ nanomaterials for lithium-ion batteries. Adv. Energy Mater. 2012, 2, 284-297.

30. Devaraju, M.K.; Sathish, M.; Honma, I. In Handbook of Sustainable Engineering; Kauffman, J., Lee, K.-M., Eds.; Springer: Dordrecht, The Netherlands, 2013; pp. 1149-1173.

31. Devaraju, M.K.; Rangappa, D.; Honma, I. Controlled synthesis of plate-like $\mathrm{LiCoPO}_{4}$ nanoparticles via supercritical method and their electrode property. Electrochem. Acta 2012, $85,548$.

32. Hong, S.; Kim, S.J.; Chung, K.Y.; Chung, M.S.; Lee, B.G.; Kim, J. Continuous synthesis of lithium iron phosphate $\left(\mathrm{LiFePO}_{4}\right)$ nanoparticles in supercritical water: Effect of mixing tee. J. Supercrit. Fluids 2013, 73, 70-79.

33. Adschiri, T.; Lee, Y.W.; Goto, M.; Takamib, S. Green materials synthesis with supercritical water. Green Chem. 2011, 13, 1380-1390.

34. Hong, S.; Kim, S.J.; Chung, K.Y.; Lee, Y.W.; Kim, J.; Sang, B. Continuous synthesis of lithium iron phosphate nanoparticles in supercritical water: Effect of process parameters. Chem. Eng. J. 2013, 229, 313-323.

35. Nugroho, A.; Kim, S.J.; Kyung, W.C.; Chung, Y.; Kim, J. Facile synthesis of hierarchical mesoporous $\mathrm{Li}_{4} \mathrm{Ti}_{5} \mathrm{O}_{12}$ microspheres in supercritical methanol. J. Power Sources 2013, 244, 164-169.

36. Nugroho, A.; Kim, S.J.; Chung, K.Y.; Kim, J. Synthesis of $\mathrm{Li}_{4} \mathrm{Ti}_{5} \mathrm{O}_{12}$ in Supercritical water for Li-Ion batteries: Reaction mechanism and high-rate performance. Electrochim. Acta 2012, 78, 623-632.

37. Nugroho, A.; Chang, W.; Kim, S.J.; Chung, K.Y.; Kim, J. Superior high rate performance of core-shell $\mathrm{Li}_{4} \mathrm{Ti}_{5} \mathrm{O}_{12} /$ Carbon Nanocomposite synthesized by a supercritical alcohol approach. RSC Adv. 2012, 2, 10805-10808. 
38. Jensen, K.; Christensen, M.; Tyrsted, C.; Brummerstedt Iversen, B. Real-time synchrotron powder X-ray diffraction study of the antisite defect formation during sub- and supercritical synthesis of $\mathrm{LiFePO}_{4}(4)$ and $\mathrm{LiFe}_{1-x} \mathrm{Mn}_{x} \mathrm{PO}_{4}$ nanoparticles. J. Appl. Crystallogr. 2011, 44, 287-294.

39. Rangappa, D.; Sone, K.; Kudo, T.; Honma, I. Directed growth of nanoarchitectured $\mathrm{LiFePO}_{4}$ electrode by solvothermal synthesis and their cathode properties. J. Power Sources 2010, 195, 6167-6171.

40. Rangappa, D.; Sone, K.; Ichihara, M.; Kudo, T.; Honma, I. Rapid one-pot synthesis of $\mathrm{LiMPO}_{4}(\mathrm{M}=\mathrm{Fe}, \mathrm{Mn})$ colloidal nanocrystals by supercritical ethanol process. Chem. Commun. 2010, 46, 7548 .

41. Devaraju, M.K.; Dinesh, R.; Honma, I. Controlled synthesis of nanocrystalline $\mathrm{Li}_{2} \mathrm{MnSiO}_{4}$ particles for high capacity cathode application in lithium-ion batteries. Chem. Commun. 2012, 48, 2698-2700.

42. Dinesh, R.; Devaraju, M.K.; Tomai, T.; Unemoto, A.; Honma, I. Ultrathin nanosheets of $\mathrm{Li}_{2} \mathrm{MSiO}_{4}(\mathrm{M}=\mathrm{Fe}, \mathrm{Mn})$ as high-capacity Li-ion battery electrode. Nano Lett. 2012, 12, 1146.

43. Devaraju, M.K.; Tomai, T.; Unemoto, A.; Honma, I. Novel processing of lithium manganese silicate nanomaterials for Li-ion battery applications. RSC Adv. 2013, 3, 608-615.

44. Devaraju, M.K.; Tomai, T.; Honma, I. Supercritical hydrothermal synthesis of rod like $\mathrm{Li}_{2} \mathrm{FeSiO}_{4}$ particles for cathode application in lithium ion batteries. Electrochem. Acta 2013, 109, 75-78.

45. Devaraju, M.K.; Truong, Q.D.; Honma, I. Synthesis of $\mathrm{Li}_{2} \mathrm{CoSiO}_{4}$ nanoparticles and structure observation by annular bright and dark field electron microscopy. $R S C A d v$. 2013, 43, 20633-20638.

46. Devaraju, M.K.; Honma, I. One-pot synthesis of $\mathrm{Li}_{2} \mathrm{FePO} 4 \mathrm{~F}$ nanoparticles via a supercritical fluid process and characterization for application in lithium-ion batteries. RSC $A d v$. 2013, 43, 19849-19852.

47. Liu, J.; Conry, T.E.; Song, X.Y.; Yang, L.; Doeff, M.M.; Richardson, T.J. Spherical nanoporous $\mathrm{LiCoPO}_{4} / \mathrm{C}$ composites as high performance cathode materials for rechargeable lithium-ion batteries. J. Mater. Chem. 2011, 21, 9984-9987.

48. Doan, T.N.L.; Taniguchi, I. Preparation of $\mathrm{LiCoPO}_{4} / \mathrm{C}$ nanocomposite cathode of lithium batteries with high rate performance. J. Power Sources 2011, 196, 5679-5684.

49. Truong, Q.D.; Devaraju, M.K.; Tomai, T.; Honma, I. Direct observation of antisite defects in $\mathrm{LiCoPO}_{4}$ cathode materials by annular dark and bright field electron microscopy. ACS Appl. Mater. Interfaces 2013, 5, 9926-9932.

50. Han, D.W.; Kang, Y.M.; Yin, R.Z.; Song, M.S.; Kwon, H.S. Effects of Fe doping onthe electrochemical performance of $\mathrm{LiCoPO}_{4} / \mathrm{C}$ composites for high power-density cathode materials. Eletrochem. Commun. 2009, 11, 137-140.

51. Ehrenberg, H.; Bramnik, N.N.; Senyshyn, A.; Fuess, H. Crystal and magnetic structures of electrochemically delithiated $\mathrm{Li}_{1-x} \mathrm{CoPO}_{4}$ phases. Solid State Sci. 2009, 11, 18-23. 
52. Bramnik, N.N.; Nikolowski, K.; Baehtz, C.; Bramnik, K.G.; Ehrenberg, H. Phase transitions occurring upon lithium insertion-extraction of $\mathrm{LiCoPO}_{4}$. Chem. Mater. 2007, 19, 908-915.

53. Izumi, F.; Ikeda, T. A Rietvled-analysis program REITAN-98 and its applications to zeolites. Mater. Sci. Forum 2000, 321-324, 198-203. 


\title{
Direct Energy Supply to the Reaction Mixture during Microwave-Assisted Hydrothermal and Combustion Synthesis of Inorganic Materials
}

\section{Roberto Rosa, Chiara Ponzoni and Cristina Leonelli}

\begin{abstract}
The use of microwaves to perform inorganic synthesis allows the direct transfer of electromagnetic energy inside the reaction mixture, independently of the temperature manifested therein. The conversion of microwave (MW) radiation into heat is useful in overcoming the activation energy barriers associated with chemical transformations, but the use of microwaves can be further extended to higher temperatures, thus creating unusual high-energy environments. In devising synthetic methodologies to engineered nanomaterials, hydrothermal synthesis and solution combustion synthesis can be used as reference systems to illustrate effects related to microwave irradiation. In the first case, energy is transferred to the entire reaction volume, causing a homogeneous temperature rise within a closed vessel in a few minutes, hence assuring uniform crystal growth at the nanometer scale. In the second case, strong exothermic combustion syntheses can benefit from the application of microwaves to convey energy to the reaction not only during the ignition step, but also while it is occurring and even after its completion. In both approaches, however, the direct interaction of microwaves with the reaction mixture can lead to practically gradient-less heating profiles, on the basis of which the main observed characteristics and properties of the aforementioned reactions and products can be explained.
\end{abstract}

Reprinted from Inorganics. Cite as: Rosa, R.; Ponzoni, C.; Leonelli, C. Direct Energy Supply to the Reaction Mixture during Microwave-Assisted Hydrothermal and Combustion Synthesis of Inorganic Materials. Inorganics 2014, 2, 191-210.

\section{Introduction}

For many years, the most widely used method for the preparation of oxides, chalcogenides, silicides and carbides was the direct solid-state reaction between powders, and it probably still represents the most widespread approach for the large-scale production of these important inorganic materials [1,2].

The main limitation of solid-state syntheses, with respect to those exploiting molecular precursors (i.e., those occurring in the liquid or gaseous phases), is the difficulty in bringing the different reactants sufficiently close to each other to allow optimum reduction of diffusion paths. In the solid state, the diffusion limitation is usually compensated by employing high temperatures and long heating periods. These conditions do not permit a subtle control of the reaction stoichiometry nor is it possible to synthesize thermally labile or metastable compounds [2]. The use of microwave (MW) energy, which was initially applied in inorganic chemical synthesis in these same solid-state ceramic routes, allows a significant reduction of the reaction times. This advantage is mainly due to the direct interaction of the electromagnetic field with the inorganic solid reactants, that is the typical feature of volumetric heating. In early studies, when temperature measurement was not 
properly conducted during microwave irradiation, an additional feature such as lowering of reaction temperatures, with respect to the conventionally performed syntheses [3-9], was reported. However, more accurate experimental set-ups demonstrated that a correct temperature measurement did not confirm this latter observation, while the possibility of obtaining metastable phases was confirmed [5].

With the discovery of the quantum size effect [10,11], solid state synthetic approaches started to be disregarded for the synthesis of advanced inorganic compounds, since engineered nanomaterials rapidly became the main object of study for material scientists and inorganic chemists worldwide [12]. Indeed, the extremely harsh synthetic conditions typical of solid-state synthesis excluded any possibility of a precise control of particle size and shape. An accurate process control, even in non-equilibrium conditions, is fundamental in order to pave the way towards new and exciting advanced applications. Extremely large surface areas and the ability to be functionalized are additional appealing characteristics of engineered nanomaterials. Soft chemistry solution routes $[13,14]$ were consequently performed and investigated in order to explore the different possibilities offered by building desired nanostructures via an almost atom-by-atom assembly (bottom-up approach), rationally designing the final product using reaction mechanism considerations (with similarity to the approach of organic chemists). These synthetic strategies include, but are not limited to, sol-gel [15-19], hydrothermal (more generally solvothermal) [20-24] and the most recently developed solution combustion synthesis [25-31]. By analogy to the evolution seen in solid state ceramic synthesis (as briefly discussed above), and later in organic chemistry [32-37], microwave energy started to be applied in these wet-chemical inorganic syntheses, even if in most of the cases it was considered a mere tool to significantly reduce the reaction times. On the other hand, although much more sporadically than what had occurred for organic syntheses, several additional advantages and characteristics arising from the use of microwave energy were also reported and claimed in the inorganic chemistry field [38]. The most frequently observed feature found when applying microwave heating in a chemical reactor is the resulting uniform particle size distribution; additionally, an effect of the magnetic field on particle morphology has been detected under microwave assisted syntheses of magnetic particles.

The aim of the present work is to focus on these aspects of microwave-assisted inorganic synthesis of engineered nanomaterials, highlighting the main differences that characterize the product obtained with respect to conventional synthesis methods. Results are expected to explain the observed differences on the basis of the microwaves' intrinsic property of being based on a pure energy transfer mechanism rather than heat transfer. Particularly, microwave-assisted hydrothermal synthesis and microwave-assisted combustion synthesis techniques probably represent the most significant examples that can highlight such differences related to the synthetic route. The reason for this is twofold. Firstly, the aqueous medium characterizing both techniques represents one of the most favorable environments for performing microwave-assisted reactions (also approaching a green chemistry perspective [39]). Secondly, both of these syntheses are characterized by synthetic and reactive conditions barely accessible by using conventional heating. Indeed, these adverse conditions can be emphasized by the presence of thick pressurized reaction vessels (utilized in hydrothermal synthesis) and highly exothermic reaction fronts (occurring during combustion 
syntheses), which in turn make it extremely difficult to transfer heat through the walls of the reactor or to continue to transfer energy after the ignition of the self sustaining reaction.

Even if, nowadays, hydrothermal synthesis has practically reached an optimal, well recognized level of controllability and versatility in the formation of a wide choice of nanostructures [40,41], nevertheless the advantages resulting from the use of microwaves as an innovative energy source need yet to be fully reviewed, especially those which are not related to a mere reduction of reaction time. Moreover, considerations of the scalability of microwave-assisted hydrothermal synthesis, of the possible continuous flow equipment and the resulting process intensification perspectives of this technology will be covered in the next sections. On the other hand, solution combustion synthesis probably represents the most innovative inorganic synthetic strategy, at least for obtaining oxide-based nanostructures. Surely, its intrinsic energy saving characteristics constitute the main attraction of this synthesis approach, and its poor ability to tailor the size and the shape of the target product also represents the main limitation and the main research challenge, to which the application of microwave energy could furnish a partial solution or at least stimulate new findings.

After a brief summary of the fundamentals of microwave energy transfer mechanisms, the next sections will be devoted to an overview of recent advances in microwave-assisted hydrothermal and microwave-assisted solution combustion synthesis for the production of selected engineered nanomaterials, with particular focus on the innovative features characterizing these techniques, which result from both the energy source employed and the synthetic approach used.

\section{Microwave Energy Transfer Fundamentals}

As is well known, the electromagnetic energy in the microwave band is characterized by frequencies between $300 \mathrm{MHz}$ and $300 \mathrm{GHZ}$, corresponding to wavelength values of approximately $1 \mathrm{~m}$ and $1 \mathrm{~mm}$, respectively, and a photon energy between $1.24 \times 10^{-6}$ and $1.05 \times 10^{-2} \mathrm{eV}$, respectively. Microwave heating fundamentally differs from conventional heating mechanisms in that the former is directly generated in the materials by the interaction of the electromagnetic field with electric and magnetic dipoles, which account for the material dielectric, electric and magnetic properties [42].

In the case of aqueous saline solution, the main subject of this review paper, the magnetic field effects on the heating mechanism can be easily neglected. Thus, the interaction of the applied alternating electromagnetic field with the reactive aqueous solution will be uniquely related to its dielectric properties as well as solution conduction.

The ability of a particular dielectric material to polarize in the presence of an applied electric field defines its permittivity (also known as dielectric constant), $\varepsilon^{\prime}$, which can be used to describe the response of the material to the electric field. Polarization phenomena involve dipoles, ions, electrons and interfaces, all of which contribute to the permittivity. In order to account for the alternating nature of the sinusoidal electric field applied (thus for the frequency-dependant nature of the dielectric constant), and for the consequent losses, which are derived from the unavoidable phase shift occurring between the polarization and the electric field, which is responsible for heating, the complex permittivity $\varepsilon^{*}$ must be introduced according to the following Equation 1 [43]: 


$$
\varepsilon^{*}=\varepsilon-j \varepsilon=\varepsilon_{0}\left(\varepsilon_{r}-j \varepsilon_{r}\right)
$$

where $\varepsilon_{0}$ represents the free space permittivity, while the index " $r$ " is referred to values relative to the corresponding empty space values. The imaginary part $\varepsilon$ " represents the so-called loss factor, which is related to the ability of the material to store energy.

The ratio between the real and the imaginary parts of the complex permittivity is called loss tangent, $\tan \delta$ (see Equation 2), and it represents the efficiency of the material to convert absorbed energy into heat (the angle $\delta$ is the phase difference between the polarization of the material and the oscillating electric field).

$$
\tan \delta=\frac{\varepsilon^{\prime \prime}}{\varepsilon^{\prime}}
$$

The average power dissipated into the material per unit volume can be represented by the following simplified Equation 3 [43,44]:

$$
P_{d}(x, y, z)=\omega \varepsilon_{0} \varepsilon^{\prime \prime}{ }_{e f f} E^{2}{ }_{r m s}
$$

where $\mathrm{P}_{\mathrm{d}}$ is the power density in the material at the position $(x, y, z)$ expressed in $\mathrm{W} / \mathrm{m}^{3}, \omega=2 \pi \mathrm{f}$ (expressed in $\mathrm{Hz}$ ) with $\mathrm{f}$ being the frequency of the incident microwaves and $E_{\mathrm{rms}}$ the root mean square of the electric field strength at the position $(x, y, z)$, expressed in $\mathrm{V} / \mathrm{m}$.

The relative effective loss factor $\varepsilon^{\prime \prime}$ eff accounts for the polarization losses (dipolar, ionic, electronic and interfacial) combined with the conductivity losses.

At the microwave frequencies, the two predominant loss mechanisms are the dipolar and the ionic ones. It is therefore obvious to what extent the reaction conditions typical of both hydrothermal synthesis and solution combustion synthesis represent the ideal environment for using microwaves as a heating source. Indeed, hydrothermal reaction conditions usually require the presence of inorganic salts (nitrates, chlorides, etc.) or other metallic precursors dissolved (or even sometimes suspended) in water combined with a mineralizing agent and an optional surfactant. Solution combustion synthesis conditions, on the other hand, rely on the presence of inorganic nitrate salts and an opportune organic fuel dissolved in water. Thus, in addition to the well-known strong microwave-absorbing ability of water, the addition of ionic species characterizing both these synthetic strategies will lead to higher microwave absorption due to ionic conductivity contributions. A representative example is the increase in the loss tangent of distilled water (at $25{ }^{\circ} \mathrm{C}$ and $2.45 \mathrm{GHz}$ ) from $c a .0 .15$ to approximately 1.6 with the addition of $0.5 \mathrm{~mol} / \mathrm{L}$ of sodium chloride (at the same temperature and frequency) [43].

Despite these remarkable characteristics, additional microwave-heating features form the basis of the advantages manifested in the synthesis of several inorganic materials, and they will be discussed separately in the following sub-sections. However, for a more exhaustive discussion of all the parameters/equations defined in this review manuscript, the readers are kindly requested to refer to the literature papers [42-44]. 


\subsection{Volumetric and Selective Nature of MW Heating}

On the basis of their interaction with electromagnetic radiation, materials can be classified as reflective, transparent or absorbing ones. In MW-absorbing materials, the microwave power penetration depth $\left(D_{\mathrm{p}}\right)$ needs to be evaluated, and for dielectric materials it can be described with the following simplified Equation 4, where $\lambda_{0}$ is the free space wavelength of the incident microwaves.

$$
D_{p}=\frac{\lambda_{0} \sqrt{\varepsilon_{r}^{\prime}}}{2 \pi \varepsilon^{\prime \prime}{ }_{r}}
$$

$D_{\mathrm{p}}$ represents the depth from the outer surface of the material at which the value of $\mathrm{Pd}_{\mathrm{d}}$ has decreased to $1 / \mathrm{e}$ (i.e., $\sim 37 \%$ ) of its surface value. For several materials and reaction media the value of $D_{\mathrm{p}}$ is significantly higher with respect to the thickness of sample generally used (at least at a laboratory scale), thus the MW power dissipated (and the subsequent heat generation) is reasonably uniform throughout the whole material. This property of microwaves, known as volumetric heating, leads to the inversion of the classical temperature profile and to a significant reduction of the temperature gradient inside the reaction mixture. The latter situation is shown in Figure 1, where a comparison between the temperature profiles in a reaction mixture undergoing both conventional hydrothermal and microwave hydrothermal treatments is depicted.

Figure 1. Example of temperature profiles occurring in a reaction mixture exposed to conventional heating (left, e.g., inside a stainless steel autoclave) and to microwave heating (right, e.g., inside a microwave transparent polytetrafluoroethylene (PTFE) reaction vessel).
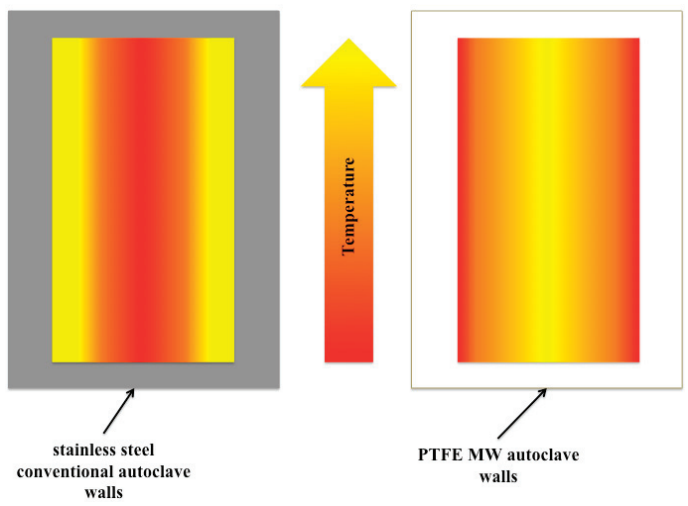

\subsection{Energy Efficiency Issues}

Direct and selective interaction of microwave energy with the reaction mixture, which favors the fast heating of the mixture in solution rather than the reactor's walls or other components, surely represents an intrinsic energy efficiency feature. It is clear that the possibility to transfer energy exactly where needed contributes to increasingly apply microwave-based technologies in a green process intensification perspective, as frequently reported in the literature during recent years $[45,46]$. 
Indeed, the obvious enhancement of reaction rates, manifested by most of the inorganic syntheses performed under microwave assistance (as will be detailed in the following section), is probably the main feature which is usually fundamental in defining microwave routes as more energy-efficient.

However, very recently the energy efficiency of microwave-assisted organic synthetic protocols has been critically assessed [47]. Mainly due to the lower electrical energy conversion capability of standard $2.45 \mathrm{GHz}$ magnetrons installed on commercial scientific equipments [48], it has been recommended to perform energy efficiency evaluations on a case by case basis, since the situation has been noted to be significantly different when moving from laboratory-scale single-mode reactors to larger batch reactors like multi-mode ones (for a detailed essay on the different microwave heating cavities and their components, the readers are kindly suggested to refer to [49]).

Concerning the specific field of inorganic synthesis, the same considerations are also valid. However, several strategies exist and are still under systematic investigation, in order to, at least, partially overcome these limitations. In particular, dedicated applicators equipped with proper impedance matching devices can significantly reduce the reflected power and power dissipated in regions different from the desired one. Moreover, the actual tendency of the market to develop new microwave generators, also able to perform a continuous impedance matching by tuning over a particular frequency range, will surely lead to more and more efficient syntheses [50].

The problems encountered with larger batch reactors are related to the penetration depth $\left(D_{\mathrm{p}}\right.$, see Equation 4). Indeed, with the increase of the batch scale, $D_{\mathrm{p}}$ could be extremely small leading to an almost heat-unaffected mixture. Understanding the importance of internal agitation in microwave-assisted chemistry [51], the latter circumstance will surely result in more pronounced temperature gradients. A further intriguing and practically un-explored possibility could be the use of microwave frequencies different from that most commonly used worldwide, i.e., $2.45 \mathrm{GHz}$. Particularly, the use of lower frequencies for a given material or solution will increase its $D_{p}$, as is clearly evident from Equation 4. Moreover, continuous flow syntheses are another interesting solution to the limitations of the reduced microwave penetration depth (when treating large batch reactors) [52-55] during the scaling up of microwave-hydrothermal technology. In this latter perspective, the use of multiple MW sources represents a further option.

On the other hand, from Section 4 it will become clear how solution combustion synthesis is not affected by all of these issues, since its energy efficiency is guaranteed by the fact that most of the required energy will be provided by harnessing the exothermic characteristics of the reaction itself.

\section{Microwave-Assisted Hydrothermal Synthesis of Engineered Nanomaterials}

Among the various wet chemical methods, the hydrothermal approach is the most promising method for the fabrication of nanostructured and microstructured materials in an acceptable crystalline phase as can be seen in Figure 2.

Indeed the ability to precipitate already crystallized powders directly from solution allows controlling the rate and uniformity of nucleation. This results in improved control of size and morphology of crystallites and in significantly reduced aggregation levels [57]. Moreover, crystallization phenomena constitute a self-purifying process, during which the growing crystals/crystallites tend to reject impurities present in the growth environment. The impurities are 
subsequently removed from the system together with the crystallizing solution, contrary to other synthesis routes, such as high temperature calcination. Thus, with the hydrothermal approach it is possible to synthesize powders in a one-step process, without the contamination typical of a reaction carried out in a closed system. Some key factors such as the reagent concentration, the reaction temperature and the reaction time are crucial for the morphology and crystallite size of the products.

Figure 2. Transmission electron microscopy (TEM) image of $\mathrm{ZrO}_{2}$ nanopowders doped with $1 \%$ Pr obtained via microwave (MW)-assisted hydrothermal synthesis performed at $8 \mathrm{MPa}$ for $30 \mathrm{~min}$, according to the chemical procedure indicated in [56].

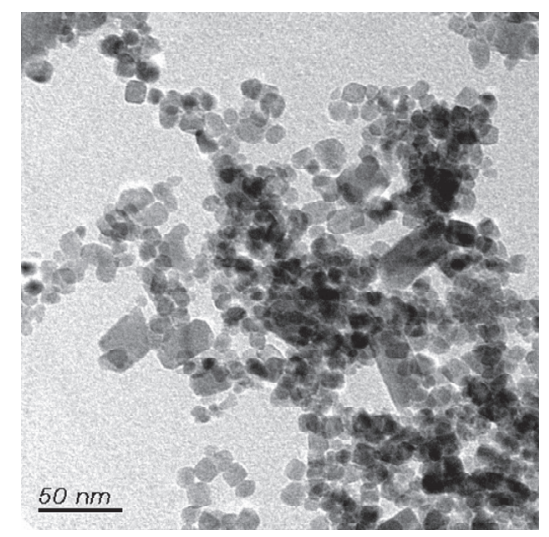

From the pioneering work by Komarneni et al. [58], the main advantages of the MW-assisted hydrothermal route over conventional hydrothermal treatments are short reaction time, energy saving, good particle dispersion, high phase purity, high homogeneity in stoichiometry, and small particle size $[59,60]$. Most of the aforementioned advantages can be easily attributed to the significant reduction of the initial heating period (up to the set temperature), which characterizes dielectric heating over more conventional heat transfer mechanisms, as schematically reported in Figure 3.

Indeed, the initial part of the heating period characterizing conventional hydrothermal syntheses can last many minutes; thus, it may result in non-uniform temperature profiles inside the autoclave (please refer to Figure 1).

By contrast, the gradient-less volumetric microwaves-based heating (right side of Figure 1) is able to provide the reaction mixture with a significantly uniform distribution of energy, which results in narrower particle size distributions [61-63].

During recent decades, hydrothermal synthetic techniques have been employed for the preparation of a wide variety of advanced engineered nanomaterials, a summary of which is reported in Table 1. Surely, the mostly studied and synthesized compounds are transition metal oxides and multi metal oxide materials $[20,59,64,65]$, although several examples can be found in scientific literature relating to the production of metal sulfides [59,64-68], hydroxyapatite $[59,69]$ and different kinds of carbon-based nanostructures [59,70,71]. 
Figure 3. Temperature profiles typical of microwave-assisted and conventionally-heated hydrothermal synthesis.

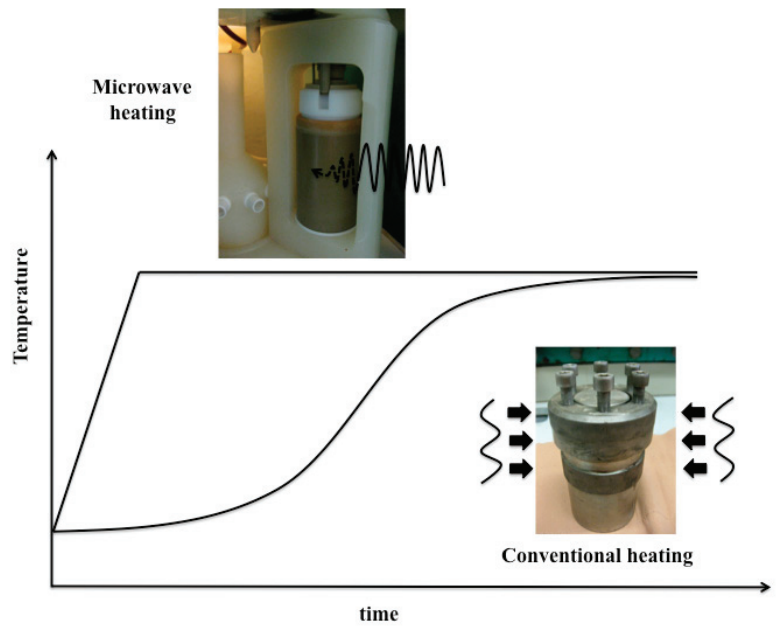

Recently, scientific attention has been focused on multiferroic compounds that exhibit the existence of simultaneous ferroelectric and ferromagnetic properties in a certain temperature range, since they have promising applications in spintronics, electromagnetic interference filters, magnetic recording media, sensors, and photovoltaic devices [72-76].

Among the multiferroic compounds, bismuth ferrite $\mathrm{BiFeO}_{3}$ (BFO) has received considerable attention in the past few years because of its characteristics, and a multitude of research work dealing with its conventional hydrothermal synthesis can be found in the scientific literature [77-79]. Most of these studies were devoted to investigating the role of several experimental processing parameters in the synthesis of a pure BFO phase, and reaction times ranging from 6-9 hours were always necessary for that purpose.

Table 1. Some of the different classes of materials synthesized by the hydrothermal technique.

\begin{tabular}{|c|c|c|c|}
\hline Class of materials & Main Examples & Some crystal shapes observed & Ref. \\
\hline Transition metal oxides & $\begin{array}{c}\mathrm{TiO}_{2}, \mathrm{ZnO}, \mathrm{ZrO}_{2} \\
\mathrm{Fe}_{2} \mathrm{O}_{3}, \mathrm{Fe}_{3} \mathrm{O}_{4}\end{array}$ & $\begin{array}{c}\text { Nanoparticles, nanotubes, } \\
\text { nanowires, nanorods, nanocubes, } \\
\text { nanoribbons }\end{array}$ & {$[20,59,64,65]$} \\
\hline Multimetal oxides & $\begin{array}{c}\mathrm{BaTiO}_{3} \\
\mathrm{La}_{1-x} \mathrm{Sr}_{x} \mathrm{MnO}_{3}, \mathrm{BiFeO}_{3}\end{array}$ & $\begin{array}{c}\text { Nanoparticles, polyhedrons, } \\
\text { nanoplatelets, nanocubes }\end{array}$ & {$[20,64,65]$} \\
\hline Metal sulfides & $\mathrm{CdS}, \mathrm{ZnS}, \mathrm{CuS}, \mathrm{SnS}$ & Nanoparticles, nanotubes, & {$[59,64-68]$} \\
\hline Biomaterials & Hydroxyapatite & $\begin{array}{l}\text { Needle-like (frequently), } \\
\text { nanospheres, nanorods, nanowires, } \\
\text { whiskers, platelets }\end{array}$ & {$[59,69]$} \\
\hline $\begin{array}{l}\text { Carbon-based } \\
\text { nanostructured } \\
\text { materials }\end{array}$ & \multicolumn{2}{|c|}{$\begin{array}{l}\text { Carbon nanotubes, nanospheres, nanofibers, graphene-based } \\
\text { materials }\end{array}$} & {$[59,70,71]$} \\
\hline
\end{tabular}


On the other hand, in the early nineties Komarneni et al. [80] proposed the microwave hydrothermal synthesis of BFO to obtain highly crystalline agglomerated particles in one heating step. This study demonstrated that the microwave-hydrothermal approach was very efficient in terms of kinetics for the synthesis and processing of both binary and ternary ceramic oxide powders. More recently [81], a comparison of three different methods for preparing BFO polycrystals has been reported: (i) the classic hydrothermal synthesis, (ii) the microwave heating in the solid state and (iii) the microwave-assisted hydrothermal method. The best material in terms of purity and enhanced reproducibility was obtained with the third method, which was also described as the most environmental-friendly, since it employed moderate temperatures $\left(T=200{ }^{\circ} \mathrm{C}\right)$ and significantly less time (30 min). In the last few years, several experimental studies concerning the microwave-hydrothermal approach have been undertaken in order to obtain single-phase crystalline bismuth ferrite nanocrystals with a high degree of homogeneity and uniformity in particle size at even faster reaction rates and low temperatures.

In a recent study by our group, an easy microwave hydrothermal synthesis route was optimized for the preparation of $\mathrm{BiFeO}_{3}$ pure-phase [82]. In particular, the work focused on the influence of process parameters (i.e., precursor ratio, mineralizer concentration, temperature, time and the use of inorganic chelating agents) on phase formation, particle size distribution and morphology. Single phase $\mathrm{BFO}$ was obtained at $180{ }^{\circ} \mathrm{C}$ using a concentration of $10 \mathrm{M} \mathrm{KOH}$ mineralizer (Figure 4) or at $200{ }^{\circ} \mathrm{C}$ using $8 \mathrm{M} \mathrm{KOH}$, in a $30 \mathrm{~min}$ total reaction time in both cases. Moreover, the presence of $\mathrm{Na}_{2} \mathrm{CO}_{3}$ acting as an electron donor allowed the reaction to be performed at lower $\mathrm{KOH}$ concentrations and temperatures. The particle morphology evolution followed the sequence: spherical, lamellar, lamellar semi-cubic, and cubic. Whereas with $\mathrm{Na}_{2} \mathrm{CO}_{3}$ addition the evolution was as follows: lamellar semi-cubic, cubic, and prismatic truncated octahedron shape. The main differences of this latter microwave-assisted hydrothermal approach [82] with respect to those mentioned above $[80,81]$ (constituting two of the most significant ones employing MW heating) for the preparation of $\mathrm{BiFeO}_{3}$ nanoparticles and nanostructured particles are summarized in Table 2 .

In all of the experiments carried out in [82], microwave heating allowed obtaining a perfect control over the heating rate and reducing the ramp to the reaction temperature to only 5 min (in comparison to the 15 min needed in the example in [81]). This precise and immediate transfer of energy, again, must be emphasized as the key step manifested in the majority of microwaveassisted synthetic inorganic protocols, leading to the observed advantages. Moreover, the temperature adopted in [82] was reduced by approximately $20{ }^{\circ} \mathrm{C}$ with respect to the majority of syntheses reported, including those exploiting microwave heating. 
Figure 4. Scanning electron microscopy (SEM) images and X-ray diffractometry (XRD) pattern of pure bismuth ferrite $\left(\mathrm{BiFeO}_{3}\right)$ phase synthesized according to the microwave-assisted hydrothermal procedure optimized in [74], i.e., at $180{ }^{\circ} \mathrm{C}$ for 30 min with a $\mathrm{KOH}$ concentration of $10 \mathrm{~mol} / \mathrm{L}$.
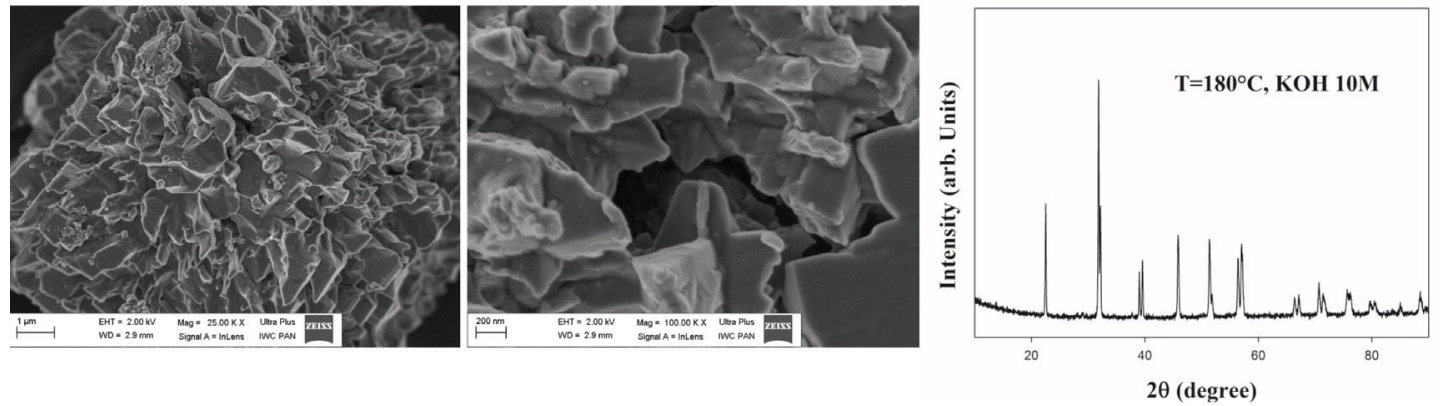

Table 2. Comparison of three different microwave-assisted hydrothermal synthesis strategies proposed for the obtainment of single $\mathrm{BiFeO}_{3}$ phase.

\begin{tabular}{cccc}
\hline Temperature $\left({ }^{\circ} \mathbf{C}\right)$ & Time (min) & Product & Ref. \\
\hline$c a .194$ & 120 & $\begin{array}{c}\text { agglomerated } \\
\text { rombohedral } \\
\mathrm{BiFeO}_{3} \text { particles }\end{array}$ & {$[80]$} \\
\hline 200 & 30 & $\begin{array}{c}\text { polyhedral } \mathrm{BiFeO}_{3} \\
\text { nano-structured } \\
\text { particles }\end{array}$ & {$[81]$} \\
\hline 180 & 30 & $\begin{array}{c}\text { nanocubic } \mathrm{BiFeO}_{3} \\
\text { aggregates }\end{array}$ & {$[82]$} \\
\hline
\end{tabular}

\section{Microwave Energy Transfer in the Ignition of Solution Combustion Synthesis}

Combustion synthesis (CS) is a relatively new inorganic material manufacturing procedure, originating from the discovery of solid flame phenomena by Merzhanov and co-workers $[83,84]$. Very quickly it became the most promising method for the synthesis of high temperature ceramics, intermetallics and different kinds of composite materials. The main reason can be found in its intrinsic energy saving characteristics, since most of the energy needed for the synthesis is released by the reaction itself. Indeed, CS exploits exothermic reactions occurring among the reactants; after a proper ignition (i.e., the reaction mixture is heated up to the so-called ignition temperature), the reactants start reacting in a self-sustaining manner, thus requiring no further energy from an external source, since the harnessing of the heat produced by the reaction itself allows completion of the reaction in the whole reactive volume [85]. Typically, two different ignition strategies are distinguishable, leading to the self-propagating high-temperature synthesis (SHS) and to the thermal explosion (TE) modes of combustion synthesis. In the SHS type, the exothermic reaction is ignited at one end of the reactive volume so that the reaction self-propagates to the opposite side of the sample, while in the TE method of combustion the entire reactive volume is heated up 
homogeneously and uniformly until the reaction takes place almost simultaneously in the entire specimen [85].

Although initially the performance of CS was limited among mixtures of powders, or could benefit from the optional use of a gaseous phase [86], nowadays CS has reached a significant level of versatility and diversity [87]. Particularly, combustion synthesis performed in aqueous solution is a relatively new method for preparation of oxide-based engineered nanomaterials [88]. In summary, solution combustion synthesis exploits exothermic self-sustaining reactions occurring between metal nitrates and different kinds of organic fuels (e.g., glycine, urea, citric acid, polyethylene glycol, etc.) in homogeneous solutions. The main steps involved in this synthesis strategy are schematically summarized in Figure 5. Also, in this case the ignition can occur locally (leading to a layer by layer propagation) or volumetrically (leading to a nearly instantaneous reaction).

Most of the more conventional soft-chemistry routes, including the above-discussed hydrothermal synthesis, even if performed by microwave-assistance, are significantly more energy and time consuming.

Moreover - although to a significantly lesser extent with respect to hydrothermal syntheses — with the ever-deepening research findings in the field of CS, a satisfactory control over the crystallite size has been achieved by opportunely modifying the ratio between the metal nitrate and the fuel, or by changing the fuel itself as well as the metal precursor anion $[88,89]$.

Being able to change the particle size distribution by simply changing the ignition strategy from a conventional hot plate to the direct interaction of almost the whole reaction mixture with microwave energy gives more desirable results. Indeed, this latter opportunity has been observed in several works [90-92] accompanied by the typical shorter reaction times, which, as in this case, are all direct consequences of the volumetric nature of microwave heating. Moreover, the fact that microwave ignition of solution combustion synthesis at the laboratory scale is more prone to occur volumetrically (i.e., referred to as Thermal Explosion in traditional solid state performed CS reactions) further assures a more uniform thermal history to the reactive solution. Moreover, the possibility that microwaves continue to furnish energy to the reaction (despite the adverse temperature gradient), even after ignition and/or completion, must be mentioned. This happens based on the dielectric properties of the forming solid products and leads to the possibility of modifying the cooling rates as well.

Solution combustion synthesis has recently shown several new trends, which deserve particular attention. Particularly, it has been noted that the nature of the fuel-oxidizer system and its ratio can also cause a radical change in the expected product, leading to the usually expected and desired oxide or eventually to metallic nanoparticles, and thereby suggesting a new synthetic methodology for metal and metallic alloy-based nanomaterials [93]. Moreover, a different combustion synthesis approach, named Carbon Combustion Synthesis, which does not occur properly in solution and which exploits the high exothermicity of the carbon oxidation to $\mathrm{CO}_{2}$, was recently developed to obtain nanostructured materials [97,98], accompanied by a continuous large-scale nanomaterial preparation procedure based on the principles of solution CS (the so-called impregnated layer and combustion) $[95,99]$. All of these latter novel approaches are summarized in Table 3 where they are compared to solution combustion synthesis itself in terms of their distinctive characteristics and 
materials obtainable/obtained. In all likelihood, coupling of these latter novelties with a significantly more energy efficient ignition strategy, like microwaves, is simply a matter of time.

Figure 5. Schematic representation of the main steps characterizing the solution combustion synthesis approach to produce oxide-based engineered nanomaterials.

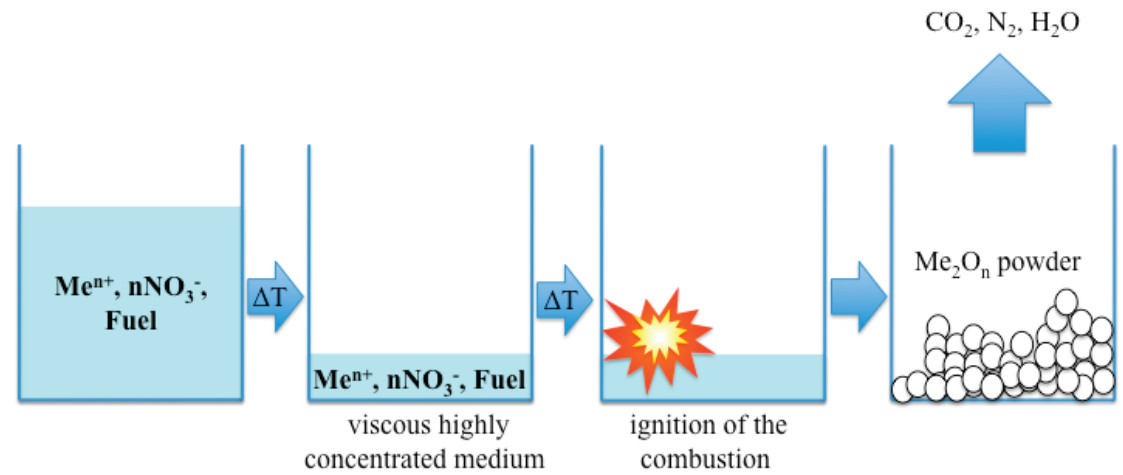

Table 3. Summary of some of the latest modifications of combustion synthesis for the preparation of engineered nanomaterials.

\begin{tabular}{|c|c|c|c|c|}
\hline $\begin{array}{l}\text { Synthetic } \\
\text { approach }\end{array}$ & $\begin{array}{c}\text { Distinctive } \\
\text { characteristics }\end{array}$ & $\begin{array}{c}\text { Main classes of } \\
\text { materials } \\
\text { obtainable }\end{array}$ & $\begin{array}{c}\text { Examples of } \\
\text { synthesized compounds }\end{array}$ & Ref. \\
\hline $\begin{array}{l}\text { Solution } \\
\text { combustion } \\
\text { synthesis }\end{array}$ & $\begin{array}{l}\text { The solution of the } \\
\text { metal precursor(s) } \\
\text { nitrate(s) and the } \\
\text { fuel is slowly } \\
\text { evaporated and } \\
\text { then ignited locally } \\
\text { or volumetrically. } \\
\text { The exothermic } \\
\text { reaction occurs } \\
\text { between fuel and } \\
\text { oxygen-containing } \\
\text { species derived } \\
\text { from the } \\
\text { decomposition of } \\
\text { nitrates }\end{array}$ & $\begin{array}{l}\text { - Binary and } \\
\text { more complex } \\
\text { metal oxide } \\
\text { nanopowders } \\
\text { - metal } \\
\text { nanopowders }\end{array}$ & $\begin{array}{c}-\mathrm{TiO}_{2}, \mathrm{ZnO}, \mathrm{LaFeO}_{3}, \mathrm{BiFeO}_{3} \\
-\mathrm{Ni}, \mathrm{Cu} \text { and their alloys }\end{array}$ & {$[88,91-93,94]$} \\
\hline
\end{tabular}


Table 3. Cont.

\begin{tabular}{|c|c|c|c|c|}
\hline $\begin{array}{l}\text { Impregnated } \\
\text { layer and } \\
\text { combustion }\end{array}$ & $\begin{array}{l}\text { The reactive } \\
\text { solution is } \\
\text { impregnated with } \\
\text { an inert porous } \\
\text { oxide support or } \\
\text { with a reactive } \\
\text { cellulose paper } \\
\text { also acting as a } \\
\text { fuel. } \\
\text { - a productivity of } \\
0.5-2 \mathrm{~kg} / \mathrm{h} \text { of } \\
\text { nanoparticles has } \\
\text { been reached by a } \\
\text { continuous } \\
\text { synthesis approach }\end{array}$ & $\begin{array}{l}\text { - binary and } \\
\text { more complex } \\
\text { oxides }\end{array}$ & $\begin{array}{c}\mathrm{ZnO}, \mathrm{MgO}, \mathrm{Ce}_{1-\mathrm{x}} \mathrm{Pt}_{\mathrm{x}} \mathrm{O}_{2}, \\
\mathrm{CuO} / \mathrm{ZnO} / \mathrm{ZrO}_{2} / \mathrm{Pd} \text { based } \\
\text { catalysts }\end{array}$ & {$[95,96]$} \\
\hline $\begin{array}{l}\text { Carbon } \\
\text { combustion } \\
\text { synthesis }\end{array}$ & $\begin{array}{l}\text { The exothermic } \\
\text { oxidation reaction } \\
\text { of carbon to carbon } \\
\text { dioxide generates a } \\
\text { reaction wave that } \\
\text { propagates through } \\
\text { the solid reactant } \\
\text { mixture. The } \\
\text { product of the } \\
\text { exothermic } \\
\text { reaction is not } \\
\text { incorporated into } \\
\text { the final product, } \\
\text { leading to several } \\
\text { advantages (e.g., } \\
\text { smaller particles). }\end{array}$ & $\begin{array}{l}\text { - Perovskite } \\
\text { oxides }\end{array}$ & $\begin{array}{c}\mathrm{BaTiO}_{3}, \mathrm{SrTiO}_{3} \\
\mathrm{LiNbO}_{3}, \mathrm{CoFe}_{2} \mathrm{O}_{4}\end{array}$ & {$[97,98]$} \\
\hline
\end{tabular}

\section{Concluding Remarks}

This manuscript does not intend to exhaustively cover all the possible applications of microwave energy in the hydrothermal as well as in the solution combustion synthesis of engineered nanomaterials; nevertheless, it does aim to present a wide and descriptive approach of the peculiar characteristics of well conceived modern syntheses using microwave energy as a heating source.

The most recent trends in microwave irradiation of chemical environments are directed toward the utilization of combined techniques [45]. For this reason, we have presented results for microwave-assisted hydrothermal and microwave-assisted solution combustion syntheses. The emerging interest in the production of selected engineered nanosized oxide-based materials pushed us toward this class of inorganic compounds. 
Both hydrothermal and solution combustion synthesis approaches significantly benefit from the ability of microwaves to directly generate the necessary heat (for the reaction completion or simply ignition) inside the reactant mixture.

A success story of a well-crystallized single phase complex oxide compound has been described: the microwave-assisted hydrothermal synthesis of perovskite $\mathrm{BiFeO}_{3}$ oxide was performed in significantly shorter reaction times with respect to conventional hydrothermal procedures and with a narrower particles' size distribution.

Similar advantages have also been noted when comparing conventional heating and microwave heating for the ignition of solution combustion synthesis.

In all cases, the ability of microwaves to directly furnish the entire reaction medium with a more uniform energy distribution, with a resulting almost gradient-less temperature profile, has been considered to be the crucial feature marking the originality of these syntheses.

Despite the reported advantages and intrinsic characteristics, the limitations of a microwave energy source have not been ignored in this review paper.

Moreover, considerations of the possible application of dielectric heating to novel aspects of both hydrothermal and solution combustion synthesis approaches or simply considerations of the scaling up of microwave technology have been made.

\section{Acknowledgments}

The authors are particularly grateful to Paolo Veronesi, University of Modena and Reggio Emilia for helping with experimental set-up, cavity geometry and electromagnetic field simulations and to Antonino Rizzuti, Polytechnic University of Bari, Italy, for part of the syntheses and characterization work. They express their thanks to Adam Presz for some SEM images, to Statutory Funds of IHHP and to Witold Lojkowski from Institute of High Pressure Physics, Polish Academy of Science, Warsaw, Poland.

The financial support from Project PRIN 2009 "Microwave applicators design: from numerical simulation to materials selection"-Prot. 2009WXXLY2_001 funded by MIUR-Italy was particularly appreciated.

\section{Conflicts of Interest}

The authors declare no conflict of interest.

\section{References}

1. Rao, K.J.; Vaidhyanathan, B.; Ganguli, M.; Ramakrishnan, P.A. Synthesis of inorganic solids using microwaves. Chem. Mater. 1999, 11, 882-895.

2. Jansen, M. A concept for synthesis planning in solid-state chemistry. Angew. Chem. Int. Ed. 2002, 41, 3746-3766.

3. Ramesh, P.D.; Vaidhyanathan, B.; Ganguli, M.; Rao, K.J. Synthesis of $\beta$-SiC powder by use of microwave radiation. J. Mater. Res. 1994, 9, 3025-3027. 
4. Ramesh, P.D.; Rao, K.J. Microwave assisted synthesis of aluminum nitride. Adv. Mater. 1995, 7, 177-179.

5. Rizzuti, A.; Leonelli, C. Crystallization of aragonite particles from solution under microwave irradiation. Powder Technol. 2008, 186, 255-262.

6. Mastrovito, C.; Lekse, J.W.; Aitken, J.A. Rapid solid-state synthesis of binary group 15 chacogenides using microwave irradiation. J. Solid State Chem. 2007, 180, 3262-3270.

7. Bhunia, S.; Bose, D.N. Microwave synthesis, single crystal growth and characterization of ZnTe. J. Crystal Growth 1998, 186, 535-542.

8. Vaidhyanathan, B.; Rao, K.J. Microwave assisted synthesis of technologically important transition metal silicides. J. Mater. Res. 1997, 12, 3225-3229.

9. Vaidhyanathan, B.; Raizada, P.; Rao, K.J. Microwave assisted fast solid state synthesis of niobates and titanates. J. Mater. Sci. Lett. 1997, 16, 2022-2025.

10. Wang, Y.; Herron, N. Nanometer-sized semiconductor clusters: materials synthesis, quantum size effects, and photophysical properties. J. Phys. Chem. 1991, 95, 525-532.

11. Berry, C.R. Structure and optical absorption of AgI microcrystals. Phys. Rev. 1967, 161, 848-851.

12. Hischier, R.; Walser, T. Life cycle assessment of engineered nanomaterials: state of the art and strategies to overcome existing gaps. Sci. Total Environ. 2012, 425, 271-282.

13. Gopalakrishnan, J. Chimie douce approaches to the synthesis of metastable oxide materials. Chem. Mater. 1995, 7, 1265-1275.

14. Hubert-Pfalzgraf, L.G. To what extent can design of molecular precursors control the preparation of high tech oxides? J. Mater. Chem. 2004, 14, 3113-3123.

15. Roy, R. Ceramics by the solution-sol-gel route. Science 1987, 238, 1664-1669.

16. Vioux, A. Nonhydrolytic sol-gel routes to oxides. Chem. Mater. 1997, 9, 2292-2299.

17. Niederberger, M.; Garnweitner, G. Organic reaction pathways in the nonaqueous synthesis of metal oxide nanoparticles. Chem. Eur. J. 2006, 12, 7282-7302.

18. Giordano, C.; Antonietti, M. Synthesis of crystalline metal nitride and metal carbide nanostructures by sol-gel chemistry. Nano Today 2011, 6, 366-380.

19. Valizadeh, A.; Mikaeili, H.; Samiei, M.; Farkhani, S.M.; Zarghami, N.; Kouhi, M.; Akbarzadeh, A.; Davaran, S. Quantum dots: Synthesis, bioapplications, and toxicity. Nanoscale Res. Lett. 2012, 7, 480.

20. Patzke, G.R.; Zhou, Y.; Kontic, R.; Conrad, F. Oxide nanomaterials: Synthetic developments, mechanistic studies, and technological innovations. Angew. Chem. Int. Ed. 2011, 50, 826-859.

21. Dias, A.; Ciminelli, V.S.T. Electroceramic materials of tailored phase and morphology by hydrothermal technology. Chem. Mater. 2003, 15, 1344-1352.

22. Hayashi, H.; Hakuta, Y. Hydrothermal synthesis of metal oxide nanoparticles in supercritical water. Materials 2010, 3, 3794-3817.

23. Demazeau, G. Solvothermal reactions: An original route for the synthesis of novel materials. J. Mater. Sci. 2008, 43, 2104-2114.

24. Namratha, K.; Byrappa, K. Novel solution routes of synthesis of metal oxide and hybrid metal oxide nanocrystals. Progr. Crystal Growth Charact. Mater. 2012, 58, 14-42. 
25. Kingsley, J.J.; Patil, K.C. A novel combustion process for the synthesis of fine particle alpha-alumina and related oxide materials. Mater. Lett. 1988, 6, 427-432.

26. Manoharan, S.S.; Patil, K.C. Combustion route to fine particle perovskite oxides. J. Solid State Chem. 1993, 102, 267-276.

27. Patil, K.C.; Aruna, S.T.; Ekambaram, S. Combustion synthesis. Curr. Opin. Solid State Mater. Sci. 1997, 2, 158-165.

28. Patil, K.C.; Aruna, S.T.; Mimani, T. Combustion synthesis: an update. Curr. Opin. Solid State Mater. Sci. 2002, 6, 507-512.

29. Mukasyan, A.S.; Epstein, P.; Dinka, P. Solution combustion synthesis of nanomaterials. Proc. Comb. Inst. 2007, 31, 1789-1795.

30. Aruna, S.T.; Mukasyan, A.S. Combustion synthesis and nanomaterials. Curr. Opin. Solid State Mater. Sci. 2008, 12, 44-50.

31. Ruiz-Gomez, M.A.; Gomez-Solis, C.; Zarazua-Morin, M.E.; Torres-Martinez, L.M.; Juarez-Ramirez, I.; Sanchez-Martinez, D.; Figueroa-Torres, M.Z. Innovative solvo-combustion route for the rapid synthesis of $\mathrm{MoO}_{3}$ and $\mathrm{Sm}_{2} \mathrm{O}_{3}$ materials. Ceram. Int. 2014, 40, 1893-1899.

32. Gedye, R.; Smith, F.; Westaway, K.; Ali, H.; Baldisera, L.; Laberge, L.; Rousell, J. The use of microwave ovens for rapid organic synthesis. Tetrahedron Lett. 1986, 27, 279-282.

33. Giguere, R.J.; Bray, T.L.; Duncan, S.M.; Majetich, G. Application of commercial microwave ovens to organic synthesis. Tetrahedron Lett. 1986, 27, 4945-4948.

34. Adam, D. Microwave chemistry: out of the kitchen. Nature 2003, 421, 571-572.

35. Loupy, A. Microwaves in Organic Synthesis; Wiley-VCH: Weinheim, Germany, 2002.

36. Kappe, C.O. Controlled microwave heating in modern organic synthesis. Angew. Chem. Int. Ed. 2004, 43, 6250-6284.

37. Corradi, A.; Leonelli, C.; Rizzuti, A.; Rosa, R.; Veronesi, P.; Grandi, R.; Baldassari, S.; Villa, C. New "green" approaches to the synthesis of pyrazole derivatives. Molecules 2007, 12, 1482-1495.

38. Leonelli, C.; Lojkowski, W. Main development directions in the application of microwave irradiation to the synthesis of nanopowders. Chem. Today 2007, 25, 34-38.

39. Anastas, P.T.; Warner, J.C. Green Chemistry: Theory and Practice; Oxford University Press: New York, NY, USA, 1998.

40. Huang, J.; Xia, C.; Cao, L.; Zeng, X. Facile microwave hydrothermal synthesis of zinc oxide one-dimensional nanostructure with three-dimensional morphology. Mater. Sci. Eng. B 2008, 150, 187-193.

41. Shi, W.; Song, S.; Zhang, H. Hydrothermal synthetic strategies of inorganic semiconducting nanostructures. Chem. Soc. Rev. 2013, 42, 5714-5743.

42. Metaxas, A.C. Foundations of Electroheat: A Unified Approach; John Wiley and Sons: Chichester, UK, 1996.

43. Gupta, M.; Eugene, W.W.L. Microwaves-Theory. In Microwaves and Metals; John Wiley and Sons: Singapore, 2007 and references therein.

44. Metaxas, A.C.; Meredith, R.J. Industrial Microwave Heating; Peter Peregrinus: London, UK, 1983. 
45. Leonelli, C.; Mason, T.J. Microwave and ultrasonic processing: Now a realistic option for industry. Chem. Eng. Process. 2010, 49, 885-900.

46. Rosa, R.; Veronesi, P.; Leonelli, C. A review on combustion synthesis intensification by means of microwave energy. Chem. Eng. Process. 2013, 71, 2-18.

47. Moseley, J.D.; Kappe, C.O. A critical assessment of the greenness and energy efficiency of microwave-assisted organic synthesis. Green Chem. 2011, 13, 794-806.

48. Nüchter, M.; Müller, U.; Ondruschka, B.; Tied, A.; Lautenschläger, W. Microwave-assisted chemical reactions. Chem. Eng. Technol. 2003, 26, 1207-1216.

49. Chan, T.V.C.T.; Reader, H.C. Understanding Microwave Heating Cavities; Artech House: Norwood, UK, 2000.

50. For further details see for example: http://www.mksinst.com, www.sairem.com.

51. Ferrero, M.A.; Kremsner, J.M.; Kappe, C.O. Nonthermal microwave effects revisited: On the importance of internal temperature monitoring and agitation in microwave chemistry. J. Org. Chem. 2008, 73, 36-47.

52. Corradi, A.B.; Bondioli, F.; Ferrari, A.M.; Focher, B.; Leonelli, C. Synthesis of silica nanoparticles in a continuous-flow microwave reactor. Powder Technol. 2006, 167, 45-48.

53. Katsuki, H.; Furuta, S.; Komarneni, S. Semi-continuous and fast synthesis of nanophase cubic $\mathrm{BaTiO}_{3}$ using a single-mode home-built microwave reactor. Mater. Lett. 2012, 83, 8-10.

54. Wiles, C.; Watts, P. Continuous flow reactors: A perspective. Green Chem. 2012, 14, 38-54.

55. Nishioka, M.; Miyakawa, M.; Daino, Y.; Kataoka, H.; Koda, H.; Sato, K.; Suzuki, T.M. Single-mode microwave reactor used for continuous flow reactions under elevated pressure. Ind. Eng. Chem. Res. 2013, 52, 4683-4687.

56. Bondioli, F.; Ferrari, A.M.; Braccini, S.; Leonelli, C.; Pellacani, G.C.; Opalińska, A.; Chudoba, T.; Grzanka, E.; Palosz, B.; Lojkowski, W. Microwave-hydrothermal synthesis of nanocrystalline Pr-doped zirconia powders at pressures up to $8 \mathrm{MPa}$, Interfacial Effects and Novel Properties of Nanomaterials. Solid State Phenom. 2003, 94, 193-196.

57. Riman, R.E. High Performance Ceramics: Surface Chemistry in Processing Technology; Pugh, R., Bergstrom, L., Eds.; Marcel-Dekker: New York, NY, USA, 1993.

58. Komarneni, S.; Roy, R.; Li, H.Q. Microwave-hydrothermal synthesis of ceramic powders. Mater. Res. Bull. 1992, 27, 1393-1405.

59. Byrappa, K.; Adschiri, T. Hydrotermal technology for nanotechnology. Prog. Cryst. Growth Charact. Mater. 2007, 57, 117-166.

60. Yoshimura, M.; Byrappa, K. Hydrothermal processing of materials: past, present and future. J. Mater. Sci. 2008, 43, 2085-2103.

61. Van Gerven, T.; Stankiewicz, A. Structure, energy, synergy, time-the fundamentals of process intensification. Ind. Eng. Chem. Res. 2009, 48, 2465-2474.

62. Schwalbe, T.; Autze, V.; Hohmann, M.; Stirner, W. Novel innovation systems for a cellular approach to continuous process chemistry from discovery to market. Org. Proc. Res. Devel. 2004, 8, 440-454. 
63. Leonelli, C.; Rizzuti, A.; Rosa, R.; Corradi, A.B.; Veronesi, P. Numerical simulation of a microwave reactor used in synthesis of nanoparticles. In Proceedings of IMPI 44th Annual Symposium, Denver, CO, USA, 14-16 July 2010.

64. Baghbanzadeh, M.; Carbone, L.; Cozzoli, P.D.; Kappe, C.O. Microwave-assisted synthesis of colloidal inorganic nanocrystals. Angew. Chem. Int. Ed. 2011, 50, 11312-11359.

65. Yao, W.T.; Yu, S.H. Recent advances in hydrothermal syntheses of low dimensional nanoarchitectures. Int. J. Nanotechnol. 2007, 4, 129-162.

66. Yan, S.; Wang, B.; Shi, Y.; Yang, F.; Hu, D.; Xu, X.; Wu, J. Hydrothermal synthesis of CdS nanoparticle/functionalized graphene sheet nanocomposites for visible-light photocatalytic degradation of methyl orange. Appl. Surf. Sci. 2013, 285P, 840-845.

67. Wan, H.; Ji, X.; Jiang, J.; Yu, J.; Miao, L.; Zhang, L.; Bie, S.; Chen, H.; Ruan, Y. Hydrothermal synthesis of cobalt sulfide nanotubes: The size control and its application in supercapacitors. J. Power Sources 2013, 243, 396-402.

68. Yan, X.; Michael, E.; Komarneni, S.; Brownson, J.R.; Yan, Z.F. Microwave- and conventional-hydrothermal synthesis of $\mathrm{CuS}, \mathrm{SnS}$ and $\mathrm{ZnS}$ : Optical properties. Ceram. Int. 2013, 39, 4757-4763.

69. Shojai, M.S.; Khorasani, M.T.; Khoshdargi, E.D.; Jamshidi, A. Synthesis methods for nanosized hydroxyapatite with diverse structures. Acta Biomat. 2013, 9, 7591-7621.

70. Hu, B.; Wang, K.; Wu, L.; Yu, S.H.; Antonietti, M.; Titirici, M.M. Engineering carbon materials from the hydrothermal carbonization process of biomass. Adv. Mater. 2010, 22, 813-828.

71. Chen, P.; Yang, J.J.; Li, S.S.; Wang, Z.; Xiao, T.Y.; Qian, Y.H.; Yu, S.H. Hydrothermal synthesis of macroscopic nitrogen-doped graphene hydrogels for ultrafast supercapacitors. Nano Energy 2013, 2, 249-256.

72. Eerenstein, W.; Mathur, N.D.; Scott, J.F. Multiferroic and magnetoelectric materials. Nature 2006, 442, 759-765.

73. Wang, J.; Neaton, J.B.; Zheng, H.; Nagarajan, V.; Ogale, S.B.; Liu, B.; Viehland, D.; Vaidhyanathan, V.; Schlom, D.G.; Waghmare, U.V.; et al. Epitaxial $\mathrm{BiFeO}_{3}$ multiferroic thin film heterostructures. Science 2003, 299, 1719-1722.

74. Hur, N.; Park, S.; Sharma, P.A.; Ahn, J.S.; Guha, S.; Cheong, S.W. Electric polarization reversal and memory in a multiferroic material induced by magnetic fields. Nature 2004, 429, 392-395.

75. Seidel, J.; Martin, L.W.; He, Q.; Zhan, Q.; Chu, Y.H.; Rother, A.; Hawkridge, M.E.; Maksymovych, P.; Yu, P.; Gajek, M.; et al. Conduction at domain walls in oxide multiferroics. Nat. Mater. 2009, 8, 229-234.

76. Choi, T.; Lee, S.; Choi, Y.J.; Kiryukhin, V.; Cheong, S.W. Switchable ferroelectric diode and photovoltaic effect in $\mathrm{BiFeO}_{3}$. Science 2009, 324, 63-66.

77. Han, S.H.; Kim, K.S.; Kim, H.-G.; Lee, H.-G.; Kang, H.-W.; Kim, J.S.; Cheon, C.I. Synthesis and characterization of multiferroic $\mathrm{BiFeO}_{3}$ powders fabricated by hydrothermal methods. Ceram. Int. 2010, 36, 1365-1375. 
78. Wang, Y.; Xu, G.; Ren, Z.; Wei, X.; Weng, W.; Du, P.; Shen, G.; Han, G. Mineralizer-assisted hydrothermal synthesis and characterization of $\mathrm{BiFeO}_{3}$ nanoparticles. J. Am. Ceram. Soc. 2007, 90, 2615-2617.

79. Chen, C.; Cheng, J.; Yu, S.; Che, L.; Meng, Z. Hydrothermal synthesis of perovskite bismuth ferrite crystallites. J. Cryst. Growth 2006, 291, 135-139.

80. Komarneni, S.; Menon, V.C.; Li, H.Q.; Roy, R.; Ainger, F. Microwave-hydrothermal processing of $\mathrm{BiFeO}_{3}$ and $\mathrm{CsAl}_{2} \mathrm{PO}_{6}$. J. Am. Ceram. Soc. 1996, 79, 1409-1412.

81. Prado-Gonjal, J.; Villafuerte-Castrejon, M.E.; Fuentes, L.; Moran, E. Microwave-hydrothermal synthesis of the multiferroic $\mathrm{BiFeO}_{3}$. Mater. Res. Bull. 2009, 44, 1734-1737.

82. Ponzoni, C.; Rosa, R.; Cannio, M.; Buscaglia, V.; Finocchio, E.; Nanni, P.; Leonelli, C. Optimization of BFO microwave-hydrothermal synthesis: Influence of process parameters. J. Alloys Compds. 2013, 558, 150-159.

83. Merzhanov, A.G.; Shkiro, V.M.; Borovinskaya, I.P. Synthesis of refractory inorganic compounds. US Patent 3726643, April 1973.

84. Merzhanov, A.G.; Shkiro, V.M.; Borovinskaya, I.P. Synthesis of refractory inorganic compounds. Byull. Izobr. 1971, 10.

85. Varma, A.; Lebrat, J.P. Combustion synthesis of advanced materials. Chem. Eng. Sci. 1992, 47, 2179-2194.

86. Merzhanov, A.G. Reviews: fundamentals, achievements, and perspectives for development of solid-flame combustion. Russ. Chem. Bull. 1997, 46, 1-27.

87. Morsi, K. The diversity of combustion synthesis processing: A review. J. Mater. Sci. 2012, 47, 68-92.

88. Rajeshwar, K.; de Tacconi, N.R. Solution combustion synthesis of oxide semiconductors for solar energy conversion and environmental remediation. Chem. Soc. Rev. 2009, 38, 1984-1998.

89. Nagaveni, K.; Hedge, M.S.; Ravishankar, N.; Subbanna, G.N.; Madras, G. Synthesis and structure of nanocrystalline $\mathrm{TiO}_{2}$ with lower band gap showing high photocatalytic activity. Langmuir 2004, 20, 2900-2907.

90. Selvam, N.C.S.; Kumar, R.T.; Kennedy, L.J.; Vijaya, J.J. Comparative study of microwave and conventional methods for the preparation and optical properties of novel $\mathrm{MgO}$-micro and nano-structures. J. Alloys Compds. 2011, 509, 9809-9815.

91. Nehru, L.C.; Swaminathan, V.; Sanjeeviraja, C. Rapid synthesis of nanocrystalline ZnO by a microwave-assisted combustion method. Powder Technol. 2012, 226, 29-33.

92. Rosa, R.; Ponzoni, C.; Veronesi, P.; Natali Sora, I.; Felice, V.; Leonelli, C. Solution combustion synthesis of perovskite oxides: Comparison between MWs and conventional ignition. In Proceedings of 14th International Conference on Microwave and High Frequency Heating, Nottingham, UK, 16-19 September 2013. The University of Nottingham: Nottingham, UK, 2013; pp. 250-253.

93. Kumar, A.; Wolf, E.E.; Mukasyan, A.S. Solution combustion synthesis of metal nanopowders: Nickel reaction pathways. AIChE J. 2011, 57, 2207-2214.

94. Luo, W.; Wang, D.; Peng, X.; Wang, F. Microwave synthesis and phase transitions in nanoscale $\mathrm{BiFeO}_{3}$. J. Sol-Gel Sci. Technol. 2009, 51, 53-57. 
95. Mukasyan, A.S.; Dinka, P. Apparatus and methods for combustion synthesis of nano-powders. US Patent WO2007019332-A1, February 2007.

96. Kumar, A.; Mukasyan, A.S.; Wolf, E.E. Impregnated layer combustion synthesis method for preparation of multicomponent catalysts for the production of hydrogen from oxidative reforming of methanol. Appl. Catal. A 2010, 372, 175-183.

97. Martirosyan, K.S.; Luss, D. Carbon combustion synthesis of oxides, US Patent 0097419 A1, May 2006.

98. Martirosyan, K.S.; Iliev, M.; Luss, D. Carbon combustion synthesis of nanostructured perovskites. Int. J. SHS 2007, 16, 36-45.

99. Dinka, P.; Mukasyan, A.S. In situ preparation of oxide-based supported catalysts by solution combustion synthesis. J. Phys. Chem. B 2005, 109, 21627-21633. 


\title{
Syntheses of Macromolecular Ruthenium Compounds: A New Approach for the Search of Anticancer Drugs
}

\section{Andreia Valente and M. Helena Garcia}

\begin{abstract}
The continuous rising of the cancer patient death rate undoubtedly shows the pressure to find more potent and efficient drugs than those in clinical use. These agents only treat a narrow range of cancer conditions with limited success and are associated with serious side effects caused by the lack of selectivity. In this frame, innovative syntheses approaches can decisively contribute to the success of "smart compounds" that might be only selective and/or active towards the cancer cells, sparing the healthy ones. In this scope, ruthenium chemistry is a rising field for the search of proficient metallodrugs by the use of macromolecular ruthenium complexes (dendrimers and dendronized polymers, coordination-cage and protein conjugates, nanoparticles and polymer-"ruthenium-cyclopentadienyl" conjugates) that can take advantage of the singularities of tumor cells (vs. healthy cells).
\end{abstract}

Reprinted from Inorganics. Cite as: Valente, A.; Garcia, M.H. Syntheses of Macromolecular Ruthenium Compounds: A New Approach for the Search of Anticancer Drugs. Inorganics 2014, 2, 96-114.

\section{Introduction}

There has been a growing awareness that nanotechnology applied to medicine has considerable potential to improve the treatment of several diseases. Specifically, in cancer therapy, the polymer-metal complex of oxaliplatin has been approved for the treatment of malignant tumors, including colorectal cancer, in 2003 [1].

The literature concerning macromolecules for drug delivery applications is mainly dedicated to platinum drugs [2-4], with some reports in initial study phases using copper [5], palladium [6], gold [7], tungsten [8] and ruthenium (which will be the focus of this review). Most of the approaches to the development of macromolecular drugs are based on the EPR (enhanced permeation and retention) effect, which was first identified by Maeda et al. in 1986 [9], and states that macromolecules selectively accumulate in tumors relative to healthy tissues, due to their defective vessel vascular structure and decreased lymphatic drainage. This passive targeting results, thus, in the passive accumulation of macromolecules in solid tumors, increasing the therapeutic index, while preventing the undesirable side effects generated by free drugs [10].This finding was a landmark in the anticancer nanomedicine field (the drug concentration in tumor can be 10 to 100 times higher than that in the blood) $[11,12]$.

However, the Food and Drug Administration (FDA) has only approved 11 nano-therapeutics for cancer therapy so far [2-4]. One of the reasons for this situation is certainly related to the problems encountered in the development of new covalently bound macromolecule-drug conjugates, such as multi-step preparation, complicated and poor reproducibility synthesis, which often cause an inevitable loss of drug activity. It is thus of upmost importance to develop newer and simpler 
strategies for conjugate drugs with carriers without using such long processes. This problem can be partially overcome by using a one-step coordination strategy, as with some of the examples fully exposed in this review.

We will mostly focus on the syntheses of macromolecular ruthenium complexes (dendrimers and dendronized polymers, coordination-cage and protein conjugates, nanoparticles and polymer-"ruthenium-cyclopentadienyl" conjugates) to be used as chemotherapeutic agents in cancer treatment. Nowadays, ruthenium complexes are established alternatives to Pt-based drugs in cancer therapy, showing different mechanisms of action and spectrums of activity and possessing the potential to overcome platinum-resistance, as well as lower toxicity [13-18]. There are not yet any commercially available ruthenium drugs, even though there are two important examples that have completed Phase I clinical trials, namely KP1019 [19] ([HInd][trans- $\mathrm{Ru}^{\mathrm{III}} \mathrm{Cl}_{4}$ (Ind)2]; Ind $=$ indazole) and NAMI-A $[20]$ ([HIm] $]$ trans- $\left.\mathrm{Ru}^{\mathrm{III}} \mathrm{Cl} 4(\mathrm{DMSO}) \mathrm{Im}\right], \mathrm{Im}=$ imidazole, DMSO = dimethylsulfoxide). Ruthenium is now a clear candidate for the search for new chemotherapeutics, since complexes bearing this metal core present several properties that make them attractive within this area, such as multiple oxidation states (II, III and IV) accessible under physiological conditions, favorable ligand-exchange kinetics with low toxicity, antitumor activity either in vitro as in vivo, as well as antimetastatic and intrinsic angiostatic activity. In this review, we will discuss the rationale behind the syntheses of these macromolecular ruthenium-based drugs and the coordination to metal strategies. We will finally discuss the best synthesis routes in order to shorten the gap between the huge number of papers published annually and the few compounds proceeding to clinical trials.

\section{Multinuclear Approaches}

The idea behind the multinuclearity in metal-conjugates is the increase of the cytotoxicity of a drug by increasing the number of metal centers. In this frame, dendrimers, coordination-cages conjugates, coordinate polymers or the coordination of a drug to a biomolecule are emerging fields in metal-based drugs, due to their multimeric scaffolds.

\subsection{Ruthenium-Based Dendrimers}

Dendrimers are synthetic, highly-branched macromolecules that arise from a central core and present a well-defined architecture, which can be easily tunable to present different molecular weights and sizes and can be straightforwardly functionalizable with the molecules of interest.

A series of first- and second-generation monodentate ( $N$-donor) ruthenium(II)-arene (arene $=p$-cymene or hexamethylbenzene) metallodendrimers based on poly(propyleneimine) dendritic scaffolds was synthesized in order to exploit the EPR effect [21]. Dinuclear arene ruthenium complexes, $\left[\mathrm{Ru}(\text { arene }) \mathrm{Cl}_{2}\right]_{2}$, react with the dendritic scaffolds by stirring at room temperature in $\mathrm{CH}_{2} \mathrm{Cl}_{2}$ to yield the neutral tetranuclear and octanuclear ruthenium metallodendrimers (Scheme 1a) [21]. The yellow-orange products are isolated as air-stable solids in high yields (79\%-98\%) [21]. The complexes are soluble in most organic solvents [21]. The ${ }^{1} \mathrm{H}$ NMR spectra of all the compounds show broadened peaks upon complexation of the multinuclear 
ruthenium moieties [21]. Evidence of the coordination of the aromatic nitrogen atom to the ruthenium metal was observed through a deshielding in the doublet assigned to aromatic protons on the carbon adjacent to the pyridyl nitrogen atom [21]. This deshielding is attributed to the electronwithdrawing effects of the coordinating metal [21]. The ruthenium functionalized dendrimers were precipitated with the inclusion of solvent molecules, trapped between the dendritic arms (confirmed by elemental analysis) [21].

Scheme 1. (a) Tetra- and octanuclear arene ruthenium dendritic systems [21]; (b) Tetra- and octa-nuclear chelating neutral $(N, O)$ and cationic $(N, N)$ ruthenium(II) metallodendrimers [22].

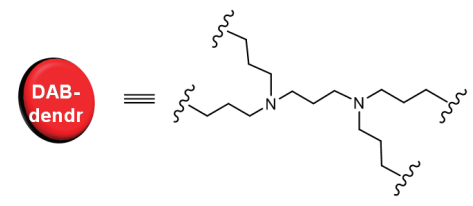

a)

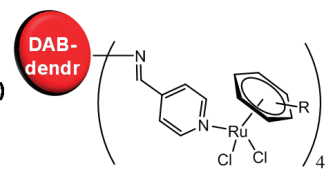

$1(\mathrm{R}=p$-cymene $)$

$2(R=$ hexamethylbenzene $)$

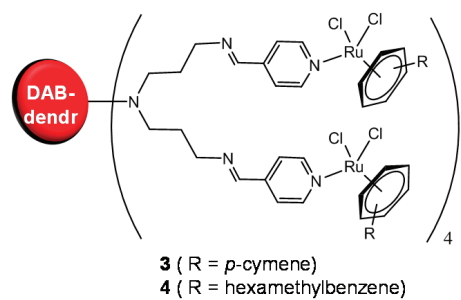

b)
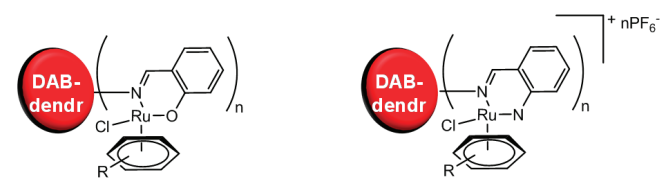

5 ( $n=4 ; R=p$-cymene)

$6(n=4 ; R=$ hexamethylbenzene)

7 ( $\mathrm{n}=8 ; \mathrm{R}=\mathrm{p}$-cymene)

$\mathbf{9}(\mathrm{n}=4 ; \mathrm{R}=\mathrm{p}$-cymene)

10 ( $n=4 ; R=$ hexamethylbenzene)

$11(\mathrm{n}=8 ; \mathrm{R}=p$-cymene)

$12(n=8 ; R=$ hexamethylbenzene)

A second series of metallodendrimers, containing tetranuclear and octanuclear chelating neutral $(N, O)$ and cationic $(N, N)$ first- and second-generation ruthenium(II) arene metallodendrimers based on poly(propyleneimine) dendritic scaffolds, was also synthesized from dinuclear arene ruthenium precursors, $\left[\mathrm{Ru}(\text { arene })_{2} \mathrm{Cl}_{2}\right]_{2}$ (arene $=p$-cymene, hexamethylbenzene), by reactions with salicylaldimine and iminopyridyl dendritic ligands in ethanol at room temperature (Scheme 1b) [22]. The $N, N$ cationic complexes are isolated as hexafluorophosphate salts. These compounds are air-stable, the neutral complexes being soluble in most polar organic solvents and the cationic salts soluble in dimethylsulfoxide, acetone and acetonitrile [22]. The ${ }^{1} \mathrm{H}$ NMR spectra of all the complexes is in agreement with the proposed structures, and the infrared spectra show shifts in the $(\mathrm{C}=\mathrm{N})$ imine absorption band $\left(\sim 1650 \mathrm{~cm}^{-1}\right)$ to lower wavenumbers $\left(\sim 1620 \mathrm{~cm}^{-1}\right)$, supporting the coordination of the imine nitrogen to the ruthenium [22]. MALDI-TOF (Matrix Assisted Laser Desorption Ionization-Time of Flight) studies confirmed that all of the dendrimer end-groups were functionalized with ruthenium(II) arene moieties [22]. 
The cytotoxicity of Metallodendrimers 1-12 was evaluated against A2780 human ovarian cancer cells after an incubation period of $72 \mathrm{~h}$ using the MTT (3-(4,5-dimethylthiazol-2-yl)-2,5diphenyltetrazolium bromide) assay (Table 1) [21,22]. The complexes showed moderate anti-proliferative activity (between 20-50 $\mu \mathrm{M}$ per metallodendrimer), with the exception of 9, which was not cytotoxic $\left(\mathrm{IC}_{50}>200 \mu \mathrm{M}\right)$. As expected, there is a correlation between the nuclearity of the dendritic compound and its cytotoxicity, i.e., monoruthenium compounds have only modest cytotoxicity, whereas the tetranuclear and octanuclear compounds present increasing cytotoxicities (Table 1).

Table 1. IC50 of ruthenium Metallodendrimers 1-12 on A2780 human ovarian cancer cells after $72 \mathrm{~h}$ of exposure.

\begin{tabular}{ccc}
\hline Compound & $\mathbf{I C}_{\mathbf{5 0}}(\boldsymbol{\mu M})$ per metallodendrimer & $\mathbf{I C}_{\mathbf{5 0}}(\boldsymbol{\mu M})$ mononuclear Ru-derivative \\
\hline $\mathbf{1}^{\mathrm{a}}$ & 43 & \\
$\mathbf{2}^{\mathrm{a}}$ & 40 & $\approx 100$ \\
$\mathbf{3}^{\mathrm{a}}$ & 21 & \\
$\mathbf{4}^{\mathrm{a}}$ & 20 & \\
\hline $\mathbf{5}^{\mathrm{b}}$ & 50 & \\
$\mathbf{6}^{\mathrm{b}}$ & 27 & \\
$\mathbf{7}^{\mathrm{b}}$ & 22 & \\
$\mathbf{8}^{\mathrm{b}}$ & 10 & $>200$ \\
$\mathbf{9}^{\mathrm{b}}$ & $>200$ & \\
$\mathbf{1 0}^{\mathrm{b}}$ & 32 & \\
$\mathbf{1 1}^{\mathrm{b}}$ & 23 & \\
$\mathbf{1 2}^{\mathrm{b}}$ & 4 & \\
\hline
\end{tabular}

$\mathrm{IC}_{50}$ cisplatin in the same experimental conditions: ${ }^{\mathrm{a}} 1.6 \mu \mathrm{M}[21] ;{ }^{\mathrm{b}} 1.5 \mu \mathrm{M}[22]$.

Replacing $p$-cymene by hexamethylbenzene enhances the cytotoxicity of the metallodendrimers by a factor of two in the case of neutral Compounds 5-8 and by a factor of six for cationic Compounds 9-12. In the case of Metallodendrimers 1-4, this change does not affect the cytotoxicity.

More recently, a new class of air-stable cationic zero generation ruthenium-based metallodendrimers prepared using nitrile-functionalized poly(alkylidenamine) has been synthesized under the basis of the recognized activity of ruthenium compounds as anticancer drugs and the known stability of these dendrimers at physiological temperature [23]. Metallodendrimers 13-16 (Scheme 2) were synthesized by peripherally functionalization of the corresponding dendrimers with the ruthenium moieties, $\left[\mathrm{Ru}\left(\eta^{5}-\mathrm{C}_{5} \mathrm{H}_{5}\right)\left(\mathrm{PPh}_{3}\right)_{2}\right]^{+}$or $\left[\mathrm{RuCl}(\mathrm{dppe})_{2}\right]^{+}$[23]. For the synthesis of $\mathbf{1 3}$ and $\mathbf{1 5}$, solutions of the corresponding core with $\left[\mathrm{Ru}\left(\eta^{5}-\mathrm{C}_{5} \mathrm{H}_{5}\right)\left(\mathrm{PPh}_{3}\right)_{2} \mathrm{Cl}\right]$ (4.5 molar ratio) and $\mathrm{TlPF}_{6}$ (4.5 molar ratio) in methanol were stirred at room temperature for approximately one day [23]. The resulting mixture was filtered, the precipitate rapidly extracted with $\mathrm{CH}_{2} \mathrm{Cl}_{2}$ and the solvent evaporated, affording the tetrakis-ruthenium dendrimers, $\mathbf{1 3}$ or 15, in the form of yellow products [23]. In the synthesis of $\mathbf{1 4}$ and 16, the five coordinate $c i s$-[RuCl(dppe)2][PF6] complex (4.5 molar ratio) was stirred in 1,2-dichloroethane at $90{ }^{\circ} \mathrm{C}$, for about two days [23]. After work-up, the compounds were dissolved in the minimum amount of $\mathrm{CH}_{2} \mathrm{Cl}_{2}$ and purified by re-precipitation with $\mathrm{Et}_{2} \mathrm{O}$, giving pure yellowish Complexes 14 or 16 [23]. All the metallodendrimers were isolated in reasonably 
good yields (57\%-74\%). Spectroscopic (UV-Vis, IR, NMR) and mass spectrometry techniques confirmed the total functionalization of the ligand cores with the respective metal complex moieties [23]. Time degradation studies of the new metallodendrimers by NMR spectroscopy in DMSO- $\mathrm{d}_{6}$ at $37{ }^{\circ} \mathrm{C}$ showed different behaviors along time between the metallodendrimers functionalized with $\left[\mathrm{Ru}\left(\eta^{5}-\mathrm{C}_{5} \mathrm{H}_{5}\right)\left(\mathrm{PPh}_{3}\right)_{2}\right]^{+}$or $\left[\mathrm{RuCl}(\mathrm{dppe})_{2}\right]^{+}[23]$. While Metallodendrimers 13 and 15, functionalized with $\left[\mathrm{Ru}\left(\eta^{5}-\mathrm{C}_{5} \mathrm{H}_{5}\right)\left(\mathrm{PPh}_{3}\right)_{2}\right]^{+}$, are unstable at physiological temperature, Metallodendrimers 14 and 16, functionalized with $\left[\mathrm{RuCl}(\mathrm{dppe})_{2}\right]^{+}$, present a higher stability in DMSO. Compound 16 does not show signals of degradation with time [23]. Currently, the cytotoxic properties of Metallodendrimers 13-16 are being studied and attempts to improve their solubility and stability in aqueous media are being made [23].

Scheme 2. Metallodendrimers 13-16 [23].
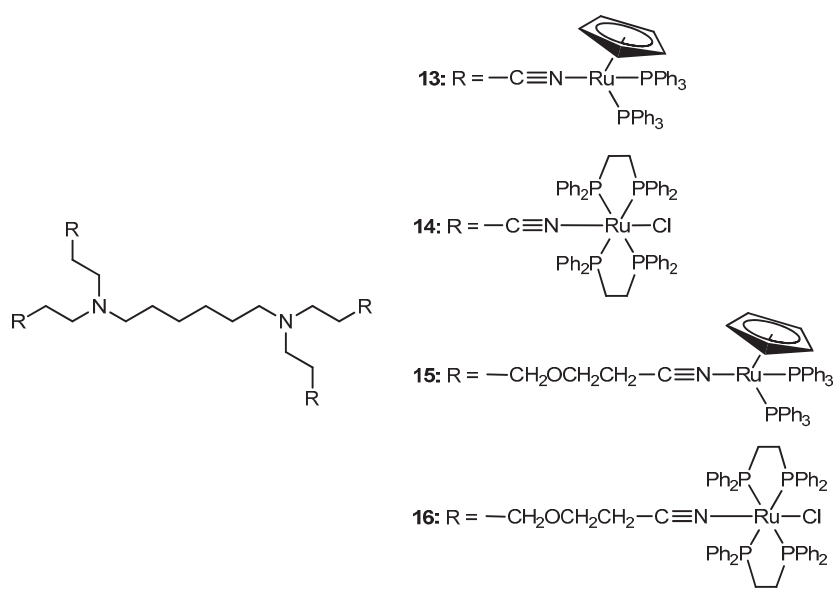

\subsection{Ruthenium-Based Coordination-Cage Conjugates}

Some research groups have been developing several ruthenium coordination-cages (metallaprisms, metallarectangles, metallacycles) for application in cancer chemotherapy [24-38].

The reaction of dinuclear arene ruthenium complexes $\left[\mathrm{Ru}_{2}(\operatorname{arene})_{2}(\mathrm{OO} \cap \mathrm{OO})_{2} \mathrm{Cl}_{2}\right]$ (arene $=p$-cymene, hexamethylbenzene; $\mathrm{OO} \cap \mathrm{OO}=2,5$-dihydroxy-1,4-benzoquinonato; 2,5-dichloro-1,4-benzoquinonato) with pyrazine or bipyridine linkers $(\mathrm{N} \cap \mathrm{N}=4,4$ '-bipyridine; 1,2-bis(4-pyridyl)ethylene) in methanol, at room temperature, using $\mathrm{AgCF}_{3} \mathrm{SO}_{3}$ as a halide scavenger, afford the synthesis of the water soluble tetranuclear metallacyclic cations of general formula $\left[\mathrm{Ru} 4(\text { arene })_{4}(\mathrm{~N} \cap \mathrm{N})_{2}(\mathrm{OO} \cap \mathrm{OO})_{2}\right]^{4+}$ (Scheme 3, Complexes 17-26) [24,25,39]. The larger rectangles, incorporating the 1,2-bis(4-pyridyl)-ethylene linker, are $c a$. five times more cytotoxic ( $\left.\mathrm{IC}_{50} \leq 6 \mu \mathrm{M}\right)$ than the 4,4'-bipyridine-containg cations $\left(\mathrm{IC}_{50} \geq 30 \mu \mathrm{M}\right)$ for the A2780 human ovarian cancer cells (Table 2) [24]. The authors suggested that these variations could result from the different sized cavities, different flexibilities and different packing arrangements (observed from the X-ray diffraction of [Ru4(hexamethylbenzene)4(4,4'-bipyridine)2(2,5-dihydroxy-1,4benzo-quinonato)2 $]^{4+} 19$ and $[\mathrm{Ru} 4($ hexamethylbenzene)4(1,2-bis(4-pyridyl)ethylene)2(2,5-di-hydroxy- 
1,4-benzoquinonato) 2$]^{4+} \mathbf{2 3}$ ) [24]. In each case, the hexamethylbenzene complexes exhibit lower $\mathrm{IC}_{50}$ than their $p$-cymene analogues, probably due to the greater lipophilicity of the second [24].

Cationic tetra- and hexa-nuclear opened metalla-assemblies incorporating 5,15-bis(4-pyridyl)10,20-diphenylporphyrin (Scheme 3, Complexes 25-26) or 5,10,15-tris(4-pyridyl)-20phenylporphyrin (Scheme 4, Complexes 30-31) panels and dinuclear arene ruthenium clips $\left[\mathrm{Ru}_{2}(p \text {-cymene })_{2}(\mathrm{OO} \cap \mathrm{OO})_{2}\right]^{2+}(\mathrm{OO} \cap \mathrm{OO})=$ oxalate, 2,5-dioxydo-1,4-benzoquinonato, dobq $)$ have been synthesized in the presence of $\mathrm{AgCF}_{3} \mathrm{SO}_{3}$ (the synthesis details are ambiguous) [25]. The compounds are sparingly soluble in water and stable in deuterated water at $60{ }^{\circ} \mathrm{C}$ for $48 \mathrm{~h}(\mathrm{NMR}$ studies) [25]. All the complexes are cytotoxic against A2780 human ovarian cancer cells, the complexes with the dobq ligand (26 and $\mathbf{3 1}$ ) being more cytotoxic than the oxalate derivatives ( 25 and 30); this feature shows the importance of the spacer in the cytotoxic activity [25].

A solution the $N, N^{\prime}$-di(4-pyridyl)-1,4,5,8-naphthalenetetracarboxydiimide donor ligand in $\mathrm{CH}_{3} \mathrm{NO}_{2}$ was added dropwise to a $\mathrm{CH}_{3} \mathrm{OH}$ solution containing equimolar amounts of $\left[\mathrm{Ru}_{2}\left(\mu^{4}-\mathrm{C}_{2} \mathrm{O}_{4}\right)(\mathrm{MeOH})_{2}\left(\eta^{6}-p-i \mathrm{PrC}_{6} \mathrm{H}_{4} \mathrm{Me}\right)_{2}\right]\left[\mathrm{O}_{3} \mathrm{SCF}_{3}\right]_{2}, \quad\left[\mathrm{Ru}_{2}(\mathrm{dobq})(\mathrm{MeOH})_{2}\left(\eta^{6}-p-\right.\right.$ $\left.\left.i \mathrm{PrC}_{6} \mathrm{H}_{4} \mathrm{Me}\right)_{2}\right]\left[\mathrm{O}_{3} \mathrm{SCF}_{3}\right]_{2}$ or $\left[\mathrm{Ru}_{2}(\right.$ donq $\left.)\left(\mathrm{H}_{2} \mathrm{O}\right)_{2}\left(\eta^{6}-p-i \mathrm{PrC}_{6} \mathrm{H}_{4} \mathrm{Me}\right)_{2}\right]\left[\mathrm{O}_{3} \mathrm{SCF}_{3}\right]_{2}$. The mixture was stirred for $48 \mathrm{~h}$ at $60{ }^{\circ} \mathrm{C}$, filtered and the solvent evaporated to dryness. Pure compounds were isolated after washing the products with diethyl ether (yield $\approx 90 \%$ ) [33].UV-Vis absorption spectra presented the expected $\pi \rightarrow \pi^{*}$ transition bands, corresponding to the extended aromatic systems of the dipyridyl ligands [33]. The X-ray analysis of the compound bearing the $\left[\mathrm{Ru}_{2}(\mathrm{dobq})(\mathrm{MeOH})_{2}\left(\eta^{6}-p-i \mathrm{PrC}_{6} \mathrm{H}_{4} \mathrm{Me}_{2}\right)_{2}\left[\mathrm{O}_{3} \mathrm{SCF}_{3}\right]_{2}\right.$ moiety proved the rectangle nature of this family of compounds [33]. All these compounds were tested against gastric (AGS) and colon (HCT-15) human cancer cells [33]. While compounds bearing the $\mu^{4}-\mathrm{C}_{2} \mathrm{O}_{4}$ and dobq spacers were found to be poorly active against these cancer cell lines, Compound 27 (Scheme 3), bearing the donq linker, proved to be better than cisplatin for the AGS cells and with comparable IC50 values for the HCT-15 cell line [33]. These results emphasize the importance of the spacer.

The synthesis of asymmetrical metallarectangles has also been tested [34,35]. In the first case, a solution of ambidentate donor sodium 4-(pyridin-4-ylethynyl)benzoate in $\mathrm{MeOH}$ was added dropwise to a solution of ruthenium acceptor $\left[\mathrm{Ru}_{2}(\right.$ donq $\left.)\left(\mathrm{H}_{2} \mathrm{O}\right)_{2}\left(\eta^{6}-p-i \mathrm{PrC}_{6} \mathrm{H}_{4} \mathrm{Me}\right)_{2}\right]\left[\mathrm{O}_{3} \mathrm{SCF}_{3}\right]_{2}$ in $\mathrm{MeOH}$ in a 1:1 molar ratio [34]. The final product was treated with diethyl ether, affording the sea-green Compound 28 (Scheme 3) [34]. Due to the asymmetry of the ambidentate donor, the formation of two isomers is possible (Scheme 5). This feature was followed by NMR spectroscopy; the four protons of the donq ligand are distinct if we have one or another isomer: for the head-to-tail isomer (A), two protons are oriented towards the $\mathrm{Ru}-\mathrm{N}$ centers and the other two protons are oriented towards the $\mathrm{Ru}-\mathrm{O}$ centers (on the same clip), thus making them chemically different; in the case of the head-to-head isomer (B), all the donq protons of a given clip have the same neighborhood, thus being equivalent [34]. In this frame, the head-to-head isomer presents two singlets in the ${ }^{1} \mathrm{H}$ NMR, while the head-to-tail isomer presents two sets of doublets [34]. In the particular case of Compound 28, the ${ }^{1} \mathrm{H}-\mathrm{NMR}$ showed the predominance of the head-to-head isomer [34]. This can be justified in terms of ring strain, as it was observed by the solid-state structure of Compound 28 [34]. The authors describe that the $\mathrm{Ru}-\mathrm{Ru}-\mathrm{N}$ angle in the head-to-tail isomer is $78.37^{\circ}$, while the $\mathrm{Ru}-\mathrm{Ru}-\mathrm{O}$ angle is $96.85^{\circ}$ [34]. In this frame, the presence of two 
pyridyl or two carboxylate groups on the same clip would give unfitting angularities and eventually lead to the terminal ligand-ends being too close or too far apart, thus making the coordination with the second clip unfavorable [34].The in vitro anticancer activity of this compound was tested against lung (A549), gastric (AGS), colon (HCT-15) and liver (SK-hep-1) human cancer cell lines. The compound is active for all these cancer cell lines, in particular for the AGS human gastric cancer cell line. When the donq linker is replaced by dobq, a non-cytotoxic compound is obtained ( $\mathrm{IC}_{50}$ in all tested cancer cell lines $>200 \mu \mathrm{M}$ ) [34].

Scheme 3. Metallarectangles 17-29 [24,25,33-35].

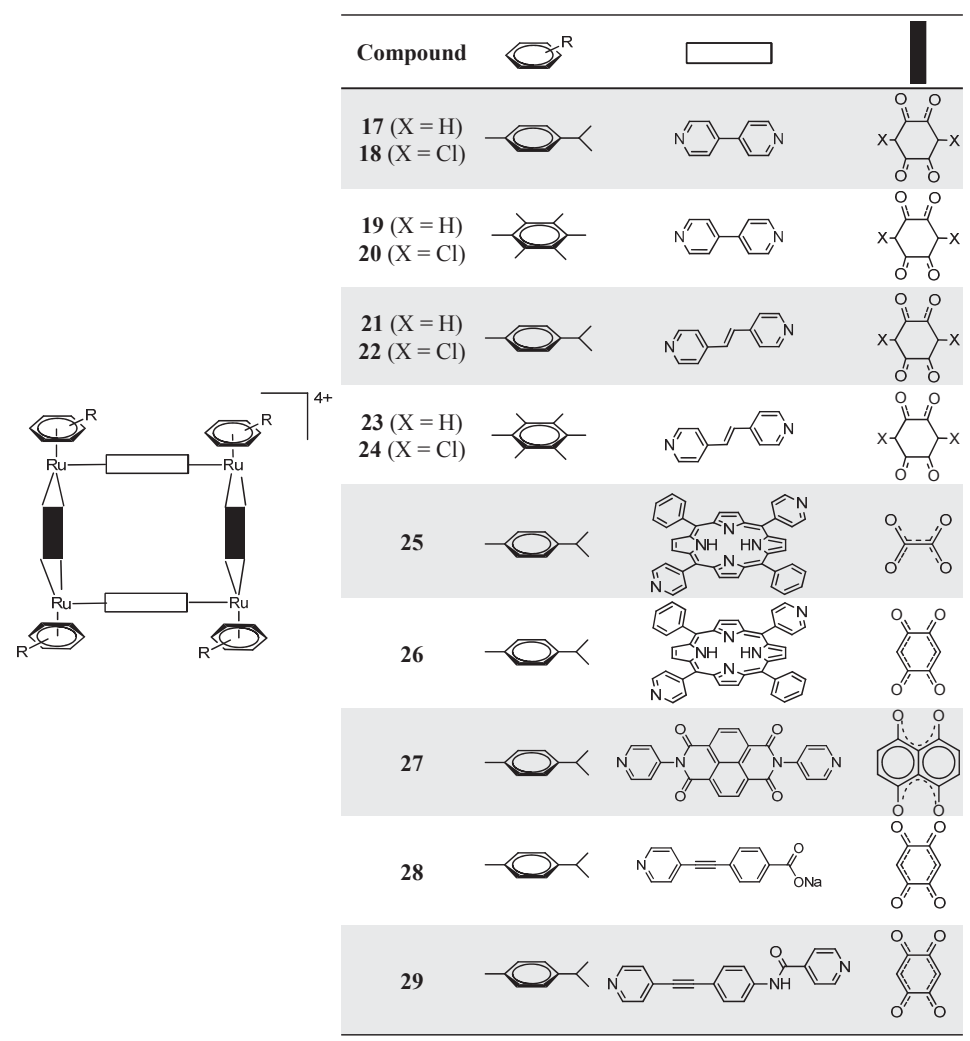

A second asymmetrical molecular rectangle was obtained by suspension of $\mathrm{N}$-(4-(pyridine-4ylenthynyl)phenyl)-isonicotinamide and $\left[\mathrm{Ru}_{2}(\right.$ donq $\left.)\left(\mathrm{H}_{2} \mathrm{O}\right)_{2}\left(\eta^{6}-p-i \mathrm{PrC}_{6} \mathrm{H}_{4} \mathrm{Me}\right)_{2}\right]\left[\mathrm{O}_{3} \mathrm{SCF}_{3}\right]_{2} \quad$ in $\mathrm{CH}_{2} \mathrm{Cl}_{2} / \mathrm{CH}_{3} \mathrm{OH}(1: 1)$ for $6 \mathrm{~h}$ at room temperature [35]. The crude product (obtained after evaporation of the solvent) was dissolved in acetone and recrystallized by slow diffusion of diethyl ether, resulting in the green crystalline solid, 29 (Scheme 3) [35]. Once again, due to the linker asymmetry, the formation of two isomers might occur. In this case, however, it seems that there is not a preferred one (data from ${ }^{1} \mathrm{H}$ NMR show the signals of both isomers) [35]. The IC50 values determined for colorectal (Colo320), lung (A549 and H1299) and breast (MCF7) human cancer cell lines reveal very low $\mathrm{IC}_{50}$ values $(0.1-10.18 \mu \mathrm{M})$, placing this compound among the best ruthenium-macromolecular compounds tested for in vitro anticancer activity [35]. 
Scheme 4. Structure of the Metalla-assemblies 30-34 [25,26,37].

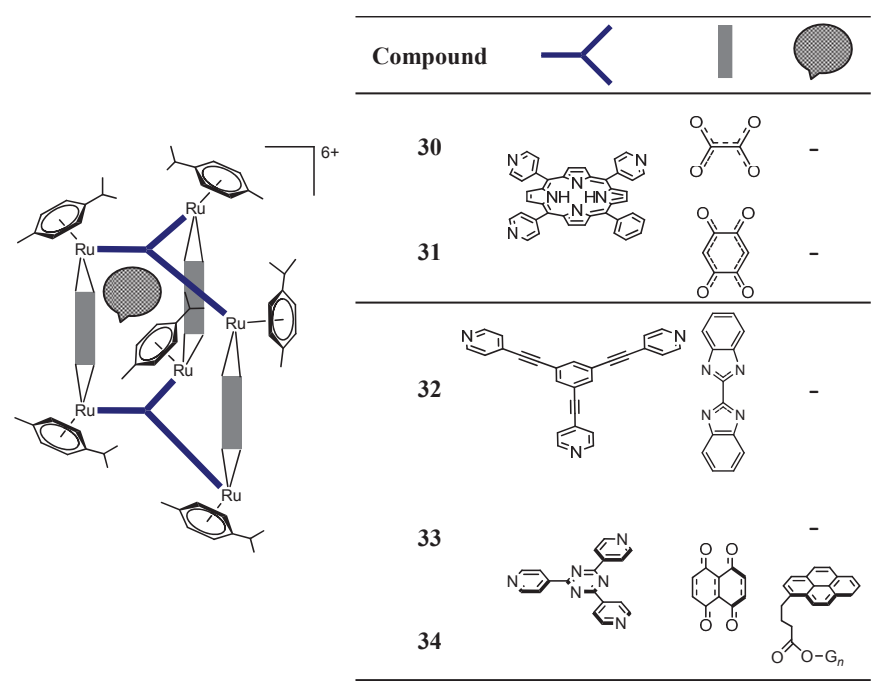

Scheme 5. Possible isomers of Compound 28.

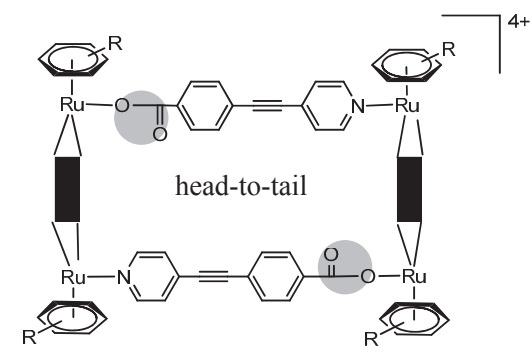

$\mathbf{A}$

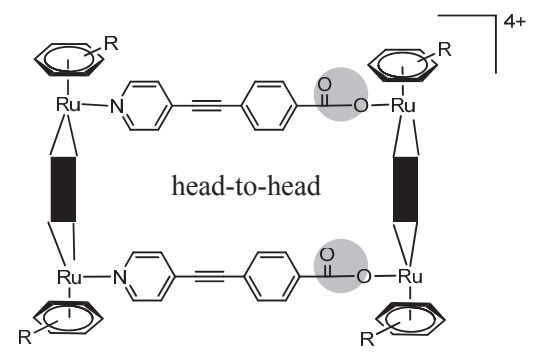

B

Self-assembly of the 5,10,15,20-tetra(4-pyridyl)porphyrin (tpp- $\left.\mathrm{H}_{2}\right)$ tetradentate panel with the dinuclear $p$-cymene ruthenium clip, $\left[\mathrm{Ru}_{2}(p \text {-cymene })_{2}(\mathrm{OO} \cap \mathrm{OO}) \mathrm{Cl}_{2}\right](\mathrm{OO} \cap \mathrm{OO}=$ oxalato; dobq $)$, affords the cationic organometallic cube, $\left[\mathrm{Ru} 8(\mathrm{p} \text {-cymene })_{8}\left(\mathrm{tpp}-\mathrm{H}_{2}\right)_{2}(\mathrm{OO} \cap \mathrm{OO})_{4}\right]^{8+}[26]$. In addition,

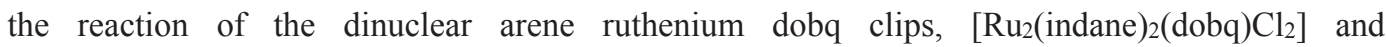
$\left.\left[\mathrm{Ru}_{2} \text { (nonylbenzene) }\right)_{2}(\mathrm{dobq}) \mathrm{Cl}_{2}\right]$, in $\mathrm{MeOH}$ for $48 \mathrm{~h}$ at reflux temperature, with tpp- $\mathrm{H}_{2}$ in the presence of $\mathrm{AgCF}_{3} \mathrm{SO}_{3}$, affords the corresponding cationic cubes, [Rus(indane) $\left.{ }_{8}\left(\mathrm{tpp}-\mathrm{H}_{2}\right)_{2}(\mathrm{dobq})_{4}\right]^{8+}$ and $\left[\mathrm{Ru} 8(\text { nonylbenzene })_{8}\left(\mathrm{tpp}-\mathrm{H}_{2}\right)_{2}(\mathrm{dobq})_{4}\right]^{8+}$, respectively [26]. However, these octanuclear ruthenium compounds are poorly soluble in $\mathrm{H}_{2} \mathrm{O}$ and show decreased cytotoxic activity compared with their hexanuclear homologues, showing, in this case, that there is not a direct correlation between the number of ruthenium centers $v s$. cytotoxicity.

The reaction of the $\left[\mathrm{Ru}_{2}\right.$ (bis-benzimidazole $\left.)(\mathrm{MeOH})_{2}\left(\eta^{6}-p-i \mathrm{PrC}_{6} \mathrm{H}_{4} \mathrm{Me}\right)_{2}\right]\left[\mathrm{O}_{3} \mathrm{SCF}_{3}\right]_{2}$ clip with 1,3,5-tris-(4-pyridylethynyl)-benzene in a 3:2 molar ratio results in self-assembled Metalla-prism 32 (Scheme 4) [37]. This compound was found to inhibit the proliferation of colon (Colo320), lung (A549 and H1299) and breast (MCF7) human cancer cell lines at low concentrations [37]. 
Table 2. $\mathrm{IC}_{50}$ of the ruthenium coordination-cage conjugates, 17-26, 30-31 and 33-34, on A2780 human ovarian cancer cells after $72 \mathrm{~h}$ of exposure.

\begin{tabular}{cc}
\hline Compound & $\begin{array}{c}\mathbf{I C}_{\mathbf{5 0}}(\boldsymbol{\mu M}) \\
\text { per coordination-cage }\end{array}$ \\
\cline { 1 - 2 } $\mathbf{1 7}^{\text {a }}$ & 66 \\
$\mathbf{1 8}^{\text {a }}$ & 43 \\
$\mathbf{1 9}^{\text {a }}$ & 27 \\
$\mathbf{2 0}^{\text {a }}$ & 33 \\
$\mathbf{2 1}^{\text {a }}$ & 6 \\
$\mathbf{2 2}^{\text {a }}$ & 29 \\
$\mathbf{2 3}^{\text {a }}$ & 4 \\
$\mathbf{2 4}^{\text {a }}$ & 23 \\
$\mathbf{2 5}^{\text {b }}$ & 11 \\
$\mathbf{2 6}^{\text {b }}$ & 5.6 \\
$\mathbf{3 0}^{\text {b }}$ & 3.1 \\
$\mathbf{3 1}^{\text {b }}$ & 2.1 \\
$\mathbf{3 3}^{34}$ & 3.1 \\
$\mathbf{3 4}^{\text {a }}$ & 2.4 \\
\hline in the same experimental conditions: & \\
\end{tabular}

Arene-ruthenium metallacages were used to encapsulate lipophilic pyrenyl functionalized poly(benzylether) dendrimers (Scheme 4, 33 vs. 34) [27,28,31]. The host-guest systems, 33, were prepared using a two-step strategy. Firstly, the dinuclear complex, $\left[\mathrm{Ru}_{2}(p \text {-cymene })_{2}\left(\mathrm{donq}_{\mathrm{C}} \mathrm{Cl}_{2}\right]\right.$ (donq $=$ 5,8-dioxydo-1,4-naphthoquinonato), was reacted with $\mathrm{AgCF}_{3} \mathrm{SO}_{3}$ in $\mathrm{MeOH}$ at room temperature affording the dinuclear intermediate. Then, 0.66 equivalents of 2,4,6-tris(4-pyridyl)1,3,5-triazine (tpt) and 0.33 equivalents of the guest molecule were added, and the solution was stirred at $60{ }^{\circ} \mathrm{C}$ for $24 \mathrm{~h}$ to obtain the corresponding inclusion compounds. The resulting hexacationic host-guest systems are obtained in a good yield $(80 \%)$ as triflate salts, $[34]\left[\mathrm{CF}_{3} \mathrm{SO}_{3}\right] 6$. Both Metallacage 33 and the host-guest system, 34, exhibit a similar cytotoxicity on the A2780 cell line (Table 2). However, these results did not clarify whether the guest is released or not after cellular internalization into the cancer cells. The cytotoxicity seemed to be inversely related with the size of the encapsulated dendrimer in the majority of cases, i.e., smaller dendrimers lead to lower cytotoxicities. Replacement of donq by doaq (5,8-dioxido-1,4-anthraquinonato) or dotq (6,11-dioxido-5,12-naphthacenedionato) led to less cytotoxic compounds [30].

\subsection{Ruthenium(II)-Coordinate Polymers}

RAPTA-C, $\left[\mathrm{RuCl}_{2}\right.$ (p-cymene)(PTA)] (PTA = 1,3,5-triaza-7-phosphaadamantane), was bounded to poly(2-chloroethyl methacrylate)(PCEMA) and poly(2-chloroethyl methacrylate-co- $N$-(2hydroxypropyl) methacrylamide) (P(HPMA-CEMA)) to generate water-soluble macromolecular drugs [40]. Two strategies for the synthesis of the RAPTA-C-polymer conjugate were employed using the nitrogen groups of PTA as a site for alkylation: (a) the synthesis of the complex and direct conjugation to the polymer; or (b) attachment of PTA to the polymer and subsequent 
complexation with the dimer, to give the polymer-RAPTA-C conjugate [40]. The high temperature needed in the direct reaction (a) of RAPTA-C with the polymer led to the loss of the $p$-cymene ligand, invalidating this procedure [40]. In the two-step reaction (b), despite the fact that only $50 \%$ of the iodated copolymer had reacted (see Scheme 6), this method was chosen as the preferred pathway for the subsequent synthesis of the water-soluble polymer, P(HPMA172-IEMA44-(RAPTAC-EMA)44), 35 (Scheme 6) [40]. One should note that these macromolecular ruthenium complexes were only synthesized in an NMR experiment using DMSO-d6 for seven days and were then recovered by dialysis [40]. The cytotoxicity of the RAPTA-C-copolymer conjugate was measured on the ovarian cancer cell line, OVCAR-3, revealing high $\mathrm{IC}_{50}$ values $(>300 \mu \mathrm{M})$ [40].

Scheme 6. Synthesis of complex copolymer-RAPTA-C ([RuCl 2 (p-cymene)(PTA) $]$ $(\mathrm{PTA}=1,3,5$-triaza-7-phosphaadamantane))conjugate (35) in DMSO-d6 [40].

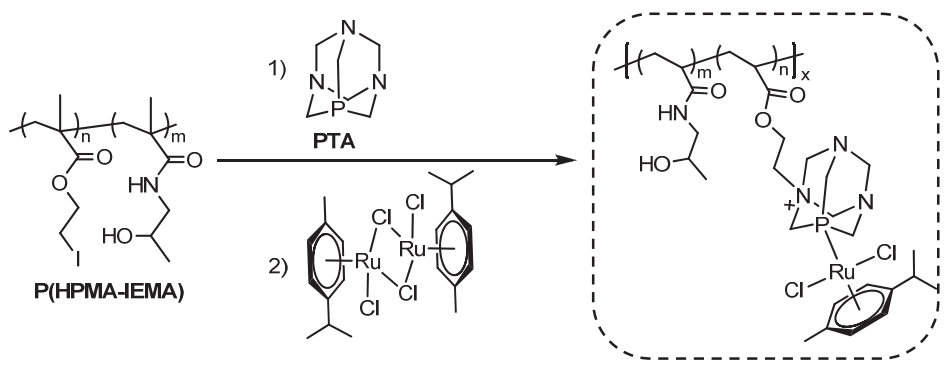

35

\subsection{Ruthenium(II)-HSA Conjugates}

Organoruthenium complexes of the general formula $\left[\mathrm{Ru}\left(\eta^{6}\right.\right.$-arene $\left.) \mathrm{Cl}(\mathrm{L})\right] \mathrm{Cl}$, where arene is 4-formylphenoxyacetyl- $\eta^{6}$-benzylamide and $\mathrm{L}$ is a cyclin-dependent kinase (Cdk) inhibitor, [3-(1H-benzimidazol-2-yl)-1H-pyrazolo[3,4-b]pyridines or indolo[3,2- $d]$ benzazepines, were conjugated to recombinant human serum albumin (rHSA) to exploit the EPR effect (Scheme 7) [41]. The conjugation of the ruthenium moiety to modified rHSA was carried out via hydrazine bond formation according to a previous reported procedure [42]. Briefly, purified rHSA is shaken with 10 equivalents a solution of succinyl $\mathrm{HCl}$ terephthalic hydrazine in dimethylformamide (DMF) for $16 \mathrm{~h}$ at room temperature (the DMF volume did not exceed 5\% $(v / v))[41]$. The reaction mixture is then ultrafiltered against the conjugation buffer (100 mM MES, 2-( $N$-morpholino)ethanesulfonic acid, $0.9 \% \mathrm{NaCl}, \mathrm{pH} 6.0)$, and the concentration determined using the Bradford assay [41]. The modified protein solution is added to solutions of several complexes in order to achieve a 3:1 metal/protein ratio and shaken for $6 \mathrm{~h}$ at room temperature [41]. Afterwards, the protein mixture solution is desalted and restored in PBS (phosphate buffered saline) [41]. MALDI-TOF-MS analysis showed that the obtained samples correspond most likely to the presence of about two bound ruthenium moieties per protein [41]. 
Scheme 7. Ruthenium-recombinant human serum albumin (rHSA) conjugates 36-40 [41]. Coordinating nitrogen in bold.

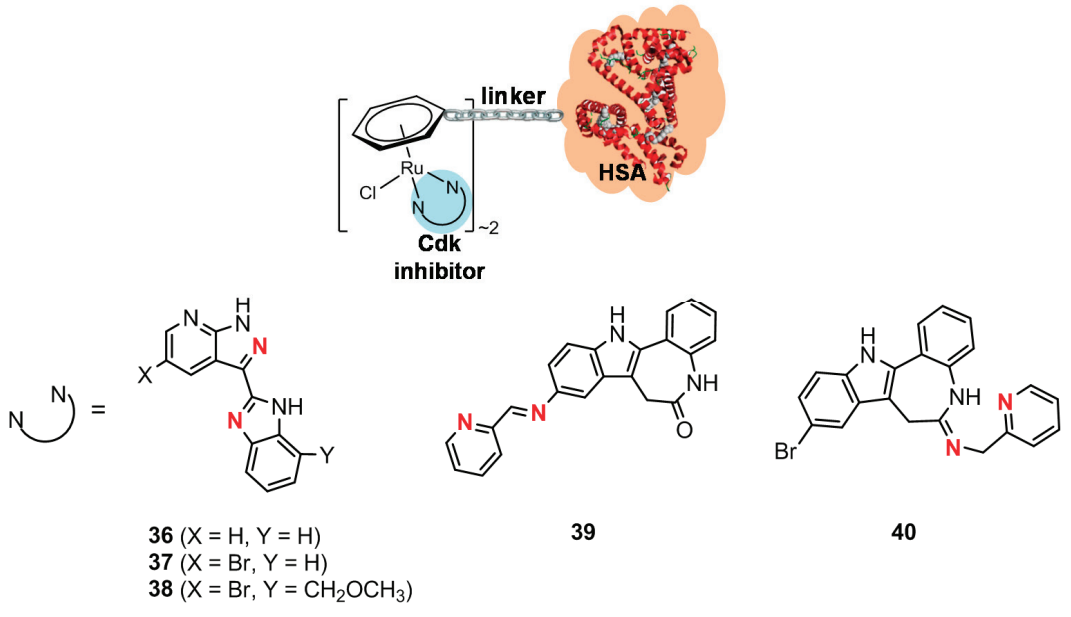

Table 3. $\mathrm{IC}_{50}$ of the different ruthenium-rHSA Conjugates 36-40 on A2780 human ovarian cancer cells after $72 \mathrm{~h}$ exposure.

\begin{tabular}{cc}
\hline Compound & $\begin{array}{c}\text { IC }_{\mathbf{5 0}}(\boldsymbol{\mu M}) \\
\text { per compound }\end{array}$ \\
\hline 36 & $>200$ \\
$36-$ rHSA & 45 \\
37 & $>200$ \\
$37-$ rHSA & 43 \\
38 & $>200$ \\
$38-$ rHSA & 46 \\
39 & $>100$ \\
$39-$ rHSA & 49 \\
40 & 85 \\
$40-$ rHSA & 26 \\
\hline
\end{tabular}

The high molecular weight compounds (36-rHSA to 40-rHSA), together with their non-protein complexes (36-40) were evaluated in vitro in an ovarian carcinoma cell line (A2780). From Table 3 , one can observe that the complexes alone are not cytotoxic. When coordinated with rHSA, there is an increase in cytotoxicity. One should not neglect that the cyclin-dependent kinase (Cdk) inhibitor ligands are much more cytotoxic for CH1 (human ovarian carcinoma), SW480 (human colon carcinoma) and A549 (human non-small cell lung carcinoma) cell lines than their corresponding ruthenium Complexes 36-40. Unfortunately, data for the A2780 cancer cell line is not provided. 


\section{Mononuclear Approaches}

\subsection{Ruthenium Nanoparticles}

Nanoparticles find increasing applications in medicinal chemistry as drug delivery agents, medicinal imaging tools or as diagnostic agents. In addition, nanoparticles can also benefit from the enhanced permeability and retention effect and can be tunable to present specific properties.

Ruthenium( 0 ) nanoparticles stabilized by a long-chain $N$-ligand derived from isonicotinic acid (L) have been prepared by the solvent-free reduction of $\left[\mathrm{Ru}\left(\eta^{6}-\mathrm{C}_{6} \mathrm{H}_{6}\right)(\mathrm{L}) \mathrm{Cl}_{2}\right]$ in a magnetically stirred stainless-steel autoclave with $\mathrm{H}_{2}(50 \mathrm{bar})$ at $100{ }^{\circ} \mathrm{C}$ for $64 \mathrm{~h}(41)$ [43]. The mean particle size was found to be $8.5 \mathrm{~nm}$ (established by transmission electron microscopy, TEM), which is relatively large. Smaller ruthenium nanoparticles stabilized by the isonicotinic ester ligand $\mathbf{L}$ were obtained by reducing $\left[\mathrm{Ru}\left(\eta^{6}\right.\right.$-arene $\left.)\left(\mathrm{H}_{2} \mathrm{O}\right)_{3}\right] \mathrm{SO}_{4}$ in ethanol in the presence of one equivalent of $\mathbf{L}$ in a magnetically stirred stainless-steel autoclave under 50 bar pressure of $\mathrm{H}_{2}$ at $100{ }^{\circ} \mathrm{C}$ for $14 \mathrm{~h}$ (Table 4; 42: arene $=\mathrm{C}_{6} \mathrm{H}_{6} ; 43$ : arene $=p-\mathrm{MeC}_{6} \mathrm{H}_{4} \mathrm{Pr}^{\mathrm{i}} ; 44$ arene $=\mathrm{C}_{6} \mathrm{Me}_{6}$ ) [43] .

The in vitro cytotoxicity of the $\mathbf{L}$-stabilized $\mathrm{Ru}$ nanoparticles, 41-44, and their corresponding small molecules (i.e., complexes of the general formula $\left[\mathrm{Ru}\left(\eta^{6}\right.\right.$-arene $\left.\left.)(\mathrm{L}) \mathrm{Cl}_{2}\right]\right)$ havebeen studied in the A2780 ovarian cancer cell line using the MTT assay. While the small molecules exhibit a good to moderate cytotoxicity, the nanoparticles exhibit only moderate cytotoxicity in the studied ovarian cancer cell line, with the exception of thep-cymene derived system, 43, which was unusually inactive (Table 4). For 41, 42 and 44, neither the nanoparticles size nor the nature of the ligands in the precursor complex appear to have an effect on cytotoxicity, since all three compounds exhibit similar IC 50 values $(29-39 \mu \mathrm{M})$. It is plausible to think that the in vitro activity of the complexes and nanoparticles is mainly due to the isonicotinic ester ligand $\mathbf{L}$, since it presents, itself, a high cytotoxicity ( $\mathrm{IC}_{50}$ of $\mathbf{L}$ in $\mathrm{A} 2780$ after $72 \mathrm{~h}$ of exposure $=5 \mu \mathrm{M}$ ).

Table 4. IC 50 of the ruthenium (0) nanoparticles, 41-44, on A2780 human ovarian cancer cells after $72 \mathrm{~h}$ of exposure.

\begin{tabular}{|c|c|c|c|}
\hline Compound & Ru nanoparticles & Mean size (nm) & $\mathrm{IC}_{50}(\boldsymbol{\mu M})$ \\
\hline 41 & & 8.5 & 29 \\
\hline 42 & & 2.8 & 34 \\
\hline 43 & & 2.3 & $>200$ \\
\hline 44 & & 2.2 & 39 \\
\hline
\end{tabular}

\subsection{Polymer- "Ruthenium-Cyclopentadienyl" Conjugate}

$\mathrm{Ru}^{\mathrm{II}} \mathrm{Cp}(\mathrm{Cp}=$ cyclopentadienyl) low molecular weight drugs [44-52] are currently promising candidates in the search fornew chemotherapeutics, due to the excellent cytotoxic results against human colon adenocarcinoma (LoVo and HT29), pancreatic (Mia PaCa), promyelocytic leukemia (HL-60), breast (MDAMB231 and MCF7), prostate (PC3) and ovarian (A2780 and A2780cisR) cancer cell lines ( $\mathrm{IC}_{50}$ values in the nano- to micro-molar range) [44-52]. Importantly, the $[\mathrm{CpRu}(\mathrm{P})(\mathrm{bpy})]^{+}$family $(\mathrm{P}=$ phosphane coligand, bpy = bipyridine) presents very good stability in 
an aqueous environment. This feature of these complexes prompted the search fornew polymer-metal complexes using the same organometallic core as potential anticancer agents.

Conceptually, polymer conjugates share several features with other macromolecular approaches (liposomes, dendrimers, nanotubes and nanoparticles), but they have the added benefit of the synthetic chemical versatility that allows the tailoring of the molecular weight and also the adding of biomimetic features [53]. In this frame, the unprecedented synthesis of $\mathbf{4 5}$ (Scheme 8), and its preliminary in vitro results have been recently published [54]. [RuCp(P)(bpyPLA) $]^{+}(\mathrm{RuPMC}$; $\mathrm{Cp}=\eta^{5}-\mathrm{C}_{5} \mathrm{H}_{5}, \quad \mathrm{P}=$ triphenylphosphane and bpyPLA $=$ 2,2'-bipyridine-4,4'-D-glucose end-capped polylactide) has been synthesized in a good yield by halide abstraction from $\left[\mathrm{Ru}\left(\eta^{5}-\mathrm{C}_{5} \mathrm{H}_{5}\right)\left(\mathrm{PPh}_{3}\right)_{2} \mathrm{Cl}\right]$ with silver $\mathrm{AgCF}_{3} \mathrm{SO}_{3}$, under reflux for $3 \mathrm{~h}$ in $\mathrm{CH}_{2} \mathrm{Cl}_{2}$ in the presence of the bpyPLA macroligand. The molecular weight of the bpyPLA macroligand can be easily tuned by playing with the monomer/initiator ratio.

A degradation study, by UV-visible spectroscopy, of the RuPMC performed in order to infer the polymer hydrolysis at physiological and at tumor cell $\mathrm{pH}(\mathrm{pH}=7.4$ and 5 , respectively) showed that RuPMC is stable over a period of at least $72 \mathrm{~h}$ in an aqueous environment at physiologic $\mathrm{pH}$, while at acidic $\mathrm{pH}$, some degradation of the PLA is observed. Such behavior suggests a $\mathrm{pH}$-dependent degradation, which is important considering drug delivery, since the measured $\mathrm{pH}$ of most solid tumors range from $\mathrm{pH} 5.7$ to $\mathrm{pH}$ 7.2, while in blood it remains well-buffered and constant at $\mathrm{pH} 7.4$ [55]. Accordingly, this feature of the polymer degradation discards the need for a biodegradable linker and provides the opportunity for site-specific drug delivery, mainly within endosomal/lysosomal compartments, where the $\mathrm{pH}$ approaches 4.5-6.0 [56].

This polymer-"ruthenium-cyclopentadienyl" conjugate $\mathbf{4 5}$ is cytotoxic against human MCF7 and MDAMB231 breast and A2780 ovarian adenocarcinoma, revealing IC50 values in the micromolar range $\left(\mathrm{IC}_{50}=3.9,3.8\right.$ and $1.6 \mu \mathrm{M}$, respectively). ICP-MS (inductively coupled plasma mass spectrometry) studies showed that the Ru-polymer conjugate enters the MCF7 estrogen receptor positive cancer cells and is retained $c a .50 \%$ in the nucleus, foreseeing its application as a therapeutic agent in, for example, hormone-responsive cancers. On the contrary, its Ru-precursor (TM34, $\left[\mathrm{Ru}^{\mathrm{II}}\left(\eta^{5}-\mathrm{C}_{5} \mathrm{H}_{5}\right)(\text { bipy })\left(\mathrm{PPh}_{3}\right)\right]^{+}$, in Scheme 8) is mainly found in the membrane $(\mathrm{ca} .80 \%)$, forecasting different mechanisms of cellular uptake and of cell death for these two compounds bearing the same cytotoxic fragment.

Direct comparison of the $\mathrm{IC}_{50}$ values between $\mathrm{RuPMC}$ and its low molecular weight parent drug, TM34, reveals a decrease on the cytotoxicity of RuPMC (3.9 vs. $0.29 \mu \mathrm{M}$ for MCF7). However, one should not neglect the potential effect that the prolonged plasma half-life of the RuPMC could have on the improvement of the chemotherapeutic efficacy, allowing a positive final outcome, as has been described for many platinum-related compounds [57-60]. This new RuPMC seems to be a viable candidate for the intended drug-delivery application, yet further studies are needed to prove its higher in vivo accumulation in cancer cells. 
Scheme 8. D-Glucose end-capped polylactide ruthenium-cyclopentadienyl (RuPMC, 45) and TM34.

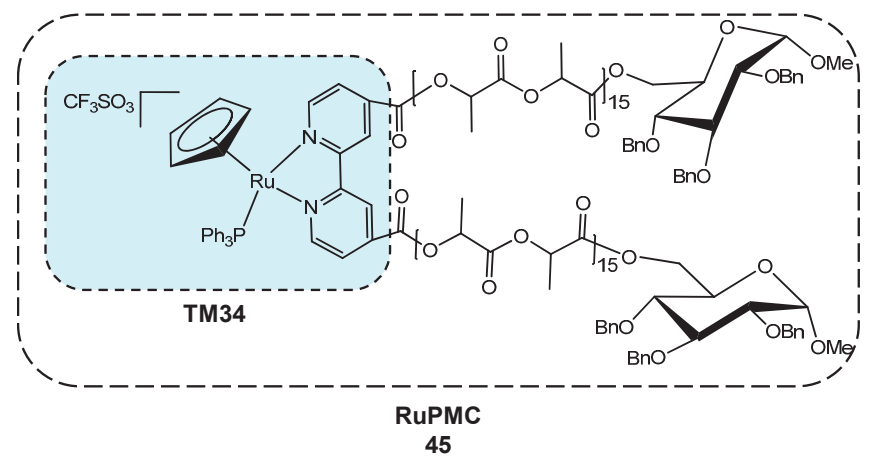

\section{Conclusions}

Regardless of the advances in the area of macromolecular compounds, there is still the need to develop high molecular weight and biodegradable carriers that can better exploit EPR-mediated tumor targeting. There is an urgency to move away from heterogeneous carriers towards better defined structures. In this frame, several strategies are being developed, which can be seen as a step forward to this end. An approach that has attracted much attention lately is a synergic effect between the EPR effect and the introduction of increasing nuclearity, which is expected to strengthen the cytotoxicity, while also raising the selectivity towards the cancer cells (sparing the healthy ones). Metallodendrimers have thus appeared as a promising option, since they combine the features of monodisperse nanoscale geometry with high end-group density at their surface. Furthermore, other supramolecular assemblies, like ruthenium-based coordination-cage conjugates and ruthenium-rHSA conjugates, showed cytotoxicity against several cancer cell lines. However, it seems that there is not always a direct correlation between the nuclearity and the cytotoxicity of the compounds, possibly due to solubility issues or to over-positively charged complexes that might originate retention at the cell membrane. Indeed, the only reported case of a conjugate bearing approximately forty four ruthenium centers per molecule (P(HPMA172-IEMA44-(RAPTA-CEMA)44) showed no benefit in terms of cytotoxicity towards the ovarian cancer cell line, OVACAR-3 ( $\left.\mathrm{IC}_{50}>300 \mu \mathrm{M}\right)$, compared to RAPTA-C ( $\left.\mathrm{IC}_{50} \approx 200 \mu \mathrm{M}\right)$.

Establishing structure-activity relationships is of primordial importance, since small changes in the chemical structure might dictate significant cytotoxicity differences. This is the case of coordination-cages, where both linkers and arene ligands have a strong influence on the cytotoxicity, probably due to the different size cavities, flexibilities and packing, as well as different lipophilicities.

Some of the problems encountered in the development of new covalently bound metal-conjugates lie on the loss of drug activity. This is the case of the reported ruthenium nanoparticles, where the macromolecular drugs lead to a marked decrease in the cytotoxic properties of the low molecular weight compounds. It is thus imperative to develop simpler strategies for the coordination of drugs to the carriers. One good example was observed on the one-step coordination strategy in ruthenium 
cyclopentadienyl derivatives, where the cytotoxicity of the final polymer-ruthenium conjugate was maintained in the low micromolar range.

Ruthenium-conjugates seem to be a promising alternative, although many studies must still be done. Most of the cytotoxic studies were performed mainly over one cancer cell line (namely, human ovarian A2780), and there is still the need to present in vivo studies in order to have a proof of concept, i.e., if these new macromolecular compounds are indeed better than their low molecular weight parental drugs by the so-called EPR effect. Furthermore, studies revealing the stability and speciation of these metal-conjugates in an aqueous environment and blood are mandatory.

In the chemical point of view, creating carriers that degrade under acidic conditions to trigger the drug release, by the slightly acidic tumor environment, is seen as a good strategy, already tested with good results in platinum drugs. Furthermore, this effect can also be achieved after the internalization by cancer cells, resulting in the accumulation of the polymer in the acidic endosomes and lysosomes. Finally, it is also expected that receptor-targeting ligands will lead to improved tumor targeting through the EPR effect. In this frame, innovative chemical reactions leading to "smart drugs" are powerful tools for the search of new chemotherapeutics presenting chemical diversity and original architectures.

\section{Acknowledgments}

The authors thank the Portuguese Foundation for Science and Technology (FCT) within the scope of projects PEst-OE/QUI/UI536/2011, PTDC-QUI-QUI-118077-2010 and FCT Investigator Programme.

\section{Conflicts of Interest}

The authors declare no conflict of interest.

\section{References}

1. Chau, I.; Cunningham, D. Oxaliplatin for colorectal cancer in the united states: better late than never. J. Clin. Oncol. 2003, 21, 2049-2051.

2. Vicent, M.J.; Duncan, R. Polymer conjugates: Nanosized medicines for treating cancer. Trends Biotechnol. 2006, 24, 39-47.

3. Vinditto, V.J.; Szoka, F.C., Jr. Cancer nanomedicines: So many papers and so few drugs! Adv. Drug Deliv. Rev. 2013, 65, 80-88.

4. Wang, R.; Billone, P.S.; Mullett, W.M.J. Nanomedicine in action: An overview of cancer nanomedicine on the market and in clinical trials. Nanomaterials 2013, 2013, 629681.

5. Zhao, X.; Loo, A.C.J.; Lee, P.P.-F.; Tan, T.T.Y.; Chu, C.K. Synthesis and cytotoxic activities of chloropyridylimineplatinum(II) and chloropyridyliminecopper(II) surface-functionalized poly(amido-amine) dendrimers. J. Inorg. Biochem. 2010, 104, 105-110.

6. Ahamad, T.; Mapolie, S.F.; Alshehri, S.M. Synthesis and characterization of polyamide metallodendrimers and their anti-bacterial and anti-tumor activities. Med. Chem. Res. 2012, 21, 2023-2031. 
7. Robilotto, T.J.; Alt, D.S.; von Recum, H.A.; Gray, T.G. Cytotoxic gold(I)-bearing dendrimers from alkyne precursors. Dalton Trans. 2011, 40, 8083-8085.

8. Hurley, A.L.; Mohler, D.L. Organometallic photonucleases: Synthesis and DNA-cleavage studies of cyclopentadienyl metal-substituted dendrimers designed to increase double-strand scission. Org. Lett. 2000, 2, 2745-2748.

9. Maeda, H.; Matsumura, Y. A new concept for macromoecular therapeutics in cancer chemotherapy: mechanisms of tumoritropic accumulation of proteins and the antitumor agent smancs. Crit. Rev. Ther. Drug. Carrier Syst. 1986, 46, 6387-6392.

10. Kopecek, J., Kopeckova, P., Minko, T.; Lu Z.R. HPMA copolymer-anticancer drug conjugates: Design, activity, and mechanism of action. Eur. J. Pharm. Biopharm. 2000, 50, 61-81.

11. Maeda, H.; Bharate, G.Y.; Daruwalla, J. Polymeric drugs for efficient tumor-targeted drug delivery based on EPR-effect. Eur. J. Pharm. Biopharm. 2009, 71, 409-419.

12. Duncan, R.; Dimitrijevic, S.; Evagorou, E.G. The role of polymer conjugates in the diagnosis and treatment of cancer. STP Pharma Sci. 1996, 6, 237-263.

13. Ang, W.H.; Dyson, P.J. Classical and non-classical ruthenium-based anticancer drugs: Towards targeted chemotherapy. Eur. J. Inorg. Chem. 2006, 20, 4003-4018.

14. Levina, A.; Mitra, A.; Lay, P.A. Recent developments in ruthenium anticancer drugs. Metallomics 2009, 1, 458-470.

15. Bruijnincx, P.C.A.; Sadler, P.J. New trends for metal complexes with anticancer activity. Curr. Opin. Chem. Biol. 2008, 12, 197-206.

16. Süss-Fink, G. Arene ruthenium complexes as anticancer agents. Dalton Trans. 2010, 39, 1673-1688.

17. Antonarakis, E.S.; Emadi, A. Ruthenium-based chemotherapeutics: Are they ready for prime time? Cancer Chemother. Pharmacol. 2010, 66, 1-9.

18. Bergamo, A.; Gaiddon, C.; Schellens, J.H.M.; Beijnen, J.H.; Sava, G. Approaching tumour therapy beyond platinum drugs: Status of the art and perspectives of ruthenium drug candidates. J. Inorg. Biochem. 2012, 106, 90-99.

19. Hartinger, C.G.; Jakupec, M.A.; Zorbas-Seifrieda, S.; Groessl, M.; Egger, A.; Berger, W.; Zorbas, H.; Dyson, P.J.; Keppler, B.K. KP1019, a new redox-active anticancer agent-Preclinical development and results of a clinical phase I study in tumor patients. Chem. Biodivers. 2008, 5, 2140-2155.

20. Alessio, E.; Mestroni, G.; Bergamo, A.; Sava, G.; Alessio, E.; Mestroni, G.; Bergamo, A.; Sava, G. Ruthenium antimetastatic agents. Curr. Topics Med. Chem. 2004, 4, 1525-1535.

21. Govender, P.; Antonels, N.C.; Mattsson, J.; Renfrew, A.K.; Dyson, P.J.; Moss, J.R.; Therrien, B.; Smith, G.S. Anticancer activity of multinuclear arene ruthenium complexes coordinated to dendritic polypyridyl scaffolds. J. Organomet. Chem. 2009, 694, 3470-3476.

22. Govender, P.; Renfrew, A.K.; Clavel, C.M.; Dyson, P.J.; Therrien, B.; Smith, G.S. Antiproliferative activity of chelating $N, O$ - and $N, N$-ruthenium(II) arene functionalised poly(propyleneimine) dendrimer scaffolds. Dalton Trans. 2011, 40, 1158-1167. 
23. Rodrigues, J.; Jardim, M.G.; Figueira, J.; Gouveia, M.; Tomás, H.; Rissanen, K. Poly(alkylidenamines) dendrimers as scaffolds for the preparation of low-generation ruthenium based metallodendrimers. New J. Chem. 2011, 35, 1938-1943.

24. Mattsson, J.; Govindaswamy, P.; Renfrew, A.K.; Dyson, P.J.; Štěpnička, P.; Süss-Fink, G.; Therrien, B. Synthesis, molecular structure, and anticancer activity of cationic arene ruthenium metallarectangles. Organometallics 2009, 28, 4350-4357.

25. Barry, N.P.E.; Zava, O.; Furrer, J.; Dyson, P.J.; Therrien, B. Anticancer activity of opened arene ruthenium metalla-assemblies. Dalton Trans. 2010, 39, 5272-5277.

26. Barry, N.P.E.; Zava, O.; Dyson, P.J.; Therrien, B. Synthesis, characterization and anticancer activity of porphyrin-containing organometallic cubes. Aust. J. Chem. 2010, 63, 1529-1537.

27. Pitto-Barry, A.; Barry, N.P.E.; Zava, O.; Deschenaux, R.; Therrien, B. Encapsulation of pyrene-functionalized poly(benzyl ether) dendrons into a water-soluble organometallic cage. Chem. Asian J. 2011, 6, 1595-1603.

28. Pitto-Barry, A.; Barry, N.P.E.; Zava, O.; Deschenaux, R.; Dyson, P.J.; Therrien, B. Double targeting of tumours with pyrenyl-modified dendrimers encapsulated in an arene-ruthenium metallaprism. Chem. Eur. J. 2011, 17, 1966-1971.

29. Barry, N.P.E.; Edafe, F.; Therrien, B. Anticancer activity of tetracationic arene ruthenium metalla-cycles. Dalton Trans. 2011, 40, 7172-7180.

30. Barry, N.P.E.; Zava, O.; Dyson, P.J.; Therrien, B. Excellent correlation between drug release and portal size in metalla-cage drug-delivery systems. Chem. Eur. J. 2011, 17, 9669-9667.

31. Pitto-Barry, A.; Zava, O.; Dyson, P.J.; Deschenaux, R.; Therrien, B. Enhancement of cytotoxicity by combining pyrenyl-dendrimers and arene ruthenium metallacages. Inorg. Chem. 2012, 51, 7119-7124.

32. Furrer, M.A.; Garci, A.; Denoyelle-Di-Muro, E.; Trouillas, P.; Giannini, F.; Furrer, J.; Clavel, C.M.; Dyson, P.J.; Süss-Fink, G.; Therrien, B. Synthesis, characterisation and in vitro anticancer activity of hexanuclear thiolato-bridged arene ruthenium metalla-prisms. Chem. Eur. J. 2013, 19, 3198-3203.

33. Dubey, A.; Min, J.W.; Koo, H.J.; Kim, H.; Cook, T.R.; Kang, S.C.; Stang, P.J.; Chi, K.-W. Anticancer potency and multi-resistant studies of self-assembled arene-ruthenium metallarectangles. Chem. Eur. J. 2013, 19, 11622-11628.

34. Jung, H.; Dubey, A.; Koo, H.J.; Vajpayee, V.; Cook, T.R.; Kim, H.; Kang, S.C.; Stang, P.J.; Chi, K.-W. Self-assembly of ambidentate pyridyl-carboxylate ligands with octahedral ruthenium metal centers: Self-selection for a single-linkage isomer and anticancer-potency studies. Chem. Eur. J. 2013, 19, 6709-6717.

35. Mishra, A.; Jung, H.; Park, J.W.; Kim, H.K.; Kim, H.; Stang, P.J.; Chi, K.-W. Anticancer activity of self-assembled molecular rectangles via arene-ruthenium acceptors and a new unsymmetrical amide ligand. Organometallics 2012, 31, 3519-3526.

36. Vajpayee, V.; Lee S.; Kim, S.-H.; Kang, S.C.; Cook, T.R.; Kim, H.; Kim, D.W.; Verma, S.; Lah, M.S.; Kim, I.S.; et al. Self-assembled metala-rectangles bearing azodipyridyl ligands: Synthesis, characterization and antitumor activity. Dalton Trans. 2013, 42, 466-475. 
37. Vajpayee, V.; mi Lee, S.; Park, J.W.; Dubey, A.; Kim, H.; Cook, T.R.; Stang, P.J.; Chi, K.-W. Growth inhibitory activity of a bis-benzimidazole-bridged arene ruthenium metalla-rectangle and-prism. Organometallics 2013, 32, 1563-1566.

38. Cook, T.R.; Vajpayee, V.; Lee, M.H.; Stang, P.J.; Chi, K.-W. Biomedical and biochemical applications of self-assembled metallacycles and metallacages. Acc. Chem. Res. 2013, 46, 2464-2474.

39. Han, Y.-F.; Jia, W.-G.; Lin, Y.-J.; Jin, G.-X. Stepwise formation of molecular rectangles of half-sandwich rhodium and ruthenium complexes containing bridging chloranilate ligands. Organometallics 2008, 27, 5002-5008.

40. Blunden, B.M.; Thomas, D.S.; Stenzel, M.H. Macromolecular ruthenium complexes as anti-cancer agents. Polym. Chem. 2012, 3, 2964.

41. Stepanenko, I.N.; Casini, A.; Edafe, F.; Novak, M.S.; Arion, V.B.; Dyson, P.J.; Jakupec, M.A.; Keppler, B.K. Conjugation of organoruthenium(II) 3-(1H-benzimidazol-2-yl)pyrazolo[3,4b]pyridines and indolo[3,2-d]benzazepines to recombinant human serum albumin: A strategy to enhance cytotoxicity in cancer cells. Inorg. Chem. 2011, 50, 12669-12679.

42. Warnecke, A.; Fichtner, I.; Garmann, D.; Jaehde, U.; Kratz, F. Synthesis and biological activity of water-soluble maleimide derivatives of the anticancer drug carboplatin designed as albumin-binding prodrugs. Bioconjugate Chem. 2004, 15, 1349-1359.

43. Süss-Fink, G.; Khan, F.-A.; Juillerat-Jeanneret, L.; Dyson, P.J.; Renfrew, A.K. Synthesis and anticancer activity of long-chain isonicotinic ester ligand-containing arene ruthenium complexes and nanoparticles. J. Clus. Sci. 2010, 21, 313-324.

44. Garcia, M.H.; Morais, T.S.; Florindo, P.; Piedade, M.F.M.; Moreno, V.; Ciudad, C.; Noe, V. Inhibition of cancer cell growth by ruthenium(II) cycplopentadienyl derivative complexes with heteroaromatic ligands, journal of inorganic biochemistry. J. Inorg. Biochem. 2009, 103, 3, 354-361.

45. Garcia, M.H.; Valente, A.; Florindo, P.; Morais, T.S.; Piedade, M.F.M.; Duarte, M.T.; Moreno, V. New ruthenium(II) mixed metallocene derived complexes: Synthesis, characterization by X-ray diffraction studies and evaluation on DNA interaction by atomic force microcopy. Inorg. Chim. Acta 2010, 363, 3765-3775.

46. Moreno, V.; Lorenzo, J.; Avilés, F.X.; Garcia, M.H.; Ribeiro, J.; Florindo, P.; Robalo, M.P. Studies of the antiproliferative activity of ruthenium(II) cyclopentadienyl derived complexes with nitrogen coordinated ligands. Bioinorg. Chem. Appl. 2010, doi:10.1155/2010/936834.

47. Moreno, V.; Font-Bardia, M.; Calvet, T.; Lorenzo, J.; Avilés, F.X.; Garcia, M.H.; Morais, T.S.; Valente, A.; Robalo, M.P. DNA interaction and cytotocixity studies of new ruthenium(II) cyclopentadienyl derivative complexes containing heteroaromatic ligands. J. Inorg. Biochem. 2011, 105, 2, 241-249.

48. Tomaz, A.I.; Jakusch, T.; Morais, T.S.; Marques, F.; Almeida, R.F.M.; de Mendes, F.; Enyedy, E.A.; Santos, I.; Pessoa, J.C.; Kiss, T.; et al. $\left[\mathrm{Ru}^{\mathrm{II}}\left(\eta^{5}-\mathrm{C}_{5} \mathrm{H}_{5}\right)(\text { bipy })\left(\mathrm{PPh}_{3}\right)\right]^{+}$a promising large spectrum antitumor agent: cytotoxic activity and interaction with human serum albumin. J. Inorg. Biochem. 2012, 117, 261-269. 
49. Morais, T.S.; Silva, T.J.L.; Marques, F.; Robalo, M.P.; Avecilla, F.; Madeira, P.J.A.; Mendes, P.J.G.; Santos, I.; Garcia, M.H. Synthesis of organometallic ruthenium(II) complexes with strong activity against several human cancer cell lines. J. Inorg. Biochem. 2012, 114, $65-74$.

50. Morais, T.S.; Santos, F.; Côrte-Real, L.; Marques, F.; Robalo, M.P.; Madeira, P.J.A.; Garcia, M.H. Biological activity and cellular uptake of $\left[\mathrm{Ru}\left(\eta^{5}-\right.\right.$ $\left.\mathrm{C}_{5} \mathrm{H}_{5}\right)\left(\mathrm{PPh}_{3}\right)\left(\mathrm{Me}_{2}\right.$ bpy) $]\left[\mathrm{CF}_{3} \mathrm{SO}_{3}\right]$. J. Inorg. Biochem. 2013, 122, 8-17.

51. Morais, T.S.; Santos, F.C.; Jorge, T.F.; Côrte-Real, L.; Madeira, P.J.A.; Marques, F.; Robalo, M.P.; Matos, A.; Santos, I.; Garcia, M.H. New water-soluble ruthenium(II) cytotoxic complex: Biological activity and cellular distribution. J. Inorg. Biochem. 2013, 130, 1-14.

52. Côrte-Real, L.; Matos, A.P.; Alho, I.; Morais, T.S.; Tomaz, A.I.; Garcia, M.H.; Santos, I.; Bicho, M.P.; Marques, F. Cellular uptake mechanisms of an antitumor ruthenium compound: The endossomal/lysosomal system as a target for anticancer metal-based drugs. Microsc. Microanal. 2013, 19,1122-1130.

53. Duncan, R. Designing polymer conjugates as lysosomotropic nanomedicines. Biochem. Soc. Trans. 2007, 35, 56-60.

54. Valente, A.; Garcia, M.H.; Marques, F.; Miao, Y.; Rousseau, C.; Zinck, P. First polymer "ruthenium-cyclopentadienyl" complex as potential anticancer agent. J. Inorg. Biochem. 2013, 127, 79-81.

55. Tannock, I.F.; Rotin, D. Acid $\mathrm{pH}$ in tumors and its potential for therapeutic exploitation. Cancer Res. 1989, 49, 4373-4384.

56. Duncan, R. The dawning era of polymer therapeutics. Nat. Rev. Drug Discov. 2003, 2, 347-360.

57. Cabral, H.; Nishiyama, N.; Okazaki, S.; Koyama, H.; Kataoka, K. Preparation and biological properties of dichloro(1,2-diaminocyclohexane)platinum(II) (DACHPt)-loaded polymeric micelles. J. Control. Rel. 2005, 101, 223-232.

58. Uchino, H.; Matsumura, Y.; Negishi, T.; Hayashi, F.; Honda, T.; Nishiyama, N.; Kataoka, K.; Naito, S.; Kakizoe, T. Cisplatin-incorporating polymeric micelles (NC-6004) can reduce nephrotoxicity and neurotoxicity of cisplatin in rats. Br. J. Cancer 2005, 93, 678-687.

59. Nishiyama, N.; Kataoka, K. Preparation and characterization of size-controlled polymeric micelle containing cis-dichlorodiammineplatinum(II) in the core. J. Control. Rel. 2001, 74, 83-94.

60. Kim, J.-H.; Kim, Y.-S.; Park, K.; Lee, S.; Nam, H.Y.; Min, K.H.; Lo, H.G.; Park, J.H.; Choi, K.; Jeong, S.Y.; et al. Antitumor efficacy of cisplatin-loaded glycol chitosan nanoparticles in tumor-bearing mice. J. Control. Rel. 2008, 127, 41-49. 


\title{
Chemistry of Ammonothermal Synthesis
}

\section{Theresia M. M. Richter and Rainer Niewa}

\begin{abstract}
Ammonothermal synthesis is a method for synthesis and crystal growth suitable for a large range of chemically different materials, such as nitrides (e.g., GaN, AlN), amides (e.g., $\mathrm{LiNH}_{2}, \mathrm{Zn}\left(\mathrm{NH}_{2}\right)_{2}$ ), imides (e.g., Th(NH) $)_{2}$, ammoniates (e.g., $\mathrm{Ga}\left(\mathrm{NH}_{3}\right)_{3} \mathrm{~F}_{3},\left[\mathrm{Al}\left(\mathrm{NH}_{3}\right)_{6}\right] \mathrm{I}_{3} \cdot \mathrm{NH}_{3}$ ) and non-nitrogen compounds like hydroxides, hydrogen sulfides and polychalcogenides (e.g., $\mathrm{NaOH}$, $\mathrm{LiHS}, \mathrm{CaS}, \mathrm{Cs}_{2} \mathrm{Te}_{5}$ ). In particular, large scale production of high quality crystals is possible, due to comparatively simple scalability of the experimental set-up. The ammonothermal method is defined as employing a heterogeneous reaction in ammonia as one homogenous fluid close to or in supercritical state. Three types of milieus may be applied during ammonothermal synthesis: ammonobasic, ammononeutral or ammonoacidic, evoked by the used starting materials and mineralizers, strongly influencing the obtained products. There is little known about the dissolution and materials transport processes or the deposition mechanisms during ammonothermal crystal growth. However, the initial results indicate the possible nature of different intermediate species present in the respective milieus.
\end{abstract}

Reprinted from Inorganics. Cite as: Richter, T.M.M.; Niewa, R. Chemistry of Ammonothermal Synthesis. Inorganics 2014, 2, 29-78.

\section{Introduction}

Ammonothermal synthesis has gained increasing research interest over the last 20 years. The first ammonothermal syntheses were carried out in analogy to the hydrothermal synthesis of oxides in the 1960s by Juza and Jacobs and pursued by Jacobs and co-workers over the following decades [1-3]. Since ammonia resembles water in its physical properties, water was replaced by ammonia in order to obtain amides, imides and nitrides in place of hydroxides and oxides. Using ammonia instead of nitrogen for nitridation allows less harsh temperature and pressure conditions, since ammonia is more reactive. Furthermore, an abundance of further materials like hydroxides, chalcogenides and hydrogen sulfides can be also obtained from supercritical ammonia.

Both hydrothermal and ammonothermal synthesis are part of the large group of solvothermal methods. The use of the term solvothermal is not defined unambiguously. Definitions vary from "any heterogenous chemical reaction in the presence of a solvent (whether aqueous or non-aqueous) above room temperature and at pressure greater than $1 \mathrm{~atm}$ in a closed system" [4] to sub- or supercritical conditions of the solvent [5]. Rabenau's definition for hydrothermal conditions is frequently used "an aqueous medium over $100 \hat{A} \check{r} C$ and 1 bar" [6] and transferred to solvothermal conditions in general by adjusting $373 \mathrm{~K}$ to "the boiling point of the solvent" [7]. The characteristics of ammonothermal synthesis and its products are mainly influenced by high pressure and temperature and usually syntheses are carried out under supercritial conditions. Above the critical point, solvents exist as homogeneous supercritical fluids, where gas and liquid phase can no more be distinguished and consequently the properties of the different phases converge. However, the properties of a 
supercritical fluid in its proper meaning and those of a fluid, with only one physical quantity above the critical state and the other one slightly below it, are hardly distinguishable. Hence, we define ammonothermal synthesis as a reaction in ammonia as one homogenous fluid next to or under supercritical conditions.

Various solvents showing distinct different chemical properties are used for solvothermal syntheses. This comprises (i) polar protic solvents like $\mathrm{H}_{2} \mathrm{O}, \mathrm{NH}_{3}, \mathrm{HF}, \mathrm{HCl}, \mathrm{HBr}$; (ii) polar non-protic solvents like tetrahydrofuran and (iii) non-polar solvents like benzene, xylene and $\mathrm{CO}_{2}$. Table 1 gives some examples for solvents used in solvothermal techniques and the obtained products. Over recent years, the research interest in solvothermal methods has greatly increased, due the constantly raising demand of crystal growth of functional materials, like, for example, semiconductors (CuInSe 2 [8], InAs [9], GaN [10], AlN [11] and $\mathrm{ZnO}$ [12]), piezoelectrics ( $\alpha$-quartz [13], $\mathrm{GaPO}_{4}$ [14]), electrodes for lithium batteries $\left(\mathrm{Li}_{1-x} \mathrm{Mn}_{2} \mathrm{O}_{4-y}\right.$ [15]), magnetic and catalytic materials $\left(\mathrm{La}_{1-x} \mathrm{Ca} / \mathrm{Sr} / \mathrm{BaMnO}_{3}[16]\right)$ and fine dielectric ceramics $\left(\mathrm{BaTiO}_{3}\right.$ [17]).

Table 1. Examples for solvothermal solvents and obtained products (see text).

\begin{tabular}{|c|c|c|c|}
\hline & Solvent & Examples for products & References \\
\hline \multirow[t]{7}{*}{ (i) } & $\mathrm{H}_{2} \mathrm{O}$ & $\mathrm{ZnO}, \alpha$-quartz, $\alpha-\mathrm{Al}_{2} \mathrm{O}_{3}, \mathrm{GaPO}_{4}$ & {$[12-14,18]$} \\
\hline & $\mathrm{H}_{2} \mathrm{O}+$ isopropyl alcohol & $\mathrm{BaTiO}_{3}$ & [17] \\
\hline & $\mathrm{H}_{2} \mathrm{O}+\mathrm{C}_{2} \mathrm{H}_{3} \mathrm{Cl}_{3}$ & Diamond & [19] \\
\hline & $\mathrm{NH}_{3}$ & $\mathrm{GaN}, \mathrm{AlN}, \mathrm{Cu}_{3} \mathrm{~N}, \mathrm{Cs}_{2} \mathrm{~S}_{2}, \mathrm{NaOH}$ & {$[10,11,20-22]$} \\
\hline & $\mathrm{HCl}, \mathrm{HBr}, \mathrm{HI}$ & $\mathrm{BiSCl}, \mathrm{BiTeBr}, \mathrm{SbSeI}$ & {$[23]$} \\
\hline & Ethanol & $\mathrm{Li}_{1-x} \mathrm{Mn}_{2} \mathrm{O}_{4-y}$ & {$[15]$} \\
\hline & Benzyl alcohol & $\mathrm{La}_{1-x} \mathrm{Ca} / \mathrm{Sr} / \mathrm{BaMnO}_{3}$ & {$[16]$} \\
\hline \multirow[t]{3}{*}{ (ii) } & Ethylendiamine & $\mathrm{Cu}_{7} \mathrm{Te}_{4}, \mathrm{CuInSe}_{2}$ & {$[8,24]$} \\
\hline & Diethylamine & $\mathrm{CuInSe}_{2}$ & [8] \\
\hline & THF & $\beta-\mathrm{MnS}$ & {$[25]$} \\
\hline \multirow[t]{5}{*}{ (iii) } & $\mathrm{C}_{6} \mathrm{H}_{6}$ & Se, $c / h$-BN, $\gamma$-MnS & {$[25,26]$} \\
\hline & Xylene & InAs & [9] \\
\hline & Toluene & $\mathrm{CuCr}_{2} \mathrm{Se}_{4}$ & [27] \\
\hline & $\mathrm{CO}_{2}$ & Poly vinyl chloride & {$[28]$} \\
\hline & $\mathrm{Br}_{2}$ & $\mathrm{SbSBr}$ & {$[23]$} \\
\hline
\end{tabular}

The choice of the solvent considerably influences the obtained product. Even different modifications occur depending on the solvent. For the reaction of $\mathrm{MnCl}_{2} \cdot 4 \mathrm{H}_{2} \mathrm{O}$ with thiourea, $\mathrm{SC}\left(\mathrm{NH}_{2}\right)_{2}$, to $\mathrm{MnS}$, for example, the use of tetrahydrofuran (THF) as solvent leads to metastable $\beta-\mathrm{MnS}$, with benzene as solvent exclusively metastable $\gamma-\mathrm{MnS}$ and with water or ethylenediamine the stable $\alpha$-MnS occur. Thus, the crystallization of the different modifications depends on the formed complexes of the solvent with the substrate, e.g., $\left[\mathrm{Mn}\left(\mathrm{H}_{2} \mathrm{O}\right)_{6}\right]^{2+}$. The knowledge of the chemical nature of the dissolved species is the crucial information to understand the formation 
mechanism of MnS [25]. Those observations manifest the importance of the complex intermediates present in the solvent for the formed product and for the structure of the product.

The best explored solvothermal method is the hydrothermal synthesis, owing to its commercial application for the synthesis of oxides and hydroxides. Nowadays, the hydrothermal method is used, for example, in the industrial synthesis of over $3000 \mathrm{t} \alpha$-quartz single crystals per year, due to their piezoelectric properties and of $\mathrm{Al}_{2} \mathrm{O}_{3}$ from more than 90 million $\mathrm{t}$ of bauxite per year, for processing to metal [4].

Already in 1839, Bunsen carried out experiments with liquids at high temperatures and high pressures (473 K, $150 \mathrm{MPa}$ ) [29]. For this purpose he used sealed glass tubes with integrated mercury manometer. Later, in 1848, he succeeded in the growth of $\mathrm{BaCO}_{3}$ and $\mathrm{SrCO}_{3}$ millimeter-long crystals from an aqueous solution at $473 \mathrm{~K}$ and $1.52 \mathrm{MPa}$ using $\mathrm{NH}_{4} \mathrm{Cl}$ as mineralizer [30]. Similar experiments for recrystallization of apophyllites were apparently conducted by Wöhler earlier [30]. Already in 1845 Schafhäutl obtained for the first time micro crystalline quartz crystals from hydrothermal conditions [31]. In 1851 Sénarmont laid the foundation for hydrothermal mechanisms in geology. He already realized the importance of pressure and temperature ...pressure to maintain the gaseous reactants in a forced dissolution and temperature to favorite certain combinations or decompositions... for the formation of the minerals and synthesized a great number of natural minerals under high temperature and high pressure conditions, in order to elucidate the natural formation conditions. Using a similar experimental setup as Bunsen did, he applied high temperatures and high pressures in sealed glass tubes. To avoid explosion of the sealed glass tubes containing the reactants and the solvent (water), he placed them inside water filled autoclaves [32].

The ammonothermal method was established inter alia in order to synthesize high quality crystals of amides for XRD structure determination and of deuteroamides for neutron diffraction [3]. The first compounds obtained from ammonothermal conditions (up to $507 \mathrm{MPa}$ and $823 \mathrm{~K}$ ) were binary amides $\left(\mathrm{Be}\left(\mathrm{NH}_{2}\right)_{2}, \mathrm{Mg}\left(\mathrm{NH}_{2}\right)_{2}[2]\right)$ and binary nitrides $\left(\mathrm{Be}_{3} \mathrm{~N}_{2}\right.$ [1]), later also imides $\left(\mathrm{Th}(\mathrm{NH})_{2}[33]\right)$, ternary compounds and other than nitrogen containing materials were synthesized [3].

Over the last twenty years the research interest in the ammonothermal method has increased considerably, since it is one of the few techniques leading to group III bulk nitrides. In comparison to other techniques, the ammonothermal method allows crystal growth on native substrate and growth of the initial native substrate itself in a very high quality. Increasing commercial efforts are directed to the ammonothermal growth of GaN and $\mathrm{AlN}$ on native substrates. GaN and AlN are semiconductors with wide band gaps used as base for optoelectronic and electronic devices (e.g., light-emitting diodes (LEDs), high electron mobility transistors, lasers with high optical storage capacity). The growth of group III nitrides as bulk crystal is much more difficult than as micro crystalline powder, but necessary for the use in optoelectronic and electronic devices [34,35].

There are several other methods known for the synthesis of bulk GaN and AlN. Up to now the most popular technique is hydride or halide vapor phase epitaxy, which is used for commercial purposes. Vapor-phase $\mathrm{GaCl}$ or $\mathrm{GaCl}_{3}$ obtained from metallic $\mathrm{Ga}$ and gaseous $\mathrm{HCl}$ is carried in a gas flow and reacts with gaseous $\mathrm{NH}_{3}$ to form $\mathrm{GaN}$. The formed $\mathrm{GaN}$ deposits usually on a non-native substrate like sapphire, silicon or GaAs. At ambient pressure, growth temperatures of 
$1000-1100^{\circ} \mathrm{C}$ are typical and growth rates of up to $0.5 \mathrm{~mm} / \mathrm{h}$ are reported. Wafers are cut from the formed bulk material and subsequently polished. They can be used in devices or as a substrate for further syntheses [36].

Metal organic vapor phase epitaxy allows the growth of thin epitaxial layers used for devices. Metalorganic precursors (e.g., triethyl or trimethyl-gallium) react with $\mathrm{NH}_{3}$ forming $\mathrm{GaN}$ on a substrate. Growth rates vary from 1-2 $\mu \mathrm{m} / \mathrm{h}$ for thin layers and up to $50 \mu \mathrm{m} / \mathrm{h}$ for bulk growth [36].

The advantages of devices made from ammonothermal $\mathrm{GaN}$ are the lower defect, strain and bowing level due to the growth on native substrate, the possibility of high scalability and no tilt boundaries, which occur even at $\mathrm{GaN}$ grown on a native seed by hydride/halide vapor phase epitaxy. If the substrate shows tilt boundaries, even if it is a native substrate but grown itself on a foreign substrate, the tilt boundaries will appear in the grown material, too [10,37-42]. High quality of the substrate is very important, since it allows the production of more devices per substrate and devices made of low-defect-density GaN or AlN promise longer working periods at higher power without breakdown [43]. Solvothermal methods in general are known for their reliable and scalable process, which permits the efficient growth of a great number of crystals within one synthesis, e.g., 1400 quartz crystals, $1700 \mathrm{~g}$ each $[36,44]$.

Slow growth rates were one of the disadvantages of the ammonothermal method in the past. According to the latest research results this problem seems to overcome. Recently, researchers increased growth rates for GaN by ammonothermal method from 24-106 $\mu \mathrm{m} / \mathrm{d}$ [45] to 250 ( $c$-plane) and $300 \mu \mathrm{m} / \mathrm{d}$ ( $m$-plane) in the presence of $\mathrm{NH}_{4} \mathrm{~F}$, used as so-called mineralizer [46]. Even $m$-plane growth rates of up to $40 \mu \mathrm{m} / \mathrm{h}(=960 \mu \mathrm{m} / \mathrm{d})$ with rates of $10-30 \mu \mathrm{m} / \mathrm{h}(=240-720 \mu \mathrm{m} / \mathrm{d})$ for all planes were reported recently [39].

\section{Ammonia as Solvent}

Ammonia and water show quite similar properties (see Table 2). Hence, the parallel from supercritical water to supercritical ammonia, drawn and realized by Juza and Jacobs, who established the ammonothermal synthesis, is not surprising [1,2]. Ammonia is a non-aqueous ionizing solvent, that means pure ammonia has a low specific electrical conductivity and dissolved electrolytes are partially or completely dissociated [47]. Ammonia was the first ionizing solvent, except for water, which has been studied thoroughly. Already at the beginning of the 20th century, inter alia Franklin, Kraus and Bronn studied the ammono-system of compounds, e.g., metal solutions in liquid ammonia [48-50]. Still, supercritical and liquid ammonia is a far less explored solvent than water. Compared to water ammonia is less protic and polar, at ambient pressure and temperature it is gaseous and shows much higher pressures at high temperatures [51]. Liquid ammonia has only small solubilities for many inorganic compounds, which yields often poorly crystallized or amorphous solids on precipitation, due to inhibited nucleation and crystal growth. Using supercritical ammonia rather than liquid ammonia overcomes this problem: Under ammonothermal conditions (supercritical fluid above a pressure of $11.3 \mathrm{MPa}$ and a temperature of $405.2 \mathrm{~K}$ [52] see Figures 1 and 2 [53]) the solubility is high enough to dissolve a large number of inorganic compounds. To dissolve a solid the relative permittivity of the solvent has to be higher than the 
lattice energy of the solid. Due to the rising relative permittivity of solvents with increasing density, which occurs at higher pressure, the solubility of mostly ionic solids increases with increasing pressure $[3,54]$. Water has a higher relative permittivity than ammonia; therefore, solids dissolve better in water than in ammonia at similar conditions (see Table 2).

Table 2. Comparison of selected properties of ammonia and water [47,52,55].

\begin{tabular}{lcc}
\hline & Water & Ammonia \\
\hline$T_{\text {crit. }} / \mathrm{K}$ & 647.65 & 405.2 \\
$p_{\text {crit. }} / \mathrm{MPa}$ & 22.1 & 11.3 \\
$\epsilon_{r}$ & $78.3(298 \mathrm{~K})$ & $16.9(298 \mathrm{~K})$ \\
Autoprotolysis & $2 \mathrm{H}_{2} \mathrm{O} \rightleftarrows \mathrm{H}_{3} \mathrm{O}^{+}+\mathrm{OH}^{-}$ & $2 \mathrm{NH}_{3} \rightleftarrows \mathrm{NH}_{4}^{+}+\mathrm{NH}_{2}^{-}$ \\
Ionic product & $10^{-14}(298 \mathrm{~K})$ & $10^{-32}(239 \mathrm{~K})$ \\
pk $_{B}$ & 15.7 & 4.75 \\
Proton affinity/eV & -7.9 & -9.2 \\
\hline
\end{tabular}

Ammonia has a higher proton affinity than water $\left(E_{p a}\left(\mathrm{NH}_{3}\right)=-9.2 \mathrm{eV} ; E_{p a}\left(\mathrm{H}_{2} \mathrm{O}\right)=-7.9 \mathrm{eV}\right.$ [47]; the energy released when a proton is attached to the molecule in the gas phase). Hence, ammonia is a more basic solvent than water $\left(\right.$ see $\mathrm{pk}_{B}\left(\mathrm{NH}_{3}\right)=4.8$ and $\mathrm{pk}_{B}\left(\mathrm{H}_{2} \mathrm{O}\right)=15.7$ [47]). Both water and ammonia show autoprotolysis since they possess at least one non-bonding pair of electrons and acidic hydrogen atoms, leading to formation of $\mathrm{H}_{3} \mathrm{O}^{+}$or $\mathrm{NH}_{4}^{+}$cations and $\mathrm{OH}^{-}$or $\mathrm{NH}_{2}^{-}$anions, respectively. Due to the endothermic nature of the autoprotolysis reactions, the magnitude of autoprotolysis increases with increasing temperature. In the same way as water is a suitable solvent for the synthesis of oxides, ammonia is a unique and excellent solvent for nitride synthesis. Additionally, liquid and supercritical ammonia find application as solvent for water sensible compounds, which do not necessarily contain nitrogen, e.g., sulfides, hydrogen sulfides [3,56,57] and hydroxides [22].

Figure 1. Pressure-temperature phase diagram of ammonia. The dashed line is extrapolated [58].

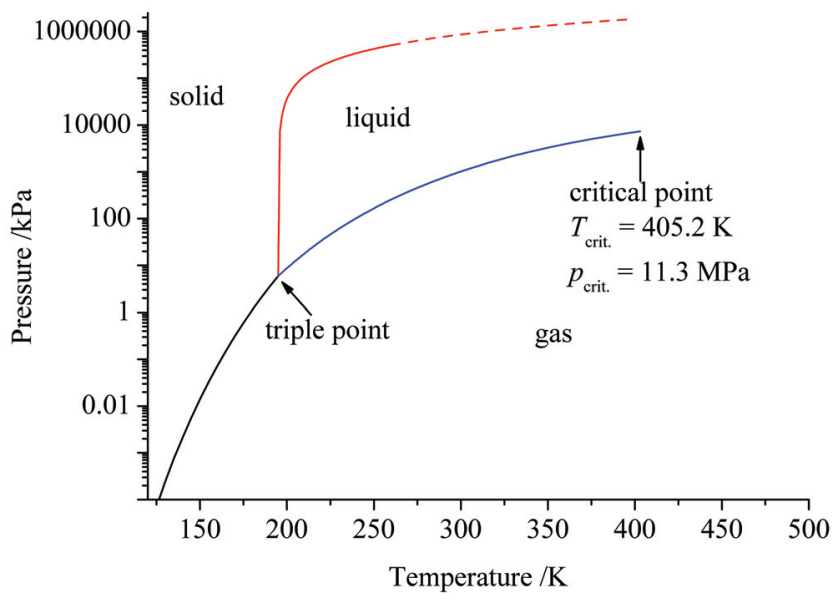


Figure 2. Pressure-temperature diagram of ammonia in dependence on the filling degree of the reaction vessel (in \%). The inset shows an enlarged view in the range around the critical point $\left(T_{\text {crit. }} 405.2 \mathrm{~K}, p_{\text {crit. }}=11.3 \mathrm{~K}\right)$ [53].

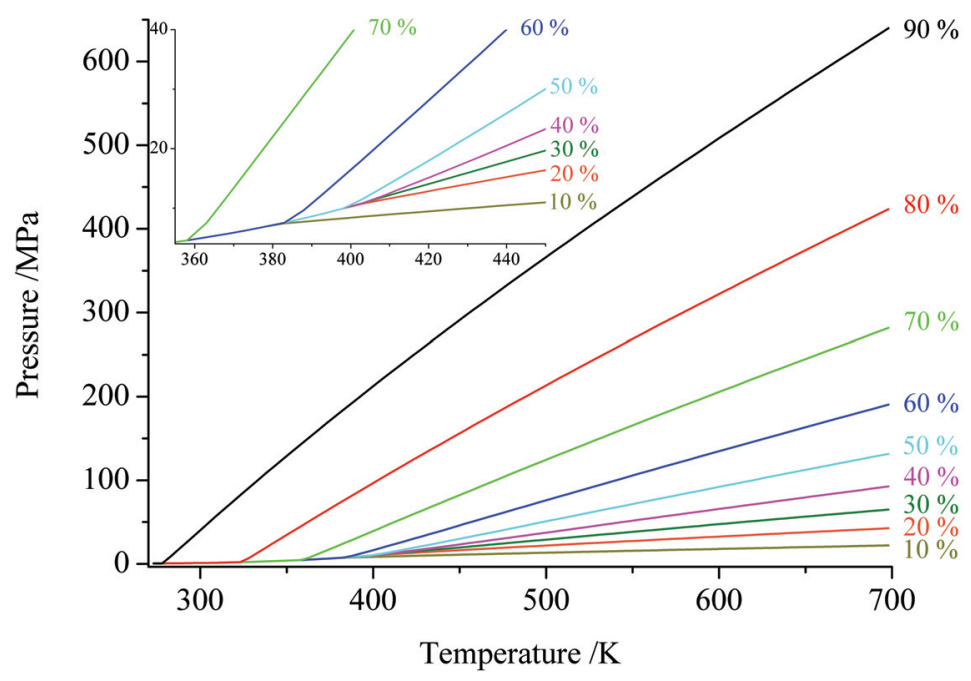

\section{Technical Details for Ammonothermal Reactions}

There are different installations for the realization of ammonothermal synthesis, starting with the materials and construction of the reaction vessel, the inner shape, liner and geometry of the reaction vessel via the filling of the reaction vessel with ammonia to the heating of the reaction vessel. In general, two types of ammonothermal syntheses can be distinguished, covering different aims: the research on fundamental questions and the research on application of the method for crystal growth. The former research branch investigates new compounds, new synthesis routes for compounds and the processes during crystal growth. The latter investigates and applies the conditions for an optimal crystal growth, including low defect and crack concentration, high growth rates and large crystal size, aiming at a commercial application. The different objectives require different laboratory installations, not only of size but also of type.

The reaction vessel is referred to as autoclave, since most of the installations use steel autoclaves and even the techniques with metallic capsules and glass tubes as reaction containers usually use steel autoclaves for mechanical stabilization of the capsule. 
Figure 3. Flow chart of an ammonothermal reaction setup for the simultaneous pressure and temperature control during reaction using two pumps. The heat exchanger is used for pre-cooling one pump and the supply pipe $[59,60]$.

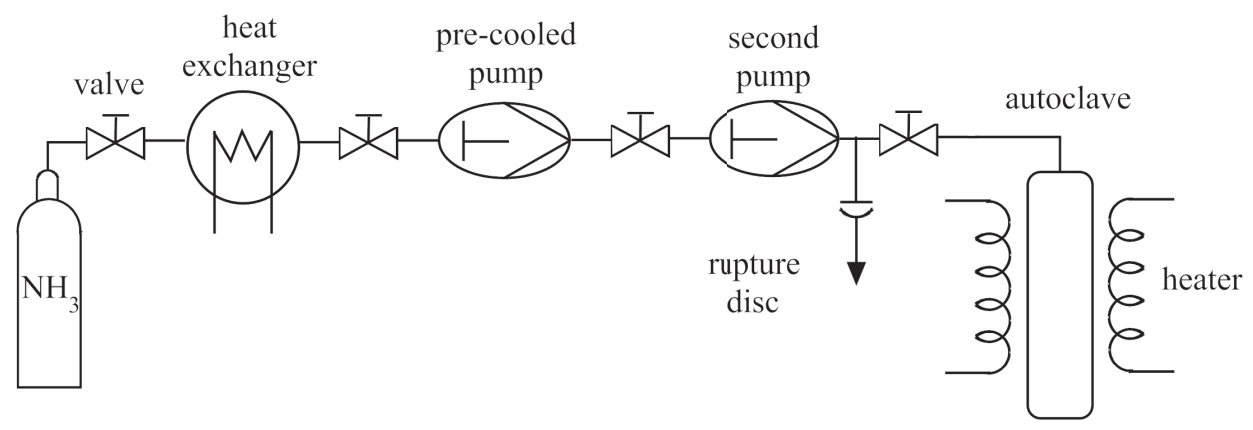

Different approaches find application to fill the autoclave with ammonia: Condensing ammonia into the autoclave by cooling, adding solid ammonia or filling the autoclave sequentially with ammonia by high pressure pumps. Condensing ammonia into the autoclave historically is realized by the help of a tensieudiometer, an apparatus for the simultaneous measurement of pressure and volume, developed by Hüttig [61]. The autoclave, already loaded with the solid reactants, can be connected to the tensieudiometer and is cooled down below the boiling point of ammonia ( $T \leq 239.79 \mathrm{~K}$ at ambient pressure [52]) and ammonia condenses in the autoclave. Since volume and pressure in the tensieudiometer, which realizes a closed system including the autoclave, are known an exact amount of ammonia can be filled inside the autoclave. To cool the autoclave down, usually the autoclave body is placed in a cooling bath of acetone or ethanol and dry ice. Adding solid ammonia, solidified by cooling in liquid nitrogen is an other option, which is necessary if glass tubes are used, since the glass tubes are sealed at high temperatures after filling. Liquid ammonia would evaporate too fast at those temperatures. Both filling methods only allow limited control of the pressure during synthesis, by the amount of added ammonia before the synthesis and the applied temperature during synthesis. Pressure control during synthesis is possible using high pressure pumps, which compress ammonia prior to reaction and control the pressure during synthesis. A system of two high pressure pumps with a pre-cooled compressor and supply pipe $(258-263 \mathrm{~K})$ guarantees the condensation of the gaseous ammonia, using only one pump allows the system to reach pressures of 5-30 MPa, since the pressure increases with increasing temperature (see Figure 3). The use of a second pump permits the variation of the pressure during synthesis and pressures of up to $450 \mathrm{MPa}[3,59,60]$.

Concerning the temperature at least two different temperature zones inside the reaction chamber have to be achieved in order to obtain a temperature gradient. The temperature gradient contributes via convection to the mass transport of the dissolved species during synthesis and is essential for the crystallization process (see section Crystallization Process). The temperature gradient can be applied by different heaters around or integrated into the autoclave, by not heating or even cooling one part of the autoclave. Autoclave models with integrated cooling were also reported, see Figure $4[3,39]$. 
Figure 4. Flow chart of an ammonothermal autoclave with integrated cooling and external heating [3].

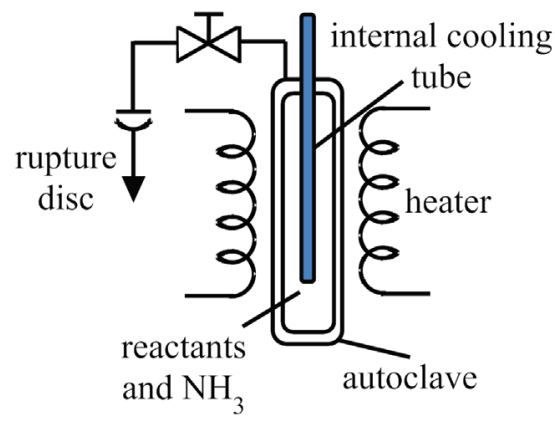

\subsection{Reaction Vessels}

The first reaction vessels for supercritical syntheses were sealed thick-walled glass tubes with integrated mercury manometer, which withstand temperatures of up to $473 \mathrm{~K}$ and pressures of up to $15 \mathrm{MPa}$ [29]. Sénarmont was the first to apply a counter-pressure to avoid explosion of the sealed glass tubes containing the reactants, by placing them inside water filled autoclaves [32]. Similar counter pressure systems are still in use for ammonothermal synthesis. Sealed glass, silver or gold ampoules are used as reaction vessels for ammonothermal synthesis, containing the starting materials and supercritical ammonia. To avoid explosion, the ampoules are placed in a steel autoclave, connected to a high pressure pump, which produces a counter-pressure of nitrogen inside the autoclave (see Figure 5). The counter-pressure should only be slightly lower than the pressure inside the ampoule. However, in order to simplify the handling the counter-pressure is usually higher than the pressure inside the ampoule. For supercritical conditions, the autoclave containing the ampoule is placed in a heater. In this way, pressures and temperatures of up to $280 \mathrm{MPa}$ and $470 \mathrm{~K}$ for glass ampoules are realized, metal ampoules enable the application of higher temperatures [3]. Recently, a similar construction was used for large scale GaN crystal growth in a vessel with internal heating. The reaction is carried out in a welded capsule, containing the starting materials and supercritical ammonia. The capsule is coated directly by a heater, followed by a ceramic shell and an externally-cooled steel shell. The inner heater reaches temperatures of up to $1023 \mathrm{~K}$ at $600 \mathrm{MPa}$, while the temperature of the outer steel shell remains below $473 \mathrm{~K}$, due to the insulating ceramic shell. The use of an internal heating allows the application of higher temperatures and higher pressures compared to autoclaves made of nickel based superalloys, additionally the use of conventional steel is less expensive in production and processing [39]. Nickel based superalloys, for example, Inconel 750 [6], Vacumelt ATS 340 [3], Inconel 718 [59] and Rene 41 [36] are used for the construction of high pressure autoclaves with external heating. Those superalloys almost resist corrosion in ammonobasic milieu up to temperatures of $\sim 873 \mathrm{~K}$ at $\geq 3000 \mathrm{MPa}$ (Inconel 750 ) and can stand even $\leq 1123 \mathrm{~K}$ at $\leq 150 \mathrm{MPa}$ (Rene 41) [62]. Autoclaves made of those alloys are loaded directly 
with the starting materials and ammonia and are heated up with an external direct heater. This explains the milder working conditions.

Figure 5. Flow chart of an ammonothermal reaction setup using a glass or metal ampoule filled with ammonia and the reactants placed in a steel autoclave connected to a high pressure pump, applying a counter-pressure of nitrogen [3].

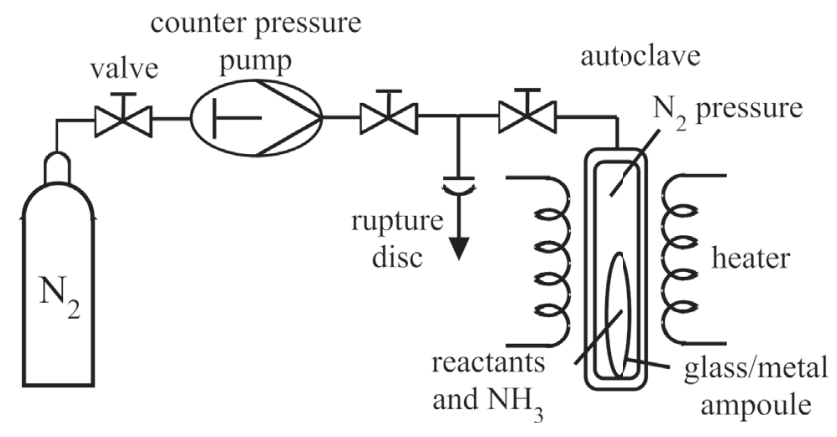

Depending on the reaction conditions, the use of a liner may be necessary. Ammonobasic conditions are usually less corrosive than ammonoacidic conditions. Thus, a nickel based superalloy as autoclave material is often sufficient. However, in ammonobasic conditions, nickel based alloys can also be affected and a supplementary liner can be useful. We have observed the formation of nickel compounds from the autoclave material at $T \geq 840 \mathrm{~K}$ with zinc or gallium as reactant. Indium metal used as reactant passed the autoclave material by diffusion along the grain boundaries and leads to the destruction of the autoclave. For ammonoacidic conditions, liners are used to protect the products from metal impurities originating from the autoclave material. Especially chromium and nickel impurities in the compounds or even chromium and nickel based compounds are observed. Precious metals are used as liner materials, particularly silver, gold and platinum, although the choice of liner material restricts the choice of the mineralizer. However, the formation of a nitride layer on the surface of the autoclave material at $T \sim 800 \mathrm{~K}$ in supercritical ammonia during synthesis, resulting in a hard surface of nitrides, seems to protect the autoclave material in some cases to a certain amount from corrosion [3].

According to the use of the autoclave, the inner geometry is constructed differently. Ammonothermal syntheses on a fundamental research level, investigating new compounds, synthesis routes and processes do not obligatory require special inner shapes of the autoclave. Only the starting materials, including mineralizer, are loaded into the autoclave in one of the two temperature zones, subsequently the formed products, the crystallization spot and the dependence on temperature and pressure are investigated. However, ammonothermal syntheses exploring the crystal growth usually use seed crystals and a feedstock of micro crystalline powder, both containing the same metal (mostly GaN or AlN but also metal amides, metal halides or pure metal) and placed in different temperature zones of the reaction vessel. The micro crystalline powder is diluted with the help of a mineralizer and transported to the seed crystals, where it deposits. In this way, large crystals are obtained. The epitaxial growth on the seed crystal can be heteroepitaxial on 
foreign substrate or homoepitaxial on native substrate. This method is suitable for large scale commercial synthesis of AlN and GaN [63]. Often a baffle is used, in order to optimize the heat and mass transport inside the autoclave, since it is capable of controlling the flow pattern in the system. Different baffle designs are used, depending on the transport direction in the system.

\section{Crystallization Process}

The ammonothermal synthesis corresponds, in its thermodynamical fundaments and many chemical aspects, to the well studied Chemical Vapor Transport. The definition of the Chemical Vapor Transport by Binnewies et al. applies on a fundamental level: "textita condensed phase, typically a solid, is volatilized in the presence of a [...] transport agent, and deposits elsewhere, usually in the form of crystals" [64]. For the ammonothermal method this means: A solid phase is dissolved in supercritical ammonia initiated by chemical reaction with the added mineralizer forming complex ions, the complex ions are transported into the crystallization zone and deposit there under reformation of the solid as micro crystalline powder or single crystals. Crucial for the transport is the solubility of the compound ( $\geq 3 \%$ [65]) and the presence of a gradient. In principle, the gradient may concern any state variable leading to a difference in solubility. Typically, temperature gradients are used in crystal growth due the most simple realization by applying two or more different heaters realizing different temperatures and consequently producing two or more different temperature zones inside the reaction vessel.

There are currently many research efforts in maximizing growth rates and crystal sizes and in minimizing defects and strain/bowing levels. However, there appears only very little work done in order to understand the reasons for the achieved improvements. Knowledge and understanding of the physical and chemical processes during ammonothermal crystal growth allows a controlled and efficient improvement of the crystal growth process. Due to the influence of various parameters, this process is very complex. Two groups of parameters can be distinguished: Chemical parameters like the solvent, the chemical nature and the concentration of nutrient and mineralizer, and thermodynamical parameters like the pressure, the temperature in dissolution and crystallization zone and the temperature gradient contribute to the crystal growth [5]. Over the last years, there have been some initial studies carried out clarifying the processes during ammonothermal synthesis and especially the formation mechanism of GaN from supercritical ammonia. The research efforts cover different points of both groups of parameters, yet the influence of most parameters are not well examined and require further intense research efforts.

By isolation of intermediate compounds, evaluation of crystallization and dissolution zone, and determination of solubility of Ga species, important information for the formation mechanism of $\mathrm{GaN}$ from supercritical ammonia are obtained. Additionally, spectroscopic data of the intermediate compounds were collected representing the base for future in-situ measurements for further exploration of the GaN formation mechanism [66,67]. Special optical cells for in-situ monitoring during ammonothermal process were developed [59,60,68]. A combination of the in-situ monitoring technology and preliminary work on intermediate compounds allows to obtain further information for a complete unravelment of the ammonothermal synthesis. In order to understand the role of applied 
temperature, temperature gradient and baffle design for an optimized transport and consequently for the crystal growth first theoretical 3-D simulations for the ammonothermal process were furnished, revealing a strong dependence of the flow pattern by the baffle shape. A positive inclination of the baffle leads to an upward directed jet stream through the baffle opening and vice versa. The baffle shape not only influences the flow pattern but also the temperature profile. These information may be used to control specifically the crystallization and the mass transport from dissolution to crystallization zone, and to avoid parasitic crystal growth [69].

\subsection{Thermodynamical Parameters}

Knowledge about thermodynamical parameters (temperatures, pressure and reaction time) during ammonothermal crystal growth is crucial to adjust the growth conditions. High pressure allows us to decrease the temperature so that comparatively mild conditions can be applied. Depending on the desired product, temperature and pressure have to be adapted. In general, high temperature and low pressure favors the formation of binary nitrides and low temperatures and high pressures the stabilization of ternary amides, ternary ammoniates or mixed ternary compounds. Regarding the temperature, different aspects have to be respected: the dissolution temperature, the growth temperature and the temperature gradient. Generally speaking, increasing temperature and pressure yields a higher solubility of the starting materials, but the nature of the reactants and the products' solubility (negative or positive temperature dependance) have to be considered. For the transport of the mobile species, a gradient, typically in temperature, is necessary, determining the transport of the mobile species in solution and the kinetics. The transport can be performed dominated by convection or by diffusion, with convection by a gradient being much faster. A vertical gradient, typically meaning a vertical position of the reaction vessel, favors the transport via convection, while a horizontal position minimizes almost entirely the transport to diffusion, which leads to much slower transport rates. However, higher transport rates often yields higher defect densities. Thus, the kinetics have to be adapted according to the advantages of a high growth rate and the disadvantages of increased defect densities [5,7]. A temperature gradient can easily be applied by different heaters, by the lack of a heater on some parts of the reaction vessel or by an induced cooling.

The influence of the thermal decomposition of ammonia obeying reaction Equation (1) during ammonothermal synthesis at temperatures up to $873 \mathrm{~K}$ is expected to be small. $\mathrm{H}_{2}$ formed from the dissociation or as by-product of chemical reactions during dissolution or recrystallization has been shown to diffuse through the autoclave wall $[3,70]$. Jacobs and Schmidt concluded that equilibrium Equation (1) has to lie more on the left side, as they could not detect any $\mathrm{N}_{2}$ after reaction and their autoclaves would not have stand pressures as high as the extrapolated values [3].

$$
2 \mathrm{NH}_{3} \rightleftarrows \mathrm{N}_{2}+3 \mathrm{H}_{2}
$$

\subsection{Chemical Parameters}

Chemical parameters have previously been studied for solvothermal methods using other solvents than ammonia. We will limit ourselves to few examples: For the basic hydrothermal synthesis 
of wurtzite-type $\mathrm{ZnO}$ (starting materials: $\mathrm{Zn}\left(\mathrm{NO}_{3}\right)_{2(\mathrm{aq})}, \mathrm{NH}_{4} \mathrm{OH}$ in $\mathrm{H}_{2} \mathrm{O}$ at ambient pressure and $373 \mathrm{~K}$ ) the mechanism starts with dissolution of the $\mathrm{ZnO}$ nutrient by means of a mineralizer forming different soluble intermediate species $[\mathrm{ZnOOH}]^{-},\left[\mathrm{Zn}(\mathrm{OH})_{4}\right]^{2-}$ and $\left[\mathrm{ZnO}_{2}\right]^{2-}$, which occur in different concentrations depending on $\mathrm{OH}^{-}$concentration and temperature and the solid $\epsilon-\mathrm{Zn}(\mathrm{OH})_{2}$, which crystallizes as solid intermediate [44]. $h$ - $\mathrm{ZnO}$ was shown to form via the crystalline intermediate $\epsilon-\mathrm{Zn}(\mathrm{OH})_{2}$, where the conversion takes place interior solid $\epsilon-\mathrm{Zn}(\mathrm{OH})_{2}$. Simultaneously, on the outer surface layers exposed to the solution, $h-\mathrm{ZnO}$ is formed directly from $\epsilon-\mathrm{Zn}(\mathrm{OH})_{2}$, or exchanged with solution. $\epsilon-\mathrm{Zn}(\mathrm{OH})_{2}$ crystallizes from soluble species $\left(\left[\mathrm{Zn}(\mathrm{OH})_{4-n}\left(\mathrm{H}_{2} \mathrm{O}\right)_{n}\right]^{2-n} ; n=0,1\right)[12]$. A possible $\mathrm{ZnO}$ formation mechanism for the growth on a $\mathrm{ZnO}$ seed crystal is shown in reaction Equation (2), while reaction Equation (3) shows the solid-solid transformation from spontaneously nucleated $\epsilon-\mathrm{Zn}(\mathrm{OH})_{2}$ to $h-\mathrm{ZnO}$.

$$
\begin{gathered}
\mathrm{ZnO}(\text { nutrient })+2 \mathrm{OH}^{-}+\mathrm{H}_{2} \mathrm{O} \rightleftarrows\left[\mathrm{Zn}(\mathrm{OH})_{4}\right]^{2-} \rightleftarrows \mathrm{Zn}(\mathrm{OH})_{2}+2 \mathrm{OH}^{-} \\
\rightleftarrows\left[\mathrm{ZnO}_{2}\right]^{2-}+2 \mathrm{H}_{2} \mathrm{O} \rightleftarrows \mathrm{ZnO}(\text { crystal })+2 \mathrm{OH}^{-}+\mathrm{H}_{2} \mathrm{O} \\
\mathrm{Zn}(\mathrm{OH})_{2} \rightleftarrows \mathrm{ZnO}+\mathrm{H}_{2} \mathrm{O}
\end{gathered}
$$

Extensive research has also been done on the mechanism during hydrothermal growth of zeolites. It has been shown, e.g., that the dissolved species taking part in the crystallization process are small and of simple structure. The growth from larger and more complex species is too time consuming and has a higher defect probability due to different docking possibilities on the crystal surface. A high defect concentration may slow down or even entirely stop the crystal growth [71]. $\left[\mathrm{Si}(\mathrm{OH})_{3} \mathrm{O}\right]^{-}$and $\left[\mathrm{Al}(\mathrm{OH})_{4}\right]^{-}$monomers are taken to represent the building species in zeolite crystal growth $[71,72]$.

During ammonothermal synthesis, various ionic species may occur. The nature of these species is strongly related to the acidity of the system. Three types of milieus arise, evoked by the used starting materials: ammonoacidic $\left(\mathrm{NH}_{4}^{+}\right.$present), ammononeutral (e.g., $\mathrm{NO}_{3}^{2-}$ present) and ammonobasic $\left(\mathrm{NH}_{2}^{-}\right.$present). The milieu determining ions $\left(\mathrm{NH}_{4}^{+}\right.$and $\left.\mathrm{NH}_{2}^{-}\right)$derive from the acidic or basic mineralizer and the autoprotolysis of ammonia. Mineralizers added to the reactants are applied to establish a defined milieu. Sometimes a tiny amount of a co-mineralizer (e.g., alkali metal halides) is added to activate the reaction. Although the role of mineralizers in chemical reactions is not always known, they are used in ammonothermal synthesis [66,67] as well as in various further methods (gas phase transport reactions [64], hydrothermal synthesis [4], synthesis in liquid ammonia [54,73,74]). Similar applies to the so-called co-mineralizers. The mineralizers fulfill different functions in the growth process: to convey the solubility of the starting material by inducing the formation of soluble and consequently mobile species, to enable and enhance the formation of new chemical bonds and compounds, and finally to detach from the desired compound to be able to act like a catalyst (especially in case of growth of binary compounds). The importance of the choice of the mineralizer can be seen in the fact that they determine the transportation direction of the product in the gradient within the autoclave (see paragraph Intermediate Species controlling Solubility and Growth Rates). 


\subsubsection{Ammonobasic Systems}

Typically, alkali metal amides $A(1) \mathrm{NH}_{2}$, alkali metals or alkali metal azides are use as ammonobasic mineralizers. Ammonia reacts with alkali metals and alkali metal azides according to reactions Equations (4) and (5) to form $\mathrm{NH}_{2}^{-}$, such that the solution turns basic. The same applies for alkaline-earth metals and some rare-earth metals. However, alkali metal amides and azides are easier to handle due to their powder shape and lower reactivity compared to the metal bulk material. Alkali metal amides are favorable if no formation of hydrogen or additional nitrogen pressure is desired.

$$
\begin{gathered}
2 \mathrm{NH}_{3}+2 A(1) \rightarrow 2 \mathrm{NH}_{2}^{-}+\mathrm{H}_{2}+2 A(1)^{+} \\
2 \mathrm{NH}_{3}+3 \mathrm{~N}_{3}^{-} \rightarrow 3 \mathrm{NH}_{2}^{-}+4 \mathrm{~N}_{2}
\end{gathered}
$$

During ammonothermal synthesis, in analogy to the experience from hydrothermal research, it is expected that the metal dissolves by help of the mineralizer, forming intermediate species of the type $\left[B\left(\mathrm{NH}_{2}\right)_{n}\right]^{m-}$, possibly also as complex imides or amide imides. Those complex anions are transported in the supercritical ammonia from the dissolution to the crystallization zone, where the crystallization takes place.

Ammonobasic mineralizers like $\mathrm{KNH}_{2}$ are known from syntheses of binary metal amides in liquid ammonia for a long time. The latter binary amides are formed from metal salt solutions in liquid ammonia with $\mathrm{KNH}_{2}$ as a little soluble precipitate. An example for this synthesis is the formation of $\mathrm{Cd}\left(\mathrm{NH}_{2}\right)_{2}$ from $\mathrm{Cd}(\mathrm{SCN})_{2}$ in liquid ammonia with $\mathrm{KNH}_{2}$ as mineralizer. The application of alkali metal amides as mineralizers only work, if there are no ternary alkali metal amides formed. Often with small amounts of mineralizer binary amides, with large amounts ternary amides are obtained. Beryllium and zinc always form ternary amides [74].

There is a large number of ternary amides of two metals synthesized in supercritical ammonia from the metals (see paragraph Ternary Amides) at comparatively high pressures and low temperatures. Ternary amides decompose to imides and further to nitrides, under release of ammonia. Before the formation of pure nitrides is completed, metal hydrides and mixed hydride nitrides may be obtained as shown in the systems $\mathrm{Th} / \mathrm{H} / \mathrm{N}$ [33], $\mathrm{Zr} / \mathrm{H} / \mathrm{N}$ [75] and $\mathrm{Ce} / \mathrm{H} / \mathrm{N}$ [76], especially at temperatures below the formation temperature for pure nitrides.

It is also known that various bulk binary nitrides are formed from the metal in supercritical ammonia using an ammonobasic mineralizer (see paragraph Nitrides), from technological point of view, the most interesting examples currently being the semiconductors GaN [77] and AlN [78]. Recent research in ammonobasic conditions indicates that the binary nitrides are formed via ternary amides functioning as intermediate species [67,79] following the assumed reaction Equation (6). $\mathrm{K}\left[\mathrm{Ga}\left(\mathrm{NH}_{2}\right)_{4}\right]$ and $\mathrm{Na}\left[\mathrm{Ga}\left(\mathrm{NH}_{2}\right)_{4}\right]$ convert to $h$-GaN at higher temperatures $[80,81]$. For GaN synthesis from $\mathrm{Ga}$ with $\mathrm{LiNH}_{2}$ in supercritical ammonia, $\mathrm{Li}\left[\mathrm{Ga}\left(\mathrm{NH}_{2}\right)_{4}\right]$ was proposed as possible intermediate compound [79] and was indeed recently found to crystallize in two modifications in the hot zone of the autoclave [67]. In the system $\mathrm{Ga} / \mathrm{Na} / \mathrm{NH}_{3}$ two ternary amides are known, namely $\mathrm{Na}\left[\mathrm{Ga}\left(\mathrm{NH}_{2}\right)_{4}\right][81]$ and $\mathrm{Na}_{2}\left[\mathrm{Ga}\left(\mathrm{NH}_{2}\right)_{4}\right] \mathrm{NH}_{2}[67,82]$ to form under ammonothermal conditions. The former predominates at high pressures, whereas the latter is obtained mainly at lower pressures. With 
potassium only one solid compound $\mathrm{K}\left[\mathrm{Ga}\left(\mathrm{NH}_{2}\right)_{4}\right][80]$ and an intriguing liquid " $\mathrm{KGa}(\mathrm{NH})_{n} \cdot x \mathrm{NH}_{3}$ " were reported [65]. Decomposition of $\mathrm{Na}\left[\mathrm{Al}\left(\mathrm{NH}_{2}\right)_{4}\right]$ under release of ammonia at temperatures below $373 \mathrm{~K}$ is known to proceed via a liquid compound. An intermediate "NaAl( $\left.\mathrm{NH}_{2}\right)_{2}(\mathrm{NH})$ " was proposed according to volumetric measurements of released ammonia. Further heating leads to a mixture of AlN and $\mathrm{NaNH}_{2}$ [81]. Knowledge about those intermediate compounds is not only interesting for the formation mechanism, but also for understanding the temperature dependance of the solubility of $\mathrm{GaN}$ in supercritical ammonia.

$$
A(1)_{n} \mathrm{Ga}\left(\mathrm{NH}_{2}\right)_{3+n} \rightleftarrows \mathrm{GaN}+n A(1) \mathrm{NH}_{2}+2 \mathrm{NH}_{3}
$$

\subsubsection{Ammonoacidic Systems}

Ammonothermal synthesis in ammonoacidic milieu is a powerful method to obtain ammoniates, nitrides and even amides. The effect of ammonacidic milieu is due to the presence and increased concentration of ammonium ions $\mathrm{NH}_{4}^{+}$. Ammonoacidic milieu is well known from syntheses in liquid ammonia [54,73], where, e.g., $\mathrm{NH}_{4} \mathrm{I}$ is used as ammonoacidic catalyst for the precipitation of $\mathrm{Mg}\left(\mathrm{NH}_{2}\right)_{2}$ from magnesium according to the following reaction [73]:

$$
\begin{aligned}
\mathrm{Mg}+2 \mathrm{NH}_{4}^{+} & \rightleftarrows \mathrm{Mg}^{2+}+2 \mathrm{NH}_{3}+\mathrm{H}_{2} \\
\mathrm{Mg}^{2+}+4 \mathrm{NH}_{3} & \rightleftarrows \mathrm{Mg}\left(\mathrm{NH}_{2}\right)_{2}+2 \mathrm{NH}_{4}^{+}
\end{aligned}
$$

Typical ammonoacidic mineralizers comprise ammonium halides $\mathrm{NH}_{4} X(X=\mathrm{F}, \mathrm{Cl}, \mathrm{Br}, \mathrm{I})$ and metal halides $B X_{n}(X=\mathrm{F}, \mathrm{Cl}, \mathrm{Br}, \mathrm{I} ; B=$ for example, $\mathrm{Al}, \mathrm{Ga}, \mathrm{Fe}, \mathrm{Zn})$.

Several aluminum halide ammoniates are known $\left[\mathrm{Al}\left(\mathrm{NH}_{3}\right)_{5} X\right] X_{2}(X=\mathrm{F}$ [83], $\mathrm{Cl}, \mathrm{Br}, \mathrm{I}$ [84]), obtained from different synthetic approaches. Ammoniates of aluminum halides are supposed to represent intermediate compounds in the ammonoacidic AlN synthesis. Analogously, there are ammoniates from gallium halides with different amounts of ammonia molecules per gallium kown. In GaN hydride or halide vapor phase epitaxy these occur as volatile precursors, accomplishing the gallium transport to the crystallization zone.

In liquid ammonia gallium halides form hexammoniates such as $\left[\mathrm{Ga}\left(\mathrm{NH}_{3}\right)_{6}\right] \mathrm{Br}_{3} \cdot \mathrm{NH}_{3}$ and $\left[\mathrm{Ga}\left(\mathrm{NH}_{3}\right)_{6}\right] \mathrm{I}_{3} \cdot \mathrm{NH}_{3}[66,85]$. Those ammoniates contain octahedrally surrounded $\mathrm{Ga}^{3+}$ forming positively charged complex ions $\left[\mathrm{Ga}\left(\mathrm{NH}_{3}\right)_{6}\right]^{3+}$, which may represent the mobile Ga-containing species in solution. At higher temperature and pressure gallium metal reacts with ammonium halides $\mathrm{NH}_{4} x(X=\mathrm{F}, \mathrm{Cl})$ to the ammoniates $\left[\mathrm{Ga}\left(\mathrm{NH}_{3}\right)_{5} \mathrm{Cl}\right] \mathrm{Cl}_{2}$ or $\mathrm{Ga}\left(\mathrm{NH}_{3}\right)_{3} \mathrm{~F}_{3}$ and $\mathrm{GaN}$ [66]. Obtaining $\left[\mathrm{Ga}\left(\mathrm{NH}_{3}\right)_{5} \mathrm{Cl}\right] \mathrm{Cl}_{2}$ and $\mathrm{Ga}\left(\mathrm{NH}_{3}\right)_{3} \mathrm{~F}_{3}$ during ammonothermal crystal growth of $\mathrm{GaN}$ next to $\mathrm{GaN}$ confirms the assumption of their role as intermediate species in the $\mathrm{GaN}$ synthesis from supercritical ammonia. $\left[\mathrm{Ga}\left(\mathrm{NH}_{3}\right)_{5} \mathrm{Cl}\right] \mathrm{Cl}_{2}$ contains octahedral units $\left[\mathrm{Ga}\left(\mathrm{NH}_{3}\right)_{5} \mathrm{Cl}\right]^{2+}$, which may again represent the Ga-transporting species in solution. In solid $\mathrm{Ga}\left(\mathrm{NH}_{3}\right)_{3} \mathrm{~F}_{3}$ gallium occurs in two different species, namely $\left[\mathrm{Ga}\left(\mathrm{NH}_{3}\right)_{4} \mathrm{~F}_{2}\right]^{+}$and $\left[\mathrm{Ga}\left(\mathrm{NH}_{3}\right)_{2} \mathrm{~F}_{4}\right]^{-}$. Thus, in solution cationic $\left[\mathrm{Ga}\left(\mathrm{NH}_{3}\right)_{4} \mathrm{~F}_{2}\right]^{+}$and anionic $\left[\mathrm{Ga}\left(\mathrm{NH}_{3}\right)_{2} \mathrm{~F}_{4}\right]^{-}$complex ions may be present. This observation may be the key to the enravelment of solubility and crystallization processes during GaN crystal growth. 


\subsubsection{Intermediate Species controlling Solubility and Growth Rates}

There is little known about the solubility of group III nitrides in supercritical ammonia. We believe it to strongly depend on the present intermediate compounds and thus on mineralizer, temperature and pressure. In the system $\mathrm{Ga} / \mathrm{NH}_{3}$ a retrograde solubility for $\mathrm{GaN}$ in supercritical ammonia using $\mathrm{KNH}_{2}$ as mineralizer was found, meaning that the solubility of $\mathrm{GaN}$ decreases with increasing temperature. This results from experiments, where a Ga nutrient was placed at the midpoint of an autoclave, presenting a temperature gradient with a hot and a cold zone, and observing the crystallization spot are shown. At $T \geq 723 \mathrm{~K}, \mathrm{GaN}$ crystallizes in the hot zone $[65,67,86]$. An equivalent behavior was observed for $\mathrm{AlN}$, which can be formed from $\mathrm{Al}$ and $\mathrm{KNH}_{2}$ probably via the intermediate $\mathrm{K}\left[\mathrm{Ga}\left(\mathrm{NH}_{2}\right)_{4}\right]$ [78]. This observation might be attributed to dynamic temperature dependant equilibria of different potassium amides and imides of gallium as intermediate species. $\mathrm{K}\left[\mathrm{Ga}\left(\mathrm{NH}_{2}\right)_{4}\right]$, with tetrahedrally coordinated $\mathrm{Ga}$, is known from synthesis in liquid ammonia [80]. At $853 \mathrm{~K}$ and $100 \mathrm{MPa}$ we obtain from $\mathrm{Ga}$ and $\mathrm{KNH}_{2}$ pure $h$-GaN. At $733 \mathrm{~K}$ and $50 \mathrm{MPa}$ the same starting materials yield a liquid with the composition "KGa( $\left.\mathrm{NH}_{2}\right)_{2}(\mathrm{NH})$ ", which was earlier reported as " $\mathrm{KGa}(\mathrm{NH})_{n} \cdot x \mathrm{NH}_{3}$ " [65]. This liquid is supposed to behave similarly to the intermediate " $\mathrm{NaAl}\left(\mathrm{NH}_{2}\right)_{2}(\mathrm{NH})$ ", which occurs during thermal decomposition of $\mathrm{Na}\left[\mathrm{Al}\left(\mathrm{NH}_{2}\right)_{4}\right]$ under release of ammonia (see paragraph Ammonobasic Systems) [81]. The coordination of gallium in this liquid is not yet known. Initial results assume a similar behavior for the system $\mathrm{Na} / \mathrm{Ga} / \mathrm{NH}_{3}$, where the compounds $\mathrm{Na}\left[\mathrm{Ga}\left(\mathrm{NH}_{2}\right)_{4}\right][81]$ and $\mathrm{Na}_{2}\left[\mathrm{Ga}\left(\mathrm{NH}_{2}\right)_{4}\right] \mathrm{NH}_{2}$ [67,82] are known and the existence of an equivalent liquid phase is possible.

In ammonoacidic milieu, negative and positive temperature dependance of the solubilities are observed. For the temperature range $473-823 \mathrm{~K} \mathrm{GaN}$ shows a positive temperature dependance of the solubility in ammonoacidic milieu, using $\mathrm{NH}_{4} X(X=\mathrm{Cl}, \mathrm{Br}, \mathrm{I})$ as mineralizer $[87,88]$. This is observed for the syntheses of $c-\mathrm{GaN}$ and $h-\mathrm{GaN}$ with $\mathrm{Ga}$ metal or $\mathrm{GaN}$ as nutrient [88]. Additionally, there are two examples of $\mathrm{GaN}$ manifesting a negative solubility in ammonoacidic milieu reported: A change in the temperature dependance of the solubility of $\mathrm{GaN}$ from positive to negative, using $\mathrm{NH}_{4} \mathrm{Cl}$ has been noticed at temperatures above $923 \mathrm{~K}$ with pressures of $110 \mathrm{MPa}$ [62]. Also, a negative solubility has been revealed in the temperature range $823-923 \mathrm{~K}$ using $\mathrm{NH}_{4} \mathrm{~F}$ as mineralizer [46]. Up to now $\mathrm{NH}_{4} \mathrm{~F}$ and $\mathrm{NH}_{4} \mathrm{Cl}$ are the only acidic mineralizers known to evoke a negative solubility for $\mathrm{GaN}$ and consequently the crystallization in the hot zone.

Different growth rates for the negatively charged (0001) $N$-face and the positively charged (0001) Ga-face of the GaN seed crystal were observed. It is assumed that the nature of the intermediate species determines the predominant growth on one of the faces. Thus, the existence of positively charged complex ions such as $\left[\mathrm{Ga}\left(\mathrm{NH}_{3}\right)_{6}\right]^{3+}$ and $\left[\mathrm{Ga}\left(\mathrm{NH}_{3}\right)_{5} \mathrm{Cl}\right]^{2+}$ may explain a higher growth rate on the negatively charged face (see Figure 6a) [87]. Furthermore, a growth on both $c$-faces, the negatively charged $N$-face and the positively charged Ga-face, is observed using $\mathrm{NH}_{4} \mathrm{~F}$ as mineralizer [46]. The presence of both cationic $\left[\mathrm{Ga}\left(\mathrm{NH}_{3}\right)_{4} \mathrm{~F}_{2}\right]^{+}$and anionic $\left[\mathrm{Ga}\left(\mathrm{NH}_{3}\right)_{2} \mathrm{~F}_{4}\right]^{-}$complex ions as intermediates in solution, which should deposit each on the opposite charged face of the GaN seed, may explain this phenomenon (see Figure 6b). Consequently, the solubility, the crystallization 
zone and the deposition on the seed crystal of group III nitrides dependent strongly on the formed intermediate compounds.

Figure 6. Schematic crystallization of $\mathrm{GaN}$ on a seed crystal under ammonoacidic conditions. (a) by cationic $\left[\mathrm{Ga}\left(\mathrm{NH}_{3}\right)_{4} \mathrm{~F}_{2}\right]^{+}$and anionic $\left[\mathrm{Ga}\left(\mathrm{NH}_{3}\right)_{2} \mathrm{~F}_{4}\right]^{-}$intermediates, (using $\mathrm{NH}_{4} \mathrm{~F}$ as mineralizer), manifesting a negative temperature dependance of the solubility of $\mathrm{GaN}$; (b) by cationic $\left[\mathrm{Ga}\left(\mathrm{NH}_{3}\right)_{6}\right]^{3+}$ intermediates (using $\mathrm{NH}_{4} \mathrm{Br}$ or $\mathrm{NH}_{4} \mathrm{I}$ as mineralizer), manifesting a positive temperature dependance of the solubility of GaN.

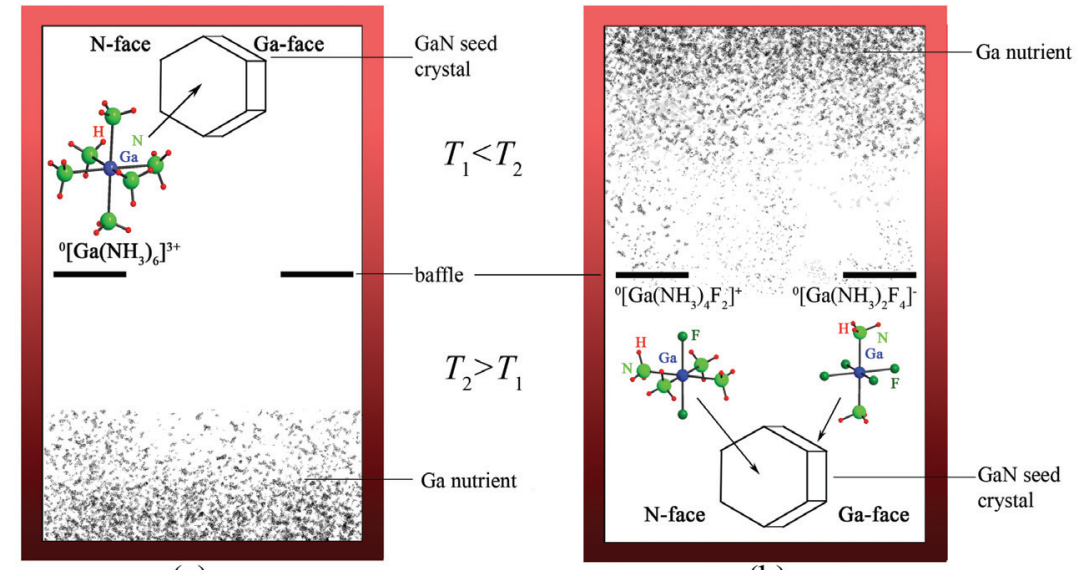

(a)

(b)

\section{Compounds from Ammonothermal Synthesis}

\subsection{Ammoniates of Metal Halides}

Ammoniates of metal halides can be grown from metal halides or from the metal and ammonium halides in supercritical ammonia (see Table 3). Such ammoniates of metal halides are suggested to represent crystallized intermediate compounds during ammonoacidic III-nitride growth [66], since ammoniates are expected to have a high solubility in supercritical ammonia (see paragraph Ammonoacidic Systems). In liquid and supercritical ammonia, one typically obtains the ammoniates with highest ammonia content known, for example, $\left[\mathrm{Al}\left(\mathrm{NH}_{3}\right)_{6}\right] \mathrm{I}_{3} \cdot \mathrm{NH}_{3}[89],\left[\mathrm{Al}\left(\mathrm{NH}_{3}\right)_{5} \mathrm{Cl}\right] \mathrm{Cl}_{2},\left[\mathrm{Al}\left(\mathrm{NH}_{3}\right)_{5} \mathrm{Br}\right] \mathrm{Br}_{2}$, $\left[\mathrm{Al}\left(\mathrm{NH}_{3}\right)_{5} \mathrm{I}\right] \mathrm{I}_{2}[84],\left[\mathrm{Ga}\left(\mathrm{NH}_{3}\right)_{6}\right] \mathrm{I}_{3} \cdot \mathrm{NH}_{3},\left[\mathrm{Ga}\left(\mathrm{NH}_{3}\right)_{6}\right] \mathrm{Br}_{3} \cdot \mathrm{NH}_{3},\left[\mathrm{Ga}\left(\mathrm{NH}_{3}\right)_{5} \mathrm{Cl}\right] \mathrm{Cl}_{2}, \mathrm{Ga}\left(\mathrm{NH}_{3}\right)_{3} \mathrm{~F}_{3}[66]$, $\left[\mathrm{Fe}\left(\mathrm{NH}_{3}\right)_{6}\right] \mathrm{I}_{2}$ and $\left[\mathrm{Mn}\left(\mathrm{NH}_{3}\right)_{6}\right] \mathrm{I}_{2}[90]$.

Other synthesis methods leading to metal ammoniates are reaction of metal halides with gaseous ammonia or reaction of metals with ammonia donors (e.g., $\mathrm{NH}_{4} \mathrm{HF}_{2}, \mathrm{NH}_{4} \mathrm{Cl}, \mathrm{NH}_{4} \mathrm{Br}$ ) producing compounds such as $\mathrm{Mg}\left(\mathrm{NH}_{3}\right)_{2} \mathrm{Cl}_{2}, \mathrm{Mg}\left(\mathrm{NH}_{3}\right)_{2} \mathrm{Br}_{2}, \mathrm{Mg}\left(\mathrm{NH}_{3}\right)_{2} \mathrm{I}_{2}$ [91], [ $\left.\mathrm{Zn}\left(\mathrm{NH}_{3}\right)_{4}\right] \mathrm{Br}_{2}, \quad\left[\mathrm{Zn}\left(\mathrm{NH}_{3}\right)_{4}\right] \mathrm{I}_{2}$ [92], $\mathrm{Ga}\left(\mathrm{NH}_{3}\right)_{2} \mathrm{~F}_{3}[93], \mathrm{Fe}\left(\mathrm{NH}_{3}\right)_{2} \mathrm{Cl}_{2},\left[\mathrm{Fe}\left(\mathrm{NH}_{3}\right)_{6}\right] \mathrm{Cl}_{2},\left[\mathrm{Fe}\left(\mathrm{NH}_{3}\right)_{6}\right] \mathrm{Br}_{2}$ [94-96] and $\left[B\left(\mathrm{NH}_{3}\right)_{5} \mathrm{Cl}_{\mathrm{Cl}}\right.$ with $B=\mathrm{Al}$ [84], Cr [97], Co [97,98], Rh [97,99], Ru [97], Os [97]. Further ammoniates may be obtained by thermal decomposition of higher ammoniates. The step-wise ammonia release on heating of 
$\left[\mathrm{Fe}\left(\mathrm{NH}_{3}\right)_{6}\right] \mathrm{Cl}_{2}$ via $\mathrm{Fe}\left(\mathrm{NH}_{3}\right)_{2} \mathrm{Cl}_{2}$ and amorphous $\mathrm{Fe}\left(\mathrm{NH}_{3}\right) \mathrm{Cl}_{2}$ to $\epsilon-\mathrm{Fe}_{3} \mathrm{~N}_{1+x}$ illustrates the formation of different metal halide ammoniates by thermal decomposition [94-96].

Table 3. Conditions for the ammonothermal crystal growth of metal halide ammoniates and of ammoniates of metal amides.

\begin{tabular}{llcccr}
\hline Compound & Reactants + mineralizer & $\boldsymbol{T} / \mathbf{K}$ & $\boldsymbol{p} / \mathbf{M P a}$ & $\boldsymbol{t} / \mathbf{d}$ & References \\
\hline $\mathrm{Al}\left(\mathrm{NH}_{3}\right)_{2} \mathrm{~F}_{3}$ & $\mathrm{AlN}+\mathrm{NH}_{4} \mathrm{~F}$ & 673 & - & 3 & {$[83]$} \\
{$\left[\mathrm{Al}\left(\mathrm{NH}_{3}\right)_{5} \mathrm{Cl}\right] \mathrm{Cl}_{2}$} & $\mathrm{AlCl}_{3}$ & 603 & - & $3-6$ & {$[84]$} \\
{$\left[\mathrm{Al}\left(\mathrm{NH}_{3}\right)_{5} \mathrm{Br}\right] \mathrm{Br}_{2}$} & $\mathrm{AlBr}_{3}$ & 623 & - & $3-6$ & {$[84]$} \\
{$\left[\mathrm{Al}\left(\mathrm{NH}_{3}\right)_{5} \mathrm{I}\right] \mathrm{I}_{2}$} & $\mathrm{AlI}_{3}$ & 673 & - & $3-6$ & {$[84]$} \\
{$\left[\mathrm{Al}\left(\mathrm{NH}_{3}\right)_{6}\right] \mathrm{I}_{3} \cdot \mathrm{NH}_{3}$} & $\mathrm{Al}+\mathrm{NH}_{4} \mathrm{I}$ & 393 & 9 & 1 & {$[89]$} \\
$\mathrm{Ga}\left(\mathrm{NH}_{3}\right)_{3} \mathrm{~F}_{3}$ & $\mathrm{Ga}+\mathrm{NH}_{4} \mathrm{~F}$ & 753 & 238 & 3 & {$[66]$} \\
{$\left[\mathrm{Ga}\left(\mathrm{NH}_{3}\right)_{5} \mathrm{Cl}\right] \mathrm{Cl}_{2}$} & $\mathrm{Ga}+\mathrm{NH}_{4} \mathrm{Cl}$ & 853 & 95 & 1 & {$[66]$} \\
{$\left[\mathrm{Ga}\left(\mathrm{NH}_{3}\right)_{6}\right] \mathrm{Br}_{3} \cdot \mathrm{NH}_{3}$} & $\mathrm{GaBr}$ & $197-373$ & $\leq 6$ & - & {$[66]$} \\
{$\left[\mathrm{Ga}\left(\mathrm{NH}_{3}\right)_{6}\right] \mathrm{I}_{3} \cdot \mathrm{NH}_{3}$} & $\mathrm{GaI}$ & $197-373$ & $\leq 6$ & - & {$[66]$} \\
{$\left[\mathrm{Mn}\left(\mathrm{NH}_{3}\right)_{6}\right] \mathrm{I}_{2}$} & $\mathrm{Mn}+\mathrm{I}_{2}$ & $673-873$ & 600 & $\leq 7$ & {$[90]$} \\
{$\left[\mathrm{Fe}\left(\mathrm{NH}_{3}\right)_{6}\right] \mathrm{I}_{2}$} & $\mathrm{Fe}+\mathrm{I}_{2}$ & $673-873$ & 600 & $\leq 7$ & {$[90]$} \\
$\mathrm{Cs} \mathrm{La}_{2}\left(\mathrm{NH}_{2}\right)_{6} \cdot \mathrm{NH}_{3}$ & $\mathrm{Cs}+\mathrm{La}_{\mathrm{La}}$ & $490-570$ & $400-600$ & $31-103$ & {$[100]$} \\
$\mathrm{Cs} \mathrm{La}_{2}\left(\mathrm{NH}_{2}\right)_{7} \cdot \mathrm{NH}_{3}$ & $\mathrm{Cs}+\mathrm{La}_{\mathrm{LaAl}}$ & $490-570$ & $400-600$ & $31-103$ & {$[100]$} \\
$\mathrm{BaAl}\left(\mathrm{NH}_{2}\right)_{8} \cdot 2 \mathrm{NH}_{3}$ & $\mathrm{Al}+\mathrm{BaAl}_{2}$ & 823 & 245 & 29 & {$[101]$} \\
$\mathrm{InF}_{2}\left(\mathrm{NH}_{2}\right) \cdot \mathrm{NH}_{3}$ & $\mathrm{InN}+\mathrm{NH}_{4} \mathrm{~F}$ & 673 & 220 & 1 & {$[83]$} \\
\hline
\end{tabular}

\subsection{Binary Amides and Deuteroamides}

Several binary amides were obtained from the metals dissolved in liquid ammonia at ambient temperature. In 1891, Joannis had already discovered liquid ammonia as useful solvent to obtain single crystals of metal amides. He obtained colorless $\mathrm{NaNH}_{2}$ crystals from a solution of $\mathrm{Na}$ in liquid ammonia [102]. Europium, ytterbium, alkali and alkaline-earth metals dissolve in liquid ammonia at ambient temperature and form intensely blue or bronze colored solutions, if in higher concentration [103]. The solutions are metastable and react to metal amides in form of colorless crystals, hydrogen and a colorless solution [104]. The formation of amides can be enhanced by higher temperatures, higher pressures, exposure to light or addition of a catalyst, e.g., elemental platinum or Fe(II)-compounds like iron oxide [49,73,74,105,106].

\subsubsection{Alkali Metal Amides}

The alkali metal amides $\mathrm{LiNH}_{2}$ [107], $\mathrm{NaNH}_{2}$ [108], $\mathrm{KNH}_{2}, \mathrm{RbNH}_{2}$ and $\mathrm{CsNH}_{2}$ [73] can be obtained from the metals in liquid ammonia at ambient temperature. The presence of a catalyst (platinum net) or exposure to light enhances the reaction rate. The reaction duration depends on the solubility of the metal in liquid ammonia, which rises with increasing atomic weight of the alkali metal. Higher temperatures accelerate the reactions considerably. For $\mathrm{KNH}_{2}, \mathrm{RbNH}_{2}$ and $\mathrm{CsNH}_{2}$ the 
reaction can be carried out within a few hours even at low temperatures ( $T \leq 273 \mathrm{~K}$ ), usually yielding micro crystalline powders [106]. The formation of $\mathrm{LiNH}_{2}$ from lithium metal and liquid ammonia at ambient temperature takes 8 days or more [73,107]. At $400 \mathrm{~K}$ and $20 \mathrm{MPa}$ the reaction can be carried out within one day without any catalyst [109], after seven days at $583 \mathrm{~K}$ and $71 \mathrm{MPa}$ crystals were obtained [1]. $\mathrm{NaNH}_{2}$ shows similar behavior [108]. To shorten the reaction time and to grow alkali metal amide crystals, it is favorable to work under ammonothermal conditions (see Table 4) [1].

Table 4. Conditions for the ammonothermal synthesis of binary amides and deuteroamides (synthesized using $\mathrm{ND}_{3}$ ).

\begin{tabular}{|c|c|c|c|c|c|c|}
\hline Compound & Reactants + mineralizer & $T / \mathbf{K}$ & $p / \mathrm{MPa}$ & $t / \mathbf{d}$ & Sample & References \\
\hline $\mathrm{LiND}_{2}$ & $\mathrm{Li}$ & 473 & 304 & - & m.c. & {$[110]$} \\
\hline $\mathrm{NaNH}_{2}$ & $\mathrm{Na}$ & 393 & $\leq 10$ & 14 & s.c. & [111] \\
\hline $\mathrm{NaND}_{2}$ & $\mathrm{Na}$ & $423-473$ & 405 & 8 & m.c. & [111] \\
\hline $\mathrm{KND}_{2}$ & $\mathrm{~K}$ & 320 & $\leq 10$ & 4 & m.c. & [112] \\
\hline $\mathrm{CsNH}_{2}$ & Cs & 423 & 180 & 2 & m.c. & [113] \\
\hline $\mathrm{CsND}_{2}$ & Cs & 423 & 180 & 2 & m.c. & [113] \\
\hline $\mathrm{Be}\left(\mathrm{NH}_{2}\right)_{2}$ & $\mathrm{Be}$ & 633 & 253 & 5 & s.c. & {$[2]$} \\
\hline $\mathrm{Be}\left(\mathrm{NH}_{2}\right)_{2}$ & $\mathrm{Be}+\mathrm{NaN}_{3}$ & 643 & 355 & 20 & s.c. & [114] \\
\hline $\mathrm{Mg}\left(\mathrm{NH}_{2}\right)_{2}$ & $\mathrm{Mg}$ & $613-653$ & 10 & 2 & m.c. & {$[115]$} \\
\hline $\mathrm{Mg}\left(\mathrm{NH}_{2}\right)_{2}$ & $\mathrm{Mg}+\mathrm{NaN}_{3}$ & 523 & 253 & $2-4$ & s.c. & {$[1,2]$} \\
\hline $\mathrm{Mg}\left(\mathrm{NH}_{2}\right)_{2}$ & $\mathrm{Mg}_{3} \mathrm{~N}_{2}$ & $633-648$ & 1 & $\leq 7$ & m.c. & [115] \\
\hline $\mathrm{Mg}\left(\mathrm{NH}_{2}\right)_{2}$ & $\mathrm{Mg}+\mathrm{NaNH}_{2}$ & $623-653$ & $212-345$ & $2-4$ & s.c. & [115] \\
\hline $\mathrm{Ca}\left(\mathrm{NH}_{2}\right)_{2}$ & $\mathrm{Ca}$ & 370 & 6 & 14 & s.c. & [116] \\
\hline $\mathrm{Sr}\left(\mathrm{NH}_{2}\right)_{2}$ & $\mathrm{Sr}+\mathrm{K}$ & 625 & 550 & 7 & s.c. & [117] \\
\hline $\mathrm{Sr}\left(\mathrm{ND}_{2}\right)_{2}$ & $\mathrm{Sr}$ & 625 & 550 & 9 & m.c. & [117] \\
\hline $\mathrm{Ba}\left(\mathrm{NH}_{2}\right)_{2}$ & $\mathrm{Ba}$ & 533 & 324 & 3 & s.c. & [1] \\
\hline $\mathrm{Ba}\left(\mathrm{NH}_{2}\right)_{2}$ & $\mathrm{Ba}$ & 398 & $\leq 20$ & 120 & s.c. & [118] \\
\hline $\mathrm{Mn}\left(\mathrm{NH}_{2}\right)_{2}$ & $\mathrm{Mn}+\mathrm{Na}_{2}\left[\mathrm{Mn}\left(\mathrm{NH}_{2}\right)_{4}\right]$ & 393 & 10 & 10 & s.c. & [119] \\
\hline $\mathrm{Zn}\left(\mathrm{NH}_{2}\right)_{2}$ & $\mathrm{Zn}+\mathrm{Na}_{2}\left[\mathrm{Zn}\left(\mathrm{NH}_{2}\right)_{4}\right] \cdot 0 \cdot 5 \mathrm{NH}_{3}$ & 523 & 380 & 60 & s.c. & [119] \\
\hline $\mathrm{La}\left(\mathrm{NH}_{2}\right)_{3}$ & $\mathrm{La}+\mathrm{KNH}_{2}$ & 623 & 405 & 6 & s.c. & [120] \\
\hline $\mathrm{Sm}\left(\mathrm{NH}_{2}\right)_{3}$ & $\mathrm{Sm}$ & $403-493$ & $200-500$ & - & - & [121] \\
\hline $\mathrm{Eu}\left(\mathrm{NH}_{2}\right)_{2}$ & $\mathrm{Eu}+\mathrm{K}$ & $523-673$ & $500-557$ & $7-9$ & s.c. & [122] \\
\hline $\mathrm{Eu}\left(\mathrm{NH}_{2}\right)_{2}$ & $\mathrm{Eu}$ & 323 & $\geq 0.9$ & 3 & m.c. & [123] \\
\hline $\mathrm{Yb}\left(\mathrm{NH}_{2}\right)_{3}$ & $\mathrm{Yb}$ & 453 & 507 & 32 & m.c. & [123] \\
\hline
\end{tabular}

s.c. means single crystal, m.c. micro crystalline.

Although crystals of the heavier alkali metal amides were obtained from liquid ammonia, the atomic positions of hydrogen could not be determined with X-ray diffraction. This stems back to the low scattering contribution of hydrogen in combination with these metals. Neutron diffraction of the corresponding deuteroamides allows determination of the atomic position for hydrogen. Under ammonothermal conditions, deuteroamides can be grown with small amounts of expensive $\mathrm{ND}_{3}$, 
while getting fast a comparatively large yield per synthesis. The exact atomic position provided the base for the interpretation of the interesting electrostatic interactions between the protons and the cations, due to an asymmetric distribution of the charge on $\mathrm{NH}_{2}^{-}[110,111,117,124,125]$. An increasing interaction with rising charge density of the cation was observed, i.e., for the amides of the lighter alkali and alkaline-earth metals ( $\mathrm{Li}, \mathrm{Na}, \mathrm{Be}, \mathrm{Mg}$ ) those interactions are stronger than for the heavier ones. In the amides of $\mathrm{Li}, \mathrm{Na}, \mathrm{Be}$ and $\mathrm{Mg}$, the anions form the motif of a cubic closed packing with the cations occupying tetrahedral holes. The resulting structures show an occupation of specific tetrahedral holes within the anion substructure by the cations and can even lead to layered structures similar to $\mathrm{LiOH}$ [126]. In lithium amide, Li occupies alternatingly $3 / 4$ of the tetrahedral holes within one layer and 1/4 within the next. Due to strong proton-cation interactions, the anion is hindered in vibration. For the heavier metals the coordination number increases to six for $\mathrm{K}, \mathrm{Rb}, \mathrm{Ca}$ and $\mathrm{Sr}$ and eight for $\mathrm{Cs}$. The interatomic interactions decrease resulting in the realization of several modifications, depending on the vibrational and rotational freedom of the amide ions influenced by temperature, as can be seen in the case of $\mathrm{KNH}_{2}[3,124,125,127,128]$.

Alkali metal amides are important starting materials in ammonothermal synthesis, due to their application as ammonobasic mineralizers. $\mathrm{NaNH}_{2}$ and $\mathrm{KNH}_{2}$ are the most used ones, since they are less reactive than $\mathrm{RbNH}_{2}$ and $\mathrm{CsNH}_{2}$, but show a higher solubility as $\mathrm{LiNH}_{2}$. The solubility of alkali metal amides in liquid ammonia increases with increasing atomic weight. $\mathrm{LiNH}_{2}$ is only very poorly soluble in liquid ammonia, $\mathrm{NaNH}_{2}$ is poorly soluble $\left(0.144 \mathrm{~g} / 100 \mathrm{~g} \mathrm{NH}_{3}\right.$ at $\left.253 \mathrm{~K}\right), \mathrm{KNH}_{2}$ is well soluble $\left(65.8 \mathrm{~g} / 100 \mathrm{~g} \mathrm{NH}_{3}\right.$ at $\left.241 \mathrm{~K}\right), \mathrm{RbNH}_{2}$ is very soluble (several hundred grams/100 $\mathrm{g} \mathrm{NH}_{3}$ at $241 \mathrm{~K})$ and $\mathrm{CsNH}_{2}$ is little less soluble as $\mathrm{RbNH}_{2}$ [73,129].

\subsubsection{Alkaline-Earth Metal Amides}

The alkaline-earth metal amides $\mathrm{Mg}\left(\mathrm{NH}_{2}\right)_{2}, \mathrm{Ca}\left(\mathrm{NH}_{2}\right)_{2}, \mathrm{Sr}\left(\mathrm{NH}_{2}\right)_{2}$ and $\mathrm{Ba}\left(\mathrm{NH}_{2}\right)_{2}$ are obtained from the metals in liquid ammonia at ambient temperature with reaction times of two days $\left(\mathrm{Ba}\left(\mathrm{NH}_{2}\right)_{2}\right)$, eight days $\left(\mathrm{Sr}\left(\mathrm{NH}_{2}\right)_{2}\right)$, four months $\left(\mathrm{Ca}\left(\mathrm{NH}_{2}\right)_{2}\right)$ [130] and up to 1.5-2 years $\left(\mathrm{Mg}\left(\mathrm{NH}_{2}\right)_{2}\right)$ [115]. $\mathrm{Mg}\left(\mathrm{NH}_{2}\right)_{2}$ and $\mathrm{Ba}\left(\mathrm{NH}_{2}\right)_{2}$ crystals, produced in this way, were not suitable for $\mathrm{X}$-ray diffraction and no $\mathrm{Be}\left(\mathrm{NH}_{2}\right)_{2}$ could be obtained. For the heavier alkaline-earth metals $(\mathrm{Ca}$, $\mathrm{Sr}, \mathrm{Ba})$ temperatures and pressures somewhat below the critical point of ammonia are sufficient to obtain well crystallized amides and deuteroamides. For the synthesis of $\mathrm{Ca}\left(\mathrm{NH}_{2}\right)_{2}, \mathrm{Ca}\left(\mathrm{ND}_{2}\right)_{2}$, $\mathrm{Sr}\left(\mathrm{NH}_{2}\right)_{2}$ and $\mathrm{Sr}\left(\mathrm{ND}_{2}\right)_{2} 370 \mathrm{~K}$ and $6 \mathrm{MPa}$ were applied for two weeks starting from the metal and ammonia [116], $\mathrm{Ba}\left(\mathrm{NH}_{2}\right)_{2}$ crystals were obtained at $398 \mathrm{~K}$ and $\leq 20 \mathrm{MPa}$ after four months [118]. Nevertheless, working under ammonothermal conditions reduces the reaction time considerably and micro crystalline $\mathrm{Ba}\left(\mathrm{NH}_{2}\right)_{2}$ and $\mathrm{Sr}\left(\mathrm{NH}_{2}\right)_{2}$ can be obtained from the respective metals in supercritical ammonia after 2 days at $573 \mathrm{~K}$ and $60 \mathrm{MPa}$. Increasing the reaction conditions for $\mathrm{Mg}\left(\mathrm{NH}_{2}\right)_{2}$ from $\sim 0.09 \mathrm{MPa}$ and ambient temperature to $\sim 10 \mathrm{MPa}$ and $613-653 \mathrm{~K}$ reduces the reaction time from 1.5-2 years to two days and forms a micro crystalline product suitable for powder X-ray diffraction [115]. $\quad \mathrm{Mg}\left(\mathrm{NH}_{2}\right)_{2}$ crystals were obtained from $\mathrm{Mg}$ metal under ammonobasic conditions (using $\mathrm{NaNH}_{2}$ or $\mathrm{NaN}_{3}$ as mineralizers) at 523-653 $\mathrm{K}$ and 10-345 MPa [1,2,115]. The reaction of $\mathrm{Mg}_{3} \mathrm{~N}_{2}$ at elevated temperatures of 633-648 $\mathrm{K}$ and $\mathrm{NH}_{3}$ pressure of $1 \mathrm{MPa}$ also yields 
micro crystalline $\mathrm{Mg}\left(\mathrm{NH}_{2}\right)_{2}$ [115]. First synthesis of $\mathrm{Be}\left(\mathrm{NH}_{2}\right)_{2}$ proceeded under ammonothermal conditions: Single crystals were obtained from the reaction of beryllium metal and ammonia with $\mathrm{NaN}_{3}$ as mineralizer at $643 \mathrm{~K}$ and $355 \mathrm{MPa}$ after 20 days [114].

\subsubsection{Lanthanum Amide, Samarium Amide, Europium Amide and Ytterbium Amide}

Apart from $\mathrm{Yb}\left(\mathrm{NH}_{2}\right)_{3}$ [123] and $\mathrm{Sm}\left(\mathrm{NH}_{2}\right)_{3}$ [121], $\mathrm{La}\left(\mathrm{NH}_{2}\right)_{3}$ [120] is the only binary trivalent rare-earth metal amide so far. Colorless single crystals are obtained from the reaction of lanthanum metal and potassium (molar ratio 80:1) in supercritical ammonia at $623 \mathrm{~K}$ and $405 \mathrm{MPa}$ after six days. The use of a mineralizer is crucial for the crystal growth, without only micro crystalline powder is produced. Using $\mathrm{NH}_{4} \mathrm{I}$ as mineralizers leads to smaller crystals than presented for the reaction in presence of the potassium mineralizer [120,131]. $\mathrm{Sm}\left(\mathrm{NH}_{2}\right)_{3}$ was obtained from samarium metal and potassium (molar ratio 23:1) in supercritical ammonia at 403-493 K and 200-500 MPa as micro crystalline powder [121]. A solution of europium in liquid ammonia already forms micro crystalline $\mathrm{Eu}^{\mathrm{II}}\left(\mathrm{NH}_{2}\right)_{2}$ at $323 \mathrm{~K}$ and $\geq 0.9 \mathrm{MPa}$. Increasing the temperature and pressure to $523-673 \mathrm{~K}$ and 500-557 $\mathrm{MPa}$ and using optionally potassium as mineralizer leads to dark red crystals. The amount of mineralizer is crucial for the formation of the binary amide, since two ternary amides, namely $\mathrm{K}\left[\mathrm{Eu}^{\mathrm{II}}\left(\mathrm{NH}_{2}\right)_{3}\right]$ and $\mathrm{K}_{3}\left[\mathrm{Eu}^{\mathrm{III}}\left(\mathrm{NH}_{2}\right)_{6}\right]$, can be obtained in the same temperature and pressure range $[122,123]$. There are two binary ytterbium amides known, $\mathrm{Yb}\left(\mathrm{NH}_{2}\right)_{2}$ and $\mathrm{Yb}\left(\mathrm{NH}_{2}\right)_{3}$, which were so far only obtained as micro crystalline powders. $\mathrm{Yb}\left(\mathrm{NH}_{2}\right)_{2}$ was prepared from ytterbium metal in liquid ammonia at ambient temperature within some hours and forms with ammonia $\mathrm{Yb}\left(\mathrm{NH}_{2}\right)_{3}$, already before all metal has reacted to $\mathrm{Yb}\left(\mathrm{NH}_{2}\right)_{2}$ [123]. Nearly pure $\mathrm{Yb}\left(\mathrm{NH}_{2}\right)_{3}$ was obtained from ammonothermal conditions (453 K, $507 \mathrm{MPa}, 32$ days), however, no successful crystal structure determination for $\mathrm{Yb}\left(\mathrm{NH}_{2}\right)_{3}$ was presented so far [123].

\subsubsection{Transition Metal, Group III and Group IV Metal Amides}

There are various synthetic methods leading to binary transition metal amides. Some transition metal amides precipitate from metal salt solutions in liquid ammonia in presence of $\mathrm{KNH}_{2}$, e.g., $\mathrm{Cd}\left(\mathrm{NH}_{2}\right)_{2}$ can be obtained from $\mathrm{Cd}(\mathrm{SCN})_{2}$ [74,132]. Earlier, binary metal amides were obtained from the reaction from the metal with gaseous or liquid ammonia or of a metal ethyl compound with ammonia, e.g., $\mathrm{Zn}\left(\mathrm{NH}_{2}\right)_{2}$ [133]. As a result of these synthesis techniques conducted at comparably low temperatures, the products are often amorphous or poorly crystallized. Under ammonothermal conditions, such poorly crystallized or amorphous binary amides can be recrystallized in form of single crystals or well crystallized powders. Alternatively, they yield from the metal in presence of a mineralizer under ammonothermal conditions: Amorphous zinc amide can be recrystallized at $723 \mathrm{~K}$ and 30.4 MPa [1]. Zinc amide was first crystallized under ammonothermal conditions, subsequently the crystal structure was determined. Crystals were obtained from zinc powder and ammonia with $\mathrm{Na}_{2}\left[\mathrm{Zn}\left(\mathrm{NH}_{2}\right)_{4}\right] \cdot 0.5 \mathrm{NH}_{3}$ as mineralizer at $523 \mathrm{~K}$ and $380 \mathrm{MPa}$ [119]. The analogous reaction of Mn and ammonia at $393 \mathrm{~K}$ and $10 \mathrm{MPa}$ (slightly lower than the critical pressure) using $\mathrm{Na}_{2}\left[\mathrm{Mn}\left(\mathrm{NH}_{2}\right)_{4}\right]$ as mineralizer yielded $\mathrm{Mn}\left(\mathrm{NH}_{2}\right)_{2}$ [119]. 
Binary group III amides are potential precursors during ammonothermal synthesis of group III nitrides. However, the correctness of the reported formula $B\left(\mathrm{NH}_{2}\right)_{3}(B=\mathrm{B}, \mathrm{Al}, \mathrm{Ga}$, In) was questioned or could not be reproduced. The lack of crystal structure data for these compounds hinders an unequivocal chemical assignment. $\mathrm{B}\left(\mathrm{NH}_{2}\right)_{3}$ obtained from $\mathrm{BCl}_{3}$ or $\mathrm{BBr}_{3}$ with $\mathrm{NH}_{4} \mathrm{Cl}$ in liquid ammonia [134] is suspected to represent polymeric $\mathrm{B}(\mathrm{NH})_{3 / 2}$ (see paragraph Imides, Nitride Imides, Nitride Amides and Amide Azides) [135]. The reaction of $\mathrm{AlBr}_{3}$ and $\mathrm{KNH}_{2}$ in liquid ammonia did not yield $\mathrm{Al}\left(\mathrm{NH}_{2}\right)_{3}$, but a mixed polymeric aluminum amide imide $\left[\mathrm{Al}\left(\mathrm{NH}_{2}\right)(\mathrm{NH})\right]_{n}$ (see paragraph Imides, Nitride Imides, Nitride Amides and Amide Azides) [135-137]. The reaction of $A(1)\left[\mathrm{Ga}\left(\mathrm{NH}_{2}\right)_{4}\right]$ with $\mathrm{NH}_{4} \mathrm{Cl}$ in liquid ammonia at $237 \mathrm{~K}$ yields an amorphous product, with the proposed formula $\mathrm{Ga}\left(\mathrm{NH}_{2}\right)_{3}$. Due to the lack of diffraction data no crystal structures are proposed, although the composition was determined by chemical analysis [80]. Polymeric gallium imide $\left[\mathrm{Ga}\left(\mathrm{NH}_{3 / 2}\right]_{n}\right.$ was reported from the reaction of $\left[\mathrm{Ga}\left(\mathrm{NMe}_{2}\right)_{3}\right]_{2}$ with liquid ammonia in reflux for 8 h (see paragraph Imides, Nitride Imides, Nitride Amides and Amide Azides) [135].

In $\left(\mathrm{NH}_{2}\right)_{3}$ crystals were obtained from $\mathrm{KNH}_{2}$ and $\mathrm{InI}_{3}$ or $\mathrm{K}_{3} \mathrm{In}\left(\mathrm{NH}_{2}\right)_{6}$ in liquid ammonia after one day. Several ternary alkali metal indium amides are known from snythesis in liquid ammonia, e.g., $\mathrm{Li}_{3} \mathrm{In}\left(\mathrm{NH}_{2}\right)_{6}, \mathrm{~K}_{2} \mathrm{In}\left(\mathrm{NH}_{2}\right)_{5}, \mathrm{~K}_{3} \mathrm{In}\left(\mathrm{NH}_{2}\right)_{6}$ [138]. However, since no structural information on these compounds is available, the compositions might be questioned.

$\mathrm{Si}\left(\mathrm{NH}_{2}\right)_{4}$ is obtained from $\mathrm{SiCl}_{4}$ in liquid ammonia at $T \leq 273 \mathrm{~K}$ and decomposes at $T \geq 373 \mathrm{~K}$ to $\mathrm{Si}(\mathrm{NH})_{2}[139,140]$. Again, no crystal structure data for $\mathrm{Si}\left(\mathrm{NH}_{2}\right)_{4}$ and $\mathrm{Si}(\mathrm{NH})_{2}$ are reported due to the lack of crystalline products. The chemical nature of the compounds for now remains to be proven.

\subsection{Ternary Amides}

There were various ternary amides of the formulas $A(1)_{n}^{I} A(1)_{m}^{I}\left(\mathrm{NH}_{2}\right)_{n+m}$, $A(1)_{n}^{I} A(2)_{m}^{I I} / M_{m}^{I I} / R_{m}^{I I}\left(\mathrm{NH}_{2}\right)_{n+2 \cdot m}, \quad A(1)_{n}^{I} B^{I I I} / R^{I I I}\left(\mathrm{NH}_{2}\right)_{n+3} \quad(A(1) \quad=\quad$ alkali metal, $A(2)=$ alkaline-earth metal, $M=$ transition metal, $R=$ rare-eart metal, $B=$ main group metal; $n=1,2,3 ; m=1,3,7)$ obtained from liquid or supercritical ammonia. Usually, they contain two different metals, from which at least one is an alkali or alkaline-earth metal. Examples for ternary amides were reported from syntheses in liquid ammonia, e.g., $A(1)\left[\mathrm{Al}\left(\mathrm{NH}_{2}\right)_{4}\right]$ (with $A(1)=\mathrm{Na}$, $\mathrm{K}$, Cs) [81,141], $\mathrm{Na}_{2} \mathrm{Al}\left(\mathrm{NH}_{2}\right)_{5}$ [82], $\mathrm{Na}\left[\mathrm{Ga}\left(\mathrm{NH}_{2}\right)_{4}\right]$ [81], $\mathrm{KBe}\left(\mathrm{NH}_{2}\right)_{3}$ [142], $\mathrm{RbBe}\left(\mathrm{NH}_{2}\right)_{3}$ [142], $\mathrm{Li}\left[\mathrm{Al}\left(\mathrm{NH}_{2}\right)_{4}\right]$ [143], $\alpha-\mathrm{K}\left[\mathrm{Al}\left(\mathrm{NH}_{2}\right)_{4}\right]$ and $\beta-\mathrm{K}\left[\mathrm{Al}\left(\mathrm{NH}_{2}\right)_{4}\right]$ [144]. By increasing temperature and pressure the list of ternary amides was extended and the structure determination often was possible (see Tables 5-7), since crystal growth was realized only under ammonothermal conditions, e.g., for $\mathrm{Na}_{2}\left[\mathrm{Ga}\left(\mathrm{NH}_{2}\right)_{4}\right] \mathrm{NH}_{2}$ [67,82]. Such compounds are expected to exhibit significantly higher solubilities in supercritical $\mathrm{NH}_{3}$. Therefore, they are suggested as intermediates formed from the reactant and the mineralizer during nitride crystal growth of, for example, GaN. The isolation and crystallization of such compounds sheds light on the formation mechanism of the nitride crystal growth.

For the preparation of ternary alkali and alkaline-earth metal amides some tendencies has been established, which can often also be applied to other ternary amides. Thus, it is recommendable to use a surplus of the less soluble metal. In general, alkali metals possess a higher solubility in 
ammonia than alkaline-earth metals. The same applies for amides of the heavier metals compared to their lighter homologues. The thermal stability of ternary amides decreases with increasing charge density of the cations. At higher temperatures nitrides of the $A(2), M, R$ or $B$ metal and binary amides of the alkali metals are formed. The water and oxygen sensitivity of the ternary amides increases with increasing atomic weight of the metal. In the case of ternary alkali metal alkaline-earth metal amides they depend more of the alkali metal than of the alkaline-earth metal [3].

Table 5. Conditions for the ammonothermal synthesis of alkali metal alkaline-earth metal ternary amides and coordination numbers of the metal atoms by amide ions.

\begin{tabular}{|c|c|c|c|c|c|c|}
\hline Compound & $C N A(1), A(1) / A(2)$ by $\mathrm{NH}_{2}^{-}$ & Reactants & $T / \mathbf{K}$ & $p / \mathbf{M P a}$ & $t / \mathrm{d}$ & References \\
\hline $\mathrm{K}_{2} \mathrm{Li}\left(\mathrm{NH}_{2}\right)_{3}$ & 6,4 & $\mathrm{~K}+\mathrm{Li} 2: 1$ & 333 & 70 & 60 & {$[145,146]$} \\
\hline $\mathrm{KLi}\left(\mathrm{NH}_{2}\right)_{2}$ & a, 4 & $\mathrm{~K}+\mathrm{Li} 1: 1$ & $333-473$ & $70-210$ & 4 & [145] \\
\hline $\mathrm{KLi}_{3}\left(\mathrm{NH}_{2}\right)_{4}$ & 8,4 & $\mathrm{~K} \leq \mathrm{Li}$ & $333-473$ & $70-210$ & 4 & [145] \\
\hline $\mathrm{KLi}_{7}\left(\mathrm{NH}_{2}\right)_{8}$ & 8,4 & $\mathrm{~K} \leq \mathrm{Li}$ & $333-473$ & $70-210$ & 4 & {$[145]$} \\
\hline $\mathrm{K}_{2}\left[\mathrm{Mg}\left(\mathrm{NH}_{2}\right)_{4}\right]$ & 7,4 & $\mathrm{~K}+\mathrm{Mg}$ & 423 & 200 & 3 & [147] \\
\hline $\mathrm{Rb}_{2}\left[\mathrm{Mg}\left(\mathrm{NH}_{2}\right)_{4}\right]$ & 7,4 & $\mathrm{Rb}+\mathrm{Mg}$ & 423 & 200 & 3 & [147] \\
\hline $\mathrm{Cs}\left[\mathrm{Mg}\left(\mathrm{NH}_{2}\right)_{4}\right]$ & $9 / 11,4$ & $\mathrm{Cs}+\mathrm{Mg}$ & 415 & 200 & 2 & {$[148]$} \\
\hline $\mathrm{NaCa}\left(\mathrm{NH}_{2}\right)_{3}$ & 6,6 & $\mathrm{Na}+\mathrm{Ca} 5: 1-1: 2$ & $740-773$ & 500 & 60 & {$[149,150]$} \\
\hline $\mathrm{KCa}\left(\mathrm{NH}_{2}\right)_{3}$ & 6,6 & $\mathrm{~K}+\mathrm{Ca} 1: 1$ & 573 & 500 & 20 & [151] \\
\hline $\mathrm{RbCa}\left(\mathrm{NH}_{2}\right)_{3}$ & 8,6 & $\mathrm{Rb}+\mathrm{Ca} 1: 2-3: 1$ & 573 & 500 & 17 & {$[152]$} \\
\hline $\mathrm{CsCa}\left(\mathrm{NH}_{2}\right)_{3}$ & 8,6 & $\mathrm{Cs}+\mathrm{Ca}$ & $573-773$ & $500-600$ & $10-35$ & [153] \\
\hline $\mathrm{KSr}\left(\mathrm{NH}_{2}\right)_{3}$ & 6,6 & $\mathrm{~K}+\mathrm{Sr} 1: 1$ & 570 & 500 & 7 & [149] \\
\hline $\mathrm{RbSr}\left(\mathrm{NH}_{2}\right)_{3}$ & 6,6 & $\mathrm{Rb}+\mathrm{Sr} 3: 1-1: 1$ & $540-573$ & 800 & 8 & {$[150]$} \\
\hline $\mathrm{CsSr}\left(\mathrm{NH}_{2}\right)_{3}$ & 8,6 & $\mathrm{Cs}+\mathrm{Sr}$ & $573-673$ & $500-600$ & $14-55$ & [153] \\
\hline $\mathrm{KBa}\left(\mathrm{NH}_{2}\right)_{3}$ & 6,6 & $\mathrm{~K}+$ Ba 3:1-1:1 & $540-573$ & 500 & 7 & {$[150]$} \\
\hline $\mathrm{RbBa}\left(\mathrm{NH}_{2}\right)_{3}$ & 6,6 & $\mathrm{Rb}+\mathrm{Ba} 3: 1-1: 1$ & $540-573$ & 500 & 7 & {$[150]$} \\
\hline $\mathrm{CsBa}\left(\mathrm{NH}_{2}\right)_{3}$ & 8,6 & $\mathrm{Cs}+\mathrm{Ba}$ & 473 & 500 & 11 & [154] \\
\hline $\mathrm{Na}_{2} \mathrm{Sr}_{3}\left(\mathrm{NH}_{2}\right)_{8}$ & 6,6 & $\mathrm{Na}+\mathrm{Sr} 1: 2$ & 570 & 500 & 4 & [149] \\
\hline
\end{tabular}

${ }^{\text {a }}$ Coordination number uncertain cf. [3].

Both the nature of the $A(1)$ and the $A(2), M, R$ or $B$ metal have an impact on the crystal structure, the number of compounds formed and the composition of the ternary amide. The charge density of both cations is crucial for the realized structure. Increasing the size of the alkali metal leads in the case of ternary lanthanum amides to different structures for $\mathrm{Na}_{3}\left[\mathrm{La}\left(\mathrm{NH}_{2}\right)_{6}\right]$ [131], $\mathrm{K}_{3}\left[\mathrm{La}\left(\mathrm{NH}_{2}\right)_{6}\right]$ [156] and $\mathrm{Rb}_{3}\left[\mathrm{La}\left(\mathrm{NH}_{2}\right)_{6}\right]$ [157]: In $\mathrm{Na}_{3}\left[\mathrm{La}\left(\mathrm{NH}_{2}\right)_{6}\right]$ all cations occupy octahedral sites in a close packing of amide ions with $\mathrm{ABC}$ stacking. In $\mathrm{K}_{3}\left[\mathrm{La}\left(\mathrm{NH}_{2}\right)_{6}\right]$ both types of cations occupy octahedral sites in a close packing of amide ions with $\mathrm{ABC}$ stacking, one layer of octahedral voids is fully occupied by $\mathrm{K}$ cations, in the next layer one third of the octahedral voids is filled with La atoms. For $\mathrm{K}_{3}\left[R\left(\mathrm{NH}_{2}\right)_{6}\right](R=\mathrm{Y}, \mathrm{La}, \mathrm{Ce}, \mathrm{Nd}, \mathrm{Sm}, \mathrm{Eu}, \mathrm{Gd}, \mathrm{Yb})$ two structure types were observed, one for rare-earth metals from $\mathrm{La}$ to $\mathrm{Gd}$ and one for $\mathrm{Y}$ and $\mathrm{Yb}$. The first group crystallizes in $C 2 / \mathrm{m}$ with all cations in octahedral holes of a close packing of amide groups, occupying layers of octahedral holes 
alternately. The second group consists of $\mathrm{K}_{3}\left[\mathrm{Y}\left(\mathrm{NH}_{2}\right)_{6}\right]$ and $\mathrm{K}_{3}\left[\mathrm{Yb}\left(\mathrm{NH}_{2}\right)_{6}\right]$, which are isotypes of $\mathrm{Rb}_{3}\left[\mathrm{Eu}\left(\mathrm{NH}_{2}\right)_{6}\right]$ and $\mathrm{Rb}_{3}\left[\mathrm{Y}\left(\mathrm{NH}_{2}\right)_{6}\right]$ [160]. Those compounds crystallize in $R 32$. $R^{3+}$ cations occupy octahedral holes in a close packing of amide groups, while $A^{+}$cations are surrounded by a larger number of amide groups. In $\mathrm{Rb}_{3}\left[\mathrm{La}\left(\mathrm{NH}_{2}\right)_{6}\right]$ [157] again the cations are surrounded octahedrally, realizing layers. Perhaps surprisingly, there is no such compound as $\mathrm{Cs}_{3}\left[\mathrm{La}\left(\mathrm{NH}_{2}\right)_{6}\right]$ known, but two amide ammoniates $\mathrm{Cs}_{3} \mathrm{La}\left(\mathrm{NH}_{2}\right)_{6} \cdot \mathrm{NH}_{3}$ and $\mathrm{Cs}_{4} \mathrm{La}\left(\mathrm{NH}_{2}\right)_{7} \cdot \mathrm{NH}_{3}[100]$, where cesium and amide ions together with ammonia molecules form the motif of a cubic close packing with lanthanum cations in octahedral voids, exclusively formed by amide groups. A change of the structure for compounds of the same composition can be observed with changing charge density of both cation types, as can be seen from alkali metal rare-earth metal amides. Thus, compounds with small charge density realize close packings of amide ions with all cations situated in octahedral holes. With increasing size of the alkali metal, layered structures of the cations are preferred and the rare-earth cations form structural units with the amide groups similar to the binary amides. In the cesium amides cesium is surrounded by twelve amide ions, the $R^{3+}$ ions occupy also octahedral sites in a close packing. $A(1)$-rich phases manifest lower coordination numbers at $A(2), M, R$ or $B$ metal, as can be seen in $\mathrm{K}_{3}\left[\mathrm{La}\left(\mathrm{NH}_{2}\right)_{6}\right]$ [156] and $\mathrm{KLa}_{2}\left(\mathrm{NH}_{2}\right)_{7}$ with $C N(\mathrm{La})$ of 8 and 6 respectively [155]. In Table 5 the coordination numbers of the cations by amide ions in ternary alkali metal alkaline-earth metal amides are listed and the change of the surrounding depending on the size of the metals can be compared.

Table 6. Conditions for the ammonothermal synthesis of ternary amides containing rare-earth metals and coordination numbers of the metal atoms by amide ions.

\begin{tabular}{lclcccc}
\hline Compound & $\boldsymbol{C N} \boldsymbol{A}(\mathbf{1}), \boldsymbol{R}$ by $\mathbf{N H}_{\mathbf{2}}^{-}$ & Reactants & $\boldsymbol{T / K}$ & $\boldsymbol{p} / \mathbf{M P a}$ & $\boldsymbol{t} / \mathbf{d}$ & References \\
\hline $\mathrm{Na}_{3}\left[\mathrm{La}\left(\mathrm{NH}_{2}\right)_{6}\right]$ & 6,6 & $\mathrm{Na}+\mathrm{La} 1: 1$ & 523 & 507 & 30 & {$[131]$} \\
$\mathrm{KLa}_{2}\left(\mathrm{NH}_{2}\right)_{7}$ & 6,8 & $\mathrm{~K}+\mathrm{La} 1: 2$ & 623 & 507 & 6 & {$[155]$} \\
$\mathrm{K}_{3}\left[\mathrm{La}\left(\mathrm{NH}_{2}\right)_{6}\right]$ & 6,6 & $\mathrm{~K}+\mathrm{La}$ & 473 & 405 & - & {$[156]$} \\
$\mathrm{RbLa}_{2}\left(\mathrm{NH}_{2}\right)_{7}$ & $\mathrm{a}$ & & & & & {$[3]$} \\
$\mathrm{Rb}_{3}\left[\mathrm{La}_{2}\left(\mathrm{NH}_{2}\right)_{6}\right]$ & 6,6 & $\mathrm{Rb}+\mathrm{La} 3: 1$ & 573 & $400-450$ & $6-12$ & {$[157]$} \\
$\mathrm{CsLa}_{2}\left(\mathrm{NH}_{2}\right)_{7}$ & 9,8 & $\mathrm{Cs}+\mathrm{La}$ & $470-570$ & $400-600$ & $3-100$ & {$[3,158]$} \\
$\mathrm{Na}_{3}\left[\mathrm{Ce}\left(\mathrm{NH}_{2}\right)_{6}\right]$ & $\mathrm{a}$ & & & & & {$[3]$} \\
$\mathrm{KCe}_{2}\left(\mathrm{NH}_{2}\right)_{7}$ & 6,8 & $\mathrm{~K}+\mathrm{Ce} 1: 1$ & 455 & $400-500$ & $5-10$ & {$[76]$} \\
$\mathrm{K}_{3}\left[\mathrm{Ce}\left(\mathrm{NH}_{2}\right)_{6}\right]$ & 6,6 & $\mathrm{~K}+\mathrm{Ce} 3: 1$ & 455 & $400-500$ & $5-10$ & {$[76]$} \\
$\mathrm{Cs}_{3} \mathrm{Ce}{ }_{2}\left(\mathrm{NH}_{2}\right)_{9}$ & 12,6 & $\mathrm{Cs}+\mathrm{Ce}$ & 490 & 600 & 21 & {$[159]$} \\
$\mathrm{Cs}_{3} \mathrm{Ce}{ }_{2}\left(\mathrm{NH}_{2}\right)_{9}$ & 12,6 & $\mathrm{Cs}+\mathrm{Ce}$ & 490 & 200 & 21 & {$[159]$} \\
$\mathrm{Na}_{3}\left[\mathrm{Nd}_{(}\left(\mathrm{NH}_{2}\right)_{6}\right]$ & 6,6 & $\mathrm{a}$ & & & & {$[3]$} \\
$\mathrm{KNd}_{2}\left(\mathrm{NH}_{2}\right)_{7}$ & 6,8 & $\mathrm{a}$ & & & & {$[3]$} \\
\hline
\end{tabular}


Table 6. Cont

\begin{tabular}{|c|c|c|c|c|c|c|}
\hline Compound & $C N A(1), R$ by $\mathrm{NH}_{2}^{-}$ & Reactants & $T / \mathrm{K}$ & $p / \mathrm{MPa}$ & $t / d$ & References \\
\hline $\mathrm{K}_{3}\left[\mathrm{Nd}\left(\mathrm{NH}_{2}\right)_{6}\right]$ & 6,6 & a & & & & [3] \\
\hline $\mathrm{Rb}_{3}\left[\mathrm{Nd}\left(\mathrm{NH}_{2}\right)_{6}\right]$ & 6,6 & $\mathrm{Rb}+\mathrm{Nd} 3: 1$ & 573 & 400 & 7 & [157] \\
\hline $\left.\mathrm{Cs}_{3} \mathrm{Nd}_{2}\left(\mathrm{NH}_{2}\right)_{9}\right]$ & 12,6 & $\mathrm{Cs}+\mathrm{Nd}$ & $430-530$ & 300 & $7-100$ & [159] \\
\hline $\mathrm{Na}_{3}\left[\mathrm{Sm}\left(\mathrm{NH}_{2}\right)_{6}\right]$ & 6,6 & a & & & & {$[3]$} \\
\hline $\mathrm{KSm}_{2}\left(\mathrm{NH}_{2}\right)_{7}$ & 6,8 & $\mathrm{~K}+\mathrm{Sm} 1: 2$ & $403-493$ & $200-500$ & - & {$[121]$} \\
\hline $\mathrm{K}_{3}\left[\mathrm{Sm}\left(\mathrm{NH}_{2}\right)\right]_{6}$ & 6,6 & $\mathrm{~K}+\operatorname{Sm} 3: 1$ & $403-493$ & $200-500$ & - & [121] \\
\hline $\mathrm{Cs}_{3} \mathrm{Sm}_{2}\left(\mathrm{NH}_{2}\right)_{9}$ & 12,6 & $\mathrm{Cs}+\mathrm{Sm}$ & 470 & 600 & 60 & [159] \\
\hline $\mathrm{KEu}\left(\mathrm{NH}_{2}\right)_{3}$ & 6,6 & $\mathrm{~K}+\mathrm{Eu} 1: 1$ & 573 & 500 & 3 & {$[122]$} \\
\hline $\mathrm{RbEu}\left(\mathrm{NH}_{2}\right)_{3}$ & 6,6 & $\mathrm{Rb}+\mathrm{Eu} 1: 1-2: 1$ & $540-73$ & 500 & 28 & {$[150]$} \\
\hline $\mathrm{Rb}_{3}\left[\mathrm{Eu}\left(\mathrm{NH}_{2}\right)_{6}\right]$ & 10,6 & $\mathrm{Rb}+\mathrm{Eu} 10: 1$ & 423 & 500 & 40 & {$[160]$} \\
\hline $\mathrm{CsEu}\left(\mathrm{NH}_{2}\right)_{3}$ & 6,6 & $\mathrm{Cs}+\mathrm{Eu}$ & 573 & $500-600$ & $9-14$ & [153] \\
\hline $\mathrm{K}_{3}\left[\mathrm{Eu}\left(\mathrm{NH}_{2}\right)_{6}\right]$ & 6,6 & $\mathrm{~K}+\mathrm{Eu} 12: 1$ & 573 & 500 & 3 & {$[122,149]$} \\
\hline $\mathrm{Na}_{2} \mathrm{Eu}_{3}\left(\mathrm{NH}_{2}\right)_{8}$ & 6,6 & $\mathrm{Na}+\mathrm{Eu} 1: 1$ & 570 & 500 & 8 & [149] \\
\hline $\mathrm{NaGd}\left(\mathrm{NH}_{2}\right)_{4}$ & 4,6 & $\mathrm{NaNH}_{2}+\mathrm{Gd} 1: 1$ & 493 & 507 & 20 & {$[161]$} \\
\hline $\mathrm{Na}_{3}\left[\mathrm{Gd}\left(\mathrm{NH}_{2}\right)_{6}\right]$ & 6,6 & $\mathrm{NaNH}_{2}+\mathrm{Gd} 3: 1$ & 573 & 304 & 51 & {$[3,161]$} \\
\hline $\mathrm{K}_{3}\left[\mathrm{Gd}\left(\mathrm{NH}_{2}\right)_{6}\right]$ & 6,6 & a & & & & [3] \\
\hline $\mathrm{Cs}_{3} \mathrm{Gd}_{2}\left(\mathrm{NH}_{2}\right)_{9}$ & 12,6 & $\mathrm{Cs}+\mathrm{Gd}$ & 440 & 600 & 160 & [162] \\
\hline $\mathrm{NaY}\left(\mathrm{NH}_{2}\right)_{4}$ & 6,6 & $\mathrm{Na}+\mathrm{Y} 1: 1$ & 523 & 507 & 7 & [163] \\
\hline $\mathrm{KY}\left(\mathrm{NH}_{2}\right)_{4}$ & 6,6 & K + Y 1:4-6 & $485-505$ & 600 & 22 & [164] \\
\hline $\mathrm{RbY}\left(\mathrm{NH}_{2}\right)_{4}$ & 11,6 & $\mathrm{Rb}+\mathrm{Y} 1: 4-6$ & $485-505$ & 600 & 22 & [164] \\
\hline $\mathrm{Na}_{3}\left[\mathrm{Y}\left(\mathrm{NH}_{2}\right)_{6}\right]$ & 6,6 & $\mathrm{Na}+\mathrm{Y} 3: 1$ & 523 & 507 & 7 & [163] \\
\hline $\mathrm{Cs}_{3} \mathrm{Y}_{2}\left(\mathrm{NH}_{2}\right)_{9}$ & 12,6 & $\mathrm{Cs}+\mathrm{Y}$ & 490 & 600 & 70 & [162] \\
\hline $\mathrm{Rb}_{3}\left[\mathrm{Y}\left(\mathrm{NH}_{2}\right)_{6}\right]$ & 10,6 & $\mathrm{Rb}+\mathrm{Y} 3: 1$ & 473 & 500 & 14 & {$[157,160]$} \\
\hline $\mathrm{K}_{3}\left[\mathrm{Y}\left(\mathrm{NH}_{2}\right)_{6}\right]$ & 10,6 & $\mathrm{~K}+\mathrm{Y} 3: 1$ & 473 & 500 & 14 & {$[157,160]$} \\
\hline $\mathrm{NaYb}\left(\mathrm{NH}_{2}\right)_{4}$ & 4,6 & $\mathrm{Na}+\mathrm{Yb}$ 1:1 & $413-463$ & 507 & 14 & [163] \\
\hline $\mathrm{Na}_{3}\left[\mathrm{Yb}\left(\mathrm{NH}_{2}\right)_{6}\right]$ & 6,6 & $\mathrm{Na}+\mathrm{Yb}$ 3:1 & 453 & 608 & 8 & {$[165]$} \\
\hline $\mathrm{KYb}\left(\mathrm{NH}_{2}\right)_{7}$ & a & & & & & {$[3,121]$} \\
\hline $\mathrm{K}_{3}\left[\mathrm{Yb}\left(\mathrm{NH}_{2}\right)_{6}\right]$ & 10,6 & $\mathrm{~K}+\mathrm{Yb} 3: 1$ & 473 & 500 & 14 & {$[157,160]$} \\
\hline $\mathrm{Rb}_{3}\left[\mathrm{Yb}\left(\mathrm{NH}_{2}\right)_{6}\right]$ & 8,6 & $\mathrm{Rb}+\mathrm{Yb} 3: 1$ & 473 & 500 & 14 & {$[157,160]$} \\
\hline $\mathrm{Cs}_{3} \mathrm{Yb}_{2}\left(\mathrm{NH}_{2}\right)_{9}$ & 12,6 & $\mathrm{Cs}+\mathrm{Yb}$ & 450 & 600 & 160 & [162] \\
\hline
\end{tabular}

${ }^{\text {a }}$ No further information in literature.

Table 7. Conditions for the ammonothermal synthesis of ternary amides of main group and transition metals and coordination numbers of the metal atoms by amide ions.

\begin{tabular}{lcccccc}
\hline Compound & $\boldsymbol{C N} \boldsymbol{A}(\mathbf{1}), \boldsymbol{B} / \boldsymbol{M}$ by $\mathbf{N H}_{\mathbf{2}}^{-}$ & Reactants & $\boldsymbol{T} / \mathbf{K}$ & $\boldsymbol{p} / \mathbf{M P a}$ & $\boldsymbol{t} / \mathbf{d}$ & References \\
\hline $\mathrm{Li}\left[\mathrm{Ga}\left(\mathrm{NH}_{2}\right)_{4}\right]$ & 4,4 & $\mathrm{Ga}+\mathrm{LiNH}_{2}$ & 673 & 250 & 3 & {$[67]$} \\
$\mathrm{Li}\left[\mathrm{Ga}\left(\mathrm{NH}_{2}\right)_{4}\right]$ & 4,4 & $\mathrm{Ga}+\mathrm{LiNH}_{2}$ & 673 & 250 & 3 & {$[67]$} \\
$\mathrm{Na}_{2}\left[\mathrm{Ga}\left(\mathrm{NH}_{2}\right)_{4}\right] \mathrm{NH}_{2}$ & 4,4 & $\mathrm{Ga}+\mathrm{NaNH}_{2}$ & 853 & 130 & 2 & {$[67,82]$} \\
$\mathrm{Na}\left[\mathrm{Ga}\left(\mathrm{NH}_{2}\right)_{4}\right]$ & 4,4 & $\mathrm{Na}+\mathrm{Ga}$ & 853 & 130 & 2 & {$[67,81]$} \\
$\mathrm{Rb}\left[\mathrm{Al}\left(\mathrm{NH}_{2}\right)_{4}\right]$ & 12,4 & $\mathrm{Rb}+\mathrm{Al}$ & $393-473$ & $80-120$ & 20 & {$[166]$} \\
$\mathrm{Cs}\left[\mathrm{Al}\left(\mathrm{NH}_{2}\right)_{4}\right]$ & 12,4 & $\mathrm{Cs}+\mathrm{Al}$ & $423-473$ & $120-600$ & 15 & {$[166]$} \\
$\mathrm{Na}_{2}\left[\mathrm{Mn}\left(\mathrm{NH}_{2}\right)_{4}\right]$ & $4 / 6,4$ & $\mathrm{Na}+\mathrm{Mn}_{2}$ & 373 & 10 & - & {$[167]$} \\
$\mathrm{K}_{2}\left[\mathrm{Zn}\left(\mathrm{NH}_{2}\right)_{4}\right]$ & 7,4 & $\mathrm{Zn}+\mathrm{KNH}_{2}$ & 720 & 249 & 2 & {$[168]$} \\
\hline
\end{tabular}


Four different types of ternary alkali metal amides can be distinguished according to their crystal structures: The first group consists of the isotypic compounds $\mathrm{NaCa}\left(\mathrm{NH}_{2}\right)_{3}[149,150]$, $\mathrm{KSr}\left(\mathrm{NH}_{2}\right)_{3}$ [149], $\mathrm{KBa}\left(\mathrm{NH}_{2}\right)_{3}$ [150], $\mathrm{RbBa}\left(\mathrm{NH}_{2}\right)_{3}$ [150], $\mathrm{KEu}\left(\mathrm{NH}_{2}\right)_{3}$ [122], $\mathrm{RbEu}\left(\mathrm{NH}_{2}\right)_{3}$ [150] and $\mathrm{NaY}\left(\mathrm{NH}_{2}\right)_{4}$ [163]. The amide groups arrange in the motif of a cubic closed packing, the cations occupy octahedral holes. $\mathrm{Na}_{2} \mathrm{Sr}_{3}\left(\mathrm{NH}_{2}\right)_{8}$ [149], $\mathrm{Na}_{2} \mathrm{Eu}_{3}\left(\mathrm{NH}_{2}\right)_{8}$ [149], $\mathrm{Na}_{3} \mathrm{La}\left(\mathrm{NH}_{2}\right)_{6}$ [131] and $\mathrm{Na}_{3} \mathrm{Y}\left(\mathrm{NH}_{2}\right)_{6}$ [163] crystallize in the same structure, irrespective of the different composition. This is possible, since in $\mathrm{Na}_{3} R\left(\mathrm{NH}_{2}\right)_{6}$ with $R=\mathrm{La}, \mathrm{Ce}, \mathrm{Nd}, \mathrm{Sm}, \mathrm{Gd}, \mathrm{Y}$ the sites are occupied completely and ordered, whereas for all other compounds a statistical occupation of the sites with different cations is observed $[148,150]$. Compared to the ternary amides of the smaller alkaline-earth metals, those compounds are more ionic.

In the second group the difference of the radii of the two types of cations is larger, which results in different coordination numbers. Those ternary amides crystallize in the space groups $C 2 / c$

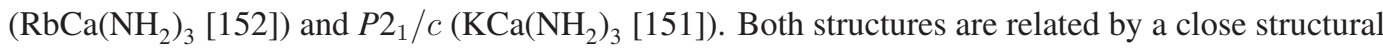
relationship, since $P 2_{1} / c$ is a translationengleiche maximal subgroup of $C 2 / c$. The change of the space group is a result of the influence of the radii of the alkali metals. For potassium a distorted octahedral surrounding is realized, however rubidium and cesium require higher coordination numbers. This group also contains the compounds $\mathrm{CsCa}\left(\mathrm{NH}_{2}\right)_{3}, \mathrm{CsSr}\left(\mathrm{NH}_{2}\right)_{3}$ and $\mathrm{CsEu}\left(\mathrm{NH}_{2}\right)_{3}[153$ ]. The resulting crystal structures are described as distorted âĂIJhexagonal perovskitesâĂIJ, where cesium and $\mathrm{NH}_{2}^{-}$form the motif of a hexagonal close packing. Ca occupies face-sharing octahedral voids exclusively surrounded by amide ions. In this way, one-dimensional chains of ${ }_{\infty}^{1}\left[\mathrm{Ca}\left(\mathrm{NH}_{2}\right)_{6}^{4-}\right]$ result [153]. The change from group one to group two may surprise: One could expect the same crystal structure for $\mathrm{KCa}\left(\mathrm{NH}_{2}\right)_{3}$ and $\mathrm{KEu}\left(\mathrm{NH}_{2}\right)_{3}$, because the binary amides $\mathrm{Ca}\left(\mathrm{NH}_{2}\right)_{2}$ and $\mathrm{Eu}\left(\mathrm{NH}_{2}\right)_{2}$ are isotypes [149].

The third group includes $\mathrm{K}\left[\mathrm{Be}\left(\mathrm{NH}_{2}\right)_{3}\right]$ and $\mathrm{Rb}\left[\mathrm{Be}\left(\mathrm{NH}_{2}\right)_{3}\right]$, where nearly trigonal planar complex anions $\left[\mathrm{Be}\left(\mathrm{NH}_{2}\right)_{3}\right]^{-}$appear. Up to now, no amide of this group was obtained from ammonothermal conditions [142].

Finally, the fourth group contains isolated tetrahedral complex anions of the type $\left[B\left(\mathrm{NH}_{2}\right)_{4}\right]^{2-}$. Examples, obtained from supercritical ammonia are one modification of dimorphic $\mathrm{K}_{2}\left[\mathrm{Zn}\left(\mathrm{NH}_{2}\right)_{4}\right][168,169]$ and $\mathrm{CsMg}\left(\mathrm{NH}_{2}\right)_{4}$ [148]. The divalent cation is surrounded by four amide groups, whereas the monovalent cations show coordination with larger numbers of amide groups. Various ternary amides of this type containing two metals were synthesized from liquid ammonia, e.g., $\mathrm{Na}_{2}\left[\mathrm{Mn}\left(\mathrm{NH}_{2}\right)_{4}\right]$ [169], $\mathrm{Li}\left[\mathrm{Al}\left(\mathrm{NH}_{2}\right)_{4}\right]$ [143,170], $\mathrm{Na}\left[\mathrm{Al}\left(\mathrm{NH}_{2}\right)_{4}\right]$ [81], $\mathrm{Na}\left[\mathrm{Ga}\left(\mathrm{NH}_{2}\right)_{4}\right]$ [81,141], $\mathrm{K}_{2}\left[\mathrm{Mn}\left(\mathrm{NH}_{2}\right)_{4}\right]$ [171] and $\mathrm{Rb}_{2}\left[\mathrm{Zn}\left(\mathrm{NH}_{2}\right)_{4}\right][171]$.

There was a remarkable change of the valence state of $\mathrm{Eu}$ from +2 to +3 observed, when a large surplus of $\mathrm{KNH}_{2}$ was used in ammonothermal synthesis of ternary amides. Apparently, an increased $\mathrm{NH}_{2}^{-}$concentration provokes formation of $\mathrm{K}_{3}\left[\mathrm{Eu}^{\mathrm{III}}\left(\mathrm{NH}_{2}\right)_{6}\right]$ rather than $\mathrm{KEu}^{\mathrm{II}}\left(\mathrm{NH}_{2}\right)_{3}[122]$. Divalent europium is known to behave similarly to divalent strontium and thus it is not surprising that $\mathrm{KEu}^{\mathrm{II}}\left(\mathrm{NH}_{2}\right)_{3}$ is an isotype of $\mathrm{KSr}^{\mathrm{II}}\left(\mathrm{NH}_{2}\right)_{3}$ [149]. Trivalent europium behaves rather similar to the trivalent lanthanides: $\mathrm{K}_{3}\left[\mathrm{Eu}^{\mathrm{III}}\left(\mathrm{NH}_{2}\right)_{6}\right]$ is an isotype of $\mathrm{K}_{3}\left[\mathrm{La}{ }^{\mathrm{III}}\left(\mathrm{NH}_{2}\right)_{6}\right]$ [156]. The same applies for the respective ternary rubidium europium amide. Due to the lower solubility of $\mathrm{NaNH}_{2}$ and the 
resulting lower $\mathrm{NH}_{2}^{-}$concentration in this system a product with lower sodium content $\mathrm{Na}_{2} \mathrm{Eu}_{3}^{\mathrm{II}}\left(\mathrm{NH}_{2}\right)_{8}$ was obtained in this system [149].

\subsection{Imides, Nitride Imides, Nitride Amides and Amide Azides}

Certain imides and nitrides can be formed via thermal decomposition of amides under release of ammonia. From in-situ powder X-ray diffraction it is known that during decomposition compounds containing $\mathrm{N}^{3-}, \mathrm{NH}_{2}^{-}$and $\mathrm{NH}^{2-}$ ions may occur. Examples are $\mathrm{Li}_{2} \mathrm{NH}, \mathrm{CaNH}, \mathrm{MgNH}[73,114]$ and $\mathrm{Th}_{2} \mathrm{~N}_{2}(\mathrm{NH})$ [33]. There are binary imides of lithium, beryllium, magnesium, calcium, strontium and barium known [73,114]. A few imides and nitride imides were obtained from ammonothermal conditions, but only in the form of micro crystalline powders, see Table 8. From the thermal degradation of ternary rare-earth metal amides the formation of $\mathrm{Yb}_{0.66}(\mathrm{NH})$ [123], $\mathrm{Ce}_{3}(\mathrm{NH})_{3} \mathrm{~N}$ [76] and $\mathrm{La}_{0.667} \mathrm{NH}[172]$ was reported.

Table 8. Conditions for the ammonothermal synthesis of micro crystalline binary imides, nitride imides and amide azides.

\begin{tabular}{llcccc}
\hline Compound & Reactants mineralizer & $\boldsymbol{T} / \mathbf{K}$ & $\boldsymbol{p} / \mathbf{M P a}$ & $\boldsymbol{t} / \mathbf{d}$ & References \\
\hline $\mathrm{MgNH}$ & $\mathrm{Mg}_{3} \mathrm{~N}_{2}$ & 773 & $\geq 5$ & 7 & {$[115]$} \\
$\mathrm{Th}(\mathrm{NH})_{2}$ & $\mathrm{Th}+\mathrm{Li} / \mathrm{Na} / \mathrm{K}$ & 573 & 608 & 29 & {$[33]$} \\
$\mathrm{Th}_{2} \mathrm{~N}_{2} \mathrm{NH}$ & $\mathrm{Th}$ & 823 & 507 & 2 & {$[1]$} \\
$\left.\mathrm{ThN}_{(} \mathrm{NH}_{2}\right)$ & $\mathrm{ThNJ}+A(1) \mathrm{NH}_{2}$ & 573 & 405 & 2 & {$[33]$} \\
$\mathrm{Th}_{3} \mathrm{~N}_{2}(\mathrm{NH})_{3}$ & $\mathrm{ThNJ}+A(1) \mathrm{NH}_{2}$ & 623 & 608 & 27 & {$[33]$} \\
$\mathrm{Si}_{2} \mathrm{~N}_{2} \mathrm{NH}$ & $\mathrm{Si}+\mathrm{KNH}_{2}$ & 873 & 600 & 5 & {$[173]$} \\
$\mathrm{ZrN}_{(}\left(\mathrm{NH}_{2}\right)$ & $\mathrm{ZrNI}+\mathrm{KN}_{3}$ & 633 & 507 & 10 & {$[75]$} \\
$\mathrm{Cs}_{2}\left(\mathrm{NH}_{2}\right) \mathrm{N}_{3}$ & $\mathrm{Cs}+\mathrm{Y}$ & $463-493$ & $500-600$ & $21-26$ & {$[174]$} \\
\hline
\end{tabular}

The reaction of $\mathrm{Mg}_{3} \mathrm{~N}_{2}$ with $\mathrm{NH}_{3}$ at $T \geq 773 \mathrm{~K}$ and $p \geq 5 \mathrm{MPa}$ yields $\mathrm{MgNH}$ with $\mathrm{Mg}\left(\mathrm{NH}_{2}\right)_{2}$ and $\mathrm{Mg}_{3} \mathrm{~N}_{2}$ impurities after one week. This finding may be explained by the following equations [115]:

$$
\begin{gathered}
\mathrm{Mg}_{3} \mathrm{~N}_{2}+\mathrm{NH}_{3} \rightleftarrows 3 \mathrm{MgNH} \\
\mathrm{MgNH}+\mathrm{NH}_{3} \rightleftarrows \mathrm{Mg}\left(\mathrm{NH}_{2}\right)_{2}
\end{gathered}
$$

$\mathrm{MgNH}$ can also be obtained by thermal decomposition of $\mathrm{Mg}\left(\mathrm{NH}_{2}\right)_{2}$ at 513-638 K. At $633 \mathrm{Ka}$ micro crystalline powder suitable for X-ray diffraction is produced [115]. $\mathrm{Th}(\mathrm{NH})_{2}$ is formed from thorium metal and ammonia at $613 \mathrm{~K}$ and $304 \mathrm{MPa}$ after 4 days as micro crystalline powder [1]. At higher temperatures of $823 \mathrm{~K}$ and $507 \mathrm{MPa}$ a micro crystalline nitride imide with the composition $\mathrm{Th}_{2} \mathrm{~N}_{2} \mathrm{NH}$ is formed [1].

A cesium amide azide $\mathrm{Cs}_{2}\left(\mathrm{NH}_{2}\right) \mathrm{N}_{3}$ is reported from the reaction of $\mathrm{Cs}$ and ammonia in presence of $\mathrm{Y}$ at 463-493 K and 500-600 MPa. The appearance of azide ions may be regarded somewhat surprising under the applied conditions, as the nitrogen of the ammonia would become oxidized during formation. Jacobs et al. explained this effect by a drastically reduced volume of the obtained 
$\mathrm{Cs}_{2}\left(\mathrm{NH}_{2}\right) \mathrm{N}_{3}$ compared to the volume of $\mathrm{CsNH}_{2}$ and $\mathrm{NH}_{3}$, assuming release of hydrogen by diffusion through the autoclave wall and perhaps also by formation of yttrium hydride. Following reaction Equation (10) a volume reduction of $\sim 29 \%$ occurs when $\mathrm{Cs}_{2}\left(\mathrm{NH}_{2}\right) \mathrm{N}_{3}$ is formed. In addition, the formation of the mixed amide azide in contrast to two compounds $\left(\mathrm{Cs}\left(\mathrm{NH}_{2}\right)+\mathrm{CsN}_{3}\right)$ is favorable due to a smaller volume of $\sim 3 \%$ [174].

$$
2 \mathrm{CsNH}_{2}+2 \mathrm{NH}_{3} \rightleftarrows \mathrm{Cs}_{2}\left(\mathrm{NH}_{2}\right) \mathrm{N}_{3}+4 \mathrm{H}_{2}
$$

However, in the past several cyanamides (or carbodiimides, respectively), formed by reaction with unintenional carbon impurities, were initially misinterpreted as representing azide compounds [175,176]. Since any carbon impurity under ammonothermal conditions in presence of alkali or alkaline-earth metals will readily form cyanamide ions [177], it may be regarded as likely that this compound rather represents an amide carbodiimide.

Group III metals manifest a strong tendency to form polymeric imides from synthesis in liquid ammonia. Thus, the reaction of $\mathrm{B} X_{3}(X=\mathrm{Cl}, \mathrm{Br})$ and $\mathrm{NH}_{4} \mathrm{Cl}$ in liquid ammonia yields a polymeric solid with the approximate formula $\left[\mathrm{B}(\mathrm{NH})_{3 / 2}\right]_{n}$ [135]. Earlier, a boron amide $\mathrm{B}\left(\mathrm{NH}_{2}\right)_{3}$ was discussed to form under similar reaction conditions [134], but this material might be identical to the polymeric $\left[\mathrm{B}(\mathrm{NH})_{3 / 2}\right]_{n}$. In a further report boron imide was obtained from thermal decomposition of $\mathrm{B}_{2} \mathrm{~S}_{3} \cdot 6 \mathrm{NH}_{3}$ at $T \geq 378 \mathrm{~K}$ [178]. A mixed aluminum amide imide $\mathrm{AlNH}_{2}(\mathrm{NH})$ was reported as intermediate species during AlN synthesis from aluminum hydride $\mathrm{AlH}_{3}$ and liquid ammonia at $T \leq 273 \mathrm{~K}$. However, the formula was only determined by chemical analysis and no crystal structure determination was reported. A pure aluminum amide $\mathrm{Al}\left(\mathrm{NH}_{2}\right)_{3}$ is reported to occur at lower temperatures $(T \leq 223 \mathrm{~K})$ from the same starting materials and to decompose to AlN via $\mathrm{AlNH}_{2}(\mathrm{NH})$ at $T \geq 243 \mathrm{~K}$ [137]. The metathesis reaction of $\mathrm{AlBr}_{3}$ with $\mathrm{KNH}_{2}$ in liquid ammonia and the reaction of $\mathrm{H}_{3} \mathrm{Al} \cdot \mathrm{NMe}_{3}$ with liquid ammonia at ambient temperature yields polymeric $\left[\mathrm{AlNH}_{2}(\mathrm{NH})\right]_{n}[135,136]$. It is very likely that the reported $\mathrm{AlNH}_{2}(\mathrm{NH})$ is the same polymeric compound [135]. Synthesis of polymeric gallium imide $\left[\mathrm{Ga}\left(\mathrm{NH}_{3 / 2}\right]_{n}\right.$ was reported from the reaction of $\left[\mathrm{Ga}\left(\mathrm{NMe}_{2}\right)_{3}\right]_{2}$ with liquid ammonia in reflux for $8 \mathrm{~h}$, the composition was deduced from elemental anaylsis and IR spectroscopy. Thermal decomposition of $\left[\mathrm{Ga}\left(\mathrm{NH}_{3 / 2}\right]_{n}\right.$ yields a mixture of nanosized $c-\mathrm{GaN}$ and $h-\mathrm{GaN}$ [135]. Reaction of silicon with $\mathrm{KNH}_{2}$ in supercritical ammonia at $873 \mathrm{~K}$ and $600 \mathrm{MPa}$ yields a silicon nitride imide $\mathrm{Si}_{2} \mathrm{~N}_{2} \mathrm{NH}$, which is an intermediate compound during synthesis of $\mathrm{Si}_{3} \mathrm{~N}_{4}$ by thermal decomposition of $\mathrm{Si}(\mathrm{NH})_{2}$. Crystal growth and subsequent structure determination of $\mathrm{Si}_{2} \mathrm{~N}_{2} \mathrm{NH}$ succeeded after ammonothermal synthesis at $873 \mathrm{~K}$ and $600 \mathrm{MPa}$. In $\mathrm{Si}_{2} \mathrm{~N}_{2} \mathrm{NH}$ silicon is coordinated tetrahedrally by four $\mathrm{N}$. The $\mathrm{SiN}_{4}$ tetrahedra are connected via corners, resulting in layers of $\mathrm{Si}-\mathrm{N}$ hexagons, which are linked by imide groups in prependicular direction [173]. Aditionnaly, in the system $\mathrm{Si} / \mathrm{NH}_{3}$, silicon imide $\mathrm{Si}(\mathrm{NH})_{2}$ and silicon amide $\mathrm{Si}\left(\mathrm{NH}_{2}\right)_{4}$ are reported (see paragraph Transition Metal, Group III and Group IV Metal Amides). $\mathrm{Si}(\mathrm{NH})_{2}$ is obtained from $\mathrm{SiCl}_{4}$ in liquid ammonia at 353-363 K, however, up to now no crystal structure data is reported and the chemical nature of the compound is still unvertain. $\mathrm{Si}(\mathrm{NH})_{2}$ serves as starting material for $\mathrm{Si}_{3} \mathrm{~N}_{4}$ synthesis by thermal decomposition [179]. 
Table 9. Conditions for the ammonothermal synthesis of metal hydrides and hydride nitrides.

\begin{tabular}{llcccc}
\hline Compound & Reactants Mineralizer & $\boldsymbol{T} / \mathbf{K}$ & $\boldsymbol{p} / \mathbf{M P a}$ & $\boldsymbol{t} / \mathbf{d}$ & References \\
\hline $\mathrm{ScH}_{2}$ & $\mathrm{Sc}+\mathrm{NH}_{4} \mathrm{I}$ & 773 & $\geq 11.3$ & & {$[161]$} \\
$\mathrm{ZrH}_{0.6} \mathrm{~N}$ & $\mathrm{ZrN}\left(\mathrm{NH}_{2}\right)$ & 633 & 600 & & {$[75]$} \\
$\mathrm{CeH}_{x}(x \leq 3)$ & $\mathrm{Ce}$ & 395 & $400-500$ & & {$[76]$} \\
$\mathrm{ThH}_{2}$ & $\mathrm{Th}+\mathrm{Na} / \mathrm{K}$ & 473 & 500 & 7 & {$[33]$} \\
$\mathrm{ThHN}_{1.23}$ & $\mathrm{Th}+\mathrm{NH}_{4} \mathrm{I}$ & 573 & 355 & 10 & {$[33]$} \\
\hline
\end{tabular}

\subsection{Metal Hydrides and Nitride Hydrides}

In some systems, even metal hydrides can be synthesized prior the formation of the metal nitride is completed (see Table 9). This applies especially for the lighter lanthanides at temperatures below the formation temperature for the pure nitride. For example, $\mathrm{CeH}_{x}$ with $x \leq 3$ was obtained next to $\mathrm{CeN}$ when pure cerium metal reacts with ammonia at $395 \mathrm{~K}$ and 400-500 MPa. The amount of hydrogen in $\mathrm{CeH}_{x}(x \leq 3)$ decreases with increasing temperature, simultaneously the amount of $\mathrm{CeN}$ increases. At $475 \mathrm{~K}$ only pure $\mathrm{CeN}$ is obtained [76]. $\mathrm{ZrH}_{0.6} \mathrm{~N}$ was obtained from $\mathrm{ZrN}\left(\mathrm{NH}_{2}\right)$ and $\mathrm{NH}_{3}$ at $633 \mathrm{~K}$ and $600 \mathrm{MPa}$ [75]. Only one compound is known from scandium under ammonothermal conditions, namely $\mathrm{ScH}_{2}$. Scandium metal does not show any reaction up to $673 \mathrm{~K}$. Using $\mathrm{NH}_{4} \mathrm{I}$ as mineralizer $\mathrm{ScH}_{2}$ was obtained from scandium metal at $773 \mathrm{~K}$ [161].

\subsection{Nitrides}

By the ammonothermal method nitride single crystals can be obtained at comparatively low temperatures $T \leq 700 \mathrm{~K} \mathrm{[3]}$ as can be seen in Table 10. The synthesis can be carried out in ammonobasic (e.g., EuN from $\mathrm{Eu}$ and $\mathrm{K}[122]$ ), neutral (e.g., $\mathrm{Cu}_{3} \mathrm{~N}$ from $\left[\mathrm{Cu}\left(\mathrm{NH}_{3}\right)_{4}\right] \mathrm{NO}_{3}[20]$ ) or ammonoacidic milieu (e.g., $\mathrm{GaN}+\mathrm{NH}_{4} \mathrm{I}$ [62]). The formation process of the nitrides is not yet well understood (compare section Crystallization Process).

\subsubsection{Alkaline-Earth Metal Nitrides}

The first binary nitride synthesized by the ammonothermal method was $\mathrm{Be}_{3} \mathrm{~N}_{2}$, which was obtained as pure cubic phase in 1966 by Juza and Jacobs from beryllium in supercritical ammonia at $673 \mathrm{~K}$ and $20.3 \mathrm{MPa}$ [2]. In this way, the usual synthesis temperatures for beryllium nitride could be drastically reduced, since the reaction of beryllium to cubic beryllium nitride in ammonia flow requires temperatures of 1173-1373 K [189] and in nitrogen flow 1600 K [190]. Similar ammonothermal reaction conditions should apply for $\mathrm{Mg}_{3} \mathrm{~N}_{2}$, although we are not aware of any publication describing a synthesis of $\mathrm{Mg}_{3} \mathrm{~N}_{2}$ from supercritical ammonia. However, $\mathrm{Mg}_{3} \mathrm{~N}_{2}$ decomposes at 633-648 $\mathrm{K}$ and $1 \mathrm{MPa}$ in liquid ammonia to $\mathrm{Mg}\left(\mathrm{NH}_{2}\right)_{2}$ and at $T \geq 773 \mathrm{~K}$ and $p \geq 5 \mathrm{MPa}$ to MgNH [115] (see paragraph Imides, Nitride Imides, Nitride Amides and Amide Azides). 
$\alpha-\mathrm{Be}_{3} \mathrm{~N}_{2}$ crystallizes in the anti-bixbyite structure like $\mathrm{Mg}_{3} \mathrm{~N}_{2}, \alpha-\mathrm{Ca}_{3} \mathrm{~N}_{2}$ [190], $\mathrm{Cd}_{3} \mathrm{~N}_{2}$ [191] and $\mathrm{Zn}_{3} \mathrm{~N}_{2}$ [192]. It is not yet established, if the nitrides of strontium $\mathrm{Sr}_{3} \mathrm{~N}_{2}$ and barium $\mathrm{Ba}_{3} \mathrm{~N}_{2}$ can be synthesized, although the ternary nitrides $\mathrm{CaMg}_{2} \mathrm{~N}_{2}$ and $\mathrm{SrMg}_{2} \mathrm{~N}_{2}$ were reported [193]. The anti-bixbyite structure manifests the motif of a cubic closest packing of the nitrogen atoms, with the metal atoms occupying $75 \%$ of the tetrahedral holes in an ordered manner. Nitrogen is surrounded by distorted metal atom octahedra [190]. $\alpha-\mathrm{Be}_{3} \mathrm{~N}_{2}, \beta-\mathrm{Be}_{3} \mathrm{~N}_{2}$ [194], $\mathrm{Mg}_{3} \mathrm{~N}_{2}, \alpha-\mathrm{Ca}_{3} \mathrm{~N}_{2}$ [190] and $\mathrm{Zn}_{3} \mathrm{~N}_{2}$ [195] are known to represent semiconductors. A decrease of the band gap value (obtained from experimental data) with increasing atomic weight is observed $\left(\alpha-\mathrm{Be}_{3} \mathrm{~N}_{2}\right.$ : direct band gap of $3.8 \mathrm{eV}$ [196], $\mathrm{Mg}_{3} \mathrm{~N}_{2}: 2.80 \mathrm{eV}, \mathrm{Ca}_{3} \mathrm{~N}_{2}: 1.55 \mathrm{eV}$ [190] and $\mathrm{Zn}_{3} \mathrm{~N}_{2}$ probably direct band gap of $1.01-1.25 \mathrm{eV}[195,197])$. Ammonothermal synthesis of nitrides with anti-bixbyite structure was only published for $\alpha-\mathrm{Be}_{3} \mathrm{~N}_{2}$, nevertheless it is a promising method for bulk growth, especially since most of the other established synthesize routes only yield micro crystalline powders or films and no bulk material, which is necessary for many applications as semiconducting material. Additionally, due to its setup as transport growth, the ammonothermal method could lower the oxygen concentration, which is crucial for nitride semiconductors.

\subsubsection{Group III and IV Nitrides}

The nitrides of group III metals are considered very promising materials for optical devices in the short-wavelength region, high-frequency high-power electronics and fast-speed communication. Furthermore, they prove high physical and chemical endurance, which makes them attractive for applications in various settings. The use in optic and electronic devices stems back to their semiconducting nature. For example, GaN shows a wide direct bandgap of $3.39 \mathrm{eV}$ [198], an electron mobility of $\sim 1500 \mathrm{~cm}^{2} / \mathrm{Vs}$ [36], a large critical breakdown electric field of $\sim 3 \mathrm{MV} / \mathrm{cm}$ and a saturation velocity of $\nu \leq 19-10^{6} \mathrm{~cm} / \mathrm{s}$. AlN and GaN find applications as blue lasers (e.g., for high capacity optical storage in CD-ROMs), in light emitting diodes, high electron mobility transistors and other devices [34,43]. The band gap for the group III nitrides decreases with increasing atomic weight of the metal constituent: AlN $E_{g}=6.2 \mathrm{eV}$ at $295 \mathrm{~K}$ [199], GaN $E_{g}=3.39 \mathrm{eV}$ [198] and InN $E_{g}=0.7-0.8 \mathrm{eV}[200,201] . h$-AlN,$h$-GaN and $h$-InN crystallize in the wurtzite-type structure (space group $P 6_{3} m c$ ), where anions and cations are surrounded tetrahedrally by the respective counter ions. 
Table 10. Conditions for the ammonothermal synthesis of binary nitrides.

\begin{tabular}{|c|c|c|c|c|c|c|}
\hline Compound & Reactants + Mineralizer & $T / \mathrm{K}$ & $p / \mathrm{MPa}$ & $t / \mathbf{d}$ & Sample & References \\
\hline$c-\mathrm{Be}_{3} \mathrm{~N}_{2}$ & $\mathrm{Be}$ & 673 & 20.3 & 7 & m.c. & [2] \\
\hline YN & $\mathrm{Y}+\mathrm{NH}_{4} \mathrm{I}$ & 623 & 61 & 7 & m.c. & {$[163,174]$} \\
\hline EuN & $\mathrm{Eu}+\mathrm{K} 40: 1$ & 673 & 500 & 7 & s.c. & [122] \\
\hline $\mathrm{LaN}$ & $\mathrm{K}_{3}\left[\mathrm{La}\left(\mathrm{NH}_{2}\right)_{6}\right]+\mathrm{KNH}_{2}$ & 650 & 500 & 10 & s.c. & [3] \\
\hline $\mathrm{LaN}$ & $\mathrm{La}+\mathrm{Na}$ & $523-773$ & $300-507$ & 10 & s.c. & {$[3,131]$} \\
\hline $\mathrm{CeN}$ & $\mathrm{Ce}+\mathrm{Cs}$ & 490 & 200 & 12 & - & [159] \\
\hline $\mathrm{SmN}$ & $\mathrm{Sm}+\mathrm{K}$ & $433-453$ & 500 & $10-30$ & - & {$[121]$} \\
\hline GdN & $\mathrm{Gd}+\mathrm{NH}_{4} \mathrm{I}$ & 523 & 507 & 23 & - & {$[161]$} \\
\hline GaN & $\mathrm{Ga}+\mathrm{LiNH}_{2} / \mathrm{K}$ & 823 & 500 & $\geq 7$ & s.c. & {$[77]$} \\
\hline $\mathrm{GaN}$ & $\mathrm{GaN}+\mathrm{NH}_{4} \mathrm{I}$ & $\leq 1123$ & $\leq 150$ & - & s.c. & {$[62]$} \\
\hline $\mathrm{GaN}$ & $\mathrm{GaN}+\mathrm{KNH}_{2}+\mathrm{KI}$ & 673 & 240 & 7 & s.c. & {$[180]$} \\
\hline$c-\mathrm{GaN}$ & {$\left[\mathrm{Ga}(\mathrm{NH})_{3 / 2}\right]_{n}+\mathrm{NH}_{4} \mathrm{I}$} & 753 & - & $2-3$ & s.c. & {$[181]$} \\
\hline GaN:Mn & $\mathrm{Ga}+\mathrm{Mn}+\mathrm{KNH}_{2}$ & $723-823$ & $400-500$ & $3-10$ & s.c. & [182] \\
\hline $\mathrm{GaN}: \mathrm{Cr}$ & $\mathrm{Ga}+\mathrm{CrBr}_{3}+\mathrm{KNH}_{2}$ & $723-823$ & $400-500$ & $3-10$ & s.c. & [182] \\
\hline $\mathrm{GaN}: \mathrm{Fe}$ & $\mathrm{Ga}+\mathrm{Fe}+\mathrm{LiNH}_{2}$ & $723-773$ & $400-500$ & $3-10$ & s.c. & [182] \\
\hline AlN & $\mathrm{Al}+\mathrm{K}$ & $723-873$ & 200 & $1-18$ & s.c & {$[78]$} \\
\hline AlN & $\mathrm{Al}+\mathrm{NH}_{4} \mathrm{Cl}$ & 723 & - & 2 & s.c & [11] \\
\hline $\mathrm{InN}$ & $\mathrm{In}+\mathrm{KNH}_{2}$ & 723 & - & - & m.c. & [43] \\
\hline $\mathrm{Fe}_{4-x} \mathrm{Ni}_{x} \mathrm{~N}$ & $\mathrm{Fe}+\mathrm{FeI}_{2}$ & $733-853$ & $600-800$ & - & s.c. & [183-185] \\
\hline$\Theta-\mathrm{Mn}_{6} \mathrm{~N}_{5+x}$ & $\mathrm{MnI}_{2}+\mathrm{NaNH}_{2}$ & $673-723$ & 600 & $60-120$ & s.c. & [167] \\
\hline$\eta-\mathrm{Mn}_{3} \mathrm{~N}_{2}$ & $\mathrm{Mn}+\mathrm{I}_{2}$ or $\mathrm{MnI}_{2}+\mathrm{NaNH}_{2}$ & $673-873$ & 600 & 30 & s.c. & {$[167,186]$} \\
\hline$\eta-\mathrm{Mn}_{3} \mathrm{~N}_{2}$ & $\mathrm{Mn}+\mathrm{K} / \mathrm{Rb}$ & $673-873$ & $\leq 600$ & 35 & s.c. & [186] \\
\hline$\epsilon-\mathrm{Mn}_{4} \mathrm{~N}$ & $\mathrm{Mn}+\mathrm{GaN} A(1) \mathrm{NH}_{2}$ & $723-823$ & $400-500$ & $3-10$ & m.c. & {$[182]$} \\
\hline $\mathrm{Ni}_{3} \mathrm{~N}$ & {$\left[\mathrm{Ni}\left(\mathrm{NH}_{3}\right)_{6}\right] \mathrm{Cl}_{2}+\mathrm{NaNH}_{2}$} & 523 & 200 & 7 & s.c. & [187] \\
\hline $\mathrm{Cu}_{3} \mathrm{~N}$ & {$\left[\mathrm{Cu}\left(\mathrm{NH}_{3}\right)_{4}\right] \mathrm{NO}_{3}$} & $623-853$ & $\geq 600$ & - & s.c. & {$[20]$} \\
\hline $\begin{array}{l}\mathrm{Cu}_{3} \mathrm{Pd}_{x} \mathrm{~N} \\
x=0.020 / 0.989\end{array}$ & $\begin{array}{l}{\left[\mathrm{Cu}\left(\mathrm{NH}_{3}\right)_{4}\right] \mathrm{NO}_{3}+\mathrm{Cu}} \\
+\left[\mathrm{Pd}\left(\mathrm{NH}_{3}\right)_{4}\right]\left(\mathrm{NO}_{3}\right)_{2}\end{array}$ & 723 & 600 & 7 & s.c. & {$[188]$} \\
\hline
\end{tabular}

s.c. means single crystal, m.c. micro crystalline.

For the growth of GaN or AlN for optoelectronic devices a feedstock setup is used, as described in paragraph Reaction Vessels(see Figure 6). This method allows the homo- and heteroepitaxial growth of large single crystals. Both ammonobasic and ammonoacidic conditions are used for large scale syntheses, in which AlN [78] requires the highest growth temperatures and InN the lowest [43]. The ammonobasic method enables the growth of $\mathrm{GaN}$ wafers up to two inches in diameter [202] or bulk single crystals of $10 \mathrm{~mm}^{2}$ by $1 \mathrm{~mm}$ thick [43] and dislocation density below $5 \cdot 10^{4} \mathrm{~cm}^{2}$ [203]. Maximal growth rates of up to $40 \mu \mathrm{m} / \mathrm{h}(=960 \mu \mathrm{m} / \mathrm{d})$ with rates of $10-30 \mu \mathrm{m} / \mathrm{h}(=240-720 \mu \mathrm{m} / \mathrm{d})$ for all planes were reported [39]. $c$-GaN in a sphalerite structure (space group $F \overline{4} 3 \mathrm{~m}$ ) is also known and can be obtained from $\left[\mathrm{Ga}(\mathrm{NH})_{3 / 2}\right]_{\mathrm{x}}$ and $\mathrm{NH}_{4} \mathrm{I}$ under ammonothermal conditions (753 K) [181]. Indium nitride, like its lighter homologues, is an intriguing semiconducting material. Although, up to know research efforts are hindered by indium metal incorporations in as-grown InN, produced by decomposition of the thermodynamic instable InN, especially at temperatures above 723 K [204]. Similar structural defects provoked by 
formation of In particles are encountered in $\operatorname{In}_{x} \mathrm{Ga}_{1-x} \mathrm{~N}$ solid solutions $(0 \leq x \leq 0.5)$ [205], which are currently used in light-emitting and laser diodes. Their broad range of the direct band gap of $E_{g}=0.77-1.75 \mathrm{eV}$ allows to cover a spectral region from near-infrared to near-ultraviolet [206]. Due to the lower thermal stability of InN and its solid solutions with $\mathrm{AlN}$ and GaN, lower temperatures in synthesis and crystal growth are required. InN is supposed to be metastable at $T \geq 258 \mathrm{~K}$, kinetic constraints are believed to inhibit the decomposition at ambient conditions [207]. To our best knowledge, only once a synthesis of InN from ammonothermal conditions has been reported and has not yet been confirmed (see Table 10) [43]. However, the low temperatures and high pressures, which can be applied with the ammonothermal method, may be useful to stabilizes InN and its solid solutions without incorporation of In metal.

Doping of group III nitride semiconductors is used to enhance the emission range and $n$-type conductivity. The most frequently used donor dopant is silicon, but also rare-earth metal doping like with erbium was applied. On the other hand, unintentional doping, usually by oxygen contaminations, leads to reduced carrier concentrations and lower transparency [208]. Erbium doped $\mathrm{GaN}$ has shown emission of two erbium induced narrow green lines at 537 and $558 \mathrm{~nm}$ in the range of the visible spectrum, with the former one peaking at $300 \mathrm{~K}$ [209]. Doping of GaN with erbium under ammonothermal conditions manifests an infrared emission at $2.029 \mathrm{eV}$, due to intra- $4 f$ transitions, although no green transition was observed, probably due to the low erbium concentration $\left(1 \times 10^{18} \mathrm{~cm}^{-3}\right.$ for the Ga-polar growth, $1 \times 10^{17} \mathrm{~cm}^{-3}$ for the N-polar growth). Additionally, erbium is discussed to work as getter for oxygen, crystallizing as erbium oxide nitride in the dissolution zone, thus lowering the oxygen concentration in the crystallization zone and consequently in the crystallized GaN. A lower concentration of Er and a higher impurity level (usually oxygen) in the nitrogen polar growth was observed, which is not surprising considering the different polarities of the seed crystal faces and the soluble species [210]. Furthermore, transition metals were used as dopants for $\mathrm{GaN}$ under ammonothermal conditions, yielding $\mathrm{GaN}: \mathrm{Mn}(\max .1 \% \mathrm{Mn}), \mathrm{GaN}: \mathrm{Fe}(\max .0 .03 \%$ $\mathrm{Fe}$ ), ferromagnetic GaN:Cr (max. 0.02\% Cr) [182], GaN:Zn and GaN:Mg [211].

Cubic tin nitride $\mathrm{Sn}_{3} \mathrm{~N}_{4}$ has been reported to form from $\mathrm{SnI}_{4}$ or $\mathrm{SnBr}_{4}$ with $\mathrm{KNH}_{2}$ in liquid (but not supercritical) ammonia at $243 \mathrm{~K}$ followed by annealing in vacuo at $573 \mathrm{~K}$ [212].

\subsubsection{Rare-Earth Metal Nitrides}

Several rare-earth metal nitrides were obtained under ammonothermal conditions, namely YN [163,174], EuN [122], LaN [3,131], CeN [159], SmN [121] and GdN [161]. The reation conditions cover ammonoacidic and ammonobasic milieu, a temperature range from $433(\mathrm{SmN})$ to $673 \mathrm{~K}(\mathrm{EuN})$ and pressures from $200(\mathrm{CeN})$ to $507 \mathrm{MPa}(\mathrm{EuN}, \mathrm{LaN}, \mathrm{SmN}, \mathrm{GdN})$ (see Table 10). ScN, YN, LaN and $\mathrm{GdN}$ attract increasing research interest, since they are strongly suspected to be semiconductors, for $\mathrm{ScN}$ it even seems unequivocal [213]. Rare-earth metal nitrides cover a large range of properties, especially concerning their metallic or insulating character, $\mathrm{CeN}$ to $\mathrm{GdN}$ are considered half-metallic, $\mathrm{TbN}$ to $\mathrm{HoN}$ insulating and $\mathrm{ErN}$ to $\mathrm{YbN}$ metallic. GdN seems to play a special role, showing ferromagnetic properties with the Curie temperature in the range of $T_{C}=58-69 \mathrm{~K}$. The intricate physical and chemical properties of those nitrides stem back mainly to their partly filled 
$4 f$ shells [214,215]. They crystallize in the rocksalt structure, with a six-fold coordination of $R^{3+}$ and $\mathrm{N}^{3-}$ ions.

\subsubsection{Transition Metal Nitrides}

Transition metal nitrides manifest a vast number of interesting physical and chemical properties such as high hardness, mechanical strength, high melting point, magnetic and semiconducting properties [216]. For example, $\eta-\mathrm{Mn}_{3} \mathrm{~N}_{2}$ exhibits an antiferromagnetic spin structure [167], $\epsilon-\mathrm{Mn}_{4} \mathrm{~N}$ has a non-collinear ferrimagnetic spin-structure with a Curie temperature in the range of $T_{C}=738-748 \mathrm{~K}[217,218], \gamma^{\prime}-\mathrm{Fe}_{4} \mathrm{~N}$ is a ferromagnetic conductor with high thermal stability [219,220] and $\mathrm{Cu}_{3} \mathrm{~N}$ is a diamagnetic semiconductor with an optical band gap of 0.8-1.9 eV [219,221]. The ammonothermal method so far yielded the following transition metal nitrides: $\Theta-\mathrm{Mn}_{6} \mathrm{~N}_{5}+x$ [167], $\eta-\mathrm{Mn}_{3} \mathrm{~N}_{2}$ [167,186], $\epsilon-\mathrm{Mn}_{4} \mathrm{~N}$ [182], $\mathrm{Fe}_{4-x} \mathrm{Ni}_{x} \mathrm{~N}$ [183-185], $\mathrm{Ni}_{3} \mathrm{~N}$ [187] and $\mathrm{Cu}_{3} \mathrm{~N}$ [20]. From a supercritical ammonia-methanol mixture at $443-563 \mathrm{~K}$ and $16 \mathrm{MPa}$ some nano crystalline nitrides were obtained, namely $\mathrm{Cr}_{2} \mathrm{~N}, \mathrm{Co}_{2} \mathrm{~N}, \mathrm{Fe}_{4} \mathrm{~N}, \mathrm{Cu}_{3} \mathrm{~N}$ and $\mathrm{Ni}_{3} \mathrm{~N}$ [222].

The synthesis conditions for the above mentioned transition metal nitrides vary remarkably. The early $3 d$-transition metals are thermodynamically more stable than the later ones, which is manifested in the synthesis of the nitrides of $\mathrm{Ti}$ to $\mathrm{Ni}$ from the metals in supercritical nitrogen at $\sim 1800 \mathrm{~K}$ and 10,000 MPa. Yet, no copper nitrides were obtained from similar conditions [223], although the ammonothermal method in neutral conditions yields up to $10 \mathrm{~mm} \cdot 10 \mathrm{~mm} \cdot 2 \mathrm{~mm} \mathrm{Cu} \mathrm{Cu}_{3} \mathrm{~N}$ crystals [20]. The neutral milieu is applied by using $\left[\mathrm{Cu}\left(\mathrm{NH}_{3}\right)_{4}\right]\left(\mathrm{NO}_{3}\right)_{2}$ as mineralizer in the molar ratio $1: 1$ with $\mathrm{Cu}$ metal at $620-850 \mathrm{~K}$ and $300-800 \mathrm{MPa}$. The reaction proceeds by the comproportion of $\left[\mathrm{Cu}\left(\mathrm{NH}_{3}\right)_{4}\right]\left(\mathrm{NO}_{3}\right)_{2}$ with $\mathrm{Cu}$ metal to $\left[\mathrm{Cu}\left(\mathrm{NH}_{3}\right)_{3}\right] \mathrm{NO}_{3}$, which subsequently forms $\mathrm{Cu}_{3} \mathrm{~N}$ via $\left[\mathrm{Cu}\left(\mathrm{NH}_{3}\right)_{2}\right] \mathrm{NO}_{3}$ [224]. The presence of $\left[\mathrm{Cu}\left(\mathrm{NH}_{3}\right)_{2}\right] \mathrm{NO}_{3}$ crystals next to $\mathrm{Cu}_{3} \mathrm{~N}$ in the product confirms this mechanism. The formation of pure $\mathrm{Cu}_{3} \mathrm{~N}$ without any presence of oxides may surprise given the proposed reaction Equation (11) of nitrate to form water and elemental nitrogen.

$$
3\left[\mathrm{Cu}\left(\mathrm{NH}_{3}\right)_{4}\right] \mathrm{NO}_{3} \rightarrow \mathrm{Cu}_{3} \mathrm{~N}+9 \mathrm{H}_{2} \mathrm{O}+4 \mathrm{~N}_{2}+6 \mathrm{NH}_{3}
$$

However, the oxygen may be catched by the autoclave metal surface. $\mathrm{Cu}_{3} \mathrm{~N}$ crystallizes in the anti- $\mathrm{ReO}_{3}$-type structure, with nitrogen octahedrally surrounded by six $\mathrm{Cu}$ atoms and $\mathrm{Cu}$ forming collinear bonds with two nearest nitrogen atoms. The structure offers vacant sites, which can be

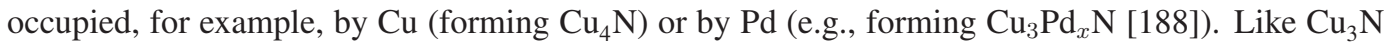
the ternary nitride $\mathrm{Cu}_{3} \mathrm{Pd}_{x} \mathrm{~N}(x=0.020 / 0.989)$ is metastable at ambient temperature and can be obtained from $\mathrm{Cu}$ and $\left[\mathrm{Cu}\left(\mathrm{NH}_{3}\right)_{2}\right] \mathrm{NO}_{3}$ in presence of $\left[\mathrm{Pd}\left(\mathrm{NH}_{3}\right)_{4}\right]\left(\mathrm{NO}_{3}\right)_{2}$ under ammonothermal conditions at $723 \mathrm{~K}$ and $600 \mathrm{MPa}$ [188]. In contrast to semiconducting $\mathrm{Cu}_{3} \mathrm{~N}$, the $\mathrm{Pd}$ doped variant exhibits metallic or semimetallic behavior [225].

Three different manganese nitrides could be obtained under ammonothermal conditions so far: $\Theta-\mathrm{Mn}_{6} \mathrm{~N}_{5}+x$ and $\eta-\mathrm{Mn}_{3} \mathrm{~N}_{2}$ from $\mathrm{MnI}_{2}$ and $\mathrm{NaNH}_{2}$ at $600 \mathrm{MPa}$ and in temperature gradients from $673 \mathrm{~K}$ to $723 \mathrm{~K}$ and $673 \mathrm{~K} 873 \mathrm{~K}$, respectively [167], $\epsilon-\mathrm{Mn}_{4} \mathrm{~N}$ as by-product next to $\mathrm{GaN}$ :Mn during doping of GaN with $\mathrm{Mn}$ at $723-823 \mathrm{~K}$ and $400-500 \mathrm{MPa}$ in ammonobasic milieu [182]. In $\eta-\mathrm{Mn}_{3} \mathrm{~N}_{2}$ the $\mathrm{Mn}$ atoms form an $f c c$ substructure with the $\mathrm{N}$ atoms occupying octahedral sites in such a way 
that perpendicular to [001] two fully occupied layers are followed by an empty one. Occupying all octahedral holes would lead to a rocksalt-type structure, like in the early transition and rare-earth metal nitrides [186]. $\Theta-\mathrm{Mn}_{6} \mathrm{~N}_{5}+x$ realizes such a defect rocksalt structure, however, suffering a tetragonal distortion due to magnetostriction at ambient temperatures [226]. The structure of $\epsilon-\mathrm{Mn}_{4} \mathrm{~N}$ also shows an $f c c$ substructure of Mn atoms. Here the nitrogen atoms only occupy $1 / 4$ of the octahedral voids in an ordered manner forming an inverse perovskite structure. Similar to the case of $\mathrm{Cu}_{3} \mathrm{~N}$, one type of manganese atoms is coordinated linearly by two nitrogen atoms, a second type is exclusively surrounded by Mn of the first type [217].

$\gamma^{\prime}-\mathrm{Fe}_{4} \mathrm{~N}$ an isotype of $\epsilon-\mathrm{Mn}_{4} \mathrm{~N}$, crystallizing in the inverse perovskite structure [183]. However, $\gamma^{\prime}-\mathrm{Fe}_{4} \mathrm{~N}$ obtained from supercritical ammonia [185] contained about $5 \mathrm{wt} . \% \mathrm{Ni}\left(\mathrm{Fe}_{4}-{ }_{x} \mathrm{Ni}{ }_{x} \mathrm{~N}\right)$ [183] The nickel most likely origins from the autoclave wall, since the nickel based alloys used for autoclave manufacturing are corroded to a certain degree under ammonoacidic conditions. $\mathrm{Fe}_{4}{ }_{x} \mathrm{Ni}_{x} \mathrm{~N}$ was obtained from $\mathrm{Fe}$ and $\mathrm{FeI}_{2}$ at 733-853 $\mathrm{K}$ and 600-800 MPa.

$\mathrm{Ni}_{3} \mathrm{~N}$ was synthesized ammonothermally from $\left[\mathrm{Ni}\left(\mathrm{NH}_{3}\right)_{6}\right] \mathrm{Cl}_{2}$ and $\mathrm{NaNH}_{2}$ at $523 \mathrm{~K}$ and $200 \mathrm{MPa}$ in 7 days [187]. $\mathrm{Ni}_{3} \mathrm{~N}$ crystallizes in the $\epsilon-\mathrm{Fe}_{3} \mathrm{~N}$-type structure, with the $\mathrm{Ni}$ atoms realizing the motif of a hexagonal closed packing and the $\mathrm{N}$ atoms occupying corner-sharing octahedra. The $\mathrm{Ni}$ atoms are coordinated by two $\mathrm{N}$ atoms.

\subsection{Non-Nitrogen Compounds}

Solvothermal methods allow crystal growth at comparatively low temperatures. Thus, oxides, carbonates, fluorides, sulfates and sulfide minerals such as proustite $\mathrm{Ag}_{3} \mathrm{AsS}_{3}$ can be grown under hydrothermal conditions [6]. However, use of water as solvent is prohibited in chemical synthesis and crystal growth if the target compound is water sensitive or forms stable solid hydrates. The ammonothermal technique in some cases proves superior even for formation of hydroxides, hydroxide hydrates, sulfides and hydrogen sulfides.

Alkali metal hydroxides, except $\mathrm{LiOH}$, are difficult to grow as crystals suitable for single crystal X-ray diffraction, since they exist in different modifications in the range of ambient temperature to their melting point. Thus, the crystal growth from the melt is inhibited, while during growth from acqueous solution hydroxide hydrates are formed. The ammonothermal method allows the growth of single crystals of $\mathrm{NaOH}, \mathrm{KOH}, \mathrm{RbOH}$ [22] and $\mathrm{CsOH}$ [227] at conditions below the transition temperature of the modification, which is stable at ambient conditions (see Table 11). Some alkali metal hydroxide hydrates were synthesized from ammonothermal synthesis as well. $\mathrm{NaOH}$ [22], $\mathrm{K}\left(\mathrm{H}_{2} \mathrm{O}\right) \mathrm{OH}, \quad \mathrm{Rb}\left(\mathrm{H}_{2} \mathrm{O}\right) \mathrm{OH}$ [228] and $\mathrm{Cs}\left(\mathrm{H}_{2} \mathrm{O}\right) \mathrm{OH}$ [227] crystals were obtained by recrystallization of the micro crystalline substance in supercritical ammonia. The reaction of alkali metal hydroxide hydrates $A(1)\left(\mathrm{H}_{2} \mathrm{O}\right) \mathrm{OH}(A(1)=\mathrm{K}$, $\mathrm{Rb}, \mathrm{Cs})$ with alkali metal amides $A(1) \mathrm{NH}_{2}(A(1)=\mathrm{K}, \mathrm{Rb}, \mathrm{Cs})$ yields crystals of $\mathrm{KOH}, \mathrm{RbOH}$ and $\mathrm{CsOH}$ [227]. This synthesis furnished the first crystallographic data of $\mathrm{CsOH}$. $\mathrm{Ca}(\mathrm{OH})_{2}$ can be obtained at $723 \mathrm{~K}$ and 69-207 MPa in one day from $\mathrm{CaO}$ and $\mathrm{NH}_{4} \mathrm{I}$ [57]. 
Table 11. Conditions for the ammonothermal synthesis of non-nitrogen compound crystals.

\begin{tabular}{|c|c|c|c|c|c|}
\hline Compound & Reactants + mineralizer & $T / \mathbf{K}$ & $p / \mathrm{MPa}$ & $t / d$ & References \\
\hline $\mathrm{NaOH}$ & $\mathrm{NaOH}$ & $523-473$ & $\leq 600$ & 10 & {$[22]$} \\
\hline $\mathrm{KOH}$ & $\mathrm{K}\left(\mathrm{H}_{2} \mathrm{O}\right) \mathrm{OH}+\mathrm{KNH}_{2}$ & $\leq 423$ & $\leq 600$ & $\sim 10$ & {$[22]$} \\
\hline $\mathrm{RbOH}$ & $\mathrm{Rb}\left(\mathrm{H}_{2} \mathrm{O}\right) \mathrm{OH}+\mathrm{RbNH}_{2}$ & $\leq 365$ & $\leq 600$ & $\sim 10$ & {$[22]$} \\
\hline $\mathrm{CsOH}$ & $\mathrm{Cs}\left(\mathrm{H}_{2} \mathrm{O}\right) \mathrm{OH}+\mathrm{CsNH}_{2}$ & 460 & 300 & 5 & [227] \\
\hline $\mathrm{CaOH}$ & $\mathrm{CaO}+\mathrm{NH}_{4} \mathrm{I}$ & 723 & 69-207 & 1 & {$[57,229]$} \\
\hline $\mathrm{K}\left(\mathrm{H}_{2} \mathrm{O}\right) \mathrm{OH}$ & $\mathrm{K}\left(\mathrm{H}_{2} \mathrm{O}\right) \mathrm{OH}$ & $390-410$ & 500 & $7-10$ & {$[228]$} \\
\hline $\mathrm{Rb}\left(\mathrm{H}_{2} \mathrm{O}\right) \mathrm{OH}$ & $\mathrm{Rb}\left(\mathrm{H}_{2} \mathrm{O}\right) \mathrm{OH}$ & $400-420$ & 180 & 6 & [228] \\
\hline $\mathrm{Cs}\left(\mathrm{H}_{2} \mathrm{O}\right) \mathrm{OH}$ & $\mathrm{Cs}\left(\mathrm{H}_{2} \mathrm{O}\right) \mathrm{OH}$ & 450 & 250 & 8 & {$[227]$} \\
\hline LiHS & $\mathrm{LiNH}_{2}+\mathrm{H}_{2} \mathrm{~S}$ & $300-370$ & - & - & {$[3,230]$} \\
\hline KHS & $\mathrm{KNH}_{2}+\mathrm{H}_{2} \mathrm{~S}$ & 393 & $\leq 30$ & 7 & {$[3,231]$} \\
\hline $\mathrm{CaS}$ & $\mathrm{CaS}+\mathrm{NH}_{4} \mathrm{I}$ & $573-673$ & 69-207 & 1 & {$[57,229]$} \\
\hline $\mathrm{SrS}$ & $\mathrm{SrS}+\mathrm{NH}_{4} \mathrm{I}$ & $573-673$ & 69-207 & 1 & {$[57,229]$} \\
\hline $\mathrm{CdS}$ & $\mathrm{CdS}+\mathrm{NH}_{4} \mathrm{I}$ & $573-673$ & 69-207 & 1 & {$[57,229]$} \\
\hline $\mathrm{CuS}$ & $\mathrm{CuI}+\mathrm{CaS}+\mathrm{NH}_{4} \mathrm{I}$ & 643 & 69-207 & 1 & [229] \\
\hline $\mathrm{Cu}_{7} \mathrm{~S}_{4}$ & $\mathrm{CuI}+\mathrm{CaS}+\mathrm{NH}_{4} \mathrm{I}$ & 643 & 69-207 & 1 & [229] \\
\hline $\mathrm{CaCu}_{2} \mathrm{~S}_{2}$ & $\mathrm{CuI}+\mathrm{CaS}+\mathrm{NH}_{4} \mathrm{I}$ & $573-673$ & 69-207 & 1 & {$[57,229]$} \\
\hline $\mathrm{NH}_{4} \mathrm{Cu}_{4} \mathrm{~S}_{3}$ & $\mathrm{CuI}+\mathrm{CaS}+\mathrm{NH}_{4} \mathrm{I}$ & $573-673$ & 69-207 & 1 & [229] \\
\hline $\mathrm{Na}_{2} \mathrm{~S}_{2}$ & $\mathrm{a}$ & & & & {$[3,232]$} \\
\hline $\mathrm{K}_{2} \mathrm{~S}_{2}$ & a & & & & {$[3,232]$} \\
\hline $\mathrm{Rb}_{2} \mathrm{~S}_{2}$ & a & & & & {$[3,232]$} \\
\hline $\mathrm{Cs}_{2} \mathrm{~S}_{2}$ & $\mathrm{Cs}+\mathrm{Se}$ & 573 & $200-300$ & - & [21] \\
\hline $\mathrm{Na}_{2} \mathrm{~S}_{3} \cdot \mathrm{NH}_{3}$ & $\mathrm{Na}+\mathrm{S}$ & $300-320$ & 200 & - & [233] \\
\hline $\mathrm{K}_{2} \mathrm{~S}_{3}$ & $\mathrm{~K}+\mathrm{S}$ & 423 & 50 & - & [234] \\
\hline $\mathrm{Rb}_{2} \mathrm{~S}_{3}$ & $\mathrm{Rb}+\mathrm{S}$ & 670 & 300 & - & [235] \\
\hline $\mathrm{Cs}_{2} \mathrm{~S}_{3}$ & $\mathrm{Cs}+\mathrm{S}$ & 370 & 50 & - & {$[235]$} \\
\hline $\mathrm{K}_{2} \mathrm{~S}_{5}$ & $\mathrm{a}$ & & & & {$[3,232]$} \\
\hline $\mathrm{Rb}_{2} \mathrm{~S}_{5}$ & $\mathrm{Rb}+\mathrm{S}$ & 450 & 5 & - & [236] \\
\hline $\mathrm{Cs}_{2} \mathrm{~S}_{5}$ & $\mathrm{Cs}+\mathrm{S}$ & $323-373$ & 10-200 & - & [237] \\
\hline $\mathrm{Cs}_{2} \mathrm{Se}$ & $\mathrm{Cs}+\mathrm{Se}$ & 573 & 200 & - & {$[3,238]$} \\
\hline $\mathrm{Na}_{2} \mathrm{Se}_{2}$ & a & & & & {$[3,232]$} \\
\hline
\end{tabular}


Table 11. Cont.

\begin{tabular}{lccccc}
\hline Compound & Reactants + mineralizer & $\boldsymbol{T} / \mathbf{K}$ & $\boldsymbol{p} / \mathbf{M P a}$ & $\boldsymbol{t} / \mathbf{d}$ & References \\
\hline $\mathrm{K}_{2} \mathrm{Se}_{2}$ & $\mathrm{a}$ & & & & {$[3,232]$} \\
$\mathrm{Rb}_{2} \mathrm{Se}_{2}$ & $\mathrm{a}$ & & & & {$[3,232]$} \\
$\mathrm{Cs}_{2} \mathrm{Se}_{2} \cdot x \mathrm{NH}_{3}$ & $\mathrm{a}$ & & & & {$[3,232]$} \\
$\mathrm{K}_{2} \mathrm{Se}_{3}$ & $\mathrm{~K}+\mathrm{Se}$ & 423 & 50 & - & {$[234]$} \\
$\mathrm{Rb}_{2} \mathrm{Se}_{3}$ & $\mathrm{Rb}+\mathrm{Se}$ & 600 & 100 & - & {$[235]$} \\
$\mathrm{Cs}_{2} \mathrm{Se}_{3}$ & $\mathrm{Cs}+\mathrm{Se}$ & 570 & 300 & - & {$[235]$} \\
$\mathrm{Rb}_{2} \mathrm{Se}_{5}$ & $\mathrm{Rb}+\mathrm{S}$ & 450 & 500 & - & {$[236]$} \\
$\mathrm{K}_{2} \mathrm{Te}_{3}$ & $\mathrm{a}$ & & & & {$[3,232]$} \\
$\mathrm{Rb}_{2} \mathrm{Te}_{3}$ & $\mathrm{Rb}+\mathrm{Te}$ & 500 & 100 & - & {$[239]$} \\
$\mathrm{Cs}_{2} \mathrm{Te}_{3}$ & $\mathrm{Cs}+\mathrm{Te}$ & 500 & 100 & - & {$[239]$} \\
$\mathrm{Rb}_{2} \mathrm{Te}_{5}$ & $\mathrm{Rb}+\mathrm{Te}$ & 473 & 200 & 7 & {$[56]$} \\
$\mathrm{Cs}_{2} \mathrm{Te}_{5}$ & $\mathrm{Cs}+\mathrm{Te}$ & 473 & 200 & 90 & {$[240]$} \\
$\mathrm{K}_{2}\left[\mathrm{CN}_{2}\right]$ & $\mathrm{Ga}+\mathrm{K}$ & 853 & 90 & - & {$[177]$} \\
\hline
\end{tabular}

${ }^{a}$ No further information in literature.

For the synthesis of alkali metal hydrogen sulfides and selenides the common methods (e.g., molten metals or hydrogen sulfide hydrates in $\mathrm{H}_{2} \mathrm{~S}$ stream, precipitation from a saturated solution) usually yield micro crystalline products. The application of liquid or supercritical ammonia in combination with $\mathrm{H}_{2} \mathrm{~S}$ on alkali metal amides leads to well crystallized alkali metal hydrogen sulfide suitable for single crystal XRD, for example, LiHS and KHS (see Table 11) [3].

Micro crystalline metal sulfides $\mathrm{CaS}, \mathrm{SrS}$ and $\mathrm{CdS}$ can be recrystallized in supercritical ammonia, using $\mathrm{NH}_{4} \mathrm{I}$ as mineralizer, at 573-673 $\mathrm{K}$ and 69-207 $\mathrm{MPa}$ in one day [57]. $\mathrm{CuS}, \mathrm{Cu}_{7} \mathrm{~S}_{4}$ and $\mathrm{NH}_{4} \mathrm{Cu}_{4} \mathrm{~S}_{3}$ were obtained at $573-673 \mathrm{~K}$ and 69-207 MPa as by-products during the synthesis of $\mathrm{CaCu}_{2} \mathrm{~S}_{2}$ from CaS, CuI, $\mathrm{NH}_{4} \mathrm{I}$ in supercritical ammonia [229] (for details see Table 11).

Reactions of alkali metals with elemental chalcogens in supercritical or subcritical ammonia (e.g., $\mathrm{Cs}_{2} \mathrm{~S}_{5}$ [237]) lead to various polychalcogenides of the types $A(1)_{2} E_{2}(A(1)=\mathrm{Na}, \mathrm{K}, \mathrm{Rb}, \mathrm{Cs}$; $E=\mathrm{S}, \mathrm{Se}, \mathrm{Te})$ and $A(1)_{2} E_{5}(A(1)=\mathrm{Na}, \mathrm{K}, \mathrm{Rb}, \mathrm{Cs} ; E=\mathrm{S}, \mathrm{Se})$ [3], namely, $\mathrm{Na}_{2} \mathrm{~S}_{3}$ [233], $\mathrm{K}_{2} \mathrm{~S}_{3}$ [234], $\mathrm{Rb}_{2} \mathrm{~S}_{3}$ [235], $\mathrm{Cs}_{2} \mathrm{~S}_{3}$ [235], $\mathrm{Cs}_{2} \mathrm{~S}_{5}$ [237], $\mathrm{K}_{2} \mathrm{Se}_{3}$ [234], $\mathrm{Rb}_{2} \mathrm{Se}_{3}$ [235], $\mathrm{Cs}_{2} \mathrm{Se}_{3}$ [235], $\mathrm{Rb}_{2} \mathrm{Te}_{3}$ [239], $\mathrm{Cs}_{2} \mathrm{Te}_{3}$ [239], $\mathrm{Rb}_{2} \mathrm{Te}_{5}$ [56], $\mathrm{Cs}_{2} \mathrm{Te}_{5}$ [240]. Also, $\mathrm{Cs}_{2} \mathrm{Se}$ [3,238] and $\mathrm{Cs}_{2} \mathrm{~S}_{2}$ [21] form under ammonothermal conditions and two alkali metal sulfide or selenide ammoniates were reported $\mathrm{Na}_{2} \mathrm{~S}_{3} \cdot \mathrm{NH}_{3}$ [233] and $\mathrm{Cs}_{2} \mathrm{Se}_{2} \cdot x \mathrm{NH}_{3}$ [3,232]. For the reaction conditions see Table 11. $\mathrm{Na}_{2} \mathrm{~S}_{3} \cdot \mathrm{NH}_{3}$ [233], $\mathrm{Cs}_{2} \mathrm{~S}_{5}$ [237] and $\mathrm{Rb}_{2} \mathrm{~S}_{5}$ [236] were synthesized under subcritical conditions, but are mentioned for reasons of completeness. Although, some of those compounds were already known prior the introduction of ammonothermal synthesis in this field, a large number of structure determinations suceeded only thanks to single crystals grown from supercritical ammonia. In all mentioned polychalcogenides anions of the type $E_{n}^{2-}(E=\mathrm{S}, \mathrm{Se}, \mathrm{Te}, n=2-5)$ occur. There is a significant reduction of the distances between the anions of the type $E_{n}^{2-}(E=\mathrm{S}$, Se, Te, $n=2-6)$ in the alkali metal polychalcogenides 
osberved with increasing atomic weight of the chalcogen atom. This leads to extended anionic networks, e.g., in $\mathrm{RbTe}_{5}$ and $\mathrm{CsTe}_{5}$ [56].

Smaller complex anions occur in $\mathrm{K}_{2} \mathrm{~S}_{3}, \mathrm{~K}_{2} \mathrm{Se}_{3}$ [234], $\mathrm{Rb}_{2} \mathrm{~S}_{3}, \mathrm{Rb}_{2} \mathrm{Se}_{3}, \mathrm{Cs}_{2} \mathrm{~S}_{3}, \mathrm{Cs}_{2} \mathrm{Se}_{3}$ [235] and $\mathrm{Cs}_{2} \mathrm{Te}_{3}$ [239]. These compounds crystallize isoytpically in the $\mathrm{K}_{2} \mathrm{~S}_{3}$-type structure and contain kinked $\left[\mathrm{S}_{3}\right]^{2-}$ and $\left[\mathrm{Se}_{3}\right]^{2-}$ anions, respectively. The alkali metal cations occupy $1 / 2$ of trigonal prisms formed by four or five $\left[\mathrm{S}_{3}\right]^{2-}$ or $\left[\mathrm{Se}_{3}\right]^{2-}$ groups, resulting in a coordination number $1+6$ for the cations, with one shorter ( $\mathrm{S} / \mathrm{Se}$ atom above plane of prism) and six larger distances ( $\mathrm{S} / \mathrm{Se}$ atoms in corners of the polyhedron) [234]. Interestingly, although $\mathrm{Cs}_{2} \mathrm{Te}_{3}$ crystallizes in the $\mathrm{K}_{2} \mathrm{~S}_{3}$-type structure, $\mathrm{Rb}_{2} \mathrm{Te}_{3}$ crystallizes with the $\mathrm{K}_{2} \mathrm{Te}_{3}$-type structure [239]. Still, both structures contain $\mathrm{Te}_{3}^{2-}$ polyanions. The reaction of alkali or alkaline-earth metals with carbon impurities under ammonothermal conditions leading to carbodiimides or cyanamides has already been discussed in paragraph Imides, Nitride Imides, Nitride Amides and Amide Azides. In this way $\mathrm{K}_{2}\left[\mathrm{CN}_{2}\right]$ was obtained as by-product during the synthesis of $\mathrm{GaN}$ from $\mathrm{Ga}$ and $\mathrm{K}$ metal with unintentional carbon impurities at $853 \mathrm{~K}$ and $90 \mathrm{MPa}$ [177]. From a supercritical ammonia-methanol mixture at 443-563 K and $16 \mathrm{MPa}$ some nano crystalline oxides were obtained, namely $\mathrm{Al}_{2} \mathrm{O}_{3}, \mathrm{TiO}_{2}$ and $\mathrm{Ga}_{2} \mathrm{O}_{3}$ [222].

\section{Conclusions}

The ammonothermal synthesis is a useful technique suitable for various applications: for commercial large scale productions just as well as for small scale fundamental research. Its advantages for commercial applications are obviously the synthesis of bulk material even of difficult to crystallize compounds (for example, AlN and GaN), the high purity and low defect concentration of the products, due to the inherent chemical material transport, the comparatively mild conditions and the high scalability. For small scale fundamental research the method offers the crystal growth and stabilization of various materials, which are difficultly to crystallize by other synthesis routes, the decrease of reaction time compared to other methods and the access to new materials, which are not accessible by other methods. Nevertheless, the method has its limitations in temperature and pressure. The maximum temperature and pressure vary strongly, depending on the used reaction vessel design and material. Additionally, the corrosion of the autoclave material affects the purity of the products and the working lifetime of the autoclave. The use of a suitable liner material (e.g., precious metals, ceramics) can reduce the corrosion considerably and new constructions with inner heating and counter pressure allow the application of higher temperatures and pressures. Recent research reports indicate the suitability of the ammonothermal method in particular for commercial GaN crystal growth, due to competitive growth rates, high quality and high scalability. However, it is crucial for both the synthesis of novel materials and the improvement of the growth of large crystals to develop a fundamental comprehension of the physical and chemical processes during ammonothermal crystal growth. Knowledge about the thermodynamical and the chemical parameters will permit a specific and well-directed growth of novel functional materials.

The preparative possibilities of ammonothermal synthesis, more than fifty years after the beginning of development, are still far from exhausted. Tasks and future directions are manifold, starting from further exploration of new chemical compounds and materials synthesized by this 
technique including solid solutions and doped systems with potential for various applications. For this task a deeper understanding of the influence of starting materials, i.e., nutrients for crystal growth as well as the chemistry of the diverse mineralizers and co-mineralizers is badly needed. There is only little knowledge about dissolved species of the various constituents eventually forming the desired products under ammonobasic, ammononeutral and ammonoacidic conditions, depending on temperature, pressure and concentrations. This directly relates to the fundamental physical properties of the ammonia-based solutions of the mineralizers and dissolved materials, which will significantly deviate from those of pure ammonia, e.g., in terms of pressure-temperature relations. Similarly, more complex solutions, like, for example, buffer systems modifying the properties of the solvent with direct influence on the chemistry within the solution. Combined solvent systems as, e.g., ammonia-alcohol mixtures specially tailored for the desired products are a further completely open field, where scientists in the field just have scratched the surface of possibilities. The information on physical properties of ammonia-based solvents and chemistry in solution during the ammonothermal process will clearly lead to new directions of exploratory chemistry. Additionally, it will aid the improved mass-production of better semiconductor materials in sense of lower impurity and defect levels, enhanced growth rates of different crystallographic faces or even improved reactor design, due to a better understanding of dissolution, transport and material deposition processes including transport direction in the gradient and solubility of the desired material within the ammono-based solution. The latter point may lead to new concepts and combinations of nutrient, mineralizer, co-mineralizer and more complex solvent combinations. In terms of technical improvements, we will surely soon see novel liner materials and concepts as well as autoclaves for higher pressures or higher temperatures to be developed, in order to broaden the approachable range in synthetic chemistry and enhance the crystal growth process for commercial products. These commercial products in future may not only be restricted to $h$-GaN crystals, but be broadened to AlN, GaN-based solid solutions, further nitride-based materials and possibly even compounds not containing nitrogen. All in all, we see great prospects for solvothermal reactions in general, but for ammonothermal synthesis, crystal growth and materials production in particular.

\section{Acknowledgments}

This work was funded by the Deutsche Forschungsgemeinschaft (DFG) within the frame of the research group FOR1600 "Chemie und Technologie der Ammonothermal-Synthese von Nitriden". We thank all cooperation partners from FOR1600, in particular the group of Eberhard Schlücker and Nicolas Alt (Friedrich-Alexander Universität Erlangen-Nürnberg), without which our experimental work in this field would not be possible.

\section{Conflicts of Interest}

The authors declare no conflict of interest. 


\section{References}

1. Juza, R.; Jacobs, H.; Gerke, H. Ammonothermalsynthese von Metallamiden und Metallnitriden. Ber. Bunsenges. Phys. Chem. 1966, 70, 1103-1105.

2. Juza, R.; Jacobs, H. Ammonothermal synthesis of magnesium and beryllium amides. Angew. Chem. Int. Ed. 1966, 5, 247.

3. Jacobs, H.; Schmidt, D. High-pressure ammonolysis in solid-state chemistry. Curr. Top. Mater. Sci. 1982, 8, 387-427.

4. Byrappa, K.; Yoshimura, M. Handbook of Hydrothermal Technology a Technology for Crystal Growth and Materials Processing; Noyes Publications/Wiliam Andrew Publishing, LLC: Park Ridge, NY, USA, 2001.

5. Largeteau, A.; Darracq, S.; Goglio, G.; Demazeau, G. Solvothermal crystal growth of functional materials. High Press. Res. 2008, 28, 503-508.

6. Rabenau, A. The role of hydrothermal synthesis in preparative chemistry. Angew. Chem. Int. Ed. 1985, 24, 1026-1040.

7. Demazeau, G. Solvothermal reactions: An original route for the synthesis of novel materials. J. Mater. Sci. 2007, 43, 2104-2114.

8. Li, B.B.; Xie, Y.; Huang, J.; Qian, Y. Synthesis by a solvothermal route and characterization of CuInSe ${ }_{2}$ nanowhiskers and nanoparticles. Adv. Mater. 1999, 11, 1456-1459.

9. Li, Y.D.; Duan, X.F.; Qian, Y.T.; Yang, L.; Ji, M.R.; Li, C.W. Solvothermal co-reduction route to the nanocrystalline III-V semiconductor InAs. J. Am. Chem. Soc. 1997, 119, 7869-7870.

10. Dwiliński, R.; Wysmolek, A.; Baranowski, J.; Kamińska, M.; Doradziński, R.; Jacobs, H. GaN synthesis by ammonothermal method. Acta Phys. Pol. A 1995, 88, 833-836.

11. Lan, Y.C.; Chen, X.L.; Cao, Y.G.; Xu, Y.P.; Xun, L.; Xu, T.; Liang, J.K. Low-temperature synthesis and photoluminescence of AlN. J. Cryst. Growth 1999, 207, 247-250.

12. Nicholas, N.J.; Franks, G.V.; Ducker, W.A. The mechanism for hydrothermal growth of zinc oxide. CrystEngComm 2012, 14, 1232-1240.

13. Nacken, R. Hydrothermale Mineralsynthese zur Züchtung von Quarzkristallen. Chem. Ztg. 1950, 74, 745-749.

14. Gleichmann, H.; Richert, H.; Hergt, R.; Barz, R.U.; Grassl, M. Hydrothermal liquid phase epitaxy of gallium orthophosphate on quartz crystal substrates. Cryst. Res. Technol. 2001, $36,1181-1188$.

15. Li, W.J.; Shi, E.W.; Chen, Z.Z.; Zhen, Y.Q.; Yin, Z.W. Solvothermal synthesis of superfine $\mathrm{Li}_{1-x} \mathrm{Mn}_{2} \mathrm{O}_{4-\sigma}$ powders. J. Solid State Chem. 2002, 163, 132-136.

16. Vázquez-Vázquez, C.; López-Quintela, A.M. Solvothermal synthesis and characterisation of $\mathrm{La}_{1-x} \mathrm{~A}_{x} \mathrm{MnO}_{3}$ nanoparticles. J. Solid State Chem. 2006, 179, 3229-3237.

17. Bocquet, J.F.; Chhor, K.; Pommier, C. Barium titanate powders synthesis from solvothermal reaction and supercritical treatment. Mater. Chem. Phys. 1999, 57, 273-280. 
18. Suchanek, W. Hydrothermal synthesis of alpha alumina $\left(\alpha-\mathrm{Al}_{2} \mathrm{O}_{3}\right)$ powders: Study of the processing variables and growth mechanisms. J. Am. Ceram. Soc. 2010, 93, 399-412.

19. Korablov, S.; Yokosawa, K.; Korablov, D.; Tohji, K.; Yamasaki, N. Hydrothermal formation of diamond from chlorinated organic compounds. Mater. Lett. 2006, 60, 3041-3044.

20. Zachwieja, U.; Jacobs, H. Ammonothermalsynthese von Kupfernitrid, $\mathrm{Cu}_{3} \mathrm{~N}$. J. Less-Common Met. 1990, 161, 175-184.

21. Böttcher, P. Zur Synthese und Struktur von $\mathrm{Cs}_{2} \mathrm{~S}_{2}$. J. Less-Common Met. 1979, 63, 99-103.

22. Jacobs, H.; Kockelkorn, J.; Tacke, T. Hydroxide des Natriums, Kaliums und Rubidiums: Einkristallzüchtung und Röntgenographische Strukturbestimmung an der bei Raumtemperatur stabilen Modifikation. Z. Anorg. Allg. Chem. 1985, 531, 119-124.

23. Popolitov, V.; Litvin, B.; Lobachev, A. Hydrothermal crystallization of semiconducting compounds of group $\mathrm{A}^{V} \mathrm{~B}^{V I} \mathrm{C}^{V I I}\left(\mathrm{~A}^{V}: \mathrm{Sb}, \mathrm{Bi} ; \mathrm{B}^{V I}: \mathrm{S}, \mathrm{Se}, \mathrm{Te} ; \mathrm{C}^{V I I}: \mathrm{I}, \mathrm{Br}, \mathrm{Cl}\right)$. Phys. Status Solidi A 1970, 3, K1-K4.

24. Li, B.; Xie, Y.; Huang, J.; Su, H.; Qian, Y. A Solvothermal route to nanocrystalline $\mathrm{Cu}_{7} \mathrm{Te}_{4}$ at low temperature. J. Solid State Chem. 1999, 146, 47-50.

25. Lu, J.; Qi, P.; Peng, Y.; Meng, Z.; Yang, Z. Metastable MnS crystallites through solvothermal synthesis. Chem. Mater. 2001, 13, 2169-2172.

26. Hao, X.; Yu, M.; Cui, D.; Xu, X.; Wang, Q.; Jiang, M. The effect of temperature on the synthesis of BN nanocrystals. J. Cryst. Growth 2002, 241, 124-128.

27. Ramesha, K.; Seshadri, R. Solvothermal preparation of ferromagnetic sub-micron spinel $\mathrm{CuCr}_{2} \mathrm{Se}_{4}$ particles. Solid State Sci. 2004, 6, 841-845.

28. Kendall, J.L.; Canelas, D.A.; Young, J.L.; deSimone, J.M. Polymerizations in supercritical carbon dioxide. Chem. Rev. 1999, 99, 543-564.

29. Bunsen, R. Über die Spannkraft einiger condensirten Gase. Ann. Phys. 1839, 46, 97-103.

30. Bunsen, R. Bemerkungen zu einigen Einwürfen gegen mehrere Ansichten über die chemisch-geologischen Erscheinungen in Island. Liebigs Ann. 1848, 65, 70-85.

31. Schafhäutl, A. Die neuesten geologischen Hypothesen und ihr Verhältnis zur Naturwissenschaft überhaupt. Gelehrte Anzeigen München 1845, 20, 577.

32. De Sénarmont, M. Sur la formation des minéraux par voie humide dans les gites métallifères concrétionnés. Ann. Chim. Phys. 1851, 32, 129-175.

33. Blunck, H.; Juza, R. Verbindungen des Thoriums mit Stickstoff und Wasserstoff. Z. Anorg. Allg. Chem. 1974, 410, 9-20.

34. Akasaki, I. Nitride semiconductors-Impact on the future world. J. Cryst. Growth 2002, 237-239, 905-911.

35. Zhu, D.; Wallis, D.; Humphreys, C. Prospects of III-nitride optoelectronics grown on Si. Rep. Progr. Phys. 2013, 76, 106501.

36. Ehrentraut, D.; Meissner, E.; Bockowski, M. Technology of Gallium Nitride Crystal Growth; Springer Materials Sciences: Berlin Heidelberg, Germany, 2010.

37. Denis, A.; Goglio, G.; Demazeau, G. Gallium nitride bulk crystal growth processes: A review. Mater. Sci. Eng. R. 2006, R50, 167-194. 
38. Dwiliński, R.; Doradziński, R.; Garczyński, J.; Sierzputowski, L.; Puchalski, A.; Kanbara, Y.; Yagi, K.; Minakuchi, H.; Hayashi, H. Bulk ammonothermal GaN. J. Cryst. Growth 2009, 311, 3015-3018.

39. Ehrentraut, D.; Pakalapati, R.T.; Kamber, D.S.; Jiang, W.; Pocius, D.W.; Downey, B.C.; Mclaurin, M.; D’Evelyn, P.M. High quality, low cost ammonothermal bulk GaN substrates. Jpn. J. Appl. Phys. 2013, 52, 1-4.

40. Kim, E. Next Generation LED-SORAA. In Proceedings of Strategies in Light: Santa Clara Convention, Silicon Valley, CA, USA, 2 August 2012.

41. Letts, E. Development of GaN wafers for solid-state lighting via the ammonothermal method. In Proceedings of 8th International Workshop on Bulk Nitride Semiconductors, Seeon, Germany, 1 October 2013.

42. D’Evelyn, P.M.; Park, D.S.; LeBoeuf, S.F.; Rowland, L.B.; Narang, K.J.; Hong, H.; Arthur, S.D.; Sandvik, M. Gallium nitride crystals and wafers and method of making. US Patent 7,786,503 B2, 31 August 2010.

43. Wang, B.; Callahan, M. Ammonothermal synthesis of III-nitride crystals. Cryst. Growth Des. 2006, 6, 1227-1246.

44. Ehrentraut, D.; Sato, H.; Kagamitani, Y.; Sato, H.; Yoshikawa, A.; Fukuda, T. Solvothermal growth of ZnO. Progr. Cryst. Growth Charact. Mater. 2006, 52, 280-335.

45. Tomida, D.; Kagamitani, Y.; Bao, Q.; Hazu, K.; Sawayama, H.; Chichibu, S.F.; Yokoyama, C.; Fukuda, T.; Ishiguro, T. Enhanced growth rate for ammonothermal gallium nitride crystal growth using ammonium iodide mineralizer. J. Cryst. Growth 2012, 353, 59-62.

46. Bao, Q.; Saito, M.; Hazu, K.; Furusawa, K.; Kagamitani, Y.; Kayano, R.; Tomida, D.; Qiao, K.; Ishiguro, T.; Yokoyama, C.; et al. Ammonothermal crystal growth of GaN using an $\mathrm{NH}_{4} \mathrm{~F}$ mineralizer. Cryst. Growth Des. 2013, 13, 4158-4161.

47. Holleman, A.; Wiberg, N.; Wiberg, E. Lehrbuch der Anorganischen Chemie, 102nd ed.; de Gruyter: Berlin, Germany, 2007.

48. Franklin, E.C.; Fernelius, W.C. The Nitrogen System of Compounds; Reinhold Publishing Corporation: New York, NY, USA, 1935.

49. Bronn, J. Über den Zustand der metallischen Lösungen. Ann. Phys. 1905, 16, 166-171.

50. Kraus, C.A. Solutions of metals in non-metallic solvents. VI. The conductance of the alkali metals in liquid ammonia. J. Am. Chem. Soc. 1921, 43, 749-770.

51. Haar, L.; Gallagher, J. Thermodynamic properties of ammonia. J. Phys. Chem. Ref. Data 1978, 7, 635-792.

52. Xiang, H.W. Vapor pressures, critical parameters, boiling points, and triple points of ammonia and trideuteroammonia. J. Phys. Chem. Ref. Data 2004, 33, 1005.

53. Lemmon, E.W.; McLinden, M.O.; Friend, D.G. Thermophysical properties of fluid systems, NIST standard reference data. Available online: http://webbook.nist.gov/chemistry/fluid/ (accessed on 9 December 2013). 
54. Shatenshtein, A.I. A study of acid catalysis in liquid ammonia. J. Am. Chem. Soc. 1937, 59, 432-435.

55. Rondinini, S.; Longhi, P.; Mussini, P.R.; Mussini, T. Autoprotolysis constants in nonaqueous solvents and aqueous organic solvent mixtures. Pure Appl. Chem. 1987, 59, 1693-1702.

56. Böttcher, P.; Kretschmann, U. Darstellung und Kristallstruktur von Dirubidiumpentatellurid, $\mathrm{Rb}_{2} \mathrm{Te}_{5}$. J. Less-Common Met. 1983, 95, 81-91.

57. Purdy, A.P. Ammonothermal crystal growth of sulfide materials. Chem. Mater. 1998, 10, 692-694.

58. Glasser, L. Equations of state and phase diagrams of ammonia. J. Chem. Educ. 2009, 86, 1457-1458.

59. Alt, N.S.A.; Schlücker, E. Hochdruck-Sichtzelle für Untersuchungen des ammonothermalen Prozesses. Chem. Ing. Tech. 2011, 83, 280-285.

60. Alt, N.S.A.; Meissner, E.; Schlücker, E. Development of a novel in situ monitoring technology for ammonothermal reactors. J. Cryst. Growth 2012, 350, 2-4.

61. Hüttig, G.F. Apparat zur gleichzeitigen Druck- und Raummessung von Gasen (Tensi-eudiometer). Z. Anorg. Allg. Chem. 1920, 114, 161-173.

62. Yoshida, K.; Aoki, K.; Fukuda, T. High-temperature acidic ammonothermal method for GaN crystal growth. J. Cryst. Growth 2013, in press.

63. Callahan, M.J.; Chen, Q.S.C. Hydrothermal and Ammonothermal Growth of $\mathrm{ZnO}$ and GaN. In Handbook of Crystal Growth, 1st ed.; Dhanaraj, G., Byrappa, K., Prasad, V., Dudley, M., Eds.; Springer: Berlin/ Heidelberg, Germany, 2010; pp. 655-689.

64. Binnewies, M.; Glaum, R.; Schmidt, M.; Schmidt, P. Chemical Vapor Transport Reactions; Walter de Gruyter: Berlin, Germany \& Boston, MA, USA, 2012.

65. Wang, B.; Callahan, M. Transport growth of GaN crystals by the ammonothermal technique using various nutrients. J. Cryst. Growth 2006, 291, 455-460.

66. Zhang, S.; Hintze, F.; Schnick, W.; Niewa, R. Intermediates in ammonothermal GaN crystal growth under ammonoacidic conditions. Eur. J. Inorg. Chem. 2013, 2013, 5387-5399.

67. Zhang, S.; Alt, N.S.A.; Schlücker, E.; Niewa, R. Novel alkali metal amidogallates as intermediates in ammonothermal GaN crystal growth. J. Cryst. Growth 2013, in press.

68. Alt, N.S.A.; Meissner, E.; Schlücker, E.; Frey, L. In situ monitoring technologies for ammonothermal reactors. Phys. Status Solidi C 2012, 9, 436-439.

69. Erlekampf, J.; Seebeck, J.; Savva, P.; Meissner, E.; Friedrich, J.; Alt, N.; Schlücker, E.; Frey, L. Numerical time-dependent 3D simulation of flow pattern and heat distribution in an ammonothermal system with various baffle shapes. J. Cryst. Growth 2014, in press.

70. Vogelsang, K.; Schröter, W.; Hoffmann, R.; Jacobs, H. Ein Beitrag zum Problem der Porenbildung. Härterei Techn. Mitt. 2002, 57, 42-48.

71. Cundy, C.S.; Cox, P.a. The hydrothermal synthesis of zeolites: Precursors, intermediates and reaction mechanism. Microporous Mesoporous Mater. 2005, 82, 1-78.

72. Moolenaar, R.J.; Evans, J.C.; McKeever, L.D. The structure of the aluminate ion in solutions at high pH. J. Phys. Chem. 1970, 74, 3629-3636. 
73. Juza, R. Amides of the alkali and the alkaline earth metals. Angew. Chem. Int. Ed. 1964, 3, 471-481.

74. Juza, R. Über die Amide der 1. und 2. Gruppe des periodischen Systems. Z. Anorg. Allg. Chem. 1937, 231, 121-135.

75. Juza, R. Über ein Nitridamid des Zirkoniums. Z. Anorg. Allg. Chem. 1974, 406, 145-152.

76. Jacobs, H.; Kablitz, D. Untersuchung des Systems Kalium/Cer/Ammoniak. Z. Anorg. Allg. Chem. 1979, 454, 35-42.

77. Dwiliński, R.; Baranowski, J.; Kamińska, M. On GaN crystallization by ammonothermal method. Acta Phys. Pol. A 1996, 90, 763-766.

78. Peters, D. Ammonothermal synthesis of aluminum nitride. J. Cryst. Growth 1990, 104, 411-418.

79. Lan, Y.; Chen, X.L.; Xu, Y.; Cao, Y.; Huang, F. Syntheses and structure of nanocrystalline gallium nitride obtained from ammonothermal method using lithium metal as mineralizator. Mater. Res. Bull. 2000, 35, 2325-2330.

80. Guarino, R.; Rouxel, J. L'amidogallate de potassium $\mathrm{KGa}\left(\mathrm{NH}_{2}\right)_{4}$ et l'imidogallate $\mathrm{KGa}(\mathrm{NH})_{2}$. L'obtention de l'amidure de gallium $\mathrm{Ga}\left(\mathrm{NH}_{2}\right)_{3}$. Bull. Soc. Chim. Fr. 1969, 7, 2284-2287.

81. Jacobs, H.; Nöcker, B. Neubestimmung von Struktur und Eigenschaften isotyper Natriumtetraamidometallate des Aluminiums und Galliums. Z. Anorg. Allg. Chem. 1993, 619, 381-386.

82. Molinié, P.; Brec, R.; Rouxel, J. Le pentaamidogallate de sodium: $\mathrm{Na}_{2} \mathrm{Ga}\left(\mathrm{NH}_{2}\right)_{5}$. C. $R$. Hebd. Seances Acad. Sci. C 1972, 274, 1388-1391.

83. Ketchum, D.; Schimek, G.; Pennington, W.; Kolis, J. Synthesis of new group III fluoride-ammonia adducts in supercritical ammonia: Structures of $\mathrm{AlF}_{3}\left(\mathrm{NH}_{3}\right)_{2}$ and $\mathrm{InF}_{2}\left(\mathrm{NH}_{2}\right)\left(\mathrm{NH}_{3}\right)$. Inorg. Chim. Act. 1999, 294, 200-206.

84. Jacobs, H.; Schröder, F.O. Penta-ammoniates of aluminium halide: The crystal structures of $\mathrm{AlX}_{3} \cdot 5 \mathrm{NH}_{3}$ with $\mathrm{X}=\mathrm{Cl}, \mathrm{Br}$, I. Z. Anorg. Allg. Chem. 2002, 628, 951-955.

85. Johnson, W.C.; Parsons, J.B. Nitrogen compounds of gallium. J. Phys. Chem. 1932, 36, 2588-2594.

86. Wang, B.; Callahan, M.; Rakes, K.; Bouthillette, L.; Wang, S.Q.; Bliss, D.; Kolis, J. Ammonothermal growth of GaN crystals in alkaline solutions. J. Cryst. Growth 2006, 287, 376-380.

87. Ehrentraut, D.; Kagamitani, Y.; Yokoyama, C.; Fukuda, T. Physico-chemical features of the acid ammonothermal growth of GaN. J. Cryst. Growth 2008, 310, 891-895.

88. Purdy, A.P. Ammonothermal synthesis of cubic gallium nitride. Chem. Mater. 1999, 11, 1648-1651.

89. Peters, D.; Bock, J.; Jacobs, H. Hexaaminaluminiumiodidammoniakat- $\left[\mathrm{Al}\left(\mathrm{NH}_{3}\right)_{6}\right] \mathrm{I}_{3} \mathrm{NH}_{3}$ Darstellung und Kristallstruktur. J. Less-Common Met. 1989, 154, 243-250. 
90. Jacobs, H.; Bock, J.; Stüve, C. Röntgenographische Strukturbestimmung und IR-spektroskopische Untersuchungen an Hexaamindiiodiden, $\left[\mathrm{M}\left(\mathrm{NH}_{3}\right)_{6}\right] \mathrm{I}_{2}$, von Eisen und Mangan. J. Less-Common Met. 1987, 134, 207-214.

91. Leineweber, A.; Friedriszik, M.W.; Jacobs, H. Preparation and crystal structures of $\mathrm{Mg}\left(\mathrm{NH}_{3}\right)_{2} \mathrm{Cl}_{2}, \mathrm{Mg}\left(\mathrm{NH}_{3}\right)_{2} \mathrm{Br}_{2}$, and $\mathrm{Mg}\left(\mathrm{NH}_{3}\right)_{2} \mathrm{I}_{2}$. J. Solid State Chem. 1999, 234, 229-234.

92. Essmann, R. Influence of coordination on N-H...X- hydrogen bonds. Part 1. [Zn( $\left.\left(\mathrm{NH}_{3}\right)_{4}\right] \mathrm{Br}_{2}$ and $\left[\mathrm{Zn}\left(\mathrm{NH}_{3}\right)_{4}\right] \mathrm{I}_{2}$. J. Mol. Struct. 1995, 356, 201-206.

93. Meyer, G.; Roos, M. Zwei Galliumfluorid-Ammoniakate: $\mathrm{Ga}\left(\mathrm{NH}_{3}\right) \mathrm{F}_{3}$ und $\mathrm{Ga}\left(\mathrm{NH}_{3}\right)_{2} \mathrm{~F}_{3}$. Z. Anorg. Allg. Chem. 1999, 625, 1129-1134.

94. Bremm, S.; Meyer, G. Reactivity of ammonium halides: Action of ammonium chloride and bromide on iron and iron(III) chloride and bromide. Z. Anorg. Allg. Chem. 2003, 629, 1875-1880.

95. Bremm, S.; Meyer, G.; Möller, A.; Amann, P.; Sobotka, B. Einwirkung von Ammoniumhalogeniden auf Eisen und Eisenhalogenide. Z. Anorg. Allg. Chem. 2002, $628,2190$.

96. Widenmeyer, M.; Hansen, T.C.; Meissner, E.; Niewa, R. Formation and decomposition of iron nitrides observed by in situ powder neutron diffraction and thermal analysis. Z. Anorg. Allg. Chem. 2014, in press.

97. Hambley, T.W.; Lay, P.A. Comparisons of $\pi$-bonding and hydrogen bonding in isomorphous compounds: $\left[\mathrm{M}\left(\mathrm{NH}_{3}\right)_{4} \mathrm{Cl}\right] \mathrm{Cl}_{2}(\mathrm{M}=\mathrm{Cr}, \mathrm{Co}, \mathrm{Rh}, \mathrm{Ir}, \mathrm{Ru}, \mathrm{Os})$. Inorg. Chem. 1986, 25, 4553-4558.

98. Podberezskaya, N.; Yudanova, T.; Magarill, S.; Ipatova, E.; Romanenko, G.; Pervukhina, N.; Borisov, S. Structures of crystals of inorganic coordination compounds with complex ions $\left[\mathrm{MA}_{5} \mathrm{X}\right]$ and $\left[\mathrm{MX}_{5} \mathrm{~A}\right]$ containing neutral (A) and acid (X) ligands, at very high packing densities. J. Struct. Chem. 1992, 32, 894-904.

99. Weishaupt, M.; Bezler, H.; Strähle, J. Darstellung und Kristallstruktur von $\left(\mathrm{NH}_{4}\right)_{2}\left[\mathrm{~V}\left(\mathrm{NH}_{3}\right) \mathrm{Cl}_{5}\right]$. Die Kristallchemie der Salze $\left(\mathrm{NH}_{4}\right)_{2}\left[\mathrm{~V}\left(\mathrm{NH}_{3}\right) \mathrm{Cl}_{5}\right],\left[\mathrm{Rh}\left(\mathrm{NH}_{3}\right) \mathrm{Cl}\right] \mathrm{Cl}_{2}$ und $\mathrm{M}_{2} \mathrm{VXCl}_{5}$ mit $\mathrm{M}=\mathrm{K}, \mathrm{NH}_{4}, \mathrm{Rb}, \mathrm{Cs}$ und $\mathrm{X}=\mathrm{Cl}, \mathrm{O}$. Z. Anorg. Allg. Chem. 1978, 440, 52-64.

100. Jacobs, H.; Schmidt, D.; Schmitz, D. Struktur und Eigenschaften der Caesiumamidolanthanatmonoammoniakate $\mathrm{Cs}_{3} \mathrm{La}\left(\mathrm{NH}_{2}\right)_{6} \cdot \mathrm{NH}_{3}$ und $\mathrm{Cs}_{4} \mathrm{La}\left(\mathrm{NH}_{2}\right)_{7} \cdot \mathrm{NH}_{3}$. J. Less-Common Met. 1981, 81, 121-133.

101. Pust, P.; Schmiechen, S.; Hintze, F.; Schnick, W. Ammonothermal synthesis and crystal structure of $\mathrm{BaAl}_{2}\left(\mathrm{NH}_{2}\right)_{8} \cdot 2 \mathrm{NH}_{3}$. Z. Anorg. Allg. Chem. 2013, 639, 1185-1187.

102. Joannis, A. Sur l'amidure de sodium et sur un chlorure de disodammonium. C. R. Hebd. Seances Acad. Sci. C 1891, 112, 392-394.

103. Mammano, N.; Sienko, M. Low-temperature X-ray study of the compound tetraaminelithium. J. Am. Chem. Soc. 1968, 90, 6322-6324.

104. Kirschke, E.J.; Jolly, W.L. The reversibility of the reaction of alkali metals with liquid ammonia. Inorg. Chem. 1967, 6, 855-862. 
105. Ruff, O.; Geisel, E. Über die Natur der sogenannten Metallammoniumverbindungen. Ber. Dtsch. Chem. Ges. 1906, 39, 828-843.

106. Juza, R.; Fasold, K.; Haeberle, C. Untersuchungen über die Amide der Alkalimetalle. Z. $r$ r Anorg. Allg. Chem. 1937, 234, 75-85.

107. Juza, R.; Opp, K. Die Kristallstruktur des Lithiumamides. Z. Anorg. Allg. Chem. 1951, $266,313-324$.

108. Juza, R.; Weber, H.H.; Opp, K. Kristallstruktur des Natriumamids. Z. Anorg. Allg. Chem. 1956, 284, 73-82.

109. Jacobs, H.; Juza, R. Neubestimmung der Kristallstruktur des Lithiumamids. Z. Anorg. Allg. Chem. 1972, 391, 271-279.

110. Nagib, M.; Jacobs, H. Neutronenbeugung am Lithiumdeuteroamid. Atomkernenergie 1973, $21,275-278$.

111. Nagib, M.; Kistrup, H.; Jacobs, H. Neutronenbeugung am Natriumdeuteroamid. Atomkernenergie 1975, 26, 87-90.

112. Bohger, P.; Zeiske, T.; Jacobs, H. Neutronenbeugung an der Tieftemperaturmodifikation von Rubidiumdeuteroamid. Z. Anorg. Allg. Chem. 1998, 624, 364-366.

113. Nagib, M.; von Osten, E.; Jacobs, H. Röntgen- und Neutronenbeugung und Bestimmung der Wärmekapazität an Caesiumamid-CsNH $\mathrm{CH}_{2}$-und Caesiumdeuteroamid-CsND 2 -bei Temperaturen von 348 bis $33 \mathrm{~K}$. Atomkernenergie 1983, 43, 47-54.

114. Jacobs, H.; Juza, R. Darstellung und Eigenschaften von Berylliumamid und -imid. Z. Anorg. Allg. Chem. 1969, 370, 248-253.

115. Jacobs, H.; Juza, R. Darstellung und Eigenschaften von Magnesiumamid und -imid. Z. Anorg. Allg. Chem. 1969, 370, 254-261.

116. Senker, J.; Jacobs, H.; Müller, M. Reorientational dynamics of amide ions in isotypic phases of strontium and calcium amide. 1. Neutron diffraction experiments. J. Phys. Chem. B 1998, 102, 931-940.

117. Nagib, M.; Jacobs, H.; Kistrup, H. Neutronenbeugung am Strontiumdeuteroamid, $\operatorname{Sr}\left(\mathrm{ND}_{2}\right)_{2}$, bei Temperaturen von 31 bis $570 \mathrm{~K}$. Atomkernenergie 1979, 33, 38-42.

118. Jacobs, H.; Hadenfeldt, C. Die Kristallstruktur von Bariumamid, $\mathrm{Ba}\left(\mathrm{NH}_{2}\right)_{2}$. Z. Anorg. Allg. Chem. 1975, 418, 132-140.

119. Fröhling, B.; Kreiner, G.; Jacobs, H. Synthesis and crystal structure of manganese(II) and zinc amides, $\mathrm{Mn}\left(\mathrm{NH}_{2}\right)_{2}$ and $\mathrm{Zn}\left(\mathrm{NH}_{2}\right)_{2}$. Z. Anorg. Allg. Chem. 1999, 625, 211-216.

120. Hadenfeldt, C.; Gieger, B.; Jacobs, H. Die Kristallstruktur von Lanthanamid, $\mathrm{La}\left(\mathrm{NH}_{2}\right)_{3}$. Z. Anorg. Allg. Chem. 1974, 410, 104-112.

121. Jacobs, H.; Kistrup, H. Über das System Kalium/Samarium/Ammoniak. Z. Anorg. Allg. Chem. 1977, 435, 127-136.

122. Jacobs, H.; Fink, U. Untersuchung des Systems Kalium/Europium/Ammoniak. Z. Anorg. Allg. Chem. 1978, 438, 151-159. 
123. Hadenfeldt, C.; Jacobs, H.; Juza, R. Über die Amide des Europiums und Ytterbiums. Z. Anorg. Allg. Chem. 1970, 379, 144-156.

124. Nagib, M.; von Osten, E.; Jacobs, H. Neutronenbeugung an drei Modifikationen des Kaliumdeuteroamids $\mathrm{KND}_{2}$. Atomkernenergie 1977, 29, 41-47.

125. Nagib, M.; Jacobs, H.; von Osten, E. Neutronenbeugung am Kaliumdeuteroamid $\mathrm{KND}_{2}$ bei 31 K. Atomkernenergie 1977, 29, 303-304.

126. Dachs, H. Bestimmung der Lage des Wasserstoffs in LiOH durch Neutronenbeugung. Z. Kristallogr. 1956, 112, 60-67.

127. Juza, R.; Jacobs, H.; Klose, W. Die Kristallstrukturen der Tieftemperaturmodifikationen von Kalium- und Rubidiumamid. Z. Anorg. Allg. Chem. 1965, 338, 171-178.

128. Jacobs, H.; Nagib, M.; Osten, E.V. Einkristallzüchtung und Kristallchemie der Alkali- und Erdalkalimetallamide. Acta Crystallogr. A 1978, 34, 168.

129. Schenk, P.; Tulhoff, H. Das System Kaliumamid/Ammoniak. Angew. Chem. 1962, 74, 962.

130. Juza, R.; Schumacher, H. Zur Kenntnis der Erdalkalimetallamide. Z. Anorg. Allg. Chem. 1963, 324, 278-286.

131. Jacobs, H.; Scholze, H. Untersuchung des Systems Na/La/ $\mathrm{NH}_{3}$. Z. Anorg. Allg. Chem. 1976, 427, 8-16.

132. Juza, R.; Fasold, K.; Kuhn, W. Untersuchungen über Zink- und Cadmiumamid. Z. Anorg. Allg. Chem. 1937, 234, 86-96.

133. Fitzgerald, F.F. Reactions in liquid ammonia. Potassium ammonozincate, cuprous nitride and an ammonobasic mercuric bromide. J. Am. Chem. Soc. 1907, 29, 656-665.

134. Joannis, M. Action du chlorure de bore sur le gaz ammoniac. C. R. Hebd. Seances Acad. Sci. 1902, 135, 1106.

135. Janik, J.F.; Wells, R.L. Gallium imide, $\left\{\mathrm{Ga}(\mathrm{NH})_{3 / 2}\right\}_{n}$, a new polymeric precursor for gallium nitride powders. Chem. Mater. 1996, 8, 2708-2711.

136. Wiberg, E.; May, A. Über die Umsetzung von Aluminiumwasserstoff mit Ammoniak und Aminen. Z. Naturforsch. 1955, 10b, 229.

137. Semenenko, K.N.; Bulychev, B.M.; Shevlyagina, E.A. Aluminium hydride. Russ. Chem. Rev. (Engl. Transl.) 1966, 35, 649-658.

138. Purdy, A.P. Indium(III) amides and nitrides. Inorg. Chem. 1994, 33, 282-286.

139. Vigouroux, E.; Hugot, C. Silicon amide and imide. C. R. Hebd. Seances Acad. Sci. C 1903, $136,1670-1672$.

140. Glemser, O.; Naumann, P. Über den thermischen Abbau von Siliciumdiimid $\mathrm{Si}(\mathrm{NH})_{2}$. Z. Anorg. Allg. Chem. 1959, 298, 134-141.

141. Molinié, P.; Brec, R.; Rouxel, J.; Herpin, P. Structures des amidoaluminates alcalins $\mathrm{MAl}\left(\mathrm{NH}_{2}\right)_{4}(\mathrm{M}=\mathrm{Na}, \mathrm{K}, \mathrm{Cs})$. Structure de l'amidogallate de sodium $\mathrm{NaGa}\left(\mathrm{NH}_{2}\right)_{4}$. Acta Crystallogr. B 1973, 29, 925-934.

142. Drew, M.; Goulter, J.; Guémas-Brisseau, L.; Palvadeau, P.; Rouxel, J.; Herpin, P. Etude structurale d'amidobéryllates de rubidium et de potassium. Acta Crystallogr. B 1974, 30, 2579-2582. 
143. Jacobs, H.; Jänichen, K. Lithiumaluminiumamid, $\mathrm{LiAl}\left(\mathrm{NH}_{2}\right)_{4}$, Darstellung, röntgenographische Untersuchung, Infrarotspektrum und thermische Zersetzung. Z. Anorg. Allg. Chem. 1985, 531, 125-139.

144. Tenten, A.; Jacobs, H. Strukturen und thermisches Verhalten von Kaliumtetraamidoaluminat, $\alpha$ - und $\beta$-KAl $\left(\mathrm{NH}_{2}\right)_{4}$. Z. Kristallogr. 1989, 186, 289-291.

145. Jacobs, H.; Harbrecht, B. Substitution in layers of cations in lithium amide: Potassium trilithium amide, $\mathrm{KLi}_{3}\left(\mathrm{NH}_{2}\right)_{4}$, and potassium heptalithium amide, $\mathrm{KLi}_{7}\left(\mathrm{NH}_{2}\right)_{8}$. Z. Anorg. Allg. Chem. 1984, 518, 87-100.

146. Kraus, F.; Korber, N. $\mathrm{K}_{2} \mathrm{Li}\left(\mathrm{NH}_{2}\right)_{3}$ and $\mathrm{K}_{2} \mathrm{Na}\left(\mathrm{NH}_{2}\right)_{3}-$ Synthesis and crystal structure of two crystal-chemically isotypic mixed-cationic amides. J. Solid State Chem. 2005, 178, 1241-1246.

147. Jacobs, H.; Kockelkorn, J. Darstellung und Eigenschaften der Amidomagnesate des Kaliums und Rubidiums $\mathrm{K}_{2}\left[\mathrm{Mg}\left(\mathrm{NH}_{2}\right)_{4}\right]$ - und $\mathrm{Rb}_{2}\left[\mathrm{Mg}\left(\mathrm{NH}_{2}\right)_{4}\right]$-Verbindungen mit isolierten $\left[\mathrm{Mg}\left(\mathrm{NH}_{2}\right)_{4}\right]^{2-}$ Tetraedern. J. Less-Common Met. 1984, 97, 205-214.

148. Jacobs, H.; Birkenbeul, J.; Schmitz, D. Strukturverwandschaft des Dicaesiumamidomagnesats, $\mathrm{Cs}\left[\mathrm{Mg}\left(\mathrm{NH}_{2}\right)_{4}\right]$, zum $\beta$ - $\mathrm{K}_{2} \mathrm{SO}_{4}$-Typ. J. Less-Common Met. 1982, 85, 79-86.

149. Jacobs, H.; Fink, U. Über Natrium- und Kaliumamidometallate des Calciums, Strontiums und Europiums. J. Less-Common Met. 1979, 63, 273-286.

150. Jacobs, H.; Kockelkorn, J.; Birkenbeul, J. Struktur und Eigenschaften der ternären Metallamide $\mathrm{NaCa}\left(\mathrm{NH}_{2}\right)_{3}, \mathrm{KBa}\left(\mathrm{NH}_{2}\right)_{3}, \mathrm{RbBa}\left(\mathrm{NH}_{2}\right)_{3}, \mathrm{Rb}\left(\mathrm{Eu}\left(\mathrm{NH}_{2}\right)_{3}\right.$ und $\mathrm{RbSr}\left(\mathrm{NH}_{2}\right)_{3}$. J. Less-Common Met. 1982, 87, 215-224.

151. Jacobs, H.; Fink, U. Darstellung und Kristallstruktur von $\mathrm{KCa}\left(\mathrm{NH}_{2}\right)_{3}$. Z. Anorg. Allg. Chem. 1977, 435, 137-145.

152. Jacobs, H.; Kockelkorn, J. Darstellung und Kristallstruktur des Rubdiumcalciumamids, $\mathrm{RbCa}\left(\mathrm{NH}_{2}\right)_{3}$. Z. Anorg. Allg. Chem. 1979, 456, 147-154.

153. Jacobs, H.; Kockelkorn, J. Über Caesiumamidometallate $\left(\mathrm{CsM}\left(\mathrm{NH}_{2}\right)_{3}\right)$ des Calciums, Strontiums und Europiums; Verbindungen mit der Struktur "Hexagonaler Perowskite". J. Less-Common Met. 1981, 81, 143-154.

154. Jacobs, H. Darstellung und Eigenschaften des Caesiumbariumamids, $\mathrm{CsBa}\left(\mathrm{NH}_{2}\right)_{3}$ : Strukturverwandschaft zum $\mathrm{NH}_{4} \mathrm{CdCl}_{3}$-Typ. J. Less-Common Met. 1982, 85, 71-78.

155. Hadenfeldt, C.; Gieger, B.; Jacobs, H. Darstellung und Kristallstruktur von $\mathrm{KLa}_{2}\left(\mathrm{NH}_{2}\right)_{7}$. Z. Anorg. Allg. Chem. 1974, 408, 27-36.

156. Hadenfeldt, C.; Gieger, B.; Jacobs, H. Darstellung und Kristallstruktur von $\left.\mathrm{K}_{3} \mathrm{La}_{(\mathrm{NH}}\right)_{6}$. Z. Anorg. Allg. Chem. 1974, 403, 319-326.

157. Jacobs, H.; Stüve, C. Rubidiumhexaamidolanthanat und -neodymat, $\mathrm{Rb}_{3}\left[\mathrm{La}\left(\mathrm{NH}_{2}\right)_{6}\right]$ und $\mathrm{Rb}_{3}\left[\mathrm{Nd}\left(\mathrm{NH}_{2}\right)_{6}\right]$; Strukturverwandtschaft zu $\mathrm{K}_{3}\left[\mathrm{Cr}\left(\mathrm{OH}_{6}\right)\right]$ und $\mathrm{K}_{4} \mathrm{CdCl}_{6}$. Z. Anorg. Allg. Chem. 1987, 546, 42-47.

158. Jacobs, H.; Schmidt, D. Über ein Caesiumheptaamidodilanthanat $\mathrm{CsLa}_{2}\left(\mathrm{NH}_{2}\right)_{7}$. J. Less-Common Met. 1981, 78, 51-59. 
159. Jacobs, H.; Schmidt, D. Struktur und Eigenschaften von perowskitartigen Caesiumamidometallaten des Cers, Neodyms und Samariums $\mathrm{Cs}_{3} \mathrm{Ln}_{2}\left(\mathrm{NH}_{2}\right)_{9}$. J. Less-Common Met. 1980, 76, 227-244.

160. Jacobs, H.; Kockelkorn, J. Über Kalium- und Rubidiumamidometallate des Europiums, Yttriums und Ytterbiums, $\mathrm{K}_{3} \mathrm{M}\left(\mathrm{NH}_{2}\right)_{6}$ und $\mathrm{Rb}_{3} \mathrm{M}\left(\mathrm{NH}_{2}\right)_{6}$. J. Less-Common Met. 1982, 85, 97-110.

161. Linde, G.; Juza, R. Amidometallate von Lanthan und Gadolinium und Umsetzung von Lanthan, Gadolinium und Scandium mit Ammoniak. Z. Anorg. Allg. Chem. 1974, 409, 191-198.

162. Jacobs, H.; Peters, D.; Hassiepen, K. Caesiumamidometallate des Gadoliniums, Ytterbiums und Yttriums mit perowskitverwandten Atomanordnungen $\mathrm{Cs}_{3} \mathrm{M}_{2}\left(\mathrm{NH}_{2}\right)_{9}$. J. Less-Common Met. 1986, 118, 31-41.

163. Stuhr, A.; Jacobs, H.; Juza, R. Amide des Yttriums. Z. Anorg. Allg. Chem. 1973, 395, 291-300.

164. Peters, D.; Jacobs, H. Übergang von dichter Anionenpackung zu perowskitartiger Struktur bei Kalium- und Rubidiumamidyttriat, $\mathrm{KY}\left(\mathrm{NH}_{2}\right)_{4}$ und $\mathrm{RbY}\left(\mathrm{NH}_{2}\right)_{4}$. J. Less-Common Met. 1986, 119, 99-113.

165. Hadenfeldt, C.; Jacobs, H. Darstellung, Eigenschaften und Kristallstruktur von $\mathrm{Na}_{3}\left[\mathrm{Yb}\left(\mathrm{NH}_{2}\right)_{6}\right]$. Z. Anorg. Allg. Chem. 1972, 393, 111-125.

166. Jacobs, H.; Jänichen, K. Darstellung und Kristallstruktur von Tetraamidoaluminaten des Rubidiums und Caesiums, $\mathrm{Rb}\left[\mathrm{Al}\left(\mathrm{NH}_{2}\right)_{4}\right]$ und $\mathrm{Cs}\left[\mathrm{Al}\left(\mathrm{NH}_{2}\right)_{4}\right]$. J. Less-Common Met. 1990, 159, 315-325.

167. Kreiner, G.; Jacobs, H. Magnetische Struktur von $\eta-\mathrm{Mn}_{3} \mathrm{~N}_{2}$. J. Alloys Compd. 1992, 183, 345-362.

168. Richter, T.M.M.; Zhang, S.; Niewa, R. Ammonothermal synthesis of dimorphic $\mathrm{K}_{2}\left[\mathrm{Zn}\left(\mathrm{NH}_{2}\right)_{4}\right]$. Z. Kristallogr. 2013, 228, 351-358.

169. Fröhling, B.; Jacobs, H. Positions of the protons in potassium tetraamidozincate, $\mathrm{K}_{2} \mathrm{Zn}\left(\mathrm{NH}_{2}\right)_{4}$. Z. Anorg. Allg. Chem. 1997, 623, 1103-1107.

170. Brec, R.; Novak, A.; Rouxel, J. Etude par spectroscopie infrarouge des amidoaluminates de lithium, sodium et potassium. Bull. Soc. Chim. Fr. 1967, 7, 2432-2435.

171. Drew, M.; Guémas, L.; Chevalier, P.; Palvadeau, P.; Rouxel, J. Etude structurale de l'amidozincate de rubidium $\mathrm{Rb}_{2} \mathrm{Zn}\left(\mathrm{NH}_{2}\right)_{4}$ et de l'amidomanganite de potassium $\mathrm{K}_{2} \mathrm{Mn}\left(\mathrm{NH}_{2}\right)_{4}$. Rev. Chim. Min. 1975, 12, 419-426.

172. Jacobs, H.; Gieger, B.; Hadenfeldt, C. Über das System Kalium/Lanthan/Ammoniak. J. Less-Common Met. 1979, 64, 91-99.

173. Peters, D.; Jacobs, H. Ammonothermalsynthese von kristallinem Siliciumnitridimid, $\mathrm{Si}_{2} \mathrm{~N}_{2} \mathrm{NH}$. J. Less-Common Met. 1989, 146, 241-249.

174. Harbrecht, B.; Jacobs, H. Hochdrucksynthese von Caesiumamidazid, $\mathrm{Cs}_{2}\left(\mathrm{NH}_{2}\right) \mathrm{N}_{3}$ aus Caesiummetall und Ammoniak. Z. Anorg. Allg. Chem. 1983, 500, 181-187. 
175. Höhn, P.; Kniep, R.; Maier, J. $\mathrm{Ba}_{9} \mathrm{~N}\left[\mathrm{~N}_{3}\right]\left[\mathrm{TaN}_{4}\right]_{2}$ ein Nitridotantalat(V) mit Nitrid- und Azid-Ionen. Angew. Chem. 1993, 105, 1409-1410.

176. Clarke, S.J.; DiSalvo, F.J. Crystal structure of nonabarium bis(tetranitridoniobate) nitride azide, $\mathrm{Ba}_{9}\left[\mathrm{NbN}_{4}\right]_{2} \mathrm{~N}\left[\mathrm{~N}_{3}\right]$. Z. Kristallogr. NCS 1997, 212, 309-310.

177. Zhang, S.; Zherebtsov, D.; DiSalvo, F.J.; Niewa, R. $\mathrm{Na}_{5}\left[\mathrm{CN}_{2}\right]_{2}[\mathrm{CN}],(\mathrm{Li}, \mathrm{Na})_{5}\left[\mathrm{CN}_{2}\right]_{2}[\mathrm{CN}]$, and $\mathrm{K}_{2}\left[\mathrm{CN}_{2}\right]$ : Carbodiimides from high-pressure synthesis. Z. Anorg. Allg. Chem. 2012, 638, 2111-2116.

178. Stock, A.; Blix, M. Über das Borimid, $\mathrm{B}_{2}(\mathrm{NH})_{3}$. Ber. Dtsch. Chem. Ges. 1901, 34, 3039-3048.

179. Blix, M.; Wirbelauer, W. Über das Siliciumsulfochlorid, $\mathrm{SiSCl}_{2}$, Siliciumimid, $\mathrm{Si}(\mathrm{NH})_{2}$, Siliciumstickstoffimid (Silicam), $\mathrm{Si}_{2} \mathrm{~N}_{3} \mathrm{H}$ und den Siliciumstickstoff, $\mathrm{Si}_{3} \mathrm{~N}_{4}$. Ber. Dtsch. Chem. Ges. 1903, 36, 4220-4228.

180. Ketchum, D.; Kolis, J. Crystal growth of gallium nitride in supercritical ammonia. J. Cryst. Growth 2001, 222, 431-434.

181. Jouet, R.J.; Purdy, A.P.; Wells, R.L.; Janik, J.F. Preparation of phase pure cubic gallium nitride, $c$-GaN, by ammonothermal conversion of gallium imide, $\left\{\mathrm{Ga}(\mathrm{NH})_{3 / 2}\right\}_{n}$. J. Clust. Sci. 2002, 13, 469-486.

182. Zajac, M.; Gosk, J.; Grzanka, E.; Stelmakh, S.; Palczewska, M.; WysmoÅĆek, A.; Korona, K.; KamiÅĎska, M.; Twardowski, A. Ammonothermal synthesis of GaN doped with transition metal ions (Mn, Fe, Cr). J. Alloys Compd. 2008, 456, 324-338.

183. Jacobs, H.; Rechenbach, D.; Zachwieja, U. Structure determination of $\gamma^{\prime}-\mathrm{Fe}_{4} \mathrm{~N}$ and $\epsilon-\mathrm{Fe}_{3} \mathrm{~N}$. J. Alloys Compd. 1995, 227, 10-17.

184. Jacobs, H.; Rechenbach, D.; Zachwieja, D. Untersuchungen zur Struktur und zum Zerfall von Eisennitriden- $\gamma^{\prime}-\mathrm{Fe}_{4} \mathrm{~N}$ und $\epsilon-\mathrm{Fe}_{3} \mathrm{~N}$. Härterei Techn. Mitt. 1995, 50, 205-213.

185. Jacobs, H.; Bock, J. Einkristallzüchtung von $\gamma^{\prime}-\mathrm{Fe}_{4} \mathrm{~N}$ in überkritischem Ammoniak. J. Less-Common Met. 1987, 134, 215-220.

186. Jacobs, H.; Stüve, C. Hochdrucksynthese der $\eta$-phase im System Mn-N: $\mathrm{Mn}_{3} \mathrm{~N}_{2}$. J. Less-Common Met. 1984, 96, 323-329.

187. Leineweber, A.; Jacobs, H.; Hull, S. Ordering of nitrogen in nickel nitride $\mathrm{Ni}_{3} \mathrm{~N}$ determined by neutron diffraction. Inorg. Chem. 2001, 40, 5818-5822.

188. Jacobs, H.; Zachwieja, U. Kupferpalladiumnitride, $\mathrm{Cu}_{3} \mathrm{Pd}_{x} \mathrm{~N}$ mit $x=0,020$ und 0,989, Perowskite mit "bindender $3 \mathrm{~d}^{10}-4 \mathrm{~d}^{10}-$ Wechselwirkung". J. Less-Common Met. 1991, 170, 185-190.

189. von Stackelberg, M.; Paulus, R. Untersuchungen über die Kristallstrukturen der Nitride und Phosphide zweiwertiger Metalle. Z. Physik. Chem. B 1933, 22, 305.

190. Reckeweg, O.; Lind, C.; DiSalvo, F.J. Rietveld refinement of the crystal structure of $\alpha-\mathrm{Be}_{3} \mathrm{~N}_{2}$ and the experimental determination of optical band gaps for $\mathrm{Mg}_{3} \mathrm{~N}_{2}, \mathrm{Ca}_{3} \mathrm{~N}_{2}$ and $\mathrm{CaMg}_{2} \mathrm{~N}_{2}$. Z. Naturforsch. 2003, 58b, 159-162. 
191. Karau, F.; Schnick, W. Synthese von Cadmiumnitrid $\mathrm{Cd}_{3} \mathrm{~N}_{2}$ durch thermischen Abbau von Cadmiumazid $\mathrm{Cd}\left(\mathrm{N}_{3}\right)_{2}$ und Kristallstrukturbestimmung aus Röntgen-Pulverbeugungsdaten. Z. Anorg. Allg. Chem. 2007, 633, 223-226.

192. Partin, D.E.; Williams, D.J.; O'Keeffe, M. The crystal structures of $\mathrm{Mg}_{3} \mathrm{~N}_{2}$ and $\mathrm{Zn}_{3} \mathrm{~N}_{2}$. J. Solid State Chem. 1997, 132, 56-59.

193. Reckeweg, O.; DiSalvo, F.J. About binary and ternary alkaline earth metal nitrides. Z. Anorg. Allg. Chem. 2001, 627, 371-377.

194. Soto, G.; Diaz, J.A.; De la Cruz, W.; Contreras, O.; Moreno, M.; Reyes, A. Epitaxial $\alpha-\mathrm{Be}_{3} \mathrm{~N}_{2}$ thin films grown on $\mathrm{Si}$ substrates by reactive laser ablation. Mater. Sci. Eng., B. 2002, 94, 62-65.

195. García Núñez, C.; Pau, J.; Hernández, M.; Cervera, M.; Ruiz, E.; Piqueras, J. On the zinc nitride properties and the unintentional incorporation of oxygen. Thin Solid Films 2012, 520, 1924-1929.

196. Soto, G.; Díaz, J.A.; Machorro, R.; Reyes-Serrato, A.; de la Cruz, W. Beryllium nitride thin film grown by reactive laser ablation. Mater. Lett. 2002, 52, 29-33.

197. Toyoura, K.; Tsujimura, H.; Goto, T.; Hachiya, K.; Hagiwara, R.; Ito, Y. Optical properties of zinc nitride formed by molten salt electrochemical process. Thin Solid Films 2005, 492, 88-92.

198. Maruska, H.P.; Tietjen, J.J. The preparation and properties of vapor-deposited single-crystalline GaN. Appl. Phys. Lett. 1969, 15, 327.

199. Perry, P.B.; Rutz, R.F. The optical absorption edge of single-crystal AlN prepared by a close-spaced vapor process. Appl. Phys. Lett. 1978, 33, 319-321.

200. Wu, J.; Walukiewicz, W.; Shan, W.; Yu, K.; Ager, J.; Haller, E.E.; Lu, H.; Schaff, W.J. Effects of the narrow band gap on the properties of InN. Phys. Rev. B 2002, 66, 201403.

201. Xie, R.J.; Bert Hintzen, H.T. Optical properties of (oxy)nitride materials: A review. J. Am. Ceram. Soc. 2013, 96, 665-687.

202. Dwiliński, R.; Doradziński, R.; Garczyński, J.; Sierzputowski, L.; Kucharski, R.; Zajac, M.; Rudziński, M.; Kudrawiec, R.; Serafińczuk, J.; Strupiński, W. Recent achievements in AMMONO-bulk method. J. Cryst. Growth 2010, 312, 2499-2502.

203. Gogova, D.; Petrov, P.P.; Buegler, M.; Wagner, M.R.; Nenstiel, C.; Callsen, G.; Schmidbauer, M.; Kucharski, R.; Zajac, M.; Dwiliński, R.; et al. Structural and optical investigation of non-polar (1-100) GaN grown by the ammonothermal method. J. Appl. Phys. 2013, 113, 203513.

204. Shubina, T.; Ivanov, S.; Jmerik, V.; Solnyshkov, D.; Vekshin, V.; KopâĂŹev, P.; Vasson, A.; Leymarie, J.; Kavokin, A.; Amano, H.; et al. Mie resonances, infrared emission, and the band gap of InN. Phys. Rev. Lett. 2004, 92, 117407.

205. Komissarova, T.A.; Jmerik, V.N.; Ivanov, S.V.; Paturi, P. Detection of metallic in nanoparticles in InGaN alloys. Appl. Phys. Lett. 2011, 99, 072107.

206. Wu, J.; Walukiewicz, W.; Yu, K.M.; Ager, J.W.; Haller, E.E.; Lu, H.; Schaff, W.J. Small band gap bowing in $\operatorname{In}_{1-x} \mathrm{Ga}_{x} \mathrm{~N}$ alloys. Appl. Phys. Lett. 2002, 80, 4741. 
207. Ranade, M.R.; Tessier, F.; Navrotsky, A.; Marchand, R. Calorimetric determination of the enthalpy of formation of $\mathrm{InN}$ and comparison with $\mathrm{AlN}$ and GaN. J. Mater. Res. 2011, 16, 2824-2831.

208. Richter, E.; Stoica, T.; Zeimer, U.; Netzel, C.; Weyers, M.; Tränkle, G. Si doping of GaN in hydride vapor-phase epitaxy. J. Electron. Mater. 2013, 42, 820-825.

209. Steckl, A.J.; Birkhahn, R. Visible emission from Er-doped GaN grown by solid source molecular beam epitaxy. Appl. Phys. Lett. 1998, 73, 1700-1702.

210. Adekore, B.T.; Callahan, M.J.; Bouthillette, L.; Dalmau, R.; Sitar, Z. Synthesis of erbium-doped gallium nitride crystals by the ammonothermal route. J. Cryst. Growth 2007, 308, 71-79.

211. Korona, K.P.; Doradziński, R.; Palczewska, M.; Pietras, M.; KamiÅĎska, M.; Kuhl, J. Properties of zinc acceptor and exciton bound to zinc in ammonothermal GaN. Phys. Status Solidi B 2003, 235, 40-43.

212. Scotti, N.; Kockelmann, W.; Senker, J. $\mathrm{Sn}_{3} \mathrm{~N}_{4}$, a Tin(IV) nitride-syntheses and the first crystal structure determination of a binary tin-nitrogen compound. Z. Anorg. Allg. Chem. 1999, 625, 1435-1439.

213. Louhadj, A.; Ghezali, M.; Badi, F.; Mehnane, N.; Cherchab, Y.; Amrani, B.; Abid, H.; Sekkal, N. Electronic structure of ScN, YN, LaN and GdN superlattices. Superlatt. Microstruct. 2009, 46, 435-442.

214. Srivastava, V.; Rajagopalan, M.; Sanyal, S.P. Theoretical investigation on structural, magnetic and electronic properties of ferromagnetic GdN under pressure. J. Magn. Magn. Mater. 2009, 321, 607-612.

215. Li, D.X.; Haga, Y.; Shida, H.; Suzuki, T. Magnetic properties of ferromagnetic GdN. Physica B 1994, 199/200, 631-633.

216. Mancera, L.; Rodr, J.A. First principles calculations of the ground state properties and structural phase transformation in YN. J. Phys.: Condens. Matter 2003, 15, 2625-2633.

217. Niewa, R. Nitridocompounds of manganese: Manganese nitrides and nitridomanganates. Z. Kristallogr. 2002, 217, 8-23.

218. Takei, W.J.; Heikes, R.R.; Shirane, G. Magnetic structure of $\mathrm{Mn}_{4} \mathrm{~N}$-type compounds. Phys. Rev. B 1962, 125, 1893-1897.

219. Borsa, D.M.; Grachev, S.; Presura, C.; Boerma, D.O. Growth and properties of $\mathrm{Cu}_{3} \mathrm{~N}$ films and $\mathrm{Cu}_{3} \mathrm{~N} / \gamma^{\prime}-\mathrm{Fe}_{4} \mathrm{~N}$ bilayers. Appl. Phys. Lett. 2002, 80, 1823-1825.

220. Sakuma, A. Self-consistent calculations for the electronic structures of iron nitrides, $\mathrm{Fe}_{3} \mathrm{~N}$, $\mathrm{Fe}_{4} \mathrm{~N}$ and $\mathrm{Fe}_{16} \mathrm{~N}_{2}$. J. Magn. Magn. Mater. 1991, 102, 127-134.

221. Wang, D.Y. Properties of various sputter-deposited CuâĂŞN thin films. J. Vac. Sci. Technol. A 1998, 16, 2084-2092.

222. Desmoulins-Krawiec, S.; Aymonier, C.; Loppinet-Serani, A.; Weill, F.; Gorsse, S.; Etourneau, J.; Cansell, F. Synthesis of nanostructured materials in supercritical ammonia: nitrides, metals and oxides. J. Mater. Chem. 2004, 14, 228-232. 
223. Hasegawa, M.; Yagi, T. Systematic study of formation and crystal structure of 3d-transition metal nitrides synthesized in a supercritical nitrogen fluid under $10 \mathrm{GPa}$ and $1800 \mathrm{~K}$ using diamond anvil cell and YAG laser heating. J. Alloys Compd. 2005, 403, 131-142.

224. Zachwieja, U.; Jacobs, H. Kolumnarstrukturen bei Tri- und Diamminnitraten, $\left[\mathrm{M}\left(\mathrm{NH}_{3}\right)_{3}\right] \mathrm{NO}_{3}$ und $\left[\mathrm{M}\left(\mathrm{NH}_{3}\right)_{2}\right] \mathrm{NO}_{3}$ des einwertigen Kupfers und Silbers. Z. Anorg. Allg. Chem. 1989, 571, 37-50.

225. Hahn, U.; Weber, W. Electronic structure and chemical-bonding mechanism of $\mathrm{Cu}_{3} \mathrm{~N}$, $\mathrm{Cu}_{3} \mathrm{NPd}$, and related $\mathrm{Cu}(\mathrm{I})$ compounds. Phys. Rev. B: Condens. Matter 1996, $53,12684-12693$.

226. Leineweber, A.; Niewa, R.; Jacobs, H.; Kockelmann, W. The manganese nitrides $\eta-\mathrm{Mn}_{3} \mathrm{~N}_{2}$ and $\Theta-\mathrm{Mn}_{6} \mathrm{~N}_{5+x}$ : Nuclear and magnetic structures. J. Mater. Chem. 2000, 10, 2827-2834.

227. Jacobs, H.; Harbrecht, B. Eine neue Darstellungsmethode für Caesiumhydroxid. Z. Naturforsch. 1981, 36b, 270-271.

228. Jacobs, H.; Tacke, T.; Kockelkorn, J. Hydroxidmonohydrate des Kaliums und Rubidiums; Verbindungen, deren Atomanordnungen die Schreibweise $\mathrm{K}\left(\mathrm{H}_{2} \mathrm{O}\right) \mathrm{OH}$ bzw. $\mathrm{Rb}\left(\mathrm{H}_{2} \mathrm{O}\right) \mathrm{OH}$ nahelegen. Z. Anorg. Allg. Chem. 1984, 516, 67-78.

229. Purdy, A.P. Ammonothermal growth of chalcogenide single crystal materials. US Patent 5,902,396, 11 May 1999.

230. Jacobs, H.; Kirchgässner, R.; Bock, J. Darstellung und Kristallstruktur von Lithiumhydrogensulfid LiHS. Z. Anorg. Allg. Chem. 1989, 569, 111-116.

231. Jacobs, H.; Erten, C. Über Kaliumhydrogensulfid, KHS. Z. Anorg. Allg. Chem. 1981, 473, 125-132.

232. Böttcher, P. Beiträge zur Kenntnis der Alkalimetallpolychalkogenide. Habilitation Thesis, RWTH Aachen, Germany, 1980.

233. Böttcher, P. Zur Kenntnis der Verbindung $\mathrm{Na}_{2} \mathrm{~S}_{3}$. Z. Anorg. Allg. Chem. 1980, 467, 149-157.

234. Böttcher, P. Die Kristallstruktur von $\mathrm{K}_{2} \mathrm{~S}_{3}$ und $\mathrm{K}_{2} \mathrm{Se}_{3}$. Z. Anorg. Allg. Chem. 1977, 432, 167-172.

235. Böttcher, P. Preparation and crystal structure of the dialkali metal trichalcogenides $\mathrm{Rb}_{2} \mathrm{~S}_{3}$, $\mathrm{Rb}_{2} \mathrm{Se}_{3}$ and $\mathrm{Cs}_{2} \mathrm{Se}_{3}$. Z. Anorg. Allg. Chem. 1980, 461, 13-21.

236. Böttcher, P. Synthesis and crystal structure of the dirubidiumpentachalcogenides $\mathrm{Rb}_{2} \mathrm{~S}_{5}$ and $\mathrm{Rb}_{2} \mathrm{Se}_{5}$. Z. Kristallogr. 1979, 150, 65-73.

237. Böttcher, P.; Kruse, K. Darstellung und Kristallstruktur von Dicaesiumpentasulfid $\left(\mathrm{Cs}_{2} \mathrm{~S}_{5}\right)$. J. Less-Common Met. 1982, 83, 115-125.

238. Böttcher, P. Zur Kenntnis von $\mathrm{Cs}_{2}$ Se. J. Less-Common Met. 1980, 76, 271-277.

239. Böttcher, P. Synthesis and crystal structure of $\mathrm{Rb}_{2} \mathrm{Te}_{3}$ and $\mathrm{Cs}_{2} \mathrm{Te}_{3}$. J. Less-Common Met. 1980, 70, 263-271.

240. Böttcher, P. Darstellung und Kristallstruktur von Dicaesiumpentatellurid, $\mathrm{Cs}_{2} \mathrm{Te}_{5}$. Z. Anorg. Allg. Chem. 1982, 491, 39-46. 


\title{
Bottom-Up, Wet Chemical Technique for the Continuous Synthesis of Inorganic Nanoparticles
}

\section{Annika Betke and Guido Kickelbick}

\begin{abstract}
Continuous wet chemical approaches for the production of inorganic nanoparticles are important for large scale production of nanoparticles. Here we describe a bottom-up, wet chemical method applying a microjet reactor. This technique allows the separation between nucleation and growth in a continuous reactor environment. Zinc oxide $(\mathrm{ZnO})$, magnetite $\left(\mathrm{Fe}_{3} \mathrm{O}_{4}\right)$, as well as brushite $\left(\mathrm{CaHPO}_{4} \cdot 2 \mathrm{H}_{2} \mathrm{O}\right)$, particles with a small particle size distribution can be obtained continuously by using the rapid mixing of two precursor solutions and the fast removal of the nuclei from the reaction environment. The final particles were characterized by FT-IR, TGA, DLS, $\mathrm{XRD}$ and SEM techniques. Systematic studies on the influence of the different process parameters, such as flow rate and process temperature, show that the particle size can be influenced. Zinc oxide was obtained with particle sizes between $44 \mathrm{~nm}$ and $102 \mathrm{~nm}$. The obtained magnetite particles have particle sizes in the range of $46 \mathrm{~nm}$ to $132 \mathrm{~nm}$. Brushite behaves differently; the obtained particles were shaped like small plates with edge lengths between $100 \mathrm{~nm}$ and $500 \mathrm{~nm}$.
\end{abstract}

Reprinted from Inorganics. Cite as: Betke, A.; Kickelbick, G. Bottom-Up, Wet Chemical Technique for the Continuous Synthesis of Inorganic Nanoparticles. Inorganics 2014, 2, 1-15.

\section{Introduction}

Nanoparticles have been identified as major compounds for many applications in the last decades. They are used in many different fields such as medicine, optics, electronics or catalysis [1]. For this reason, there is a lot of interest in facile synthetic routes for nanoparticles with controllable size and narrow size distribution. There are many different possibilities for the production of particles but due to its simplicity, low cost, and easy application in industrial production, stirred tank batch reactor processes are still the most employed wet chemical systems [2,3]. However, this method has often limitations for the preparation of nanoparticles on an industrial scale, because of long mixing times and thus uncontrolled nucleation and growth. To obtain nanoparticles with particle sizes smaller than $100 \mathrm{~nm}$ very short mixing times are required. Although there are methods which can be employed on a laboratory scale to obtain rapid mixing, their scale up is quite difficult [4,5]. In addition, it would be of great benefit if the synthesis could be performed continuously, because this would eliminate differences in nanoparticle properties from batch to batch [6-8]. There are continuous techniques, such as mixing starting material solutions on a macroscopic scale (e.g., tee shaped connectors) or microreactors [9]. These techniques have been used already for the synthesis of anatase- $\mathrm{TiO}_{2}$, gold, and cobalt nanoparticles as well as tricalcium phosphate ceramics [10-13]. In general, all the above-mentioned techniques require an improvement with respect to the mixing time. There are several studies, which indicate that the effect of mixing has an important influence on the particle size distribution. Experimental, as well as theoretical, precipitation experiments using a tee-mixer and barium sulfate as exemplary 
material show that the particles becomes smaller with increasing mixing intensity $[14,15]$. In further studies, it was found that confined impinging jet reactors are more efficient than tee-mixers. Using such a reactor type, it is possible to generate polymer nanoparticles which have potential application in biomedicine; for example for controlled drug delivery [16,17]. Biocompatible nanomaterial for biomedicine and pharmaceutical applications can also be produced by using a novel continuous industrial reactor, called NETmix. This reactor is a network of interconnected chambers and channels creating zones of complete mixing and segregation. This technique is used already for the synthesis of hydroxyapatite nanoparticles with extremely high purity and crystallinity [18]. Fast mixing is also fulfilled when a microjet reactor (Figure 1) is used. The excellent improvement is that the reagent solutions are forced with high pressure through a narrow cone in a reaction chamber that is constantly flushed with a gas flow. As a result, the obtained product is removed directly from the reaction chamber so that clogging is avoided.

Figure 1. Schematic set-up of the microjet reactor.

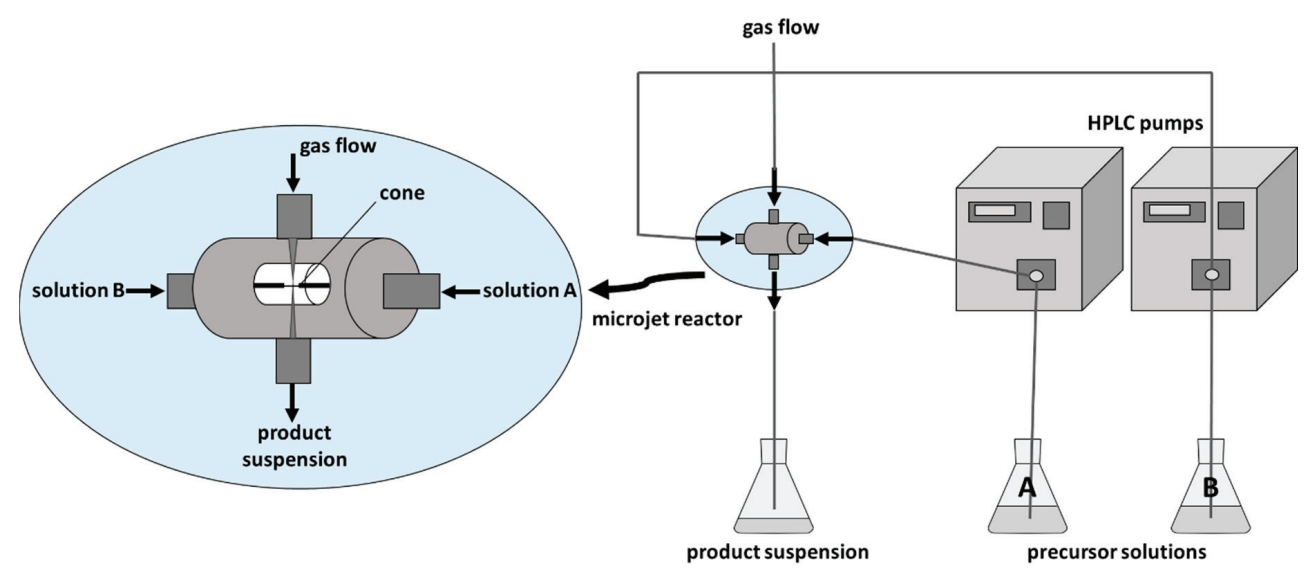

This technique can be used to perform different precipitation reactions continuously. Two pumps are used to transport the solutions containing the starting materials as dissolved substances to the microjet reactor. The collision takes place in a confined reaction environment, which is given by the format of the microjet reactor. Due to the fluid dynamics in the microjet reactor, there is a very short mixing time. Consequently, there is a maximum number of nuclei in an absolute homogeneous environment. In addition the nucleation rate is increased compared to the nucleus growth $[19,20]$. Directly after the nuclei are formed, they are transported from the reaction room to a tubing where the particle growth occurs. The length of this tubing up to the collection vessel influences the particle growth. The method has the advantage of being able to prepare nanoparticles even from a system with very low solubility products, e.g. barium sulfate [21]. However, it is also able to produce metal oxides, such as titania [22]. One great advantage is that the particles are obtained in a suspension, which could be used for a direct application, e.g. in spray coating or inkjet printing. 
In this study, we investigated the microjet reactor technique for the synthesis of three types of inorganic nanoparticles, i.e., zinc oxide $(\mathrm{ZnO})$, magnetite $\left(\mathrm{Fe}_{3} \mathrm{O}_{4}\right)$, and brushite $\left(\mathrm{CaHPO}_{4} \cdot 2 \mathrm{H}_{2} \mathrm{O}\right)$. These particles are not only interesting for academic reasons, but also have applications in optoelectronics and clinical, as well as biomedical devices [23-25]. The goal was to define the possibilities and limitations of this technique with regard to the different process parameters, such as flow rate and temperature, on the result of the precipitation reaction. Here, we do not focus on the importance of the time between nuclei formation and collection of the products, which also influences the size of the particles as this will be investigated in a further study.

\section{Results and Discussion}

The synthesis of inorganic nanoparticles was carried out using a microjet reactor system. In order to reveal the wide application field of the microjet reactor we performed the synthesis of three different species: zinc oxide $(\mathrm{ZnO})$, magnetite $\left(\mathrm{Fe}_{3} \mathrm{O}_{4}\right)$, as well as brushite $\left(\mathrm{CaHPO}_{4} \cdot 2 \mathrm{H}_{2} \mathrm{O}\right)$. All of these three systems show a low solubility under the applied reaction conditions. Two isocratic preparative HPLC pumps were used to transport the solutions containing the starting materials as dissolved substances. In the microjet-reactor, these two solutions clash and the precipitation reaction takes place. The precipitate was directly removed from the reactor by the use of a nitrogen gas flow. This process was performed with various flow rates of the precursor solutions $(150 \mathrm{~mL} / \mathrm{min}, 200 \mathrm{~mL} / \mathrm{min}$ and $250 \mathrm{~mL} / \mathrm{min})$ and at different temperatures $\left(25{ }^{\circ} \mathrm{C}, 50{ }^{\circ} \mathrm{C}\right.$ and $75{ }^{\circ} \mathrm{C}$ ). The reproducibility of the method was investigated by performing all experiments several times. The obtained material was thoroughly washed with water and the resulting compound was characterized applying FT-IR-spectroscopy, XRD, TGA and DLS analysis, as well as SEM. The final products were analyzed with respect to changes in the composition, the particle size and morphology depending on the process parameters.

\subsection{Zinc Oxide}

The synthesis of zinc oxide was performed by using aqueous solutions of zinc chloride and sodium hydroxide as starting materials (Equation 1) for the solution $\mathrm{A}$ and $\mathrm{B}$, respectively.

$$
\mathrm{ZnCl}_{2}+2 \mathrm{NaOH} \rightarrow \mathrm{ZnO}+2 \mathrm{NaCl}+\mathrm{H}_{2} \mathrm{O} .
$$

Under conventional precipitation conditions in an open vessel, the same starting materials deliver disc-like $\mathrm{ZnO}$ submicrometer structures with diameters between $300 \mathrm{~nm}$ and $500 \mathrm{~nm}$ [26].

Smaller particles could be obtained applying controlled double-jet-precipitation, which produces primary particles with diameters between 20-30 nm that tend to agglomerate in ellipsoidal particles with sizes of a few hundred nanometers [5].

The particles that were obtained by using the microjet reactor were characterized using various techniques. FT-IR-analysis of the prepared materials showed no specific signals with exception of $\mathrm{OH}$ and $\mathrm{CO}$ bands of adsorbed $\mathrm{CO}_{2}$ and $\mathrm{H}_{2} \mathrm{O}$ as well as a strong $\mathrm{ZnO}$ band around $400 \mathrm{~cm}^{-1}$.

Thermogravimetric analysis (Figure 2) was performed to determine the amount of adsorbed $\mathrm{CO}_{2}$ and $\mathrm{H}_{2} \mathrm{O}$. The results show that the samples contain between $5 \%$ and $6 \%$ adsorbed species. The development of the mass loss looks similar for all samples. 
Figure 2. Thermogravimetric analysis of the final products. The samples show a mass loss of between 5 and $6 \%$.

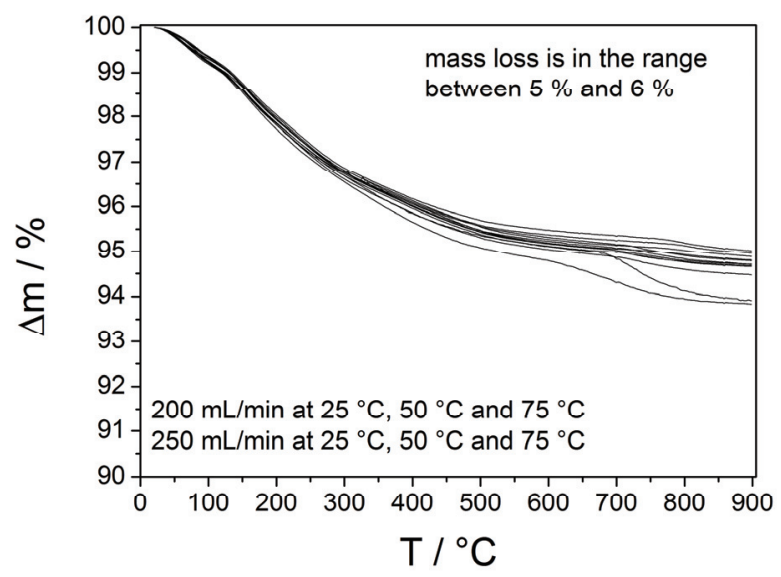

X-ray powder diffraction was applied to study the phase composition and crystallite size of the obtained material in dependence on the different synthesis parameters. The XRD pattern show that in each case pure zinc oxide is generated (Figure 3). The crystallite sizes decrease with increasing temperature and increasing flow rate (Table 1).

A further important parameter is the particle size including the size distribution, which is given by the standard deviation of the particle size. These parameters were determined using dynamic light scattering (Figure 4). The samples were dispersed in ethanol by the exposition to ultrasound for $5 \mathrm{~min}$. The results show that the particles are easily dispersible and their size depends on the process parameters. The particle size decreases with increasing temperature and increasing flow rate, in addition the particle size distribution becomes smaller (Table 2).

Figure 3. X-ray powder pattern of the obtained particles. The results show that pure zinc oxide was obtained.

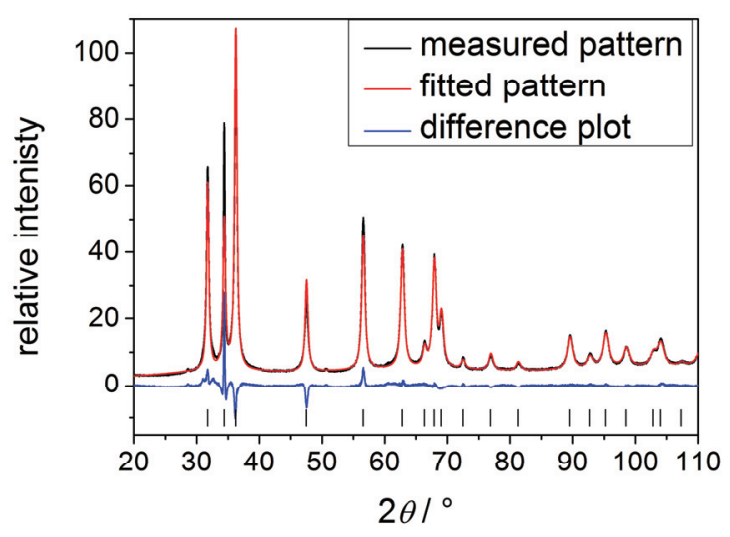


Table 1. Crystallite size in dependence on the process parameters.

\begin{tabular}{cc}
\hline Process parameters & Crystallite size \\
\hline $200 \mathrm{~mL} / \mathrm{min} / 25^{\circ} \mathrm{C}$ & $22.2 \pm 0.5$ \\
$200 \mathrm{~mL} / \mathrm{min} / 50^{\circ} \mathrm{C}$ & $20.4 \pm 0.7$ \\
$200 \mathrm{~mL} / \mathrm{min} / 75^{\circ} \mathrm{C}$ & $16.3 \pm 0.3$ \\
$250 \mathrm{~mL} / \mathrm{min} / 25^{\circ} \mathrm{C}$ & $22.7 \pm 0.5$ \\
$250 \mathrm{~mL} / \mathrm{min} / 50^{\circ} \mathrm{C}$ & $21.3 \pm 0.4$ \\
$250 \mathrm{~mL} / \mathrm{min} / 75^{\circ} \mathrm{C}$ & $16.9 \pm 0.3$ \\
\hline
\end{tabular}

Figure 4. Particle sizes of the obtained zinc oxide particles determined by dynamic light scattering.
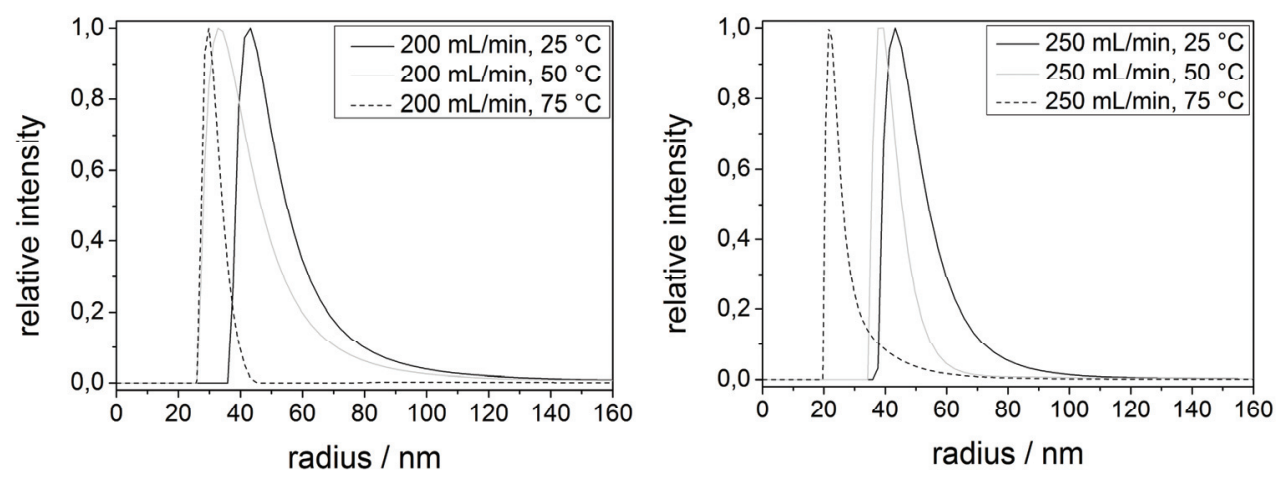

Table 2. Particle size determined using dynamic light scattering.

\begin{tabular}{cc}
\hline Process parameters & Radius $/ \mathbf{n m}$ \\
\hline $200 \mathrm{~mL} / \mathrm{min} / 25^{\circ} \mathrm{C}$ & $51 \pm 7$ \\
$200 \mathrm{~mL} / \mathrm{min} / 50{ }^{\circ} \mathrm{C}$ & $41 \pm 8$ \\
$200 \mathrm{~mL} / \mathrm{min} / 75^{\circ} \mathrm{C}$ & $27 \pm 3$ \\
$250 \mathrm{~mL} / \mathrm{min} / 25^{\circ} \mathrm{C}$ & $43 \pm 6$ \\
$250 \mathrm{~mL} / \mathrm{min} / 50^{\circ} \mathrm{C}$ & $36 \pm 4$ \\
$250 \mathrm{~mL} / \mathrm{min} / 75^{\circ} \mathrm{C}$ & $22 \pm 2$ \\
\hline
\end{tabular}

The particle morphology was investigated by means of scanning electron microscopy (Figures 5 and 6). The images confirm that the particles are in the nanometer size range. However, SEM analysis does not show the pronounced differences in the particles sizes that were observed in the DLS measurements for the parameter variations. Generally, it can be observed in SEM that the particles are all sphere-shaped and the size distribution becomes more uniform with increasing temperature. 
Figure 5. SEM images of zinc oxide synthesized with a flow rate of $200 \mathrm{~mL} / \mathrm{min}$ at $25^{\circ} \mathrm{C}$ (left) and at $75^{\circ} \mathrm{C}$ (right).
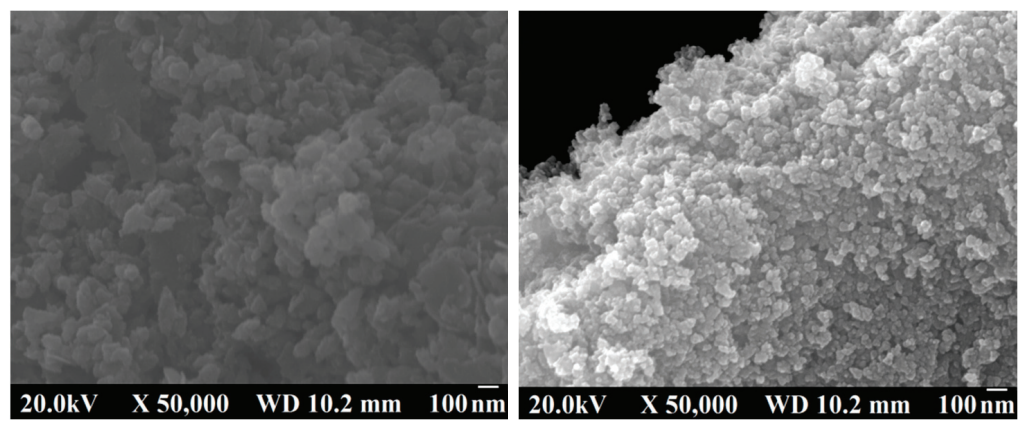

Figure 6. SEM images of zinc oxide synthesized at $50{ }^{\circ} \mathrm{C}$ with a flow rate of 200 $\mathrm{mL} / \mathrm{min}$ (left) and with a flow rate of $250 \mathrm{~mL} / \mathrm{min}$ (right).
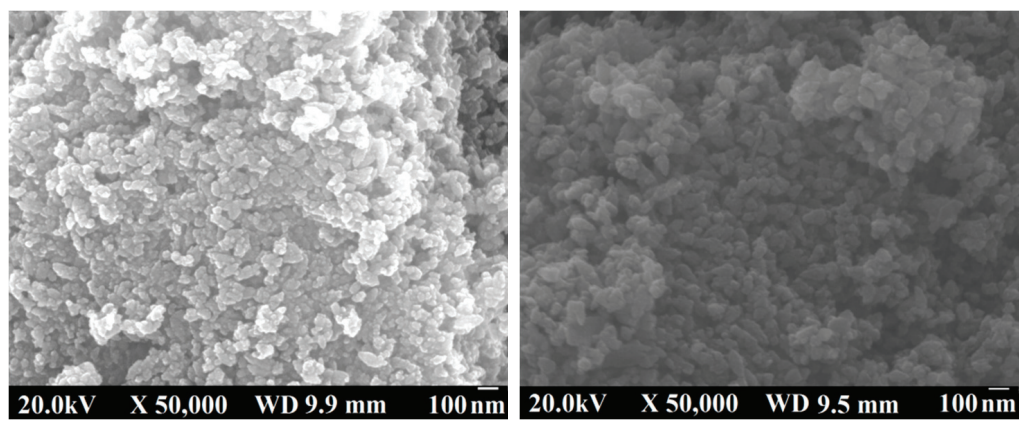

\subsection{Magnetite}

Systematic studies with respect to the synthesis of magnetite nanoparticles using a microjet reactor were performed with an aqueous solution of ferric and ferrous chloride as solution $\mathrm{A}$ and an ammonia solution B (Equation 2).

$$
\mathrm{FeCl}_{2}+2 \mathrm{FeCl}_{3}+8 \mathrm{NH}_{4} \mathrm{OH} \rightarrow \mathrm{Fe}_{3} \mathrm{O}_{4}+8 \mathrm{NH}_{4} \mathrm{Cl}+4 \mathrm{H}_{2} \mathrm{O} \text {. }
$$

Ferrous chloride must be applied in excess because the synthesis was performed under air. Consequently, the $\mathrm{Fe}^{2+}$ ions tend to oxidize and form $\mathrm{Fe}^{3+}$ ions [27]. Magnetite nanoparticles were already obtained applying conventional synthetic routes using the same starting materials [28].

FT-IR analysis of the particles that were obtained in the microjet reactor does not show specific bands for the products with exception of the Fe-O band around $500 \mathrm{~cm}^{-1}$.

Thermo gravimetric analysis (Figure 7) was performed to determine if the samples contain any adsorbed species like water. The particles show a mass loss between 4 and $7 \%$, which can be explained by adsorbed water or the production of water by condensation of free hydroxyl groups. 
Figure 7. Thermo gravimetric analysis of the final products. The samples show a mass loss of between 4 and $7 \%$.

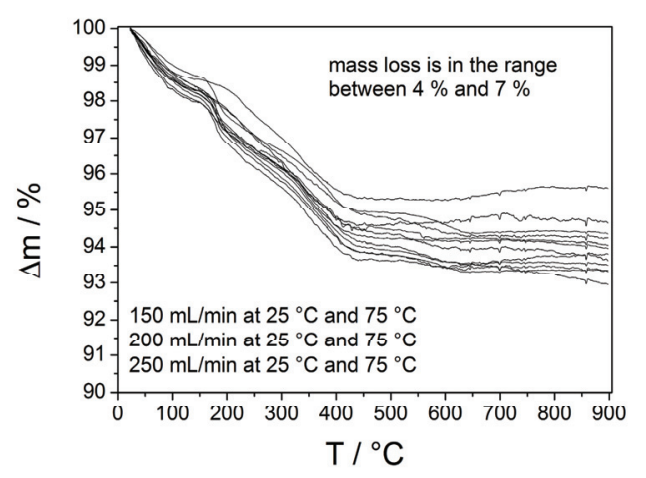

The phase composition and crystallite size of the obtained particles were determined by X-ray powder diffraction (Figure 8). The results show that magnetite with crystallite sizes around $10 \mathrm{~nm}$ were obtained in the microjet reactor. There are a few very weak reflections which cannot be correlated to magnetite. Consequently, there is a small fraction of an impurity phase. The reflection at approximately $2 \theta=32^{\circ}$ suggest this phase to be maghemite.

Figure 8. XRD pattern of the obtained particles. The results show that magnetite was obtained.

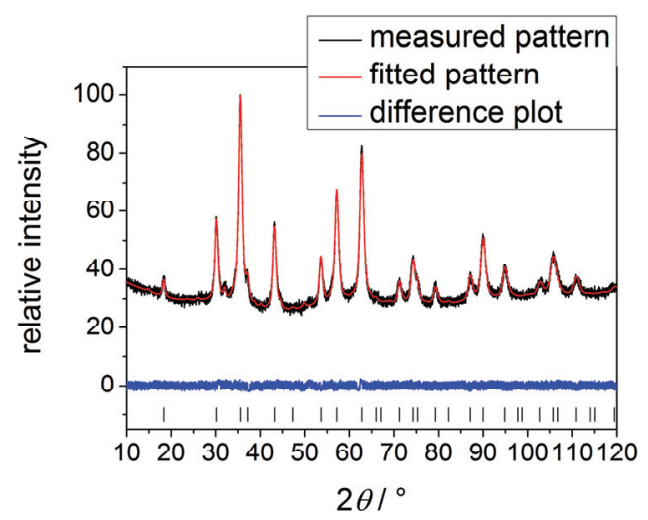

The particle size of the attained material was determined by using dynamic light scattering (Figure 9). The results reveal that particles between $46 \mathrm{~nm}$ and $112 \mathrm{~nm}$ were obtained. Just as in case of the $\mathrm{ZnO}$ particles the particle sizes including the size distribution decrease with increasing process temperature and flow rate (Table 3).

Previous studies applying rapid mixing techniques showed much smaller nanoparticle sizes around $7 \mathrm{~nm}$ [4]. The difference between the technique presented here and previous studies is the altered time for growth of the particles, which depends in our setup on the length of the tubing between microjet-reactor and collecting vessel. We are currently investigating these parameters in an additional study. 
Figure 9. Particle size of the synthesized magnetite determined by dynamic light scattering.
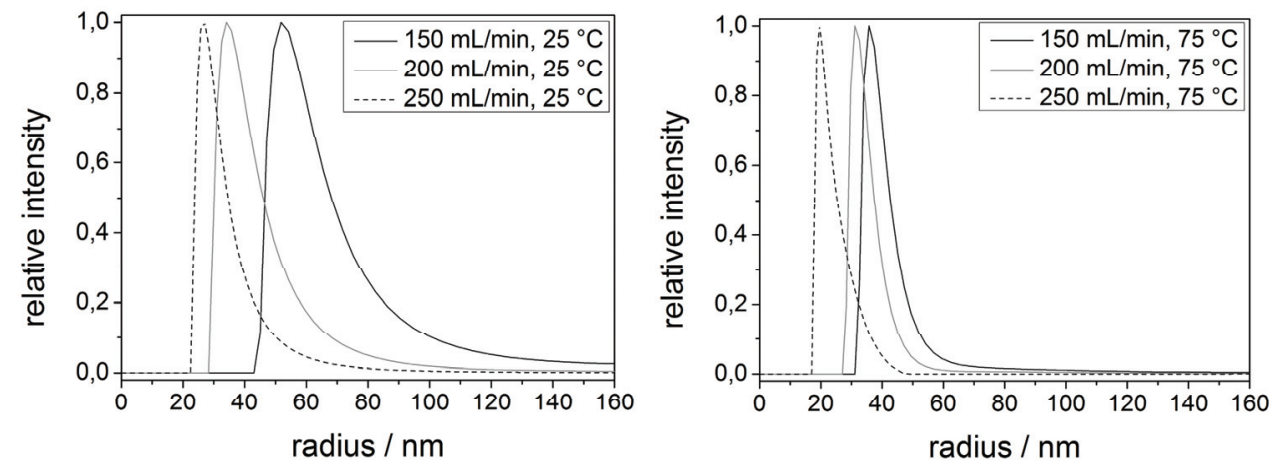

Table 3. Particle size determined using dynamic light scattering.

\begin{tabular}{cc}
\hline Process parameters & Radius $/ \mathbf{n m}$ \\
\hline $150 \mathrm{~mL} / \mathrm{min} / 25^{\circ} \mathrm{C}$ & $66 \pm 9$ \\
$200 \mathrm{~mL} / \mathrm{min} / 25^{\circ} \mathrm{C}$ & $42 \pm 7$ \\
$250 \mathrm{~mL} / \mathrm{min} / 25^{\circ} \mathrm{C}$ & $32 \pm 5$ \\
$150 \mathrm{~mL} / \mathrm{min} / 75^{\circ} \mathrm{C}$ & $41 \pm 4$ \\
$200 \mathrm{~mL} / \mathrm{min} / 75^{\circ} \mathrm{C}$ & $35 \pm 4$ \\
$250 \mathrm{~mL} / \mathrm{min} / 75^{\circ} \mathrm{C}$ & $23 \pm 3$ \\
\hline
\end{tabular}

SEM was applied to determine the morphology of the obtained magnetite particles (Figure 10). The results show that the particles are sphere-shaped and become smaller with increasing flow rate and temperature.

Figure 10. SEM images of the obtained magnetite particles synthesized at $25^{\circ} \mathrm{C}$ with a flow rate of $150 \mathrm{~mL} / \mathrm{min}$ (left) and at $75^{\circ} \mathrm{C}$ with a flow rate of $250 \mathrm{~mL} / \mathrm{min}$ (right).
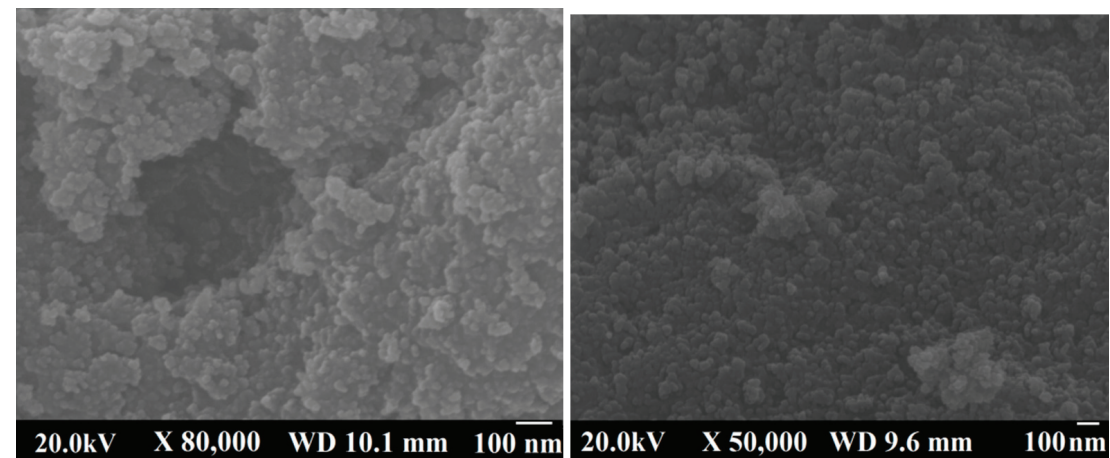


\subsection{Calcium Hydrogen Phosphate/Brushite}

As a third system the synthesis of calcium hydrogen phosphate particles using the mircojetreactor was investigated. An aqueous solution of calcium nitrate (solution A) and di-ammonium hydrogen phosphate (solution B) were mixed in the microjet reactor (Equation 3). The $\mathrm{pH}$ of both solutions was adjusted to 5 in order to obtain the calcium hydrogen phosphate in the brushite phase.

$$
\mathrm{Ca}\left(\mathrm{NO}_{3}\right)_{2} \cdot 4 \mathrm{H}_{2} \mathrm{O}+\mathrm{HPO}_{4}\left(\mathrm{NH}_{4}\right)_{2} \rightarrow \mathrm{CaHPO}_{4} \cdot 2 \mathrm{H}_{2} \mathrm{O}+2 \mathrm{NH}_{4} \mathrm{NO}_{3}+2 \mathrm{H}_{2} \mathrm{O} \text {. }
$$

Using the same starting materials, but applying a conventional batch reactor synthesis route, plate-like brushite particles in the micrometer range were obtained [29]. Employing the microjet reactor for this reaction it turned out that the precipitation reaction does not proceed at $25{ }^{\circ} \mathrm{C}$. The material obtained using $75^{\circ} \mathrm{C}$ as process temperature was analyzed with respect to composition and morphology. FT-IR analyses (Figure 11) of the obtained materials show that the synthesis of calcium hydrogen phosphate was successful at $75{ }^{\circ} \mathrm{C}$. The spectra show absorption bands between $1200 \mathrm{~cm}^{-1}$ and $400 \mathrm{~cm}^{-1}$ which is the typical P-O region and indicates P-O vibrations as well as vibrations of a $\mathrm{HPO}_{4}$ group. In addition, absorption bands relating to water are visible. At $1650 \mathrm{~cm}^{-1}$ there is the typical absorption band for the $\mathrm{H}_{2} \mathrm{O}$ bending. Furthermore, between $3550 \mathrm{~cm}^{-1}$ and $3000 \mathrm{~cm}^{-1}$, the absorption bands relating to the $\mathrm{OH}$ stretching of water are visible. This agrees well with FT-IR data of calcium hydrogen phosphate reported in the literature [30,31].

Figure 11. FT-IR spectra of the obtained materials. Absorption bands in the P-O region are observable as well as absorption bands relating to water. For each condition two spectra were shown in order to illustrate the reproducibility.

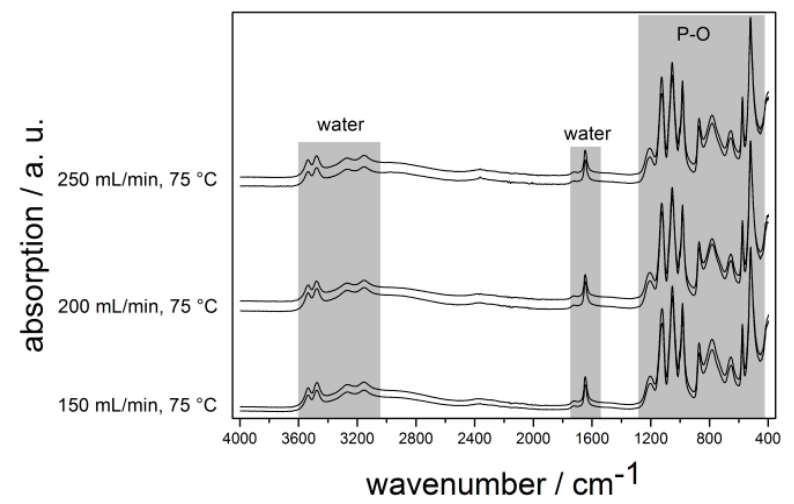

Thermo gravimetric analysis was performed to analyze the thermal decomposition of the obtained material (Figure 12). The results show that the decomposition takes place in two steps, which confirms that calcium hydrogen phosphate was obtained in the brushite phase. The first decomposition step proceeds between $100{ }^{\circ} \mathrm{C}$ and $350{ }^{\circ} \mathrm{C}$ degree and is relating to the loss of two molecules of crystal water. Consequently $\mathrm{CaHPO}_{4}$ is formed. The second decomposition step takes place between $350{ }^{\circ} \mathrm{C}$ and $600{ }^{\circ} \mathrm{C}$ and is relating to the loss of 0.5 water molecules per $\mathrm{Ca}^{2+}$ ion and the formation of $\mathrm{Ca}_{2} \mathrm{P}_{2} \mathrm{O}_{7}$. This is the typical pattern for decomposition of brushite. 
Figure 12. Thermal decomposition of the obtained material. The decomposition takes place in two steps, which is typical for the thermal decomposition of calcium hydrogen phosphate in the brushite phase.

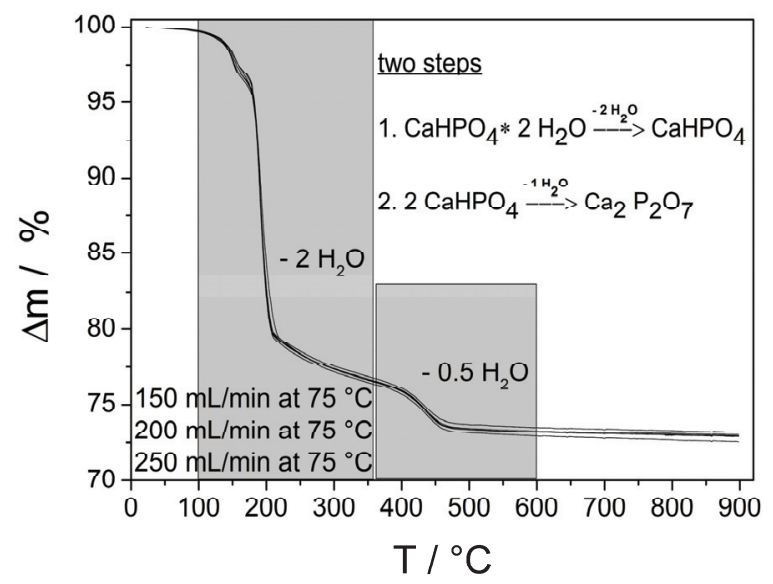

The results of the X-ray powder diffraction measurements (Figure 13) confirm that pure brushite was obtained. The particles show a high anisotropy in their crystallite sizes. An average crystallite size could be determined which is in the range of 200 to $300 \mathrm{~nm}$ depending on the reaction conditions.

Figure 13. X-ray powder pattern. Pure calcium hydrogen phosphate in the brushite phase was obtained.

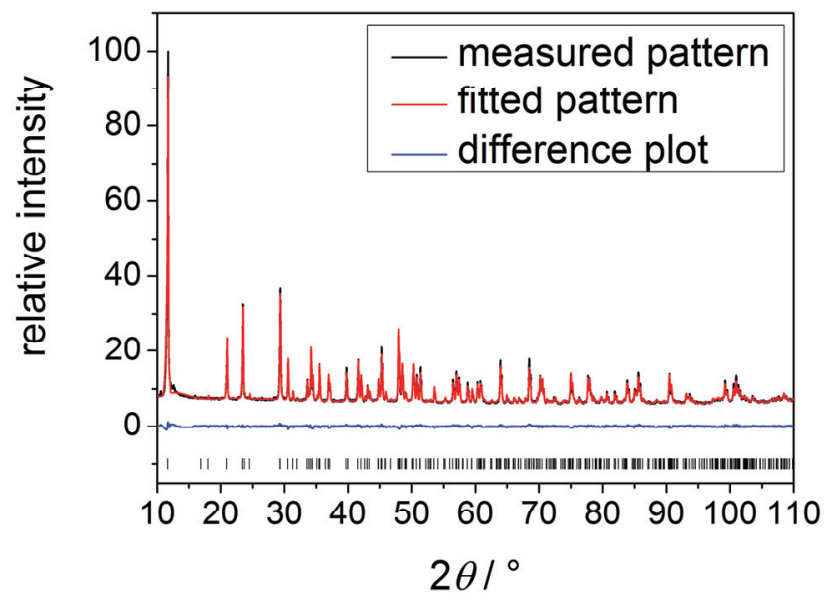

SEM was applied to analyze the morphology of the obtained material (Figure 14). The results show that the particles are shaped like small plates based on the layered structure of brushite. The layers grow faster in two directions so that plates are formed. The edge lengths of these plates were determined to be between $100 \mathrm{~nm}$ and $500 \mathrm{~nm}$. 
Figure 14. SEM image of the obtained material. Brushite synthesized at $75{ }^{\circ} \mathrm{C}$ with a flow rate of $250 \mathrm{~mL} / \mathrm{min}$.

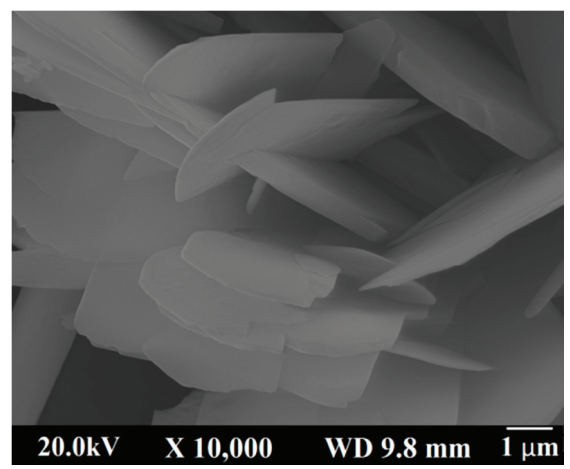

All three examples showed that the continuous production of nanoparticles, in case of $\mathrm{ZnO}$ and $\mathrm{Fe}_{3} \mathrm{O}_{4}$, or submicron sized plates in case of brushite is possible with the wet chemical microjet reaction technique. All samples showed that flow rates as well as temperatures have an important influence on the size and size-distribution of the particles. In the microjet environment the nuclei are formed and the particle growth most likely occurs in the tube between the reactor and the collecting vessel. We did not investigate the effect of this distance on the particle growth yet. This will be the focus of a further study.

\section{Experimental Section}

\subsection{Materials}

Zinc chloride, sodium hydroxide and ferric chloride were purchased from Grüssing GmbH (Filsum, Germany). Calcium nitrate and di-ammonium hydrogen phosphate were purchased from Fluka (Buchs, Switzerland). Ferrous chloride was purchased from Alfa Aesar (Karlsruhe, Germany). Ammonia was purchased from VWR (Fontenay-sous-Bois, France). All chemicals were used without further purification.

\subsection{Instruments and Characterization}

FT-IR measurements were performed under ambient air (40 scans at a resolution of $4 \mathrm{~cm}^{-1}$ ) in attenuated total reflectance (ATR) mode on a Bruker Vertex 70 spectrometer. X-ray powder diffraction was carried out on two different diffractometers a Panalytical X'Pert and a Bruker D8 Advance-system, Bragg-Brentano geometry and $\mathrm{CuK} \alpha$ radiation was used in both cases. The quantitative analysis was carried out by the Rietveld-method using the program TOPAS [32] and crystallographic data for the different species (zinc oxide [33], magnetite [34] and brushite [35]). Thermogravimetric analysis (TGA) was carried out on a Netzsch Iris TG 209. The sample was placed in an alumina crucible which was then heated from room temperature to $900{ }^{\circ} \mathrm{C}$ under nitrogen atmosphere with a rate of $20 \mathrm{~K} \mathrm{~min}^{-1}$. 
Scanning electron microscopy (SEM) images were recorded on a JEOL SEM-7000 microscope. The SEM samples were prepared by placing some grains on a specimen stub with attached carbon adhesive foil followed by deposition of a gold layer. Dynamic light scattering (DLS) measurements were carried out on an ALV/CGS-3 compact goniometer system with an ALV/LSE-5003 multiple $\tau$ correlator at a wavelength of $632.8 \mathrm{~nm}$ (He-Ne Laser) and at a $90^{\circ}$ goniometer angle. The particle radius was then determined by the analysis of the correlation-function via the $\mathrm{g} 2(\mathrm{t})$ method followed by a logarithmic number-weighting (n.w.) of the distribution function.

\subsection{Synthesis}

The following experiments were performed in a microjet reactor construction. Two LaPrep P110 preparative HPLC pumps (VWR) are responsible for the transport of the solutions containing the starting materials as dissolved substances. The reaction takes place in a microjet reactor (Synthesechemie, Heusweiler, Germany and MJR PharmJet, Homburg, Germany) with a cone diameter of 300 micrometers. The precipitate was directly removed from the reactor by the use of a nitrogen gas flow. The length of the tube between the microjet reactor and the collecting vessel was $150 \mathrm{~cm}$. Zinc oxide was synthesized using a $1 \mathrm{M}$ aqueous zinc chloride and a $2 \mathrm{M}$ aqueous sodium hydroxide solution as starting materials. Magnetite was obtained using a $0.4 \mathrm{M}$ aqueous ammonia solution and an aqueous solution containing $0.0625 \mathrm{M}$ ferric and ferrous chloride respectively. Brushite was synthesized by using $0.2 \mathrm{M}$ aqueous solution of calcium nitrate and a $0.1 \mathrm{M}$ aqueous solution of di-ammonium hydrogen phosphate, the $\mathrm{pH}$ of both solutions was adjusted to 5 using acetic acid or ammonia. The synthesis of each species was performed using different process parameters. The temperature was varied between $25{ }^{\circ} \mathrm{C}$ and $75{ }^{\circ} \mathrm{C}$, the flow rate was varied between $150 \mathrm{~mL} / \mathrm{min}$ and $250 \mathrm{~mL} / \mathrm{min}$.

\section{Conclusions}

The microjet-reactor technique is a promising method for the continuous synthesis of inorganic nanoparticles. Systematic studies on the effect of the process parameters, such as flow rate and process temperature, show that the particle size is controllable by means of these parameters. Our aim was the continuous synthesis of inorganic nanoparticles with controllable particle size. In our work we successfully demonstrated that it is possible to obtain pure zinc oxide nanoparticles using the microjet-reactor system. The prepared particles are uniformly shaped with a particle size of between $44 \mathrm{~nm}$ and $102 \mathrm{~nm}$ depending on the reaction conditions. The same could be shown for the synthesis of magnetite nanoparticles that were obtained with particle sizes between $46 \mathrm{~nm}$ and $132 \mathrm{~nm}$. In both cases, the size distributions were quite small and decreased with increasing reaction temperature. Furthermore, we demonstrated the synthesis of calcium hydrogen phosphate (brushite) by using the microjet-reactor. In this case brushite as a layered structure formed small plates.

\section{Conflicts of Interest}

The authors declare no conflict of interest. 


\section{References}

1. Kango, S.; Kalia, S.; Celli, A.; Njuguna, J.; Habibi, Y.; Kumar, R. Surface modification of inorganic nanoparticles for development of organic-inorganic nanocomposites-A review. Prog. Polym. Sci. 2013, 38, 1232-1261.

2. Castro, F.; Kuhn, S.; Jensen, K.; Ferreira, A.; Rocha, F.; Vicente, A.; Teixeira, J.A. Process intensification and optimization for hydroxyapatite nanoparticles production. Chem. Eng. Sci. 2013, 100, 352-359.

3. Ying, Y.; Chen, G.; Zhao, Y.; Li, S.; Yuan, Q. A high throughput methodology for continuous preparation of monodispersed nanocrystals in microfluidic reactors. Chem. Eng. J. 2008, 135, 209-215.

4. Ström, V.; Olsson, R.T.; Rao, K.V. Real-time monitoring of the evolution of the magnetism during precipitation of superparamagnetic nanoparticles for bioscience application. J. Mater. Chem. 2010, 20, 4168-4175.

5. Van den Rul, H.; Mondelaers, D.; van Bael, M.K.; Mullens, J. Water-based wet chemical synthesis of (doped) ZnO nanostructures. J. Sol-Gel Sci. Tech. 2006, 39, 41-47.

6. Jones, A.; Rigopoulos, S.; Zauner, R. Crystallisation and precipitation engineering. Comput. Chem. Eng. 2005, 29, 1159-1166.

7. Chen, J.; Zheng, C.; Chen, G. Interaction of macro- and micromixing on particle size distribution in reactive precipitation. Chem. Eng. Sci. 1996, 51, 1957-1966.

8. Mersmann, A. Crystallization and precipitation. Chem. Eng. Process. 1999, 38, 345-353.

9. Luo, G.; Du, L.; Wang, Y.; Lu, Y.; Xu, J. Controllable preparation of particles with microfluidics. Particuology 2011, 9, 545-558.

10. Chen, G.; Luo, G.; Yang, X.; Sun, Y.; Wang, J. Anatase- $\mathrm{TiO}_{2}$ nano-particle preparation with a micro-mixing technique and its photocatalytic performance. Mater. Sci. Eng. A 2004, 380, 320-325.

11. Wagner, J.; Kirner, T.; Mayer, G.; Albert, J.; Köhler, J.M. Generation of metal nanoparticles in a microchannel reactor. Chem. Eng. J. 2004, 101, 251-260.

12. Zinoveva, S.; De Silva, R.; Louis, R.D.; Datta, P.; Kumar, C.S.S.R.; Goettert, J.; Hormes, J. The wet chemical synthesis of Co nanoparticles in a microreactor system: A time-resolved investigation by X-ray absorption spectroscopy. Nucl. Instrum. Methods Phys. Res. Sect. A 2007, 582, 239-241.

13. Du, L.; Wang, Y.J.; Lu, Y.C.; Luo, G.S. Preparation of highly purified $\beta$-tricalcium phosphate ceramics with a microdispersion process. Chem. Eng. J. 2013, 221, 55-61.

14. Schwarzer, H.C.; Schwertfirm, F.; Manhart, M.; Schmid, H.J.; Peukert, W. Predictive simulation of nanoparticle precipitation based on the population balance equation. Chem. Eng. Sci. 2006, 61, 167-181.

15. Schwarzer, H.C.; Peukert, W. Experimental Investigation into the Influence of Mixing on Nanoparticles Precipitation. Chem. Eng. Technol. 2002, 25, 6, 657-661. 
16. Lince, F.; Marchisio, D.L.; Barresi, A.A. A comparative study for nanoparticle production with passive mixers via solvent-displacement: Use of CFD models for optimization and design. Chem. Eng. Process. 2011, 50, 356-368.

17. Lince, F.; Marchisio, D.L.; Barresi, A.A. Smart mixers and reactors for the production of pharmaceutical nanoparticles: Proof of concept. Chem. Eng. Res. Des. 2009, 87, 543-549.

18. Silva, V.M.T.M.; Quadros, P.A.; Laranjeira, P.E.M.S.C.; Dias, M.M.; Lopes, J.C.B. A novel Continuous Industrial Process for Producing Hydroxyapatite Nanoparticles. J. Dispersion Sci. Technol. 2008, 29, 542-547.

19. Penth, B. (K)ein Fall für die Fällung. Chem. Tech. 2004, 3, 18-20.

20. Penth, B. Kontinuierliche Produktion in Mikroreaktoren. German Patent DE 102006004350 A1, August 2006.

21. Rüfer, A.; Räuchle, K.; Krahl, F.; Reschetilowski, W. Kontinuierliche Darstellung von Bariumsulfat-Nanopartikeln im MicroJet-Reaktor. Chem. Ing. Tech. 2009, 81, 1949-1954.

22. Dittert, B.; Gavrilovic, A.; Schwarz, S.; Angerer, P.; Steiner, H.; Schöftner, R. Phase content controlled $\mathrm{TiO}_{2}$ nanoparticles using the MicroJetReactor technology. J. Eur. Ceram. Soc. 2011, 31, 2475-2480.

23. Djutisic, A.B.; Ng, A.M.C.; Chen, X.Y. ZnO nanostructures for optoelectronics: Material properties and device applications. Prog. Quantum Electron. 2010, 34, 191-259.

24. Sugawara, A.; Asaoka, K.; Ding, S.J. Calcium phosphate-based cements: Clinical needs and recent progress. J. Mater. Chem. B 2013, 1, 1081-1089.

25. Vékás, L.; Tombácz, E.; Turcu, R.; Morjan, I.; Avdeev, M.V.; Krasia-Christoforou, T.; Socoliuc, V. Synthesis of Magnetite Nanoparticles and Magnetic Fluids for Biomedical Applications. Nanomedicine-Basic and Clinical Applications in Diagnostics and Therapy. Else KrönerFresenius Symp. Basel Karger 2011, 2, 35-52.

26. Samanta, P.K.; Mishra, S. Wet chemical growth and optical property of ZnO nanodiscs. Optik 2013, 124, 2871-2873.

27. RuizMoreno, R.G.; Martínez, A.I.; Falcony, C.; Castro-Rodriguez, R.; Bartolo-Pérez, P.; Castro-Román, M. One pot synthesis of water compatible and monodisperse magnetite nanoparticles. Mater. Lett. 2013, 92, 181-183.

28. Fang, M.; Ström, V.; Olsson, R.T.; Belova, L.; Rao, K.V. Particle size and magnetic properties dependence on growth temperature for rapid mixed co-precipitated magnetite nanoparticles. Nanotechnology 2012, 23, 145601.

29. Arifuzzaman, S.M.; Rohani, S. Experimental study of brushite precipitation. J. Cryst. Growth 2004, 267, 624-634.

30. Petrov, I.; Soptrajanov, B.; Fuson, N.; Lawson, J.R. Infra-red investigation of dicalcium phosphates. Spectrochim. Acta 1967, 23A, 2637-2646.

31. Trpkovska, M.; Soptrajanov, B.; Malkov, P. FTIR reinvestigation of the spectra of synthetic brushite and its partially deuterated analogues. J. Mol. Struct. 1999, 480-481, 661-666.

32. Topas, V4.2; General profile and structure analysis software for powder diffraction data, User Manual; Bruker AXS: Karlsruhe, Germany, 2008. 
33. Khan, A.A. X-ray determination of thermal expansion of zinc oxide. Acta Cryst. A 1968, $24,403$.

34. Okudera, H.; Kihara, K.; Matsumoto, T. Temperature Dependence of Structure Parameters in Natural Magnetite: Single Crystal X-ray Studies from 126 to 773 K. Acta Cryst. B 1996, 52, 450-457.

35. Beevers, C.A. The Crystal Structure of Dicalcium Phosphate Dihydrate, $\mathrm{CaHPO}_{4} \cdot 2 \mathrm{H}_{2} \mathrm{O}$. Acta Cryst. 1958, 11, 273-277. 


\title{
Synthesis of Diazonium Tetrachloroaurate(III) Precursors for Surface Grafting
}

\author{
Sabine N. Neal, Samuel A. Orefuwa, Atiya T. Overton, Richard J. Staples and \\ Ahmed A. Mohamed
}

\begin{abstract}
The synthesis of diazonium tetrachloroaurate(III) complexes [R-4- $\left.\mathrm{C}_{6} \mathrm{H}_{4} \mathrm{~N} \equiv \mathrm{N}\right] \mathrm{AuCl}_{4}$ involves protonation of anilines $\mathrm{CN}-4-\mathrm{C}_{6} \mathrm{H}_{4} \mathrm{NH}_{2}, \mathrm{C}_{8} \mathrm{~F}_{17}-4-\mathrm{C}_{6} \mathrm{H}_{4} \mathrm{NH}_{2}$, and $\mathrm{C}_{6} \mathrm{H}_{13}-4-\mathrm{C}_{6} \mathrm{H}_{4} \mathrm{NH}_{2}$ with tetrachloroauric acid $\mathrm{H}\left[\mathrm{AuCl}_{4}\right] 3 \mathrm{H}_{2} \mathrm{O}$ in acetonitrile followed by one-electron oxidation using [NO]PF6. FT-IR shows the diazonium stretching frequency at $2277 \mathrm{~cm}^{-1}(\mathrm{CN}), 2305 \mathrm{~cm}^{-1}\left(\mathrm{C}_{8} \mathrm{~F}_{17}\right)$, and $2253 \mathrm{~cm}^{-1}\left(\mathrm{C}_{6} \mathrm{H}_{13}\right)$. Thermogravimetric Analysis (TGA) shows the high stabilities of the electron-withdrawing substituents $\mathrm{C}_{8} \mathrm{~F}_{17}$ and $\mathrm{CN}$ compared with the electron-donating substituent $\mathrm{C}_{6} \mathrm{H}_{13}$. Residual Gas Analysis (RGA) shows the release of molecular nitrogen as the main gas residue among other small molecular weight chlorinated hydrocarbons and chlorobenzene. Temperature-Dependent X-Ray Powder Diffraction (TD-XRD) shows the thermal decomposition in $\mathrm{C}_{6} \mathrm{H}_{13}$ diffraction patterns at low temperature of $80{ }^{\circ} \mathrm{C}$ which supports the TGA and RGA (TGA-MS) conclusions. X-ray structure shows $\mathrm{N} \equiv \mathrm{N}$ bond distance of approximately $1.10 \AA$ and $\mathrm{N} \equiv \mathrm{N}-\mathrm{C}$ bond angle of $178^{\circ}$.
\end{abstract}

Reprinted from Inorganics. Cite as: Neal, S.N.; Orefuwa, S.A.; Overton, A.T.; Staples, R.J.; Mohamed, A.A. Synthesis of Diazonium Tetrachloroaurate(III) Precursors for Surface Grafting. Inorganics 2013, 1, 70-84.

\section{Introduction}

Modification of surfaces by redox grafting of diazonium salts is a progressing area of materials chemistry [1-12]. Reduction of aryl diazonium salts has been studied on carbon $[3,4,6]$, semiconductors [6], and nanoparticles surfaces [13-19]. Grafted organic layers demonstrated distinctive performance in the formation of corrosion inhibitor film on iron [10,20], modification of graphene [2,11,12] and diamond [5,21], preparation of diazonium-modified enzyme electrodes [22], immobilization of proteins [5,23], grafting polymers [24], and printing gold via soft lithography $[25,26]$. In addition to surface modification, aryl diazonium salts have been utilized in palladium-catalyzed cross-coupling reactions. In particular, Heck reactions involving aryl diazonium salts have been widely used in the synthesis of natural products. These electrophiles can also be used in Suzuki-Miyaura, carbonylative, Stille, and carbon-heteroatom cross-couplings [27].

Figure 1. Reductive grafting mechanism of diazonium on surfaces.

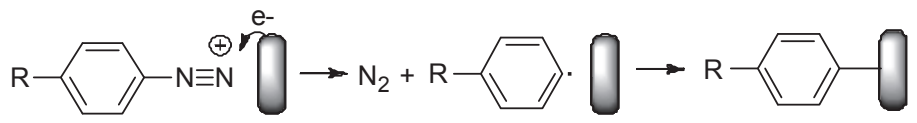


Electrochemical reductive grafting of diazonium has proven to be an effective, versatile, and simple method for producing organic monolayers (Figure 1) [1]. Despite the wide applications of diazonium salts in fundamental and materials chemistry there are many serious drawbacks: their intrinsic instability at room temperature, difficulty to isolate and purify, and their explosive nature [28-30]. In order to avoid some of their limitations diazonium salts must undergo the targeted application in the same medium without isolation. This can be achieved by the in situ diazotization of aryl amines followed by reductive grafting [31].

The electron density model described the bonding in diazonium by synergistic $\mathrm{N} \rightarrow \mathrm{C} \sigma$-bonding and $\mathrm{C} \rightarrow \mathrm{N} \pi$-back-bonding [32-34]. A stabilizing effect for the $\mathrm{C}-\mathrm{N}$ bond includes the formation of charge-transfer complexes, metal-based anion, and coordination [35-37]. Based on the relative size of diazonium and the void of the polyether ring, basicity of the oxygen atoms, and steric hindrance in the ring, it is possible to stabilize the diazonium by complexation with macrocyclic polyethers [34,35]. The formation of aryl diazonium ion-crown ether complexes increased the thermal and photochemical stabilities of aryl diazonium ions in solution and in the solid state. Metal-based anion approach was also utilized in order to stabilize the C-N bond [36]. A complex of aryl diazonium with the anion $\left[\mathrm{ZnCl}_{4}\right]^{2-}$ was synthesized and $\mathrm{X}$-ray structure was determined [36]. Coordination of the in situ generated diazonium demonstrated to be a plausible route for the stabilization of aliphatic diazonium salts [37].

The synthesis of gold complexes of potential applications in materials chemistry is a rising field of interest [38,39]. We describe a facile procedure for the synthesis of stable diazonium tetrachloroaurate(III) complexes. Preliminary results on the synthesis and grafting have been reported in a communication to Inorganic Chemistry [39].

\section{Results and Discussion}

\subsection{Synthesis and Characterization}

In diazotization reactions, a considerably greater amount of $\mathrm{HCl}, \mathrm{H}_{2} \mathrm{SO}_{4}$, or $\mathrm{HClO}_{4}$ acid should be used even if strong basic amines are used as reagents. The tetrachloroauric(III) acid based procedure can be utilized in preparation of a wide range of diazonium compounds in organic solvents without the need for mineral acids (Scheme 1) [39]. Protonation of $\mathrm{CN}-4-\mathrm{C}_{6} \mathrm{H}_{4} \mathrm{NH}_{2}$ with $\mathrm{H}\left[\mathrm{AuCl}_{4}\right] \cdot 3 \mathrm{H}_{2} \mathrm{O}$ in water resulted in the formation of $\mathrm{CN}-4-\mathrm{C}_{6} \mathrm{H}_{4} \mathrm{NH}_{2} \mathrm{AuCl}_{3}, \mathbf{1}$ (Scheme 2). However, the protonation in acetonitrile formed the anilinium tetrachloroaurate(III) complex [CN-4$\left.\mathrm{C}_{6} \mathrm{H}_{4} \mathrm{NH}_{3}\right] \mathrm{AuCl}_{4}, 2$ (Scheme 3), which was easily oxidized by [NO]PF 6 to form the yellow diazonium tetrachloroaurate(III) complex $\left[\mathrm{CN}-4-\mathrm{C}_{6} \mathrm{H}_{4} \mathrm{~N} \equiv \mathrm{N}\right] \mathrm{AuCl}_{4}, \mathbf{3}$, in a high yield. Similarly, the diazonium tetrachloroaurate(III) complexes $\left[\mathrm{C}_{8} \mathrm{~F}_{17}-4-\mathrm{C}_{6} \mathrm{H}_{4} \mathrm{~N} \equiv \mathrm{N}\right] \mathrm{AuCl}_{4}, \quad 4$, and $\left[\mathrm{C}_{6} \mathrm{H}_{13}-4-\right.$ $\left.\mathrm{C}_{6} \mathrm{H}_{4} \mathrm{~N} \equiv \mathrm{N}\right] \mathrm{AuCl}_{4}, \mathbf{5}$, were synthesized in high yields. The diazonium cation was verified in solution by azo coupling with 2-naphthol to give the dark orange color of diazine. The diazonium tetrachloroaurate(III) complexes are soluble in chloroform, acetonitrile, dimethylformamide, and dimethylsulfoxide. The good solubility is an important advantage over diazonium salts of $\mathrm{BF}_{4}^{-}$, $\mathrm{Cl}^{-}$, and $\mathrm{PF}_{6}{ }^{-}$. Although caution should be exercised when handling all diazonium salts, there were no indications that gold diazonium compounds are particularly hazardous. 
Scheme 1. Synthesis of diazonium tetrachloroaurate(III) complexes.

$$
\mathrm{R}=\mathrm{CN}, \mathrm{C}_{8} \mathrm{~F}_{17}, \mathrm{C}_{6} \mathrm{H}_{13}
$$

Scheme 2. Protonation of CN-4-C $6 \mathrm{H}_{4} \mathrm{NH}_{2}$ in water formed aniline gold(III) trichloride, 1.

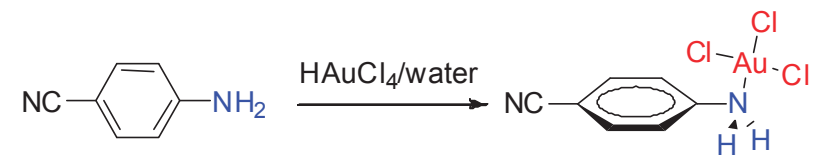

1

Scheme 3. Protonation of $\mathrm{CN}-4-\mathrm{C}_{6} \mathrm{H}_{4} \mathrm{NH}_{2}$ in acetonitrile formed anilinium tetrachloroaurate(III), 2.

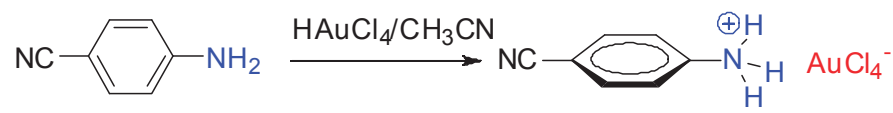

FT-IR spectrum of 3 in the solid state showed the $v_{\mathrm{N} \equiv \mathrm{N}}$ stretching frequency at $2277 \mathrm{~cm}^{-1}$ and ${ }^{1} \mathrm{H}$ NMR spectrum in $\mathrm{CDCl}_{3} / \mathrm{DMSO}-d_{6}$ displayed two doublets assigned to the phenyl protons at $\delta=7.71$ and $8.33 \mathrm{ppm}$, remarkably shifted from 6.65 and $7.45 \mathrm{ppm}$ in the 4-aminobenzonitrile ligand (Figure 2). FT-IR spectrum of 4 displayed the $v_{\mathrm{N} \equiv \mathrm{N}}$ stretching frequency at $2305 \mathrm{~cm}^{-1}$ and ${ }^{1} \mathrm{H}$ NMR spectrum in $\mathrm{CDCl}_{3} / \mathrm{DMSO}-d_{6}$ displayed the phenyl protons at $\delta=7.67$ and $8.59 \mathrm{ppm}$. FTIR spectrum of 5 displayed the $v_{\mathrm{N} \equiv \mathrm{N}}$ stretching frequency at $2253 \mathrm{~cm}^{-1}$ and ${ }^{1} \mathrm{H} \mathrm{NMR}$ spectrum in $\mathrm{CDCl}_{3} / \mathrm{DMSO}-d_{6}$ displayed the phenyl protons at $\delta=7.75$ and $8.60 \mathrm{ppm}$.

\subsection{X-ray Structure}

From acetonitrile solvent at room temperature well-shaped yellow crystals of diazonium tetrachloroaurate(III) complexes were obtained. Structures $\mathbf{1}-\mathbf{3}$ have been reported in reference [39]. X-ray structure of $\mathbf{5}$ is shown in Figure 3 and X-ray data is presented in Table 1. The crystals are quite stable and no sign of decomposition was seen in the X-ray frames. The $\mathrm{N} \equiv \mathrm{N}$ distance is typical of diazonium, approximately $1.10 \AA$. The unit cell shows the arrangement of the tetrachloroaurate anions around the diazonium. Each diazonium group is surrounded by four $\left[\mathrm{AuCl}_{4}\right]^{-}$normal to the $\mathrm{N} \equiv \mathrm{N}$ axis. The $\mathrm{N}($ outer $) .. \mathrm{Cl}$ distances are $3.217,3.267,3.300$, and $3.468 \AA$ (Figure 4). The outer nitrogen is connected to four chloride centers in a square-planar arrangement. The close proximity to the $\mathrm{N} \equiv \mathrm{N}$ group, $\mathrm{Cl} \ldots \mathrm{N} \equiv \mathrm{N}$ interaction, and the fact that the chloride is less nucleophilic in the tetrachloroaurate anion than the free chloride are presumably contributing factors for the increased stability of the diazonium salts. 
Figure 2. FT-IR of diazonium tetrachloroaurate(III) complexes $3(\mathrm{CN}), \mathbf{4}\left(\mathrm{C}_{8} \mathrm{~F}_{17}\right)$, and $5\left(\mathrm{C}_{6} \mathrm{H}_{13}\right)$.

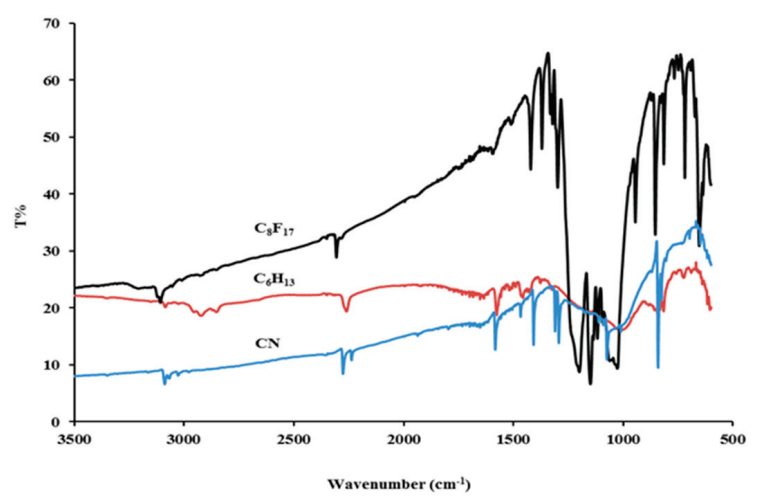

Several diazonium salts have been isolated in the last few decades and their X-ray structures have been reported [40-45]. The structure of benzene diazonium chloride showed $\mathrm{N} \equiv \mathrm{N}$...Cl distance 3.22-3.56 $\AA$. The first example of diazonium stabilization by multiple and close contacts with tosylate anion shows the shortest distances between the diazonium nitrogen and the tosylate oxygen of 2.673-2.770 $\AA$ [46]. shorter than the sum of van der Waals radii (2.90 $\AA)$ [47]. The ionic structures of metal-based diazonium complexes [R-4- $\left.\mathrm{C}_{6} \mathrm{H}_{4} \mathrm{~N} \equiv \mathrm{N}\right] \mathrm{X}\left(\mathrm{X}=\mathrm{SbCl}_{6}, \mathrm{FeCl}_{4}, \mathrm{Cu}_{2} \mathrm{Br}_{2}\right)$ and $\left[\mathrm{R}-4-\mathrm{C}_{6} \mathrm{H}_{4} \mathrm{~N} \equiv \mathrm{N}\right]_{2} \mathrm{ZnCl}_{4}$ show the shortest interionic distances between the diazonium and the metal anion occur between the halide and the outer nitrogen than to the ammonium nitrogen $[42,43]$. Metal-based diazonium complexes structurally characterized so far indicate that the bond order in diazonium nitrogen-nitrogen is close to a triple bond distance of approximately $1.1 \AA$.

Table 1. Crystal data, data collection, and structure refinement for $\left[\mathrm{C}_{6} \mathrm{H}_{13}-4-\right.$ $\left.\mathrm{C}_{6} \mathrm{H}_{4} \mathrm{~N} \equiv \mathrm{N}\right] \mathrm{AuCl}_{4}$.

\begin{tabular}{cc}
\hline Empirical formula & $\mathbf{C}_{\mathbf{1 2}} \mathbf{H}_{\mathbf{1 7}} \mathbf{A u C l}_{\mathbf{4}} \mathbf{N}_{\mathbf{2}}$ \\
\hline Formula weight & 528.04 \\
Temperature, $\mathrm{K}$ & $173(2)$ \\
Wavelength, $\AA$ & 0.71073 \\
Crystal system & Monoclinic \\
Space group & $\mathrm{P} 2_{1} / \mathrm{c}$ \\
$\mathrm{a}(\AA) ;\left(^{\circ}\right)$ & $15.5144(3)$ \\
$\mathrm{b}(\AA) ;\left(^{\circ}\right)$ & $38.4270(8)$ \\
$\mathrm{c}(\AA) ;\left(^{\circ}\right)$ & $90.0250(10)$ \\
Volume, $\AA^{3}$ & $8.7773(2)$ \\
$\mathrm{Z}$ & $5232.78(19)$ \\
Density $($ cal. $), \mathrm{Mg} / \mathrm{m}^{3}$ & 12 \\
Abs. coefficient, $\mathrm{mm}{ }^{-1}$ & 2.011 \\
GOF on $F^{2}$ & 21.395 \\
R1, wR2 $[I>2 \sigma(\mathrm{I})]$ & 1.061 \\
\hline
\end{tabular}


Figure 3. Structure of $\left[\mathrm{C}_{6} \mathrm{H}_{13}-4-\mathrm{C}_{6} \mathrm{H}_{4} \mathrm{~N} \equiv \mathrm{N}\right] \mathrm{AuCl}_{4}$, 5, at $30 \%$ probability. Bond distances $(\AA)$ : $\mathrm{N}(1 \mathrm{~A})-\mathrm{N}(2 \mathrm{~A})$ 1.086(11) and $\mathrm{N}(2)-\mathrm{C}(1)$ 1.400(12). Bond angles $\left(^{\circ}\right)$ : $\mathrm{N}(1 \mathrm{~A})-\mathrm{N}(2 \mathrm{~A})-\mathrm{C}(1 \mathrm{~A})$ 178.7(9).

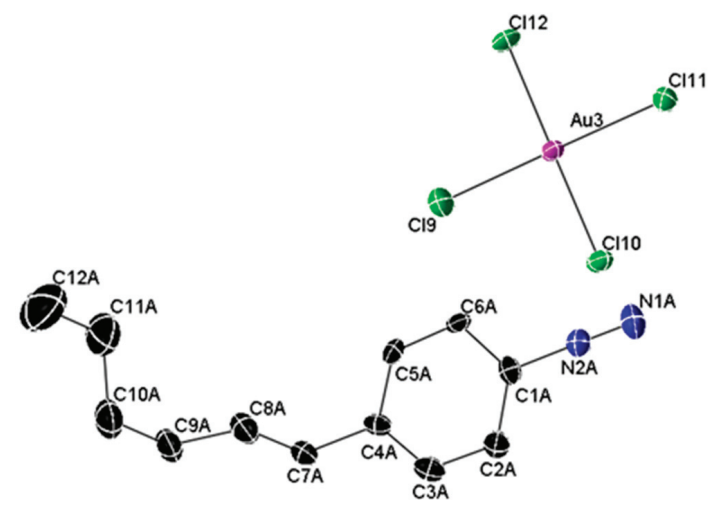

Figure 4. Unit cell of $\left[\mathrm{C}_{6} \mathrm{H}_{13}-4-\mathrm{C}_{6} \mathrm{H}_{4} \mathrm{~N} \equiv \mathrm{N}\right] \mathrm{AuCl}_{4}$.

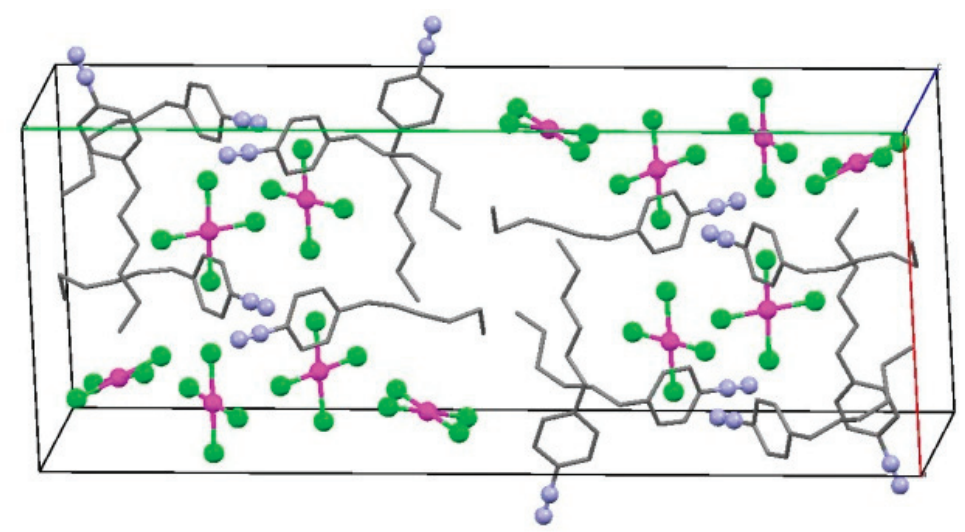

\subsection{Thermal Stability and Residual Gas Analysis Studies}

The enormous literature on the thermal stability of diazonium salts covers the greatest variety with inorganic stabilizing anions. Study clearly indicates an important influence of the stabilizing anion, substituent, and water in the unit cell. A correlation between the rate of diazonium nitrogen evolution and the electronic configuration and the electronegativity of the metal ion has been studied [48]. It cannot be concluded from the correlation study if the type of metal has a direct effect on diazonium stability due to the failure to stabilize diazonium salts with some of the metal chlorides used.

When examined by Thermal Gravimetric Analysis (TGA) at a heating rate of $2.0{ }^{\circ} \mathrm{C} / \mathrm{min}$ the diazonium tetrachloroaurate(III) complexes started the decomposition at approximately $100{ }^{\circ} \mathrm{C}$. The TGA curve of $\mathbf{4}$ displays the loss of nitrogen and chloride in the first stage of $10 \%$ which ends at about $100{ }^{\circ} \mathrm{C}$ followed by a more abrupt weight loss until $150{ }^{\circ} \mathrm{C}$. From $150{ }^{\circ} \mathrm{C}$ to $400{ }^{\circ} \mathrm{C}$ the 
sample losses $c a$. 40\% weight (Figure 5). The poor volatility of the fluorinated ligand conceivably is the reason for the sluggish weight loss. The percentage gold residue from $\mathbf{5}$ is $23 \%$ (theoretical $23 \%$ ). TGA of 3 displays a $40 \%$ gold residue (theoretical $42 \%$ ) and $40 \%$ (theoretical 37\%) for 5 .

Temperature-Dependent X-Ray Powder Diffraction (TD-XRD) patterns at 25, 50, 100, and $150{ }^{\circ} \mathrm{C}$ display peaks associated with the decomposition of $\mathbf{4}$, however, the peaks associated with the elemental gold formation are absent within the same temperature range (Figure 6). The diazonium tetrachloroaurate(III) peaks disappeared after heating above $150{ }^{\circ} \mathrm{C}$ with the concomitant appearance of a new set of peaks. The cubic gold reflections became more intense within the 250-300 ${ }^{\circ} \mathrm{C}$ range. The TD-XRD associated peaks of 5 (Figure 7) show elemental gold at lower temperature than 4 . The diffraction patters also confirmed the highly crystalline nature of gold residues after complete decomposition of $\mathbf{4}$ and $\mathbf{5}$. Bragg reflections at $2 \theta 38.1^{\circ}, 44.5^{\circ}, 64.8^{\circ}$, and $78.8^{\circ}$ could be indexed based on the face-centered cubic gold structure.

The gases released from diazonium tetrachloroaurate(III) pyrolysis were identified by Residual Gas Analysis (RGA) studies. Figure 8 shows the partial pressure of nitrogen for $\mathbf{4}$ and $\mathbf{5}$. In addition to nitrogen, the gases released from each complex in the temperature range $100-450{ }^{\circ} \mathrm{C}$ include chlorobenzene, chlorinated small molecular weight hydrocarbons, and chlorine. The fluorous chain and phenyl groups can be clearly seen leaving as $\mathrm{PhCl}, \mathrm{PhF}$, and low molecular weight halogenated hydrocarbon fractions $\mathrm{CH}_{2} \mathrm{Cl}_{2}, \mathrm{CCl}_{4}, \mathrm{CHCl}_{3}, \mathrm{C}_{2} \mathrm{HCl}_{3}, \mathrm{CH}_{3} \mathrm{~F}$, and $\mathrm{CF}_{4}$ (Table 2). In pyrolysis gas chromatography, the major gases of $\left[\mathrm{R}_{2} \mathrm{~N}-4-\mathrm{C}_{6} \mathrm{H}_{4} \mathrm{~N} \equiv \mathrm{N}\right]_{2} \mathrm{ZnCl}_{4}$ decomposition between $160{ }^{\circ} \mathrm{C}$ and $250{ }^{\circ} \mathrm{C}$ were, in addition to nitrogen, the corresponding chloroaromatics due to the replacement of diazonium by chlorine [49].

Table 2. Partial pressure of gases (Torr) released from Residual Gas Analysis (RGA) decomposition of $\left[\mathrm{C}_{8} \mathrm{~F}_{17}-4-\mathrm{C}_{6} \mathrm{H}_{4} \mathrm{~N} \equiv \mathrm{N}\right] \mathrm{AuCl}_{4}$ at $450{ }^{\circ} \mathrm{C}$.

\begin{tabular}{cccc}
\hline Gas & Partial pressure & Gas & Partial pressure \\
\hline $\mathrm{N}_{2}$ & $2.60 \times 10^{-7}$ & $\mathrm{Cl}_{2}$ & $1.08 \times 10^{-11}$ \\
$\mathrm{CH}_{3} \mathrm{~F}$ & $9.10 \times 10^{-1 \circ}$ & $\mathrm{C}_{6} \mathrm{H}_{5} \mathrm{Cl}$ & $6.47 \times 10^{-12}$ \\
$\mathrm{CH}_{2} \mathrm{Cl}_{2}$ & $5.47 \times 10^{-1 \circ}$ & $\mathrm{C}_{6} \mathrm{H}_{5} \mathrm{~F}$ & $5.21 \times 10^{-12}$ \\
$\mathrm{CHCl}_{3}$ & $2.90 \times 10^{-11}$ & $\mathrm{CCl}_{4}$ & $4.29 \times 10^{-12}$ \\
$\mathrm{CF}_{4}$ & $1.10 \times 10^{-11}$ & & \\
\hline
\end{tabular}

Decomposition of the diazonium tetrachloroaurate(III) complexes, ready evolution of nitrogen, under their respective temperatures using melting point apparatus occurred without melting. It appears that for diazonium tetrachloroaurate(III) complexes there are small temperature ranges over which the gases are evolved. When a heat source was applied to $\mathbf{3}$ the crystals seemed to release gases beginning at about $129{ }^{\circ} \mathrm{C}$ and continued until about $134{ }^{\circ} \mathrm{C}$. When a heat source was applied to 5 the gases were released at temperature range of $110-114^{\circ} \mathrm{C}$ and in $\mathbf{4}$ the gases were released at lower range of $96-97^{\circ} \mathrm{C}$. 
Figure 5. TGA of $\left[\mathrm{CN}-4-\mathrm{C}_{6} \mathrm{H}_{4} \mathrm{~N} \equiv \mathrm{N}\right] \mathrm{AuCl}_{4}, \quad\left[\mathrm{C}_{8} \mathrm{~F}_{17}-4-\mathrm{C}_{6} \mathrm{H}_{4} \mathrm{~N} \equiv \mathrm{N}\right] \mathrm{AuCl}_{4}$, and $\left[\mathrm{C}_{6} \mathrm{H}_{13}-4-\mathrm{C}_{6} \mathrm{H}_{4} \mathrm{~N} \equiv \mathrm{N}\right] \mathrm{AuCl}_{4}$.

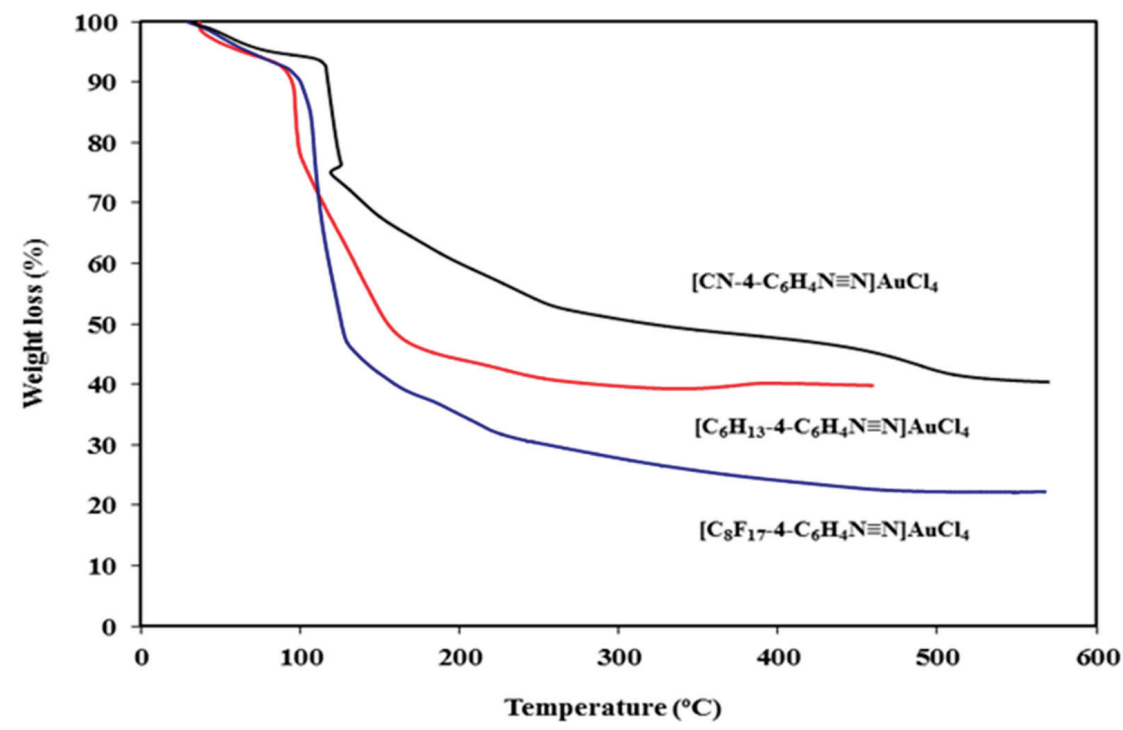

Figure 6. Temperature-Dependent $\mathrm{X}$-ray Powder Diffraction patterns of $\left[\mathrm{C}_{8} \mathrm{~F}_{17-4-}\right.$ $\left.\mathrm{C}_{6} \mathrm{H}_{4} \mathrm{~N} \equiv \mathrm{N}\right] \mathrm{AuCl}_{4}$.

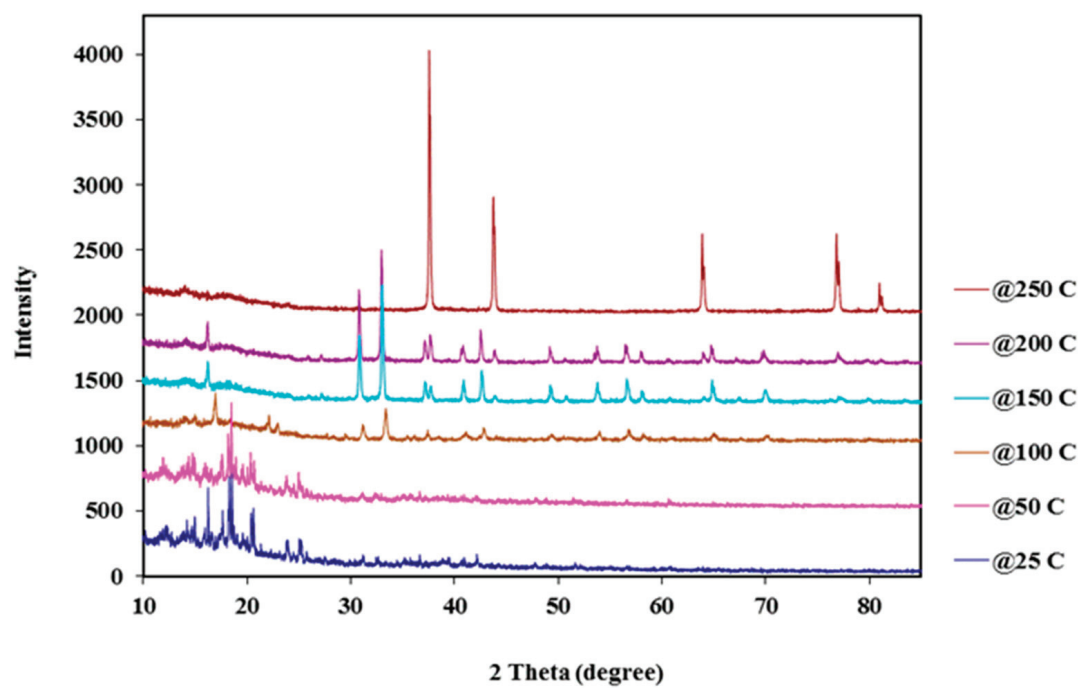


Figure 7. Temperature-Dependent $\mathrm{X}$-ray Powder Diffraction patterns of $\left[\mathrm{C}_{6} \mathrm{H}_{13}-4-\right.$ $\left.\mathrm{C}_{6} \mathrm{H}_{4} \mathrm{~N} \equiv \mathrm{N}\right] \mathrm{AuCl}_{4}$.

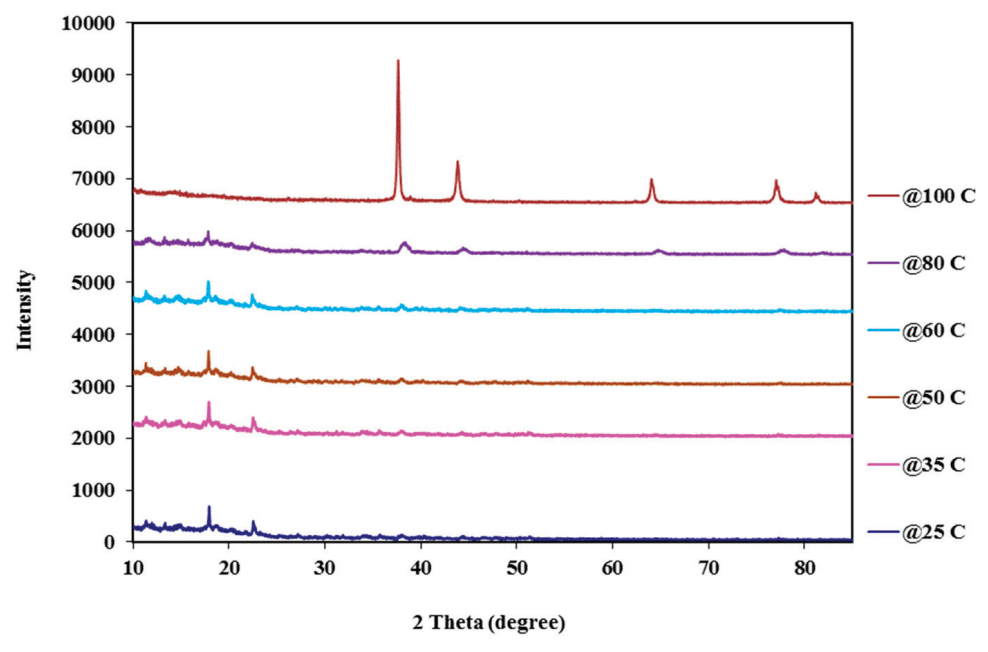

Figure 8. Residual Gas Analysis (RGA) of $\left[\mathrm{C}_{8} \mathrm{~F}_{17}-4-\mathrm{C}_{6} \mathrm{H}_{4} \mathrm{~N} \equiv \mathrm{N}\right] \mathrm{AuCl}_{4}$ and $\left[\mathrm{C}_{6} \mathrm{H}_{13}-4-\right.$ $\left.\mathrm{C}_{6} \mathrm{H}_{4} \mathrm{~N} \equiv \mathrm{N}\right] \mathrm{AuCl}_{4}$.

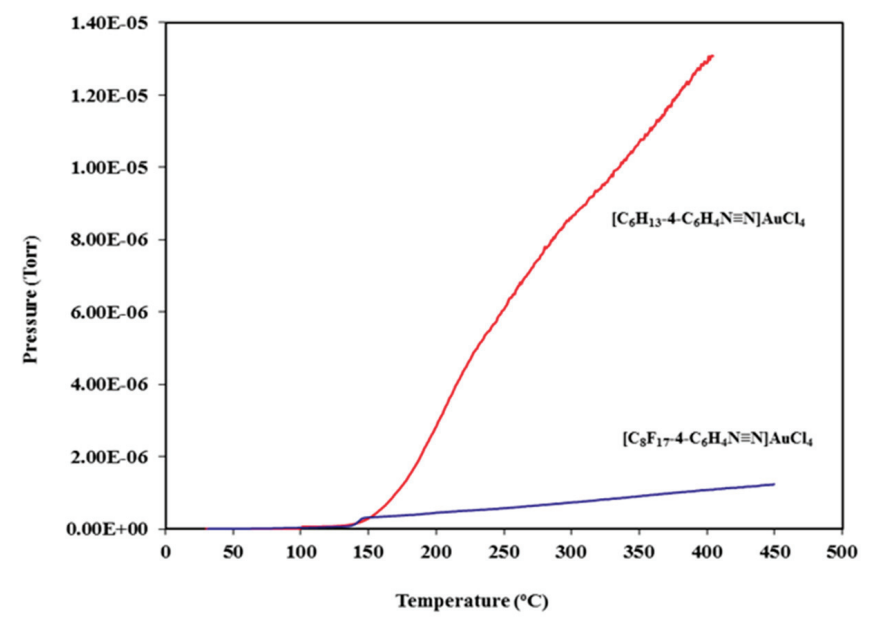

\section{Experimental Section}

\subsection{General Procedures}

Unless stated otherwise, all manipulations were carried out in either a $\mathrm{N}_{2}$-filled Vacuum Atmospheres Co. glove box or on a Schlenk line using $\mathrm{N}_{2}$. Toluene, acetonitrile, CN-4- $\mathrm{C}_{6} \mathrm{H}_{4} \mathrm{NH}_{2}$, $\mathrm{C}_{8} \mathrm{~F}_{17}-4-\mathrm{C}_{6} \mathrm{H}_{4} \mathrm{NH}_{2}, \mathrm{C}_{6} \mathrm{H}_{13}-4-\mathrm{C}_{6} \mathrm{H}_{4} \mathrm{NH}_{2}, \mathrm{CDCl}_{3}, \mathrm{DMSO}-d_{6},[\mathrm{NO}] \mathrm{PF}_{6}$, and $\mathrm{H}\left[\mathrm{AuCl}_{4}\right] 3 \mathrm{H}_{2} \mathrm{O}$ were purchased from Sigma-Aldrich. All other commercially available reagents were used as received. 


\subsection{Physical Measurements}

Infrared spectra were recorded in the $4000-400 \mathrm{~cm}^{-1}$ range using a Perkin-Elmer FT-IR Spectrum 1000 spectrophotometer. C, H, and N analyses were carried out by Columbia Analytical Services, Tucson, Arizona. ${ }^{1} \mathrm{H}$ and ${ }^{13} \mathrm{C}$ NMR spectra were recorded on a JEOL $400 \mathrm{MHz}$. Chemical shifts are reported relative to the chloroform solvent peak.

\subsection{Thermogravimetric Analysis and Residual Gas Analysis}

Thermal stability was studied using a Perkin-Elmer TG/DTA Thermogravimetric analyzer. The scan rate was set at a $2{ }^{\circ} \mathrm{C} / \mathrm{min}$ from room temperature to $500{ }^{\circ} \mathrm{C}$. The TGA analysis was carried out in air and in argon atmosphere. Residual gas analyses were carried out using RGA Pro 2000 from Stanford Research Systems. Non-ambient (Temperature Program) X-ray diffraction analysis was carried out on a Panalytical X'Pert Pro X-ray Diffractometer (Model PW3040 Pro) using copper K-alpha radiation $(\lambda=0.154178 \mathrm{~nm})$. The instrument was operated at $40 \mathrm{KV}$ and $20 \mathrm{~mA}$ on an HTK 1200 oven stage.

\subsection{X-ray Diffraction}

Data for complexes $\mathrm{CN}-4-\mathrm{C}_{6} \mathrm{H}_{4} \mathrm{NH}_{2} \mathrm{AuCl}_{3}, \quad \mathbf{1}, \quad\left[\mathrm{CN}-4-\mathrm{C}_{6} \mathrm{H}_{4} \mathrm{NH}_{3}\right] \mathrm{AuCl}_{4}, \quad$ 2, and [CN-4$\left.\mathrm{C}_{6} \mathrm{H}_{4} \mathrm{~N} \equiv \mathrm{N}\right] \mathrm{AuCl}_{4}, \mathbf{3}$, were collected using a Bruker D8 tricycles diffractometer with APEX II detector CCD based equipped with an LT-2 low-temperature apparatus operating at $110 \mathrm{~K}$. Data for 5 was collected at $213 \mathrm{~K}$ with a Siemens SMART CCD diffractometer equipped with an LT-2 low-temperature apparatus. A suitable crystal was chosen and mounted on a glass fiber using grease. Cell parameters were determined and refined using APEX II software on all observed reflections which corrects for Lp and decay [50,51]. Absorption corrections were applied using SADABS supplied by George Sheldrick [52]. The structures are solved by the direct method using the SHELXS-97 program and refined by least squares method on $\mathrm{F}^{2}$, SHELXL-97, incorporated in SHELXTL-PC V 5.03 [53,54].

\subsection{Syntheses}

Synthesis of $\mathbf{C N}-4-\mathbf{C}_{6} \mathbf{H}_{4} \mathbf{N H}_{2} \mathbf{A u C l}_{3}$, 1: To a $67 \mathrm{mg}(0.5 \mathrm{mmol})$ of CN-4-C6 $4 \mathrm{H}_{4} \mathrm{NH}_{2}$ suspended in 15 of $\mathrm{mL}$ distilled water was added $190 \mathrm{mg}(0.5 \mathrm{mmol}) \mathrm{H}\left[\mathrm{AuCl}_{4}\right] 3 \mathrm{H}_{2} \mathrm{O}$ at room temperature. The water insoluble yellow complex was stirred for $2 \mathrm{~h}$. The yellow precipitate was filtered, washed twice with $5 \mathrm{~mL}$ of water, and dried under vacuum to give $153 \mathrm{mg}$. Yield $64.01 \%$. ${ }^{1} \mathrm{H} \mathrm{NMR}$ $\left(\mathrm{CDCl}_{3} / \mathrm{DMSO}-d_{6}\right): \delta 7.20$ (d, $\left.9.7 \mathrm{~Hz}, 2 \mathrm{H}\right), 7.58$ (d, $\left.9.7 \mathrm{~Hz}, 2 \mathrm{H}\right) .{ }^{13} \mathrm{C}$ NMR (CDCl$\left./ 3 / \mathrm{DMSO}-d_{6}\right)$ : $\delta 119.62(\mathrm{C}-1), 125.0(\mathrm{C}-2, \mathrm{C}-3), 133.63(\mathrm{C}-4), 143.0(\mathrm{CN})$. Elemental analysis calculated for $\mathrm{C}_{7} \mathrm{H}_{6} \mathrm{AuCl}_{3} \mathrm{~N}_{2}: \% \mathrm{C}=19.95, \% \mathrm{H}=1.43, \% \mathrm{~N}=6.65$. Exp: $\% \mathrm{C}=19.89, \% \mathrm{H}=1.40, \% \mathrm{~N}=6.75$.

Synthesis of $\left[\mathbf{C N}-4-\mathbf{C}_{6} \mathbf{H}_{4} \mathbf{N H}_{3}\right] \mathbf{A u C l}_{4}$, 2: To a $67 \mathrm{mg}(0.5 \mathrm{mmol})$ of $\mathrm{CN}-4-\mathrm{C}_{6} \mathrm{H}_{4} \mathrm{NH}_{2}$ dissolved in 10 $\mathrm{mL}$ of $\mathrm{CH}_{3} \mathrm{CN}$ was added $197 \mathrm{mg}(0.5 \mathrm{mmol}) \mathrm{H}\left[\mathrm{AuCl}_{4}\right] 3 \mathrm{H}_{2} \mathrm{O}$ at room temperature. The yellow solution was stirred for $2 \mathrm{~h}$ and $30 \mathrm{~mL}$ of cold ether was added. The reaction mixture was stirred 
for additional $2 \mathrm{~h}$ and the precipitate was filtered, washed twice with $5 \mathrm{~mL}$ cold ether, and dried under vacuum to give $228 \mathrm{mg}$. Yield 87.69\%. ${ }^{1} \mathrm{H}$ NMR ( $\left.\mathrm{CDCl}_{3} / \mathrm{DMSO}-\mathrm{d}_{6}\right): \delta 6.70(\mathrm{~d}, 9.3 \mathrm{~Hz}, 2 \mathrm{H})$, 7.17 (d, $9.3 \mathrm{~Hz}, 2 \mathrm{H}) .{ }^{13} \mathrm{C}$ NMR (CDCl $3 / \mathrm{DMSO}_{6}$ ): $\delta 104.5$ (C-1), 118.9 (C-2), 133.39 (C-3, C-4), $144.24(\mathrm{CN})$. Elemental analysis calculated for $\mathrm{C}_{7} \mathrm{H}_{7} \mathrm{AuCl}_{4} \mathrm{~N}_{2}: \% \mathrm{C}=18.36, \% \mathrm{H}=1.54$, $\% \mathrm{~N}=6.12$. Exp: $\% \mathrm{C}=18.28, \% \mathrm{H}=1.56, \% \mathrm{~N}=6.09$.

Synthesis of $\left[\mathbf{C N}-4-\mathbf{C}_{6} \mathbf{H}_{4} \mathbf{N} \equiv \mathbf{N}\right] \mathbf{A u C l}_{4}$, 3: To a $118 \mathrm{mg}(1.0 \mathrm{mmol})$ of $\mathrm{CN}-4-\mathrm{C}_{6} \mathrm{H}_{4} \mathrm{NH}_{2}$ dissolved in $10 \mathrm{~mL}$ of $\mathrm{CH}_{3} \mathrm{CN}$ was added $391 \mathrm{mg}(1.0 \mathrm{mmol}) \mathrm{H}\left[\mathrm{AuCl}_{4}\right] 3 \mathrm{H}_{2} \mathrm{O}$ at $0{ }^{\circ} \mathrm{C}$. A $184 \mathrm{mg}(1.0 \mathrm{mmol})$ [NO]PF6 was added and stirring continued at $0{ }^{\circ} \mathrm{C}$. The yellow solution was stirred for $2 \mathrm{~h}$ and $30 \mathrm{~mL}$ of cold ether was added. The reaction mixture was stirred for additional $2 \mathrm{~h}$ and the precipitate was filtered, washed twice with $5 \mathrm{~mL}$ of cold ether, and dried under vacuum to give $420 \mathrm{mg}$. Yield $91.90 \%$. ${ }^{1} \mathrm{H}$ NMR $\left(\mathrm{CDCl}_{3} / \mathrm{DMSO}-d_{6}\right): \delta 7.71(\mathrm{~d}, 9.7 \mathrm{~Hz}, 2 \mathrm{H}), 8.33(\mathrm{~d}, 9.7 \mathrm{~Hz}, 2 \mathrm{H}) .{ }^{13} \mathrm{C} \mathrm{NMR}\left(\mathrm{CDCl}_{3} / \mathrm{DMSO}-\right.$ $\left.\mathrm{d}_{6}\right): \delta 115.4(\mathrm{C} 1), 120.3(\mathrm{C} 2), 122.4(\mathrm{C} 3), 133.3 .24(\mathrm{C} 4), 134.3(\mathrm{CN})$. Elemental analysis calculated for $\mathrm{C}_{7} \mathrm{H}_{4} \mathrm{AuCl}_{4} \mathrm{~N}_{3}: \% \mathrm{C}=17.93, \% \mathrm{H}=0.86, \% \mathrm{~N}=8.96$. Exp: $\% \mathrm{C}=17.95, \% \mathrm{H}=0.79, \% \mathrm{~N}=8.84$. FT-IR (solid): $v_{\mathrm{N}=\mathrm{N}}$ stretching frequency at $2277 \mathrm{~cm}^{-1}$. UV-Vis $\left(2.13 \times 10^{-4} \mathrm{M}\right.$ in $\left.\mathrm{CH}_{3} \mathrm{CN}\right)$ : $318 \mathrm{~nm}\left(10,938 \mathrm{M}^{-1} \mathrm{~cm}^{-1}\right)$.

Synthesis of $\left[\mathbf{C}_{8} \mathbf{F}_{\mathbf{1 7}}-\mathbf{4}-\mathbf{C}_{6} \mathbf{H}_{4} \mathbf{N} \equiv \mathbf{N}\right] \mathbf{A u C l}_{4}, \mathbf{4}$ : To a $512 \mathrm{mg}(1.0 \mathrm{mmol})$ of $\mathrm{C}_{8} \mathrm{~F}_{17}-4-\mathrm{C}_{6} \mathrm{H}_{4} \mathrm{NH}_{2}$ dissolved in $20 \mathrm{~mL}$ of toluene at $0{ }^{\circ} \mathrm{C}$ was added $400 \mathrm{mg}(1.0 \mathrm{mmol}) \mathrm{H}\left[\mathrm{AuCl}_{4}\right] 3 \mathrm{H}_{2} \mathrm{O}$ dissolved in 3 $\mathrm{mL}$ of acetonitrile. The solution was stirred for $2 \mathrm{~h}$ before a $173 \mathrm{mg}(1.0 \mathrm{mmol})$ [NO]PF 6 dissolved in $3 \mathrm{~mL}$ of acetonitrile was added. The dark red solution was stirred for an additional $2 \mathrm{~h}$ at $0{ }^{\circ} \mathrm{C}$ under nitrogen during which canary yellow microcrystals precipitated. The microcrystals were filtered, washed twice with $5 \mathrm{~mL}$ of cold toluene, and dried under vacuum to give $835 \mathrm{mg}$. Yield 96.70\%. ${ }^{1} \mathrm{H} \mathrm{NMR}\left(\mathrm{CDCl}_{3} / \mathrm{DMSO}-d_{6}\right): \delta 7.67$ (d, $\left.9.7 \mathrm{~Hz}, 2 \mathrm{H}\right), 8.59$ (d, $\left.9.7 \mathrm{~Hz}, 2 \mathrm{H}\right) .{ }^{13} \mathrm{C} \mathrm{NMR}$ $\left(\mathrm{CDCl}_{3} / \mathrm{DMSO}-d_{6}\right): \delta 120.4$ (C-1), 129.5 (C-2), 133.6 (C-3), 138.0 (C-4). Elemental analysis calculated for $\mathrm{C}_{14} \mathrm{~F}_{17} \mathrm{H}_{4} \mathrm{AuCl}_{4} \mathrm{~N}_{2}: \% \mathrm{C}=19.51, \% \mathrm{H}=0.47, \% \mathrm{~N}=3.25$. Exp: $\% \mathrm{C}=19.33, \% \mathrm{H}=$ $0.66, \% \mathrm{~N}=3.11$. FT-IR (solid): $v_{\mathrm{N} \equiv \mathrm{N}}$ stretching frequency at $2305 \mathrm{~cm}^{-1}$. UV-Vis $\left(1.89 \times 10^{-4} \mathrm{M}\right.$ in $\left.\mathrm{CH}_{3} \mathrm{CN}\right): 305 \mathrm{~nm}\left(2983 \mathrm{M}^{-1} \mathrm{~cm}^{-1}\right)$.

Synthesis of $\left[\mathbf{C}_{6} \mathbf{H}_{13}-4-\mathbf{C}_{6} \mathbf{H}_{4} \mathbf{N} \equiv \mathbf{N}\right] \mathbf{A u C l}_{4}$, 5: To a $178 \mathrm{mg}(1.0 \mathrm{mmol})$ of $\mathrm{C}_{6} \mathrm{H}_{13}-4-\mathrm{C}_{6} \mathrm{H}_{4} \mathrm{NH}_{2}$ dissolved in $20 \mathrm{~mL}$ of toluene at $0{ }^{\circ} \mathrm{C}$ was added $400 \mathrm{mg}(1.0 \mathrm{mmol}) \mathrm{H}\left[\mathrm{AuCl}_{4}\right] 3 \mathrm{H}_{2} \mathrm{O}$ dissolved in $3 \mathrm{~mL}$ of acetonitrile. The solution was stirred for $2 \mathrm{~h}$ before a $173 \mathrm{mg}(1.0 \mathrm{mmol})$ [NO]PF 6 dissolved in $3 \mathrm{~mL}$ of acetonitrile was added. The solution was stirred for an additional $2 \mathrm{~h}$ at $0{ }^{\circ} \mathrm{C}$ under nitrogen and was kept in the fridge overnight to form yellow microcrystals out of olive green solution. The precipitate was filtered, washed twice with $5 \mathrm{~mL}$ of cold toluene, and dried under vacuum to give $425 \mathrm{mg}$. Yield 80.49\%. ${ }^{1} \mathrm{H}$ NMR ( $\left.\mathrm{CDCl}_{3} / \mathrm{DMSO}-d_{6}\right): \delta 7.75(\mathrm{~d}, 8.1 \mathrm{~Hz}, 2 \mathrm{H}), 8.60$ $(\mathrm{d}, 8.1 \mathrm{~Hz}, \mathrm{H})$. Elemental analysis calculated for $\mathrm{C}_{12} \mathrm{H}_{17} \mathrm{AuCl}_{4} \mathrm{~N}_{2}: \% \mathrm{C}=27.31, \% \mathrm{H}=3.14$, $\% \mathrm{~N}=5.25$. Exp: $\% \mathrm{C}=27.29, \% \mathrm{H}=3.24, \% \mathrm{~N}=5.31$. FT-IR (solid): $v_{\mathrm{N}=\mathrm{N}}$ stretching frequency at $2253 \mathrm{~cm}^{-1}$. UV-Vis $\left(5.8 \times 10^{-4}\right.$ in $\left.\mathrm{CH}_{3} \mathrm{CN}\right): 279 \mathrm{~nm}\left(14,884 \mathrm{M}^{-1} \mathrm{~cm}^{-1}\right)$. 


\section{Conclusions}

We described the synthesis of stable diazonium tetrachloroaurate(III) complexes of potential applications in surface grafting. The structures are similar to inorganic based anions diazonium salts. The synthesized compounds are soluble in several organic solvents and stable at room temperature in the solid state and solution. Research continues on the diazonium tetrachloroaurate(III) complexes to synthesize robust gold-carbon nanoparticles and films.

\section{Acknowledgments}

Andrew Goudy of Delaware State University is acknowledged for the TGA, RGA, and TDXRD measurements.

\section{Conflicts of Interest}

The authors declare no conflict of interest.

\section{References}

1. Chehimi, M.M. Aryl Diazonium Salts: New Coupling Agents in Polymer and Surface Science; Wiley-VCH: Weinheim, Germany, 2012.

2. Sun, Z.; James, D.K.; Tour, J.M. Graphene Chemistry: Synthesis and Manipulation. J. Phys. Chem. Lett. 2011, 2, 2425-2432.

3. Breton, T.; Bélanger, D. Modification of Carbon Electrode with Aryl Groups having an Aliphatic Amine by Electrochemical Reduction of in situ Generated Diazonium Cations. Langmuir 2008, 24, 8711-8718.

4. Allongue, P.; Delamar, M.; Desbat, B.; Fagebaume, O.; Hitmi, R.; Pinson, J.; Saveant, J.M. Covalent Modification of Carbon Surfaces by Aryl Radicals Generated from the Electrochemical Reduction of Diazonium Salts. J. Am. Chem. Soc. 1997, 119, 201-207.

5. Salmi, Z.; Lamouri, A.; Decorse, P.; Jouini, M.; Boussadi, A.; Achard, J.; Gicquel, A.; Mahouche-Chergui, S.; Carbonnier, B.; Chehimi, M.M. Grafting Polymer-Protein Bioconjugate to Boron-Doped Diamond using Aryl Diazonium Coupling Agents. Diamond Rel. Mater. 2013, 40, 60-80.

6. Lehr, J.; Garrett, D.J.; Paulik, M.G.; Flavel, B.S.; Brooksby, P.A.; Williamson, B.E.; Downard, A.J. Patterning of Metal, Carbon, and Semiconductor Substrates with Thin Organic Films by Microcontact Printing with Aryldiazonium Salt Inks. Anal. Chem. 2010, 82, 7027-7070.

7. Aswal, D.K.; Koiry, S.P.; Jousselme, B.; Gupta, S.K.; Palacin, S.; Yakhmi, J.V. Hybrid Molecule-on-Silicon Nanoelectronics: Electrochemical Processes for Grafting and Printing of Monolayers. Physica E 2009, 41, 325-344.

8. Gooding, J.J.; Ciampi, S. The Molecular Level Modification of Surfaces: From Self-Assembled Monolayers to Complex Molecular Assemblies. Chem. Soc. Rev. 2011, 40, 2704-2718. 
9. Bélanger, D.; Pinson, J. Electrografting: A Powerful Method for Surface Modification. Chem. Soc. Rev. 2011, 40, 3995-4048.

10. Combellas, C.; Delamar, M.; Kanoufi, F.; Pinson, J.; Podvorica, F.I. Spontaneous Grafting of Iron Surfaces by Reduction of Aryldiazonium Salts in Acidic or Neutral Aqueous Solution. Application to the Protection of Iron against Corrosion. Chem. Mater. 2005, 17, 3968-3975.

11. Zhu, Y.; Higginbotham, A.L.; Tour, J.M. Covalent Functionalization of Surfactant-Wrapped Graphene Nanoribbons. Chem. Mater. 2009, 21, 5284-5291.

12. Lomeda, J.R.; Doyle, C.D.; Kosynkin, D.V.; Hwang, W.-F.; Tour, J.M. Diazonium Functionalization of Surfactant-Wrapped Chemically Converted Graphene Sheets. J. Am. Chem. Soc. 2008, 130, 16201-16206.

13. Gehan, H.; Fillaud, L.; Felidj, N.; Aubard, J.; Lang, P.; Chehimi, M.M.; Mangeney, C.A. General Approach Combining Diazonium Salts and Click Chemistries for Gold Surface Functionalization by Nanoparticle Assemblies. Langmuir 2010, 26, 3975-3980.

14. Mirkhalaf, F.; Paprotny, J.; Schiffrin, D.J. Synthesis of Metal Nanoparticles Stabilized by Metal-Carbon Bonds. J. Am. Chem. Soc. 2006, 128, 7400-7401.

15. Ghosh, D.; Chen, S.W. Palladium Nanoparticles Passivated by Metal-Carbon Covalent Linkages. J. Mater. Chem. 2008, 18, 755-762.

16. Ratheesh Kumar, V.K.; Gopidas, K.R. Synthesis and Characterization of Gold-Nanoparticle-Cored Dendrimers Stabilized by Metal-Carbon Bonds. Chem. Asian J. 2010, 5, 887-896.

17. Ratheesh Kumar, V.K.; Gopidas, K.R. Palladium Nanoparticle-Cored G1-Dendrimer Stabilized by Carbon-Pd Bonds: Synthesis, Characterization and use as Chemoselective, Room Temperature Hydrogenation Catalyst. Tetrahedron Lett. 2011, 52, 3102-3105.

18. Ratheesh Kumar, V.K.; Krishnakumar, S.; Gopidas, K.R. Synthesis, Characterization and Catalytic Applications of Palladium Nanoparticle-Cored Dendrimers Stabilized by Metal-Carbon Bonds. Eur. J. Org. Chem. 2012, 3447-3458.

19. Laurentius, L.; Stoyanov, S.R.; Gusarov, S.; Kovalenko, A.; Du, R.; Lopinski, G.P.; McDermott, M.T. Diazonium-Derived Aryl Films on Gold Nanoparticles: Evidence for a Carbon-Gold Covalent Bond. ACS Nano 2011, 5, 4219-4227.

20. Adenier, A.; Bernard, M.C.; Chehimi, M.M.; Cabet-Deliry, E.; Desbat, B.; Fagebaume, O.; Pinson, J.; Podvorica, F. Covalent Modification of Iron Surfaces by Electrochemical Reduction of Aryldiazonium Salts. J. Am. Chem. Soc. 2001, 123, 4541-4549.

21. Nakamura, T.; Suzuki, M.; Ishihara, M.; Ohana, T.; Tanaka, A.; Koga, Y. Photochemical Modification of Diamond Films: Introduction of Perfluorooctyl Functional Groups on Their Surface. Langmuir 2004, 20, 5846-5849.

22. Harper, J.C.; Polsky, R.; Wheeler, D.R.; Brozik, S.M. Maleimide-Activated Aryl Diazonium Salts for Electrode Surface Functionalization with Biological and Redox Active Molecules. Langmuir 2008, 24, 2206-2211.

23. Corgier, B.P.; Marquette, C.A.; Blum, L.J. Diazonium-Protein Adducts for Graphite Electrode Microarrays Modification: Direct and Addressed Electrochemical Immobilization. J. Am. Chem. Soc. 2005, 127, 18328-18332. 
24. Mévellec, V.; Roussel, S.; Tessier, L.; Chancolon, J.; Mayne-L’Hermite, M.; Deniau, G.; Viel, P.; Palacin, S. Grafting Polymers on Surfaces: A New Powerful and Versatile Diazonium Salt-Based One-Step Process in Aqueous Media. Chem. Mater. 2007, 19, 6323-6330.

25. Garrett, D.J.; Lehr, J.; Miskelly, G.M.; Downard, A.J. Microcontact Printing using the Spontaneous Reduction of Aryldiazonium Salts. J. Am. Chem. Soc. 2007, 129, 15456-15457.

26. Hossain, M.Z.; Walsh, M.A.; Hersam, M.C. Scanning Tunneling Microscopy, Spectroscopy, and Nanolithography of Epitaxial Graphene Chemically Modified with Aryl Moieties. J. Am. Chem. Soc. 2010, 132, 15399-15403.

27. Roglans, A.; Pla-Quintana, A.; Moreno-Manas, M. Diazonium Salts as Substrates in Palladium-Catalyzed Cross-Coupling Reactions. Chem. Rev. 2006, 106, 4622-4643.

28. Patai, S. The Chemistry of Diazonium and Diazo Groups. The Chemistry of Functional Groups; John Wiley \& Sons Inc: New York, NY, USA, 1978; Volume 2.

29. Saunders, K.H. The Aromatic Diazo-Compounds and Their Technical Applications; Edward Arnold \& Co.: London, UK, 1949.

30. Zollinger, H. Diazotization of Amines and Dediazoniation of Diazonium Ions. In The Chemistry of Amino, Nitroso, Nitro and Related Groups; Patai, S., Ed.; Wiley \& Sons: New York, NY, USA, 1996; pp. 636-637.

31. Chamoulaud, G.; Bélanger, D. Spontaneous Derivatization of a Copper Electrode with in situ Generated Diazonium Cations in Aprotic and Aqueous Media. J. Phys. Chem. C 2007, 111, 7501-7507.

32. Glaser, R.; Horan, C.J. Benzenediazonium Ion. Generality, Consistency, and Preferability of the Electron Density Based Dative Bonding Model. J. Org. Chem. 1995, 60, 7518-7528.

33. Glaser, R.; Horan, C.J.; Lewis, M.; Zollinger, H. $\sigma$-Dative and $\pi$-Backdative Phenyl Cation-Dinitrogen Interactions and Opposing Sign Reaction Constants in Dual Substituent Parameter Relations. J. Org. Chem. 1999, 64, 902-913.

34. Gokel, G.W.; Cram, D.J. Molecular Complexation of Arenediazonium and Benzoyl Cations by Crown Ethers. J. Chem. Soc. Chem. Commun. 1973, 481-482.

35. Kuokkanen, T.; Haataja, A. Effect of Solvent on the Complexation and Thermal Stability of Benzenediazonium Tetrafluoroborate in the Presence of Crown Ethers. Acta Chem. Scand. 1993, 47, 872-876.

36. Morosin, B.; Lingafelter, E.C. The Crystal Structure of Tetramethylammonium Tetrachlorozincate and Tetrachlorocobaltate. Acta Crystallogr. 1959, 12, 611-612.

37. Doctorovich, F.; Escola, N.; Trápani, C.; Estrin, D.A.; Lebrero, M.C.G.; Turjanski, A.G. Stabilization of Aliphatic and Aromatic Diazonium Ions by Coordination: An Experimental and Theoretical Study. Organometallics 2000, 19, 3810-3817.

38. Mohamed, A.A. Advances in the Coordination Chemistry of Nitrogen Ligand Complexes of Coinage Metals. Coord. Chem. Rev. 2010, 254, 1918-1947.

39. Overton, A.T.; Mohamed, A.A. Gold Diazonium Complexes for Electrochemical Reductive Grafting. Inorg. Chem. 2012, 51, 5500-5502.

40. Gougoutas, J.Z.; Johnson, J. Structure and Solid-State Chemistry of 3-Carboxy-2Naphthalenediazonium Bromide. J. Am. Chem. Soc. 1978, 100, 5816-5820. 
41. Greenberg, B.; Okaya, Y. Crystal and Molecular Structure of 2-Diazonium-4-Phenolsulfonate Monohydrate, $\mathrm{C}_{6} \mathrm{H}_{3} \mathrm{~N}_{2}{ }^{+} . \mathrm{SO}_{3}{ }^{-}$.OH. $\mathrm{H}_{2} \mathrm{O}$. Acta Cryst. B 1969, 25, 2101-2108.

42. Mostad, A.; Rømming, C. The Crystal Structure of p-Benzenebisdiazonium Tetrachlorozincate. Acta Chem. Scand. 1968, 22, 1259-1266.

43. Romming, C. The Structure of Benzene Diazonium Chloride. Acta Chem. Scand. 1963, 17, 1444-1454.

44. Romming, C. The Crystal Structure of p-Benzenediazonium Sulphonate. Acta Chem. Scand. 1972, 26, 523-533.

45. Romming, C.; Tjornhom, T. The Crystal Structure of the 1:1 Complex Benzenediazonium Chloride-Acetic Acid. Acta Chem. Scand. 1968, 22, 2934-2942.

46. Filimonov, V.D.; Trusova, M.; Postnikov, P.; Krasnokutskaya, E.A.; Lee, Y.M.; Hwang, H.Y.; Kim, H.; Chi, K.-W. Unusually Stable, Versatile, and Pure Arenediazonium Tosylates: Their Preparation, Structures, and Synthetic Applicability. Org. Lett. 2008, 10, 3961-3964.

47. Pauling, L. The Nature of the Chemical Bond, 3rd ed.; Cornell University Press: Ithaca, NY, USA, 1960.

48. Gremillion, A.F.; Jonassen, H.B.; O’Connor, R.J. The Thermal Stabilities and Infrared Spectra of some Metal Salt Stabilized Diazonium Salts. J. Am. Chem. Soc. 1959, 81, 6134-6138.

49. Savitsky, A.; Siggia, S. Analysis of Primary Aromatic Amines and Nitrite by Diazotization and Pyrolysis Gas Chromatography. Anal. Chem. 1974, 46, 149-152.

50. SMART, Version 4.043; Software for the CCD Detector System; Bruker Analytical X-ray Systems: Madison, WI, USA, 1995.

51. SAINT, Version 4.035; Software for the CCD Detector System; Bruker Analytical X-ray Systems: Madison, WI, USA, 1995.

52. Blessing, R.H. SADABS. Program for absorption corrections using Siemens CCD based on the method of Robert Blessing. Acta Cryst. A 1995, 51, 33.

53. Scheldrick, G.M. SHELXS-97; Program for the Solution of Crystal Structure; University of Göttingen, Göttingen, Germany, 1997.

54. SHELXTL 5.03; Program Library for Structure Solution and Molecular Graphics; Bruker Analytical X-ray Systems: Madison, WI, USA, 1995. 


\title{
Synthesis and Characterisation of Lanthanide $\mathrm{N}$-Trimethylsilyl and -Mesityl Functionalised Bis(iminophosphorano)methanides and -Methanediides
}

\section{George Marshall, Ashley J. Wooles, David P. Mills, William Lewis, Alexander J. Blake and Stephen T. Liddle}

\begin{abstract}
We report the extension of the series of $\left\{\mathrm{BIPM}^{\mathrm{TMS}} \mathrm{H}\right\}^{-}\left(\mathrm{BIPM}^{\mathrm{R}}=\mathrm{C}\left\{\mathrm{PPh}_{2} \mathrm{NR}\right\}_{2}\right.$, $\mathrm{TMS}=$ trimethylsilyl) derived rare earth methanides by the preparation of [ $\left.\mathrm{Ln}\left(\mathrm{BIPM}^{\mathrm{TMS}} \mathrm{H}\right)(\mathrm{I})_{2}(\mathrm{THF})\right]$ $(\mathrm{Ln}=\mathrm{Nd}, \mathrm{Gd}, \mathrm{Tb}), \mathbf{1 a}-\mathbf{c}$, in $34-50 \%$ crystalline yields via the reaction of $\left[\mathrm{Ln}(\mathrm{I})_{3}(\mathrm{THF})_{3.5}\right]$ with $\left[\mathrm{Cs}\left(\mathrm{BIPM}^{\mathrm{TMS}} \mathrm{H}\right)\right]$. Similarly, we have extended the range of $\left\{\mathrm{BIPM}^{\mathrm{Mes}} \mathrm{H}\right\}^{-}(\mathrm{Mes}=2,4,6-$ trimethylphenyl) derived rare earth methanides with the preparation of $\left[\mathrm{Gd}\left(\mathrm{BIPM}^{\mathrm{Mes}} \mathrm{H}\right)(\mathrm{I})_{2}(\mathrm{THF})_{2}\right]$, 3, $(49 \%)$ and $\left[\mathrm{Yb}\left(\mathrm{BIPM}^{\mathrm{Mes}} \mathrm{H}\right)(\mathrm{I})_{2}(\mathrm{THF})\right], 4,(26 \%)$, via the reaction of $\left[\mathrm{Ln}(\mathrm{I})_{3}(\mathrm{THF})_{3.5}\right]$ with $\left[\left\{\mathrm{K}\left(\mathrm{BIPM} \mathrm{Mes}^{\mathrm{Mes}}\right)\right\}_{2}\right]$. Attempts to prepare dysprosium and erbium analogues of $\mathbf{3}$ or $\mathbf{4}$ were not successful, with the ion pair species $\left[\operatorname{Ln}\left(\mathrm{BIPM}^{\mathrm{Mes}} \mathrm{H}\right)_{2}\right]\left[\mathrm{BIPM}^{\mathrm{Mes}} \mathrm{H}\right](\mathrm{Ln}=\mathrm{Dy}, \mathrm{Er}), \mathbf{5 a}-\mathbf{b}$, isolated in $31-39 \%$ yield. The TMEDA $\left(N^{\prime}, N^{\prime}, N^{\prime \prime}, N^{\prime \prime}\right.$-tetramethylethylenediamine) adducts $\left[\mathrm{Ln}\left(\mathrm{BIPM}^{\mathrm{Mes}} \mathrm{H}\right)(\mathrm{I})_{2}(\mathrm{TMEDA})\right](\mathrm{Ln}=\mathrm{La}, \mathrm{Gd}), \mathbf{6 a}-\mathbf{b}$, were prepared in quantitative yield via the dissolution of $\left[\mathrm{La}\left(\mathrm{BIPM}^{\mathrm{Mes}} \mathrm{H}\right)(\mathrm{I})_{2}(\mathrm{THF})\right]$ or $\mathbf{3}$ in a TMEDA/THF solution. The reactions of $\left[\mathrm{Ln}\left(\mathrm{BIPM}^{\mathrm{Mes}} \mathrm{H}\right)(\mathrm{I})_{2}(\mathrm{THF})\right][\mathrm{Ln}=\mathrm{La}, \mathrm{Ce}, \mathrm{Pr}$, and $\mathrm{Gd}(\mathbf{3})]$ or $\mathbf{6 a}-\mathbf{b}$ with a selection of bases did not afford $\left[\mathrm{La}\left(\mathrm{BIPM}^{\mathrm{Mes}}\right)(\mathrm{I})(\mathrm{S})_{n}\right](\mathrm{S}=$ solvent$)$ as predicted, but instead led to the isolation of the heteroleptic complexes $\left[\mathrm{Ln}\left(\mathrm{BIPM}^{\mathrm{Mes}}\right)\left(\mathrm{BIPM}^{\mathrm{Mes}} \mathrm{H}\right)\right](\mathrm{Ln}=\mathrm{La}, \mathrm{Ce}, \mathrm{Pr}$ and $\mathrm{Gd}), \mathbf{7 a}-\mathbf{d}$, in low yields due to ligand scrambling.
\end{abstract}

Reprinted from Inorganics. Cite as: Marshall, G.; Wooles, A.J.; Mills, D.P.; Lewis, W.; Blake, A.J.; Liddle, S.T. Synthesis and Characterisation of Lanthanide $N$-Trimethylsilyl and -Mesityl Functionalised Bis(iminophosphorano)methanides and -Methanediides. Inorganics 2013, 1, 46-69.

\section{Introduction}

Since Cavell et al. reported the first rare earth bis(iminophosphorano)methanediide complex, namely $\left[\mathrm{Sm}\left(\mathrm{BIPM}^{\mathrm{TMS}}\right)(\mathrm{NCy} 2)(\mathrm{THF})\right]\left(\mathrm{BIPM}^{\mathrm{TMS}}=\left\{\mathrm{C}\left(\mathrm{PPh}_{2} \mathrm{NSiMe}_{3}\right)_{2}\right\}^{2-}\right)[1]$, a wide range of $\mathrm{BIPM}^{\mathrm{R}}$ - derived rare earth complexes have been reported with the $\mathrm{BIPM}^{\mathrm{R}}$ ligand being either mono-deprotonated $\left(\left\{\mathrm{BIPM}^{\mathrm{R}} \mathrm{H}\right\}^{-}\right)$and coordinating as a methanide, or doubly deprotonated $\left(\left\{\mathrm{BIPM}^{\mathrm{R}}\right\}^{2-}\right)$ and coordinating as either a methanediide or carbene [2-4]. These complexes have shown extensive utility in a range of areas, including hydroamination/cyclisation, hydrosilylation and polymerisation reactions [5,6], and our work towards: (a) the preparation of rare earth heterobimetallics [7]; (b) unusual reactivity towards small molecules [8-10]; and (c) the stabilisation of the Ce(IV) oxidation state [11]. In our studies we have employed primarily the $\mathrm{BIPM}^{\mathrm{TMS}}$ and $\mathrm{BIPM}^{\mathrm{Mes}}\left(\left\{\mathrm{C}\left(\mathrm{PPh}_{2} \mathrm{NMes}\right)_{2}\right\}^{2-} ;\right.$ Mes $=2,4,6-$ trimethylphenyl $)$ ligand frameworks [7,12-16], however, during our studies we have encountered several synthetic limitations in our attempts to prepare $\mathrm{BIPM}^{\mathrm{R}}$-derived rare earth complexes for the complete rare earth series. We have employed both alkane elimination and salt metathesis strategies towards the 
preparation of methanediide complexes of the general formula $\left[\mathrm{Ln}\left(\mathrm{BIPM}^{\mathrm{R}}\right)(\mathrm{X})(\mathrm{THF})_{n}\right]$ $\left(\mathrm{R}=\mathrm{TMS}\right.$ or Mes; $\mathrm{X}=\mathrm{I}, \mathrm{CH}_{2} \mathrm{SiMe}_{3}$ or $\mathrm{CH}_{2} \mathrm{Ph}$ ), with each approach having advantages and limitations.

The reaction of a range of rare earth tri-benzyl complexes $\left[\mathrm{Ln}\left(\mathrm{CH}_{2} \mathrm{Ph}\right)_{3}(\mathrm{THF})_{3}\right](\mathrm{Ln}=\mathrm{La}, \mathrm{Ce}$, $\mathrm{Pr}, \mathrm{Nd}, \mathrm{Sm}, \mathrm{Gd}, \mathrm{Dy}, \mathrm{Er}, \mathrm{Y})$ or $\left[\mathrm{Y}\left(\mathrm{CH}_{2} \mathrm{SiMe}_{3}\right)_{3}(\mathrm{THF})_{3}\right]$ with the protonated pro-ligand $\mathrm{BIPM}^{\mathrm{TMS}} \mathrm{H}_{2}$ afforded different products depending on the size of the rare earth centre [16-18]. In the case of the smaller rare earths, the methanediide alkyl complexes $\left[\mathrm{Ln}\left(\mathrm{BIPM}^{\mathrm{TMS}}\right)(\mathrm{R})(\mathrm{THF})\right]\left(\mathrm{R}=\mathrm{CH}_{2} \mathrm{Ph}\right.$ : $\mathrm{Ln}=\mathrm{Dy}, \mathrm{Er}, \mathrm{Y} ; \mathrm{R}=\mathrm{CH}_{2} \mathrm{SiMe}_{3}$ : $\mathrm{Ln}=\mathrm{Y}$ ) were isolated [16-18], however for the larger rare earths the only isolable products were the bis-BIPM complexes $\left[\mathrm{Ln}\left(\mathrm{BIPM}^{\mathrm{TMS}}\right)\left(\mathrm{BIPM}^{\mathrm{TMS}} \mathrm{H}\right)\right](\mathrm{Ln}=\mathrm{La}$, $\mathrm{Ce}, \mathrm{Pr}, \mathrm{Nd}, \mathrm{Sm}, \mathrm{Gd}$ ) [16]. This variation in reactivity was ascribed to the lanthanide contraction [19], with ligand scrambling occurring in the attempted preparations of the larger rare earth analogues despite the high steric demands of the BIPM ${ }^{\mathrm{TMS}}$ ligand [16]. By a similar methodology we prepared $\left[\mathrm{Ln}\left(\mathrm{BIPM}^{\mathrm{TMS}}\right)(\mathrm{I})(\mathrm{THF})_{2}\right] \quad\left(\mathrm{Ln}=\mathrm{Y}\right.$, Er) via the reaction of $\left[\mathrm{Ln}\left(\mathrm{CH}_{2} \mathrm{Ph}\right)_{2}(\mathrm{I})(\mathrm{THF})_{3}\right]$ with $\mathrm{BIPM}^{\mathrm{TMS}} \mathrm{H}_{2}$ [15], but unfortunately this methodology could not be applied across the rare earth series due to the inaccessibility of $\left[\mathrm{Ln}\left(\mathrm{CH}_{2} \mathrm{Ph}\right)_{2}(\mathrm{I})(\mathrm{THF})_{3}\right]$ for rare earths larger than erbium [12].

Salt metathesis strategies were first employed in the preparation of [Y(BIPM $\left.\left.{ }^{\mathrm{TMS}} \mathrm{H}\right)(\mathrm{I})_{2}(\mathrm{THF})\right]$, which was isolated in $64 \%$ yield via the reaction of $\left[\left\{\mathrm{K}\left(\mathrm{BIPM}^{\mathrm{TMS}} \mathrm{H}\right)\right\}_{2}\right]$ with $\left[\mathrm{Y}(\mathrm{I})_{3}(\mathrm{THF})_{3.5}\right]$ in refluxing THF over 4 hours [7]. Fine-tuning of the reaction conditions was required with excessive reaction times leading to decomposition. Perhaps surprisingly, applying a similar strategy to $\mathrm{La}$ with the reaction of $\left[\mathrm{La}(\mathrm{I})_{3}(\mathrm{THF})_{4}\right]$ and $\left[\left\{\mathrm{K}\left(\mathrm{BIPM}^{\mathrm{TMS}} \mathrm{H}\right)_{2}\right]\right.$ does not afford $\left[\mathrm{La}\left(\mathrm{BIPM}^{\mathrm{TMS}} \mathrm{H}\right)(\mathrm{I})_{2}(\mathrm{THF})\right]$ as expected; no reaction is observed at ambient temperature and decomposition is observed at elevated temperatures [12]. Gratifyingly, however, the reaction of $\left[\mathrm{Ln}(\mathrm{I})_{3}(\mathrm{THF})_{4}\right](\mathrm{Ln}=\mathrm{La}, \mathrm{Ce})$ with $\left[\mathrm{Rb}\left(\mathrm{BIPM}^{\mathrm{TMS}} \mathrm{H}\right)(\mathrm{THF})_{n}\right]$ affords $\left[\mathrm{Ln}\left(\mathrm{BIPM}^{\mathrm{TMS}} \mathrm{H}\right)(\mathrm{I})_{2}(\mathrm{THF})\right](\mathrm{Ln}$ $=\mathrm{La}, \mathrm{Ce})$ in high yield with no forcing conditions required $[11,13]$. This variation exemplifies the importance of selecting the correct synthetic reagent for the reaction in hand. The reaction of $\left[\mathrm{Ln}\left(\mathrm{BIPM}^{\mathrm{TMS}} \mathrm{H}\right)(\mathrm{I})_{2}(\mathrm{THF})\right](\mathrm{Ln}=\mathrm{Ce}, \mathrm{Y})$ with $[\mathrm{K}(\mathrm{Bn})]$ affords the rare earth carbene complexes $\left[\mathrm{Ln}\left(\mathrm{BIPM}^{\mathrm{TMS}}\right)(\mathrm{I})(\mathrm{S})_{n}\right](\mathrm{Ln}=\mathrm{Y}, \mathrm{S}=\mathrm{THF}, n=2 ; \mathrm{Ln}=\mathrm{Ce}, \mathrm{S}=1$,2-dimethoxyethane, $n=1)$ in good yield $[7,11]$.

To fully investigate the importance of the steric demands of the $N-\mathrm{SiMe}_{3}$ group in BIPM ${ }^{\mathrm{TMS}}$, we employed a different BIPM ligand, namely the $N$-aryl substituted BIPM ${ }^{\mathrm{Mes}}$ system. In contrast to the difficulties experienced when employing salt metathesis strategies with the BIPM ${ }^{\mathrm{TMS}}$ framework, we previously prepared $\left[\mathrm{Ln}\left(\mathrm{BIPM}^{\mathrm{Mes}} \mathrm{H}\right)(\mathrm{I})_{2}(\mathrm{THF})_{2}\right](\mathrm{Ln}=\mathrm{La}, \mathrm{Ce}, \mathrm{Pr}, \mathrm{Nd}, \mathrm{Sm})$ via the straight-forward reaction of $\left[\mathrm{Ln}(\mathrm{I})_{3}(\mathrm{THF})_{n}\right]$ with $\left[\left\{\mathrm{K}\left(\mathrm{BIPM}^{\mathrm{Mes}} \mathrm{H}\right)\right\}_{2}\right][12,14]$. Similarly to the $\mathrm{BIPM}^{\mathrm{TMS}}$ system $\left[\mathrm{La}\left(\mathrm{BIPM}^{\mathrm{Mes}} \mathrm{H}\right)(\mathrm{I})_{2}(\mathrm{THF})_{2}\right]$ was converted to the rare earth carbene complex $\left[\mathrm{La}\left(\mathrm{BIPM}^{\mathrm{Mes}}\right)(\mathrm{I})(\mathrm{THF})_{3}\right]$ in $53 \%$ yield via reaction with $[\mathrm{K}(\mathrm{Bn})][12]$.

Whilst a range of complexes of the formula $\left[\left\{\operatorname{Ln}\left(B I P M^{\mathrm{TMS}} \mathrm{H}\right)(\mathrm{Cl})(\mu-\mathrm{Cl})\right\}_{2}\right]$ have been reported previously by the reaction of $\left[\mathrm{Ln}(\mathrm{Cl})_{3}\right]$ and $\left[\left\{\mathrm{K}\left(\mathrm{BIPM}{ }^{\mathrm{TMS}} \mathrm{H}\right)\right\}_{2}\right][20]$, we have solely utilised iodide precursors. This is to reduce the likelihood of salt occlusion occurring as $\mathrm{KI}, \mathrm{RbI}$ and $\mathrm{CsI}$ have a much lower propensity for salt occlusion in comparison to $\mathrm{LiCl}$ or $\mathrm{KCl}$, and as salt occlusion can often negatively affect reactivity and promote unwanted side reactions this is a major advantage of utilising $\left[\operatorname{Ln}(\mathrm{I})_{3}(\mathrm{THF})_{n}\right]$ precursors. As ligand scrambling and Schlenk-type equilibra proved 
problematic in alkane elimination strategies, we focused on salt metathesis strategies in our attempts to complete the range of rare earth $\mathrm{BIPM}^{\mathrm{R}} \mathrm{H}(\mathrm{R}=\mathrm{TMS}, \mathrm{Mes})$ complexes of the general formula $\left[\mathrm{Ln}\left(\mathrm{BIPM}^{\mathrm{R}} \mathrm{H}\right)(\mathrm{I})_{2}(\mathrm{THF})_{n}\right]$. These complexes would provide an insight into the structure and bonding of rare earth complexes as well as having utility in the preparation of methanediide complexes of the general formula $\left[\mathrm{Ln}\left(\mathrm{BIPM}^{\mathrm{R}}\right)(\mathrm{I})(\mathrm{THF})_{n}\right]$. With these complexes in hand we would be able to investigate what, if any, effect the varying metal size would have on their structure and reactivity.

\section{Results and Discussion}

As rare earth ions are predominantly paramagnetic, any NMR spectroscopic studies performed are often difficult to interpret, which makes it problematic to both follow reaction progress and to identify the products of reactions. For this reason single crystal X-ray diffraction studies are essential to unambiguously identify the outcome of reactions involving paramagnetic rare earth metals. Unfortunately, we often observe that some complexes do not crystallise readily, despite repeated attempts, one reason for which may be that they do not possess an optimal metal/ligand size ratio for crystal growth [21]. For this reason we commonly employ a range of rare earths of varying sizes, Table 1, in our studies to ensure we have the best chance at fully identifying the products of reactions. Due to the difficulties in identifying reaction products without X-ray diffraction studies, we have only included structurally authenticated complexes in this report.

Table 1. Six-coordinate ionic radii and covalent radii ( $\AA$ ) of Ln(III) complexes [22,23].

\begin{tabular}{cccccc}
\hline Metal & Ionic radius & Covalent radius & Metal & Ionic radius & Covalent radius \\
\hline $\mathrm{Sc}$ & 0.745 & 1.70 & $\mathrm{Gd}$ & 0.938 & 1.96 \\
$\mathrm{Y}$ & 0.900 & 1.90 & $\mathrm{~Tb}$ & 0.923 & 1.94 \\
$\mathrm{La}$ & 1.032 & 2.07 & $\mathrm{Dy}$ & 0.912 & 1.92 \\
$\mathrm{Ce}$ & 1.01 & 2.04 & $\mathrm{Ho}$ & 0.901 & 1.92 \\
$\mathrm{Pr}$ & 0.99 & 2.03 & $\mathrm{Er}$ & 0.890 & 1.89 \\
$\mathrm{Nd}$ & 0.983 & 2.01 & $\mathrm{Tm}$ & $\mathrm{N} / \mathrm{A}$ & 1.90 \\
$\mathrm{Pm}$ & $\mathrm{N} / \mathrm{A}$ & 1.99 & $\mathrm{Yb}$ & 0.868 & 1.87 \\
$\mathrm{Sm}$ & 0.958 & 1.98 & $\mathrm{Lu}$ & 0.861 & 1.87 \\
$\mathrm{Eu}$ & 0.947 & 1.98 & & & \\
\hline
\end{tabular}

\subsection{Preparation of BIPM $M^{T M S} H$ Rare Earth Methanides}

As previously discussed, we have reported the preparation of $\left[\mathrm{Ln}\left(\mathrm{BIPM}^{\mathrm{TMS}} \mathrm{H}\right)(\mathrm{I})_{2}(\mathrm{THF})\right]$ $(\mathrm{Ln}=\mathrm{La}, \mathrm{Ce})$ in high yields $\left(77 \%\right.$ and $89 \%$, respectively) via the reaction of $\left[\mathrm{Ln}(\mathrm{I})_{3}(\mathrm{THF})_{4}\right]$ with the heavy group 1 ligand transfer reagent $\left[\mathrm{Rb}\left(\mathrm{BIPM}^{\mathrm{TMS}} \mathrm{H}\right)(\mathrm{THF})_{n}\right]$ under ambient conditions $[11,13]$. As this strategy was successful for the two largest rare earth metals (see Table 1), we extended this methodology across the rare earth series using the cesium ligand transfer reagent to maximise our chances of success. The reactions of $\left.\left[\mathrm{Ln}(\mathrm{I})_{3}(\mathrm{THF})_{3.5}\right)\right](\mathrm{Ln}=\mathrm{Nd}, \mathrm{Gd}, \mathrm{Tb})$ with $\left[\mathrm{Cs}\left(\mathrm{BIPM}^{\mathrm{TMS}} \mathrm{H}\right)\right]$ afforded, following filtration and workup, $\left[\operatorname{Ln}\left(\mathrm{BIPM}^{\mathrm{TMS}} \mathrm{H}\right)(\mathrm{I})_{2}(\mathrm{THF})\right](\mathrm{Ln}=\mathrm{Nd}, \mathbf{1 a}, 37 \%$; $\mathrm{Gd}, \mathbf{1} \mathbf{b}$, $50 \%$; Tb, 1c, 34\%) with concomitant elimination of CsI (Scheme 1). As Nd(III), Gd(III) and 
$\mathrm{Tb}(\mathrm{III})$ are highly paramagnetic, NMR spectroscopic studies were inconclusive, and due to this each complex was crystallised from either THF or toluene to ensure purity of the sample. Unfortunately this also led to lower isolated yields (36-54\%) compared to the diamagnetic La $(77 \%)$ or weakly paramagnetic Ce $(89 \%)$ analogues which could both be identified by NMR spectroscopy.

Scheme 1. Preparation of $1 \mathbf{1}-\mathbf{c}$.

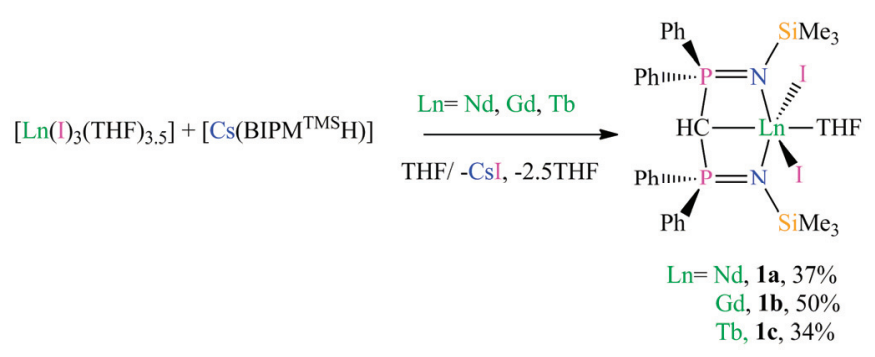

The identities of $\mathbf{1 a}-\mathbf{c}$ were confirmed by single crystal X-ray diffraction studies, elemental analysis and solution magnetic studies (vide infra, Table 2). The solid-state structures of $\mathbf{1 a} \mathrm{C}_{7} \mathrm{H}_{8}$ and $1 \mathrm{c} \mathrm{OC}_{4} \mathrm{H}_{8}$ are shown in Figures 1 and 2, respectively, with selected bond lengths and angles shown in Table S1. Each complex exhibits a distorted octahedral geometry with the metal centre coordinated by tridentate $\left\{\mathrm{BIPM}^{\mathrm{TMS}} \mathrm{H}\right\}^{-}$through the methanide carbon atom and the two imino nitrogens [N-Ln-N angles: 1a, 116.28(14) ${ }^{\circ}$; 1b, 93.6(2) ${ }^{\circ}$; 1c, 93.40(10 $)^{\circ}$ ], two iodide ligands and a THF molecule. Despite exhibiting the same overall structure there is a variation in conformation of the iodides and THF molecules in 1a-c. Complex 1a is isostructural to [ $\left.\mathrm{Ln}\left(\mathrm{BIPM}^{\mathrm{TMS}} \mathrm{H}\right)(\mathrm{I})_{2}(\mathrm{THF})\right]$ $(\mathrm{Ln}=\mathrm{La}, \mathrm{Ce})[11,13]$, with the coordinated THF molecule being trans to the methanide carbon [O1-Nd1-C1 angle: $151.54(13)^{\circ}$ ] with the two iodides being mutually trans [I1-Nd1-I2 angle: $\left.156.167(13)^{\circ}\right]$. In contrast, $\mathbf{1 b}-\mathbf{c}$ are isostructural to $\left[\mathrm{Ln}\left(\mathrm{BIPM}^{\mathrm{TMS}} \mathrm{H}\right)(\mathrm{I})_{2}(\mathrm{THF})\right](\mathrm{Ln}=\mathrm{Dy}, \mathrm{Y})$ [7,12], and exhibit the THF molecule cis to the methanide carbon rather than trans [O1-Gd1-C1: 86.5(2) ${ }^{\circ}$; O1-Tb1-C1: $87.30(10)^{\circ}$ ], with the two iodide ligands being mutually cis [I1-Gd1-I2: 97.20(2) $)^{\circ}$ I1-Tb1-I2: $\left.96.364(9)^{\circ}\right]$. The variation of conformation may be due to the varying size of the metal centre present as the larger rare earths $\mathrm{La}, \mathrm{Ce}$ and $\mathrm{Nd}$ favour the trans conformation with the smaller rare earths Gd, Tb, Dy and Y favouring the cis conformation (for radii see Table 1). However, this could also be due to solvent effects on crystallisation favouring different conformations during crystal packing as $\mathbf{1 a}$ and $\left[\operatorname{Ln}\left(\mathrm{BIPM}^{\mathrm{TMS}} \mathrm{H}\right)(\mathrm{I})_{2}(\mathrm{THF})\right](\mathrm{Ln}=\mathrm{La}, \mathrm{Ce})[11,13]$ were crystallised from toluene and adopt the trans geometry, whereas $\mathbf{1 b}-\mathbf{c}$ and $\left[\mathrm{Ln}\left(\mathrm{BIPM}^{\mathrm{TMS}} \mathrm{H}\right)(\mathrm{I})_{2}(\mathrm{THF})\right](\mathrm{Ln}=\mathrm{Dy}, \mathrm{Y})[7,12]$ were crystallised from THF and adopt the cis conformation. There is a general shortening of the Ln-C, Ln-N, Ln-I and Ln-O bond distances between 1a-1c which is in agreement with the lanthanide contraction (see Table 1) [19], and is consistent with the bond distances reported for $\left[\mathrm{Ln}\left(\mathrm{BIPM}^{\mathrm{TMS}} \mathrm{H}\right)(\mathrm{I})_{2}(\mathrm{THF})\right](\mathrm{Ln}=\mathrm{La}, \mathrm{Ce}, \mathrm{Dy}, \mathrm{Y})$ [7,11-13]. The bond distances about the metal centres in $\mathbf{1 a}-\mathbf{c}$ are all within the range of previously reported bond distances [24], and are unremarkable. The mean endocyclic P-C and P-N bond distances in 1a-c and the previously reported $\left[\mathrm{Ln}\left(\mathrm{BIPM}^{\mathrm{TMS}} \mathrm{H}\right)(\mathrm{I})_{2}(\mathrm{THF})\right](\mathrm{Ln}=\mathrm{La}, \mathrm{Ce}, \mathrm{Dy}, \mathrm{Y})$ [7,11-13], are statistically 
indistinguishable suggesting the $\left\{\mathrm{BIPM}^{\mathrm{TMS}} \mathrm{H}\right\}^{-}$coordinates to the metal centre in a similar way despite the variation in metal centre.

Figure 1. Molecular structure of $\mathbf{1 a} \mathrm{C}_{7} \mathrm{H}_{8}$ with selected atom labelling. Displacement ellipsoids are drawn at $50 \%$ probability, with lattice solvent and non-methanide hydrogen atoms omitted for clarity.

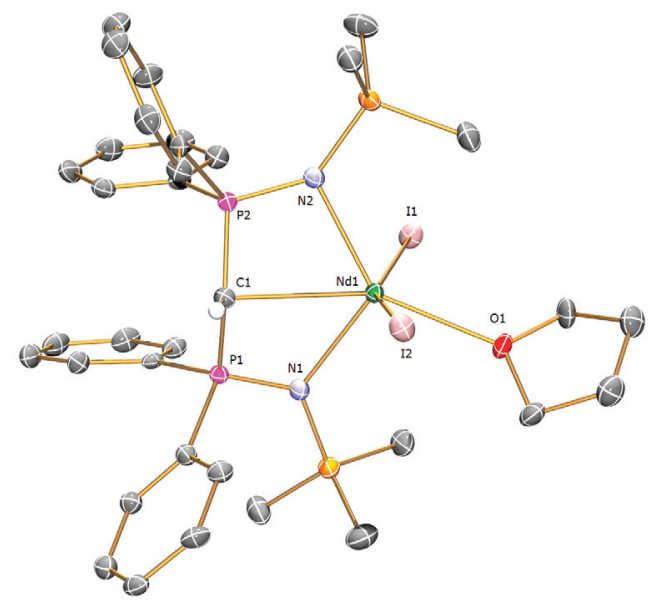

Figure 2. Molecular structure of $\mathbf{1 c} \mathrm{OC}_{4} \mathrm{H}_{8}$ with selected atom labelling. Displacement ellipsoids are drawn at 50\% probability, with disordered components, lattice solvent and non-methanide hydrogen atoms omitted for clarity. The structure of $\mathbf{1 b}$ is very similar.

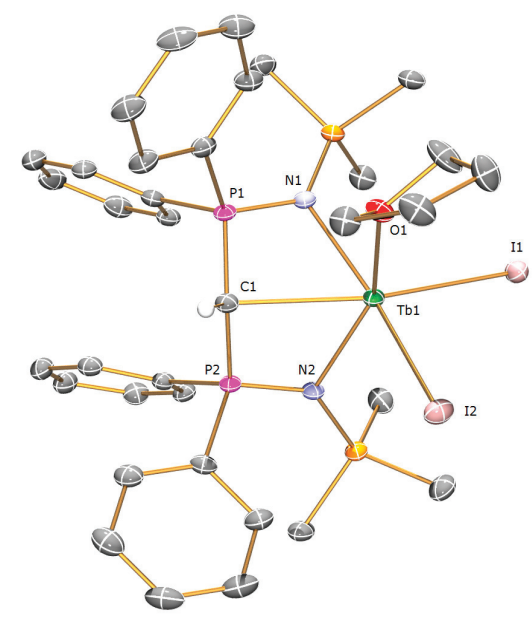


Scheme 2. Preparation of 2.

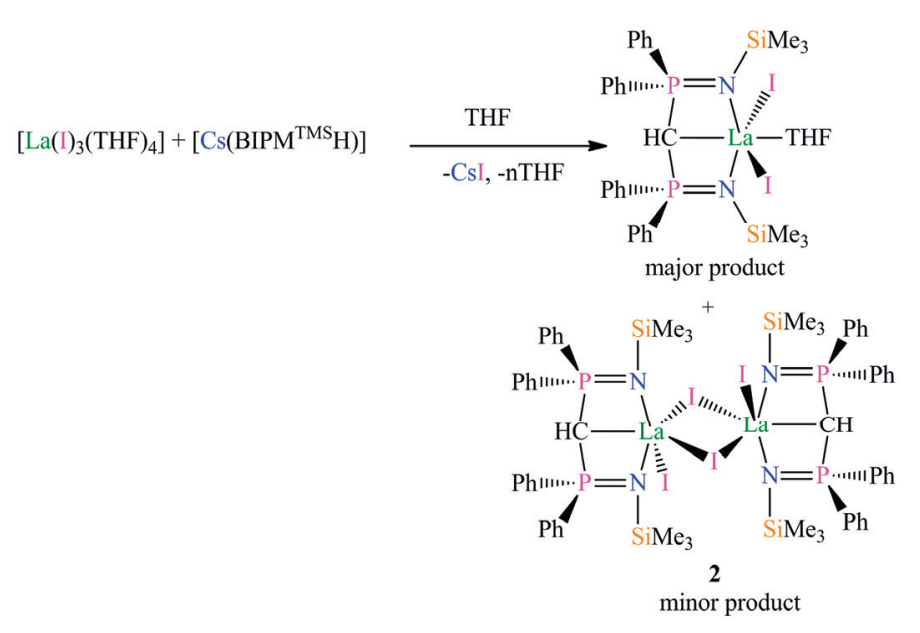

During our studies we have prepared many samples of $\left[\operatorname{Ln}\left(\mathrm{BIPM}^{\mathrm{TMS}} \mathrm{H}\right)(\mathrm{I})_{2}(\mathrm{THF})\right]$ and on one occasion during preparation of $\left[\mathrm{La}\left(\mathrm{BIPM}^{\mathrm{TMS}} \mathrm{H}\right)(\mathrm{I})_{2}(\mathrm{THF})\right]$ we isolated, from toluene solution, a small crop of colourless crystals which appeared to be of a different morphology to our previously reported $\left[\mathrm{La}\left(\mathrm{BIPM}^{\mathrm{TMS}} \mathrm{H}\right)(\mathrm{I})_{2}(\mathrm{THF})\right]$ [13]. To ensure purity of the sample a single crystal X-ray diffraction study was performed which confirmed its identity as $\left[\left\{\mathrm{La}\left(\mathrm{BIPM}^{\mathrm{TMS}} \mathrm{H}\right)(\mathrm{I})(\mu-\mathrm{I})\right\}_{2}\right], 2$ $2 \mathrm{C}_{7} \mathrm{H}_{8}$ (Scheme 2). Complex 2 is dimeric in the solid-state with each lanthanum centre adopting a heavily distorted octahedral geometry and being coordinated by a $\left\{\mathrm{BIPM}^{\mathrm{TMS}} \mathrm{H}\right\}^{-}$in a tridentate fashion [N1-La1-N2 angle: $118.3(2)^{\circ}$ ], by one terminal iodide and by two iodides that are bridging the two lanthanide centres. The dimeric motif of $\mathbf{2}$ is likely caused by a scarcity of coordinating solvent present during crystallisation with the dimeric form allowing greater saturation of the coordination sphere of the lanthanide centres compared to a solvent free monomeric form. Once isolated, 2 has a very low solubility in arene solvents (e.g., $d_{6}$-benzene and $d_{8}$-toluene), which precluded solution NMR spectroscopic studies, while dissolution in more polar solvents to increase solubility (e.g., $d_{8}$-THF) led to solvated monomeric complexes such as $\left[\mathrm{La}\left(\mathrm{BIPM}^{\mathrm{TMS}} \mathrm{H}\right)(\mathrm{I})_{2}\left(d_{8}\right.\right.$ THF)]. Although NMR spectroscopy was not conclusive, the identity of $\mathbf{2}$ was confirmed by elemental analysis. The dimeric form of $\mathbf{2}$ is analogous to the chloride congeners reported by Roesky et al., namely $\left[\left\{\operatorname{Ln}\left(\mathrm{BIPM}^{\mathrm{TMS}} \mathrm{H}\right)(\mathrm{Cl})(\mu-\mathrm{Cl})\right\}_{2}\right](\mathrm{Ln}=\mathrm{Sm}$,Dy, Er, Yb, Lu, Y), which despite being prepared in THF solution adopt solvent free dimeric conformations when crystallised from toluene [20].

The solid-state structure of $22 \mathrm{C}_{7} \mathrm{H}_{8}$ is depicted in Figure 3 with selected bond lengths and angles shown in Table S1. There is a variation in La1-I bond distances in $\mathbf{2}$, with the two bridging iodides being bound asymmetrically, with bond lengths of 3.2253(8) $\AA$ (La1-I2) and 3.3114(6) $\AA$ (La1-I2a), but both are still longer than the La1-I1 distance of 3.1144(7) $\AA$ due to the bridging vs terminal nature of the iodide ligands. Although the mean La1-N distance in 2 [2.443(6) $\AA$ ] is statistically indistinguishable to the La1-N distances in $\left[\mathrm{La}\left(\mathrm{BIPM}^{\mathrm{TMS}} \mathrm{H}\right)(\mathrm{I})_{2}(\mathrm{THF})\right]$ (mean: 2.438(6) $\AA$ ), there is a large variation in the La1-C1 bond distance, with the La1-C1 distance in 2 [2.778(8) $\AA$ ] being shorter than the La-C distance in $\left[\mathrm{La}\left(\mathrm{BIPM}^{\mathrm{TMS}} \mathrm{H}\right)(\mathrm{I})_{2}(\mathrm{THF})\right][2.859(8) \AA]$ [13]. This 
shortening of the La1-C1 bond distance is likely due to the absence of O-donor solvents in 2, compared to $\left[\mathrm{La}\left(\mathrm{BIPM}^{\mathrm{TMS}} \mathrm{H}\right)(\mathrm{I})_{2}(\mathrm{THF})\right][13]$, as, according to the HSAB principle, the hard lanthanum centre is predicted to exhibit a stronger interaction with the oxygen of THF rather than the relatively soft methanide carbon, leading to the longer La-C distance in $\left[\mathrm{La}\left(\mathrm{BIPM}^{\mathrm{TMS}} \mathrm{H}\right)(\mathrm{I})_{2}(\mathrm{THF})\right][13]$.

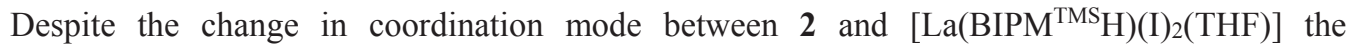
$\left\{\mathrm{BIPM}^{\mathrm{TMS}} \mathrm{H}\right\}^{-}$ligand appears to be bound to lanthanum in a similar manner in each complex, as evidenced by the mean endocyclic P-C and P-N bond distances and P1-C1-P2 angle in 2 [1.720(8), 1.607(7) $\AA$ and $138.3(5)^{\circ}$, respectively] being statistically indistinguishable to the corresponding values in $\left[\mathrm{La}\left(\mathrm{BIPM}^{\mathrm{TMS}} \mathrm{H}\right)(\mathrm{I})_{2}(\mathrm{THF})\right]\left[1.734(8), 1.610(7) \AA\right.$ and $135.9(5)^{\circ}$, respectively] [13].

Figure 3. Molecular structure of $22 \mathrm{C}_{7} \mathrm{H}_{8}$ with selected atom labelling. Displacement ellipsoids are drawn at $50 \%$ probability, with lattice solvent and non-methanide hydrogen atoms omitted for clarity.

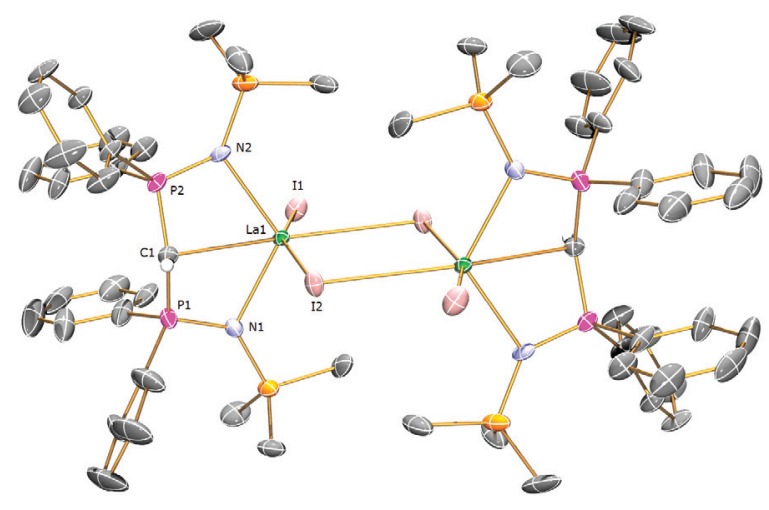

We have previously reported the conversion of $\left[\mathrm{Ln}\left(\mathrm{BIPM}^{\mathrm{TMS}} \mathrm{H}\right)(\mathrm{I})_{2}(\mathrm{THF})\right](\mathrm{Ln}=\mathrm{Ce}, \mathrm{Y})$ to $\left[\mathrm{Ce}\left(\mathrm{BIPM}^{\mathrm{TMS}}\right)(\mathrm{I})(\mathrm{DME})\right]$ and $\left[\mathrm{Y}\left(\mathrm{BIPM}^{\mathrm{TMS}}\right)(\mathrm{I})(\mathrm{THF})_{2}\right]$, respectively, via reaction with $[\mathrm{K}(\mathrm{Bn})]$. This approach provides access to rare earth $\left\{\mathrm{BIPM}^{\mathrm{TMS}}\right\}^{2-}$ derived methanediide complexes for both the larger and smaller rare earths $(\mathrm{Ce}$, and $\mathrm{Y}$, respectively, Table 1). To fully investigate the nature of the $\left\{\mathrm{BIPM}^{\mathrm{R}}\right\}^{2-}$ ligand on the stability of these systems we have investigated the $N$-Mesityl variant of $\left\{\mathrm{BIPM}^{\mathrm{TMS}}\right\}^{2-}$, namely $\left\{\mathrm{BIPM}^{\mathrm{Mes}}\right\}^{2-}$.

\subsection{Preparation of $\left\{B I P M^{\text {Mes }} H\right\}$ Rare Earth Methanides}

We have previously reported the preparation of $\left[\mathrm{Ln}\left(\mathrm{BIPM}^{\mathrm{Mes}} \mathrm{H}\right)(\mathrm{I})_{2}(\mathrm{THF})_{2}\right](\mathrm{Ln}=\mathrm{La}, \mathrm{Ce}, \mathrm{Pr}$, $\mathrm{Nd}, \mathrm{Sm})$ in variable yield $(40-78 \%)$ via the reaction of $\left[\mathrm{Ln}(\mathrm{I})_{3}(\mathrm{THF})_{n}\right]$ with $\left.\left[\left\{\mathrm{K}_{(\mathrm{BIPM}}{ }^{\mathrm{Mes}} \mathrm{H}\right)\right\}_{2}\right][12,14]$. In contrast to the preparation of the $\left\{\mathrm{BIPM}^{\mathrm{TMS}} \mathrm{H}\right\}^{-}$analogues (vide supra), no forcing conditions or use of heavier group 1 ligand transfer reagents (e.g., $\left.\left[\mathrm{Cs}\left(\mathrm{BIPM}^{\mathrm{Mes}} \mathrm{H}\right)\right]\right)$ was required. This is likely due to the decreased steric bulk of the $\left\{\mathrm{BIPM}^{\mathrm{Mes}} \mathrm{H}\right\}^{-}$ligand compared to $\left\{\mathrm{BIPM}{ }^{\mathrm{TMS}} \mathrm{H}\right\}^{-}$leading to more reactive ligand transfer reagents as the alkali metal is less sterically shielded. 
As we had previously prepared $\left[\mathrm{Ln}\left(\mathrm{BIPM}^{\mathrm{Mes}} \mathrm{H}\right)(\mathrm{I})_{2}(\mathrm{THF})_{2}\right]$ for the larger rare earths $(\mathrm{Ln}=\mathrm{La}$, $\mathrm{Ce}, \mathrm{Pr}, \mathrm{Nd}, \mathrm{Sm}$; See Table 1), we attempted to extend this series to investigate any changes in structure or reactivity imparted on the complex by varying the metal centre. Analogous to our previous reports, the reaction of half an equivalent of $\left[\left\{\mathrm{K}\left(\mathrm{BIPM}^{\mathrm{Mes}} \mathrm{H}\right)\right\}_{2}\right]$ with $\left[\mathrm{Ln}(\mathrm{I})_{3}(\mathrm{THF})_{3.5}\right](\mathrm{Ln}$

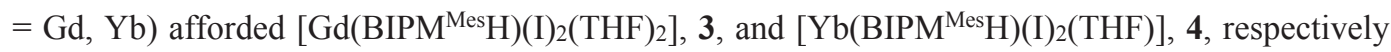
(Scheme 3). Each complex was identified by elemental analyses, solution magnetic studies (vide infra) and by single crystal X-ray diffraction studies. However, while the X-ray diffraction data for $33 \mathrm{C}_{7} \mathrm{H}_{8}$ is of good quality ( $\left.R_{\text {int }}=0.034, R=0.0419, R_{w}=0.109\right)$ and confirmed its identity as $\left[\mathrm{Gd}\left(\mathrm{BIPM}^{\mathrm{Mes}} \mathrm{H}\right)(\mathrm{I})_{2}(\mathrm{THF})_{2}\right] 3 \mathrm{C}_{7} \mathrm{H}_{8}$, the data-set obtained for $43 \mathrm{C}_{7} \mathrm{H}_{8}$ is poor $\left(R_{\text {int }}=0.0744\right.$, $\left.R=0.1097, R_{w}=0.2865\right)$, and despite exhaustive attempts more satisfactory data could not be obtained. While the data-set collected on crystals of $43 \mathrm{C}_{7} \mathrm{H}_{8}$ is of poor quality and precludes any assessment of the metrical parameters of the complex, the connectivity is clear-cut, and together with elemental analysis and comparison to lighter rare earth analogues, we are confident in our assignment of $\mathbf{4}$. The difficulty in obtaining crystals of $\mathbf{4}$ of suitable quality for single crystal X-ray diffraction studies is perhaps surprising as $\left[\mathrm{Ln}\left(\mathrm{BIPM}^{\mathrm{Mes}} \mathrm{H}\right)(\mathrm{I})_{2}(\mathrm{THF})_{2}\right](\mathrm{Ln}=\mathrm{La}, \mathrm{Ce}, \mathrm{Pr}, \mathrm{Nd}, \mathrm{Sm}$, Gd) all crystallise readily from toluene solutions to afford large crystals suitable for single crystal $\mathrm{X}$-ray diffraction studies. The change in crystallinity is possibly due to $\mathbf{4}$ possessing only one THF molecule coordinated to ytterbium, compared to the two THF molecules coordinated in $\left[\mathrm{Ln}\left(\mathrm{BIPM}^{\mathrm{Mes}} \mathrm{H}\right)(\mathrm{I})_{2}(\mathrm{THF})_{2}\right](\mathrm{Ln}=\mathrm{La}, \mathrm{Ce}, \mathrm{Pr}, \mathrm{Nd}, \mathrm{Sm}, \mathrm{Gd})[12,14]$. This variation in coordination number and ligand environment may lead to less efficient crystal packing, however, the lack in crystallinity may also be due to $\mathbf{4}$ not containing the optimal metal/ligand size ratio for crystal growth [21].

The solid-state structure of $33 \mathrm{C}_{7} \mathrm{H}_{8}$ is shown in Figure 4, with selected bond lengths and angles shown in Table $\mathrm{S} 1$. As $\mathbf{3} 3 \mathrm{C}_{7} \mathrm{H}_{8}$ crystallises with the same cell settings as $\left[\mathrm{Ln}\left(\mathrm{BIPM}^{\mathrm{Mes}} \mathrm{H}\right)(\mathrm{I})_{2}(\mathrm{THF})_{2}\right](\mathrm{Ln}=\mathrm{La}, \mathrm{Ce}, \mathrm{Pr}, \mathrm{Nd}, \mathrm{Sm})[12,14]$, they adopt the same distorted pentagonal bipyramidal structure, with the gadolinium centre being coordinated by tridentate $\left\{\mathrm{BIPM}^{\mathrm{Mes}} \mathrm{H}\right\}^{-}$[N1-Gd1-N2 angle: $\left.113.23(10)^{\circ}\right]$, two iodides and two THF molecules. The two iodides can be considered as occupying the axial sites, with the I1-Gd1-I2 angle of $155.765(9)^{\circ}$ revealing the degree of distortion away from idealised pentagonal bipyramidal geometry due to the coordination of the bulky $\left\{\mathrm{BIPM}^{\mathrm{Mes}} \mathrm{H}\right\}^{-}$ligand. As expected, due to the lanthanide contraction, the bond distances about the gadolinium centre in $\mathbf{3}$ are generally shorter than those observed in $\left[\mathrm{Ln}\left(\mathrm{BIPM}^{\mathrm{Mes}} \mathrm{H}\right)(\mathrm{I})_{2}(\mathrm{THF})_{2}\right](\mathrm{Ln}=\mathrm{La}, \mathrm{Ce}, \mathrm{Pr}, \mathrm{Nd}, \mathrm{Sm})$, due to the smaller radius of $\mathrm{Gd}(\mathrm{III})$ (Table 1), and are each within the range of previously reported distances [24], but are otherwise unremarkable. The $\left\{\mathrm{BIPM}^{\mathrm{Mes}} \mathrm{H}\right\}^{-}$ligand in $\mathbf{3}$ appears to be bound to the metal centre in an analogous manner to $\left[\mathrm{Ln}\left(\mathrm{BIPM}^{\mathrm{Mes}} \mathrm{H}\right)(\mathrm{I})_{2}(\mathrm{THF})_{2}\right](\mathrm{Ln}=\mathrm{La}, \mathrm{Ce}, \mathrm{Pr}, \mathrm{Nd}, \mathrm{Sm})[12,14]$, as evidenced by the mean endocyclic P-C, P-N distances and P1-C1-P2 angle in 3 [1.723(4) $\AA, 1.626(3) \AA$ and 134.3(2) respectively] being statistically indistinguishable to corresponding values reported for [Ln(BIPM $\left.\left.{ }^{\mathrm{Mes}} \mathrm{H}\right)(\mathrm{I})_{2}(\mathrm{THF})_{2}\right](\mathrm{Ln}=\mathrm{La}, \mathrm{Ce}, \mathrm{Pr}, \mathrm{Nd}, \mathrm{Sm})$ [ranges P-C: 1.719(4)-1.731(4) $\AA$; P-N: 1.612(3)-1.634(3) $\AA$ and P-C-P: 133.7(3)-134.1(2) $][12,14]$.

Whilst we were successful in the preparation of $\left[\operatorname{Ln}\left(\mathrm{BIPM}^{\mathrm{Mes}} \mathrm{H}\right)(\mathrm{I})_{2}(\mathrm{THF})_{n}\right]$ for the larger rare earths $(\mathrm{Ln}=\mathrm{La}, \mathrm{Ce}, \mathrm{Pr}, \mathrm{Nd}, \mathrm{Sm}, \mathrm{Gd})$ and smaller rare earth ytterbium, we had difficulty in the 
preparation of analogues for intermediate sized rare earths, namely dysprosium and erbium (Table 1). It is difficult to follow reaction progress between $\left[\operatorname{Ln}(\mathrm{I})_{3}(\mathrm{THF})_{3.5}\right](\mathrm{Ln}=\mathrm{Dy}, \mathrm{Er})$ and half an equivalent of $\left[\left\{\mathrm{K}\left(\mathrm{BIPM}^{\mathrm{Mes}} \mathrm{H}\right)\right\}_{2}\right]$, as the highly paramagnetic nature of Dy(III) $\left(4 f^{7}\right)$ and $\operatorname{Er}(\mathrm{III})$ $\left(4 f^{9}\right)$ lead to inconclusive NMR spectra, and also because [ $\left.\operatorname{Ln}(\mathrm{I})_{3}(\mathrm{THF})_{3.5}\right]$ has low solubility in THF so the elimination of KI cannot be monitored easily as a suspension is observed throughout the reaction. As we followed the same preparative method that yielded $\left[\mathrm{Ln}\left(\mathrm{BIPM}^{\mathrm{Mes}} \mathrm{H}\right)_{(\mathrm{I}) 2}(\mathrm{THF})_{n}\right]$ (vide supra), we worked up the reaction mixture in a similar manner, namely filtration and recrystallisation from hot toluene solutions. In the cases of dysprosium and erbium this did not afford $\left[\mathrm{Ln}\left(\mathrm{BIPM}^{\mathrm{Mes}} \mathrm{H}\right)(\mathrm{I})_{2}(\mathrm{THF})_{n}\right](\mathrm{Ln}=\mathrm{Dy}, \mathrm{Er})$ as expected, but instead led to the isolation of the separated ion pair species $\left[\mathrm{Ln}\left(\mathrm{BIPM}^{\mathrm{Mes}} \mathrm{H}\right)_{2}\right]\left[\mathrm{BIPM}^{\mathrm{Mes}} \mathrm{H}\right](\mathrm{Ln}=\mathrm{Dy}, \mathbf{5} \mathbf{a} ; \mathrm{Er}, \mathbf{5} \mathbf{b})$ in moderate yields (5a: 39\%; 5b: 31\%, based on BIPM) (Scheme 3). Our hypothesis for the isolation of $\mathbf{5 a}-\mathbf{b}$ is that the reaction of $\left[\mathrm{Ln}(\mathrm{I})_{3}(\mathrm{THF})_{3.5}\right](\mathrm{Ln}=\mathrm{Dy}, \mathrm{Er})$ with half an equivalent of $\left[\left\{\mathrm{K}\left(\mathrm{BIPM}^{\mathrm{Mes}} \mathrm{H}\right)\right\}_{2}\right]$ proceeds sluggishly under ambient conditions, primarily due to the inherent insolubility of $\left[\operatorname{Ln}(\mathrm{I})_{3}(\mathrm{THF})_{3.5}\right](\mathrm{Ln}=\mathrm{Dy}, \mathrm{Er})$ in THF [25]. During workup, filtration separates insoluble $\left[\operatorname{Ln}(\mathrm{I})_{3}(\mathrm{THF})_{3.5}\right](\mathrm{Ln}=\mathrm{Dy}, \mathrm{Er})$ and yields a solution of $\left[\left\{\mathrm{K}\left(\mathrm{BIPM}{ }^{\mathrm{Mes}} \mathrm{H}\right)\right\}_{2}\right]$ in excess to $\left[\operatorname{Ln}(\mathrm{I})_{3}(\mathrm{THF})_{3.5}\right](\mathrm{Ln}=\mathrm{Dy}, \mathrm{Er})$, which, when heated in toluene during attempted recrystallisation, would lead to a rapid reaction, where $\left[\operatorname{Ln}(\mathrm{I})_{3}(\mathrm{THF})_{3.5}\right](\mathrm{Ln}=\mathrm{Dy}, \mathrm{Er})$ would effectively react with three equivalents of $\left[\left\{\mathrm{K}\left(\mathrm{BIPM}^{\mathrm{Mes}} \mathrm{H}\right)\right\}_{2}\right]$ to afford $\mathbf{5 a}-\mathbf{5 b}$, with concomitant elimination of KI.

Scheme 3. Preparation of 3-5a-b.

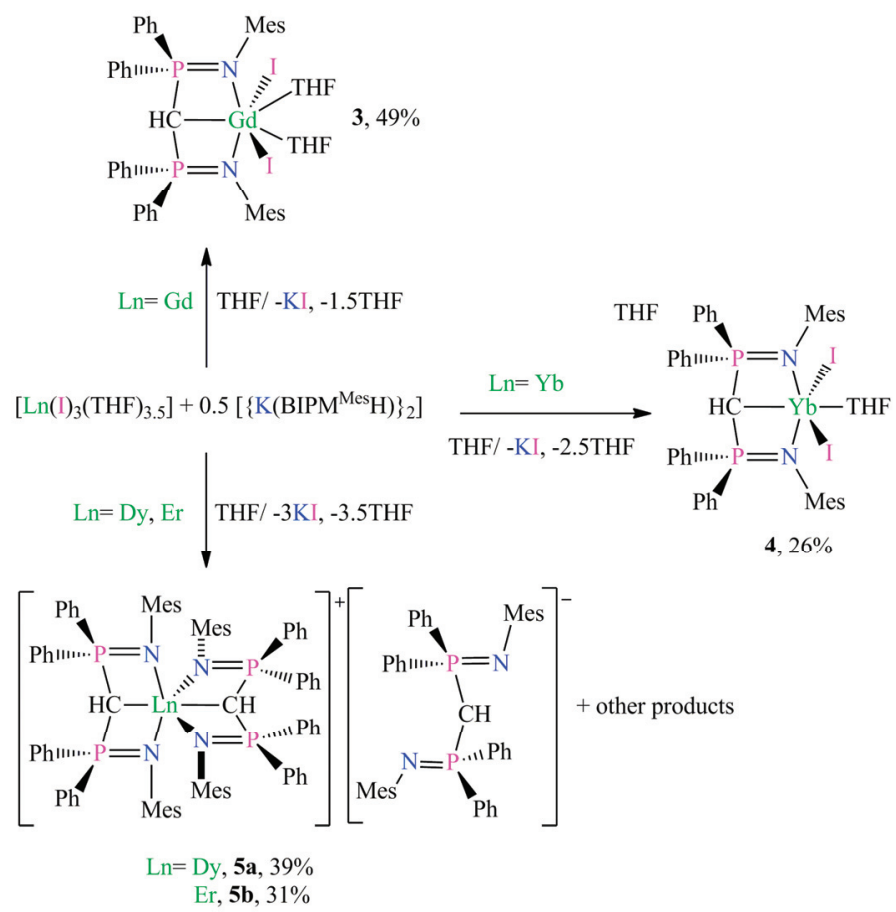


Repeated attempts to prepare $\left[\mathrm{Ln}\left(\mathrm{BIPM}^{\mathrm{Mes}} \mathrm{H}\right)(\mathrm{I})_{2}(\mathrm{THF})_{n}\right](\mathrm{Ln}=\mathrm{Dy}, \mathrm{Er})$ by varying reaction times and solvents (THF, 1,2-dimethoxyethane, $\mathrm{Et}_{2} \mathrm{O}$ ) were not successful, and when forcing conditions were employed the reaction proceeded rapidly rather than in a slow and controlled manner, leading to isolation of $\mathbf{5 a - b}$. Complexes $\mathbf{5 a}-\mathbf{b}$ were identified by solution magnetic moment measurements (vide infra), elemental analyses and by single crystal X-ray diffraction studies.

Figure 4. Molecular structure of $33 \mathrm{C}_{7} \mathrm{H}_{8}$ with selected atom labelling. Displacement ellipsoids are drawn at $50 \%$ probability, with lattice solvent and non-methanide hydrogen atoms omitted for clarity.

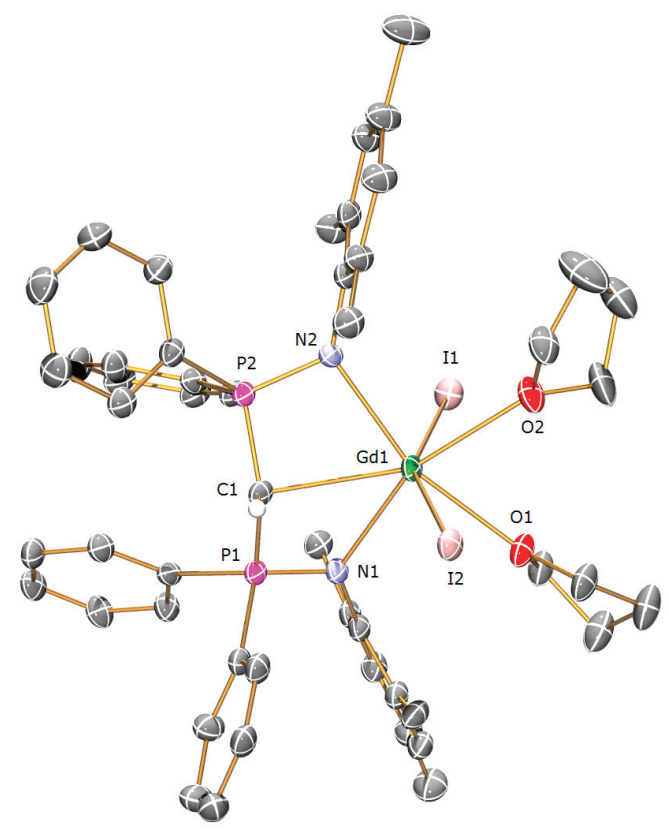

As complexes $\mathbf{5 a} 4 \mathrm{C}_{7} \mathrm{H}_{8}$ and $\mathbf{5 b} 5 \mathrm{C}_{7} \mathrm{H}_{8}$ have very similar solid-state structures and metrical parameters, only $\mathbf{5 a} 4 \mathrm{C}_{7} \mathrm{H}_{8}$ is discussed in detail. Selected bond lengths and angles of $\mathbf{5 a} 4 \mathrm{C}_{7} \mathrm{H}_{8}$ and $\mathbf{5 b} 5 \mathrm{C}_{7} \mathrm{H}_{8}$ are shown in Table S1. The cationic $\left[\mathrm{Dy}\left(\mathrm{BIPM}{ }^{\mathrm{Mes}} \mathrm{H}\right)_{2}\right]^{+}$component of $\mathbf{5 a}$ is shown in Figure 5, while, for clarity, the anionic $\left[\mathrm{BIPM}^{\mathrm{Mes}} \mathrm{H}\right]^{-}$component is shown separately in Figure 6.

The dysprosium centre in 5a is coordinated by two mutually orthogonal $\left\{B \mathrm{BIM}^{\mathrm{Mes}} \mathrm{H}\right\}^{-}$ligands, each exhibiting a tridentate binding mode, leading to a distorted octahedral geometry. Each $\left\{\mathrm{BIPM}^{\mathrm{Mes}} \mathrm{H}\right\}^{-}$is coordinated to dysprosium in a similar mode, as shown by the statistically indistinguishable Dy1-C1 [2.676(2) $\AA]$ and Dy1-C44 [2.679(2) $\AA]$ distances, but there is a variation in Dy-N distances, with each $\left\{\mathrm{BIPM}^{\mathrm{Mes}} \mathrm{H}\right\}^{-}$exhibiting one shorter Dy-N distance [Dy1-N2: 2.3445(18) $\AA$; Dy1-N3: 2.3584(17) $\AA$ ] and one longer Dy-N distance [Dy1-N1: 2.3849(19) A; Dy1-N4: 2.3866(19) $\AA]$. The mean endocyclic P-C and P-N distances, and P-C-P angle in the cationic component of 5a [1.742(2), 1.632(2) $\AA$ and $128.65(13)^{\circ}$, respectively] are similar to the corresponding distances in $\left[\mathrm{Ln}\left(\mathrm{BIPM}^{\mathrm{Mes}} \mathrm{H}\right)(\mathrm{I})_{2}(\mathrm{THF})_{2}\right](\mathrm{Ln}=\mathrm{La}, \mathrm{Ce}, \mathrm{Pr}, \mathrm{Nd}, \mathrm{Sm})[12,14]$, but there is a slight 
elongation of the P-C bonds [5a: 1.742(2) A compared to range 1.719(4)-1.731(4) $\AA$ ] and lowering of the P-C-P angle [5a: $128.65(13)^{\circ}$ compared to range $133.7(3)-134.1(2)^{\circ}$ ], which is likely a reflection of the coordination of two bulky $\left\{\mathrm{BIPM}^{\mathrm{Mes}} \mathrm{H}\right\}^{-}$ligands to one metal centre leading to increased steric hindrance about the endocyclic ring.

The anionic component of 5a $\left[\mathrm{BIPM}^{\mathrm{Mes}} \mathrm{H}\right]^{-}$exhibits shortened endocyclic P-C and P-N distances [mean values of 1.709(2) and $1.592 \AA$, respectively] and a larger P-C-P angle [P5-C87P6: $\left.133.89(15)^{\circ}\right]$ in comparison to the $\left\{\mathrm{BIPM}^{\mathrm{Mes}} \mathrm{H}\right\}^{-}$ligands in the cationic component, due to the anion not being coordinated to a metal centre. The P-C and P-N bonds in the N-P-C-P-N framework of the anionic $\left[\mathrm{BIPM}^{\mathrm{Mes}} \mathrm{H}\right]^{-}$fragment are shorter, and longer, respectively, than the distances reported in $\mathrm{BIPM}^{\mathrm{Mes}} \mathrm{H}_{2}$ [26], suggesting a degree of delocalisation of charge about the N-P-C-P-N framework.

Figure 5. Cationic component of $\mathbf{5 a} 4 \mathrm{C}_{7} \mathrm{H}_{8}$. Displacement ellipsoids are drawn at $50 \%$ probability, with lattice solvent and non-methanide hydrogen atoms omitted for clarity.

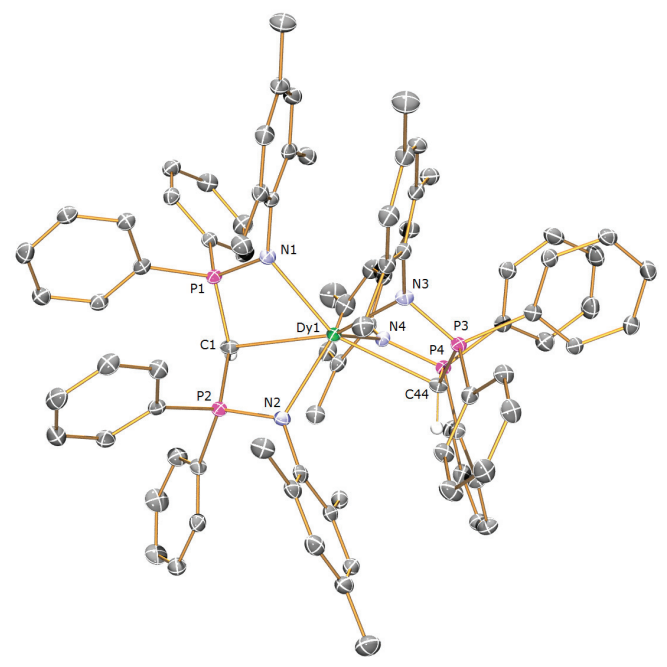

With [Ln(BIPM $\left.\left.{ }^{\mathrm{Mes}} \mathrm{H}\right)(\mathrm{I})_{2}(\mathrm{THF})_{2}\right](\mathrm{Ln}=\mathrm{Ce}, \mathrm{Pr}, \mathrm{Nd}, \mathrm{Sm})$ and $\mathbf{3}$ in hand, we attempted to prepare a range of $\left\{\mathrm{BIPM}^{\mathrm{Mes}}\right\}^{2-}$ derived rare earth methanediides in an analogous manner to our previously reported $\left[\mathrm{La}\left(\mathrm{BIPM}^{\mathrm{Mes}}\right)(\mathrm{I})(\mathrm{THF})_{3}\right] \quad[12]$, which was prepared via the reaction of $\left[\mathrm{La}\left(\mathrm{BIPM}^{\mathrm{Mes}} \mathrm{H}\right)(\mathrm{I})_{2}(\mathrm{THF})_{2}\right]$ with $[\mathrm{K}(\mathrm{Bn})]$. Unfortunately this preparative route proved to be capricious (vide infra), with a potential cause of the reaction not proceeding smoothly being the ineffectiveness of the labile coordinated THF molecules to fully saturate and stabilise the rare earth centre during the reaction. Replacement of these THF molecules with a bulkier bidentate donor solvent, namely TMEDA ( $N^{\prime}, N^{\prime}, N^{\prime \prime}, N^{\prime \prime}$-tetramethylethylenediamine) was predicted to provide increased saturation of the rare earth metal centre and lead to an improved route to complexes of the formula $\left[\operatorname{Ln}\left(\mathrm{BIPM}^{\mathrm{Mes}}\right)(\mathrm{I})(\mathrm{S})_{n}\right](\mathrm{S}=$ donor solvent $)$. 
Figure 6. Anionic component of $5 \mathbf{a} 4 \mathrm{C}_{7} \mathrm{H}_{8}$. Displacement ellipsoids are drawn at $50 \%$ probability, with lattice solvent and non-methanide hydrogen atoms omitted for clarity.

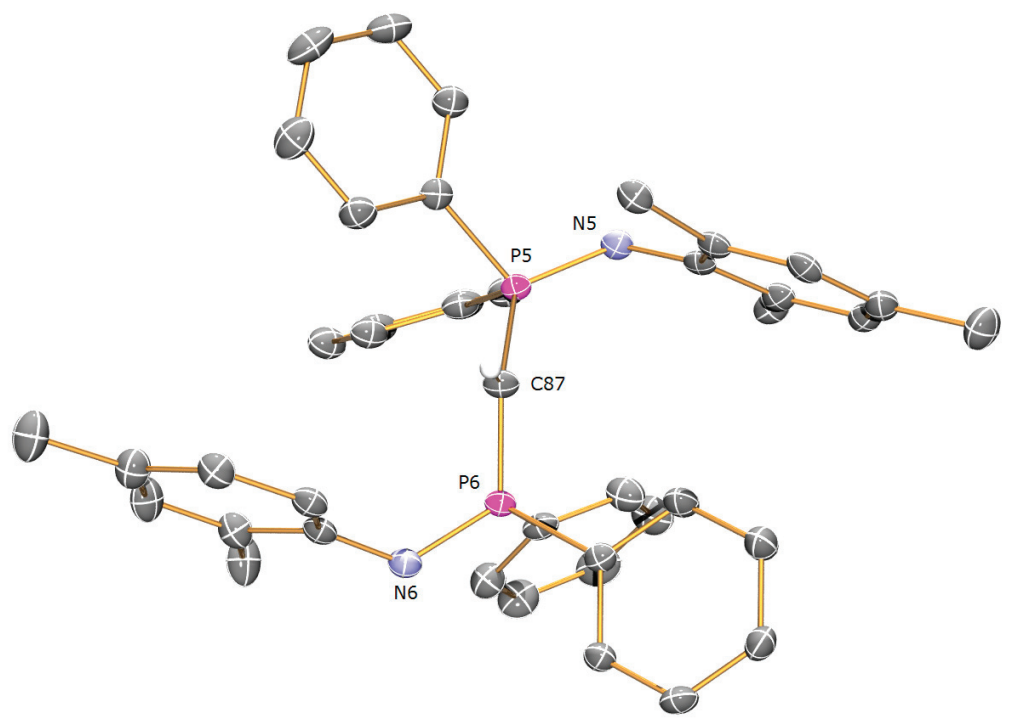

We initially investigated the lanthanum congener, as its $\mathrm{La}(\mathrm{III}) 4 f^{\circ}$ state is diamagnetic allowing us to follow the reaction progress easily by NMR spectroscopy. The straightforward reaction of $\left[\mathrm{La}\left(\mathrm{BIPM}^{\mathrm{Mes}} \mathrm{H}\right)(\mathrm{I})_{2}(\mathrm{THF})_{2}\right]$ [12] with TMEDA in THF solution over $18 \mathrm{~h}$ afforded [La(BIPM $\left.\left.{ }^{\mathrm{Mes}} \mathrm{H}\right)(\mathrm{I})_{2}(\mathrm{TMEDA})\right], \mathbf{6 a}$, in essentially quantitative yield (Scheme 4).

NMR spectroscopy performed on $\mathbf{6 a}$ revealed it to have similar resonances to $\left[\mathrm{La}\left(\mathrm{BIPM}{ }^{\mathrm{Mes}} \mathrm{H}\right)(\mathrm{I})_{2}(\mathrm{THF})_{2}\right]$, with the ${ }^{1} \mathrm{H}$ and ${ }^{13} \mathrm{C}\left\{{ }^{1} \mathrm{H}\right\}$ NMR spectra of $\mathbf{6 a}$ exhibiting resonances for the methanide hydrogen and carbon at $3.91 \mathrm{ppm}\left({ }^{2} J_{P H}=8.8 \mathrm{~Hz}\right)$, and $8.44 \mathrm{ppm}\left(J_{\mathrm{PC}}=138 \mathrm{~Hz}\right)$, respectively, which are both slightly downfield compared to the equivalent resonances reported for $\left[\mathrm{La}\left(\mathrm{BIPM}^{\mathrm{Mes}} \mathrm{H}\right)(\mathrm{I})_{2}(\mathrm{THF})_{2}\right]\left(3.36 \mathrm{ppm},{ }^{2} J_{\mathrm{PH}}=14.5 \mathrm{~Hz}\right.$ and $\left.5.73 \mathrm{ppm}, J_{\mathrm{PC}}=136 \mathrm{~Hz}\right) .{ }^{12} \mathrm{The}{ }^{31} \mathrm{P}\left\{{ }^{1} \mathrm{H}\right\}$ NMR spectrum of $\mathbf{6 a}$ exhibits a resonance at $15.70 \mathrm{ppm}$ which is slightly downfield to the corresponding resonance reported for $\left[\mathrm{La}\left(\mathrm{BIPM}^{\mathrm{Mes}} \mathrm{H}\right)(\mathrm{I})_{2}(\mathrm{THF})_{2}\right](11.46 \mathrm{ppm})$ [12].

While elemental analysis and NMR spectroscopy supported the formulation of $\mathbf{6 a}$, a single crystal X-ray diffraction study was performed to confirm its structure. The solid-state structure of 6a $3 \mathrm{C}_{7} \mathrm{H}_{8}$ is shown in Figure 7, with selected bond lengths and angles complied in Table S1. The lanthanum centre in $\mathbf{6 a}$ adopts a heavily distorted pentagonal bipyramidal geometry with the two iodides occupying the axial sites [I1-La1-I2 angle: $\left.158.395(12)^{\circ}\right]$. The tridentate $\left\{\mathrm{BIPM}^{\mathrm{Mes}} \mathrm{H}\right\}^{-}$ [N1-La1-N2 angle:110.72(13 $\left.)^{\circ}\right]$ and the two amine nitrogens of TMEDA occupy the equatorial sites. The La1-NTMEDA distances [La1-N3: 2.852(5) $\AA$; La1-N4: 2.844(4) $\AA$ ] are far longer than the La1-NBIPM distances [La1-N1: 2.564(4) $\AA$; La1-N2: 2.526(4) $\AA$ ] consistent with the $\mathrm{N}^{-}{ }^{-}{ }^{-}{ }^{+} \mathrm{C}-{ }^{-} \mathrm{P}-$ ${ }^{+} \mathrm{N}^{-}$charge distribution about the $\left\{\mathrm{BIPM}{ }^{\mathrm{Mes}} \mathrm{H}\right\}^{-}$framework leading to an increased electrostatic interaction between La1 and the imino nitrogens. Despite the variation of donor solvent coordinated to lanthanum, the mean La1-NBIPM, La1-I and La1-C1 bond distances [2.545(4), 
3.2229(5) and 2.822(5) $\AA$, respectively] are very similar to, if not statistically indistinguishable, from the corresponding distances in $\left[\mathrm{La}\left(\mathrm{BIPM}^{\mathrm{Mes}} \mathrm{H}\right)(\mathrm{I})_{2}(\mathrm{THF})_{2}\right][2.537(3), 3.2042(4)$ and 2.833(4) $\AA$, respectively] [12]. Similarly, the $\left\{\mathrm{BIPM}^{\mathrm{Mes}} \mathrm{H}\right\}^{-}$ligand exhibits statistically indistinguishable endocyclic P-C and P-N distances [mean distances: 1.732(5) and 1.621(5) $\AA$, respectively], and P1-C1-P2 angle $\left[134.1(3)^{\circ}\right]$ to the THF congener [1.726(4) $\AA, 1.617(3) \AA$ and $133.8(2)^{\circ}$, respectively] [12].

Following the successful isolation of $\mathbf{6 a}$, we prepared a heavier rare earth analogue, namely $\left[\mathrm{Gd}\left(\mathrm{BIPM}^{\mathrm{Mes}} \mathrm{H}\right)(\mathrm{I})_{2}(\mathrm{TMEDA})\right], \mathbf{6 b}$, via the same methodology. As Gd(III) is smaller than La(III) (Table 1) this would provide us with a range of metal sizes to fully investigate if the size of the metal centre has any effect on the successful preparation of our target $\left\{\mathrm{BIPM}^{\mathrm{Mes}}\right\}^{2-}$ methanediide complexes (vide infra). Complex $\mathbf{6 b}$ was prepared and utilised in situ in attempted deprotonation/salt elimination reactions, but a small sample was recrystallised from toluene to afford single crystals suitable for X-ray diffraction studies. Although $\mathbf{6 b}$ crystallises in a different cell setting to $\mathbf{6 a}$ (Cmca vs. $P$-1), leading to the TMEDA molecule possessing positional disorder about the mirror plane, the overall structures are very similar with the gadolinium centre in $\mathbf{6 b}$ adopting a heavily distorted pentagonal bipyramidal geometry. As expected due to the lanthanide contraction the bond distances about the gadolinium centre in $\mathbf{6 b}$ are each shortened by $c a$. 0.07-0.14 $\AA$ compared to the corresponding distances about lanthanum in $\mathbf{6 a}$, and are all well within the range of previously reported bond distances [24].

With $\left[\mathrm{Ln}\left(\mathrm{BIPM}^{\mathrm{Mes}} \mathrm{H}\right)(\mathrm{I})_{2}(\mathrm{THF})_{2}\right](\mathrm{Ln}=\mathrm{La}, \mathrm{Ce}, \mathrm{Pr}, \mathrm{Gd})$ and $\left[\mathrm{Ln}\left(\mathrm{BIPM}^{\mathrm{Mes}} \mathrm{H}\right)(\mathrm{I})_{2}(\mathrm{TMEDA})\right]$ $(\mathrm{Ln}=\mathrm{La}, \mathrm{Gd})$ secured, we turned our focus to the preparation of $\left\{\mathrm{BIPM}^{\mathrm{Mes}}\right\}^{2-}$ derived rare earth methandediide complexes.

Scheme 4. Preparation of $6 \mathbf{a}-\mathbf{b}$.
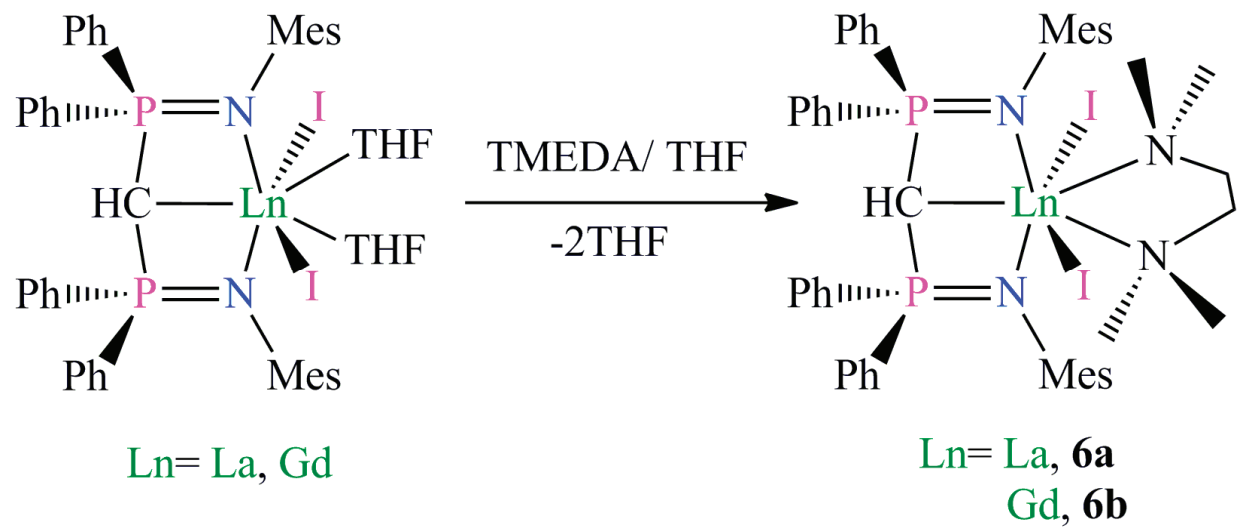
Figure 7. Molecular structure of $6 \mathbf{3} 3 \mathrm{C}_{7} \mathrm{H}_{8}$ with selected atom labelling. Displacement ellipsoids are drawn at $50 \%$ probability, with lattice solvent and non-methanide hydrogen atoms omitted for clarity. The molecular structure of $\mathbf{6 b} 2 \mathrm{C}_{7} \mathrm{H}_{8}$ is very similar.

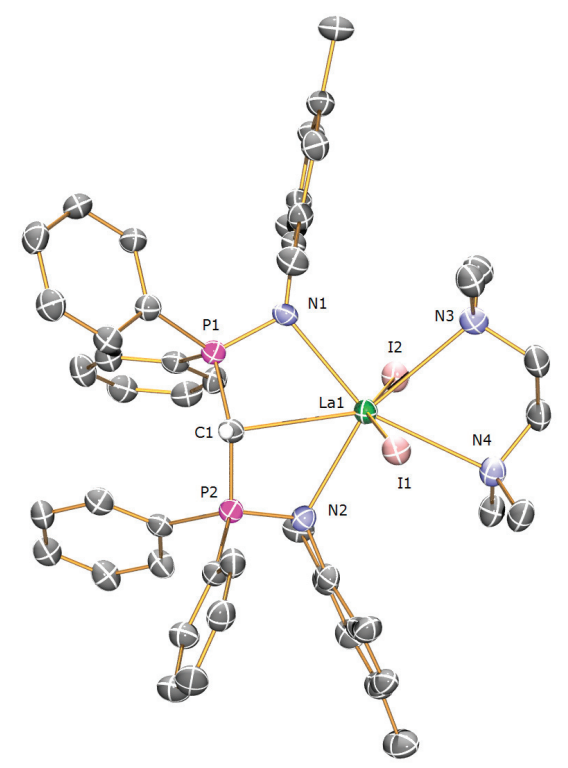

\subsection{Attempted Preparation of BIPM Mes Rare Earth Carbene Complexes}

We have previously reported that the reaction of $\left[\mathrm{La}\left(\mathrm{BIPM}^{\mathrm{Mes}} \mathrm{H}\right)(\mathrm{I})_{2}(\mathrm{THF})\right]$ with $[\mathrm{K}(\mathrm{Bn})]$ afforded the methanediide complex $\left[\mathrm{La}\left(\mathrm{BIPM}^{\mathrm{Mes}}\right)(\mathrm{I})(\mathrm{THF})_{3}\right]$ in $53 \%$ yield [12]. Unfortunately, this reaction appears to be capricious in nature, and despite following the reported methodology the reaction often yields a mixture of products from which $\left[\mathrm{La}\left(\mathrm{BIPM}^{\mathrm{Mes}}\right)(\mathrm{I})(\mathrm{THF})_{3}\right]$ cannot be isolated cleanly. As NMR spectroscopy revealed a mixture of products, of which none could be unambiguously identified, the reaction mixture was recrystallised from toluene which afforded $\left[\mathrm{La}\left(\mathrm{BIPM}^{\mathrm{Mes}}\right)\left(\mathrm{BIPM}^{\mathrm{Mes}} \mathrm{H}\right)\right], \mathbf{7} \mathbf{a}$, in $8 \%$ yield. The low yield of $\mathbf{7 a}$ is a reflection of the reaction not proceeding smoothly and affording a mixture of products, of which only $7 \mathbf{a}$ was crystalline and able to be extracted cleanly. Complex 7a was identified by single crystal X-ray diffraction studies (vide infra), NMR studies and elemental analysis. The ${ }^{31} \mathrm{P}\left\{{ }^{1} \mathrm{H}\right\}$ NMR spectrum of $7 \mathbf{a}$ exhibits two singlet resonances, at 2.88 and $10.51 \mathrm{ppm}$, which are assigned to the methanediide and methanide centres, respectively, by comparison to the resonances reported for $\left[\mathrm{La}\left(\mathrm{BIPM}^{\mathrm{Mes}}\right)(\mathrm{I})(\mathrm{THF})_{3}\right](4.84$ ppm) and [La(BIPM $\left.\left.{ }^{\mathrm{Mes}} \mathrm{H}\right)(\mathrm{I})_{2}(\mathrm{THF})_{2}\right](11.46 \mathrm{ppm})[12]$. The ${ }^{1} \mathrm{H}$ and ${ }^{13} \mathrm{C}\left\{{ }^{1} \mathrm{H}\right\}$ NMR spectra of $7 \mathbf{a}$ reveal methanide resonances of 2.26 (no coupling observed) and $4.59 \mathrm{ppm}\left(J_{\mathrm{PC}}=127 \mathrm{~Hz}\right.$ ), which are both upfield of the values reported for $\left[\mathrm{La}\left(\mathrm{BIPM}^{\mathrm{Mes}} \mathrm{H}\right)(\mathrm{I})_{2}(\mathrm{THF})_{2}\right]\left(3.36 \mathrm{ppm},{ }^{2} \mathrm{~J}_{\mathrm{PH}}=14.5 \mathrm{~Hz}\right.$ and $5.73 \mathrm{ppm}, J_{\mathrm{PC}}=136 \mathrm{~Hz}$, respectively), while the methanediide is observed in the ${ }^{13} \mathrm{C}\left\{{ }^{1} \mathrm{H}\right\}$ NMR spectrum of $\mathbf{7 a}$ at $45.06 \mathrm{ppm}$, which is also upfield to the value reported for $\left[\mathrm{La}\left(\mathrm{BIPM}^{\mathrm{Mes}}\right)(\mathrm{I})(\mathrm{THF})_{3}\right]\left(58.76 \mathrm{ppm}, J_{\mathrm{PC}}=148.4 \mathrm{~Hz}\right)[12]$. 
The isolation of $\mathbf{7 a}$ is reminiscent of our attempts to prepare $\left[\mathrm{La}\left(\mathrm{BIPM}^{\mathrm{TMS}}\right)(\mathrm{Bn})(\mathrm{THF})_{n}\right]$ via the reaction of $\left[\mathrm{La}(\mathrm{Bn})_{3}(\mathrm{THF})_{3}\right]$ and $\mathrm{BIPM}^{\mathrm{TMS}} \mathrm{H}_{2}$ which instead afforded $\left[\mathrm{La}\left(\mathrm{BIPM}^{\mathrm{TMS}}\right)\left(\mathrm{BIPM}^{\mathrm{TMS}} \mathrm{H}\right)\right]$, the $\mathrm{BIPM}^{\mathrm{TMS}}$ analogue of $\mathbf{7 a}[16]$. In the cases of both $\mathbf{7 a}$ and $\left[\mathrm{La}\left(\mathrm{BIPM}^{\mathrm{TMS}}\right)\left(\mathrm{BIPM}^{\mathrm{TMS}} \mathrm{H}\right)\right]$, the observed products are likely due to the instability of the intermediate complex $\left[\mathrm{La}\left(\mathrm{BIPM}^{\mathrm{Mes}} \mathrm{H}\right)(\mathrm{Bn})(\mathrm{I})(\mathrm{THF})_{n}\right]$ or $\left[\mathrm{La}\left(\mathrm{BIPM}^{\mathrm{TMS}} \mathrm{H}\right)(\mathrm{Bn})_{2}(\mathrm{THF})_{n}\right]$, which would each be susceptible to ligand scrambling due to the highly labile nature of lanthanide alkyl bonds.

As the preparation of $\left[\mathrm{La}\left(\mathrm{BIPM}^{\mathrm{Mes}}\right)(\mathrm{I})(\mathrm{THF})_{3}\right]$ via the reaction of $\left[\mathrm{La}\left(\mathrm{BIPM}^{\mathrm{Mes}} \mathrm{H}\right)(\mathrm{I})_{2}(\mathrm{THF})_{2}\right]$ with $[K(B n)]$ proved to be unreliable we attempted the reaction with other rare earth metals to investigate of the size of the metal present affected the result of the reaction. Also, in an attempt to stabilise the postulated " $\left[\mathrm{Ln}\left(\mathrm{BIPM}^{\mathrm{Mes}} \mathrm{H}\right)(\mathrm{Bn})(\mathrm{I})(\mathrm{THF})_{n}\right]$ " intermediate, which we hypothesise is undergoing ligand scrambling during reaction, we varied both the alkyl and coordinated solvent present. The alkyl could be substituted by utilising a base that is bulkier than $[\mathrm{K}(\mathrm{Bn})]$, namely $\left[\mathrm{K}\left(\mathrm{CHPh}_{2}\right)\right]$ or $\left[\mathrm{K}\left(\mathrm{CPh}_{3}\right)\right]$, while the coordinated solvent was varied by utilising $\mathbf{6 a}-\mathbf{b}$ in place of $\left[\mathrm{Ln}\left(\mathrm{BIPM}^{\mathrm{Mes}} \mathrm{H}\right)(\mathrm{I})_{2}(\mathrm{THF})_{2}\right]$.

Unfortunately the reactions of $\left[\mathrm{Ln}\left(\mathrm{BIPM}^{\mathrm{Mes}} \mathrm{H}\right)(\mathrm{I})_{2}(\mathrm{THF})\right](\mathrm{Ln}=\mathrm{La}, \mathrm{Ce}, \mathrm{Pr}, \mathrm{Gd})$ or $\mathbf{6 a}-\mathbf{b}$ with $[\mathrm{K}(\mathrm{R})]$ $\left(\mathrm{R}=\mathrm{Bn}, \mathrm{CHPh}_{2}, \mathrm{CPh}_{3}\right)$ did not afford $\left[\mathrm{Ln}\left(\mathrm{BIPM}^{\mathrm{Mes}}\right)(\mathrm{I})(\mathrm{S})_{n}\right]$ as anticipated, but instead led to mixtures of products in each case. The only isolable and identifiable products from these reactions were 7a, $\left[\mathrm{Ce}\left(\mathrm{BIPM}^{\mathrm{Mes}}\right)\left(\mathrm{BIPM}^{\mathrm{Mes}} \mathrm{H}\right)\right], \mathbf{7 b},\left[\operatorname{Pr}\left(\mathrm{BIPM}^{\mathrm{Mes}}\right)\left(\mathrm{BIPM}^{\mathrm{Mes}} \mathrm{H}\right)\right], \mathbf{7 c}$, or $\left[\mathrm{Gd}\left(\mathrm{BIPM}^{\mathrm{Mes}}\right)\left(\mathrm{BIPM}^{\mathrm{Mes}} \mathrm{H}\right)\right], 7 \mathbf{d}$, each in low yields (Scheme 5). Complexes $\mathbf{7 b}-\mathbf{d}$ were each identified by single crystal X-ray diffraction studies (vide infra), and while a clean sample of $\mathbf{7 b}$ was isolated which allowed full characterisation (elemental analysis and solution magnetic studies), isolated samples of 7c and 7d were contaminated with impurities which precluded full analysis. Despite the lack of full characterisation for $\mathbf{7} \mathbf{c}$ and $\mathbf{7 d}$ we are confident our formulation is correct as they are analogous to $7 \mathbf{a}-\mathbf{b}$, and it appears that varying the size of the metal present has little effect on the outcome of the reaction.

Scheme 5. Preparation of 7a-d.

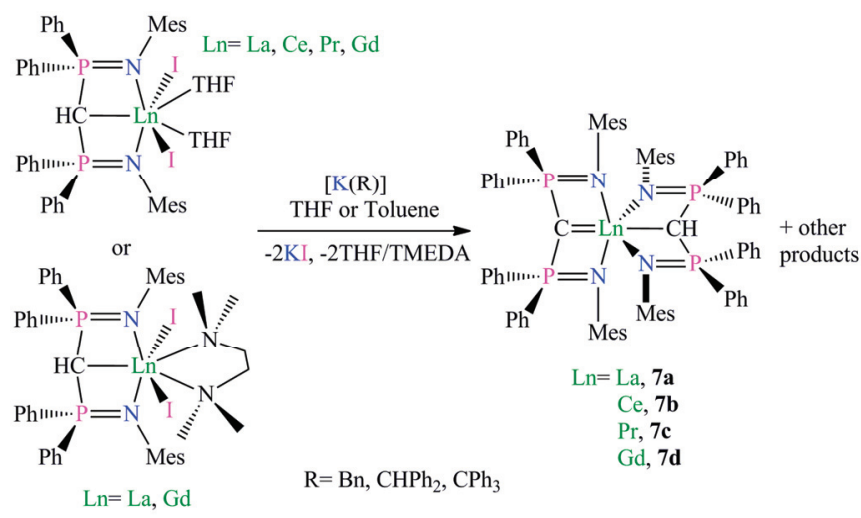


Figure 8. Molecular structure of $7 \mathbf{a} 3 \mathrm{C}_{7} \mathrm{H}_{8}$ with selected atom labelling. Displacement ellipsoids are drawn at $50 \%$ probability, with lattice solvent and non-methanide hydrogen atoms omitted for clarity. The molecular structures of $7 \mathbf{b}-\mathbf{d}$ are very similar.

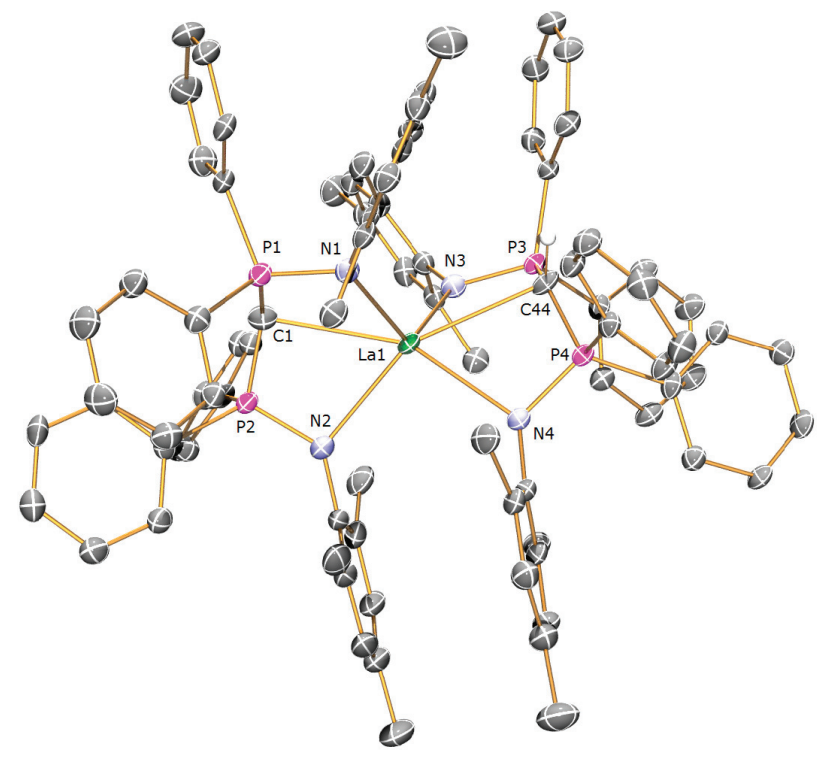

The complexes 7a-d exhibit very similar solid-state structures, with the rare earth metal coordinated by mutually orthogonal $\left\{B I P M^{M e s}\right\}^{2-}$ and $\left\{B I P M^{M e s} H\right\}^{-}$ligands, each bound in a tridentate fashion. A representative structure of $7 \mathbf{a} 3 \mathrm{C}_{7} \mathrm{H}_{8}$ is shown in Figure 8 with selected bond lengths and angles for each complex shown in Table S1. Despite exhibiting the same overall structure there is a variation in metrical parameters between $\mathbf{7 a}, \mathbf{c}-\mathbf{d}$ and $\mathbf{7 b}$, which we propose is due to a variation in solvent of crystallisation. As each of $7 \mathbf{a}-\mathbf{d}$ exhibit one $\left\{\mathrm{BIPM}^{\mathrm{Mes}} \mathrm{H}\right\}^{-}$ligand bound to the metal centre as a methanide and one $\left\{\mathrm{BIPM}^{\mathrm{Mes}}\right\}^{2-}$ ligand bound as a methanediide, varying $\mathrm{Ln}-\mathrm{C}$ distances would be expected as the metal centre would have an increased electrostatic interaction to the dianionic methanediide centre over the monoanionic methanide centre. This is the case for $\mathbf{7 b}$, which exhibits a longer Ce1-C1 distance of 2.819(11) $\AA$, and a shorter Ce1-C44 distance of 2.681(11) $\AA$, which leads to the assignment of $\mathrm{C} 1$ as being the methanide centre, and $\mathrm{C} 44$ being the methanediide centre. This is also analogous to the previously reported $\mathrm{BIPM}^{\mathrm{TMS}}$ congeners $\left[\mathrm{Ln}\left(\mathrm{BIPM}^{\mathrm{TMS}}\right)\left(\mathrm{BIPM}^{\mathrm{TMS}} \mathrm{H}\right)\right](\mathrm{Ln}=\mathrm{La}, \mathrm{Ce}, \mathrm{Pr}, \mathrm{Sm}, \mathrm{Gd})$, which each exhibit one long and one short Ln-C interaction [16].

However, in the cases of $\mathbf{7 a}$ and $\mathbf{7} \mathbf{c}-\mathbf{d}$, each $\left\{\mathrm{BIPM}^{\mathrm{Mes}}\right\}$ ligand appears to be bound to the metal in an identical manner, which is exemplified by statistically indistinguishable Ln-C bond distances

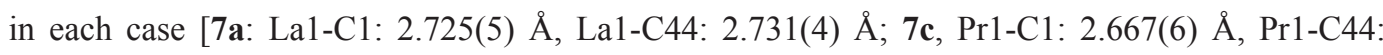
2.662(6) $\AA ;$ 7d, Gd1-C1: 2.605(11) $\AA$, Gd1-C44: 2.573(10) $\AA$ ]. We propose that this variation in coordination is simply an artefact of crystallisation, with the crystal packing in 7a,c-d being random, with the resulting data-set revealing an averaged geometry about the metal centre leading to equivalent $\mathrm{Ln}-\mathrm{C}$ bond distances. This is supported by the mean La1-C distances in $7 \mathbf{a}$ of 
2.728(5) $\AA$ being intermediate to the Ce1-C distances in 7b of 2.681(11) and 2.819(11) $\AA$, which would be expected if the two bond distances were averaged out. The other possibility is that each $\left\{\mathrm{BIPM}^{\mathrm{Mes}}\right\}$ ligand in $\mathbf{7 a}$ is bound as a methanide leading to a formal oxidation state assignment of $\mathrm{La}(\mathrm{II})$, analogous to the previously reported $\left[\mathrm{Sm}\left(\mathrm{BIPM}^{\mathrm{Mes}} \mathrm{H}\right)_{2}\right]$ [27], but this is easily ruled out by $7 \mathbf{a}$ being diamagnetic and its ${ }^{31} \mathrm{P}\left\{{ }^{1} \mathrm{H}\right\}$ NMR spectrum exhibiting two resonances consistent with the presence of two different ligand environments.

As expected due to the lanthanide contraction (Table 1) [19], there is a shortening of the mean Ln-C and Ln-N bond distances across the series from $7 \mathbf{a}$ to $7 \mathbf{d}$, but these distances are otherwise unremarkable. In each complex the $\left\{\mathrm{BIPM}^{\mathrm{Mes}}\right\}$ ligands are bound in a similar manner [endocyclic P-C distances ranging 1.671(12)-1.740(11) $\AA$ and P-N distances ranging 1.618(9)-1.684(9) $\AA$ ], with each adopting a pseudo-boat conformation [P-C-P angles: range: $\left.130.2(7)-134.3(7)^{\circ}\right]$. This conformation is in contrast to the $\left\{\mathrm{BIPM}^{\mathrm{TMS}}\right\}^{2-}$ ligands in $\left[\mathrm{Ln}\left(\mathrm{BIPM}^{\mathrm{TMS}}\right)\left(\mathrm{BIPM}^{\mathrm{TMS}} \mathrm{H}\right)\right]$, which exhibit near planar geometries, with P-C-P angles of $c a$. $166^{\circ}[16]$.

\subsection{Solution State Magnetic Properties of BIPM $M^{T M S}$ and BIPM Mes Rare Earth Complexes}

The room temperature solution magnetic moments of $\mathbf{1 a}-\mathbf{c}, \mathbf{3}, \mathbf{4}, \mathbf{5 a}-\mathbf{b}$ and $\mathbf{7 b}$ were determined utilising the Evans method [28]. These are compiled in Table 2 along with their ground state terms and theoretical magnetic moments. The theoretical magnetic moments of rare earth complexes can be approximated by $\mu_{J}=g J V(J+1)$ [where $\left.g J=3 / 2+[S(S+1)-L(L+1)] / 2 J(J+1)\right]$ according to the Van Vleck equation for magnetic susceptibility [29], assuming the ${ }^{2 S+1} L J$ ground state is well separated from excited states and crystal field splitting is negligible. This is generally true for rare earths, with the exception of $\mathrm{Sm}(\mathrm{III})$ and $\mathrm{Eu}(\mathrm{III})$, which exhibit low lying excited states of ${ }^{6} \mathrm{H}_{7 / 2}$ and ${ }^{7} \mathrm{~F}_{1}$, respectively, which each contribute to the room temperature magnetic moments [19]. As shown in Table 2 there is reasonable agreement between the theoretical and observed magnetic moments for each complex reported in this work.

Table 2. Theoretical and observed solution magnetic moments.

\begin{tabular}{|c|c|c|c|c|}
\hline Complex & Rare earth ion & Ground state term & $\mu_{\mathrm{J}}\left(\mu_{B}\right)^{\mathrm{a}}$ & $\mu_{\text {eff }}\left(\mu_{\mathrm{B}}\right)$ \\
\hline $1 a$ & $\mathrm{Nd}(\mathrm{III})$ & ${ }^{4} \mathrm{I}_{9 / 2}$ & 3.68 & 4.14 \\
\hline $1 b$ & Gd(III) & ${ }^{8} \mathrm{~S}_{7 / 2}$ & 7.94 & 8.47 \\
\hline $1 \mathrm{c}$ & $\mathrm{Tb}(\mathrm{III})$ & ${ }^{7} \mathrm{~F}_{6}$ & 9.72 & 9.46 \\
\hline 3 & Gd(III) & ${ }^{8} \mathrm{~S}_{7 / 2}$ & 7.94 & 8.00 \\
\hline 4 & $\mathrm{Yb}(\mathrm{III})$ & ${ }^{2} \mathrm{~F}_{7 / 2}$ & 4.53 & 4.29 \\
\hline $5 a$ & Dy(III) & ${ }^{6} \mathrm{H}_{15 / 2}$ & 10.63 & 9.81 \\
\hline $5 \mathbf{b}$ & Er(III) & ${ }^{4} \mathrm{I}_{15 / 2}$ & 9.59 & 10.25 \\
\hline $7 b$ & $\mathrm{Ce}(\mathrm{III})$ & ${ }^{2} \mathrm{~F}_{5 / 2}$ & 2.54 & 1.88 \\
\hline
\end{tabular}

\section{Experimental Section}

All manipulations were carried out using standard Schlenk techniques, or an MBraun UniLab glovebox, under an atmosphere of dry nitrogen. Solvents were dried by passage through activated 
alumina towers and degassed before use. All solvents were stored over potassium mirrors (with the exception of THF which was stored over activated $4 \AA$ molecular sieves). Deuterated solvents were distilled from potassium, degassed by three freeze-pump-thaw cycles and stored under nitrogen. [Cs(BIPM $\left.\left.{ }^{\mathrm{TMS}} \mathrm{H}\right)\right]$ [13], [Ln(I) $\left.3(\mathrm{THF})_{3.5}\right](\mathrm{Ln}=\mathrm{Nd}, \mathrm{Gd}, \mathrm{Dy}, \mathrm{Er}, \mathrm{Yb})$ [25], [\{K(BIPM $\left.\left.\left.{ }^{\mathrm{Mes}} \mathrm{H}\right)\right\}_{2}\right][6]$, $\left[\mathrm{Ln}\left(\mathrm{BIPM}^{\mathrm{Mes}} \mathrm{H}\right)(\mathrm{I})_{2}(\mathrm{THF})_{2}\right](\mathrm{Ln}=\mathrm{La}, \mathrm{Ce}, \operatorname{Pr})[12,14], \quad\left[\mathrm{La}\left(\mathrm{BIPM}^{\mathrm{TMS}} \mathrm{H}\right)(\mathrm{I})_{2}(\mathrm{THF})\right][13]$, and $[\mathrm{K}(\mathrm{Bn})][30]$ were prepared according to published procedures. $\left[\mathrm{Tb}(\mathrm{I})_{3}(\mathrm{THF})_{3.5}\right]$ was prepared according to a modified literature procedure $[25]$. $\left[\mathrm{K}\left(\mathrm{CHPh}_{2}\right)\right]$ and $\left[\mathrm{K}\left(\mathrm{CPh}_{3}\right)\right]$ were prepared by the reaction of $\mathrm{KOBu}^{t} / \mathrm{Bu}^{n} \mathrm{Li}$ with either diphenylmethane or triphenylmethane in hexanes, analogously to the preparation of $[\mathrm{K}(\mathrm{Bn})][30]$. All other materials were purchased and dried before use.

${ }^{1} \mathrm{H},{ }^{13} \mathrm{C}$ and ${ }^{31} \mathrm{P}$ NMR spectra were recorded on a Bruker 400 spectrometer operating at 400.2, 100.6 and $162.0 \mathrm{MHz}$, respectively; chemical shifts are quoted in ppm and are relative to tetramethylsilane $\left({ }^{1} \mathrm{H},{ }^{13} \mathrm{C}\right)$ or external $85 \% \mathrm{H}_{3} \mathrm{PO}_{4}\left({ }^{31} \mathrm{P}\right)$. FTIR spectra were recorded on a Bruker Tensor 27 spectrometer. Elemental microanalyses were carried out by Mr. Stephen Boyer at the Microanalysis Service, London Metropolitan University, UK.

Preparation of $\left[\mathbf{N d}\left(\mathbf{B I P M}^{\mathrm{TMS}} \mathbf{H}\right)(\mathbf{I})_{2}\right.$ (THF)] (1a): THF $(40 \mathrm{~mL})$ was added to a precooled $\left(-78{ }^{\circ} \mathrm{C}\right)$ mixture of $\left[\mathrm{Cs}\left(\mathrm{BIPM}^{\mathrm{TMS}} \mathrm{H}\right)\right](0.69 \mathrm{~g}, 1.00 \mathrm{mmol})$ and $\left[\mathrm{Nd}(\mathrm{I})_{3}(\mathrm{THF})_{3.5}\right](0.78 \mathrm{~g}, 1.00$ $\mathrm{mmol}$ ) and the resulting mixture was allowed to warm to room temperature with stirring over $18 \mathrm{~h}$. The mixture was filtered to remove CsI and all volatiles were removed in vacuo to afford a pale blue solid. Recrystallisation from toluene $(5 \mathrm{~mL})$ afforded $\mathbf{1 a} \mathrm{C}_{7} \mathrm{H}_{8}$ as pale blue crystals. Yield 0.42 g, 37\%. Anal. Calcd for $\mathrm{C}_{42} \mathrm{H}_{55} \mathrm{I}_{2} \mathrm{~N}_{2} \mathrm{NdOP}_{2} \mathrm{Si}_{2}$ : C, 45.05; H, 4.95; N, 2.50. Found: C, 44.89; H, 4.86; N, 2.58. FTIR v/cm ${ }^{-1}$ (Nujol): 1377 (m), 1366 (w), 1214 (w), 1064 (m), 992 (w), 839 (m), $770(\mathrm{w}), 746$ (w). $\mu_{\text {eff }}$ (Evans method, $298 \mathrm{~K}, \mathrm{C}_{6} \mathrm{D}_{6}$ ): $4.14 \mu_{\mathrm{B}}$.

Preparation of $\left[\mathbf{G d}\left(\mathbf{B I P M} \mathbf{M M S}^{\mathrm{TM}} \mathbf{H}\right)(\mathbf{I})_{2}\right.$ (THF)] (1b): THF $(40 \mathrm{~mL})$ was added to a precooled $\left(-78{ }^{\circ} \mathrm{C}\right)$ mixture of of $\left[\mathrm{Cs}\left(\mathrm{BIPM}^{\mathrm{TMS}} \mathrm{H}\right)\right](0.69 \mathrm{~g}, 1.00 \mathrm{mmol})$ and $\left[\mathrm{Gd}(\mathrm{I})_{3}(\mathrm{THF})_{3.5}\right](0.79 \mathrm{~g}, 1.00 \mathrm{mmol})$ and the resulting mixture was allowed to warm to room temperature with stirring over $18 \mathrm{~h}$. The mixture was filtered to remove CsI and the solution reduced in volume to $c a .5 \mathrm{~mL}$. Cooling of the solution to $-30{ }^{\circ} \mathrm{C}$ afforded $\mathbf{1 b} \mathrm{OC}_{4} \mathrm{H}_{8}$ as yellow crystals. Yield $0.56 \mathrm{~g}, 50 \%$. Anal. Calcd for $\mathrm{C}_{39} \mathrm{H}_{55} \mathrm{GdI}_{2} \mathrm{~N}_{2} \mathrm{O}_{2} \mathrm{P}_{2} \mathrm{Si}_{2}$ : C, 42.09; H, 4.98; N, 2.52. Found: C, 42.07; H, 4.95; N, 2.61. FTIR v/cm ${ }^{-1}$ (Nujol): 1437 (m), 1152 (m), 1114 (s), 1057 (s), 920 (w), 839 (m), 752 (w), 745 (w), 725 (w), 712 (w), 695 (w), 660 (w), 551 (m), 504 (w). $\mu_{\text {eff }}$ (Evans method, 298 K, C6 D6): $8.47 \mu_{\mathrm{B} .}$

Preparation of $\left[\mathbf{T b}\left(\mathbf{B I P M} \mathbf{M}^{\mathrm{TMS}} \mathbf{H}\right)(\mathbf{I})_{2}(\mathbf{T H F})\right](\mathbf{1 c})$ : THF $(40 \mathrm{~mL})$ was added to a precooled $\left(-78{ }^{\circ} \mathrm{C}\right)$ mixture of $\left[\mathrm{Tb}(\mathrm{I})_{3}(\mathrm{THF})_{3.5}\right](0.79 \mathrm{~g}, 1.00 \mathrm{mmol})$ and $\left[\mathrm{Cs}\left(\mathrm{BIPM}^{\mathrm{TMS}} \mathrm{H}\right)\right](0.69 \mathrm{~g}, 1.00 \mathrm{mmol})$ and the resulting mixture was allowed to warm to room temperature with stirring over $18 \mathrm{~h}$. The mixture was filtered to remove CsI and the resulting solution reduced in volume to $c a .5 \mathrm{~mL}$. Cooling of the solution to $4{ }^{\circ} \mathrm{C}$ afforded $1 \mathrm{c} \mathrm{OC}_{4} \mathrm{H}_{8}$ as yellow crystals. Yield $0.38 \mathrm{~g}, 34 \%$. Anal. Calcd for $\mathrm{C}_{39} \mathrm{H}_{55} \mathrm{I}_{2} \mathrm{~N}_{2} \mathrm{O}_{2} \mathrm{P}_{2} \mathrm{Si}_{2} \mathrm{~Tb}: \mathrm{C}, 42.02 ; \mathrm{H}, 4.97 ; \mathrm{N}, 2.51$. Found: C, 41.92; H, 4.88; N, 2.62. FTIR v/cm ${ }^{-1}$ (Nujol): 1437 (m), 1154 (m), 1114 (m), 1056 (m), 938 (w), 920 (w), 840 (m), 771 (m), 753 (w), 725 (w), 712 (w), 695 (w), 551 (m). $\mu_{\text {eff }}$ (Evans method, 298 K, C6 6 ): $9.46 \mu_{\text {B. }}$

Preparation of $\left[\left\{\mathbf{L a}\left(\mathbf{B I P M} \mathbf{M}^{\mathrm{TMS}} \mathbf{H}\right)(\mathbf{I})\left(\mu_{-} I\right)\right\}_{2}\right]$ (2): During our studies we prepared many samples of $\left[\mathrm{La}\left(\mathrm{BIPM}^{\mathrm{TMS}} \mathrm{H}\right)(\mathrm{I})_{2}(\mathrm{THF})\right]$, and on one occasion, following routine workup and recrystallisation, 
isolated a crop of crystals of $2 \mathrm{C}_{7} \mathrm{H}_{8}$ suitable for single crystal X-ray diffraction studies. Anal. Calcd for $\mathrm{C}_{76} \mathrm{H}_{94} \mathrm{I}_{4} \mathrm{La}_{2} \mathrm{~N}_{4} \mathrm{P}_{4} \mathrm{Si}_{4}$ : C, 43.78; H, 4.54; N, 2.69. Found: C, 43.77; H, 4.49; N, 2.53. FTIR v/cm ${ }^{-1}$ (Nujol): 3054 (w), 1438 (m), 1415 (w), 1261 (m), 1214 (w), 1181 (w), 1116 (m), 1070 (m), $991(\mathrm{~m}), 839$ (m), $770(\mathrm{~m}), 745(\mathrm{~m}), 695$ (m) 407 (m). The low solubility of 2 in arene solvents precluded NMR spectroscopy being performed in $d_{6}$-benzene or $d_{8}$-toluene, while dissolution in donor solvents such as $d_{8}$-THF afforded the solvated complex [La(BIPM $\left.\left.{ }^{\mathrm{TMS}} \mathrm{H}\right)(\mathrm{I})_{2}\left(d_{8}-\mathrm{THF}\right)\right]$ [13].

Preparation of $\left.\left[\mathbf{G d}\left(\mathbf{B I P M} \mathbf{M e s}^{\mathrm{Mes}} \mathbf{H}\right)(\mathbf{I})_{2} \text { (THF }\right)_{2}\right]$ (3): THF $(40 \mathrm{~mL})$ was added to a precooled $\left(-78{ }^{\circ} \mathrm{C}\right)$ mixture of $\left[\left\{\mathrm{K}\left(\mathrm{BIPM}^{\mathrm{Mes}} \mathrm{H}\right)\right\}_{2}\right](0.69 \mathrm{~g}, 0.50 \mathrm{mmol})$ and $\left[\mathrm{Gd}(\mathrm{I})_{3}(\mathrm{THF})_{3.5}\right](0.79 \mathrm{~g}, 1.00 \mathrm{mmol})$ and the resulting mixture was raised to room temperature with stirring over $18 \mathrm{~h}$. The mixture was filtered to remove $\mathrm{KI}$ and all volatiles were removed in vacuo to afford a yellow solid. Recrystallisation from hot toluene $(3 \mathrm{ml})$ afforded $3 \mathrm{a} 3 \mathrm{C}_{7} \mathrm{H}_{8}$ as yellow crystals on cooling to $4{ }^{\circ} \mathrm{C}$. Yield $0.72 \mathrm{~g}, 49 \%$. Anal. Calcd for $\mathrm{C}_{72} \mathrm{H}_{83} \mathrm{GdI}_{2} \mathrm{~N}_{2} \mathrm{O}_{2} \mathrm{P}_{2}$ : C, 58.37; H, 5.65; N, 1.89. Found: C, 58.17; H, 5.57; N, 1.74. FTIR v/cm ${ }^{-1}$ (Nujol): 1435 (m), 1213 (m), 1155 (m), 940 (w), 854 (m), $741(\mathrm{~m}), 695(\mathrm{~m}), 663(\mathrm{w}), 590(\mathrm{w}), 560(\mathrm{w}), 535$ (m). $\mu_{\text {eff }}$ (Evans method, $298 \mathrm{~K}, \mathrm{C}_{6} \mathrm{D}_{6}$ ): $8.00 \mu$ B.

Preparation of $\left[\mathbf{Y b}\left(\mathbf{B I P M}{ }^{\mathrm{Mes}} \mathbf{H}\right)(\mathbf{I})_{2}\right.$ (THF)] (4):THF $(40 \mathrm{~mL})$ was added to a precooled $\left(-78{ }^{\circ} \mathrm{C}\right)$ mixture of $\left[\mathrm{Yb}(\mathrm{I})_{3}(\mathrm{THF})_{3.5}\right](1.21 \mathrm{~g}, 1.50 \mathrm{mmol})$ and $\left[\left\{\mathrm{K}\left(\mathrm{BIPM}^{\mathrm{Mes}} \mathrm{H}\right)\right\}_{2}\right](1.05 \mathrm{~g}, 0.75 \mathrm{mmol})$, and the resulting orange mixture was raised to room temperature with stirring over $18 \mathrm{~h}$. The mixture was filtered to remove $\mathrm{KI}$ and all volatiles removed in vacuo to afford an orange solid. Recrystallisation from hot toluene $(15 \mathrm{ml})$ afforded $43 \mathrm{C}_{7} \mathrm{H}_{8}$ as orange crystals on cooling to -30 ${ }^{\circ} \mathrm{C}$. Yield $0.55 \mathrm{~g}, 26 \%$. Anal. Calcd for $\mathrm{C}_{47} \mathrm{H}_{51} \mathrm{I}_{2} \mathrm{~N}_{2} \mathrm{OP}_{2} \mathrm{Yb}$ : C, 49.14; H, 4.48; N, 2.44. found: C, 49.34; H, 4.58; N, 2.10. FTIR v/cm ${ }^{-1}$ (Nujol): 1588 (w), 1302 (w), 1261 (m), 1214 (m), 1156 (m), 1106 (s), $1014(\mathrm{~s}), 859(\mathrm{w}), 792(\mathrm{w}), 771(\mathrm{~m}), 733(\mathrm{~m}), 588(\mathrm{w}), 572(\mathrm{w}), 536(\mathrm{w}) \cdot \mu_{\mathrm{eff}}$ (Evans method, $298 \mathrm{~K}, \mathrm{THF}): 4.29 \mu \mathrm{B}$.

Preparation of [Dy(BIPM $\left.\left.{ }^{\text {Mes }} \mathbf{H}\right)_{2}\right]\left[\right.$ [BIPM $\left.{ }^{\text {Mes }} \mathbf{H}\right](\mathbf{5 a})$ : THF $(20 \mathrm{~mL})$ was added to a precooled $\left(-78^{\circ} \mathrm{C}\right)$ mixture of $\left[\left\{\mathrm{K}\left(\mathrm{BIPM}^{\mathrm{Mes}} \mathrm{H}\right)\right\}_{2}\right](0.69 \mathrm{~g}, 0.50 \mathrm{mmol})$ and $\left[\mathrm{Dy}(\mathrm{I})_{3}(\mathrm{THF})_{3.5}\right](0.80 \mathrm{~g}, 1.00 \mathrm{mmol})$ and the resulting mixture was allowed to raise to room temperature with stirring over $18 \mathrm{~h}$. The mixture was filtered to remove $\mathrm{KI}$ and volatiles removed in vacuo to yield a pale yellow solid. Recrystallisation from a hot toluene solution $(3 \mathrm{ml})$ afforded $\mathbf{5 a} 4 \mathrm{C}_{7} \mathrm{H}_{8}$ as yellow crystals on cooling to ambient temperature. Yield $0.32 \mathrm{~g}, 39 \%$. Anal. Calcd for $\mathrm{C}_{157} \mathrm{H}_{161} \mathrm{DyN}_{6} \mathrm{P}_{6}$ : C, 76.03; H, 6.54; N, 3.39. Found: C, 69.03; H, 6.72; N, 3.58. Despite repeated attempts more satisfactory elemental analyses could not be obtained, with the low carbon value ascribed to carbide formation [31] causing incomplete combustion during analysis. FTIR v/cm ${ }^{-1}$ (Nujol): 1604 (w), 1587 (w), 1573 (w), 1435 (m), 1332 (w), 1208 (m), 1154 (w), 972 (w), 940 (w), 853 (w) 739 (m), 694 (m). $\mu_{\text {eff }}$ (Evans method, 298 K, $\mathrm{C}_{6} \mathrm{D}_{6}$ ): $9.81 \mu_{\mathrm{B}}$.

Preparation of [Er(BIPM $\left.\left.{ }^{\text {Mes }} \mathbf{H}\right)_{2}\right]\left[\mathbf{B I P M}^{\mathrm{Mes}} \mathbf{H}\right](\mathbf{5 b})$ : THF $(20 \mathrm{~mL})$ was added to a precooled $\left(-78^{\circ} \mathrm{C}\right)$ mixture of $\left[\operatorname{Er}(\mathrm{I})_{3}(\mathrm{THF})_{3.5}\right](1.20 \mathrm{~g}, 1.50 \mathrm{mmol})$ and $\left[\left\{\mathrm{K}\left(\mathrm{BIPM}^{\mathrm{Mes}} \mathrm{H}\right)\right\}_{2}\right](1.05 \mathrm{~g}, 0.75 \mathrm{mmol})$, and the resultant beige mixture allowed to raise to room temperature with stirring over $72 \mathrm{~h}$. The resulting suspension was filtered and volatiles were removed in vacuo to afford a pink solid. The solid was washed with hexanes and recrystallised from hot toluene $(15 \mathrm{~mL})$ to afford $\mathbf{5 b} 5 \mathrm{C}_{7} \mathrm{H}_{8}$ as 
pale yellow crystals on cooling to $-30{ }^{\circ} \mathrm{C}$. Yield $0.40 \mathrm{~g}, 31 \%$. Anal. Calcd for $\mathrm{C}_{164} \mathrm{H}_{169} \mathrm{ErN}_{6} \mathrm{P}_{6}$ : $\mathrm{C}$, 76.43; H, 6.61; N, 3.26. Found: C, 76.32: H, 6.48: N, 3.37. FTIR v/cm ${ }^{-1}$ (Nujol): 1261 (s), 1205 (w), 1098 (s), 1020 (s), 971 (w), 853 (w), 800 (s), 694 (m), 525 (m). $\mu_{\text {eff }}$ (Evans method, 298 K, THF): $10.25 \mu \mathrm{B}$.

\section{Preparation of $\left[\mathrm{La}\left(\mathrm{BIPM}^{\mathrm{Mes}} \mathrm{H}\right)(\mathrm{I})_{2}(\mathrm{TMEDA})\right](6 \mathrm{a})$ and $\left[\mathrm{Gd}\left(\mathrm{BIPM}^{\mathrm{Mes}} \mathrm{H}\right)(\mathrm{I})_{2}(\mathrm{TMEDA})\right](6 \mathrm{~b})$ :} Complexes $\mathbf{6 a}$ and $\mathbf{6 b}$ were prepared by the dissolution of $\left[\mathrm{Ln}\left(\mathrm{BIPM}^{\mathrm{Mes}} \mathrm{H}\right)(\mathrm{I})_{2}(\mathrm{THF})\right](\mathrm{Ln}=\mathrm{La}, \mathrm{Gd})$ in a THF/TMEDA solution followed by stirring for $18 \mathrm{~h}$. In each case all volatiles were removed in vacuo to afford $\mathbf{6 a}(\mathrm{Ln}=\mathrm{La})$ or $\mathbf{6 b}(\mathrm{Ln}=\mathrm{Gd})$ as off-white and yellow solids, respectively, in quantitative yield. Recrystallisation of a small portion of each sample from toluene afforded crops of crystals of $\mathbf{6 a} 3 \mathrm{C}_{7} \mathrm{H}_{8}$ and $\mathbf{6} \mathbf{b} 2 \mathrm{C}_{7} \mathrm{H}_{8}$, respectively, suitable for single crystal X-ray diffraction studies. Data for $6 \mathbf{6} 3 \mathrm{C}_{7} \mathrm{H}_{8}$ : Anal. Calcd for $\mathrm{C}_{70} \mathrm{H}_{83} \mathrm{I}_{2} \mathrm{LaN}_{4} \mathrm{P}_{2}$ : C, 58.59; H, 5.83; N, 3.90. Found: C, 58.47; H, 5.93; N, 4.02. ${ }^{1} \mathrm{H}$ NMR (298 K, C6 6 ): 1.65-2.40 (34 H, m, br, Mes-CH3, $\mathrm{NCH}_{2}, \mathrm{NCH}_{3}$ ), $3.91\left(1 \mathrm{H}, \mathrm{t},{ }^{2} \mathrm{~J}_{\mathrm{PH}}=8.8 \mathrm{~Hz}, H \mathrm{CP}_{2}\right), 6.55-7.15(24 \mathrm{H}, \mathrm{m}, \mathrm{br}, \mathrm{Ar}-H) .{ }^{13} \mathrm{C}\left\{{ }^{1} \mathrm{H}\right\} \mathrm{NMR}\left(298 \mathrm{~K}, \mathrm{C}_{6} \mathrm{D}_{6}\right)$ : $8.44\left(\mathrm{CH}, \mathrm{t}, J_{\mathrm{PC}}=138 \mathrm{~Hz}, \mathrm{HCP}\right), 20.51\left(\mathrm{Mes}-\mathrm{CH}_{3}\right), 20.65\left(\mathrm{Mes}-\mathrm{CH}_{3}\right), 21.18\left(\mathrm{Mes}-\mathrm{CH}_{3}\right), 21.44$ $\left(\mathrm{Mes}-\mathrm{CH}_{3}\right), 49.84\left(\mathrm{NCH}_{3}\right), 57.87\left(\mathrm{NCH}_{2}\right), 125.44(\mathrm{Ar}-\mathrm{CH}), 125.82(\mathrm{Ar}-\mathrm{C}), 129.08(\mathrm{Ar}-\mathrm{CH})$, 129.81 (Ar-CH), 130.61 (Ar-CH), 131.11 (Ar-CH), 131.31 (Ar-CH), 132.17 (Ar-C), 132.58 (Ar-CH), 135.53 (Ar-C), 137.64 (Ar-C), 142.50 (Ar-C). ${ }^{31} \mathrm{P}\left\{{ }^{1} \mathrm{H}\right\}$ NMR (298 K, $\left.\mathrm{C}_{6} \mathrm{D}_{6}\right)$ : 15.70 (s). FTIR $v / \mathrm{cm}^{-1}$ (Nujol): 3053 (w), 1436 (m), 1215 (m), 1158 (m), 401 (m). As full spectroscopic data supported the formulation of $\mathbf{6 a}$, full spectroscopic data was not obtained for paramagnetic $\mathbf{6 b}$ which was subsequently prepared and utilised in situ. During our investigations we attempted many preparations of $\left[\mathrm{Ln}\left(\mathrm{BIPM}^{\mathrm{Mes}}\right)(\mathrm{I})(\mathrm{THF})_{n}\right](\mathrm{Ln}=\mathrm{La}, \mathrm{Ce}, \mathrm{Pr}, \mathrm{Gd})$ utilising a range of methanide precursors including $\left[\mathrm{Ln}\left(\mathrm{BIPM}^{\mathrm{Mes}}\right)(\mathrm{I})_{2}(\mathrm{THF})_{2}\right] \quad(\mathrm{Ln}=\mathrm{La}, \mathrm{Ce}, \mathrm{Pr}, \mathrm{Gd})$ and $\left[\mathrm{Ln}\left(\mathrm{BIPM}^{\mathrm{Mes}}\right)(\mathrm{I})_{2}(\mathrm{TMEDA})\right](\mathrm{Ln}=\mathrm{La}, \mathbf{6 a} ; \mathrm{Gd}, \mathbf{6 b})$ and bases including $[\mathrm{K}(\mathrm{Bn})],\left[\mathrm{K}\left\{\mathrm{CHPh}_{2}\right\}\right]$ and $\left[\mathrm{K}\left\{\mathrm{C}(\mathrm{Ph})_{3}\right\}\right]$. In each case $\left[\mathrm{Ln}\left(\mathrm{BIPM}^{\mathrm{Mes}}\right)(\mathrm{I})(\mathrm{THF})_{n}\right]$ was not isolated cleanly with mixtures of products observed in each case. The sole isolable products from these reactions were $\left[\mathrm{Ln}\left(\mathrm{BIPM}^{\mathrm{Mes}} \mathrm{H}\right)\left(\mathrm{BIPM}^{\mathrm{Mes}}\right)\right](\mathrm{Ln}=\mathrm{La}, \mathbf{7 a} ; \mathrm{Ce}, \mathbf{7 b} ; \mathrm{Pr}, \mathbf{7 c} ; \mathrm{Gd}, \mathbf{7 d})$, with representative preparations of $7 \mathbf{a}$ and $7 \mathbf{b}$ given below.

Preparation of [ $\left.\mathbf{L a}\left(\mathbf{B I P M}^{\mathrm{Mes}} \mathbf{H}\right)\left(\mathrm{BIPM}^{\mathrm{Mes}}\right)\right]$ (7a): THF $(15 \mathrm{~mL})$ was added to a pre-cooled $\left(-78{ }^{\circ} \mathrm{C}\right)$ mixture of $\left[\mathrm{La}\left(\mathrm{BIPM}^{\mathrm{Mes}} \mathrm{H}\right)(\mathrm{I})_{2}(\mathrm{THF})\right] 3$ toluene $(0.71 \mathrm{~g}, 0.49 \mathrm{mmol})$ and $\left[\mathrm{K}\left(\mathrm{CHPh}_{2}\right)\right](0.10 \mathrm{~g}, 0.49$ $\mathrm{mmol})$. The resulting orange suspension was stirred at this temperature for $10 \mathrm{~m}$ and then raised to room temperature with stirring over $18 \mathrm{~h}$. The resulting deep brown suspension was filtered to remove $\mathrm{KI}$ and all volatiles removed in vacuo to afford a brown solid. Recrystallisation from toluene $(4 \mathrm{~mL})$ afforded colourless crystals of $7 \mathbf{a} 3 \mathrm{C}_{7} \mathrm{H}_{8}$. Yield $70 \mathrm{mg}, 8 \%$. Anal. Calcd for $\mathrm{C}_{107} \mathrm{H}_{109} \mathrm{LaN}_{4} \mathrm{P}_{4}: \mathrm{C}, 74.99 ; \mathrm{H}, 6.41 ; \mathrm{N}, 3.27$. Found: C, 74.77; H, 6.78; N, 3.17. ${ }^{1} \mathrm{H}$ NMR (d6-benzene, $298 \mathrm{~K}): \delta 2.10\left(12 \mathrm{H}\right.$, s, br, o-Mes-CH3), $2.26\left(1 \mathrm{H}, \mathrm{s}, \mathrm{HCP}_{2}\right), 2.37(12 \mathrm{H}$, s, br, $o$-Mes- $\left.\mathrm{CH}_{3}\right), 2.46$ (6 H, s, p-Mes-CH3), 2.57 (6 H, s, p-Mes-CH3), 6.6-7.1 (28 H, m, br, Ar- $\mathrm{CH}$ ), $7.37(8 \mathrm{H}, \mathrm{s}, \mathrm{br}, \mathrm{Ar}-\mathrm{CH}), 7.6-7.9(12 \mathrm{H}, \mathrm{m}, \mathrm{br}, \mathrm{Ar}-\mathrm{CH}) .{ }^{13} \mathrm{C}\left\{{ }^{1} \mathrm{H}\right\}$ NMR $\left(d_{6}\right.$-benzene, $\left.298 \mathrm{~K}\right): \delta 4.59$ $\left(\mathrm{t}, J_{\mathrm{PC}}=127 \mathrm{~Hz}, \mathrm{HCP}\right), 20.67\left(\mathrm{Mes}-\mathrm{CH}_{3}\right), 20.83\left(\mathrm{Mes}-\mathrm{CH}_{3}\right), 21.20\left(\mathrm{Mes}-\mathrm{CH}_{3}\right), 22.80\left(\mathrm{Mes}-\mathrm{CH}_{3}\right)$, 45.06 (s, $C \mathrm{P}_{2}$ ), 125.45 (Ar-C), 126.09 (Ar-C), 126.75 (Ar-CH), 128.09 (m, Ar- $\left.\mathrm{CH}\right), 129.03$ (Ar- $\left.\mathrm{CH}\right)$, $129.64(\mathrm{Ar}-\mathrm{CH}), 130.34(\mathrm{Ar}-\mathrm{CH}), 130.57(\mathrm{Ar}-\mathrm{CH}), 131.12(\mathrm{Ar}-\mathrm{CH}), 132.17(\mathrm{Ar}-\mathrm{CH}), 134.54(\mathrm{Ar}-\mathrm{C})$, 
135.18 (br, Ar-C), 137.65 (Ar-C), 143.07 (Ar-C). ${ }^{31} \mathrm{P}\left\{{ }^{1} \mathrm{H}\right\}$ NMR (d6-benzene, $\left.298 \mathrm{~K}\right): 2.88\left(\mathrm{CP}_{2}\right)$, $10.51\left(\mathrm{HCP}_{2}\right)$. FTIR v/cm-1 (Nujol): 1589 (w), 1261 (s), 1098 (s), 1020 (s), 854 (w), 800 (s), 663 (m).

Preparation of $\left[\mathbf{C e}\left(\mathbf{B I P M}^{\mathrm{Mes}} \mathbf{H}\right)\left(\mathbf{B I P M}^{\mathrm{Mes}}\right)\right] \mathbf{( 7 b )}$ : THF $(25 \mathrm{~mL})$ was added to a pre-cooled $\left(-78^{\circ} \mathrm{C}\right)$ mixture of $\left[\mathrm{Ce}\left(\mathrm{BIPM}^{\mathrm{Mes}} \mathrm{H}\right)(\mathrm{I})_{2}(\mathrm{THF})\right](3.00 \mathrm{~g}, 2.54 \mathrm{mmol})$ and $[\mathrm{K}(\mathrm{Bn})](0.33 \mathrm{~g}, 2.54 \mathrm{mmol})$ and the resulting mixture allowed to warm to room temperature with stirring over $20 \mathrm{~h}$. The resulting mixture was filtered and all volatiles removed in vacuo to afford a brown solid. The solid was washed with hexanes and the resulting brown powder was recrystallised from toluene $(5 \mathrm{~mL})$ to afford $7 \mathbf{b} 3 \mathrm{C}_{7} \mathrm{H}_{8}$ as yellow crystals, as identified by unit cell check [32]. Yield $0.10 \mathrm{~g}, 3 \%$. On standing, the hexanes extract yielded $7 \mathbf{b} 2 \mathrm{C}_{6} \mathrm{H}_{14}$ as yellow crystals suitable for single crystal X-ray diffraction studies. Yield 0.14 g, 4\%. Anal. Calcd for $\mathrm{C}_{86} \mathrm{H}_{85} \mathrm{CeN}_{4} \mathrm{P}_{4}$ : C, 71.80; H, 5.96; N, 3.89. Found: C, 71.67; H, 5.88; N, 3.79. FTIR v/cm-1 (Nujol): 1261 (m), 1212 (m), 1153 (m), 1099 (s), 1019 (s), 800 (s), 721 (w), 694 (w), 519 (w). $\mu_{\text {eff }}$ (Evans method, 298 K, THF): $1.88 \mu_{\mathrm{B}}$.

\section{X-ray Crystallography}

Crystal data for compounds $\mathbf{1 - 7} \mathbf{d}$ are given in Table S2. Bond lengths and angles are listed in Table S1. Crystals were examined variously on a Bruker APEX CCD area detector diffractometer using graphite-monochromated MoK $\alpha$ radiation $(\lambda=0.71073 \AA)$, or on an Oxford Diffraction SuperNova Atlas CCD diffractometer using mirror-monochromated $\mathrm{CuK} \alpha$ radiation $(\lambda=1.5418 \AA)$. Intensities were integrated from data recorded on 0.3 (APEX) or $1^{\circ}$ (SuperNova) frames by $\omega$ rotation. Cell parameters were refined from the observed positions of all strong reflections in each data set. Semi-empirical absorption correction based on symmetry-equivalent and repeat reflections (APEX) or Gaussian grid face-indexed absorption correction with a beam profile correction (Supernova), were applied. The structures were solved variously by direct and heavy atom methods and were refined by full-matrix least-squares on all unique $F^{2}$ values, with anisotropic displacement parameters for all non-hydrogen atoms, and with constrained riding hydrogen geometries; $U_{\text {iso }}(\mathrm{H})$ was set at 1.2 (1.5 for methyl groups) times $U_{\text {eq }}$ of the parent atom. The largest features in final difference syntheses were close to heavy atoms and were of no chemical significance. The data-set obtained for $\mathbf{4}$ is of low quality, and while the connectivity is clear, no assessment could be made of the geometric parameters, and despite exhaustive attempts, a better data-set could not be obtained. Highly disordered solvent molecules of crystallisation in $\mathbf{4}$ and $\mathbf{7 a - d}$ could not be modelled and were treated with the Platon SQUEEZE procedure [33]. Programs were Bruker AXS SMART [34] and CrysAlisPro (control) [35], Bruker AXS SAINT [34] and CrysAlisPro (integration) [35], and SHELXTL [36] and OLEX2 [37] were employed for structure solution and refinement and for molecular graphics. Crystal data have been deposited with the Cambridge Structural Database CCDC numbers 970500-970513.

\section{Conclusions}

We have successfully extended the series of $\left\{\mathrm{BIPM}^{\mathrm{TMS}} \mathrm{H}\right\}^{-}$derived rare earth methanides by the preparation of $\left[\mathrm{Ln}\left(\mathrm{BIPM}^{\mathrm{TMS}} \mathrm{H}\right)(\mathrm{I})_{2}(\mathrm{THF})\right](\mathrm{Ln}=\mathrm{Nd}, \mathrm{Gd}, \mathrm{Tb}), \mathbf{1 a}-\mathbf{c}$, in moderate to good yields. Similarly, we have successfully extended the range of $\left\{\mathrm{BIPM}^{\mathrm{Mes}} \mathrm{H}\right\}^{-}$derived rare earth methanides 
with the preparation of $\left[\mathrm{Gd}\left(\mathrm{BIPM}^{\mathrm{Mes}} \mathrm{H}\right)(\mathrm{I})_{2}(\mathrm{THF})_{2}\right], \mathbf{3}$, and $\left[\mathrm{Yb}\left(\mathrm{BIPM}^{\mathrm{Mes}} \mathrm{H}\right)(\mathrm{I})_{2}(\mathrm{THF})\right]$, 4, but solubility issues of $\left[\mathrm{Ln}(\mathrm{I})_{3}(\mathrm{THF})_{3.5}\right]$ prevented the preparation of dysprosium and erbium analogues, with $\left[\operatorname{Ln}\left(\mathrm{BIPM}^{\mathrm{Mes}} \mathrm{H}\right)_{2}\right]\left[\left(\mathrm{BIPM}^{\mathrm{Mes}} \mathrm{H}\right)\right],(\mathrm{Ln}=\mathrm{Dy}, \mathbf{5 a} ; \mathrm{Er}, \mathbf{5 b})$ being the only isolable products of these reactions. Dissolution of $\left[\operatorname{Ln}\left(\mathrm{BIPM}^{\mathrm{Mes}} \mathrm{H}\right)(\mathrm{I})_{2}(\mathrm{THF})\right](\mathrm{Ln}=\mathrm{La}$, Gd $)$ in a TMEDA/THF solution afforded the TMEDA adduct complexes [ $\left.\operatorname{Ln}\left(\mathrm{BIPM}^{\mathrm{Mes}} \mathrm{H}\right)(\mathrm{I})_{2}(\mathrm{TMEDA})\right]$ $(\mathrm{Ln}=\mathrm{La}, \mathbf{6 a} ; \mathrm{Gd}, \mathbf{6 b})$ in essentially quantitative yields. Attempts to prepare [La(BIPM $\left.\left.{ }^{\mathrm{Mes}}\right)(\mathrm{I})(\mathrm{S}) n\right]$ and other rare earth analogues were not successful, with the reactions of $\left[\operatorname{Ln}\left(\mathrm{BIPM}^{\mathrm{Mes}} \mathrm{H}\right)(\mathrm{I})_{2}(\mathrm{~S})\right]$ ( $\mathrm{Ln}=\mathrm{La}, \mathrm{Ce}, \mathrm{Pr}, \mathrm{Gd} ; \mathrm{S}=$ THF or TMEDA) with a range of bases yielding mixtures of products, of which, only $\left[\mathrm{Ln}\left(\mathrm{BIPM}^{\mathrm{Mes}}\right)\left(\mathrm{BIPM}^{\mathrm{Mes}} \mathrm{H}\right)\right](\mathrm{Ln}=\mathrm{La}, \mathbf{7 a} ; \mathrm{Ce}, \mathbf{7 b} ; \mathrm{Pr}, \mathbf{7 c} ; \mathrm{Gd}, \mathbf{7 d})$ could be identified.

\section{Acknowledgments}

We thank the Royal Society for a University Research Fellowship (S.T.L.), and the EPSRC, European Research Council, and the University of Nottingham for generously supporting this work.

\section{Conflicts of Interest}

The authors declare no conflict of interest.

\section{References}

1. Aparna, K.; Ferguson, M.; Cavell, R.G. A Monomeric Samarium Bis(Iminophosphorano) Chelate Complex with a Sm=C Bond. J. Am. Chem. Soc. 2000, 122, 726-727.

2. Liddle, S.T.; Mills, D.P.; Wooles, A.J. Bis(phosphorus-stabilized)methanide and methandiide derivatives of Group 1-5 and f-element metals. Organomet. Chem. 2010, 36, 29-55.

3. Liddle, S.T.; Mills, D.P.; Wooles, A.J. Early metal bis(phosphorus-stabilized)carbene chemistry. Chem. Soc. Rev. 2011, 40, 2164-2176.

4. Roesky, P.W. Bis(phosphinimino)methanides as ligands in the chemistry of the rare earth elements. Z. Anorg. Allg. Chem. 2006, 632, 1918-1926.

5. Rastätter, M.; Zulys, A.; Roesky, P.W. A bis(phosphinimino)methanide lanthanum amide as catalyst for the hydroamination/cyclisation, hydrosilylation and sequential hydroamination/hydrosilylation catalysis. Chem. Commun. 2006, 874-876.

6. Ahmed, S.A.; Hill, M.S.; Hitchcock, P.B. Synthesis and $\mathrm{M}-\mathrm{C} \gamma$ Hemilability of Group 2 Bis(phosphinimino)methanides. Organometallics 2006, 25, 394-402.

7. Liddle, S.T.; Mills, D.P.; Gardner, B.M.; McMaster, J.; Jones, C.; Woodul, W.D. A Heterobimetallic Gallyl Complex Containing an Unsupported Ga-Y Bond. Inorg. Chem. 2009, 48, 3520-3522.

8. Mills, D.P.; Soutar, L.; Lewis, W.; Blake, A.J.; Liddle, S.T. Regioselective C-H Activation and Sequential C-C and C-O Bond Formation Reactions of Aryl Ketones Promoted by an Yttrium Carbene. J. Am. Chem. Soc. 2010, 132, 14379-14381. 
9. Mills, D.P.; Soutar, L.; Cooper, O.J.; Lewis, W.; Blake, A.J.; Liddle, S.T. Reactivity of the Yttrium Alkyl Carbene Complex [Y(BIPM) $\left.\left(\mathrm{CH}_{2} \mathrm{C}_{6} \mathrm{H}_{5}\right)(\mathrm{THF})\right]$ (BIPM = $\left.\left\{\mathrm{C}\left(\mathrm{PPh}_{2} \mathrm{NSiMe}_{3}\right)_{2}\right\}\right)^{2-}$ : From Insertions, Substitutions, and Additions to Nontypical Transformations. Organometallics 2013, 32, 1251-1264.

10. Mills, D.P.; Lewis, W.; Blake, A.J.; Liddle, S.T. Reactivity Studies of a T-Shaped Yttrium Carbene: $\mathrm{C}-\mathrm{F}$ and $\mathrm{C}-\mathrm{O}$ Bond Activation and $\mathrm{C}=\mathrm{C}$ Bond Formation Promoted by $\left[\mathrm{Y}(\mathrm{BIPM})(\mathrm{I})(\mathrm{THF})_{2}\right]\left(\mathrm{BIPM}=\mathrm{C}\left(\mathrm{PPh}_{2} \mathrm{NSiMe}_{3}\right)_{2}\right)$. Organometallics 2013, 32, 1239-1250.

11. Gregson, M.; Lu, E.; McMaster, J.; Lewis, W.; Blake, A.J.; Liddle, S.T. A Cerium(IV)-Carbon Multiple Bond. Angew. Chem. Int. Ed. 2013, 52, 13016-13019.

12. Wooles, A.J.; Cooper, O.J.; McMaster, J.; Lewis, W.; Blake, A.J.; Liddle, S.T. Synthesis and Characterization of Dysprosium and Lanthanum Bis(iminophosphorano)methanide and -methanediide Complexes. Organometallics 2010, 29, 2315-2321.

13. Wooles, A.J.; Gregson, M.; Cooper, O.J.; Middleton-Gear, A.; Mills, D.P.; Lewis, W.; Blake, A.J.; Liddle, S.T. Group 1 Bis(iminophosphorano)methanides, Part 1: N-Alkyl and Silyl Derivatives of the Sterically Demanding Methanes $\mathrm{H}_{2} \mathrm{C}\left(\mathrm{PPh}_{2} \mathrm{NR}\right)_{2}(\mathrm{R}=$ Adamantyl and Trimethylsilyl). Organometallics 2011, 30, 5314-5325.

14. Wooles, A.J.; Gregson, M.; Robinson, S.; Cooper, O.J.; Mills, D.P.; Lewis, W.; Blake, A.J.; Liddle, S.T. Group 1 Bis(iminophosphorano)methanides, Part 2: N-Aryl Derivatives of the Sterically Demanding Methanes $\mathrm{H}_{2} \mathrm{C}\left(\mathrm{PPh}_{2} \mathrm{NR}\right)_{2} \quad(\mathrm{R}=$ 2,4,6-trimethylphenyl or 2,6diisopropylphenyl). Organometallics 2011, 30, 5326-5337.

15. Mills, D.P.; Wooles, A.J.; McMaster, J.; Lewis, W.; Blake, A.J.; Liddle, S.T. Heteroleptic $\left[\mathrm{M}\left(\mathrm{CH}_{2} \mathrm{C}_{6} \mathrm{H}_{5}\right)_{2}(\mathrm{I})(\mathrm{THF})_{3}\right]$ Complexes $(\mathrm{M}=\mathrm{Y}$ or Er): Remarkably Stable Precursors to Yttrium and Erbium T-Shaped Carbenes. Organometallics 2009, 28, 6771-6776.

16. Wooles, A.J.; Mills, D.P.; Lewis, W.; Blake, A.J.; Liddle, S.T. Lanthanide tri-benzyl complexes: structural variations and useful precursors to phosphorus-stabilised lanthanide carbenes. Dalton Trans. 2010, 39, 500-510.

17. Liddle, S.T.; McMaster, J.; Green, J.C.; Arnold, P.L. Synthesis and structural characterisation of an yttrium-alkyl-alkylidene. Chem. Commun. 2008, 1747-1749.

18. Mills, D.P.; Cooper, O.J.; McMaster, J.; Lewis, W.; Liddle, S.T. Synthesis and reactivity of the yttrium-alkyl-carbene complex $\left[\mathrm{Y}(\mathrm{BIPM})\left(\mathrm{CH}_{2} \mathrm{C}_{6} \mathrm{H}_{5}\right)(\mathrm{THF})\right]\left(\mathrm{BIPM}=\left\{\mathrm{C}\left(\mathrm{PPh}_{2} \mathrm{NSiMe}_{3}\right)_{2}\right\}\right)$. Dalton Trans. 2009, 4547-4555.

19. Cotton, S. Lanthanide and Actinide Chemistry; Wiley: Chichester, UK, 2006.

20. Gamer, M.T.; Dehnen, S.; Roesky, P.W. Synthesis and Structure of Yttrium and Lanthanide Bis(phosphinimino)methanides. Organometallics 2001, 20, 4230-4236.

21. Evans, W.J.; Lee, D.S.; Rego, D.B.; Perotti, J.M.; Kozimor, S.A.; Moore, E.K.; Ziller, J.W. Expanding Dinitrogen Reduction Chemistry to Trivalent Lanthanides via the $\mathrm{LnZ}_{3} / \mathrm{Alkali}$ Metal Reduction System: Evaluation of the Generality of Forming $\operatorname{Ln} 2\left(\mu-\eta^{2}: \eta^{2}-N_{2}\right)$ Complexes via LnZ3/K. J. Am. Chem. Soc. 2004, 126, 14574-14582.

22. Cordero, B.; Gomez, V.; Platero-Prats, A.E.; Reves, M.; Echeverria, J.; Cremades, E.; Barragan, F.; Alvarez, S. Covalent radii revisited. Dalton Trans. 2008, 2832-2838. 
23. Shannon, R.D. Revised effective ionic radii and systematic studies of interatomic distances in halides and chalcogenides. Acta Crystallogr. Sect. A 1976, A32, 751-767.

24. Allen, F.H. The Cambridge Structural Database: A quarter of a million crystal structures and rising. Acta Crystallogr. Sect. B 2002, 58, 380-388.

25. Izod, K.; Liddle, S.T.; Clegg, W. A Convenient Route to Lanthanide Triiodide THF Solvates. Crystal Structures of $\mathrm{LnI}_{3}(\mathrm{THF})_{4}[\mathrm{Ln}=\mathrm{Pr}]$ and $\mathrm{LnI}_{3}(\mathrm{THF})_{3.5}[\mathrm{Ln}=\mathrm{Nd}, \mathrm{Gd}, \mathrm{Y}]$. Inorg. Chem. 2004, 43, 214-218.

26. Hill, M.S.; Hitchcock, P.B.; Karagouni, S.M. A. Group 1 and 13 complexes of aryl-substituted bis(phosphinimino)methyls. J. Organomet. Chem. 2004, 689, 722-730.

27. Hill, M.S.; Hitchcock, P.B. Synthesis of a homoleptic Sm(II) bis(phosphinimino)methanide. Dalton Trans. 2003, 4570-4571.

28. Evans, D.F. The determination of the paramagnetic susceptibility of substances in solution by nuclear magnetic resonance. J. Chem. Soc. (Resumed) 1959, 2003-2005.

29. Vleck, J.H.V. Theory of Electric and Magnetic Susceptibilities; Oxford University Press: Oxford, UK, 1932.

30. Schlosser, M.; Hartmann, J. Transmetalation and Double Metal Exchange: A Convenient Route to Organolithium Compounds of the Benzyl and Allyl Type. Angew. Chem. Int. Ed. Engl. 1973, 12, 508-509.

31. Hitchcock, P.B.; Lappert, M.F.; Maron, L.; Protchenko, A.V.; Lanthanum Does Form Stable Molecular Compounds in the +2 Oxidation State. Angew. Chem. Int. Ed. 2008, 47, 1488-1491.

32. Crystals of $7 \mathbf{b} 3 \mathrm{C}_{7} \mathrm{H}_{8}$ were identified by unit cell check comparisons to $\mathrm{La}, \operatorname{Pr}$ and Gd analogues.

33. Spek, A.L. Platon, version 1.17; University of Utrecht, Utrecht, The Netherlands, 2000.

34. SMART and SAINT Bruker AXS Inc.: Madison, WI, USA, 2001.

35. CrysAlis PRO; version1.171.35.19; Agilent Technologies: Yarnton, UK, 2010.

36. Sheldrick, G.M. A short history of SHELX. Acta Crystallogr. Sect. A 2008, A64, 112-122.

37. Dolomanov, O.V.; Bourhis, L.J.; Gildea, R.J.; Howard, J.A.K.; Puschmann, H. OLEX2: A complete structure solution, refinement and analysis program. J. Appl. Crystallogr. 2009, 42, 339-341. 


\title{
Facile and Selective Synthetic Approach for Ruthenium Complexes Utilizing a Molecular Sieve Effect in the Supporting Ligand
}

\section{Dai Oyama, Ayumi Fukuda, Takashi Yamanaka and Tsugiko Takase}

\begin{abstract}
It is extremely important for synthetic chemists to control the structure of new compounds. We have constructed ruthenium-based mononuclear complexes with the tridentate 2,6di(1,8-naphthyridin-2-yl)pyridine (dnp) ligand to investigate a new synthetic approach using a specific coordination space. The synthesis of a family of new ruthenium complexes containing both the dnp and triphenylphosphine $\left(\mathrm{PPh}_{3}\right)$ ligands, $\left[\mathrm{Ru}(\mathrm{dnp})\left(\mathrm{PPh}_{3}\right)(\mathrm{X})(\mathrm{L})\right]^{n^{+}}\left(\mathrm{X}=\mathrm{PPh}_{3}, \mathrm{NO}_{2}{ }^{-}, \mathrm{Cl}^{-}, \mathrm{Br}^{-}\right.$; $\mathrm{L}=\mathrm{OH}_{2}, \mathrm{CH}_{3} \mathrm{CN}, \mathrm{C}_{6} \mathrm{H}_{5} \mathrm{CN}, \mathrm{SCN}^{-}$), has been described. All complexes have been spectroscopically characterized in solution, and the nitrile complexes have also been characterized in the solid state through single-crystal X-ray diffraction analysis. Dnp in the present complex system behaves like a "molecular sieve" in ligand replacement reactions. Both experimental data and density functional theory (DFT) calculations suggest that dnp plays a crucial role in the selectivity observed in this study. The results provide useful information toward elucidating this facile and selective synthetic approach to new transition metal complexes.
\end{abstract}

Reprinted from Inorganics. Cite as: Oyama, D.; Fukuda, A.; Yamanaka, T.; Takase, T. Facile and Selective Synthetic Approach for Ruthenium Complexes Utilizing a Molecular Sieve Effect in the Supporting Ligand. Inorganics 2013, 1, 32-45.

\section{Introduction}

A more accurate regulation of the structure leads to the construction of appropriate reaction systems. For example, some isomeric pairs of $[\mathrm{Ru}(\mathrm{tpy})(\mathrm{L}) \mathrm{Cl}]^{n^{+}}$type complexes (tpy $=2,2^{\prime}: 6^{\prime}, 2^{\prime \prime}-$ terpyridine, $\mathrm{L}=$ asymmetrical pyridyl-based bidentate ligands; quinaldic acid (qu) and 2-(1-methyl3-pyrazolyl)pyridine (pypz-Me)) have been prepared and structurally characterized as precatalysts to investigate the effect of isomeric structural features on the catalytic epoxidation process $[1,2]$. In the complex $\left[\mathrm{Ru}(\mathrm{tpy})(\mathrm{qu})\left(\mathrm{OH}_{2}\right)\right]^{+}$, the cis isomer has been established to be an excellent catalyst for the chemoselective epoxidation through limited differences in electronic structural features exist between the isomeric pair [1]. In the complex $\left[\mathrm{Ru}(\mathrm{tpy})(\mathrm{pypz}-\mathrm{Me})\left(\mathrm{OH}_{2}\right)\right]^{2+}$, on the other hand, the trans isomer exhibits better activity because it contains a pyridine $\mathrm{C}-\mathrm{H}$ bond nearly parallel to the $\mathrm{Ru}-\mathrm{O}$ bond, whereas for the $c i$ is isomer this position is occupied by a $\mathrm{C}-\mathrm{CH}_{3}$ group and thus exerts a much stronger steric effect [2]. These examples indicate that it is important to clearly distinguish the molecular structures of the compounds. Therefore, much attention has been paid to study both facile and selective synthesis for complex compounds.

In an effort to discover new molecular systems, we have recently reported ruthenium-based mononuclear complexes with the pyridyl-bridged di(1,8-naphthyridin-2-yl) (dnp) ligand [3]. The tridentate dnp has two noncoordinating nitrogen atoms and is able to form intramolecular hydrogen bonds between the coordinated water and dnp. In addition, dnp has a narrower coordination space 
on the equatorial site than the parent ligand, tpy (Chart 1). Therefore, size complementarity of the entering molecule with the coordination space of dnp plays an important role and is apparent in size-selective recognition of entering molecules such as nitriles and halides. We report that dnp in the present complex system behaves like a "molecular sieve" in ligand replacements and it leads to a facile and selective synthesis of a new family of ruthenium complexes.

Chart 1. Chemical structures of tpy (left) and dnp (right).

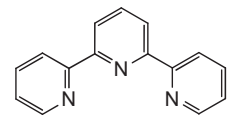

tpy

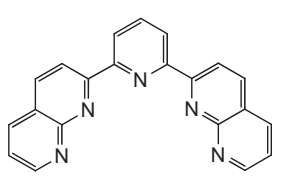

$\operatorname{dnp}$

\section{Results and Discussion}

\subsection{Synthesis of Ruthenium Complexes Utilizing the Molecular Sieve Effect of the dnp Ligand}

\subsubsection{Synthesis of the Precursor}

Dnp was prepared by the Friedländer condensation of two equivalents of 2aminonicotinaldehyde with 2,6-diacetylpyridine according to procedures that have been reported earlier [4,5]. Precursor 1 was synthesized by treating $\left[\mathrm{RuCl}_{2}\left(\mathrm{CH}_{3} \mathrm{CN}\right)_{2}\left(\mathrm{PPh}_{3}\right)_{2}\right]$ [6] with dnp in an ethanolic solution (Scheme 1). The analogous complexes containing tpy initially formed chlorido complexes, which can only be hydrated with the assistance of the silver ion to cleave the $\mathrm{Ru}-\mathrm{Cl}$ bond $[7,8]$. However, the present system spontaneously hydrates under the reaction conditions. Dnp has two additional fused pyridine rings attached to two side-coordinating pyridines of tpy. These rings presumably promote hydration both by electronic repulsion of the chloride leaving group and stabilization of the entering water through hydrogen bonds.

Scheme 1. Preparation of the precursor.

2
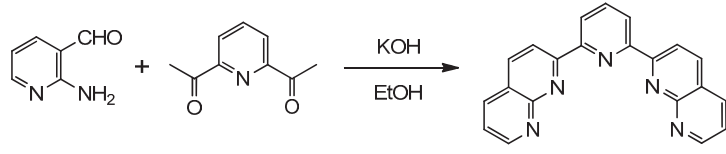

$\frac{\left[\mathrm{RuCl}_{2}\left(\mathrm{CH}_{3} \mathrm{CN}\right)_{2}\left(\mathrm{PPh}_{3}\right)_{2}\right]}{\mathrm{EtOH}}$

$\operatorname{dnp}(91 \%)$

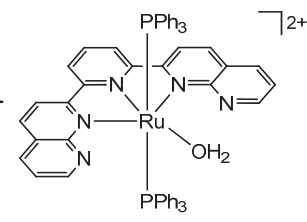

1 (red, 45\%)

1 was characterized by both ${ }^{1} \mathrm{H}$ and ${ }^{31} \mathrm{P}\left\{{ }^{1} \mathrm{H}\right\}$ nuclear magnetic resonance (NMR) spectroscopy in acetone- $d_{6}$, and the resulting spectra showed well-resolved signals. A signal observed at $8.23 \mathrm{ppm}$ disappeared on the addition of $\mathrm{D}_{2} \mathrm{O}$, which could be attributed to the protons of the aqua ligand [9]. The ${ }^{31} \mathrm{P}\left\{{ }^{1} \mathrm{H}\right\}$ NMR spectrum of $\mathbf{1}$ showed a singlet at $27.29 \mathrm{ppm}$, which indicates two triphenylphosphine $\left(\mathrm{PPh}_{3}\right)$ ligands situated trans to each other. The crystal structure of 1 by single-crystal X-ray analysis also supports this result in solution [3].

2.1.2. Synthesis of Complexes 
In dnp, the coordination space of the equatorial position is narrower than that of the similar tpy. By using this steric feature, it is possible to impart selectivity when replacing the labile aqua ligand with another one. The aqua ligand of 1 was replaced with the rodlike molecule $\mathrm{CH}_{3} \mathrm{CN}$ at room temperature to give the corresponding 2 (acetonitrile complex) (Figure 1a). In addition, 3 (benzonitrile

(PhCN)-bound complex) formed in the reaction with $\mathrm{PhCN}$, though PhCN contains a bulky phenyl group. It was confirmed by both X-ray structural and various spectroscopic analyses that the aqua ligand of 1 can be replaced by nitriles (see below). When a substitution reaction was performed using the linear thiocyanate anion $\left(\mathrm{SCN}^{-}\right)$to investigate the effect of electronic repulsion between dnp and incoming ligands, corresponding 4 (SCN-coordinated complex) was obtained. Based on ${ }^{1} \mathrm{H}$ NMR and Electrospray ionization mass spectrometry (ESI-MS) analyses, the SCN ligand in 4 was observed to be coplanar with dnp. It is well-known that $\mathrm{SCN}^{-}$is an ambidentate ligand. Although we could not identify the coordination atom from the infrared spectrum data $\left(v_{\mathrm{N} \equiv \mathrm{C}}=2134 \mathrm{~cm}^{-1}\right)$ of $\mathbf{4}, \mathrm{SCN}^{-}$would likely coordinate with its smaller (relative to sulfur) nitrogen atom in $\mathbf{4}$ because $\mathrm{SCN}^{-}$was coordinated selectively to the ruthenium center at the nitrogen atom in a similar complex containing dnp [10].

On the other hand, the aqua ligand of $\mathbf{1}$ did not exchange with the nitrite ion $\left(\mathrm{NO}_{2}{ }^{-}\right)$, which is another ambidentate ligand; instead, the axial ligand $\left(\mathrm{PPh}_{3}\right)$ underwent substitution to produce 5 (Figure 1b). Two characteristic bands in the fingerprint region $\left(1438\right.$ and $\left.1304 \mathrm{~cm}^{-1}\right)$ from the IR (infrared) spectrum of $\mathbf{5}$ suggest that $\mathbf{5}$ is a nitrogen atom-coordinated nitro species [11,12]. In addition to $\mathrm{NO}_{2}^{-}, \mathbf{1}$ reacted with halide ions $\mathrm{Cl}^{-}$and $\mathrm{Br}^{-}$to give the axial ligand-substituted $\mathbf{6}$ (chlorido complex) and 7 (bromido complex), respectively. It was confirmed by both ${ }^{1} \mathrm{H}$ NMR and mass spectral analyses that complexes 5-7 each have one $\mathrm{PPh}_{3}$ ligand and retain the aqua ligand.

Figure 1. Synthetic routes for complexes 2-8. Eq-subst. and ax-subst. denote equatorial position substitution and axial position substitution, respectively.

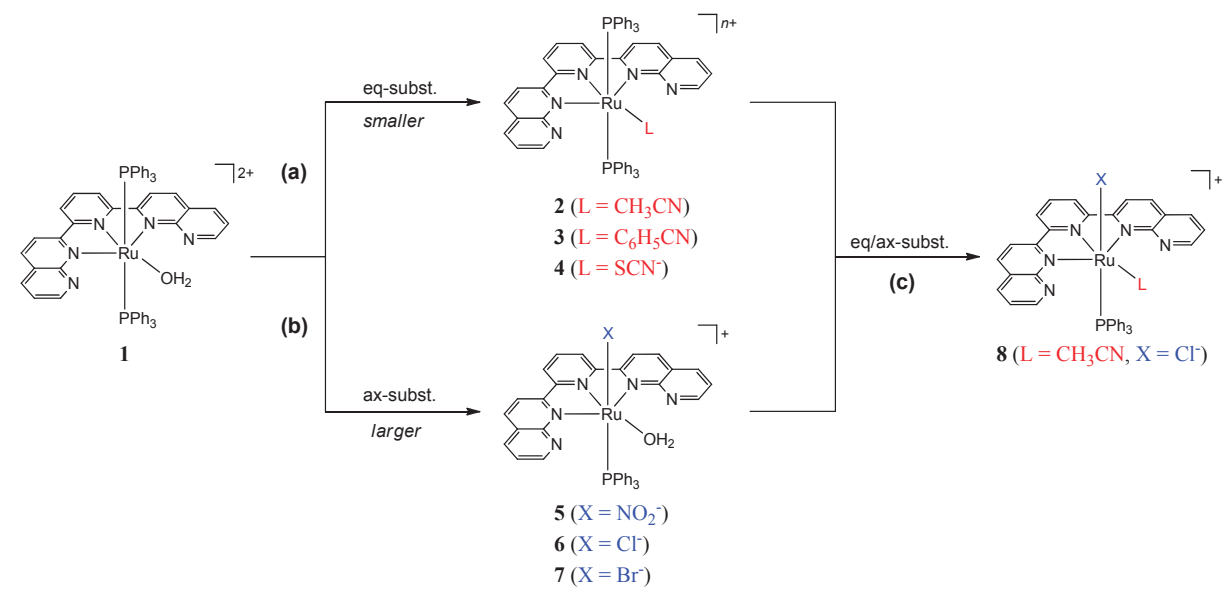


Reaction of the acetonitrile-substituted complex with chloride (i.e., 2 and $\mathrm{Cl}^{-}$) and the chlorido complex with acetonitrile (i.e., 6 and $\mathrm{CH}_{3} \mathrm{CN}$ ) both lead to 8 (double-substituted complex) (Figure 1c). To summarize, the synthetic reactions using $\mathbf{1}$ are classified into two groups based on the combination of size selectivity of dnp and complementarity of size and shape of the incorporated molecule. The ligand having both linear molecular shape and smaller coordination atoms (the second period elements) incorporates into the coordination space of dnp to replace the coordinated water molecule (Figure 1a). On the other hand, nonlinear molecules or the third or later period elements are unable to approach the coordination space of dnp. As a result, an axial ligand, rather than the aqua ligand, is involved in the substitution reaction (Figure 1b). Thus, the supporting dnp acts as a so-called "molecular sieve."

\subsection{Spectral and Structural Features of the Complexes}

\subsubsection{Electronic Absorption Spectra}

The electronic absorption spectral data for the series complexes are summarized in Table 1. The complexes exhibit intense high-energy $d \rightarrow \pi^{*}$ metal-to-ligand charge transfer (MLCT) and $\pi \rightarrow \pi^{*}$ intraligand transitions in the UV region. The weak UV absorptions observed in the 310-360 nm range have been assigned to unresolved ligand-field $d \rightarrow d$ transitions on the ruthenium(II) center. In addition, the stronger visible transitions in the 370-600 $\mathrm{nm}$ range have been assigned to low-energy MLCT transitions [13]. Dnp may be considered as a dipyrido-fused analogue of tpy, which is both more delocalized and more electronegative [14]. As a result, dnp is a much better charge acceptor. This difference is evidenced by the absorption maxima of $\mathbf{8}$ and the corresponding terpyridine analogue $\left(\left[\mathrm{Ru} \text { (tpy) }\left(\mathrm{PPh}_{3}\right)\left(\mathrm{CH}_{3} \mathrm{CN}\right) \mathrm{Cl}\right]^{+}\right)$, where the latter (tpy-complex) MLCT band is at $466 \mathrm{~nm}$ [15], and 8 absorbs at $563 \mathrm{~nm}$. It is worth noting that the more planar system gives rise to a better delocalization and consequently exhibits lower energy absorption.

Table 1. Electronic absorption data for complexes $\mathbf{1}-\mathbf{8}^{\mathrm{a}}$.

\begin{tabular}{|c|c|c|c|c|}
\hline Complex & \multicolumn{3}{|c|}{$\lambda_{\max } / \mathbf{n m}\left(\varepsilon / \mathbf{M}^{-1} \mathrm{~cm}^{-1}\right)$} & Solvent \\
\hline 1 & $\begin{array}{c}523(3500) \\
327(22400)\end{array}$ & $373(16700)$ & $355(15800)$ & acetone \\
\hline 2 & $\begin{array}{c}477(3100) \\
319(24300)\end{array}$ & $\begin{array}{l}374(20400) \\
274(42000)\end{array}$ & $356(16300)$ & methanol \\
\hline 3 & $\begin{array}{c}492(4300) \\
312(28700)\end{array}$ & $453(4600)$ & $372(18600)$ & methanol \\
\hline 4 & $\begin{array}{c}547(3400) \\
279(28800)\end{array}$ & $373(12800)$ & $321(19100)$ & acetonitrile \\
\hline 5 & $\begin{array}{c}551(4100) \\
327(18800)\end{array}$ & $370(15900)$ & $343(18800)$ & acetone \\
\hline 6 & $580(3700)$ & $352(19900)$ & $330(27400)$ & acetone \\
\hline 7 & $590(4600)$ & $350(25500)$ & $327(21800)$ & acetone \\
\hline 8 & $\begin{array}{r}563(3400) \\
320(25300) \\
\end{array}$ & $\begin{array}{l}374(15800) \\
240(37200)\end{array}$ & $353(18600)$ & methanol \\
\hline
\end{tabular}


Figure 2 shows the visible absorption spectra of $\left[\mathrm{Ru}(\mathrm{dnp})\left(\mathrm{PPh}_{3}\right)\left(\mathrm{OH}_{2}\right) \mathrm{X}\right]^{n+}$-type aqua complexes $\left(\mathrm{X}=\mathrm{PPh}_{3}: \mathbf{1}, \mathrm{NO}_{2}: \mathbf{5}, \mathrm{Cl}: \mathbf{6}\right.$, and $\mathrm{Br}: 7$ ) in acetone solution. The MLCT bands of anion-bound complexes $(\mathbf{5}, \mathbf{6}$, and $\mathbf{7})$ are red-shifted with regard to the corresponding $\mathbf{1}$ (phosphine complex) because of the relative destabilization of $d \pi(\mathrm{Ru})$ levels caused by the anionic ligands. The relative shifts in the MLCT transitions to lower energies ( $\mathrm{X}=\mathrm{Br}^{-}<\mathrm{Cl}^{-}<\mathrm{NO}_{2}^{-}<\mathrm{PPh}_{3}$ ) follow the spectrochemical series. Ligand variation has altered the MLCT band energies, suggesting that substitution of these ligands moves the $\mathrm{d} \pi$ orbital energies of the ruthenium(II) metal center.

Figure 2. Visible absorption spectra of aqua complexes $\mathbf{1}$ and 5-7 $\left(1.0 \times 10^{-4} \mathrm{M}\right.$ in acetone).

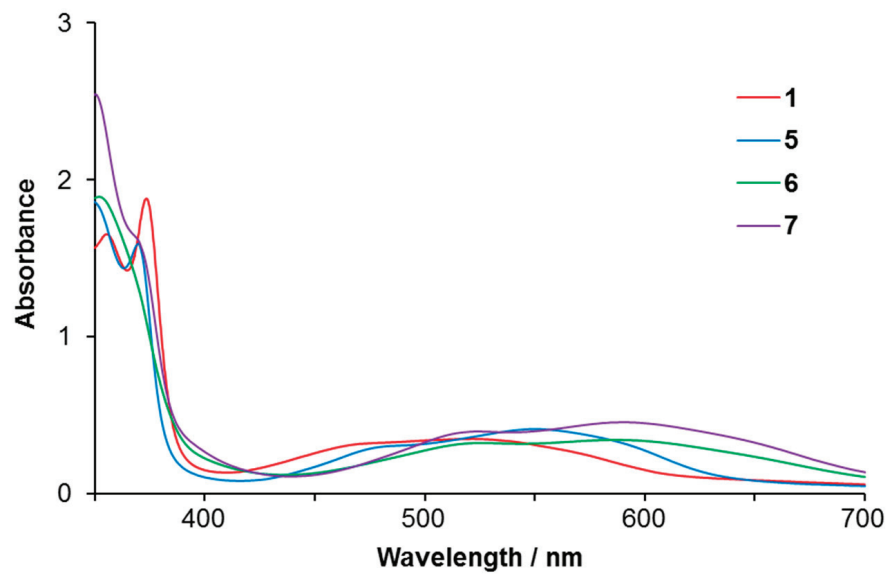

\subsubsection{Molecular Structures}

Single-crystal X-ray analyses of the nitrile complexes $(\mathbf{2}, \mathbf{3}$, and $\mathbf{8})$ have been conducted to understand the geometry of series complexes in detail. The molecular structure of $\mathbf{1}$ has been reported elsewhere [3]. Selected parameters are summarized in Table 2, and the ORTEP diagrams for these cations are shown in Figures 3-5. All of the $\mathrm{Ru}-\mathrm{N}$ distances of dnp are in the range 2.118(2)-2.167(6) $\AA$ with the exception of the central $\mathrm{Ru}-\mathrm{N}$ bond, which is shorter (1.9660(14)-2.007(7) $\AA$ ), as expected (Table 2). The phosphine ligands are in axial positions with respect to the tridentate dnp. The Ru-P bond distances of bis-phosphine complexes (2.4306(7) $\AA$ for 2, 2.430(2) and 2.436(2) $\AA$ for 3) are longer than that of the 2.3272(7) $\AA$ distance in 8, which has a trans chlorido ligand. However, these distances are in the range previously observed in $\mathrm{Ru}(\mathrm{II})$-phosphine complexes [15-18]. The nitrile units $(\mathrm{N} \equiv \mathrm{CR})$ are essentially linear and the $\mathrm{Ru}-\mathrm{N}$, $\mathrm{N}-\mathrm{C}$, and $\mathrm{C}-\mathrm{C}$ bond distances are similar to typical values in other $\mathrm{Ru}(\mathrm{II})-\mathrm{N} \equiv \mathrm{CR}$ complexes [15]. The phenyl ring of benzonitrile in $\mathbf{3}$ is nearly coplanar with dnp; the dihedral angle between the central pyridyl ring and the phenyl ring is $13.0(4)^{\circ}$. This geometry is attributed to steric hindrance between the phenyl rings of $\mathrm{PPh}_{3}$ and $\mathrm{PhCN}$. In addition, the bond distance of $\mathrm{Ru}-\mathrm{Cl}(2.4412(7) \AA)$ in $\mathbf{8}$ is within the typical range for $\mathrm{Ru}(\mathrm{II})$-chlorido complexes bearing tridentate pyridyl ligands [15]. 
Table 2. Selected bond distances $(\AA)$ and angles $\left(^{\circ}\right)$ for $\mathbf{2}, \mathbf{3}$, and $\mathbf{8}$.

\begin{tabular}{|c|c|c|c|c|c|c|}
\hline \multirow{2}{*}{$\begin{array}{c}\text { Parameter } \\
\text { Bond distances }\end{array}$} & \multicolumn{2}{|c|}{2} & \multicolumn{2}{|c|}{3} & \multicolumn{2}{|c|}{$8 \cdot 2 \mathrm{H}_{2} \mathrm{O}$} \\
\hline & Ru1-P1 & $2.4306(7)$ & Ru1-P1 & $2.436(2)$ & Ru1-P1 & $2.3272(7)$ \\
\hline & Ru1-N2 & $2.118(2)$ & Ru1-P2 & $2.430(2)$ & Ru1-Cl1 & $2.4412(7)$ \\
\hline & Ru1-N3 & $1.968(2)$ & Ru1-N2 & $2.167(6)$ & Ru1-N2 & $2.1206(15)$ \\
\hline & Ru1-N4 & $2.051(2)$ & Ru1-N3 & $2.007(7)$ & Ru1-N3 & $1.9660(14)$ \\
\hline & N4-C30 & $1.123(4)$ & Ru1-N4 & $2.163(6)$ & Ru1-N4 & $2.1442(15)$ \\
\hline & C30-C31 & $1.464(5)$ & Ru1-N6 & $2.042(8)$ & Ru1-N6 & $2.0517(15)$ \\
\hline & - & - & N6-C22 & $1.141(12)$ & N6-C40 & $1.130(3)$ \\
\hline & - & - & $\mathrm{C} 22-\mathrm{C} 23$ & $1.438(14)$ & $\mathrm{C} 40-\mathrm{C} 41$ & $1.465(3)$ \\
\hline \multirow[t]{2}{*}{ Bond angles } & Ru1-N4-C30 & 180.0 & Ru1-N6-C22 & $179.3(6)$ & Ru1-N6-C40 & $174.2(3)$ \\
\hline & N4-C30-C31 & 180.0 & $\mathrm{~N} 6-\mathrm{C} 22-\mathrm{C} 23$ & $176.3(9)$ & N6-C40-C41 & $178.2(3)$ \\
\hline Dihedral angle ${ }^{\mathrm{a}}$ & - & - & - & $13.0(4)$ & - & - \\
\hline
\end{tabular}

${ }^{a}$ The central pyridyl ring of dnp $v s$. the phenyl ring of benzonitrile.

Figure 3. Molecular structure of the cation in complex 2. Counteranions and hydrogen atoms are omitted for clarity.

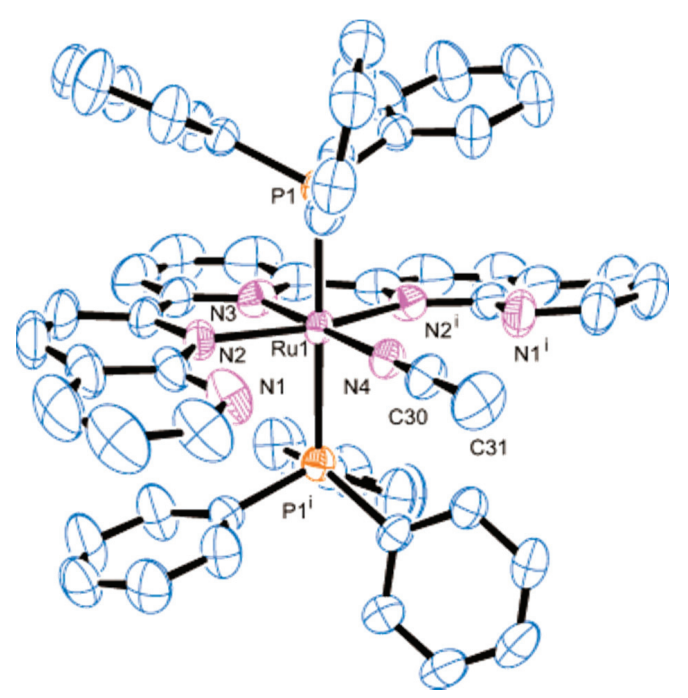

A remarkable structural feature is that the interatomic distances between noncoordinating nitrogen atoms of dnp are short. As described above, the complex system contains dnp that has two naphthyridine moieties on both sides of pyridine. The additional naphthyridine moieties could cause significant steric hindrance for $\mathrm{Cl}^{-}$binding in $\mathbf{1}$ (or 2). Thus, the presence of dnp seems to influence the selective coordination to the equatorial position. To examine this steric effect, density functional theory (DFT) calculations have been performed on $\mathbf{8}$ (and its geometrical isomer $\mathbf{8}^{\prime}$ ). The DFT-optimized structure for $\mathbf{8}$ is similar to its experimental structure. For example, for $\mathbf{8}$, the calculated $\mathrm{Ru}-\mathrm{N}$ and $\mathrm{N}-\mathrm{C}$ bond distances and the angle of $\mathrm{N}-\mathrm{C}-\mathrm{C}$ in the acetonitrile ligand are $2.09 \AA, 1.15 \AA$, and $179.5^{\circ}$, respectively, which are comparable to the experimental values (Table 2). Figure 6 depicts the optimized structures of $\mathbf{8}$ and $\mathbf{8}^{\prime}$ and demonstrates greater steric hindrance at the equatorial ligand plane of $\mathbf{8}^{\prime}$ than $\mathbf{8}$. There is a large calculated energy difference between $\mathbf{8}$ and $\mathbf{8}^{\prime}$. 
8 prefers trans $-\mathrm{P}, \mathrm{Cl}$ geometry, which is $14.1 \mathrm{kcal} / \mathrm{mol}$ lower than that of $\mathbf{8}^{\prime}$. As shown in Figure 6 , this geometrical preference is due to the narrower coordination space generated by the naphthyridine moieties in $\mathbf{8}$, which prefers a linear $\mathrm{CH}_{3} \mathrm{CN}$ coordination. This calculated result is strongly in accord with the fact that $\mathbf{8}^{\prime}$ does not experimentally form.

Figure 4. Molecular structure of the cation in complex 3. Counteranions and hydrogen atoms are omitted for clarity.

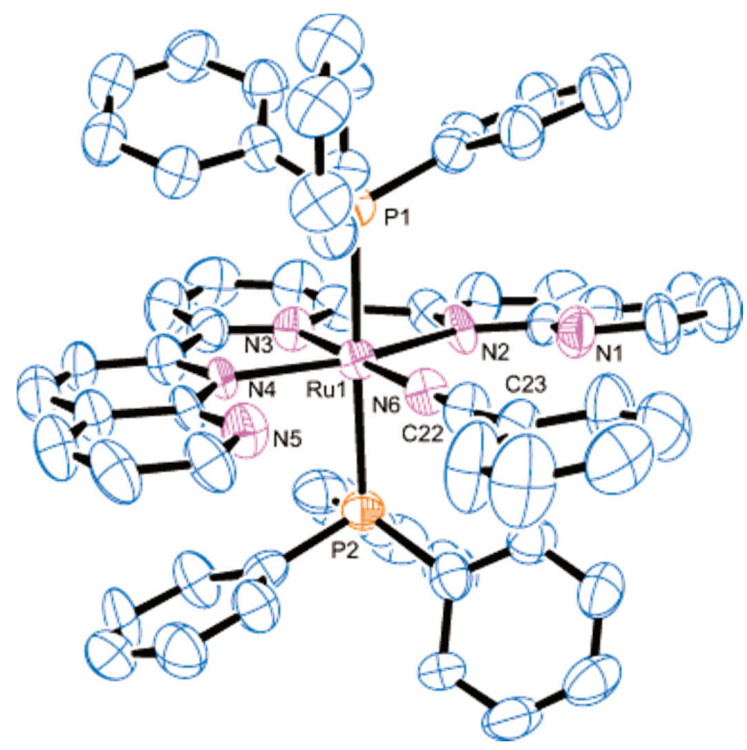

Figure 5. Molecular structure of the cation in complex 8. The counteranion, solvent molecules, and hydrogen atoms are omitted for clarity.

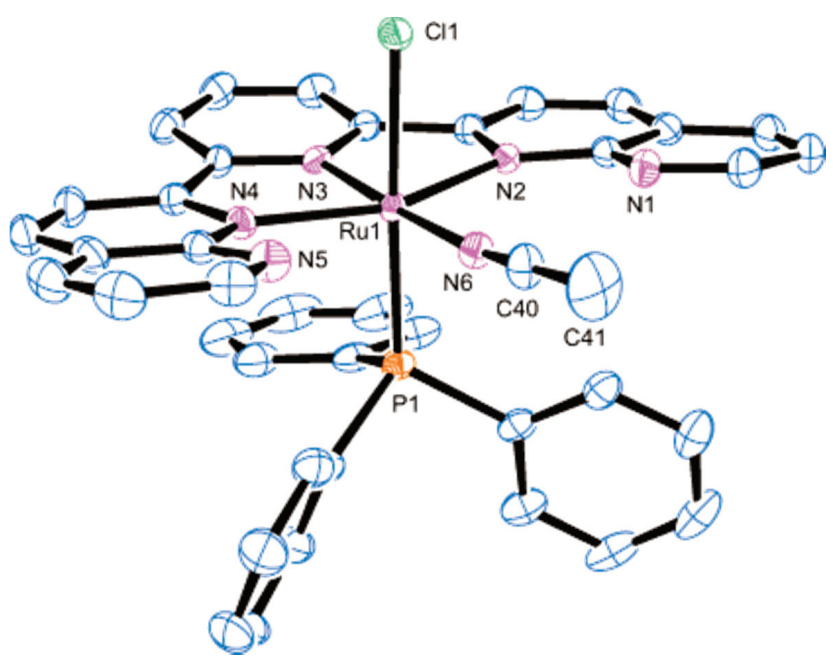


Figure 6. Space-filling models of the lowest energy structures of geometrical isomers $\left(\mathbf{8}\right.$ and $\mathbf{8}^{\prime}$ ) with the electronic energy difference.

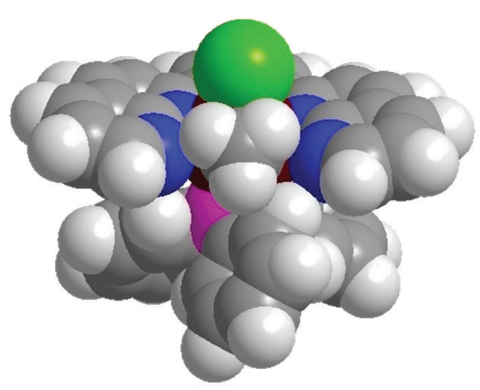

8

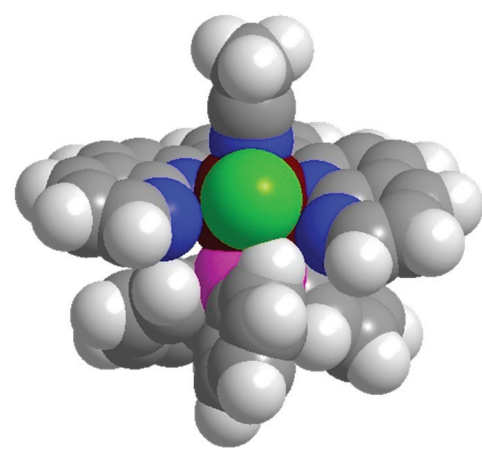

8'

$(\Delta E=+14.1 \mathrm{kcal} / \mathrm{mol})$

\section{Experimental Section}

\subsection{Material and Methods}

All solvents purchased for organic synthesis were anhydrous and used without further purification. Dnp [4,5] and $\left[\mathrm{RuCl}_{2}\left(\mathrm{CH}_{3} \mathrm{CN}\right)_{2}\left(\mathrm{PPh}_{3}\right)_{2}\right]$ [6] were prepared according to previously reported procedures.

Elemental analysis data were obtained on a Perkin Elmer $2400 \mathrm{II}$ series $\mathrm{CHN}$ analyzer. ${ }^{1} \mathrm{H}$ and ${ }^{31} \mathrm{P}\left\{{ }^{1} \mathrm{H}\right\}$ NMR spectra were recorded on a JEOL JMN-AL300 spectrometer $\left(25^{\circ} \mathrm{C}\right)$ operating at ${ }^{1} \mathrm{H}$ and ${ }^{31} \mathrm{P}$ frequencies of 300 and $121 \mathrm{MHz}$, respectively. ESI-MS data were obtained on a Bruker Daltonics microTOF. Electronic absorption spectra were obtained in 1-cm quartz cuvettes on a JASCO V-570 UV/VIS/NIR spectrophotometer. IR spectra were obtained using the KBr pellet method with a JASCO FT-IR 4100 spectrometer. DFT calculations were performed on 8 and $\mathbf{8}^{\prime}$. The ground-state, gas-phase structures of these complexes were optimized at the DFT level (B3LYP) [19,20]. The DGDZVP basis set was used for Ru atoms [21,22]. The 6-31G(d) basis set was employed for $\mathrm{H}, \mathrm{C}, \mathrm{N}, \mathrm{P}$, and $\mathrm{Cl}$ atoms [23,24]. A vibrational analysis was carried out to confirm the optimized geometry is a true minimum with no imaginary frequency. All of the calculations were performed using the Gaussian 09W program package [25].

\subsection{Synthesis of the Complexes}

\subsubsection{Synthesis of $\left[\mathrm{Ru}(\mathrm{dnp})\left(\mathrm{PPh}_{3}\right)_{2}\left(\mathrm{OH}_{2}\right)\right]\left(\mathrm{PF}_{6}\right)_{2}(\mathbf{1})$}

An ethanolic solution $(60 \mathrm{~mL})$ containing $\left[\mathrm{RuCl}_{2}\left(\mathrm{CH}_{3} \mathrm{CN}\right)_{2}\left(\mathrm{PPh}_{3}\right)_{2}\right](200 \mathrm{mg}, 0.257 \mathrm{mmol})$, dnp (94 mg, $0.268 \mathrm{mmol}$ ), and $\mathrm{PPh}_{3}(68 \mathrm{mg}, 0.257 \mathrm{mmol}$ ) was refluxed for $2 \mathrm{~h}$. The solution was filtered and evaporated to $10 \mathrm{~mL}$ under reduced pressure. An aqueous solution of $\mathrm{KPF}_{6}$ was added and the mixture was allowed to cool overnight. The precipitate was collected by filtration, washed with diethyl ether, and dried in vacuo. The crude product was purified by column chromatography on 
$\mathrm{Al}_{2} \mathrm{O}_{3}$ (eluent: acetone). Yield: $148 \mathrm{mg}(45 \%)$. Anal. Calcd. for $\left[\mathrm{Ru}(\mathrm{dnp})\left(\mathrm{PPh}_{3}\right)_{2}\left(\mathrm{OH}_{2}\right)\right]\left(\mathrm{PF}_{6}\right)_{2} \cdot \mathrm{CH}_{3} \mathrm{CN}$ : $\mathrm{C}_{59} \mathrm{H}_{48} \mathrm{~N}_{6} \mathrm{OF}_{12} \mathrm{P} 4 \mathrm{Ru}: \mathrm{C}$, 54.09; H, 3.69; N, 6.42. Found: C, 54.31; H, 3.79; N, 6.41\%. ESI-MS $\left(\mathrm{CH}_{3} \mathrm{CN}\right): \quad m / z \quad 349.5\left(\left[\mathrm{M}-\mathrm{PPh}_{3}-\mathrm{H}_{2} \mathrm{O}\right]^{2+}\right), 358.5 \quad\left(\left[\mathrm{M}-\mathrm{PPh}_{3}\right]^{2+}\right), 480.6 \quad\left(\left[\mathrm{M}-\mathrm{H}_{2} \mathrm{O}\right]^{2+}\right) . \quad{ }^{1} \mathrm{H} \quad \mathrm{NMR}$ (acetone- $d 6$ ): $\delta 9.42$ (dd, $J=4.5,1.8 \mathrm{~Hz}, 2 \mathrm{H}, \mathrm{dnp}), 8.69-8.59(\mathrm{~m}, 6 \mathrm{H}, \mathrm{dnp}), 8.43$ (d, $J=8.7 \mathrm{~Hz}, 2 \mathrm{H}$, dnp), 8.23-8.14 (m, 2H, dnp and $\mathrm{H}_{2} \mathrm{O}$ ), 8.02 (dd, $\left.J=8.4,4.2 \mathrm{~Hz}, 2 \mathrm{H}, \mathrm{dnp}\right), 7.19$ (t, $J=7.5 \mathrm{~Hz}, 6 \mathrm{H}$, $\left.\mathrm{PPh}_{3}\right), 6.91$ (t, $\left.J=9.0 \mathrm{~Hz}, 12 \mathrm{H}, \mathrm{PPh}_{3}\right)$, and 6.79-6.73 (m, 12H, PPh $)$ ppm. ${ }^{31} \mathrm{P}\left\{{ }^{1} \mathrm{H}\right\} \mathrm{NMR}$ (acetone-d6): $\delta 27.29 \mathrm{ppm}$.

\subsubsection{Synthesis of $\left[\mathrm{Ru}(\mathrm{dnp})\left(\mathrm{PPh}_{3}\right)_{2}(\mathrm{RCN})\right]\left(\mathrm{PF}_{6}\right)_{2}\left(\mathrm{R}=\mathrm{CH}_{3}(\mathbf{2}) ; \mathrm{R}=\mathrm{C}_{6} \mathrm{H}_{5}(\mathbf{3})\right)$}

An acetonitrile solution (30 mL) containing 1 (56 mg, $0.044 \mathrm{mmol})$ was stirred for $24 \mathrm{~h}$ at room temperature. The volume was reduced to $5 \mathrm{~mL}$ using a rotary evaporator, and orange crystals were precipitated by adding diethyl ether $(20 \mathrm{~mL})$. The precipitate was collected by filtration, washed with diethyl ether, and dried in vacuo. The crude product was finally recrystallized from acetonitrile and diethyl ether, yielding 2 as an orange powder. Yield: $49 \mathrm{mg}$ (86\%). Anal. Calcd. for $\left[\mathrm{Ru}(\mathrm{dnp})\left(\mathrm{PPh}_{3}\right)_{2}\left(\mathrm{CH}_{3} \mathrm{CN}\right)\right]\left(\mathrm{PF}_{6}\right)_{2} \cdot \mathrm{H}_{2} \mathrm{O}: \mathrm{C}_{59} \mathrm{H}_{48} \mathrm{~N}_{6} \mathrm{OF}_{12} \mathrm{P}_{4} \mathrm{Ru}: \mathrm{C}, 54.09 ; \mathrm{H}, 3.69 ; \mathrm{N}, 6.42$. Found: $\mathrm{C}, 53.77 ; \mathrm{H}, 3.68 ; \mathrm{N}, 6.57 \%$. ESI-MS $\left(\mathrm{CH}_{3} \mathrm{CN}\right): \mathrm{m} / z \quad 349.6\left(\left[\mathrm{M}-\mathrm{PPh}_{3}-\mathrm{CH}_{3} \mathrm{CN}\right]^{2+}\right), 480.6$ $\left(\left[\mathrm{M}-\mathrm{CH}_{3} \mathrm{CN}\right]^{2+}\right) .{ }^{1} \mathrm{H}$ NMR (acetonitrile- $\left.d_{3}\right): \delta 9.35(\mathrm{dd}, J=4.5,1.8 \mathrm{~Hz}, 2 \mathrm{H}, \mathrm{dnp}), 8.31-8.26(\mathrm{~m}$, 4H, dnp), 8.20-8.17 (m, 2H, dnp), 8.07 (t, $J=8.1 \mathrm{~Hz}, 1 \mathrm{H}, \mathrm{dnp}), 7.89-7.81$ (m, 4H, dnp), 7.13 (t, $\left.J=7.6 \mathrm{~Hz}, 6 \mathrm{H}, \mathrm{PPh}_{3}\right)$, and 6.85-6.70 (m, 24H, PPh 3$) \mathrm{ppm}[26] .{ }^{31} \mathrm{P}\left\{{ }^{1} \mathrm{H}\right\}$ NMR (acetonitrile- $\left.d_{3}\right)$ : $\delta 31.16 \mathrm{ppm}$.

A similar reaction between 1 (50 mg, $0.039 \mathrm{mmol})$ and benzonitrile gave 3 with an $82 \%$ (52 $\mathrm{mg}$ ) yield. Anal. Calcd. for $\left[\mathrm{Ru}(\mathrm{dnp})\left(\mathrm{PPh}_{3}\right)_{2}\left(\mathrm{C}_{6} \mathrm{H}_{5} \mathrm{CN}\right)\right]\left(\mathrm{PF}_{6}\right)_{2}: \mathrm{C}_{64} \mathrm{H}_{48} \mathrm{~N}_{6} \mathrm{~F}_{12} \mathrm{P} 4 \mathrm{Ru}: \mathrm{C}, 56.77 ; \mathrm{H}, 3.57 ; \mathrm{N}$, 6.21. Found: C, 56.88; H, 3.41; N, 6.26\%. ESI-MS $\left(\mathrm{CH}_{3} \mathrm{CN}\right): m / z 349.6\left(\left[\mathrm{M}-\mathrm{PPh}_{3}-\mathrm{C}_{6} \mathrm{H}_{5} \mathrm{CN}\right]^{2+}\right)$, $480.6\left(\left[\mathrm{M}-\mathrm{C}_{6} \mathrm{H}_{5} \mathrm{CN}\right]^{2+}\right.$ ). ${ }^{1} \mathrm{H}$ NMR (acetone- $d 6$ ): $\delta 9.47$ (dd, $\left.J=3.9,1.8 \mathrm{~Hz}, 2 \mathrm{H}, \mathrm{dnp}\right), 8.69-8.53$ (m, 6H, dnp), 8.33 (d, $J=8.7 \mathrm{~Hz}, 2 \mathrm{H}, \mathrm{dnp}), 7.94$ (dd, $J=8.1,3.9 \mathrm{~Hz}, 2 \mathrm{H}, \mathrm{dnp}), 7.81$ (t, $J=7.5 \mathrm{~Hz}, 1 \mathrm{H}$, dnp), 7.21-7.16 (m, 7H, $\mathrm{PPh}_{3}$ and $\left.\mathrm{PhCN}\right), 6.96-6.89\left(\mathrm{~m}, 26 \mathrm{H}, \mathrm{PPh}_{3}\right.$ and $\left.\mathrm{PhCN}\right)$, and 6.77-6.75 (m, 2H, $\mathrm{PhCN}$ ) ppm. ${ }^{31} \mathrm{P}\left\{{ }^{1} \mathrm{H}\right\}$ NMR (acetone- $d 6$ ): $\delta 30.02 \mathrm{ppm}$.

\subsubsection{Synthesis of $\left[\mathrm{Ru}(\mathrm{dnp})\left(\mathrm{PPh}_{3}\right)_{2}(\mathrm{SCN})\right]\left(\mathrm{PF}_{6}\right)(4)$ and $\left[\mathrm{Ru}(\mathrm{dnp})\left(\mathrm{PPh}_{3}\right)\left(\mathrm{OH}_{2}\right) \mathrm{X}\right]\left(\mathrm{PF}_{6}\right)\left(\mathrm{X}=\mathrm{NO}_{2}\right.$} (5), $\mathrm{Cl}(\mathbf{6}), \mathrm{Br}(7))$

In a typical preparation, a methanolic solution $(40 \mathrm{~mL})$ containing $1(50 \mathrm{mg}, 0.039 \mathrm{mmol})$ and 1.1 equiv. of NaSCN (10 mg) was refluxed for $30 \mathrm{~min}$. The volume was reduced to $5 \mathrm{~mL}$ and a saturated solution of $\mathrm{KPF}_{6}$ was added. The resulting solid was filtered and then washed with water followed by diethyl ether. The crude product was recrystallized from acetone/diethyl ether. The yield was $32 \mathrm{mg}(69 \%)$ for 4. ESI-MS $\left(\mathrm{CH}_{3} \mathrm{CN}\right): m / z 757.0\left(\left[\mathrm{M}-\mathrm{PPh}_{3}\right]^{+}\right), 1019.1\left([\mathrm{M}]^{+}\right) .{ }^{1} \mathrm{H}$ NMR (acetone- $d_{6}$ ): $\delta 9.54$ (dd, $\left.J=3.9,1.8 \mathrm{~Hz}, 2 \mathrm{H}, \mathrm{dnp}\right), 8.42-8.33(\mathrm{~m}, 6 \mathrm{H}, \mathrm{dnp}), 8.15$ (d, $J=8.7 \mathrm{~Hz}, 2 \mathrm{H}$, dnp), 8.03 (t, $J=8.1 \mathrm{~Hz}, 1 \mathrm{H}, \mathrm{dnp}), 7.86$ (dd, $J=8.1,3.9 \mathrm{~Hz}, 2 \mathrm{H}, \mathrm{dnp}), 7.14-6.99$ (m, 18H, $\mathrm{PPh}_{3}$ ), and 6.83 (t, $\left.J=6.9 \mathrm{~Hz}, 12 \mathrm{H}, \mathrm{PPh}_{3}\right) \mathrm{ppm} .{ }^{31} \mathrm{P}\left\{{ }^{1} \mathrm{H}\right\}$ NMR (acetone- $\left.d_{6}\right): \delta 27.38 \mathrm{ppm}$. IR (KBr): $2134 \mathrm{~cm}^{-1}(v \mathrm{~N} \equiv \mathrm{C})$. 
A similar reaction between $\mathbf{1}$ and $\mathrm{NaNO}_{2}$ under the same conditions described above gave $\mathbf{5}$ in $74 \%$ yield $(26 \mathrm{mg})$. ESI-MS $\left(\mathrm{CH}_{3} \mathrm{CN}\right): \mathrm{m} / z 745.5\left(\left[\mathrm{M}-\mathrm{H}_{2} \mathrm{O}\right]^{+}\right) .{ }^{1} \mathrm{H}$ NMR (acetone- $\left.d_{6}\right): \delta 9.50$ (dd, $J=4.5,1.8 \mathrm{~Hz}, 2 \mathrm{H}, \mathrm{dnp}), 8.79-8.54\left(\mathrm{~m}, 9 \mathrm{H}, \mathrm{dnp}\right.$ and $\left.\mathrm{H}_{2} \mathrm{O}\right), 8.13(\mathrm{t}, J=8.1 \mathrm{~Hz}, 1 \mathrm{H}, \mathrm{dnp}), 8.03$ (dd, $J=4.8,2.1 \mathrm{~Hz}, 2 \mathrm{H}, \mathrm{dnp}), 7.20-7.16\left(\mathrm{~m}, 3 \mathrm{H}, \mathrm{PPh}_{3}\right)$, and 6.95-6.92 (m, 12H, $\left.\mathrm{PPh}_{3}\right) \mathrm{ppm} .{ }^{31} \mathrm{P}\left\{{ }^{1} \mathrm{H}\right\}$ NMR (acetone- $d 6): \delta 38.33$ ppm. IR (KBr): $1438,1304 \mathrm{~cm}^{-1}\left(v \mathrm{NO}_{2}\right)$.

A similar reaction between 1 and $\mathrm{Et}_{4} \mathrm{NCl}$ under the same conditions described above gave $\mathbf{6}$ in $67 \%$ yield $(23 \mathrm{mg})$. ESI-MS $\left(\mathrm{CH}_{3} \mathrm{CN}\right): \mathrm{m} / z 734.1\left(\left[\mathrm{M}-\mathrm{H}_{2} \mathrm{O}\right]^{+}\right) .{ }^{1} \mathrm{H}$ NMR (acetone- $\left.d 6\right)$ : $\delta 9.46$ (dd, $J=4.5,1.8 \mathrm{~Hz}, 2 \mathrm{H}, \mathrm{dnp}), 8.74-8.70$ (m, 4H, dnp), 8.57 (dd, $J=8.4,1.8 \mathrm{~Hz}, 4 \mathrm{H}, \mathrm{dnp}), 8.48$ (s, 1H, $\left.\mathrm{H}_{2} \mathrm{O}\right), 8.05-7.91$ (m, 3H, dnp), 7.20-7.13 (m, 3H, $\left.\mathrm{PPh}_{3}\right)$, and 6.95-6.91 (m, 12H, $\left.\mathrm{PPh}_{3}\right) \mathrm{ppm} .{ }^{31} \mathrm{P}\left\{{ }^{1} \mathrm{H}\right\}$ NMR (acetone- $d 6): \delta 43.11 \mathrm{ppm}$.

A similar reaction between 1 and $\mathrm{Bu} 4 \mathrm{NBr}$ under the same conditions described above gave $\mathbf{7}$ in 94\% yield (35 mg). ESI-MS $\left(\mathrm{CH}_{3} \mathrm{CN}\right): \mathrm{m} / z$ 780.1 $\left(\left[\mathrm{M}-\mathrm{H}_{2} \mathrm{O}\right]^{+}\right), 808.1\left(\left[\mathrm{M}-\mathrm{H}_{2} \mathrm{O}+\mathrm{N}_{2}\right]^{+}\right) .{ }^{1} \mathrm{H}$ NMR (acetone- $d_{6}$ ): $\delta 9.46$ (dd, $J=4.5,2.1 \mathrm{~Hz}, 2 \mathrm{H}$, dnp), 8.74-8.70 (m, 4H, dnp), 8.59 (dd, $J=8.7,2.1$ $\mathrm{Hz}, 4 \mathrm{H}, \mathrm{dnp}), 8.38$ (s, 1H, $\mathrm{H}_{2} \mathrm{O}$ ), 8.06-7.98 (m, 3H, dnp), 7.20-7.16 (m, 3H, PPh $)$, and 6.95-6.91 $\left(\mathrm{m}, 12 \mathrm{H}, \mathrm{PPh}_{3}\right) \mathrm{ppm} .{ }^{31} \mathrm{P}\left\{{ }^{1} \mathrm{H}\right\} \mathrm{NMR}\left(\right.$ acetone- $\left.d_{6}\right): \delta 43.32 \mathrm{ppm}$.

\subsubsection{Synthesis of $\left[\mathrm{Ru}(\mathrm{dnp})\left(\mathrm{PPh}_{3}\right)\left(\mathrm{CH}_{3} \mathrm{CN}\right) \mathrm{Cl}\right] \mathrm{Cl}(\mathbf{8})$}

An acetonitrile solution $(30 \mathrm{~mL})$ containing $1(30 \mathrm{mg}, 0.023 \mathrm{mmol})$ and $\mathrm{Et}_{4} \mathrm{NCl}(8 \mathrm{mg}, 0.048$ $\mathrm{mmol}$ ) was refluxed for $6 \mathrm{~h}$. The volume was reduced to $5 \mathrm{~mL}$ using a rotary evaporator, and purple crystals were precipitated by adding diethyl ether $(15 \mathrm{~mL})$. The precipitate was collected by filtration, washed with diethyl ether, and dried in vacuo. The crude product was recrystallized from methanol/diethyl ether, yielding $\mathbf{8}$ as a violet powder. Yield: $15 \mathrm{mg}$ (83\%). Anal. Calcd. for $\left[\mathrm{Ru}(\mathrm{dnp})\left(\mathrm{PPh}_{3}\right)\left(\mathrm{CH}_{3} \mathrm{CN}\right) \mathrm{Cl}\right] \mathrm{Cl} \cdot 3 \mathrm{H}_{2} \mathrm{O}: \mathrm{C}_{42} \mathrm{H}_{37} \mathrm{~N}_{6} \mathrm{O}_{3} \mathrm{PRu}: \mathrm{C}, 56.95 ; \mathrm{H}, 4.31 ; \mathrm{N}, 9.72$. Found: $\mathrm{C}$, 56.58; H, 4.23; N, 9.57\%. ESI-MS $\left(\mathrm{CH}_{3} \mathrm{CN}\right): m / z 734.1\left(\left[\mathrm{M}-\mathrm{CH}_{3} \mathrm{CN}\right]^{+}\right) .{ }^{1} \mathrm{H}$ NMR (acetonitrile- $\left.d_{3}\right)$ : $\delta 9.34$ (dd, $J=4.5,1.8 \mathrm{~Hz}, 2 \mathrm{H}, \mathrm{dnp}), 8.41-8.34$ (m, 6H, dnp), 8.17 (d, $J=8.7 \mathrm{~Hz}, 2 \mathrm{H}, \mathrm{dnp}), 8.03$ (t, $J=8.1 \mathrm{~Hz}, 1 \mathrm{H}, \mathrm{dnp}), 7.78(\mathrm{dd}, J=8.1,4.2 \mathrm{~Hz}, 2 \mathrm{H}, \mathrm{dnp}), 7.15-7.08\left(\mathrm{~m}, 3 \mathrm{H}, \mathrm{PPh}_{3}\right)$, and 6.93-6.85 $\left(\mathrm{m}, 12 \mathrm{H}, \mathrm{PPh}_{3}\right) \mathrm{ppm}[26] .{ }^{31} \mathrm{P}\left\{{ }^{1} \mathrm{H}\right\} \mathrm{NMR}$ (acetonitrile- $\left.d_{3}\right): \delta 46.95 \mathrm{ppm}$.

\subsection{X-ray Crystallographic Analyses}

Single crystals of the perchlorate salt of $\mathbf{2}$ and $\mathbf{8} \cdot 2 \mathrm{H}_{2} \mathrm{O}$ were obtained by diffusion of diethyl ether into an acetonitrile solution of each of the complexes. Single crystals of $\mathbf{3}$ were obtained by diffusion of diethyl ether into a benzonitrile solution of the complex. An orange crystal of 2 with dimensions $0.30 \times 0.30 \times 0.15 \mathrm{~mm}$, an orange crystal of $\mathbf{3}$ with dimensions $0.20 \times 0.10 \times 0.05 \mathrm{~mm}$, and a deep violet crystal of $\mathbf{8} \cdot 2 \mathrm{H}_{2} \mathrm{O}$ with dimensions $0.30 \times 0.25 \times 0.25 \mathrm{~mm}$ were mounted on a glass fiber. Measurements were made on a Rigaku RAXIS-RAPID diffractometer with graphite monochromated Mo K $\alpha$ radiation $(\lambda=0.71075 \AA)$. Data were collected to a maximum $2 \theta$ value of $55^{\circ}$. All calculations were conducted using the CrystalStructure crystallographic software package [27] except for refinement, which was performed using SHELXL97 [28]. The structures were solved by direct methods [29,30] and were expanded using Fourier techniques. Multi-scan absorption corrections were applied [31]. The non-hydrogen atoms were refined anisotropically, and hydrogen atoms were included as raiding 
atoms. Crystallographic parameters of $\mathbf{2}, \mathbf{3}$, and $\mathbf{8} \cdot 2 \mathrm{H}_{2} \mathrm{O}$ are summarized in Table 3 . Crystallographic data have been deposited with the Cambridge Crystallographic Data Centre as Supplementary Publication Nos. CCDC-962347 for 2, 962348 for 3, and 962349 for $\mathbf{8} \cdot 2 \mathrm{H}_{2} \mathrm{O}$.

Table 3. Crystallographic data for $\mathbf{2 , 3}$, and $\mathbf{8} \cdot 2 \mathrm{H}_{2} \mathrm{O}$.

\begin{tabular}{|c|c|c|c|}
\hline Parameter & 2 & 3 & $8 \cdot 2 \mathrm{H}_{2} \mathrm{O}$ \\
\hline Chemical formula & $\mathrm{C}_{59} \mathrm{H}_{46} \mathrm{~N}_{6} \mathrm{O}_{8} \mathrm{Cl}_{2} \mathrm{P}_{2} \mathrm{Ru}$ & $\mathrm{C}_{64} \mathrm{H}_{48} \mathrm{~N}_{6} \mathrm{~F}_{12} \mathrm{P}_{4} \mathrm{Ru}$ & $\mathrm{C}_{41} \mathrm{H}_{35} \mathrm{~N}_{6} \mathrm{O}_{2} \mathrm{Cl}_{2} \mathrm{PRu}$ \\
\hline Formula weight & 1200.97 & 1354.07 & 846.72 \\
\hline Temperature (K) & $296(1)$ & $296(1)$ & $173(1)$ \\
\hline Crystal system & monoclinic & monoclinic & Monoclinic \\
\hline Space group & $C 2 / c$ & $C c$ & $C 2 / c$ \\
\hline \multicolumn{4}{|l|}{ Unit cell parameters } \\
\hline$a(\AA)$ & $17.7754(3)$ & $17.1743(4)$ & $26.4297(5)$ \\
\hline$b(\AA)$ & $13.2405(2)$ & $16.1763(4)$ & $16.2228(3)$ \\
\hline$c(\AA)$ & $22.6972(4)$ & $21.0790(4)$ & $19.4965(4)$ \\
\hline$B\left({ }^{\circ}\right)$ & $96.4561(7)$ & $97.8336(7)$ & $114.9980(7)$ \\
\hline$V\left(\AA^{3}\right)$ & $5308.03(15)$ & $5801.5(2)$ & $7576.3(3)$ \\
\hline$Z$ & 4 & 4 & 8 \\
\hline Calculated density $\left(\mathrm{g} \mathrm{cm}^{-3}\right)$ & 1.503 & 1.550 & 1.485 \\
\hline$\mu(\mathrm{Mo} \mathrm{K} \alpha)\left(\mathrm{mm}^{-1}\right)$ & 0.520 & 0.468 & 0.642 \\
\hline No. of measured reflections & 25463 & 46099 & 34745 \\
\hline No. of observed reflections & 6075 & 12645 & 8632 \\
\hline Refinement method & \multicolumn{3}{|c|}{ Full-matrix least-squares on $F^{2}$} \\
\hline Parameters & 356 & 785 & 474 \\
\hline$R 1(I>2 \sigma(I))^{\mathrm{a}}$ & 0.0444 & 0.0580 & 0.0311 \\
\hline $\mathrm{w} R 2$ (all data) ${ }^{\mathrm{b}}$ & 0.1292 & 0.2164 & 0.0803 \\
\hline$S$ & 1.050 & 1.126 & 1.038 \\
\hline
\end{tabular}

\section{Conclusions}

We have described the synthesis and X-ray crystallographic characterization of a new ruthenium complex system containing the highly functional dnp ligand. Computational analysis suggests that the incorporation of dnp not only stabilizes the complex but also enables this system to be synthesized with improved stereospecificity. The results provide useful information to elucidate this facile and selective synthetic approach to new transition metal complexes. For example, regulation of linkage isomerization in ruthenium complexes involving $\mathrm{SCN}^{-}$could contribute to materials science in the development of photosensitizers for dye-sensitized solar cells (DSCs).

\section{Acknowledgments}

We thank the Foundation for Japanese Chemical Research (424-R) for financial support. Moreover, we are grateful to R. Naoi of Fukushima University for assistance with the spectroscopic measurements. 


\section{Conflicts of Interest}

The authors declare no conflict of interest.

\section{References}

1. Chowdhury, A.D.; Das, A.; Irshad, K.; Mobin, S.M.; Lahiri, G.K. Isomeric complexes of $\left[\mathrm{Ru}^{\mathrm{II}}(\operatorname{trpy})(\mathrm{L}) \mathrm{Cl}\right]\left(\right.$ trpy $=2,2^{\prime}: 6^{\prime}, 2^{\prime \prime}$-terpyridine and $\mathrm{HL}=$ quinaldic acid): Preference of isomeric structural form in catalytic chemoselective epoxidation process. Inorg. Chem. 2011, 50, 1775-1785.

2. Dakkach, M.; López, M.I.; Romero, I.; Rodríguez, M.; Atlamsani, A.; Parella, T.; Fontrodona, X.; Llobet, A. New Ru(II) complexes with anionic and neutral N-donor ligands as epoxidation catalysts: An evaluation of geometrical and electronic effects. Inorg. Chem. 2010, 49, $7072-7079$.

3. Oyama, D.; Yamanaka, T.; Fukuda, A.; Takase, T. Modulation of intramolecular hydrogen bonding strength by axial ligands in ruthenium(II) complexes. Chem. Lett. 2013, 42, 1554-1555.

4. Campos-Fernández, C.S.; Thomson, L.M.; Galán-Mascarós, J.R.; Ouyang, X.; Dunbar, K.R. Homologous series of redox-active, dinuclear cations $\left[\mathrm{M}_{2}\left(\mathrm{O}_{2} \mathrm{CCH}_{3}\right)_{2}(\text { pynp })_{2}\right]^{2+}(\mathrm{M}=\mathrm{Mo}, \mathrm{Ru}, \mathrm{Rh})$ with the bridging ligand 2-(2-pyridyl)-1,8-naphthyridine (pynp). Inorg. Chem. 2002, 41, $1523-1533$.

5. Tseng, H.-W.; Zong, R.; Muckerman, J.T.; Thummel, R. Mononuclear ruthenium(II) complexes that catalyze water oxidation. Inorg. Chem. 2008, 47, 11763-11773.

6. Al-Far, A.M.; Slaughter, L.M. cis-cis-trans-Bis(acetonitrile$\kappa N$ )dichloridobis(triphenylphosphine- $\kappa P$ )ruthenium(II) acetonitrile disolvate. Acta Crystallogr. 2008, E64, m184.

7. Kaveevivitchai, N.; Zong, R.; Tseng, H.-W.; Chitta, R.; Thummel, R.P. Further observations on water oxidation catalyzed by mononuclear Ru(II) complexes. Inorg. Chem. 2012, 51, 2930-2939.

8. Suen, H.F.; Wilson, S.W.; Pomerantz, M.; Walsh, J.L. Photosubstitution reactions of terpyridine complexes of ruthenium(II). Inorg. Chem. 1989, 28, 786-791.

9. Zong, R.; Naud, F.; Segal, C.; Burke, J.; Wu, F.; Thummel, R. Design and study of bi[1,8]naphthyridine ligands as potential photooxidation mediators in $\mathrm{Ru}(\mathrm{II})$ polypyridyl aquo complexes. Inorg. Chem. 2004, 43, 6195-6202.

10. Oyama, D.; Yamanaka, Y.; Watanabe, Y.; Takase, T. Fukushima University, Fukushima, Japan. Unpublished work, 2013.

11. Nakamoto, K. Infrared and Raman Spectra of Inorganic and Coordination Compounds, 4th ed.; John Wiley \& Sons: New York, NY, USA, 1986; pp. 221-227.

12. Ooyama, D.; Nagao, N.; Nagao, H.; Miura, Y.; Hasegawa, A.; Ando, K.-I.; Howell, F.S.; Mukaida, M.; Tanaka, K. Redox- and thermally-induced nitro-nitrito linkage isomerizations of ruthenium(II) complexes having nitrosyl as a spectator ligand. Inorg. Chem. 1995, 34, 6024-6033. 
13. Juris, A.; Balzani, V.; Barigelletti, F.; Campagna, S.; Belser, P.; von Zelewsky, A. Ru(II) polypyridine complexes: Photophysics, photochemistry, electrochemistry, and chemiluminescence. Coord. Chem. Rev. 1988, 84, 85-277.

14. Thummel, R.P.; Decloitre, Y. Polyaza cavity-shaped molecules. VIII. Ruthenium(II) complexes with 3,3'-annelated derivatives of 2-(2'-pyridyl)quinoline and 2-(2'-pyridyl)-1,8naphthyridine. Inorg. Chim. Acta 1987, 128, 245-249.

15. Ooyama, D.; Saito, M. Synthesis, characterization and reactivity of polypyridyl ruthenium(II) carbonyl complexes with phosphine derivatives: ruthenium-carbon bond labilization based on steric and electronic effects. Inorg. Chim. Acta 2006, 359, 800-806.

16. Chen, J.; Szalda, D.J.; Fujita, E.; Creutz, C. Iron(II) and ruthenium(II) complexes containing $\mathrm{P}, \mathrm{N}$, and H ligands: structure, spectroscopy, electrochemistry, and reactivity. Inorg. Chem. 2010, 49, 9380-9391.

17. Ooyama, D.; Sato, M. A synthetic precursor for hetero-binuclear metal complexes, $\left[\mathrm{Ru}(\mathrm{bpy})(\mathrm{dppy})_{2}(\mathrm{CO})_{2}\right]\left(\mathrm{PF}_{6}\right)_{2}$ (bpy $=2,2$ '-bipyridine, dppy $=2$-(diphenylphosphino)pyridine). Appl. Organomet. Chem. 2004, 18, 380-381.

18. Ooyama, D.; Sato, M. Crystal structure of $\left(2,2^{\prime}\right.$-bipyridine- $\left.N, N^{\prime}\right)($ diphenyl-2phosphinopyridine- $P$ )chloro(dicarbonyl)ruthenium(II) hexafluorophosphate. Anal. Sci. 2003, $19, \mathrm{x} 39-\mathrm{x} 40$.

19. Becke, A.D. Density-functional thermochemistry. III. The role of exact exchange. J. Chem. Phys. 1993, 98, 5648-5652.

20. Lee, C.; Yang, W.; Parr, R.G. Development of the Colle-Salvetti correlation-energy formula into a functional of the electron density. Phys. Rev. B 1988, 37, 785-789.

21. Sosa, C.; Andzelm, J.; Elkin, B.C.; Wimmer, E.; Dobbs, K.D.; Dixon, D.A. A local density functional study of the structure and vibrational frequencies of molecular transition-metal compounds. J. Phys. Chem. 1992, 96, 6630-6636.

22. Godbout, N.; Salahub, D.R.; Andzelm, J.; Wimmer, E. Optimization of Gaussian-type basis sets for local spin density functional calculations. Part I. Boron through neon, optimization technique and validation. Can. J. Chem. 1992, 70, 560-571.

23. Hehre, W.J.; Ditchfield, R.; Pople, J.A. Self-consistent molecular orbital methods. XII. Further extensions of Gaussian-type basis sets for use in molecular orbital studies of organic molecules. J. Chem. Phys. 1972, 56, 2257-2261.

24. Francl, M.M.; Pietro, W.J.; Hehre, W.J.; Binkley, J.S.; Gordon, M.S.; DeFrees, D.J.; Pople, J.A. Self-consistent molecular orbital methods. XXIII. A polarization-type basis set for second-row elements. J. Chem. Phys. 1982, 77, 3654-3665.

25. Frisch, M.J.; Trucks, G.W.; Schlegel, H.B.; Scuseria, G.E.; Robb, M.A.; Cheeseman, J.R.; Scalmani, G.; Barone, V.; Mennucci, B.; Petersson, G.A.; et al. Gaussian 09W, revision D.01; Gaussian, Inc.: Wallingford, CT, USA, 2009.

26. Methyl protons of both complexes could not be assigned due to their overlapping with solvent signals.

27. Rigaku. CrystalStructure, Version 3.8; Rigaku and Rigaku Americas: Woodlands, TX, USA, 2007.

28. Sheldrick, G.M. SHELX, SHELXL-97; University of Göttingen: Göttingen, Germany, 1997. 
29. Altomare, A.; Cascarano, G.; Giacovazzo, C.; Guagliardi, A.; Burla, M.; Polidori, G.; Camalli, M. SIR92 - A program for automatic solution of crystal structures by direct methods. J. Appl. Crystallogr. 1994, 27, 435.

30. Altomare, A.; Burla, M.; Camalli, M.; Cascarano, G.; Giacovazzo, C.; Guagliardi, A.; Molitern, A.; Polidori, G.; Spagna, R. SIR97: A new tool for crystal structure determination and refinement. J. Appl. Crystallogr. 1999, 32, 115-119.

31. Higashi, T. ABSCOR; Rigaku Corporation: Tokyo, Japan, 1995. 
MDPI AG

Klybeckstrasse 64

4057 Basel, Switzerland

Tel. +41616837734

Fax +41 613028918

http://www.mdpi.com/

Inorganics Editorial Office

E-mail: inorganics@mdpi.com

http://www.mdpi.com/journal/inorganics 



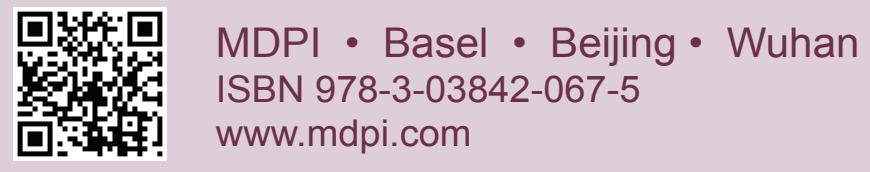

